QA: NA

TDR-MGR-RL-000002 REV 01

July 2003

\title{
Preclosure Safety Analysis Guide
}

Prepared for:

U.S. Department of Energy

Office of Repository Development

P.O. Box 30307

North Las Vegas, Nevada 89036-0307

Prepared by:

Bechtel SAIC Company, LLC

1180 Town Center Drive

Las Vegas, Nevada 89144

Under Contract Number

DE-AC28-01RW12101 


\section{DISCLAIMER}

This report was prepared as an account of work sponsored by an agency of the United States Government. Neither the United States Government nor any agency thereof, nor any of their employees, nor any of their contractors, subcontractors or their employees, makes any warranty, express or implied, or assumes any legal liability or responsibility for the accuracy, comp leteness, or any third party's use or the results of such use of any information, apparatus, product, or process disclosed, or represents that its use would not infringe privately owned rights. Reference herein to any specific commercial product, process, or service by trade name, trademark, manufacturer, or otherwise, does not necessarily constitute or imply its endorsement, recommendation, or favoring by the United States Government or any agency thereof or its contractors or subcontractors. The views and opinions of authors expressed herein do not necessarily state or reflect those of the United States Government or any agency thereof. 
Prepared by:

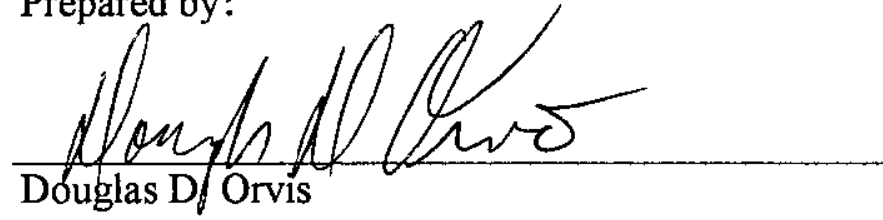

Preclosure Safety Analysis

Approved by:
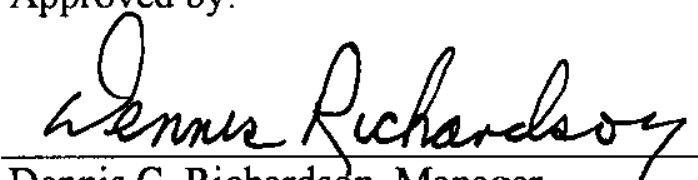

Dennis C. Richardson, Manager

Preclosure Safety Analysis
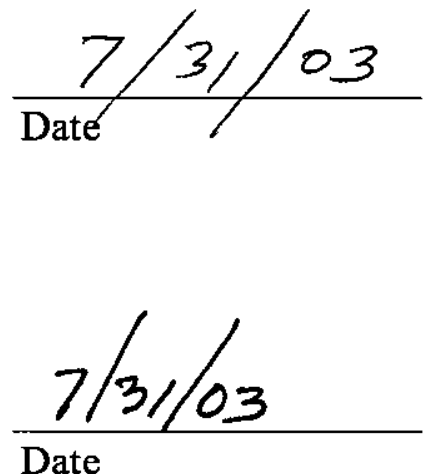


\section{ACKNOWLEDGEMENTS}

The contributions of the following team members is hereby acknowledged:

Douglas A. Brownson, Shyang-Fenn (Alex) Deng, Thomas D. Dunn, Robert J. Garrett, Norman

Kahler, Barbara A. Merrill, Richard P. Morissette, Daniel A. Thomas, Guy E. Ragan, Shiaw-Der (Steve) Su, Sen-Sung Tsai, and Jo A. Ziegler. 


\section{CONTENTS}

\section{Page}

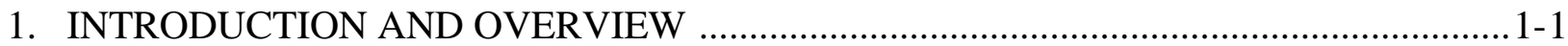

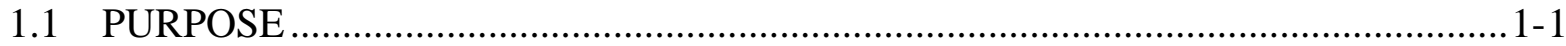

1.2 SCOPE

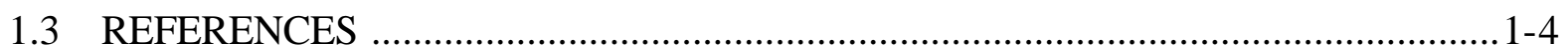

1.3.1 Documents Cited .............................................................................1-4

1.3.2 Codes, Standards, Regulations, and Procedures.........................................1-4

2. REGULATORY REQUIREMENTS AND GUIDANCE .................................................2-1

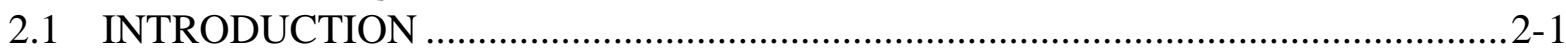

2.2 PRIMARY REGULATORY DOCUMENTS RELEVANT TO PRECLOSURE

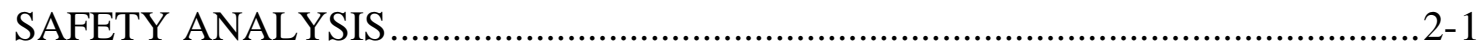

2.2.1 Relevant Sections of 10 CFR Part 63 ...................................................2-1

2.2.2 Other Pertinent Regulatory Guidance .......................................................2-3

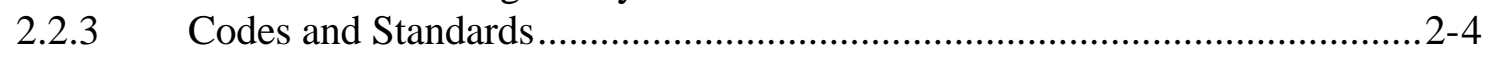

2.2.4 Department of Energy Orders and Standards ...........................................2-4

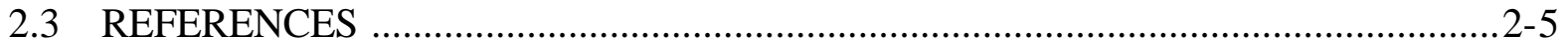

2.3.1 Documents Cited .......................................................................... 2-5

2.3.2 Codes, Standards, Regulations, and Procedures..........................................2-5

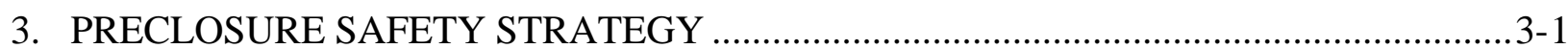

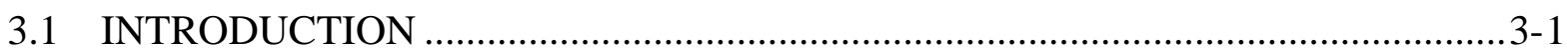

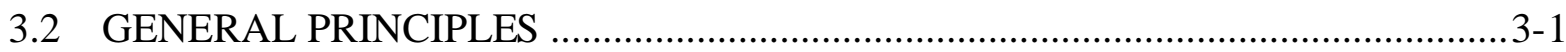

3.3 PRECLOSURE SAFETY CASE...................................................................... 3-1

3.3.1 Preclosure Safety Analysis .................................................................. 3-2

3.3.2 Margin and Defense in Depth.................................................................. 3-2

3.3.3 Consequence Analysis of Category 1 and Category 2 Event
Sequences and Beyond Category 2 Event Sequences ....................................3-3

3.3.4 Nuclear Industry Precedent and Experience............................................3-4

3.3.5 Evaluation Approach...................................................................... 3-5

3.3.6 Identification and Classification of SSCs Important to Safety......................3-6

3.3.7 Conservative or Bounding Approaches ...................................................... 3-6

3.3.8 Preferred Approach .......................................................................... 3-7

3.3.9 License Specifications and Surveillances................................................3-7

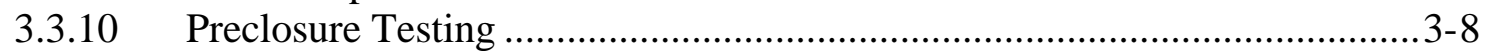

3.3.11 Performance Confirmation ....................................................................... 3-8

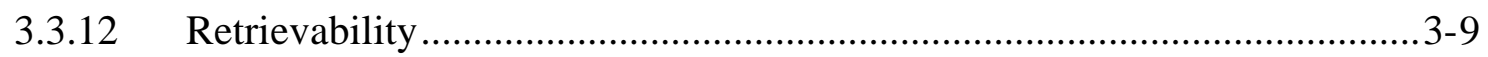

3.4 STRATEGY FOR PREVENTING OR MITIGATING PRECLOSURE OFFSITE RADIATION EXPOSURE .............................................................

3.4.1 Identification of Important-to-Safety Features and Controls .......................3-9

3.4.2 Design Bases for Facilities and Limits on Operations ................................3-10

3.4.3 Safety Strategy for Repository Preclosure Operational Functions ...............3-10

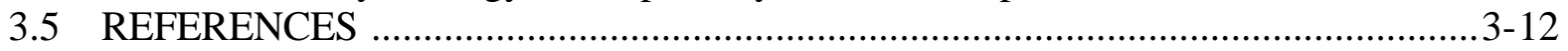

3.5.1 Documents Cited ………………………...................................... 3-12 


\section{CONTENTS (Continued)}

Page

3.5.2 Codes, Standards, Regulations, and Procedures

$3-12$

4. OVERVIEW OF PRECLOSURE SAFETY ANALYSIS ELEMENTS AND

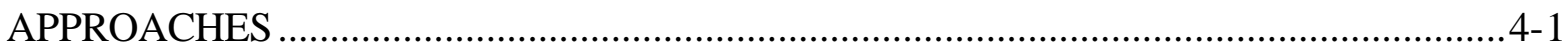

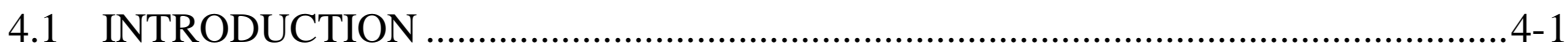

4.2 BACKGROUND .......................................................................................

4.3 OVERVIEW OF PROCESS FOR PERFORMING A PRECLOSURE SAFETY

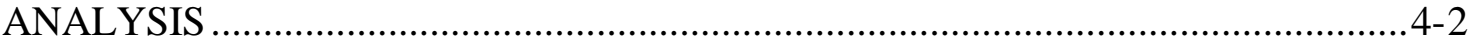

4.3.1 Flow Diagram of Preclosure Safety Analysis Process .................................4-3

4.3.2 Applications of Preclosure Safety Analyses................................................4-13

4.4 DEVELOPING AND DOCUMENTING THE PRECLOSURE SAFETY

ANALYSIS IN THE LICENSE APPLICATION ……………………................. 4-15

4.4.1 Level of Design Detail in the License Application for Construction

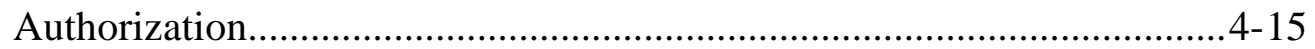

4.4.2 Information Base for Preclosure Safety Analysis in Support of License Application for Construction Authorization...................................4-16

4.4.3 Preclosure Safety Analysis as Basis for the License Application...............4-18

4.4.4 Preclosure Safety Analysis for Retrieval Operations ..................................4-19

4.5 ENSURING PERFORMANCE OF STRUCTURES, SYSTEMS, AND

COMPONENTS IMPORTANT TO SAFETY ....................................................

4.6 RADIATION SAFETY - ALARA …………….............................................. 4-22

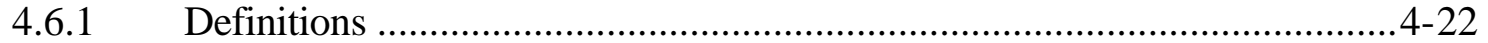

4.6.2 ALARA Design Considerations ......................................................... $4-23$

4.6.3 Organizational Responsibilities for ALARA Design ..................................4-24

4.6.4 ALARA Design Process ………………….........................................4-24

4.7 PSA WORKFLOW AND INTEGRATION ..........................................................

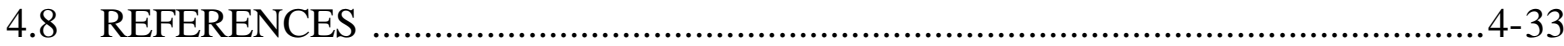

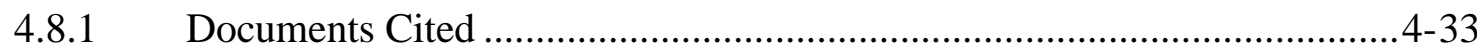

4.8.2 Codes, Standards, Regulations, and Procedures.........................................4-34

5. DESCRIPTION OF SITE, FACILITIES, AND OPERATIONS ………………….............5-1

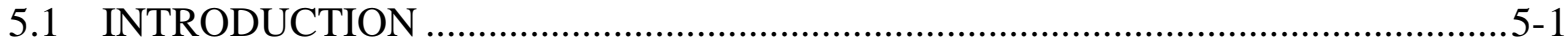

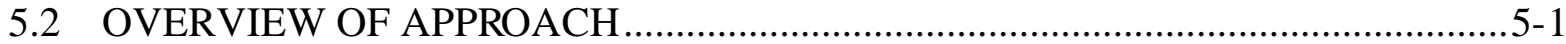

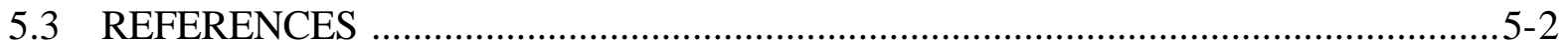

5.3.1 Documents Cited ................................................................................

5.3.2 Codes, Standards, Regulations, and Procedures............................................ 5-2

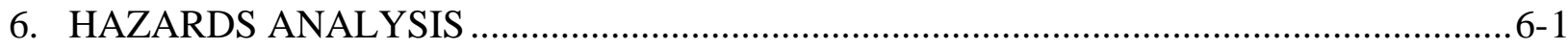

6.1 EXTERNAL EVENTS HAZARDS ANALYSIS ................................................... 6-1

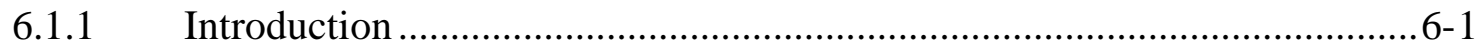

6.1.2 Overview of Approach...........................................................................

6.1.3 Details of Basic Approach to Screening with Examples ...............................6-3

6.2 INTERNAL EVENTS HAZARDS ANALYSIS ................................................ 6-17

6.2.1 Introduction ..................................................................................... 


\section{CONTENTS (Continued)}

Page

6.2.2 Overview of Basic Approach ................................................................6-17

6.2.3 Approach for Evaluating Applicability of Generic Internal Events to Repository Functional Areas

6.2.4 Examples of Evaluating the Applicability of Generic Events to Repository Function Areas......................................................................6-24

6.2.5 Internal Events Hazards List ..................................................................... 6-32

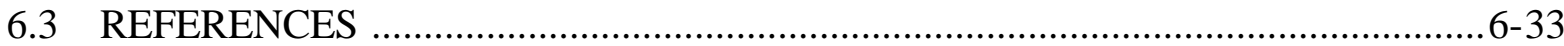

6.3.1 Documents Cited ...............................................................................6-33

6.3.2 Codes, Standards, Regulations, and Procedures......................................6-34

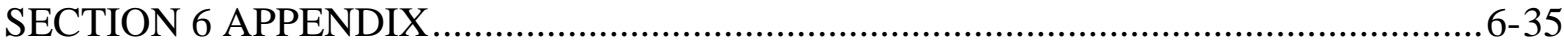

7. EVENT SEQUENCE FREQUENCY ANALYSIS ....................................................

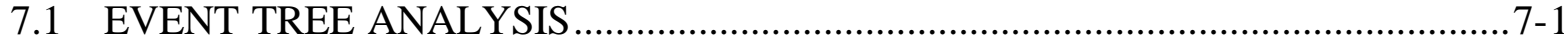

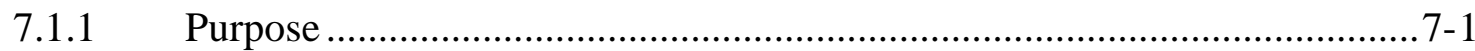

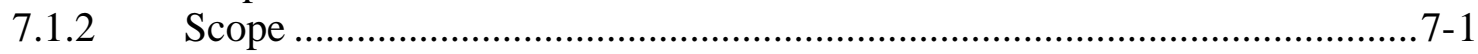

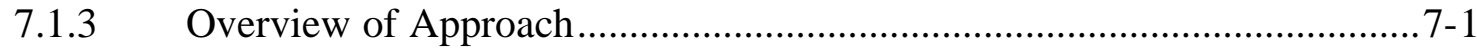

7.1.4 Details of Approach................................................................................

7.1.5 Examples of Applications of Event Tree Analysis .................................... 7-16

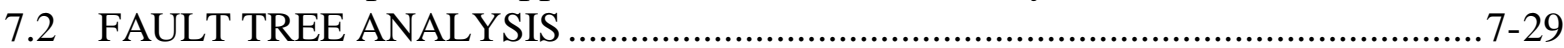

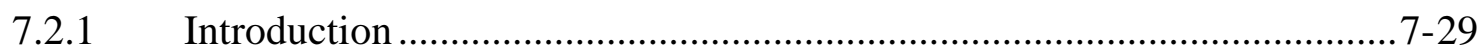

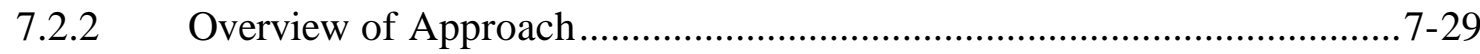

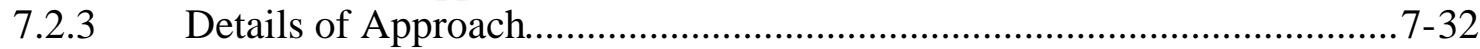

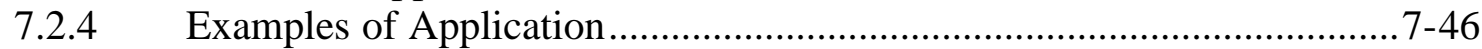

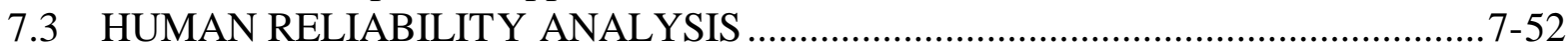

7.3.1 Purpose ....................................................................................... $7-52$

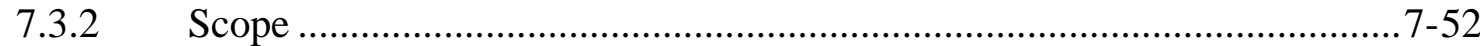

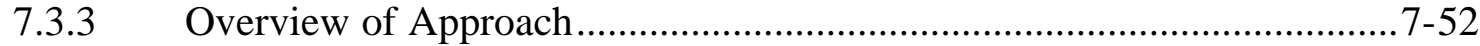

7.3.4 Details of Approach........................................................................... $7-54$

7.4 COMMON-CAUSE AND DEPENDENT FAILURES ANALYSIS .......................7-79

7.4.1 Purpose ...................................................................................... $7-79$

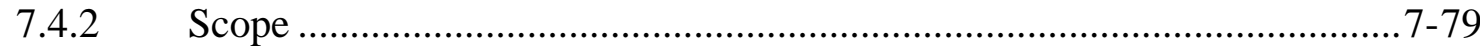

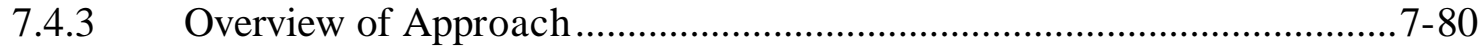

7.4.4 Details of Approach............................................................................ 7-85

7.4.5 Steps in Performing Dependent Failure Analysis for a Repository ...........7-95

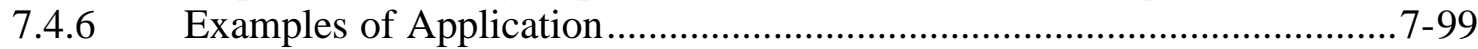

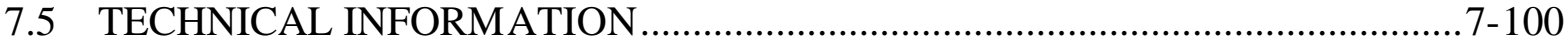

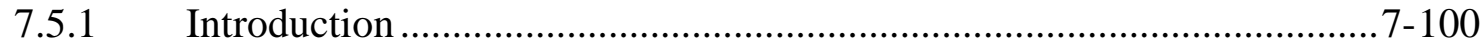

7.5.2 Overview of Approach..................................................................... $7-100$

7.5.3 Details of Approach.................................................................. 7-102

7.6 EVENT SEQUENCE FREQUENCY BINNING .......................................... $7-136$

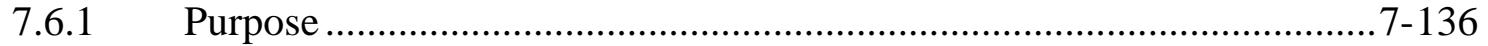

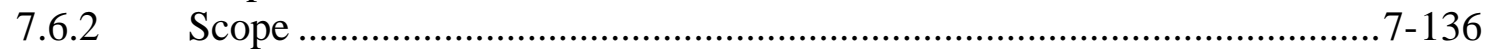

7.6.3 Overview of Approach................................................................ $7-136$ 


\section{CONTENTS (Continued)}

Page

7.6.4 Details of Approach...............................................................................

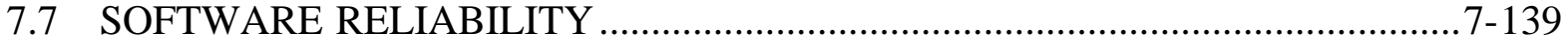

7.7.1 Computer Software Reliability Analysis in PSA ....................................7-140

7.7.2 Non-computer Software Reliability in PSA......................................... 7-141

7.8 REFERENCES ………..........................................................................

7.8.1 Documents Cited .........................................................................

7.8.2 Codes, Standards, Regulations, and Procedures.........................................

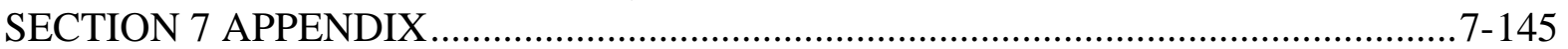

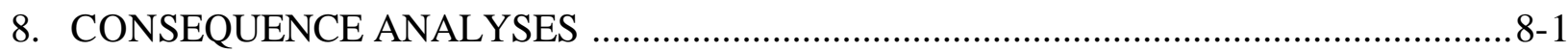

8.1 PERFORMANCE OBJECTIVES AND EXPOSURE STANDARDS ……................ $8-1$

8.2 INPUTS TO CONSEQUENCE ANALYSES ……...........................................

8.2.1 Source Terms ................................................................................

8.2.2 Meteorological Data and Site Boundary Distance for Determination of Atmospheric Dispersion Factors............................................................ 8-11

8.2.3 Dose Conversion Factors .................................................................. 8-11

8.2.4 Radionuclide Release Fractions ........................................................

8.2.5 Mitigation Factor ........................................................................... 8-15

8.3 CALCULATIONS OF DOSES TO WORKERS AND MEMBERS OF THE PUBLIC FROM CATEGORY 1 EVENT SEQUENCES FROM AIRBORNE RELEASES AND EXPOSURES TO DIRECT RADIATION ………………….... 8-15

8.3.1 Calculations of Doses to Workers and Members of the Public from Airborne Radionuclides ........................................................................ 8-15

8.3.2 Onsite and Offsite Direct Radiation Exposures during Normal Operations and Category 1 Event Sequences ............................................ 8-21

8.4 CALCULATIONS OF DOSES TO MEMBERS OF THE PUBLIC FROM CATEGORY 2 EVENT SEQUENCES FROM AIRBORNE RELEASES AND EXPOSURES TO DIRECT RADIATION..........................................................

8.4.1 Calculations of Doses to the Public from Airborne Radionuclides.............8-24

8.4.2 Uncertainty Analysis of Category 2 Consequences .................................. 8-24

8.4.3 Evaluation of Doses to Hypothetical Members of the Public from Category 2 Event Sequences Against Regulatory Dose Limits .................. 8-26

8.4.4 Offsite Direct Radiation Exposures from Category 2 Event Sequences ....8-26

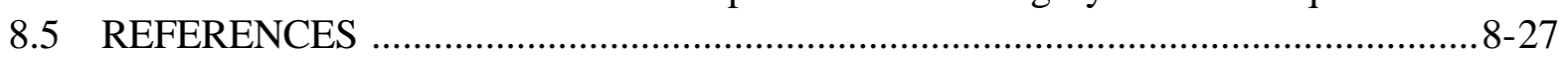

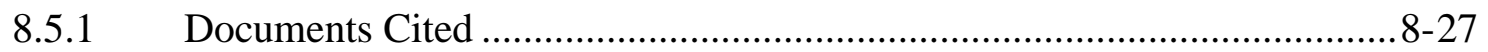

8.5.2 Codes, Standards, Regulations, and Procedures......................................... 8-29

9. UNCERTAINTY AND SENSITIVITY ANALYSIS, GENERAL CONCEPTS, AND

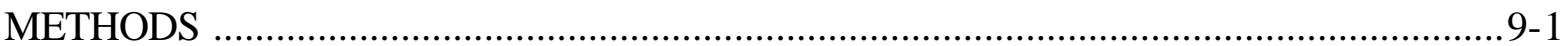

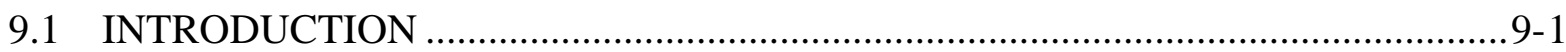

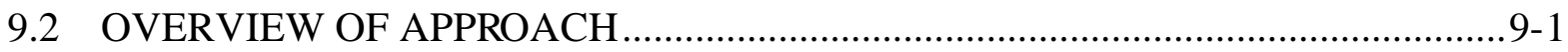

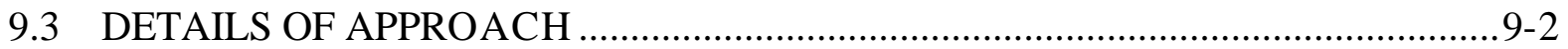

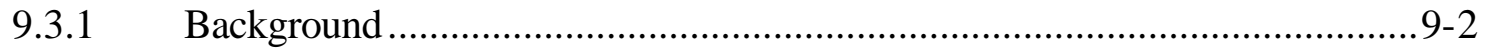




\section{CONTENTS (Continued)}

Page

9.3.2 Identifying Sources of Uncertainty in Models and Input Information.........9-4

9.3.3 Representing Uncertainties in Input and Output Variables ........................9-6

9.3.4 Propagating Uncertainties in Frequency and Consequence Analyses........9-11

9.3.5 Uncertainty Analysis versus Sensitivity Analysis .................................9-12

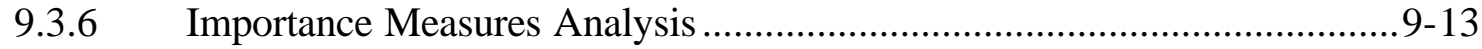

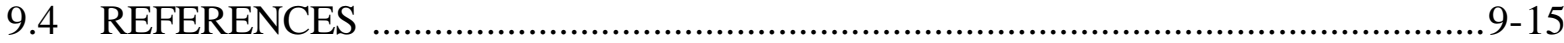

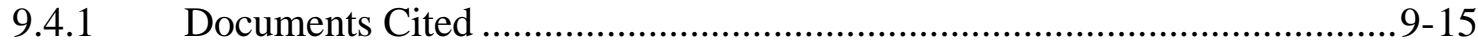

9.4.2 Codes, Standards, Regulations, and Procedures................................... 9-15

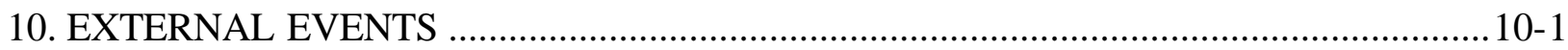

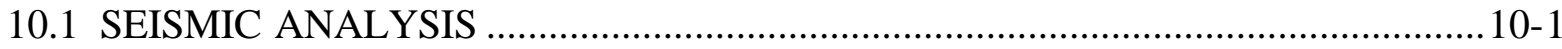

10.1.1 Introduction ...................................................................................

10.1.2 Regulatory Bases and Preclosure Seismic Design Strategy .......................10-2

10.1.3 Methods for assigning Design Basis Ground Motion (DBGM) to SSCs Important to Safety ......................................................................10-7

10.1.4 Methods for Frequency Quantification and Demonstration of Regulatory Compliance Using Seismic Probabilistic Risk Assessment and Seismic Margins Analyses................................................................10-22

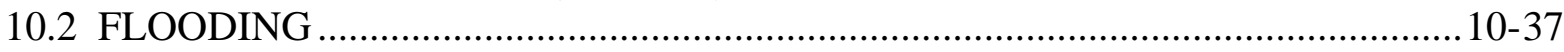

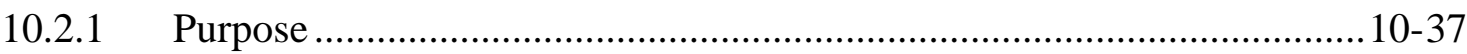

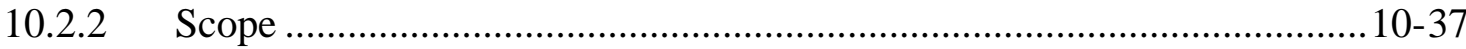

10.2.3 Overview of Approach.......................................................................10-37

10.2.4 Details of Approach......................................................................... 10-37

10.2.5 Flooding Protection Requirements....................................................10-40

10.2.6 Consequence Analysis .................................................................... 10-40

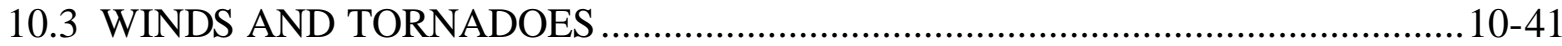

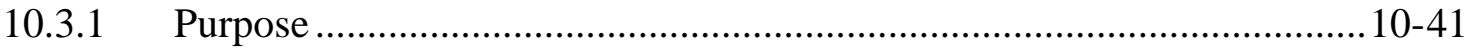

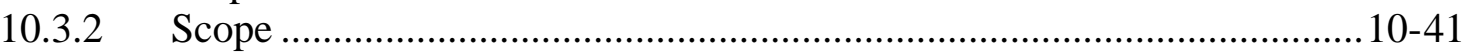

10.3.3 Overview of Approach........................................................................10-41

10.3.4 Details of Approach.............................................................................10-42

10.3.5 Wind and Tornado Protection Requirements .........................................10-48

10.4 LIGHTNING AND EXTREME WEATHER ………......................................10-48

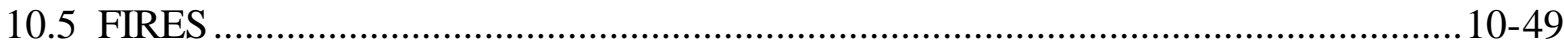

10.5.1 Fires in MGR Operations Areas.....................................................10-49

10.5.2 Wildland Fires ............................................................................. 10-55

10.6 OTHER EXTERNAL EVENTS ………………...........................................10-56

10.6.1 Loss-of-Offsite Power ....................................................................

10.6.2 Aircraft Hazard Analysis …………………...................................10-56

10.6.3 Military and Industrial Hazards ............................................................10-61

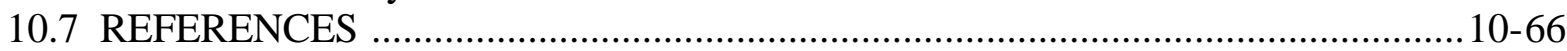

10.7.1 Documents Cited ........................................................................ 10-66

10.7.2 Codes, Standards, Regulations, and Procedures......................................10-68

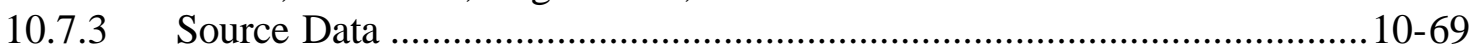




\section{CONTENTS (Continued)}

Page

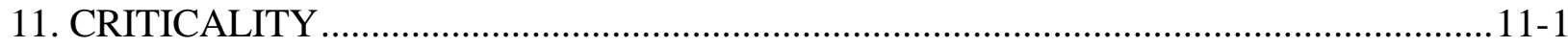

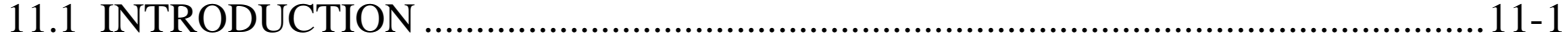

11.2 REGULATORY REQUIREMENTS …….............................................................11-1

11.3 REPOSITORY PRECLOSURE CRITICALITY SAFETY STRATEGY ….............11-1

11.4 CRITICALITY ANALYSIS PROCESS ………….........................................11-2

11.4.1 Identify the Systems, Structures, Components, and Processes Associated with Criticality Hazards ..........................................................11-3

11.4.2 Identify Those Waste Forms That Have the Potential to Achieve Criticality ............................................................................................11-7

11.4.3 Develop Criticality Event Trees ...........................................................11-7

11.4.4 Quantify the Criticality Event Trees.................................................11-10

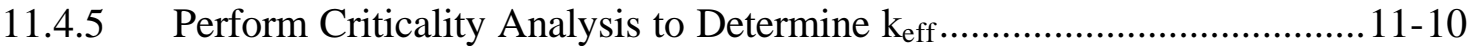

11.4.6 Perform Criticality Consequence Analyses .............................................11-10

11.4.7 Document the Results ...................................................................11-11

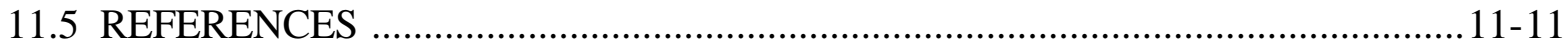

11.5.1 Documents Cited ...........................................................................11

11.5.2 Codes, Standards, Regulations, and Procedures.......................................11-11

12. SAFETY SIGNIFICANT CLASSIFICATION OF SSCs ITS ........................................12-1

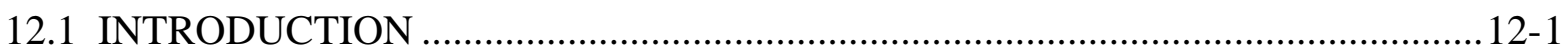

12.2 SUMMARY OF THE PSA PROCESS …………………………………...... 12-2

12.3 BASIS OF THE RISK-INFORMED SC CLASSIFICATION PROCESS ...............12-5

12.4 THE SC CLASSIFICATION PROCESS …………............................................

12.5 FUNCTIONAL FAILURE ANALYSIS IN RISK INFORMED SC

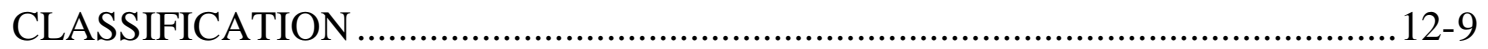

12.6 RISK-INFORMED SC CLASSIFICATION OF SSCS ASSOCIATED WITH CATEGORY 1 EVENT SEQUENCES ……………..........................................12-11

12.6.1 Compliance Demonstration for Normal Operation Releases and Category 1 Event Sequences ................................................................12-11

12.6.2 Process for Risk-Informed SC Classification of SSCs in Category 1 Event Sequences .........................................................................12-12

12.7 RISK INFORMED SC CLASSIFICATION OF SSCS ASSOCIATED WITH CATEGORY 2 EVENT SEQUENCES ........................................................12-14

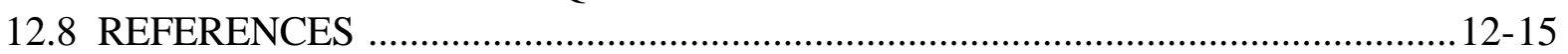

12.8.1 Documents Cited ..........................................................................12-15

12.8.2 Codes, Standards, Regulations, and Procedures.......................................12-15

13. SELECTION OF 10 CFR 63.2 DESIGN BASES FOR STRUCTURES, SYSTEMS, AND COMPONENTS IMPORTANT TO SAFETY ………......................................13-1

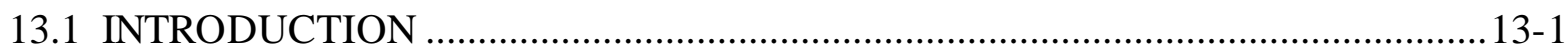

13.2 BACKGROUND INFORMATION ..................................................................13-1

13.3 METHOD FOR DEVELOPING 10 CFR 63.2 DESIGN BASES ............................13-3

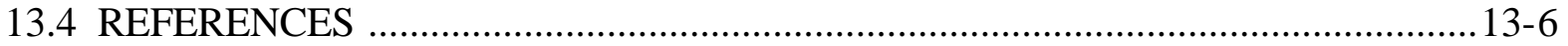




\section{CONTENTS (Continued)}

\section{Page}

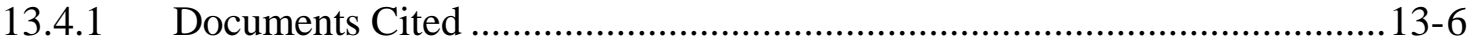

13.4.2 Codes, Standards, Regulations, and Procedures.................................... 13-6

14. DOCUMENTATION AND PREPARATION OF LICENSE APPLICATION .................14-1

14.1 PRECLOSURE SAFETY ANALYSIS DOCUMENTATION ................................14-1

14.1.1 Internal and External Hazards Analyses....................................................14-1

14.1.2 Categorization of Event Frequencies .................................................14-1

14.1.3 Consequence Analysis ..................................................................... 14-2

14.1.4 Preclosure Safety Analysis .................................................................. 14-3

14.1.5 Identify SSCs ITS and Important to Waste Isoloation...............................14-4

14.2 PRECLOSURE SAFETY ANALYSIS AND LICENSE APPLICATION

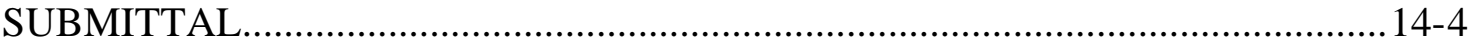

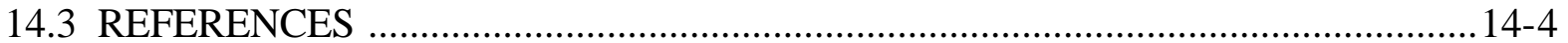

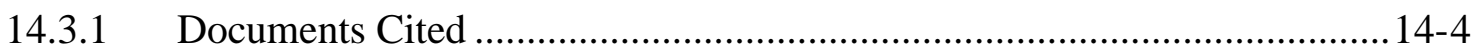

14.3.2 Codes, Standards, Regulations, and Procedures....................................... 14-5

GLOSSARY

GLOSSARY-1 


\section{INTENTIONALLY LEFT BLANK}




\section{FIGURES}

Page

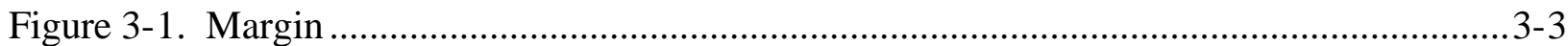

Figure 4-1. Preclosure Safety Analysis............................................................................... 4-4

Figure 4-2. Process for Preclosure Safety Analysis Using Available Level of Design

Detail ..............................................................................................................

Figure 4-3a. Hazards Analysis System (1of2) ………......................................................... 4-6

Figure 4-3b. Hazards Analysis System (2 of 2) ...............................................................

Figure 4-4a. Work Interface Flow Chart (1 of 2)................................................................

Figure 4-4b. Work Interface Flow Chart (2 of 2) ................................................................4-9

Figure 7-1. Example of a Fork Style Event Tree for a Hypothetical Waste Handling

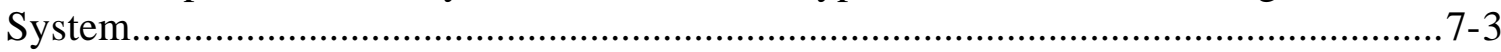

Figure 7-2. Example of a Stair-Step Style ET for a Hypothetical Waste Handling

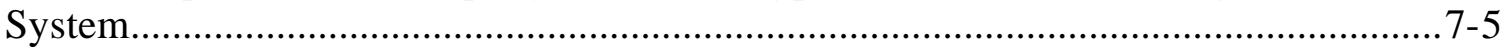

Figure 7-3. Steps in Event Tree Construction..................................................................

Figure 7-4. ET for Hypothetical Uncontrolled Descent Due to Random-Failure Initiator.......7-17

Figure 7-5. Simplified ET for Hypothetical Uncontrolled Descent (First Example) ............... 7-23

Figure 7-7. ET for Hypothetical Fire Initiated Uncontrolled Descent ..................................... 7-26

Figure 7-8. ET for Hypothetical Human Error Initiated Uncontrolled Descent ………............ 7-28

Figure 7-9. Standard Fault-Tree Symbols ...........................................................................

Figure 7-10. Illustration of Fault Tree Development ……................................................... 7-41

Figure 7-11. Pressure Tank System ...........................................................................

Figure 7-12. Fault Tree Example for Pressure Tank Rupture (1 of 2).................................... 7-50

Figure 7-13. Simplified Fault Tree for Pressure Tank Example.............................................. 7-53

Figure 7-14. Example of FT Containing Type A Human Actions .......................................... 7-59

Figure 7-15. Example of FT Containing Type B Human Actions........................................... 7-60

Figure 7-16. Example of ET with Type C Human Action in Event Headings ..........................7-61

Figure 7-17. Operator Action Tree: A Generalized Representation of Type C HAs ...............7-72

Figure 7-18. Example of Human Reliability Analysis Tree …………………………..........7-78

Figure 7-19. Physical Elements of Dependent Events ............................................................ 7-84

Figure 7-20A. Baseline Event Tree Without CCFs ............................................................... 7-88

Figure 7-20B. ET with Fire-Initiated Common-Cause Failure of a Heating, Ventilation, and Air-Conditioning, and High-Efficiency Particulate Air Filter System...................7-88

Figure 7-21. Illustration of Logic Models for Independent Failures ....................................... 7-92

Figure 7-22. Illustration of Logic Models for Common-Cause Failures .................................7-93

Figure 7-23. Exponential Probability of Failure …………............................................. 7-104

Figure 7-24. Unavailability with Inspection and Test ......................................................7-106

Figure 7-25. Probability of Restoration - Exponential Repair Model....................................7-107

Figure 10-1. Event Sequence Diagram for Internal Initiated Drop Event ..............................10-11

Figure 10-2. Event Sequence Diagram for Seismic Initiated Drop Event ..............................10-11

Figure 10-3. Event Sequence Diagram for Fire Initiated Drop Event ....................................10-12

Figure 10-4. Event Sequence Diagram for Seismic and Fire Initiated Drop Event.................10-13

Figure 10-5. Example of Baseline Seismic Event Tree Derived from Event Sequence

Diagram for Load Drop.......................................................................................10-14

Figure 10-6. Event Sequence Diagram for Collapse of Transfer-Cell Structure ....................10-21 


\section{FIGURES (Continued)}

Figure 10-7. Seismic Event Tree for Collapse of Transfer-Cell $10-21$

Figure 10-8. Seismic Event Tree - Structures, Systems, and Components Designed to DBGM - 1 Earthquake $10-24$

Figure 10-9. Seismic Event Tree - Structures, Systems, and Components Designed to DBGM-1, but Earthquake Accelerations are Greater than DBGM-1 .........................10-25

Figure 10-10. Example Fragility Curves .......................................................................10-27

Figure 10-11. Example of Fire Event Tree for Drop of Spent Fuel Assembly ........................10-54

Figure 11-1. Criticality Analysis Flow Chart ..................................................................11-4

Figure 11-1. Criticality Analysis Flow Chart (Continued) ..................................................11-6

Figure 12-1. Preclosure Safety Analysis ......................................................................12-3

Figure 12-2. Relative Risk Significance Regions .............................................................12-7

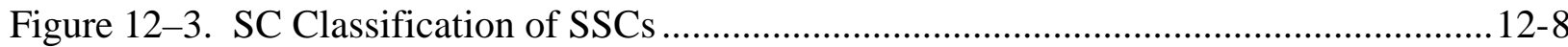

Figure 12-4. SC Classification Process ..................................................................12-10

Figure 13-1. Relationship of Repository Design Bases to 10 CFR 63.2 Design Bases and the Safety Analysis Report (SAR) ......................................................................13-2

Figure 13-2. Basic Steps in Developing 10 CFR 63.2 Design Bases ......................................13-5 


\section{TABLES}

Page

Table 3-1. Preclosure Safety Strategy........................................................................... 3-11

Table 4-1. Sample Approach for Demonstrating Compliance with 10 CFR 63.112(e) ..........4-21

Table 4-2 Preclosure Safety Analysis Work Instructions .....................................................4-29

Table 6-1. Generic External Events ................................................................................6-4

Table 6-2. Example Summary of External Events Hazards Analysis Screening ....................6-11

Table 6-3. Example External Events Hazards List ..........................................................6-12

Table 6-4. Example External Events Hazards Screened Out..............................................6-12

Table 7-1. Boolean Operations ...................................................................................... 7-33

Table 7-2a. Example of Task Analysis ........................................................................

Table 7-2b. Example of Task Analysis (Continued) …...................................................... 7-64

Table 7-3. Example Probabilities of Errors of Commission in Operating Manual

Controls 7-67

Table 7-4. Types of Dependent Events Based on their Impact on Preclosure Safety of a

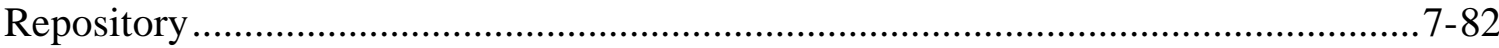

Table 7-5. A Guide to Unreliability of Various System Arrangements with

Consideration of Dependent Failures....................................................................... 7-86

Table 7-6. Generic Beta Factors ................................................................................ 7-98

Table 7-7. Sources of Facility-Specific and Operations-Specific Experience Information....7-103

Table 7-8. Example of Generic Component Failure Rates Database .................................7-116

Table 7-9. Crane Failure Demand Rates .................................................................... 7-136

Table 8-1. Dose Standard for Normal Operations and Category 1 Event Sequences................8-2

Table 8-2. Dose Standard for Category 2 Event Sequences ............................................. 8-3

Table 8-3. Average and Maximum PWR and BWR CSNF Assemblies ...............................8-4

Table 8-4. Example of PWR and BWR CSNF Radionuclide Inventories .............................8-5

Table 8-5. CSNF Assembly Initial Crud Activities ......................................................... 8-7

Table 8-6. Examples of Category 1 Crud Source Terms (25-year decay) ..............................8 8

Table 8-7. Examples of Category 2 Crud Source Terms (5-year decay) ................................8-8

Table 8-8. Radionuclide Content of HLW Canisters ........................................................... 8-10

Table 8-9. Respirable Release Fractions for CSNF ...................................................... 8-13

Table 8-9. Example of Annual Releases from the Subsurface Due to Normal Operations ......8-18

Table 8-10. Example of Calculating Annualized Cesium-137 Release for Category 1

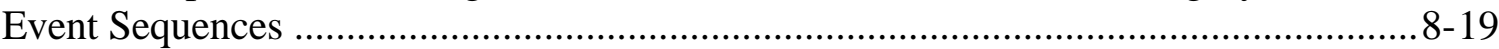

Table 9-1 Properties of the Mean of a Lognormal Distribution ............................................9-11

Table 10-1 Bases for Assigning Design Basis Ground Motions to SSCs IT ..........................10-7

Table 10-2. DBGMs Based on Seismic Sequence Consequences .....................................10-18

Table 10-3. Illustration of Convolution Analysis ........................................................10-35

Table 10-4. Assumptions for SMA Example................................................................. 10-36

Table 10-5. Example Maximum Estimated and Observed Wind Speeds near Yucca

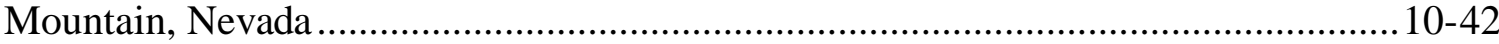

Table 10-6. Design Basis Tornado Characteristics .......................................................... 10-44

Table 10-7. Tornado Wind Speed (miles per hour) by Region........................................... 10-44

Table 10-8. Example Tornado Wind Speed for 5-Degree Latitude and Longitude Box

Containing Yucca Mountain, Nevada ................................................................. 10-46 
TABLES (Continued)

Page

Table 10-9. Spectrum II Missiles .

$10-48$

Table 12-1. Development of a Preclosure Safety Analysis ................................................. 12-4

Table 12-2. Relative Risk Significance Regions .......................................................... 12-6

Table 12-3. Classifications Based on Risk Significance ...................................................... 12-9

Table 12-4. Steps for Performing an SC Classification Analysis of SSCs Associated

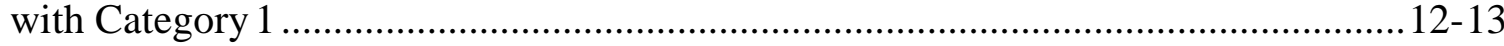




\section{ACRONYMS}

AC alternating current (electrical power)

ALARA as low as is reasonably achievable

ANSI/ANS American Nuclear Standards Institute/American Nuclear Society

ASCE American Society of Civil Engineers

ASME

ATS The American Society of Mechanical Engineers

$\mathrm{BC} 2$ assembly transfer system

$\mathrm{BI}$ beyond Category 2 (event sequence)

BSC

BWR

Birmbaum Importance

CA Bechtel SAIC Company LLC boiling water reactor

$\mathrm{CCF}$

construction authorization

$\mathrm{C} / \mathrm{SC}$

common-cause failure

CSNF

crud, surface contamination

DBGM

commercial spent nuclear fuel

DC

design basis ground motion

DOE

direct current (electrical power)

DCF

U.S. Department of Energy

DPC

dose conversion factor

dual purpose canister

$\mathrm{EF}$

error factor

EEHA

external events hazards analysis

EEHL external events hazards list

EMF electromagnetic force

ESD

ESF

ET

event sequence diagram

Exploratory Studies Facility

ETA

event tree

FC

event tree analysis

FEPs

FHSA

frequency category (seismic)

FMEA

FT

FTA

features, events, and processes

fire-hazards screening analysis

FV

Failure Modes and Effects Analyses

fault tree

fault tree analysis

GF guaranteed failure

GROA Geologic Repository Operations Area

HA human action

HCLPF high confidence of low probability of failure

HEP

human error probability 


\section{ACRONYMS (Continued)}

HEPA high-efficiency particulate air

HFE human failure event

HLW high-level radioactive waste

HRA human reliability analysis

HVAC heating, ventilation, and air-conditioning

IE initiating event

IEEE Institute of Electrical and Electronics Engineers

IM importance measure

ITS important to safety

LA License Application

LA-CA License Application for Construction Authorization

LB lower bound

LLW low-level radioactive waste

LN lognormal

LOSP loss of offsite power

MAPE mean annual probability of exceedance

MCNP MCNP-A General Monte Carlo N-Particle Transport Code

MGR monitored geologic repository

NFPA National Fire Protection Association

NPP nuclear power plant

NRC U.S. Nuclear Regulatory Commission

NTS Nevada Test Site

OAT operator action tree

PCP Performance Confirmation Program

PDF probability distribution function

PGA peak ground acceleration

PMF Probable Maximum Flood

PRA probabilistic risk analysis

PSA preclosure safety analysis

PWR pressurized water reactor

QA quality assurance

R\&P receive and possess

RAW risk-achievement worth

$\mathrm{RF}$ respirable fraction

$\mathrm{RF} \quad$ random failure

RRW risk-reduction worth 


\section{ACRONYMS (Continued)}

SAR safety analysis report

SC safety category

SET seismic event tree

SMA seismic margins analysis

SME seismic margins earthquake

SNF spent nuclear fuel

SSCs structures, systems, and components

SSE safe shutdown earthquake

T\&M test and maintenance

TEDE total effective dose equivalent

TSPA total system performance assessment

UB upper bound

WHB Waste Handing Building

WP waste package

YMP Yucca Mountain Project

YMRP Yucca Mountain Review Plan 


\section{INTENTIONALLY LEFT BLANK}




\section{INTRODUCTION AND OVERVIEW}

A preclosure safety analysis (PSA) is a required element of the License Application (LA) for the high-level radioactive waste repository at Yucca Mountain. This guide provides analysts and other Yucca Mountain Repository Project (the Project) personnel with standardized methods for developing and documenting the PSA. The definition of the PSA is provided in 10 CFR 63.2, while more specific requirements for the PSA are provided in 10 CFR 63.112, as described in Sections 1.2 and 2 .

The PSA requirements described in 10 CFR Part 63 were developed as risk-informed performance-based regulations. These requirements must be met for the LA. The PSA addresses the safety of the Geologic Repository Operations Area (GROA) for the preclosure period (the time up to permanent closure) in accordance with the radiological performance objectives of 10 CFR 63.111. Performance objectives for the repository after permanent closure (described in 10 CFR 63.113) are not mentioned in the requirements for the PSA and they are not considered in this guide. The LA will be comprised of two phases: the LA for construction authorization (CA) and the LA amendment to receive and possess (R\&P) high-level radioactive waste (HLW). PSA methods must support the safety analyses that will be based on the differing degrees of design detail in the two phases.

The methods described herein combine elements of probabilistic risk assessment (PRA) and deterministic analyses that comprise a risk-informed performance-based safety analysis.

This revision to the PSA guide was prepared for the following objectives:

1. To correct factual and typographical errors.

2. To provide additional material suggested from reviews by the Project, the U.S. Department of Energy (DOE), and U.S. Nuclear Regulatory Commission (NRC) Staffs.

3. To update material in accordance with approaches and/or strategies adopted by the Project.

In addition, a principal objective for the planned revision was to ensure that the methods and strategies would meet the acceptance criteria of the Yucca Mountain Review Plan (YMRP) (NRC 2003).

\subsection{PURPOSE}

The purpose of this guide is to describe and standardize methods judged to be in conformance with NRC regulations and guidance for developing and documenting the PSA as part of the LA for the repository at Yucca Mountain. In addition, this document provides approaches for obtaining:

- Uniformity in analyses

- $\quad$ Auditable analyses and databases

- A basis for training safety analysts 
- Improved communications among the design and licensing groups and the DOE

- $\quad$ A distinction in the analysis scope and approaches for the CA and R\&P phases

- $\quad$ Preferred methods for analyzing and documenting preclosure safety.

Changes to this guide may be motivated by requirements in the recently released YMRP (NRC 2003) or requests from the operating contractor, the DOE, or the NRC.

\subsection{SCOPE}

This guide is intended to provide technical guidance for the preparation of the PSA for the repository at Yucca Mountain in support of the LA. This guide provides safety analysts with relevant regulations, regulatory guidance, and licensing precedents, as well as instructions for performing each of the required analyses.

This guide is aimed at safety analysts who perform system-safety and radiological dose-consequence analyses associated with internal and external hazards. These activities require knowledge of design and operational features of the repository and of the geographical, geological, and meteorological features of the site. Such knowledge is provided by design and scientific organizations that are not directly associated with preclosure safety analyses. This guide is not intended to provide methods for design or specialized safety analyses, such as shielding calculations, fire-protection analysis, or seismic structural analysis. This guide does, however, define work interfaces between the PSA group and various Project organizations.

This guide provides references for details and background information concerning methods and regulatory matters. The methods described herein are recommended for use on the Project. The methods are generally applicable to varying levels of design detail. Where important differences exist between analyses that are more suitable for $\mathrm{CA}$ than those required for $\mathrm{R} \& \mathrm{P}$, this guide favors support of CA and may defer preparation of R\&P-specific sections until needed.

The PSA is independent and separate from the total system performance assessment (TSPA), which addresses postclosure safety. The PSA is concerned with events involving natural phenomena, active systems, and human actions that could occur within a time scale of 1 to several 100 years, the preclosure period. The TSPA addresses events involving passive elements and natural processes that could occur over tens of thousands of years following permanent closure of the repository. Two areas of analysis have some similarity between PSA and TSPA: (1) identifying natural phenomena hazards and (2) calculating radiological consequences. Identifying and screening credible hazards from natural phenomena is performed in an external events hazards analysis that provides input to the PSA. The TSPA has a separate procedure for identifying and screening features, events, and processes (FEPs). The PSA includes a review of FEPs for relevance as potential preclosure hazards. The PSA includes calculations of potential radiological consequences to workers and to the public. Some of the methodology and biological dose conversion factors used in the PSA are similar to, or the same as, those used in the TSPA.

The PSA is an iterative process that continues throughout the design and operational evolution of the repository design. The contents of the PSA are defined in 10 CFR 63.112(a) through (f). The analyses initially identify instances in which functions are required to prevent or to mitigate 
potential hazards and radiological releases. Prevention and mitigation functions are provided by structures, systems, and components (SSCs) determined to be important to safety (ITS) that are identified and evaluated for reliability as part of the PSA process. The analyses also support the development of the risk-informed design bases (per 10 CFR 63.2) for developing design criteria (as described in 10 CFR 63.112(f)) that are incorporated into Project design criteria documents. The PSA supports the repository safety strategy (see Section 3) by identifying and evaluating the event sequences initiated by human-induced and naturally occuring hazards that define the design bases. In addition, the PSA demonstrates how the performance requirements of 10 CFR 63.111, the design criteria of 10 CFR 63.112(f), and the system reliability considerations of 10 CFR 63.112(e) are satisfied.

This guide is organized into modules in which each module covers a limited range of subject matter, as follows:

- Section 1-Overview of the PSA process and the organization of this guide.

- $\quad$ Sections 2 through 4-Background information on regulatory requirements, the safety strategy used to define the goals of the safety analysis, and an overview of the PSA process to accomplish these goals. Section 4 also describes interactions between the PSA group and other organizations that contribute to safety and design analysis, and licensing.

- $\quad$ Section 5-Defining the types of site and facility design information required as input to the PSA.

- Sections 6 through 9-Methods for performing hazards analyses, event sequence analyses, consequence analyses, and uncertainty analyses.

- Section 10-Methods for analyzing external events (e.g., fires, earthquakes, loss of offsite power).

- $\quad$ Section 11-Preclosure criticality.

- $\quad$ Sections 12 and 13-Defining the processes for using PSA results to identify and classify SSCs ITS (assigning the labels of Safety Category or Non-Safety Category) and to select 10 CFR 63.2 design bases for the SSCs ITS.

- $\quad$ Section 14-Guidance on documenting PSA results and output of the processes described in Sections 2 through 13. This guidance includes comprehensive documentation of the analyses required to support the LA for CA in accordance with the YMRP (NRC 2003).

\section{- Glossary.}




\subsection{REFERENCES}

\subsubsection{Documents Cited}

NRC (U.S. Nuclear Regulatory Commission) 2003. Yucca Mountain Review Plan, Final Report. NUREG-1804, Rev. 2. Washington, D.C.: U.S. Nuclear Regulatory Commission, Office of Nuclear Material Safety and Safeguards. TIC: 254568.

\subsubsection{Codes, Standards, Regulations, and Procedures}

10 CFR 63. 2002. Energy: Disposal of High-Level Radioactive Wastes in a Proposed Geologic Repository at Yucca Mountain, Nevada. Readily available. 


\section{REGULATORY REQUIREMENTS AND GUIDANCE}

\subsection{INTRODUCTION}

This section introduces the fundamental regulatory requirements and related guidance, codes, and standards that are addressed while performing the PSA. Section3, Preclosure Safety Strategy, describes how the Project will meet regulatory requirements and how the PSA supports the strategy. Other sections address specific safety topics and identify the specific regulations, guidance documents, codes, and standards related to that safety topic.

The governing regulations for the Project are cited in 10 CFR Part 63, but there ae many sections of the CFR that do not relate directly to preclosure safety issues. Further, there are numerous regulatory guides developed for licensing of nuclear reactors that will be applied to the PSA in varying degrees. As appropriate, various sections of the guide will reference specific regulatory guides.

In addition to regulations in 10 CFR Part 63, the NRC Staff has developed the YMRP (NRC 2003) to provide guidance on: (1) the contents and level of discussion that the NRC Staff expect to see in the PSA and (2) the acceptance criteria that the NRC Staff has established for each topic. Although this guide was prepared with the goal of providing appropriate approaches and content that are accepted by the NRC, the analyst is advised to review the final YMRP to ensure that the content and approach will satisfy the acceptance criteria.

In addition to the YMRP (NRC 2003), additional guidance and precedents from the regulation of reactor plants and other nuclear fuel-cycle programs may be adapted in the licensing of the repository. In particular, many sections of the Standard Review Plan for Safety Analysis Reports for Nuclear Power Plants, NUREG-0800, (NRC 1987), provide design guidance that is adapted to the repository. As appropriate, other sections of this guide cite sections of NUREG-0800 (NRC 1987).

\subsection{PRIMARY REGULATORY DOCUMENTS RELEVANT TO PRECLOSURE SAFETY ANALYSIS}

This section lists the regulatory requirements by number and subject with some commentary to give perspective to the analyst on how the requirements are addressed in this guide. This section does not present a verbatim quote of the requirements that can be found in the source material. As appropriate, other sections of this guide present direct quotes of the regulations. Similarly, the analyst is provided direction to other pertinent guidance documents and codes and standards, but none of the contents are included herein.

\subsubsection{Relevant Sections of 10 CFR Part 63}

\$63.2 Definitions - The analyst should become familiar with all of the definitions, but take particular note of the following:

- $\quad$ Design bases

- $\quad$ Event sequence (and definitions of Category 1 and Category 2 event sequences)

- $\quad$ Important to safety 


\section{- $\quad$ Initiating event}

- $\quad$ Preclosure safety analysis

- Retrieval

- Total effective dose equivalent (TEDE).

$\S 63.102$ Concepts, Paragraph (f) Preclosure Safety Analysis

This paragraph provides a statement that initiating events have to be "reasonable" with respect to the setting and precedents for other facilities with comparable or higher risks.

$\S 63.111$ Performance objectives for the Geologic Repository Operations Area through permanent closure

This is the primary regulation that provides dose limits for workers and members of the public. It is regarded as part of the risk-informed performance-based regulation. It provides the allowable consequences versus the probability of occurrence of event sequences of Category 1 or Category 2. In particular, 10 CFR 63.111 contains several subparagraphs that analysts should read and understand. The significance of some of the various subparagraphs are discussed below:

\section{$\S 63.111$ (a) Protection against radiation exposures and releases of radioactive material}

In subparagraph (1), this regulation requires that repository operations meet the requirements of 10 CFR Part 20, which gives dose limits for both workers and the public, while subparagraph (2) requires that public doses from Category 1 event sequences must meet the preclosure standard given in $\$ 63.204$. These two requirements are expressed as annual doses and apply to both normal operations and event sequences in the Category 1 frequency range.

\section{$\S 63.111$ (b) Numerical guides for design objectives}

In subparagraph (1), this regulation requires that the repository be designed so that aggregated releases and exposures associated with Category 1 event sequences meet the requirements of $\S 63.111$ (a). This requires that dose analyses for Category 1 event sequence consider both worker and public doses. The analysis of doses against these limits for Category 1 requires a different approach than dose for Category 2 event sequences.

In subparagraph (2), this regulation requires that public doses from Category 2 event sequences meet the limits cited directly in the subparagraph. Several dose criteria are given, but the criterion used in this guide as the primary limit for public dose for Category 2 event sequences is the 5 rem TEDE at any point on the site boundary; worker doses are not required for Category 2 event sequences. There is no requirement to assess aggregated doses for Category 2 event sequences.

$\S 63.112$ Requirements for Preclosure Safety Analysis of the Geologic Repository Operations Area

This section of 10 CFR Part 63 prescribes what the PSA is to include. In large measure, the contents of this PSA guide have been selected and written to address all of the subparagraphs of 
10 CFR 63.112. Analysts should become familiar with $\$ 63.112$ before commencing any analysis.

\section{$\$ 63.304$ Preclosure standard}

This section provides guidance for protection of the environment that is more restrictive than the public dose limits given in 10 CFR Part 20. The limit is specified as an annual dose of 15 mrem in contrast to the 100 mrem annual dose permitted by 10 CFR Part 20. As noted above, $\S 63.304$ applies only to Category 1 event sequences (which include normal operations).

\subsubsection{Other Pertinent Regulatory Guidance}

Yucca Mountain Review Plan (YMRP) (NRC 2003)-Analysts should review sections relevant to PSA to ensure that the content and approach of any analysis will meet the acceptance criteria of the YMRP. Although this guide was prepared with the goal of providing appropriate approaches and content, the final YMRP should be consulted.

Standard Review Plan for Safety Analysis Reports for Nuclear Power Plants, NUREG-0800, (NRC 1987)-Several sections of NUREG-0800 have been adapted in the licensing and design strategies. For example, the preclosure seismic design follows portions of Sections 3.7. Further, Chapter 19 provides guidance on the use of probablistic risk assessment in regulatory decision making. As appropriate, other sections of this guide, topical reports by the Project, or design description documents may cite sections of the NRC Standard Review Plan that are adapted or used as guidance, with which analysts should become familiar.

Other NRC technical reports from the NUREG or NUREG/CR series-Several of such reports provide the bases for analyses described in this guide. Analysts should review the referenced source documents to augment the information provided in this guide and should seek updated versions and/or more recent NRC-issued reports on the same topic. The NUREG series, for example, includes standard review plans for non-reactor facilities, such as NUREG-1567, Standard Review Plan for Spent Fuel Dry Storage Facilities (NRC 2000). Other NUREGs provide techncial approaches developed and accepted by the NRC, such as NUREG-1278, Handbook of Human Reliability Analysis with Emphasis on Nuclear Power Plant Applications Final Report. (Swain and Guttmann 1983). The NUREG/CR series, prepared by NRC contractors, provide analytical methods and technical information that have been incorporated into this guide and could be the source of additional information that supports the PSA. For example, NUREG/CR-2300, PRA Procedures Guide, A Guide to the Performance of Probabilistic Risk Assessments for Nuclear Power Plants (NRC 1983) is used in the PSA process.

Regulatory Guides-Regulatory guides have been issued by the NRC to establish its position on acceptable approaches for meeting a particular portion of a regulation. The most widely applied set of regulatory guides are in Division 1, Power Reactors, and relate to safety and licensing issues associated with nuclear reactor power plants that are regulated according to $10 \mathrm{CFR}$ Part 50. By and large, those regulatory guides were developed from deterministic safety analyses, although a few more recent ones address application of risk-informed decision making (e.g., Regulatory Guide 1.174, An Approach for Using Probabilistic Risk Assessment in Risk- 
Informed Decisions on Plant-Specific Changes to the Licensing Basis; Regulatory Guide 1.176, An Approach for Plant-Specific, Risk-Informed Decisionmaking: Graded Quality Assurance; Draft Regulatory Guide DG-1122, An Approach for Determining the Technical Adequacy of Probabilistic Risk Assessment Results for Risk-Informed Activities). Although 10 CFR Part 50 does not strictly apply to the monitored geologic repository (MGR) or to other non-reactor facilities, the positions established in the Division 1 regulatory guides have established precedents that often carry over to other divisions. The Licensing Group will establish which Division 1 regulatory guides are being applied, totally, in part, or with exceptions to the Project. Analysts should become aware of these licensing positions that are relevant to a particular area of PSA or related design and operations.

In addition, regulatory guides in Division 3, Fuels and Materials Facilities, provide additional information that may be applicable to the MGR safety strategy and design. For example, Regulatory Guide 3.71 addresses design features to prevent criticality.

\subsubsection{Codes and Standards}

Many of the regulatory guides cite industry codes and standards that are deemed acceptable to the NRC, sometimes with exceptions. The MGR design and licensing organizations will apply the codes and standards to define design criteria that meet the design bases (per the definition in 10 CFR 63.2) for items important to safety that are derived from the PSA and applicable precedents. Analysts should review such codes and standards to the depth necessary to understand how their application satisfies important to safety design bases, and/or influences the frequency and/or dose evaluations of event sequences.

The principal codes and standards include those issued by the following organizations:

- $\quad$ ANSI/ANS-American Nuclear Standards Institute/American Nuclear Society

- $\quad$ ASCE-American Society of Civil Engineers

- $\quad$ ASME-The American Society of Mechanical Engineers

- $\quad$ IEEE-Institute of Electrical and Electronics Engineers

- $\quad$ NFPA-National Fire Protection Association.

In recent years, standards on the preparation of probabilistic risk assessments (PRAs) have been issued by the ANS and the ASME that have been reveiwed by the NRC with which analysts should become familiar.

\subsubsection{Department of Energy Orders and Standards}

The DOE has issued a series of orders and standards that may be applied to the MGR. Analysts should become familiar with such orders and standards to the extent necessary to understand how their application satisfies important to safety design bases and/or influences the frequency and/or dose evaluations of event sequences.

For example, as part of the fire protection program for the MGR, fire hazards analysts may address DOE Order 420.1 Facility Safety and DOE G 440.1-5 Implementation Guide for Use 
with DOE Orders 420.1 and 440.1-Fire Safety Program. The analyst dealing with potential fireinitiated event sequences should become familiar with the requirements of these documents.

In addition, the PSA may apply or reference certain DOE Standards (designated as DOE-STD). For example, the DOE-STD-1020, Natural Phenomena Hazards Design And Evaluation Criteria for Department of Energy Facilities, presents design bases in a risk-graded framework. This DOE standard may be referenced to augment guidance provided by the NRC for the riskinformed, performance-based licensing strategy for the MGR.

\subsection{REFERENCES}

\subsubsection{Documents Cited}

NRC (U.S. Nuclear Regulatory Commission) 1983. PRA Procedures Guide, A Guide to the Performance of Probabilistic Risk Assessments for Nuclear Power Plants. NUREG/CR-2300. Two volumes. Washington, D.C.: U.S. Nuclear Regulatory Commission. TIC: 205084.

NRC 1987. Standard Review Plan for the Review of Safety Analysis Reports for Nuclear Power Plants. NUREG-0800. LWR Edition. Washington, D.C.: U.S. Nuclear Regulatory Commission. TIC: 203894.

NRC 2000. Standard Review Plan for Spent Fuel Dry Storage Facilities. NUREG-1567. Washington, D.C.: U.S. Nuclear Regulatory Commission. TIC: 247929.

NRC 2003. Yucca Mountain Review Plan, Final Report. NUREG-1804, Rev. 2. Washington, D.C.: U.S. Nuclear Regulatory Commission, Office of Nuclear Material Safety and Safeguards. TIC: $\underline{254568}$.

Swain, A.D. and Guttmann, H.E. 1983. Handbook of Human Reliability Analysis with Emphasis on Nuclear Power Plant Applications Final Report. NUREG/CR-1278. Washington, D.C.: U.S. Nuclear Regulatory Commission. TIC: 246563.

\subsubsection{Codes, Standards, Regulations, and Procedures}

10 CFR 20. 1999. Energy: Standards for Protection Against Radiation. Readily available.

10 CFR 63. Energy: Disposal of High-Level Radioactive Wastes in a Geologic Repository at Yucca Mountain, Nevada. Readily available.

DOE G 440.1-5. 1995. Implementation Guide for Use with DOE Orders 420.1 and 440.1 Fire Safety Program. Washington, D.C.: U.S. Department of Energy. Readily available.

DOE O 420.1A. Facility Safety. Washington, D.C.: U.S. Department of Energy. Readily available.

DOE-STD-1020-2002. Natural Phenomena Hazards Design and Evaluation Criteria for Department of Energy Facilities. Washington, D.C.: U.S. Department of Energy.

TIC: 253058 . 
Regulatory Guide 1.174, Rev. 01 Draft. 2001. An Approach for Using Probabilistic Risk Assessment in Risk-Informed Decisions on Plant-Specific Changes to the Licensing Basis. Washington, D.C.: U.S. Nuclear Regulatory Commission. Readily available.

Regulatory Guide 1.176. 1998. An Approach for Plant-Specific, Risk-Informed

Decisionmaking: Graded Quality Assurance. Washington, D.C.: U.S. Nuclear Regulatory Commission. Readily available.

Regulatory Guide 3.71. 1998. Nuclear Criticality Safety Standards for Fuels and Material Facilities. Washington, D.C.: U.S. Nuclear Regulatory Commission. Readily available. 


\section{PRECLOSURE SAFETY STRATEGY}

\subsection{INTRODUCTION}

This section describes the strategy that will be used to prevent or mitigate unacceptable preclosure radiological consequences for the high-level radioactive waste repository. The strategy is focused on the offsite dose performance objectives presented in 10 CFR 63.111 and has considered the preclosure activities that occur prior to the postclosure period. The strategy is a general plan that does not provide requirements for the repository.

\subsection{GENERAL PRINCIPLES}

When the LA is submitted, the safety case for the repository will be presented in a Safety Analysis Report (SAR). The safety case will address the logic, analyses, and calculations that describe how the repository SSCs meet performance objectives, and will include material incorporated by reference and other docketed material. The SAR will provide the basis for a decision by the NRC to authorize construction and eventually to license the repository. The preclosure safety case will be based on 10 CFR 63.2 design bases (i.e., functions and controlling parameters) for SSCs and the results of analyses and calculations presented in the PSA. The preclosure safety strategy is an approach that describes how a risk-informed design should be considered to facilitate compliance with 10 CFR Part 63 preclosure performance objectives.

\subsection{PRECLOSURE SAFETY CASE}

The preclosure period for evaluating event sequences will be consistent with the anticipated life of the repository. For simplicity, a 100-year preclosure period will be used in the PSA. A preclosure period of 100 years equates to a $1 \times 10^{-2}$ per year event sequence probability cutoff for Category 1 event sequences, and it equates to a $1 \times 10^{-6}$ per year event sequence probability cutoff for Category 2 event sequences. Using the 100-year period provides margin in evaluating event sequences for preclosure operations SSCs because the expected duration for emplacement activities is expected to be less than 50 years. The preclosure period must encompass the phases of preclosure operations preceding the time of permanent closure of the repository.

The Design Basis Event Frequency and Dose Calculation for Site Recommendation (BSC 2001a) assumed a 100-year operational phase for a higher-temperature operating mode. This operational period is valid for lower-temperature operating modes that have longer preclosure operational phases (BSC 2001b). However, if an operating mode is selected that extends the preclosure period of subsurface drift ventilation beyond 100 years, the effects on the event sequence probability cutoffs for subsurface events must be assessed. For ease of analysis, the preclosure period could be divided into two phases. Phase 1 would encompass the activities associated with emplacing waste in the subsurface facilities. This phase would include phased construction of the subsurface and potentially the surface facilities. Phase 2 would begin after emplacement activities are completed. If the flexible thermal design focuses on a lower-temperature operating mode, then cooling of the waste package could extend the Phase 2 preclosure period to 275 years after emplacement operations end. Because there is no expected movement of waste packages during the cooling period, the hazards to the waste package are reduced. Furthermore, the resulting likelihood of Category 1 or Category 2 event sequences is 
reduced. Phase 2 may start when emplacement is completed (e.g., after 50 years of emplacement activities) and extend until permanent closure (the next 275 years for a total preclosure period of 325 years).

\subsubsection{Preclosure Safety Analysis}

The NRC specifies at 10 CFR 63.111(c) that compliance with the preclosure performance objectives in 10 CFR 63.111(a) and 10 CFR 63.111(b) will be demonstrated through a PSA. The PSA provides a quantitative estimate of repository preclosure performance. The purpose of the PSA is to ensure that relevant internal and external hazards that could result in unacceptable consequences have been evaluated and that preventive or mitigative features are included in the repository design such that the limits on radiation exposures specified in 10 CFR 63.111(a) will not be exceeded and the design will meet the requirements at 10 CFR 63.111(b).

The PSA provides a framework for risk-informed performance-based decision-making that is to be applied to identifying SSCs ITS, measures for providing defense in depth, license specifications, and surveillance intervals. The PSA identifies the potential natural and operational hazards for the preclosure period; assesses potential events and event sequences and their consequences; and identifies the SSCs and activities of personnel intended to prevent or mitigate each accident sequence. Event and event sequence identification and analysis comprise an iterative process integrally tied to repository design. Consequently, the PSA and event sequence identification and analysis will continue to evolve with design maturation.

The Project will design and operate the facility to maintain public and occupational radiation exposures as low as is reasonably achievable (ALARA). It is expected that industry precedent will be used for design and shielding as well as operating procedures, as there are strong parallels to other nuclear facilities and operations.

\subsubsection{Margin and Defense in Depth}

Although margin is mot required or specified in the NRC regulation at $10 \mathrm{CFR}$ Part 63, margin will nevertheless be included as part of the preclosure safety case for reasons such as analysis uncertainties, operational flexibility, and additional safety confidence. Defense in depth is included to ensure that preclosure safety is not wholly dependent on any single element of the design, construction, operation, or maintenance of the facility. A facility that includes defense in depth should be less susceptible to adverse consequences due to SSC failures and external challenges. A facility that includes defense in depth should also provide inherent margin.

Margin, as used in this section, refers to the difference between calculated event sequence consequences and a preclosure regulatory compliance limit as shown in Figure 3-1, which illustrates the concept of margin for an assumed event sequence. The event sequence used to show compliance with preclosure regulatory limits takes credit for licensing design basis functions, as defined in 10 CFR 63.2 (see Section 13). The dose calculation for the compliance event sequence is compared to the regulatory limit to define how much of a margin the DOE has in complying with the applicable preclosure regulatory limits. The dose calculations performed by the DOE and documented in the SAR will be for showing compliance with the preclosure 
regulatory limits. No commitment will be made to the NRC to maintain any portion of the margin.

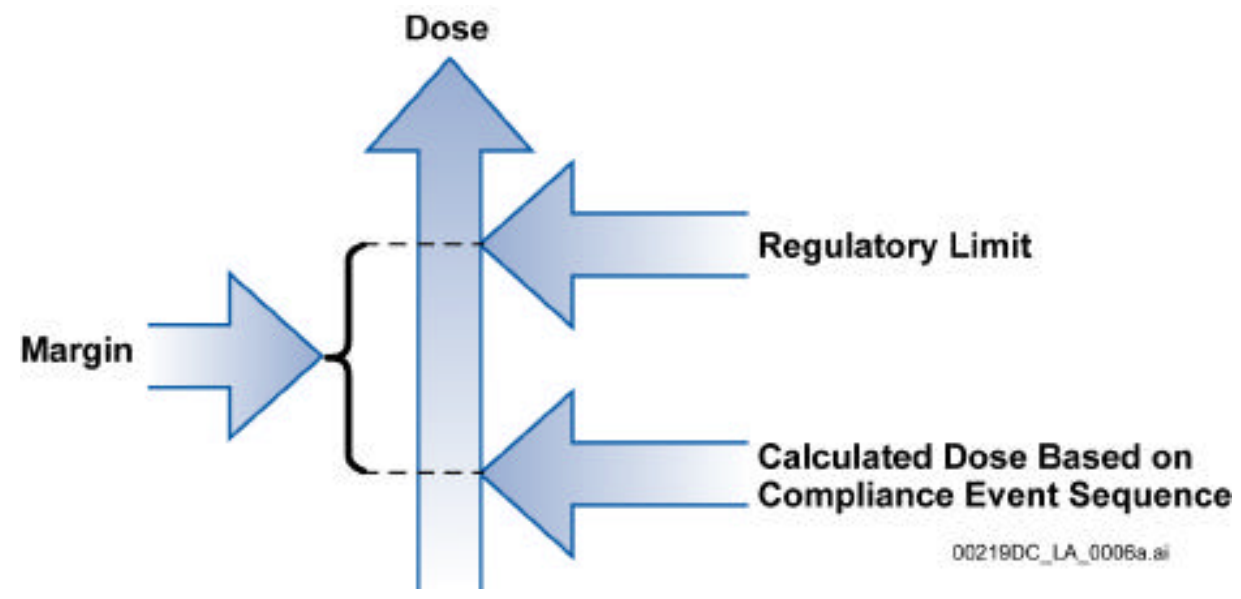

Figure 3-1. Margin

The specific margin based on the PSA presented in the SAR is expected to assist in demonstrating the defensibility of the analyses used to show compliance with the regulatory requirements. The Project will use one-half of the preclosure limits prescribed by 10 CFR Part 63 as a guideline or goal for evaluating the significance of dose consequences in developing the design that will be the basis for the SAR in the LA for CA. The use of one-half of the regulatory limits early in design development is a reasonable goal and the approach is similar to the use of design goals in the nuclear industry. The purpose of this guideline is to alert the Project to the need for consideration of alternative or additional features for prevention or mitigation of the consequences of an event sequence. This design goal will be captured in the PSA development for the SAR. When the LA for R\&P is submitted, the design will be evaluated against the preclosure regulatory dose limits. Even if the calculated consequences are lower, the updated SAR will state clearly that the calculations are presented to show that the regulatory limits are met. In other words, ownership of the margin will be maintained by the DOE.

Defense in depth is the application of redundant or diverse physical and administrative barriers or other protective measures to mitigate unanticipated conditions, processes, and events, such that failure of any one barrier or SSC to perform as intended does not result in failure of the system to comply with the regulatory limits for preclosure safety. The application of defense in depth is risk informed. Defense-in-depth measures may be added where appropriate to reduce risk, but they may not be designated as important to safety if they are not required to demonstrate compliance with the performance objectives.

\subsubsection{Consequence Analysis of Category 1 and Category 2 Event Sequences and Beyond Category 2 Event Sequences}

The regulatory limit for probability of event sequences that must be analyzed is at least one chance in 10,000 of occurring during the preclosure period. For the assumed 100-year preclosure period, this translates to greater than or equal to $10^{-6}$ to less than $10^{-2}$ per year for Category 2 event sequences and greater than or equal to $10^{-2}$ per year for Category 1 event 
sequences. The safety analysis must demonstrate that releases from these event sequences will meet the perspective Category 1 and Category 2 regulatory limits as specified in 10 CFR 63.111.

Beyond Category 2 event sequences, assuming a 100-year operational period, are those event sequences with probability less than $10^{-6}$ per year. To provide confidence in the repository design, in some cases the PSA may include evaluation of the consequences of selected beyond Category 2 event sequences using the best estimate of expected conditions. The purpose of such evaluations of beyond Category 2 event sequences is to identify any additional defense-in-depth functions that may be credited/added to mitigate consequences of these event sequences. Any such defense-in-depth functions credited/added would not be considered important to safety and these analyses will not be part of the safety case as presented in the LA.

\subsubsection{Nuclear Industry Precedent and Experience}

The strategy for the preclosure operational period is to use technology and concepts that have been proven for the safe handling of radioactive wastes over many years in the commercial nuclear industry and DOE activities.

Commercial nuclear industry and other nuclear fuel cycle facility precedent and experience will be used, where appropriate, in the design and analysis of the repository operational facilities. Commercial nuclear industry and other nuclear fuel cycle facility precedent also provides confidence in the PSA approach and provides data and lessons learned for direct incorporation into the hazards and consequence analyses.

The PSA will use commercial nuclear and spent fuel storage facility precedents that are appropriate for the Project. The use of precedent provides additional assurance that the processes used in the PSA for a repository at Yucca Mountain are acceptable to the NRC, which allows the NRC to focus on the application of the processes to the repository system. This should also facilitate the NRC review process. Industry precedent should be used (or adapted) when its use results in demonstrating compliance with regulatory requirements and its application do not result in significant over-conservatism in the design development.

10 CFR Part 63 is risk-informed and performance-based. It requires identification of SSCs ITS, which is a broader recognition of radiological risk than the traditional safety-related definition. Many of the industry and licensing precedents that exist are based on the traditional safety-related concept, along with a more deterministic approach to safety analysis. Although industry and licensing precedents should form the building blocks for the development of the PSA, in many cases, it is the intent and philosophy of the precedents that should be used and adapted to the risk-informed context of the repository licensing requirements. For example, the use of regulatory guides that are based on the safety-related concept may be appropriate for application to SSCs ITS by association with Category 2 event sequences, but they may be overly conservative with respect to risk for SSCs ITS that are associated with Category 1 event sequences (see Section 12). However, for natural phenomena, the direct application of industry and licensing precedents may be appropriate (e.g., protection against floods or tornadoes). 
When evaluating the applicability of industry and licensing precedents, the following points will be considered:

- $\quad$ Differences in the regulatory basis or philosophy

- $\quad$ Regulatory definitions (e.g., events, important to safety, safety related)

- $\quad$ Performance objectives

- $\quad$ Licensing period.

Recent precedents related to risk-informed regulation will be used whenever appropriate. Using recent precedents will help achieve the appropriate balance between application of traditional industry and licensing precedents and current risk-informed regulatory philosophy.

\subsubsection{Evaluation Approach}

A risk-informed approach is used to evaluate preclosure safety for the repository, which means that deterministic precedents are not applied a priori. The risk-informed regulation results in balancing deterministic and probabilistic approaches. For example, the design of the preclosure facility to protect against external floods, extreme winds, tornado winds, and tornado missiles primarily will be deterministic and precedent influenced. Probabilistic analyses may provide insight into the appropriate intensity of site-specific hazards that the facility should withstand (e.g., magnitude of seismic events) to avoid or mitigate the consequences of event sequences initiated by such events. When evaluating internal events, probabilistic techniques to evaluate the potential hazard may be more appropriate. There will be no arbitrary single-failures considered in the safety evaluation. Failures based on a risk-informed approach are described in Section 4.

\subsubsection{Mechanistic Evaluation}

Mechanistic evaluations of the facility represent the preferred approach to evaluating event sequences. Mechanistic evaluations represent potential causes and effects of failures and actions. A nonmechanistic failure would be an arbitrary assumed failure of a component that is not linked to a cause (e.g., an assumed breach of a transportation cask without a cause for the breach). There will be no nonmechanistic internal failures assumed in the safety analysis.

In mechanistic evaluations, the event probabilities are not necessarily factored in, although thresholds (which may be qualitative or based on engineering judgment) for credible scenarios that should be addressed in the design are usually included. A systematic, robust approach will be used to identify potential hazards (external and internal). These potential hazards represent possible initiating events that must be evaluated for applicability. Potential event sequences are developed based on failures or consequences resulting from the initiating event. Potential common mode failures and human error are included in the development of event sequence evaluations.

\subsubsection{Risk-Informed Evaluation}

As part of the risk-informed approach, mechanistic scenarios include a probability of occurrence. In this manner, event sequences can be categorized based on the event sequence probability of 
occurrence. In accordance with 10 CFR Part 63, event sequences that are expected to occur at least once in the life of the facility are termed Category 1. Similarly, event sequences that have at least one chance in 10,000 of occurring in the life of the facility are termed Category 2. Event sequences that have less than one chance in 10,000 of occurring in the life of the facility do not have to be evaluated. If it is determined that the probability of failure of a specific safety function must be less than $10^{-4}$ per year to meet the dose limits specified for a Category 1 or Category 2 event sequence, then consideration will be given to providing the function in a diverse fashion.

As noted in Section 3.3.2, to provide confidence in the repository preclosure design, in some cases the PSA may include evaluation of the consequences of selected event seque nces that are below the probability threshold, using the best estimate of expected conditions. The purpose of such evaluations is to ensure that an event sequence with large consequences is not excluded based solely on probability. Any features added to mitigate the consequences of such events would not be considered important to safety. These analyses will not be part of the regulatory safety case, but they may provide additional confidence in repository performance.

Application of measures to provide defense in depth will be based on the probability of the event or the magnitude of the consequence. Factors to consider when deciding on defense-in-depth measures include the following:

- $\quad$ Industry precedents

- Margin available

- $\quad$ Degree of reliance on a single SSC in an event sequence

- Uncertainties

- Amount of diversity included in design.

\subsubsection{Identification and Classification of SSCs Important to Safety}

As part of the development of the PSA, SSCs ITS must be identified. Consistent with a risk-informed regulation and the evaluation process discussed above, the relative risk significance of an SSC will be considered when classifying SSCs ITS. The process for classification of SSCs is described in Section 12.

\subsubsection{Conservative or Bounding Approaches}

Reasonable values and approaches will be used in evaluating the preclosure safety aspects of the facility. Simple, bounding evaluations will be used when this approach does not overly constrain the design or the operations of the facility. For example, if a simple, conservative evaluation of an event sequence can be shown to meet regulatory limits with existing SSCs and does not result in unusual classification of an SSC or the addition of SSCs, then the analysis is complete. However, if the bounding treatment of an event sequence results in additional SSCs or nontypical design and quality requirements to meet regulatory limits, then a more rigorous analysis of the data may be warranted. 
The processes for dose assessments for determining the consequences of event sequences, described in Section 8, will use the precedent established by reactor plant and spent fuel storage facility methodologies.

\subsubsection{Preferred Approach}

There are many options available to ensure that event sequences are adequately prevented or mitigated. While the approach to addressing event sequences may vary, there is a preferred strategy that will govern how the Project addresses event sequences:

- $\quad$ Design features are preferable to administrative features

- $\quad$ Passive features are preferable to active features

- $\quad$ Automatic features are preferable to manual features

- Separation is preferable to co-location.

Additionally, a risk-informed approach will be used to determine an acceptable preclosure design based on the risk-significance. The process for identifying 10 CFR 63.2 preclosure safety design bases is described in Section 13. Protection will progress from a single component or system to redundant components and systems and, when common-mode failures are possible, to diverse components and systems. Developing a design that maximizes the implementation of these elements can result in a facility with less overall risk and minimal operational complexity.

\subsubsection{License Specifications and Surveillances}

License specifications establish when repository SSCs ITS must be operable (including allowed outage times) and establish limiting conditions for the operation of SSCs ITS and limits on the types and form of waste to be received. This is to provide additional assurance that the repository preclosure operations will be performed safely.

Licensing specifications will be derived from the PSA, in accordance with the risk-informed, performance based approach and guidance provided by Regulatory Guide 1.177, An Approach for Plant-Specific, Risk-Informed Decisionmaking: Technical Specifications (see Section 4.3.1.4). Licensing specifications may include: restrictions on the chemical form of radioactive waste; restrictions on waste package characteristics; requirements on testing, calibration, or inspection to ensure license conditions are observed; controls to restrict access to the site; preventative maintenance activities; and administrative controls related to management, procedures, record keeping, review, and audit. The licensing specifications will be developed to provide confidence that the facility will operate within the limits of the PSA. Factors to consider in developing licensing specifications include type and number of risks identified in the PSA, industry and regulatory precedents, and manufacturer specifications.

Surveillances are the periodic (e.g., monthly, quarterly, or annually) operational tests of SSCs to demonstrate the ability of the SSCs to perform required safety functions.

The NRC requires that probable license specifications, including the identification and justification for the selection of those variables, conditions, or other items, be identified in the LA. 
In the PSA process, summarized in Section4, the PSA will produce a description of event sequences that include:

Initiating event cause and frequency of occurrence with documented bases for the applied value (source of information and indication of the quality assurance program associated with the data source).

A list of SSCs ITS credited in the prevention or mitigation of the potential consequences of a given sequence and the conditional probability of failure ascribed to each SSC with documented bases for the applied failure probabilities (e.g., test and surveillance intervals, and operating environment, provisions for redundant components or subsystems).

A list of human interactions credited in the mitigation of the potential consequences of a given sequence and probabilities of human failure events with documented bases, including reliance on certain instrumentation and controls and use of emergency operating procedures.

Such information, along with engineering judgment, will be used to develop risk-informed technical specifications. Such license specifications that may result could include:

Limiting conditions for operation for the interior operational environment (e.g., interior temperature, radiation levels, humidity) that exceeds the bases used in establishing event frequencies and failure probabilities.

Limiting conditions for operation for a system credited in the compliance case.

Surveillance requirements (e.g., test and maintenance intervals) that support the system unavailability bases.

The licensing specifications will, to the extent practicable, be risk-informed and thereby be based on a quantitative evaluation of the effect of the specified item on the probability factors and/or dose reduction factors that are credited in the safety case. Analysts will apply, as appropriate, concepts presented in Regulatory Guide 1.177.

\subsubsection{Preclosure Testing}

Testing activities that need to occur during the preclosure period will be evaluated in the PSA. Tests that need to be performed to demonstrate the operational readiness of the facility will be performed before start-up and during the operating phase of the repository. These tests will demonstrate the adequacy of the facility to operate within the preclosure licensing basis.

\subsubsection{Performance Confirmation}

The Performance Confirmation Program (PCP) is based on meeting identified performance objectives specified in 10 CFR Part 63, Subpart E. As noted in the Supplementary Information for 10 CFR Part 63 (66 FR 55732) and the YMRP (NRC 2003), the broad reference to the performance objectives under Subpart E in the definition of performance confirmation reflects the need to consider the preclosure performance objective for preserving the retrieval option in defining the PCP. To support the preclosure safety case, the PCP will evaluate the adequacy of 
assumptions, data, and analyses related to this performance objective that permit construction of the repository and the subsequent emplacement of wastes.

\subsubsection{Retrievability}

The NRC requires that the GROA be designed to preserve the option of waste retrieval throughout the period during which wastes are being emplaced and thereafter, until the completion of the PCP and NRC review of the information obtained from such a program. The SAR will include an analysis demonstrating that retrieval of any or all of the waste packages can be accomplished on a reasonable schedule. As an initial assumption, for simplicity, a nominal 100-year preclosure period will be used in assuring that retrieval operations have not been precluded in the design of the facility. The analysis will be based on an assumed schedule that would permit retrieval in about the same time as that required to construct the GROA and emplace waste. The SAR will provide the basis for NRC approval of the assumed 100-year preclosure period, based on the emplacement schedule, operational considerations, and the PCP. An explicit safety analysis for the retrieval contingency will not be included as part of the LA. Should retrieval become necessary, a SAR amendment with an appropriate PSA for the associated design, retrieval, and alternate storage operations will be submitted to NRC to support approval of a license amendment to permit such operations.

\subsection{STRATEGY FOR PREVENTING OR MITIGATING PRECLOSURE OFFSITE RADIATION EXPOSURE}

\subsubsection{Identification of Important-to-Safety Features and Controls}

To ensure that radiation doses associated with Category 1 and Category 2 event sequences do not exceed the limits in 10 CFR 63.111(a)(2) and 63.111(b)(2), the repository design will incorporate a combination of prevention and mitigation features and controls. Prevention is the use of design features to reduce the postulated frequency of events that result in a radiological release from the GROA to less than one chance in 10,000 of occurring before permanent closure. Mitigation is the use of design features and barriers to ensure that the consequences of a postulated radiological release event sequence are within the regulatory limits for doses to workers and the public. Mitigation includes features intended to reduce releases from the routine operations that are included in the Category 1 event sequence annual dose summation. The PSA is used to identify the preventive features, mitigative features, and operational controls that are required to demonstrate compliance with radiation dose limits.

This preclosure safety strategy requires using prevention features in the repository design wherever reasonable. Eliminating or minimizing the potential for radiological release events provides design and operational benefits. From an operations perspective, surveillance and maintenance of active safety features for mitigating the consequences of events have been demonstrated to add to nuclear facility operational complexity, and recovery from events has proved to be more challenging than anticipated. This strategy is implemented by performing the PSA as an integral part of the design process in a manner consistent with a performance-based, risk-informed philosophy. A risk-informed approach uses risk insights, engineering analysis and judgement, and equipment performance history to demonstrate the importance of the repository preclosure operational functions that have the most safety significance and to establish design 
criteria and management controls based upon these risk insights. This integral design approach ensures that the design features and operational controls important to safety are selected in a manner that ensures safety while minimizing design and operational complexity through the use of proven technology.

\subsubsection{Design Bases for Facilities and Limits on Operations}

The preclosure safety strategy requires that SSCs ITS must be designed, constructed, and operated in such a manner that they will survive credible external events and natural phenomena and that Category 1 and Category 2 event sequence dose limits will not be exceeded.

\subsubsection{Safety Strategy for Repository Preclosure Operational Functions}

The safety strategy for repository preclosure operational functions is based on receiving waste, transferring waste into waste packages, sealing waste packages, transferring waste packages to emplacement drifts, and emplacing waste packages. These functions are based on site recommendation design features and illustrate the application of the preclosure safety strategy discussed in previous sections. The safety strategy for each of these functions is either prevention augmented by mitigation or mitigation augmented by prevention.

Summary descriptions of the safety strategy for each of the five repository preclosure operations functions and a potential list of safety strategies for each are summarized in Table 3-1. 
Table 3-1. Preclosure Safety Strategy

\begin{tabular}{|c|c|c|}
\hline $\begin{array}{c}\text { Example } \\
\text { Basic Operations }\end{array}$ & $\begin{array}{l}\text { Canistered Fuel } \\
\text { Safety Strategy }\end{array}$ & $\begin{array}{c}\text { Uncanistered Fuel } \\
\text { Safety Strategy }\end{array}$ \\
\hline \multicolumn{3}{|c|}{ Receipt of Waste } \\
\hline $\begin{array}{l}\text { Survey } \\
\text { Remove impact limiters } \\
\text { Remove personal barriers } \\
\text { Remove hold downs } \\
\text { Upright cask } \\
\text { Transfer cask to cart }\end{array}$ & $\begin{array}{l}\text { Prevent events that could } \\
\text { exceed shipping cask design } \\
\text { basis } \\
\text { (preclude breach) }\end{array}$ & $\begin{array}{l}\text { Prevent events that could } \\
\text { exceed shipping cask design } \\
\text { basis } \\
\text { (preclude breach) }\end{array}$ \\
\hline $\begin{array}{l}\text { Vent and Sample cask } \\
\text { Unbolt cask cover } \\
\text { Remove cover } \\
\text { Remove materials from cask } \\
\text { Install cover } \\
\text { Bolt cask cover } \\
\text { Store canistered waste } \\
\text { Store SNF assemblies } \\
\text { Decontaminate cask } \\
\text { Remove WP cover } \\
\text { Load WP } \\
\text { Install WP cover } \\
\text { Decontaminate WP }\end{array}$ & $\begin{array}{l}\text { Prevent events that could } \\
\text { exceed canister design basis } \\
\text { (preclude breach) }\end{array}$ & $\begin{array}{l}\text { Minimize the number of } \\
\text { events that could result in } \\
\text { uncanistered fuel drops; } \\
\text { minimize radiation releases } \\
\text { from drop events }\end{array}$ \\
\hline \multicolumn{3}{|c|}{ Sealing the Waste package } \\
\hline $\begin{array}{l}\text { Weld WP } \\
\text { Inspect WP welds } \\
\text { Stress relieve WP welds }\end{array}$ & $\begin{array}{l}\text { Prevent events that could } \\
\text { exceed canister design basis } \\
\text { (preclude breach) }\end{array}$ & $\begin{array}{l}\text { Minimize the number of } \\
\text { events that could result in } \\
\text { waste package drops; } \\
\text { minimize radiation releases } \\
\text { from drop events }\end{array}$ \\
\hline \multicolumn{3}{|c|}{ Transfer of the Waste Package (WP) to the Emplacement Drift } \\
\hline $\begin{array}{l}\text { Move WP and pallet to tunnel } \\
\text { entrance } \\
\text { Descent to drift entrance } \\
\text { Park at drift entrance }\end{array}$ & $\begin{array}{l}\text { Prevent events that could } \\
\text { exceed WP design basis } \\
\text { (preclude breach) }\end{array}$ & $\begin{array}{l}\text { Prevent events that could } \\
\text { exceed WP design basis } \\
\text { (preclude breach) }\end{array}$ \\
\hline $\begin{array}{l}\text { Move WP and pallet to tunnel } \\
\text { entrance } \\
\text { Descent to drift entrance } \\
\text { Park at drift entrance }\end{array}$ & $\begin{array}{l}\text { Prevent events that could } \\
\text { exceed WP design basis } \\
\text { (preclude breach) }\end{array}$ & $\begin{array}{l}\text { Prevent events that could } \\
\text { exceed WP design basis } \\
\text { (preclude breach) }\end{array}$ \\
\hline \multicolumn{3}{|c|}{ Emplacement } \\
\hline $\begin{array}{l}\text { Move WP and pallet from } \\
\text { tunnel entrance to permanent } \\
\text { drift position }\end{array}$ & $\begin{array}{l}\text { Prevent events that could } \\
\text { exceed WP design basis } \\
\text { (preclude breach) }\end{array}$ & $\begin{array}{l}\text { Prevent events that could } \\
\text { exceed WP design basis } \\
\text { (preclude breach) }\end{array}$ \\
\hline
\end{tabular}

NOTE: $W P=$ waste package 


\subsection{REFERENCES}

\subsubsection{Documents Cited}

BSC (Bechtel SAIC Company) 2001a. Design Basis Event Frequency and Dose Calculation for Site Recommendation. CAL-WHS-SE-000001 REV 01 ICN 02. Las Vegas, Nevada: Bechtel SAIC Company. ACC: MOL.20011211.0094.

BSC 2001b. Preliminary Preclosure Safety Assessment for Monitored Geologic Repository Site Recommendation. TDR-MGR-SE-000009 REV 00 ICN 03. Las Vegas, Nevada: Bechtel SAIC Company. ACC: MOL.20010705.0172.

NRC (U.S. Nuclear Regulatory Commission) 2003. Yucca Mountain Review Plan, Final Report. NUREG-1804, Rev. 2. Washington, D.C.: U.S. Nuclear Regulatory Commission, Office of Nuclear Material Safety and Safeguards. TIC: $\underline{254568 .}$

\subsubsection{Codes, Standards, Regulations, and Procedures}

10 CFR 63. 2002. Energy: Disposal of High-Level Radioactive Wastes in a Proposed Geologic Repository at Yucca Mountain, Nevada. Readily available.

Regulatory Guide 1.177. 1998. An Approach for Plant-Specific, Risk-Informed Decisionmaking: Technical Specifications. Washington, D.C.: U.S. Nuclear Regulatory Commission. Readily available. 


\section{OVERVIEW OF PRECLOSURE SAFETY ANALYSIS ELEMENTS AND APPROACHES}

\subsection{INTRODUCTION}

This section provides an overview of how the PSA will be performed for the repository at Yucca Mountain. The PSA comprises several kinds of analyses that must be integrated into a cohesive evaluation and documented. Further, the PSA process supports developing 10 CFR 63.2 design bases, design criteria, design requirements, SSC classification, design evaluation, Q-List development, and the preclosure safety strategy in LA documentation.

The PSA, in toto, will provide input to the LA documentation and submittal that meets the acceptance criteria of the YMRP (NRC 2003). As such, the LA will document areas that are not in the scope of responsibility of preclosure safety analysts, but rather in the workscope of various design engineers, radiological protection/shielding analysts, criticality analysts, meteorologists, geologists and other specialists. The preclosure safety analysts will obtain information from the various specialists as needed to perform hazards analyses, event sequence analysis, fault-tree analysis, human reliability analysis, and radiological consequence evaluations. As noted in Section 1, the purpose of this guide is primarily for the preclosure safety analysts to provide methods to apply in safety analyses. In addition, this guide provides an instrument for communication with the other specialty groups that support the preparation of the PSA and LA. This section provides an overview of the preclosure analysis (see Figure 4-1) and of the interfaces and workflow between the various organizations (see Figures 4-2 and 4-3).

The PSA process must support the LA for CA and the LA for R\&P. The process must be sufficiently flexible and robust to support the LA given the level of design detail available for the SSCs of the GROA at the time of the LA for CA.

\subsection{BACKGROUND}

The requirements for performing and documenting a PSA for a repository, per the definition of 10 CFR 63.2, are defined in 10 CFR 63.112. The methods described are responsive to NRC methods and review acceptance criteria cited in the YMRP (NRC 2003). The repository licensing process for waste emplacement consists of two steps: a license for CA and a license to R\&P. A PSA is required in support of both licensing steps. Each licensing step requires an NRC safety determination that is based on, respectively, the initial PSA for the LA-CA, and the updated PSA for the LA to R\&P. The licensing plan is to submit the amount of design information in the LA that provides sufficient information for the NRC safety evaluation.

Because 10 CFR Part 63 was developed as a risk-informed, performance-based rule, the PSA is adapting a risk-informed, performance-based approach. While parts of the safety strategy (see Section 3) are based on deterministic principles and regulatory precedents, a large portion of the safety evaluation for the preclosure operations apply elements of risk analysis. The methods described in this guide are consistent with NRC regulations and guidance. The methods are compatible with NRC guidelines (Milstein 2000, NRC 1983) for performing an integrated safety analysis (which was the term ascribed to the PSA prior to the promulgation of the Final Rule 
10 CFR Part 63). The NRC guidelines permit the licensee to apply appropriate methods to produce results and documentation that are deemed suitably comprehensive by the NRC.

\subsection{OVERVIEW OF PROCESS FOR PERFORMING A PRECLOSURE SAFETY ANALYSIS}

The PSA applies elements of risk analysis that are imbedded in the hazards and event sequence analyses. The PSA comprises a structured, multi-tiered evaluation of hazards and event sequences. The PSA applies the risk-analysis triplet that asks the three questions:

- What can happen? (hazard identification and scenario development)

- How likely is it? (frequency or likelihood analysis)

- What are the consequences? (radiological doses to workers or public; criticality).

The questions can be answered qualitatively, as well as quantitatively, and therefore, can be applied to deterministic, as well as probabilistic analyses.

These same three questions are applied over and over as the PSA progresses through the hazards analysis phase, event sequence analyses, consideration of safety-specific analyses, and as the design detail evolves. The PSA also includes elements of risk management by identifying means for preventing, reducing the likelihood of, or mitigating hazards.

The performance of a comprehensive hazards analysis and event sequence analyses in the preliminary stages of design requires the application of the knowledge and experience of a multi-disciplinary team comprised of personnel who are cognizant of one or more areas related to safety and design:

- Hazards analysis and event sequence analysis for radiological safety

- Design of mechanical systems for handling, opening, sealing, loading, and transporting waste forms

- Design of structural, electrical, and instrumentation and control systems

- $\quad$ Design of pool water-treatment and cooling systems (if needed)

- Design of heating, ventilation, and air-conditioning (HVAC) and high-efficiency particulate air (HEPA) filter systems for radioactive areas

- Design of waste package

- $\quad$ Radiological consequence analyses

- $\quad$ Criticality safety

- $\quad$ Fire hazards and fire protection 
- Design for radiation protection, shielding, and as low as is reasonably achievable (ALARA)

- Systems reliability modeling, including fault tree, failure modes and effects analysis, human factors, and common-cause failures

- Licensing regulations for processing, packaging, and disposal of site-generated radiological and hazardous waste.

As needs dictate, other disciplines should be addressed. In addition to engaging multiple disciplines in the development of the PSA, the formal review of PSA products should engage cognizant personnel (subject mater experts) to ensure that the PSA is complete.

PSA activities and all PSA analyses and documentation will be carried out in accordance with Project procedures under the Quality Assurance program.

\subsubsection{Flow Diagram of Preclosure Safety Analysis Process}

Figure 4-1 illustrates the PSA process that will support the preparation of the Safety Analysis Report. Individual sections of this desktop guide describe how each of the specific elements are performed and documented.

The upper left of Figure 4-1 indicates that design, site, and operational information, from various disciplines, are inputs to the PSA. While PSA activities will provide input to the LA documentation and submittal that meets the acceptance criteria of the YMRP, some PSA activities are not in the scope of responsibility of preclosure safety analysts, such as shielding analysis. In addition, portions of the evaluation of event sequences, consequences, and criticality analyses, represented in the central (dashed border) area of Figure 4-1, rely on input from various specialists. The interfaces and workflow between the various organizations are depicted in Figures 4-2 through 4-4 and described in Section 4.7.

The elements of the PSA process, for the stages of design maturity, are described in the following paragraphs. Bolded paragraph lead-ins refer to PSA elements shown in Figure 4-1.

\subsubsection{Hazards Analyses}

Internal and External Hazard Identification-Hazards analysis is a systematic identification and evaluation of naturally occurring and human-induced hazards (see Section6). To ensure completeness, the analysis begins with checklists of generic categories of hazards to identify which are applicable to a repository. The preclosure hazards at a geologic repository are not like those at a complex facility such as a nuclear power plant or petroleum refinery that contains and controls large amounts of thermal and chemical energy that can contribute to the initiation and magnitude of consequences should an accident occur. The high-level radioactive waste forms are contained in a series of physical barriers, including fuel rod cladding, canisters, transport casks, and waste packages. Thus, some form of energy must be imparted, generally from an external source, to a waste form to initiate some undesired sequence of events. 


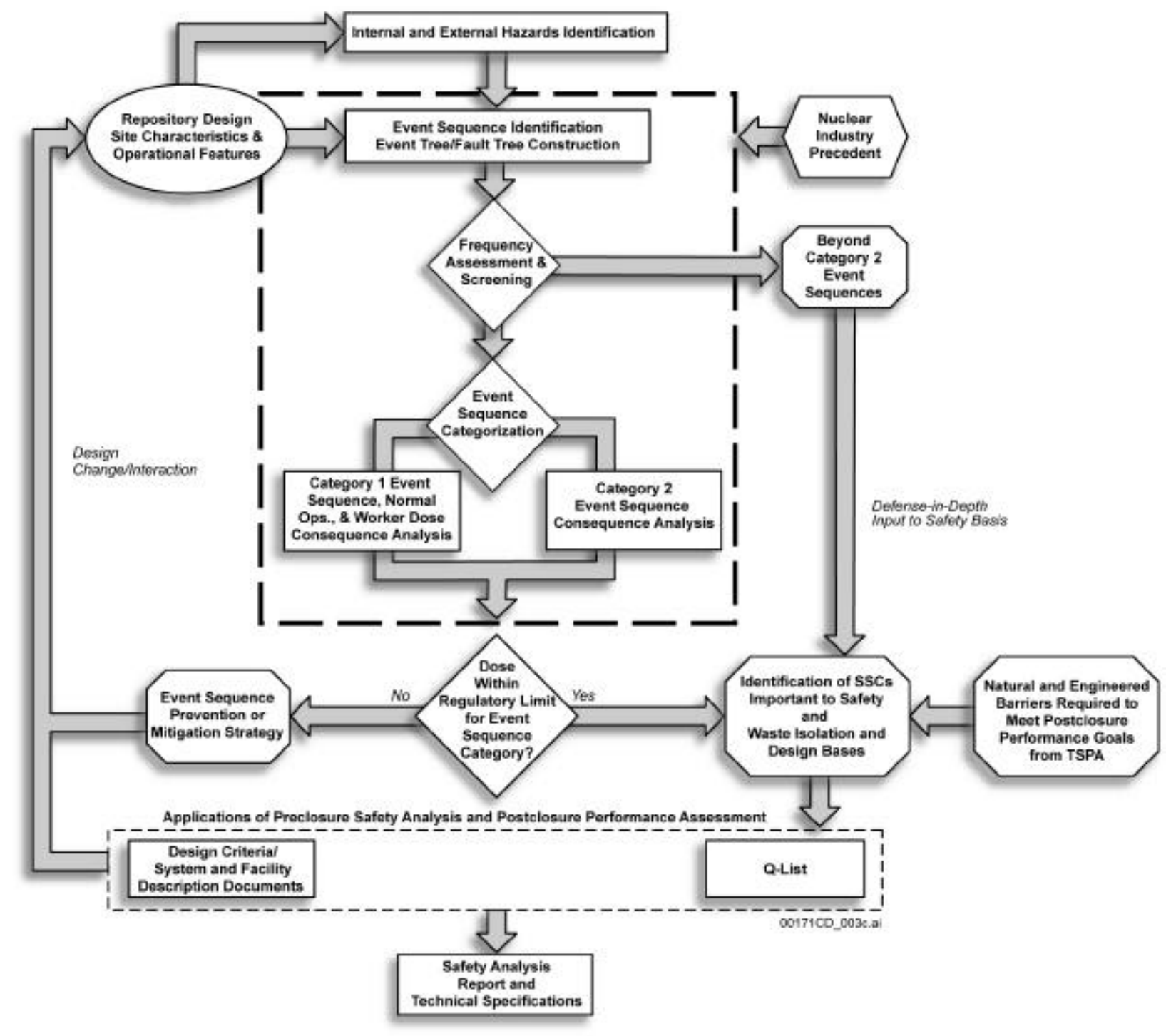

Figure 4-1. Preclosure Safety Analysis 


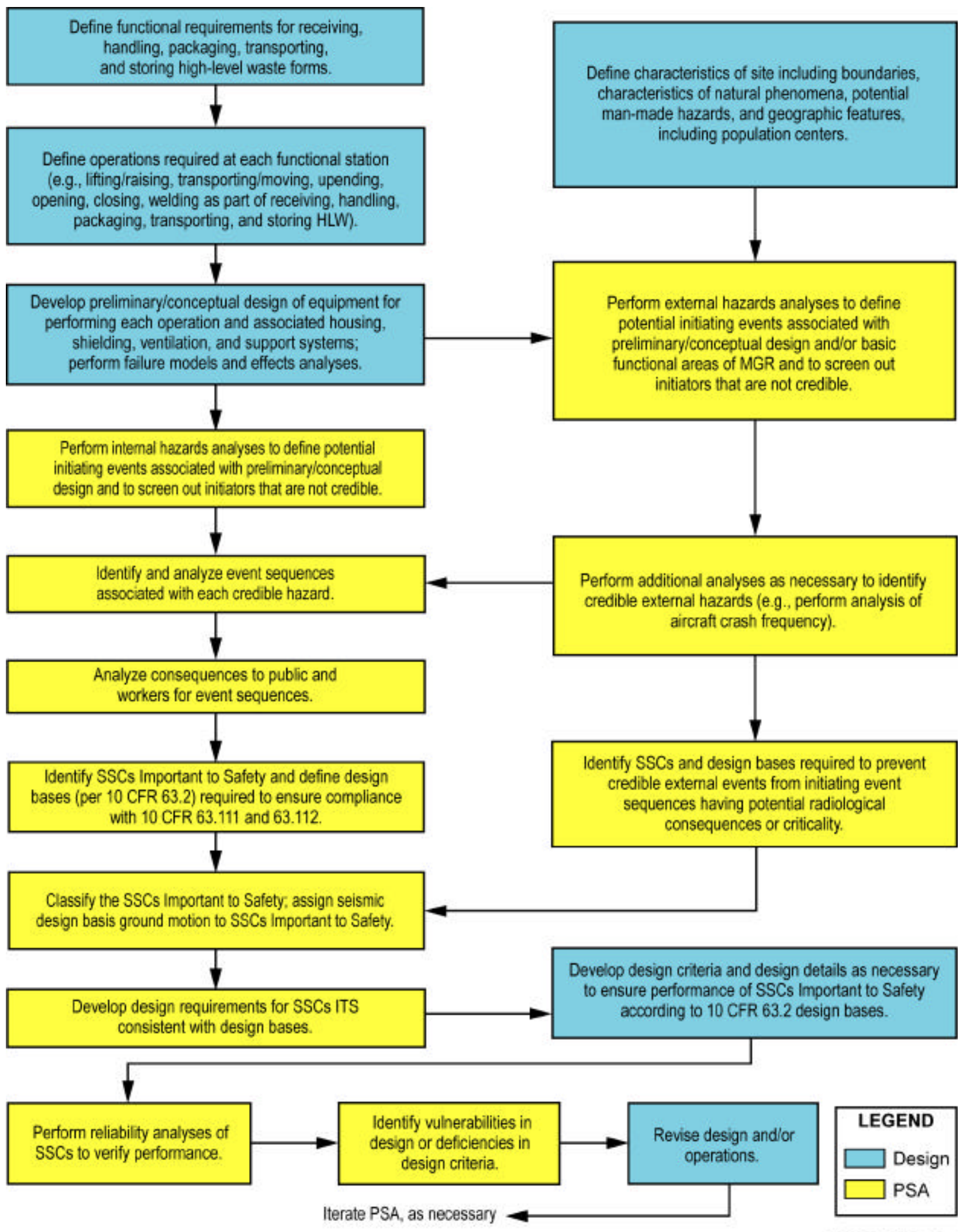

D03300C_PSAG_001.ai

Figure 4-2. Process for Preclosure Safety Analysis Using Available Level of Design Detail 


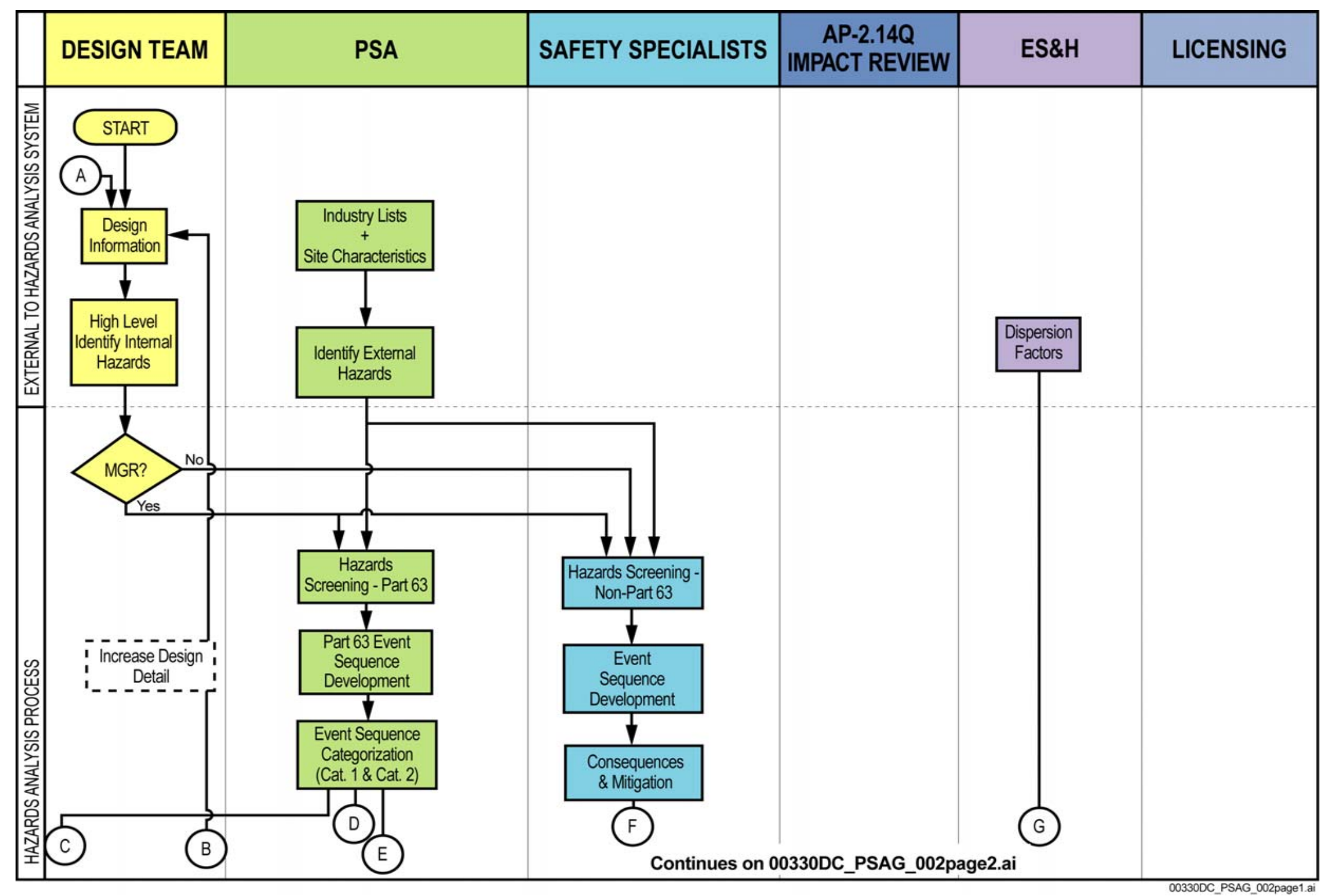

Figure 4-3a. Hazards Analysis System (1 of2) 


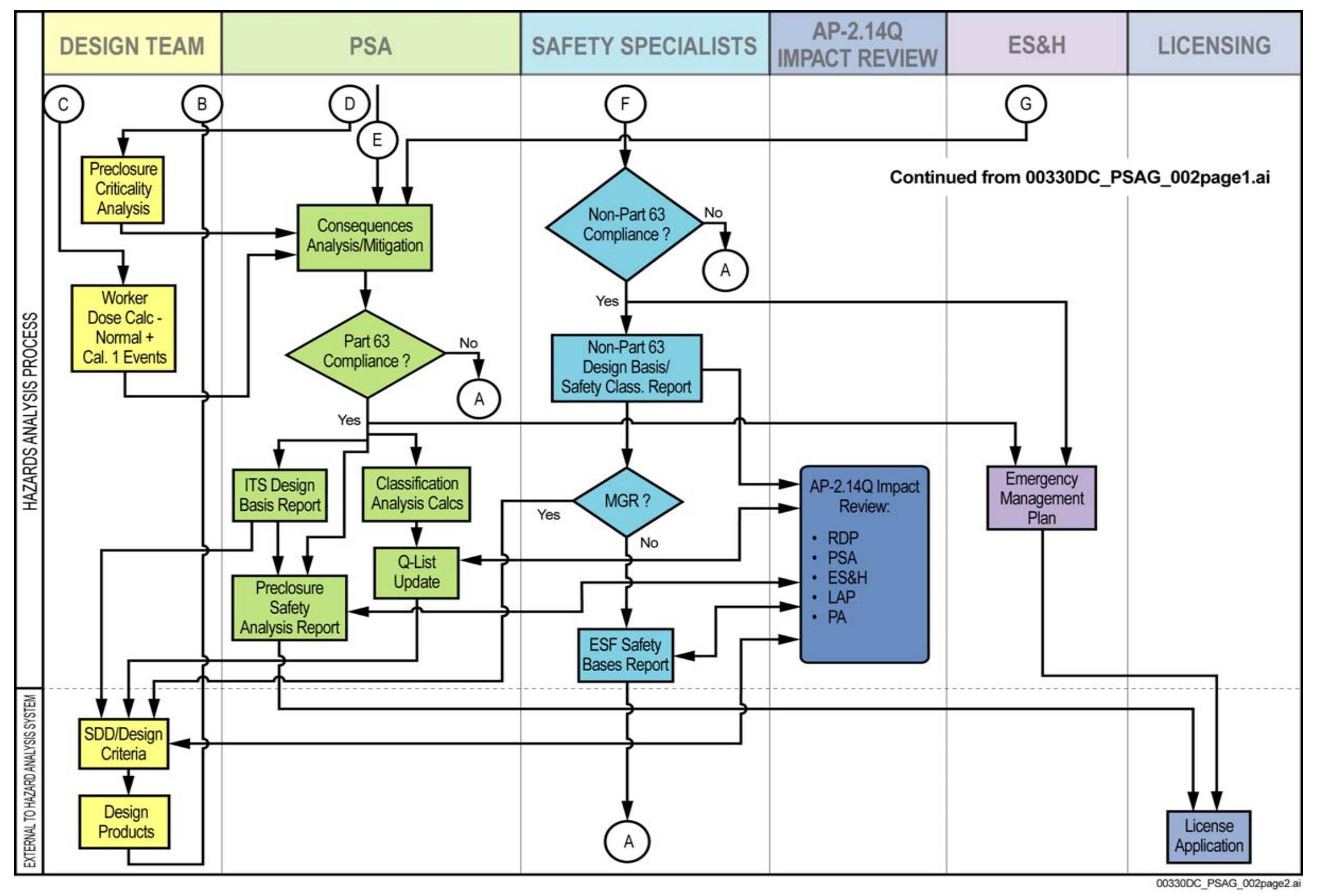

Figure 4-3b. Hazards Analysis System (2 of 2) 


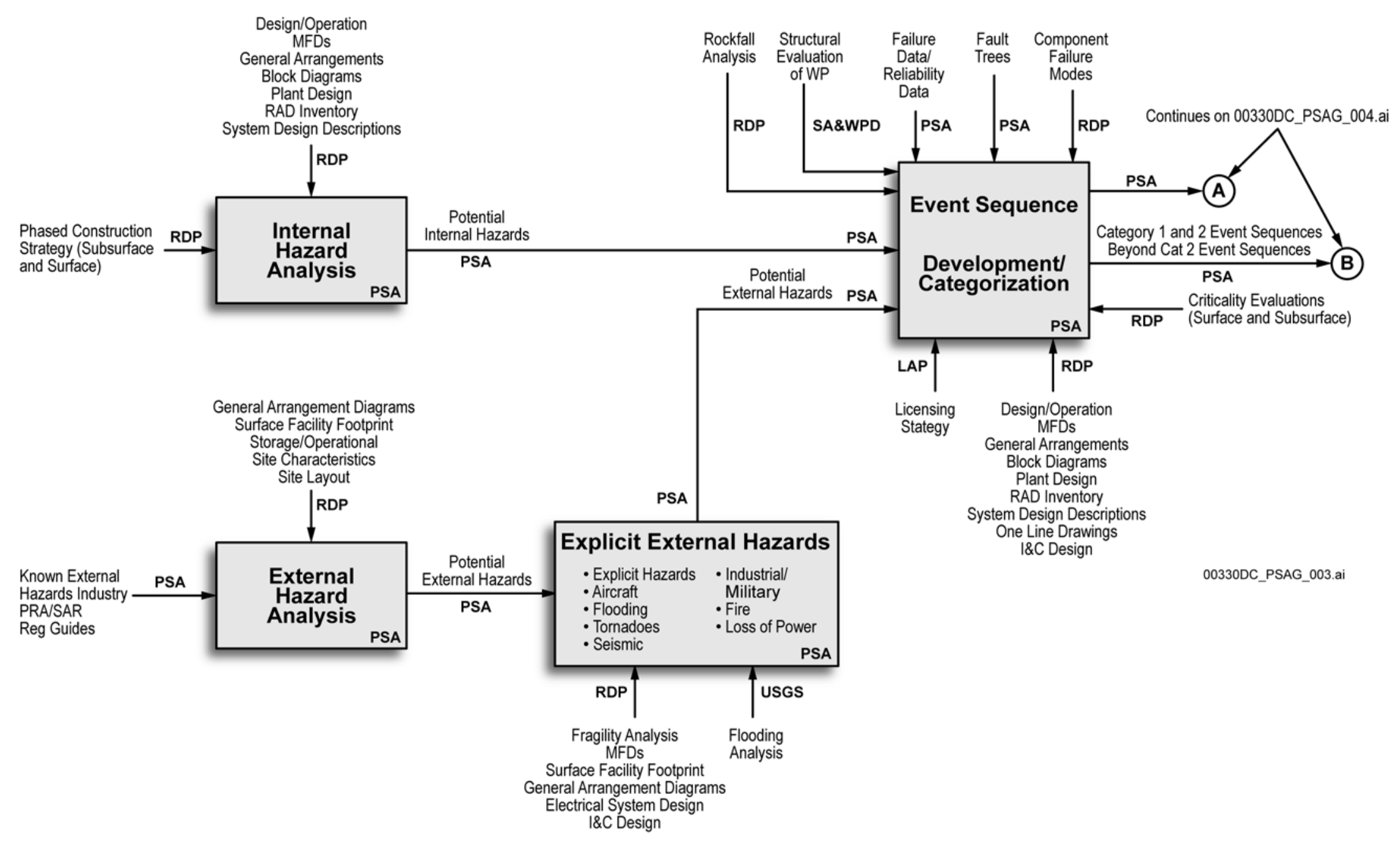

Figure 4-4a. Work Interface Flow Chart (1 of 2) 


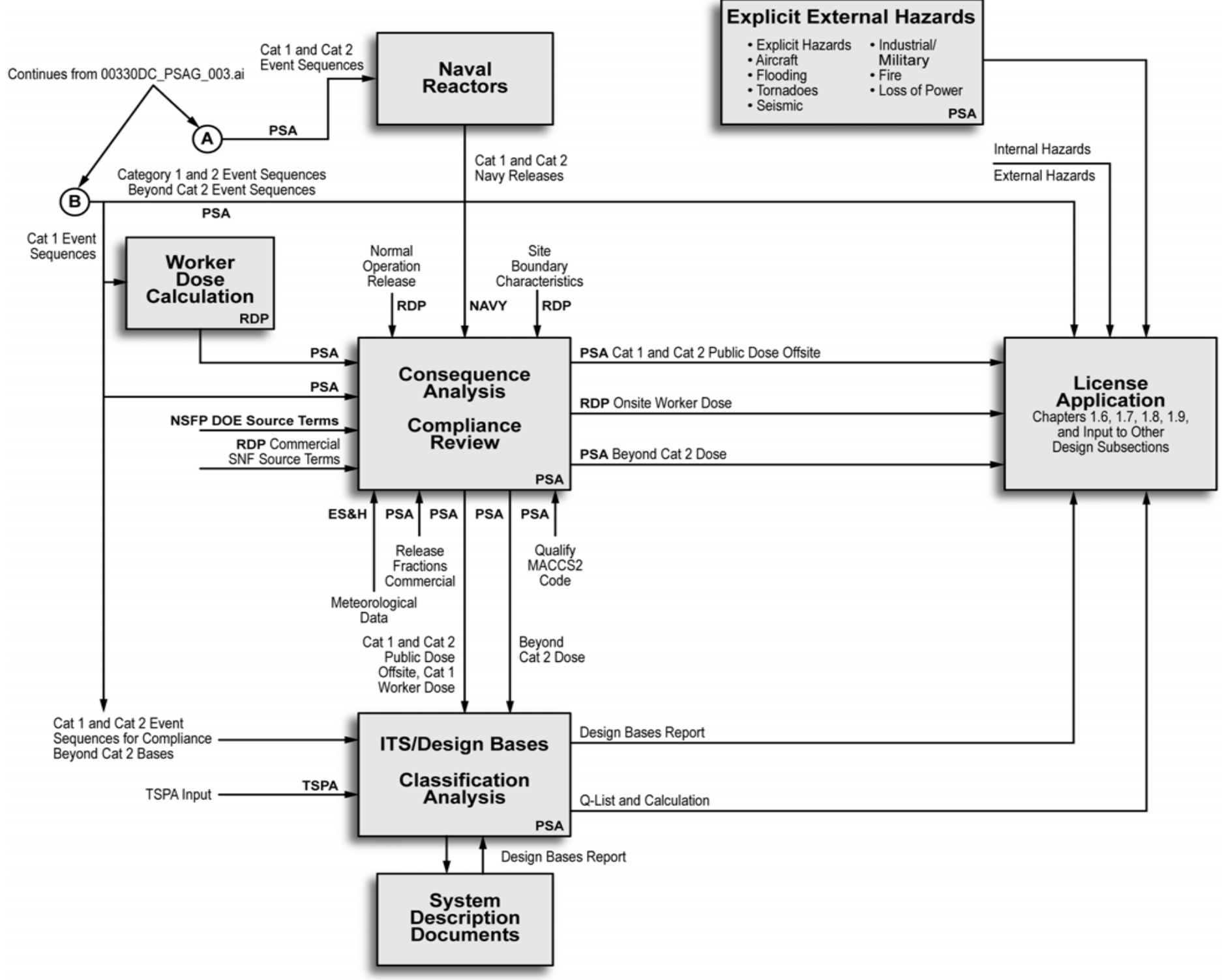

Figure 4-4b. Work Interface Flow Chart (2 of 2) 
Natural phenomena, such as earthquakes and tornadoes, are sources of energy, as well as the processes for lifting, moving, transporting, and welding that are inherent in repository operations. The role of the hazard analysis is to identify sources of energy that can have the potential to harmfully interact with a waste form. In the structured internal event hazards analysis, the forms of energy are categorized as Collision/Crushing, Chemical Contamination/Flooding, Explosion/Implosion, Fire, Radiation/Magnetic/Electrical/Fissile (i.e., potential criticality), or Thermal. The external events hazards analysis identifies credible natural phenomena such as earthquakes that could impart sufficient energy to the facilities to pose a hazard to a waste form.

The hazards analysis for the subsurface facilities include items such as potential rockfall onto work packages and hazards associated with construction that are isolated from, but concurrent with, waste emplacement and storage. The hazards analyses approach is, nevertheless, applicable.

The evaluation of hazards provides the technical bases for either including or excluding specific hazards from the PSA. Initially, qualitative evaluations are applied to screen out inapplicable or not credible hazards, from hazards either internal or external to the repository facilities. External hazards include natural phenomena and human-induced events. Each credible hazard is considered as a potential initiator of event sequences that could lead to releases of radioactivity or radiological exposure of workers, subject to further analyses as described in the next section.

\subsubsection{Event Sequence Analysis}

The central box in Figure 4-1 contains several analysis elements that comprise the PSA process. The analytic elements are described below, as they are applied in event sequence analysis for internal initiating events. The process applies several of the methods familiar to probabilistic risk assessment. (Section 4.3.1.3 describes a variation on the process that is applied to external initiating event and natural phenomena, and which may invoke deterministic analysis or regulatory precedents.)

The output of the internal events hazards analysis provides input to the event sequence analysis by identifying credible events in each operational area that could potentially initiate an accident sequence. The event sequence analysis identifies in more detail what events have to occur to result in a radiological accident and evaluates their credibility and potential consequences. The event sequence analysis may incorporate analyses and design strategies from safety-specific disciplines (e.g., criticality and fire-protection) and across disciplines (e.g., criticality, fire, and radiological exposure).

Sequence Identification: Event Tree and Fault Tree Construction-The internal hazards are classified by potential energy sources, associated with each operation in the facility, that could directly or indirectly impact various radioactive waste forms. Energy sources include drops, collisions, tipovers and slapdowns, fires, explosions, flooding, criticality, chemical, radiation, thermal, and human interactions. Potential accident scenarios (or event sequences) may be displayed in the form of event trees that include an initiating event (from an identified hazard) and one or more enabling events that must occur to result in a release of radioactivity, a criticality, or an abnormal worker exposure. The event tree format provides a framework for 
estimating the likelihood of event sequences by displaying the frequency of the initiating event and the conditional probabilities of contributing (enabling) events.

Potential criticality event sequences are subjected to specialized analyses, described in Section 11, to demonstrate that sufficient design and operational controls are in place to ensure the probability of a criticality is below the threshold for credibility.

Frequency Assessment: Screening-The frequency (or annual probability of occurrence) is estimated with quantitative analyses for each event sequence that potentially results in a release of radioactivity or abnormal worker exposure. The framework of the event tree is used to display the frequency of the initiator and the conditional probabilities of each enabling event in a sequence. The frequency of each event sequence is calculated as the product of the initiator frequency and the probabilities of the enabling events.

The frequencies of initiating events for internal hazards are estimated from the annual frequency of each operation multiplied by the conditional probability of the initiating event per operation. For example, the frequency of a canister drop is estimated by the product of the frequency of canister lifts (i.e., the number per year) and the conditional probability of dropping the canister per lift. The annual frequencies of each operational step are determined from programmatic information that specifies the maximum number of transport casks, spent fuel assemblies, spent fuel canisters, high-level radioactive waste canisters, and waste packages that are expected to be processed each year during the preclosure operations. The conditional probability of each enabling event (usually a failure of some preventive or mitigative feature), such as a drop of a waste form, is estimated from generic data for similar operations. In many cases for the preliminary event sequence screening analyses, conservative probabilities are assumed for the conditional events (e.g., assuming a probability of 1.0 that all fuel rods breach in a drop sequence). This conservatism is warranted in most cases in the early screening because design criteria or design details are not in place. As noted below, one objective of the internal event analysis is to define where prevention or mitigation controls are needed. Nevertheless, the event tree framework helps to display and keep track of the assumed probabilities and their bases.

The quantitative screening applies the 10 CFR 63.2 definition of event sequence to screen out event sequences whose estimated frequency results in a probability of less than one chance in 10,000 of occurring during the preclosure operations. For a 100-year preclosure period, the screening frequency is defined as $1 \times 10^{-6}$ per year. Such event sequences are termed beyond Category 2 event sequences and are screened out as noted by the octagonal box in Figure 4-1. Because of uncertainties, the frequency screening is conservatively applied initially so that event sequences within a factor of 10 of the threshold are retained in a list of event sequences until they may be shown to be less than $10^{-6}$ per year.

Event Sequence Categorization-In this step of the analyses, the frequency of each event sequence that survived the frequency screening is categorized as Category 1 or Category 2 as defined by 10 CFR 63.2. This categorization is important because it establishes which portion of the performance objectives of 10 CFR 63.111 govern each sequence.

Consequence Analysis-In this portion of the analysis, the potential consequences of releases or exposures are calculated for Category 1 and Category 2 event sequences. Figure 4-1 illustrates 
two boxes for the respective consequence analyses for Category 1 and category 2 event sequences. In some cases, the release or exposure characteristics are similar for two or more event sequences permitting sequences to be grouped. For Category 1 event sequences, consequences are evaluated as potential contributors to chronic exposures and are aggregated for Category 1 event sequences. Further, worker doses are calculated for Category 1 event sequences. For Category 2 event sequences, consequences are evaluated for each Category 2 event sequence, individually, as an acute exposure. No worker doses are calculated for Category 2 event sequences. Consequence analyses are also performed to support prevention or mitigation strategies for external events, as described in Section 4.3.1.3.

The assessment of doses to the public and to workers for each event sequence is evaluated for credible exposure pathways.

Section 8 describes the dose pathways considered in more detail.

The output of the event sequence analysis is a tabulation of the event sequences by category and the consequences associated with each. Where appropriate, a bounding event sequence for each category is identified for each operational area. The characteristics of the bounding event sequence define the 10 CFR 63.2 design bases requirements for SSCs ITS associated with that operational area.

Dose Within Regulatory Limit for Event Sequence Category?-This evaluation determines whether a specific repository design is licensable. If any deficiencies are noted wherein the respective performance objectives for Category 1 or Category 2 event sequences are not met (i.e., resulting in a "No"), the Project develops an event prevention or mitigation solution to correct the deficiency. The solution may result in a design change or additional administrative control.

Ultimately, the answer must be "Yes" to be licensable. SSCs that ensure that credible event sequences are in compliance with 10 CFR Part 63 are termed important to safety (ITS). Other SSCs ITS are those credited in screening out a beyond Category 2 event sequence, whose consequences would be non-compliant. This step is shown in Figure 4-1 as "Identification of SSCs Important to Safety and Waste Isolation and Safety Basis." Section 4.5 describes the requirements for ensuring the performance of SSCs ITS. Section 12 presents the classification process for SSCs ITS and to waste isolation. Otherwise, this guide does not discuss waste isolation or other post-closure matters.

As necessary through design evolutions, portions or all of the PSA steps are iterated until the performance objectives of 10 CFR 63.111 are met with the preliminary design.

\subsubsection{External Event Preclosure Safety Analysis}

The event sequence analysis of external events involves some variations on the process used to evaluate internal hazards (see Section 10). In most instances, the safety strategy for external event initiators is prevention of sequence initiation or SSC survivability through design. Consequently, sequences that could result in releases or exposures would be expected to be beyond the Category 2 cutoff. As appropriate, however, potential event sequences are defined and their potential consequences are calculated and evaluated against the dose limits of 
10 CFR 63.111. If prevention or mitigation is necessary to meet the regulations, the SSC(s) involved will be designed to withstand the effects of external events of prescribed intensity, either using NRC precedents or site-specific events. The following are portions of the external event analyses that are not illustrated explicitly in Figure 4-1.

External Event Hazards and Screening Analysis-Potentially credible hazards that survive the initial qualitative and quantitative screening of the external events hazards analysis, such as earthquakes, winds, tornado missiles, lightning, external fires, loss of offsite power, aircraft crashes, and industrial-military activities, are subjected to further analyses. Such analyses may include quantitative evaluation of their likelihood to determine if the y can credibly occur during the preclosure operations, or credibly cause a radiological release.

Selection of Design Basis External Events-This is the outcome of the external events hazards and screening analysis, including the specification of the frequency and intensity of design basis earthquakes, tornadoes, loss of offsite power, and similar events. The external event sequences are considered in light of how undesired consequences (i.e., radiological, criticality, or fire and explosion) might be generated by interaction of the external event with operations or storage areas within the facility.

Event Sequence Prevention and Mitigation Strategy-This step produces design requirements such that event sequences initiated by external events cannot credibly result in an unacceptable release of or exposure to radioactivity. For example, cranes and similar devices may need to be designed to halt in a safe condition without dropping a waste form upon loss of offsite power. The buildings housing handling, packaging, and lag-storage of waste forms may need to be designed to withstand design basis earthquakes and other natural phenomena without initiating or failing to mitigate a release of or exposure to radioactivity and without initiating a criticality. This step is part of the activity, "Identification of SSCs Important to Safety and Waste Isolation and Safety Basis," shown in Figure 4-1.

\subsubsection{Applications of Preclosure Safety Analyses}

Insights from the event sequence frequency analysis and associated consequence analysis help to define requirements for SSCs to prevent, or mitigate effects of, initiating events and contributing events. A given SSC may be significant to preventing an initiating event, preventing progression of an event sequence, or preventing or mitigating the release of radioactivity. Those SSCs that are necessary to prevent, reduce the likelihood, or mitigate consequences such that the Category 1 and Category 2 event sequences meet the performance requirements of 10 CFR 63.111 are designated as SSCs ITS. The ultimate application of the PSA is support of the preclosure safety basis in the LA.

The following areas use results from the PSA:

- $\quad$ - -List (YMP 2001)-Those SSCs designated as SSCs ITS are included in the QList. The Q-List also includes SSCs designated as important to waste isolation, but these are determined from the TSPA, not the PSA. The classification is developed from results of safety analyses as described in Section 12. 
- Design Criteria/System Description Documents-Nuclear safety, 10 CFR 63.2 design bases are developed for those SSCs designated as ITS. The design bases ensure that the necessary preventive and mitigative functions identified for the SSC are included in the final design. The nuclear safety design bases are stated in the system description documents.

- Design Evaluation/Support-As the level of design detail evolves and design concepts are put forth, concurrent supplemental safety analyses are performed to evaluate whether or not the design bases are met, or to help the designers evaluate a proposed preliminary design. These analyses may be qualitative or quantitative. A qualitative evaluation, for example, might be used to demonstrate that the transportation cask handling operations can not result in a drop of a transport cask from a height greater than the cask design basis. A quantitative analysis might apply a fault tree model to demonstrate that the reliability of an SSC meets the probability criteria (e.g., to demonstrate that the HVAC system of a waste handling facility remains operational for a given time with a specified probability). Should the qualitative or quantitative analyses identify a deficiency or vulnerability in the preliminary design, the designers would revise the design, operations, or both, accordingly.

In some instances, alternative design concepts for certain handling, packaging, or storage of waste may be under consideration by the design engineers. For example, alternatives for unloading a transportation cask may include dry (in air) or wet (under water) conditions. Similarly, design alternatives may include: remote vs. local control of operations; robotic vs. human control; handling only canistered spent nuclear fuel vs. a mixture of canistered and uncanistered spent nuclear fuel. Where decisions on such alternatives are pending at the time of submittal of License Application for Construction Authorization (LA-CA), the PSA explores the safety significance of each alternative (e.g., rates and concepts of handling or characteristics of the waste forms). The PSA either presents the event sequence frequency and consequences for the bounding alternative of each operation, or the results for the baseline design with a discussion of the sensitivity of results to each of the alternatives.

In addition, application of the PSA will include development of emergency operating procedures and licensing (or technical) specifications:

- $\quad$ Emergency Operating Procedures-For example, results of event sequence frequency analyses based on event-tree construction and quantification (Section 7.1) based on the methods of human reliability analysis (Section 7.4) will provide insights into the need for, or adequacy of, emergency operating procedures and/or instrumentation and controls to apply to mitigate the progression and/or consequences of Category 1 or 2 event sequences.

- $\quad$ Licensing Specifications -In addition to the $Q$-List, various parts of the PSA will identify the reliability or availability factors credited in event sequence frequency analyses and/or consequence mitigation. The availablity factor may be based on test and surveillance intervals, operating environment, and provisions for redundant components or subsystems. Similarly, the PSA may identify a list of human interactions credited in 
mitigation of event sequences and potential consequences. The probabilities of human failure events credited in the analyses may be based on the use of certain instrumentation and controls and the use of emergency operating procedures. Such information, along with engineering judgment, will be used to develop risk-informed licensing (or technical) specifications. Such license specifications that may result could include:

- Limiting conditions for operation for the interior operational environment (e.g., interior temperature, radiation levels, humidity) that exceeds the bases used in establishing event frequencies and failure probabilities

- Limiting conditions for operation for a system or one train of a system (e.g., part of the control system) credited in the compliance case

- Surveillance requirements (e.g., test and maintenance intervals) that support the system unavailability bases.

The licensing specifications will, to the extent practicable, be risk-informed and thereby be based on a quantitative evaluation of the effect of the specified item on the probability factors and/or dose reduction factors that are credited in the safety case. Analysts will apply, as appropriate, concepts presented in Regulatory Guide 1.177, An Approach for Plant-Specific, Risk-Informed Decisionmaking: Technical Specifications.

As illustrated in Figure 4-1, the performance of the PSA is an iterative process incorporating site characteristics, design information, and safety strategies. The PSA process is performed and documented under Project procedures. Results of the respective analyses are incorporated into the Safety Analysis Report.

\subsection{DEVELOPING AND DOCUMENTING THE PRECLOSURE SAFETY ANALYSIS IN THE LICENSE APPLICATION}

In support of the LA-CA, the PSA process begins with information on conceptual design and operations, including application of a preclosure safety strategy, application of good practices from similar operations, industry codes and standards, and NRC regulatory precedents. A structured hazards analysis is performed to identify potential hazards, external and internal to the repository facilities, that initiate event sequences that could result in releases of radioactivity. Information on the natural phenomena and man-made hazards at the site and region should be well characterized. SSCs ITS are identified from the analyses of hazards and event sequences. Design requirements derived from 10 CFR 63.2, design bases, that prevent or mitigate potential accidents are defined for the SSCs ITS and are incorporated into the Project design criteria document. As the 10 CFR 63.2 design bases are incorporated into the design, the PSA is updated to reflect the design commitments. For example, if a design feature eliminates a hazard or reduces the likelihood of an accident sequence, the PSA is revised.

\subsubsection{Level of Design Detail in the License Application for Construction Authorization}

The purpose of the LA is to present the safety case for a repository, and it must demonstrate that a repository will meet the postclosure and preclosure performance objectives. To demonstrate 
that a repository can meet postclosure performance objectives, a total system performance analysis is performed that is independent of the PSA. To demonstrate that a repository can meet the preclosure safety objectives, a PSA is performed. The PSA for the LA-CA must be at sufficient depth, commensurate with the available design detail, that provides sufficient assurance that the preclosure performance objectives of 10 CFR 63.111 will be met in the final design of a repository. A principal role of the preliminary PSA is defining the design bases that ensure that preclosure performance objectives can be met in the final design, in accordance with 10 CFR 63.112.

The LA should include a description of the systems that are required to protect the health and safety of the public and workers from Category 1 and Category 2 event sequences as defined in 10 CFR 63.2 for the preclosure period. The SSCs ITS are identified as those required to meet preclosure performance objectives of 10 CFR 63.111. The LA should also include a description of systems that process radioactive waste and protect SSCs ITS from interactions from other SSCs. In addition, the LA should identify design features that protect the health and safety of the worker during normal operations, including the preliminary program for ensuring ALARA in a repository design. Further, the LA should define the design and operational strategies for addressing the safety-specific disciplines of criticality and fire-protection. The strategies, criteria, standards, and associated analyses for criticality and fire protection should be incorporated into the PSA.

This guide is not to be interpreted as either a licensing strategy (which is available under separate cover and summarized in Section 3 of this guide) or as a guide for writing the License Application. The guide recognizes and incorporates material from the project whitepaper, Level Of Design Detail Necessary For The License Application For Construction Authorization (CRWMS-M\&O 1999), in describing the kinds and levels of design information that will be available or under development as the PSA proceeds. Further, it is noted that during a Technical Exchange held in July 2001, the NRC Staff provided a draft paper, Differentiated Approach to Providing Information in the License Application (NRC 2001), that describes acceptable levels of design details. The methodology of this guide will be applied to design information at a level of design detail that is in accordance with the aforementioned position papers to support the preparation and documentation of the LA.

\subsubsection{Information Base for Preclosure Safety Analysis in Support of License Application for Construction Authorization}

The premise of the PSA process is that sufficient information exists to: (1) define the kinds of event sequences (scenarios) that can credibly occur in the kinds of operations that are known or expected to be necessary for receiving, handling, processing, packaging, transporting, and storing waste forms, (2) estimate their frequency (likelihood), and (3) estimate their consequences. Section 5 states the requirements for descriptions of operating facilities and the site. At the time of the LA-CA, the hazards and event sequence analyses should be based on the information available that will consist of the following:

- $\quad$ Regulatory requirements per 10 CFR Part 63 
- $\quad$ Site information (location, geography, geology, seismicity, and meteorology) that is well characterized by Exploratory Studies Facility, Nevada Test Site, and generally available information

- $\quad$ Industry codes and standards

- $\quad$ Regulatory and industry precedents for similar facilities

- Knowledge of good practices employed in similar operations that will be, or expected to be, adopted in a repository

- $\quad$ Experience and knowledge of members of multi-disciplinary PSA team

- $\quad$ Conceptual designs and principals of construction and operation.

Information on conceptual designs, construction, and operation should be derived from the general system descriptions provided in the project description document and system description documents. The information listed below provides a large portion of the bases for hazards analysis and event sequence development, such as:

1. Characterization of waste forms (age, thermal output, enrichment, burnup, radionuclide inventories) and their vulnerabilities to damage (e.g., physical form, cladding, allowable drop height)

2. Rate of waste receipt for each year of operation

3. Subsurface layout of drifts, positions of waste packages within the emplacement drifts, and installation of drip shields as defined by post-closure performance assessment considerations

4. Ground support, ventilation, and fire-protection systems of the subsurface facilities

5. Concepts for rescue, recovery, and decontamination of disabled transport and emplacement equipment

6. Concepts for waste package transport and emplacement in subsurface, including control, instrumentation, communication, and power supply system

7. Waste package design bases for potential accidental conditions (i.e., allowable drop heights, impacts, thermal or fire loading); criticality control features

8. Waste package sealing (welding or other); process for waste package remediation

9. Waste package radionuclide source terms for spent fuel assemblies, high-level defense waste 
10. Preliminary surface facility layout, functional descriptions of operations for receiving, handling, packaging, staging, and transporting waste forms, including the rate of throughput

11. Surface facility construction concepts and commitments to NRC regulations, industrial codes and standards, including design for ventilation or filtration of radiological areas, seismic, tornadoes and winds, floods, and fire protection

12. Nuclear or radiological design bases and requirements (commitments) for surface and subsurface SSCs

13. Plan and schedule for concurrent construction (development) of the surface and subsurface facilities.

The documented basis for description of functions, operations, and features to be incorporated into the facility design should be derived from project documents.

\subsubsection{Preclosure Safety Analysis as Basis for the License Application}

Figure 4-1 illustrates the overall PSA process. Figure 4-2 provides additional explanation for applying the PSA process as the design evolves. In the figure, the shaded boxes represent design processes and the open boxes represent portions of the PSA process.

The basic functional requirements of a repository are clearly defined and the basic operations required to carry out those functions can be defined, although design alternatives may exist to perform those functions. Design engineers initially focus on success and devise means to carry out each operation. The role of the hazards and safety analysts is to postulate potential failures and accident scenarios that could be associated with each functional area, including scenarios involving mechanical or hardware failures, software failures, human errors, and common-cause failures. This activity is supported by Failure Modes and Effects Analyses for process steps and/or mechanical systems that are performed by design personnel with guidance from PSA personnel.

Various alternatives may be devised by designers for one or more operations to improve throughput (e.g., to achieve better reliability or improved maintainability), ensure licensability (e.g., a design meeting NRC guidelines), or reducing cost (e.g., a simpler design). Designers may also consider alternative designs that reduce the likelihood of accidents, either radiological or industrial, e.g., to implement the preclosure safety strategy. (Based on the results of the hazards and event sequence analyses of the PSA, design alternatives may be proposed to better meet regulatory requirements.)

Each of the functional operations requires suitable control and instrumentation systems, supporting systems such as alternating current (AC) and direct current (DC) electrical power or fuel pool water supply, filtration, and cooling systems, and decontamination systems. Further, each of the functional operations requires appropriate housing having an HVAC system, including HEPA filtration where necessary, and fire protection systems. The housing of the operations involving radioactive wastes will be designed, as appropriate, to withstand credible 
natural hazards such as earthquakes, tornadoes, and winds to preclude the initiation of event sequences.

Thus, even with limited design detail, the kinds of hazards and potential event sequences associated with the surface and subsurface operations can be identified and evaluated for their relative risk, and SSCs ITS can be identified.

\title{
4.4.4 Preclosure Safety Analysis for Retrieval Operations
}

Per the definitions of 10 CFR 63.2,

Retrieval means the act of permanently removing radioactive waste from the underground location at which the waste had been previously emplaced for disposal;

\begin{abstract}
AND
Important to safety. With respect to structures, systems, and components, means those ... whose function is: 1) To provide reasonable assurance that high-level waste can be received, and retrieved without exceeding the requirements of $\S 63.111(\mathrm{~b})(1)$ for Category 1 event sequences.
\end{abstract}

These definitions, therefore, include the retrieval campaign as part of the preclosure period that is subject to a preclosure safety analysis. However, a detailed safety analysis for a retrieval campaign is not expected to be provided in the LA for construction authorization, but would be a part of a license application specific for the retrieval operations.

Although this guide does not provide any special or different methodology for evaluating radiological safety of a retrieval campaign, the techniques and overall process would be applied in a similar manner. In general, the retrieval campaign would be just the reverse of the emplacement campaign with respect to handling and transporting waste packages to the surface. There are, however, some special considerations, different from than those associated with the original receipt, handling, and emplacement operations, that will have to be addressed in a retrieval campaign that are specific to a retrieval program once it is defined, planned, and scheduled. Among such considerations are:

- $\quad$ Condition of main and emplacement drifts with respect to accessibility,

- $\quad$ Condition of waste packages with respect to handling capability,

- $\quad$ Required handling, processing, and staging of waste packages after they are brought back to the surface and the facilities that are needed.

Nevertheless, the methodology for preclosure safety analysis presented in this guide is applicable. That is, the techniques for hazards analyses (Section6), event sequence analysis (Section 7), radiological consequences (Section 8), and the other sections, will be applied to the specific conditions that are defined for a retrieval campaign. 
It is expected that the LA for construction authorization will not provide details of a potential retrieval program, but will contain sufficient information to demonstrate that retrieval can be performed if required.

\subsection{ENSURING PERFORMANCE OF STRUCTURES, SYSTEMS, AND COMPONENTS IMPORTANT TO SAFETY}

The process described above results in the identification of SSCs ITS based on function and provides insights into requirements for reliability of the SSCs and their support systems such as power supplies and associated instrumentation and controls. For other SSCs, the degree of mitigation may be identified, such as required filter efficiency for a HEPA filter. In some cases, the process identifies the need for a safety function that may not be in the evolving design drawings and facility descriptions within the design available at the time of LACA. In these instances, only the 10 CFR 63.2 design bases and design requirements for those safety functions which will be included in the system description documents.

Regulation 10 CFR 63.112(e) requires an analysis of the performance of the SSCs to identify those that are ITS. This analysis should identify and describe the controls that are relied on to limit or prevent potential event sequences or mitigate their consequences. This analysis should also identify measures taken to ensure the availability of safety systems. As stated in 10 CFR 63.112(e), the areas to be discussed include, but are not necessarily limited to, consideration of thirteen areas listed in Table 4-1. For each area, the table provides examples of programmatic strategies or controls that will be in place at the time of LA-CA. Further, 10 CFR 63.112(f) requires a description and discussion of the design, both surface and subsurface, of the operations area, including the relationship between design criteria and the requirements specified by preclosure performance objectives (see 10 CFR 63.111(a) and (b)) and the design bases and their relationship to the design criteria.

As noted in Section 4.3, the LA-CA includes a description of the functions and operations of surface and subsurface facilities as the bases for the PSA. The PSA identifies the event sequences that could result in radiological exposures of the public or workers. In accordance with 10 CFR 63.112(f)(1), the design criteria of the SSCs ITS are derived from design bases (per 10 CFR 63.2) that ensure that the performance objectives of 10 CFR 63.111(a) and (b) are met, either as requirements to prevent or limit the likelihood of, or to mitigate the consequences of, the event sequences. The 10 CFR 63.2 design bases for SSCs ITS are derived from the PSA event sequence frequency and consequence analyses. The design requirements and criteria are incorporated into the system description documents of SSCs ITS and which include the associated design bases. In accordance with $10 \mathrm{CFR}$ 63.112(f)(2), the descriptions of a repository design and 10 CFR 63.2 design bases provided in the LA-CA either demonstrate how the design bases are met or will be met at the time of the LA-R\&P (Section 13 describes the process).

Even where the level of design detail is preliminary, the analyses included in the PSA processes identify the required safety functions, the design criteria for SSCs to achieve these safety functions, and commitments to ensure that the safety functions will be realized in the LA-R\&P design. The PSA process will be updated as the design evolves to LA-R\&P and the requirements of 10 CFR 63.112 (a) through (f) will be completely satisfied and documented. 
Table 4-1. Sample Approach for Demonstrating Compliance with 10 CFR 63.112(e)

\begin{tabular}{|c|c|c|}
\hline Item & 10 CFR 63.112(e) Requirement & Potential Approach for LA-CA \\
\hline$(1)$ & $\begin{array}{l}\text { Means to limit concentration of radioactive } \\
\text { material in air; }\end{array}$ & $\begin{array}{l}\text { Radiation Protection Program strategy; Radiation } \\
\text { confinement areas; Design criteria/bases for HVAC }\end{array}$ \\
\hline (2) & $\begin{array}{l}\text { Means to limit the time required to perform } \\
\text { work in the vicinity of radioactive materials; }\end{array}$ & $\begin{array}{l}\text { Radiation Protection Program strategy; Use of remote } \\
\text { handling and maintenance equipment }\end{array}$ \\
\hline (3) & Suitable shielding; & $\begin{array}{l}\text { Radiation Protection Program strategy; Design bases for } \\
\text { shielding; Preliminary shielding analysis of principal } \\
\text { operations areas }\end{array}$ \\
\hline (4) & $\begin{array}{l}\text { Means to monitor and control the dispersal } \\
\text { of radioactive contamination; }\end{array}$ & $\begin{array}{l}\text { Radiation Protection Program strategy; Radiation } \\
\text { confinement areas; Design bases for HVAC; Design } \\
\text { criteria for Radiation Monitoring System }\end{array}$ \\
\hline (5) & $\begin{array}{l}\text { Means to control access to high radiation } \\
\text { areas or airborne radioactivity area; }\end{array}$ & $\begin{array}{l}\text { Radiation Protection Program strategy; Radiation } \\
\text { confinement areas; Design bases for Radiation } \\
\text { Monitoring System ; Design bases for interlocks and } \\
\text { administrative controls }\end{array}$ \\
\hline (6) & Means to prevent and control criticality; & $\begin{array}{l}\text { Criticality safety strategy; Design bases for criticality } \\
\text { controls of operational areas and waste packages }\end{array}$ \\
\hline (7) & $\begin{array}{l}\text { Radiation alarm system to warn of } \\
\text { significant increases of radiation levels, } \\
\text { concentrations of radioactive material in air, } \\
\text { and increased radioactivity in effluents; } \\
\end{array}$ & $\begin{array}{l}\text { Radiation Protection Program strategy; Design bases for } \\
\text { Radiation Monitoring System; Preliminary analyses of } \\
\text { performance of Radiation Monitoring System }\end{array}$ \\
\hline (8) & $\begin{array}{l}\text { Ability of structures, systems, and } \\
\text { components to perform their intended safety } \\
\text { functions, assuming the occurrence of event } \\
\text { sequences; }\end{array}$ & $\begin{array}{l}\text { Design bases for SSCs including performance } \\
\text { requirements derived from hazards and event sequence } \\
\text { analyses, operating environments, and ability to withstand } \\
\text { natural phenomena }\end{array}$ \\
\hline (9) & $\begin{array}{l}\text { Explosion and fire detection systems and } \\
\text { appropriate suppression systems; }\end{array}$ & Fire Protection strategy; Preliminary fire hazards analyses \\
\hline$(10)$ & $\begin{array}{l}\text { Means to control radioactive waste and } \\
\text { radioactive effluents, and permit prompt } \\
\text { termination of operations and evacuation of } \\
\text { personnel during an emergency; }\end{array}$ & $\begin{array}{l}\text { Radiation Protection Program strategy; Design bases for } \\
\text { waste treatment building and systems; Design bases for } \\
\text { Radiation Monitoring System including alarms; } \\
\text { Preliminary emergency plans }\end{array}$ \\
\hline$(11)$ & $\begin{array}{l}\text { Means to provide reliable and timely } \\
\text { emergency power to instruments, utility } \\
\text { service systems, and operating systems } \\
\text { important to safety if there is a loss of } \\
\text { primary electric power; }\end{array}$ & $\begin{array}{l}\text { Design bases for primary and backup power sources for } \\
\text { SSCs ITS as appropriate to their safety function and need } \\
\text { for continuing power or other support (e.g., radiation } \\
\text { monitoring and continuation of cooling or air circulation) } \\
\text { on loss of primary power source }\end{array}$ \\
\hline$(12)$ & $\begin{array}{l}\text { Means to provide redundant systems } \\
\text { necessary to maintain, with adequate } \\
\text { capacity, the ability of utility services } \\
\text { important to safety; and }\end{array}$ & $\begin{array}{l}\text { Design bases for primary and redundant subsystems and } \\
\text { power sources for SSCs ITS as appropriate to their safety } \\
\text { function and reliability requirements (e.g., to ensure } \\
\text { sufficient small likelihood of an event sequence, or to } \\
\text { ensure availability of mitigation function); Process flow, } \\
\text { piping and instrumentation diagrams, and electrical one- } \\
\text { line diagrams, as appropriate, to demonstrate the } \\
\text { capability }\end{array}$ \\
\hline$(13)$ & $\begin{array}{l}\text { Means to inspect, test, and maintain SSCs } \\
\text { ITS, as necessary, to ensure their continued } \\
\text { functioning and readiness. }\end{array}$ & $\begin{array}{l}\text { Design requirements to ensure that inspections, tests, } \\
\text { and maintenance can be carried out; Preliminary } \\
\text { commitments to administrative controls (e.g., preliminary } \\
\text { licensing specifications) for carrying out periodic } \\
\text { surveillance and tests to ensure availability of SSCs ITS }\end{array}$ \\
\hline
\end{tabular}




\subsection{RADIATION SAFETY - ALARA}

The repository will receive, prepare, and package spent nuclear fuel and high-level radioactive waste for emplacement underground. This represents a potential hazard that must be handled in a manner that achieves radiation safety for the general public and repository workers. A combination of management commitments, radiation safety considerations for design development, and regulatory requirements and guidance are employed to achieve designs that support radiation safety at the Yucca Muntain Repository. This section, which focuses on occupational workers and the on-site general public, describes how as low as is reasonably achievable (ALARA) is incorporated in the design of repository facilities.

The design of the facility ensures that offsite general public ALARA goals are met by complying with the pre-closure performance objectives as specified in 10 CFR 63.111 as well as the annual effluent dose limit of 10 mrem in 10 CFR 20.1101(d).

Paragraph 20.1101(b) of Title 10 of the CFR Part 20, Standards for Protection Against Radiation, states that licensees shall achieve occupational doses that are as low as is reasonably achievable. The design will ensure that annual doses to occupational radiation workers will not exceed the total effective dose equivalent (TEDE) limit in 10 CFR Part 20 of $5 \mathrm{rem} / \mathrm{yr}$, nor will organ doses exceed those specified in 10 CFR Part 20.

Potential occupational radiation exposure from licensed radiation sources is evaluated and minimized throughout the facility design process using general radiation zoning, and design ALARA evaluations. General radiation zoning is established early in the facility design and used during the design development. ALARA evaluations are performed when the preliminary design matures and as it proceeds to the final design. The design will be reviewed for ALARA concerns in accordance with 10 CFR Part 20 to ensure that occupational worker doses are within the specified limits.

\subsubsection{Definitions}

ALARA (acronym for "as low as is reasonably achievable") - Making every reasonable effort to maintain doses from radiation as far below the dose limits specified in 10 CFR Part 20 as is practical, consistent with the purpose for which the licensed activity is undertaken, taking into account the state of technology, the economics of improvements in relation to state of technology, the economics of improvements in relation to benefits to the public health and safety, and other societal and socioeconomic considerations, and in relation to utilization of nuclear energy and licensed materials in the public interest.

Collective dose-The sum of doses received by a group of individuals involved in the performance of a particular task or series of tasks. The total facility dose is the sum of these collective doses by group.

External dose-The portion of the dose equivalent received from radiation sources outside the body.

Individual dose-The dose received by an individual exposed to ionizing radiation during the course of their work activities. The dose may be due to work on a single or multiple tasks. 
Internal dose-The portion of the dose equivalent received from radioactive material taken into the body.

Onsite member of the public-Any individual inside the controlled the area who is not a radiation worker. For example, the construction workers involved in the phased construction of the Project facility, where part of the Project facility is operating while another part of the facility is being built.

Member of the public-Any individual except when that individual is receiving an occupational dose.

\subsubsection{ALARA Design Considerations}

The purpose of this section is to summarize the elements that show the preliminary design of the facility is adequate to protect the radiological health and safety of YMR workers if the Considerations are followed.

The following five general ALARA considerations are listed in their typical order of preference to eliminate or minimize potential worker doses. Priority is given to those features that are most effective. Prevention is preferable to mitigation, and passive systems are preferable to active. Specific ALARA consideration in the YMR design include the following:

\section{Eliminate or reduce radiation sources}

Examples: remove radiation source prior to occupancy, reduce quantity of source present, prevent source increase by contamination buildup, provide features to aid decontamination.

\section{Contain or confine radiation sources -}

Examples: consider leak tightness, provide proper airflow and filtration, incorporate water conditioning, control contamination at the source, manage any waste produced.

\section{Minimize time exposed to radiation or airborne radioactive material -}

Examples: specify reliable equipment to reduce maintenance, use automation to preclude worker exposure, design arrangements to accommodate efficient inspections and maintenance, use special devices to speed access and maintenance, arrange for component removal for repair/calibration, provide adequate manways and lighting, arrange efficient access/egress.

\section{Maximize distance from radiation sources -}

Examples: use remote operating equipment, locate instruments and readouts in low dose areas, provide for remote handling tools for maintenance, use cameras and microphones for surveillance and inspections, arrange layout to maximizes source to worker distance.

\section{Use radiation shielding -}

Examples: assure adequate shields based on worker time in the area, consider use of special purpose shields, consider the need for temporary shielding installation, avoid streaming arrangements, carefully consider shield penetrations, anticipate hot spot buildup in defining shielding needs, use fortuitous shielding arrangements. 


\subsubsection{Organizational Responsibilities for ALARA Design}

The Repository Design Project Manager is responsible for implementing the ALARA design process and instructions.

Preclosure Safety Analysis (PSA) is responsible for identifying Category 1 Event Sequences (including frequency) for the ALARA design process.

Designers/Engineers will develop preliminary ALARA design.

Discipline ALARA Representatives will review and verify designs for ALARA conformance.

Design Supervisors will ensure Designers/Engineers receive ALARA training and incorporate ALARA design considerations and features into the preliminary design

ALARA Specialists will identify ALARA design criteria implementation approaches and provide ALARA support to Designers/Engineers and Nuclear Engineering.

Nuclear Engineering performs and documents on-site dose calculations and identifies radiological conditions.

\subsubsection{ALARA Design Process}

The design process for Preliminary Design ALARA includes:

- $\quad$ Establishing ALARA design goals, criteria and considerations for preliminary design (4.6.4.1)

- $\quad$ Classifying anticipated radiological conditions in facility areas (4.6.4.2)

- $\quad$ Implementing Preliminary Design ALARA (4.6.4.3)

- $\quad$ Estimating annual individual and collective doses to workers (4.6.4.4)

- $\quad$ Performing preliminary ALARA Design Review (4.6.4.5)

- $\quad$ Modifying the design to meet the ALARA goals (4.6.4.6)

- $\quad$ Providing justification for exceptions to the ALARA design goals (4.6.4.7).

\subsubsection{Preliminary Design ALARA Goals and Criteria}

The ALARA Design Goals for occupational workers are to ensure that both individual and collective annual doses are maintained at ALARA levels during normal operations and as a result of Category 1 event sequences. The frequency of Category 1 event sequences will be included in ALARA dose assessments. The following ALARA design goals are established for Preliminary Design: 
- $\quad$ Individual Dose:

The ALARA design goal for individual worker doses is to minimize the number of individuals that have the potential of receiving more than $500 \mathrm{mrem} / \mathrm{yr}$ total effective dose equivalent (TEDE). That goal is 10 percent of the annual TEDE limit in 10 CFR 20.1201, and includes both internal and external doses.

The ALARA goal for on-site members of the general public is to maintain individual doses less than 10-20 percent of the annual TEDE limit of 100 mrem in 10 CFR 20.1301.

- $\quad$ Collective Dose:

The ALARA design goal for collective doses is to maintain the average annual individual dose for each worker group at less than $500 \mathrm{mrem} / \mathrm{yr}$ total effective dose equivalent (TEDE). That goal is 10 percent of the annual TEDE limit for individuals in 10 CFR 20.1201, and includes internal and external doses. Worker groups are defined groups of individuals with the same or similar work duties, such as operators, maintenance, and radiation safety personnel. (In combination with the Individual Dose Goal, it is expected that no individual worker in a work group could have a dose substantially above $500 \mathrm{mrem} / \mathrm{yr}$ and the group still satisfy the Collective Dose Goal.)

Optimization methods (i.e., cost benefit considerations) shall be used to assure that occupational dose will be ALARA. In developing the Preliminary Design, qualitative cost benefit considerations will be used for comparing design alternatives and justifying design decisions, where appropriate. In determining whether a dose-reducing design alternative is reasonable, $\$ 10,000$ per person-rem averted will guide decisions.

\subsubsection{Radiological Conditions Classified for Facility Areas}

Radiological conditions in facility areas during normal operations and as a result of Category 1 event sequences provided by PSA are fundamental inputs for the ALARA design process. The classification of facility areas provides Designers/Engineers useful information for minimizing occupational radiation doses by incorporating in design appropriate features, such as access control, equipment layout and shielding design. Each area of the facility will be classified by radiological conditions, both dose rate range and contamination information. This classification information is available to Designers/Engineers in developing and evaluating Preliminary Designs and alternatives. Areas should be re-classified as the radiological conditions change during the design evolution. Nuclear Engineering will:

- Determine design basis radioactivity source terms (normal operation and Category 1 event sequences)

- $\quad$ Classify facility areas by dose rate (normal operation and Category 1 event sequences)

- Document the facility area classifications on diagrams and make these available for use by Designers/Engineers. 


\subsubsection{Implementing Preliminary Design ALARA}

This section applies to structures, systems and components involving radioactive material or radiation exposure during normal operation, maintenance, in-service surveillance, performance confirmation, or as a result of Category 1 event sequences.

Working with the ALARA Specialist, the Designer develops the preliminary ALARA design. A description of the ALARA features considered in developing the design is prepared, and reviewed by the Discipline ALARA Representative. It is incorporated in the dose calculation discussed in Section 4.6.4.4.

\subsubsection{Dose Calculations}

Nuclear Engineering with the support of the Designer/Engineer and ALARA Specialist will estimate the annual individual and collective doses to workers for each facility area, system or process involving radioactive material or radiation exposure on site. The dose calculations will be documented in accordance with AP-3.12Q, including the pertinent information on the ALARA design from Section 4.6.4.3.

The off site dose calculations will be performed by PSA to confirm that the offsite public ALARA goals are met.

\subsubsection{Preliminary Design ALARA Review}

The potential benefits of incorporating ALARA into the design are typically greatest at the early design stages. At key points during Preliminary Design, design reviews are held to critically examine the design. A multi-discipline team, involving Design Engineers, Environmental Safety and Health, Design ALARA and other groups, as appropriate, reviews and evaluates the adequacy of the design for incorporation of ALARA design criteria and considerations. This also helps ensure that ALARA design features do not introduce non-radiological hazards. Designs that are not acceptable are returned to the Designer/Engineer for modification or justification for exception. Results of the ALARA Design Reviews are documented and retained in accordance with the design review documentation process.

\subsubsection{Design Modifications}

The ALARA Design Review may identify the need to evaluate design alternatives or modify the existing design. Additionally, the normal ALARA design processes may also identify those needs. The evaluation process for alternatives or modifications will proceed using the appropriate steps in Sections 4.6.4.3 and 4.6.4.4. Alternatives or modifications that affect the radiological conditions will be evaluated per Section4.6.4.2 and revised radiological classification information will be disseminated to Designers/Engineers.

\subsubsection{Exceptions to ALARA goals}

The Designer/Engineer will work with the ALARA Specialist to provide justification for an exception or modify the design. The justification for the exception is prepared as directed by the RDP Manager, and is included in the ALARA design-considerations document. If the 
justification is not accepted by the Design Discipline Supervisor, Radiation Protection Manager, and the RDP Manager, then design modifications are developed, as required, to meet the ALARA design goals following the ALARA Design Process.

\subsection{PSA WORKFLOW AND INTEGRATION}

Sections 4.2 through 4.6 describe the analyses and processes for developing the PSA. This section illustrates where and how information flows into the preclosure safety analysis from various disciplines within the Project organization, and its interrelationship to analyses performed by preclosure analysts.

The preclosure Hazards Analysis System, shown in Figure 43 (1 of 2 and 2 of 2) presents another view of how the radiological safety analyses of the PSA group is integrated with hazards analyses and licensing evaluations performed by other organizations. The integration includes the design team (that includes criticality, shielding and radiation protection), safety specialists (e.g., fires hazards analysts, industrial and mining safety), environmental health and safety (e.g., meteorology and atmospheric dispersion factors, emergency management plan)), and licensing (e.g., ensuring compliance). The radiological hazards and event sequence frequency and consequence analyses performed by the PSA group is just one facet of the overall radiological and non-radiological safety evaluation that will be performed in support of the LA.

Figure 44 ( 1 of 2 and 2 of 2) provides a detailed breakdown of the PSA process and the information flow. The legend defines the names and abbreviations of the organizations that provide input or analyses to the PSA. The boxes in the figure represent specific areas of work and indicate, in the lower right corner, the organization responsible for performing that area of work. In most of the boxes, the "PSA" group is shown as the responsible organization but there is one instance where the "NUE" (Nuclear Engineering) and one instance where the "RDP" (Repository Design Project) is responsible. Similarly, the lines indicate the information flow, the content of each information stream, and the responsible organization. In the case of the information sources, there are many organizations represented.

By and large, the left-to-right flow of information and work processes in Figure 44 is a more detailed representation of the process summarized in Figures 4-1 and 4-2 that was developed to help project planning and integration. Other sections of the PSA guide describe each of the work areas and the particular information needs for each. Most of the specific inputs to a given work area are self-explanatory and will not be discussed in this section, but it is important to note that the PSA is an integrated effort. For example, the Repository Design Project (RDP) not only provides drawings and descriptions of the design and operations, RDP will also provide Failure Modes and Effects Analyses (FMEA) for process steps and mechanical systems (prepared primarily by design engineers with assistance from the PSA group). FMEA is shown as Component Failure Modes in Figure 4-4a. Further, RDP will provide structural analyses, including effects of seismic ground motions, and seismic fragility evaluations of SSCs to support the seismic PSA analyses, as described in Section 10.1. Similarly, the Structural Analysis and Waste Package Design group (SA\&WPD) will provide structural evaluations of the waste packages to define the design basis drop heights and limits against other potential impacts, such as rockfall. 
One item in Figure 4-4 that needs explanation, however, is the information labeled "TSPA Input" that supports the "ITS/Design Bases - Classification Analysis." The output from this work area is the "Q-List" that identifies "classifies" SSCs that are subject to quality assurance (QA) measures per 10 CFR 63.142. Although the post-closure safety analysis (Total System Performance Analysis) is totally independent from the preclosure analyses and methodology, the classification of SSCs for the purpose of applying QA measures also includes SSCs that are deemed "important to waste isolation." The PSA staff is responsible for compiling the Q-List and, therefore, relies on input from the TSPA to identify the SSCs important to waste isolation.

All of the analyses and information represented in Figure 44 will be performed in accordance with the quality assurance program and documentation requirements. Applicable Project procedures for each work area (i.e., the boxes) will produce one or more discrete analysis packages that will be assigned unique Project document identifiers. Further, there may be multiple outputs from each work area representing preliminary and refined analyses as the design matures and more design becomes available.

Table 42 presents the PSA "work instructions" in the form of a checklist that shows how the PSA group will initiate the process by obtaining necessary design and site information, perform the hazards analyses, etc. Key organizational interfaces are listed, as are the expected transfers of output information from the PSA group to other organizations (e.g., see "O utput to RDP" under item 2). 


\section{Table 4-2. Preclosure Safety Analysis Work Instructions}

Obtain design, site characteristics, and operational concepts information

Design and operational concepts (early design and operational concepts info is obtained from products like mechanical flow diagrams, preliminary general arrangements; however, the responsible design engineer is the best source of preliminary info)

Mechanical handling systems (Insert Name of Lead)

Mechanical systems (Insert Name of Lead)

Civil/Structural/Architectural systems (Insert Name of Lead)

Plant design (Insert Name of Lead)

Geotech systems (Insert Name of Lead)

Waste package (Insert Name of Lead)

Site Characteristics (this info comes from various sources, some key areas are listed, but not all inclusive)

Civil/Structural/Architectural (Insert Name of Lead)

Science and Analysis (Insert Name of Lead)

Perform hazards analyses to identify potential hazards

External hazards analysis

Potential external hazards list

Key interfaces

Science and Analysis (Insert Name of Lead)

Civil/Structural/Architectural (Insert Name of Lead)

Plant design (facility footprint) (Insert Name of Lead)

Civil/Structural/Architectural (facility footprint, areas with radiological inventory) (Insert Name of Lead)

Internal hazards analysis

Potential internal hazards list

Key interfaces

Mechanical handling systems (Insert Name of Lead)

Mechanical systems (Insert Name of Lead)

Civil/Structural/Architectural systems

(Insert Name of Lead)

Plant design (Insert Name of Lead)

Geotech systems (Insert Name of Lead)

Waste package (Insert Name of Lead) 
Table 4-2 Preclosure Safety Analysis Work Instructions (Continued)

\section{OUTPUT TO RDP}

Provide results of external hazards analysis to preclosure criticality (Insert Name of Lead) Provide results of internal hazards analysis to preclosure criticality (Insert Name of Lead) Provide results of internal hazards analysis to radiological worker safety (Insert Name of Lead) Integrate with development of project fire hazards analyses (Insert Name of Lead)

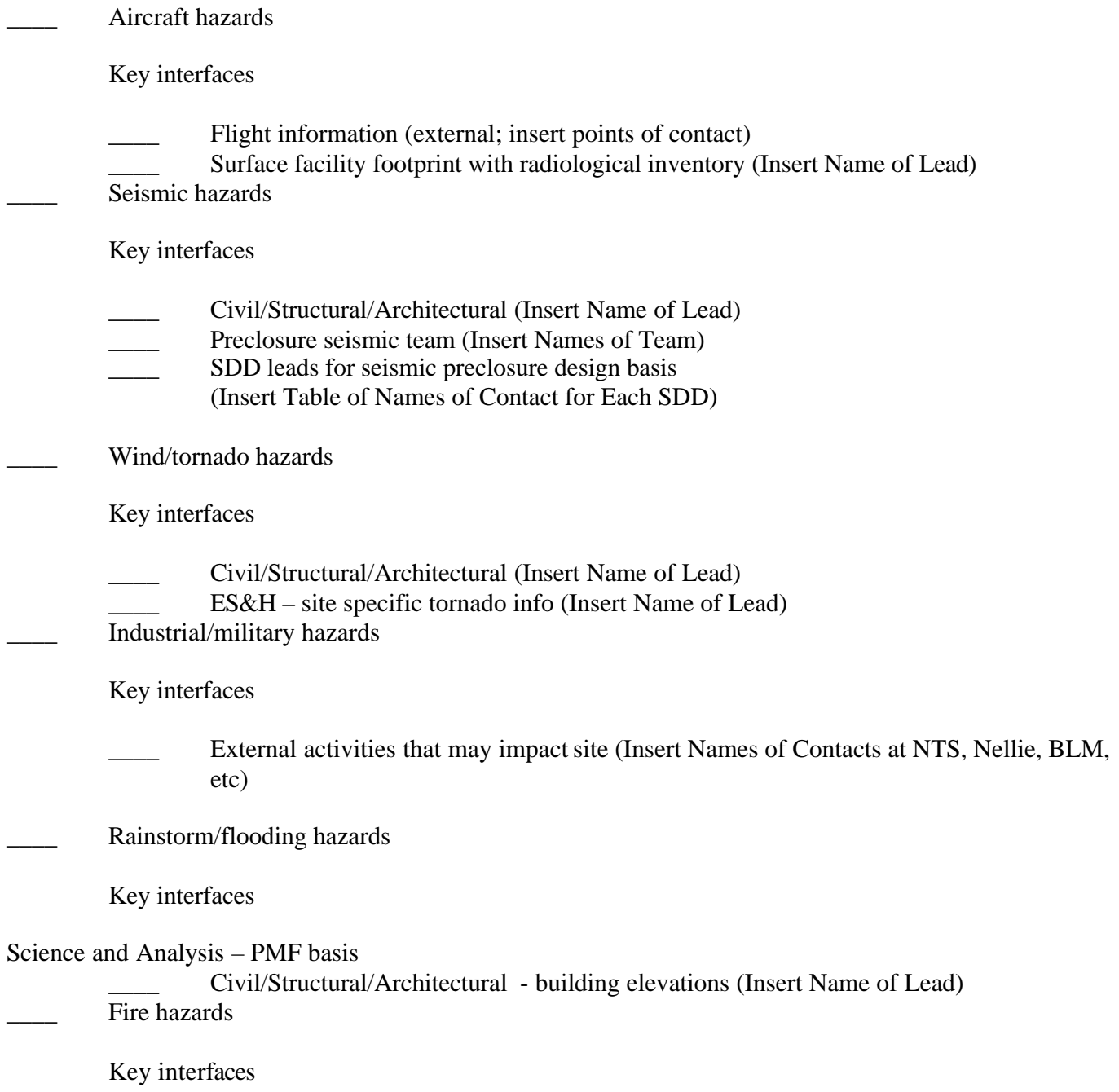




\section{Table 4-2 Preclosure Safety Analysis Work Instructions (Continued)}

b)

Develop/obtain event sequence categorization supporting information

Failure rate/Reliability database/analysis (evaluate data for appropriateness, identify implied constraints/controls based on using data)

Key interfaces

System design leads - component failure modes, component history

Key interfaces

Fault tree analyses - develop, as needed, to support development of event trees

System design leads - component failure modes, component history

c) Develop event sequences and categorize as Category 1, Category 2, or beyond Category 2

Ensure potential hazards on external hazards list are evaluated in specific hazards analysis or include in event sequence evaluations (each potential external hazard must be dispositioned)

Ensure potential hazards on internal hazards list are evaluated in event sequence evaluations (each potential internal hazard must be dispositioned)

Key interfaces

System design leads

Categorize event sequences as Category 1, Category 2, or Beyond Category 2

\section{OUTPUT TO RDP}

Provide Category 1 and 2 event sequences to preclosure criticality (Insert Name of Lead) Provide Category 1 event sequences to radiological worker safety (Insert Name of Lead) Provide Category 1 and 2 event sequences that involve naval fuel to Navy (Insert Name of Lead)

Develop consequence analyses

Develop release fractions for commercial SNF

Obtain release fractions for DOE fuel from National Spent Fuel Program

Obtain offsite normal releases (Insert Name of Lead)

Obtain releases from Category 1 and 2 event sequences that involve naval fuel from Navy (Insert Name of Lead)

Obtain dispersion factors from ES\&H (Insert Name of Lead)

Ensure consequence computer code is qualified. Qualify code, if required

Evaluate consequences of Category 1 and 2 event sequences
Demonstrate consequences of each Category 2 event sequence are less than 5 rem TEDE (and other 63 performance objectives)
Demonstrate consequences of each Category 1 event sequence is less than 15 mrem TEDE
Demonstrate consequences of each Category 1 combination of event sequence is less than 15 mrem TEDE
Demonstrate frequency weighted consequences Category 1 event sequences, and including normal operations, are less than $15 \mathrm{mrem}$ TEDE
Obtain from radiological worker safety validation that the consequences to workers for Category 1 event sequence is less than 5 rem TEDE 


\section{Table 4-2 Preclosure Safety Analysis Work Instructions (Continued)}

5. Identify SSCs that are required to prevent and/or mitigate event sequences

a) Identify SSCs that are important to safety

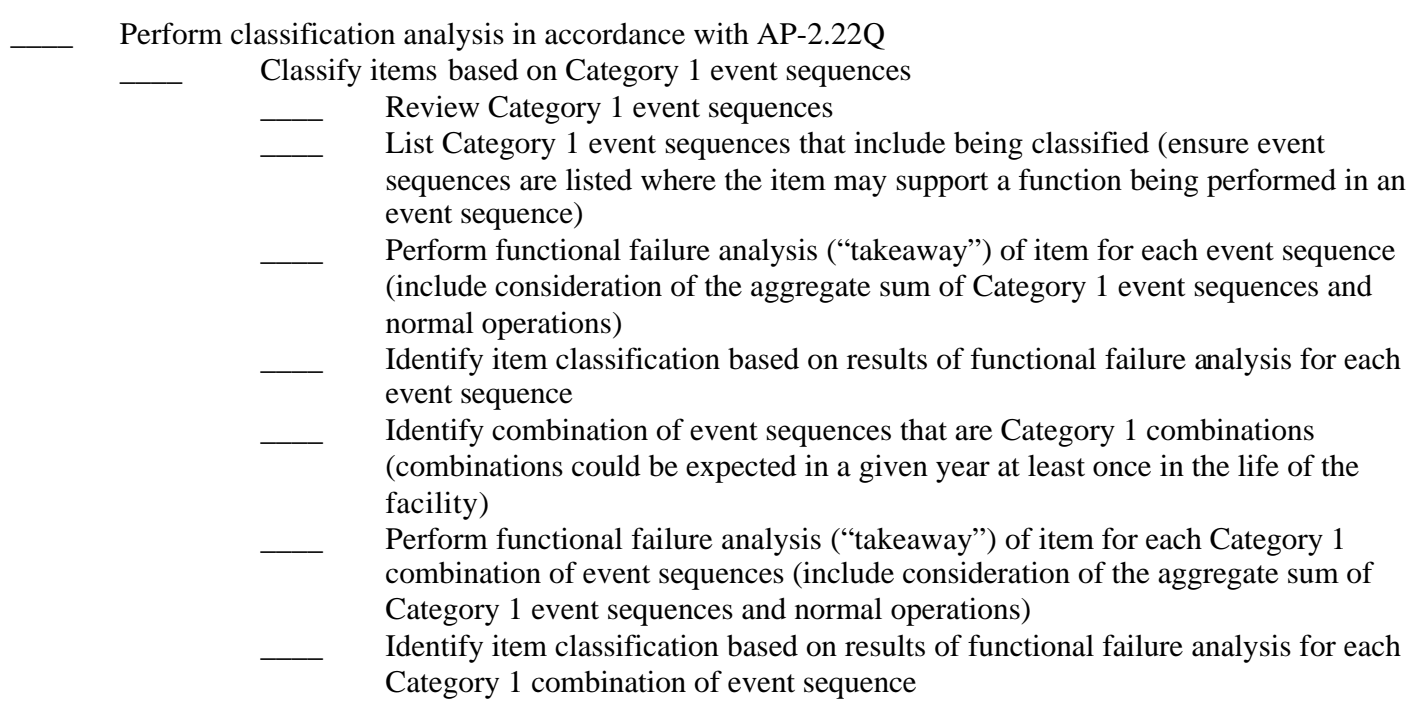

Classify items based on Category 2 event sequences
\begin{tabular}{l}
$-\quad$ Review Category 2 event sequences \\
\hline
\end{tabular}
_ List Category 2 event sequences that include being classified (ensure event sequences are listed where the item may support a function being performed in an event sequence)
Perform functional failure analysis ("takeaway") of item for each event sequence Identify item classification based on results of functional failure analysis for each event sequence

Classify items based on Important to Waste Isolation (although not part of the PSA), currently there is a single classification analysis for important to safety and waste isolation

Based on input from Science and Analysis/TSPA, identify items that are taken credit for in the TSPA

Classify item based on the highest classification level identified based the results of the Category 1 and Category 2 "functional failure analyses" and the important to waste isolation classification

b) For each item identified as important to safety, establish preclosure 10 CFR 63.2 design basis

Review event sequences

List event sequences that include classified item

Establish the credited design bases (e.g., function, failure rate, minimum/maximum values).

Include administrative controls, required surveillance, procedural requirements, training, etc.

Provide 10 CFR 63.2 preclosure design basis to appropriate system design lead

Support system design lead in developing design criteria to ensure 10 CFR 63.2 preclosure design basis will be met 
Table 4-2 Preclosure Safety Analysis Work Instructions (Continued)

6.

Develop Preclosure Safety Analysis (demonstration that Preclosure Safety performance objectives and other $10 \mathrm{CFR} 63.112(\mathrm{e})$ preclosure requirements are met

Describe hazards process

List potential external hazards list

List potential internal hazards list

Describe evaluation of hazards and categorization process

Demonstrate each potential external and internal hazard has been dispositioned

List Category 1 event sequences

List Category 2 event sequences

Describe consequence analysis process

Summarize consequence results for Category 1 and Category 2 compliance sequences

Describe process to identify items important to safety

Summarize important to safety SSCs

Describe process to establish 10 CFR 63.2 preclosure design basis

Summarize compliance with preclosure performance objectives

Category 1 event sequences, including normal operations, public

_ Category 1 event sequences, including normal operations, worker

Category 2 event sequences, public

Summarize compliance with 10 CFR 63.112(e) preclosure safety analysis requirements

Summarize that from a preclosure safety perspective, the option for full retrieval has been preserved

$7 \quad$ Develop SAR sections on preclosure safety analysis

\subsection{REFERENCES}

\subsubsection{Documents Cited}

CRWMS-M\&O 1999. Level Of Design Detail Necessary For The License Application For Construction Authorization. B00000000-01717-1710-00003, Rev 00. JUNE 1999. ACC:

Milstein, R. 2000. "Integrated Safety Analysis Guidance Document, Draft NUREG 1513." Attachment to SECY-00-0111: Final Rule to Amend 10 CFR Part 70, Domestic Licensing of Special Nuclear Material. Washington, D.C.: U.S. Nuclear Regulatory Commission. Accessed 07/25/2000. TIC: 247970. http://www.nrc.gov/NRC/COMMISSION/SECYS/secy2000$\underline{0111 / 2000-0111 \text { scy.html. }}$.

NRC (U.S. Nuclear Regulatory Commission) 1983. PRA Procedures Guide, A Guide to the Performance of Probabilistic Risk Assessments for Nuclear Power Plants. NUREG/CR-2300. Two volumes. Washington, D.C.: U.S. Nuclear Regulatory Commission. TIC: 205084.

NRC 2001. Draft Differentiated Approach to Providing Information in the License Application. Washington, D.C.: U.S. Nuclear Regulatory Commission. MOL.20011003.0107

NRC 2003. Yucca Mountain Review Plan, Final Report. NUREG-1804, Rev. 2. Washington, D.C.: U.S. Nuclear Regulatory Commission, Office of Nuclear Material Safety and Safeguards. TIC: $\underline{254568}$. 
YMP (Yucca Mountain Site Characterization Project) 2001. Q-List. YMP/90-55Q, Rev. 7. Las Vegas, Nevada: Yucca Mountain Site Characterization Office.

ACC: MOL.20010409.0366.

\subsubsection{Codes, Standards, Regulations, and Procedures}

10 CFR 63. 2002. Energy: Disposal of High-Level Radioactive Wastes in a Proposed Geologic Repository at Yucca Mountain, Nevada. Readily available.

Regulatory Guide 1.109, Rev. 1. 1977. Calculation of Annual Doses to Man from Routine Releases of Reactor Effluents for the Purpose of Evaluating Compliance with 10 CFR Part 50, Appendix I. Washington, D.C.: U.S. Nuclear Regulatory Commission. ACC:

NNA.19870806.0032.

Regulatory Guide 1.177. 1998. An Approach for Plant-Specific, Risk-Informed Decisionmaking: Technical Specifications. Washington, D.C.: U.S. Nuclear Regulatory Commission. Readily available. 


\section{DESCRIPTION OF SITE, FACILITIES, AND OPERATIONS}

\subsection{INTRODUCTION}

Documentation of the PSA for the LA and suppoting analyses (where appropriate) must include a general description of the structures, systems, and components, equipment, and process activities in the repository operations area. In addition, the PSA must provide a description of data pertaining to the repository site and surrounding region with sufficient detail to identify naturally occurring and human-induced hazards in the repository area (10 CFR 63.112).

Guidance for developing a description of the site characteristics, surface and subsurface facilities, and operations sufficient to support the hazards and event sequence analyses for preclosure radiological safety is presented in this section. A discussion of the applicable natural phenomena, external man-made hazards, and nearby facilities that could potentially affect the repository area is included. Site and facility characteristics applicable to repository postclosure safety are not discussed in this section.

\subsection{OVERVIEW OF APPROACH}

Material to be provided in support of the PSA will be contained in a brief summary section. Site and design features that are used in the hazards or event sequence analyses will be summarized with pointers to detailed sections of the license application submittal.

Information will be included that is relevant to performing preclosure hazards analyses, event sequence analyses, and consequence analyses. References will be provided to information sources and detailed descriptions found elsewhere in the license application submittal. A general description of the structures, systems, components, equipment, process (i.e., operational), and activities in the repository area will be provided (10 CFR 63.112(a), 10 CFR 63.112(f)).

The preclosure safety analysts will incorporate relevant portions of site as necessary to document the safety analysis. Other sections of the licensing application documents will provide the details of site information required by the YMRP. In particular, the YMRP identifies the types of site information that the NRC expects to see in the LA. This information is provided in the following list. Analysts should refer to the YMRP for further explanation of what is required. For example, portions of the YMRP are applicable to external event hazards screening (see Section 6.1) and for consequence analyses (see Section 8). (NRC 2003)

Brief descriptions of site factors that could affect preclosure safety will be provided as a basis in the PSA, including:

- $\quad$ Site geography (location relative to prominent natural and man-made features such as mountains, rivers, airports, population centers, hazardous commercial facilities, and hazardous manufacturing facilities)

- $\quad$ Regional demography (information based on recent census data)

- Local meteorology and regional climatology (e.g., temperatures, atmospheric stability, wind speeds, extreme winds, tornadoes) 
- Natural phenomena and other external events sufficient to assess the likelihood of occurrence and to assess the impact on preclosure safety; discussion of relationship to features, events, and processes used in postclosure radiological analyses

- $\quad$ Regional and local surface and ground-water hydrology

- $\quad$ Site geoglogy and seismology

- $\quad$ Site igneous activity

- $\quad$ Site geomorphology

- $\quad$ Site geotechnical

- $\quad$ Land use, structures and facilities, residual radioactivity.

Similarly, preclosure safety analysts will incorporate relevant design information as necessary to document the safety analysis. The design and operational features, including inter-relationships between structures, systems, and components that affect event sequence prevention or initiation, progression, and mitigation will be described to the detail necessary to support the hazards and event sequence analyses. Other sections of the licensing application documents will provide the details of the design information required by Section 2.1.1.2 of the YMRP (NRC 2003). The areas of review for acceptance crieteria and review methods in Sections 2.1.1.2.1 through 2.1.1.2.3 of the YMRP (NRC 2003) provide very extensive lists of information, which include: locations of surface facilities and their functions, design details of SSCs, equipment, and utilities, and high-level waste characteristics. PSA analysts should review the previously mentioned sections of the YMRP (NRC 2003) to ensure that required information will be available and documented in the LA. There should be a continuing information flow and exchange between the PSA and Design groups as outlined in Section 4.7. The PSA group will support the design evolution to ensure that the preclosure safety strategy, discussed in Section 3, is achieved.

\subsection{REFERENCES}

\subsubsection{Documents Cited}

NRC (U.S. Nuclear Regulatory Commission) 2003. Yucca Mountain Review Plan, Final Report. NUREG-1804, Rev. 2. Washington, D.C.: U.S. Nuclear Regulatory Commission, Office of Nuclear Material Safety and Safeguards. TIC: $\underline{254568 .}$.

\subsubsection{Codes, Standards, Regulations, and Procedures}

10 CFR 63. 2002. Energy: Disposal of High-Level Radioactive Wastes in a Proposed Geologic Repository at Yucca Mountain, Nevada. Readily available. 


\section{HAZARDS ANALYSIS}

This section presents the methods for performing hazards analyses, which is the first activity for the PSA process described in Section 4. Section 6.1 describes the approach for conducting the external events hazards analysis (EEHA). Section 6.2 describes the approach for conducting the internal events hazards analysis. The Section 6 Appendix provides a listing of various documents that may prove useful in conducting an EEHA.

\subsection{EXTERNAL EVENTS HAZARDS ANALYSIS}

\subsubsection{Introduction}

The EEHA provides a systematic method to identify and screen hazards stemming from natural phenomena and man-made activities that have the potential for initiating repository preclosure event sequences. A generic and comprehensive list of potential hazards is compiled in the EEHA. Qualitative and quantitative screening analyses are applied to reduce the number of potential hazards. The output of the screening process is a list of potential external hazards that must be evaluated as part of the repository design process or subjected to further evaluation to determine the credibility of the hazard and its potential radiological consequences. This list is called the external events hazards list (EEHL).

This section presents the methodology for performing an EEHA. External hazards include natural phenomena and man-made activities and facilities that are beyond the direct control of repository operations. Such hazards also include onsite construction activities that may be concurrent with waste receipt, waste handling, and storage operations, but these are under the control of repository operations. Section 6.2 describes the approach for performing a counterpart analysis of hazards that are internal to the repository operations.

\subsubsection{Overview of Approach}

The PSA is a risk-informed, performance-based approach. As such, its purpose is to address the following three questions:

1. What can happen?

2. How likely is it?

3. What are the consequences?
(What event sequences are possible?)

(What is the probability or frequency of the event sequence?)

(What are the radiological releases, exposures, or criticality conditions? Intermediate consequences may be addressed to synthesize potential event sequences.)

This approach is similar to the methods used for Process Hazards Analysis, as described in Guidelines for Hazard Evaluation Procedures (AIChE 1992).

The first question is applied in the EEHA to hazards that are potential initiating events for radiological release event sequences. The "what" is defined at the first le vel by a list of generic events. The possibility of initiating an event sequence having radiological consequences (the 
third question) is implicit, but is not addressed initially. Instead, the EEHA addresses the second question (How likely is it?) to determine if a given hazard is a credible preclosure repository initiating event. Knowledge of the site characteristics is required to answer this question. Potential intermediate consequence of the event sequences are considered to the extent that the direct consequences of an event sequence (e.g., landslide) could interact with the repository operational processes to induce a radiological release. Knowledge of the repository operations and the locations of radioactive material, and the layout of the facility, are required to determine the potential vulnerabilities to the respective external hazards. If a hazard category can be eliminated (screened out) it will not be necessary to consider potential event sequences, radiological consequences, or design solutions to withstand the hazard.

Screening Criteria-The question "How likely is it?" is addressed by performing the following series of qualitative and quantitative screening evaluations to determine whether or not:

1. The potential hazard exists at the repository site

2. The rate of the physical process of the hazard can produce undesired effects during the repository preclosure period (e.g., up to 325 years)

3. The consequences of the hazard are significant enough to affect operations or waste storage during the preclosure period

4. The event frequency is greater than $1 \times 10^{-6}$ events per year.

The criteria are addressed sequentially so that when the answer to the query is negative, the analysis stops and the hazard is screened out and will not appear in the external events hazard list. Examples of application of these criteria are presented in Section 6.1.3.

Documented rationale must be provided to support every response to the criteria. Such documentation must be in accordance with established procedures for documentation and categorization of data, if applicable.

Responses to the first, second, and fourth criteria are independent of the facility design. To the extent possible, the analysis should screen out those natural phenomena that are known to be impossible or non-existent in the region (e.g., ocean-front hazards such as a tsunami). The removal of these types of hazards may be accomplished through either a pre-screening to remove events from the (global) generic list of hazards or through the applic ation of the same logic formally and repeatedly in the evaluation. In this guide, the latter method is used in the examples. Care must be taken to not screen out natural phenomena that may have site-specific applicability, such as flooding. Responses to the third criteria should be largely independent of the facility design. However, major changes in facility structures and operational concepts should be examined in light of the third screening criteria. 
The product of this analysis is the EEHL, which contains the potentially credible external hazards that cannot be screened out. The hazards listed, however, will be categorized according to future actions and commitments. The hazards will be categorized according to the following criteria:

1. Design Basis-The hazard is included in the 10 CFR 63.2 design bases for preclosure safety (e.g., the design bases of SSCs ITS require that SSCs ITS are able to withstand an earthquake without ensuing a loss of safety function).

2. Analysis Required-The hazard is not in the design bases and cannot be screened out without additional or corroborative analyses. The EEHL will be updated as such analyses are completed, with credible hazards re-categorized as initiating events for event sequences.

For ease of review, a companion table will list the hazards removed through the screening process and a summary statement detailing the basis for the removal.

\subsubsection{Details of Basic Approach to Screening with Examples}

This section illustrates the process for performing an EEHA through the application of the screening criteria previously discussed to a generic list of repository external hazards. The approach consists of the following four steps:

Step 1. Compile a comprehensive list of external hazards (natural phenomena and man-made) from generic sources (e.g., AIChE 1992).

Step 2. Acquire information on the site and facility.

Step 3. Apply the screening criteria, supported by analyses, where appropriate.

Step 4. Produce a list of external hazards subject to design solutions (i.e., become part of the 63.2 design bases) or to further analyses (e.g., event sequence modeling or consequence analysis).

The four steps are discussed in the following sections.

\subsubsection{Generic Events Checklist}

The analysis begins with the development of a comprehensive list of events that could impact the repository operations areas and initiate an event sequence that results in a radioactive material release, other radiological exposure of workers or the public, or a potential criticality condition. The generic list is not project-specific, but provides a starting point for the systematic approach that is intended to identify potentially hazardous external events. The generic list of external hazards (Table 6-1) was synthesized from lists of hazards developed by others (AIChE 1992). Its intent is to provide the most comprehensive list to ensure a thorough treatment of possible hazards. Should other potential external hazards be identified in the course of supporting LA submittal, these hazards should be subjected to the same screening analysis methodology and criteria as the generic hazards. 
An event is considered a potential initiator of a radiological event sequence if, and only if, all of the screening criteria presented in Section 6.1.2 are determined to be applicable.

Table 6-1. Generic External Events

\begin{tabular}{|c|c|c|}
\hline $\begin{array}{l}\text { External } \\
\text { Category }\end{array}$ & Definition & $\begin{array}{l}\text { Potential Concern for } \\
\text { Preclosure Safety }\end{array}$ \\
\hline 1 Aircraft crash & Accidental impact of an aircraft on the site. & $\begin{array}{l}\text { Penetration or loss of } \\
\text { confinement of radioactivity; } \\
\text { compounded by concurrent fire }\end{array}$ \\
\hline 2 Avalanche & $\begin{array}{l}\text { A large mass of snow, ice, soil, or rock, or } \\
\text { mixtures of these materials, falling, sliding, or } \\
\text { flowing under the force of gravity. }\end{array}$ & $\begin{array}{l}\text { Blockage of North Portal, } \\
\text { burying of waste package } \\
\text { transporter, collapse or } \\
\text { distortion of s tructures housing } \\
\text { radioactivity, disruption of } \\
\text { electric power }\end{array}$ \\
\hline 3 Coastal erosion & $\begin{array}{l}\text { The wearing away of soil and rock by waves } \\
\text { and tidal action (see Erosion). }\end{array}$ & Not applicable \\
\hline 4 Dam failure & $\begin{array}{l}\text { Failure of a large man-made barrier that } \\
\text { creates and restrains a large body of water. }\end{array}$ & $\begin{array}{l}\text { If possible, could invade surface } \\
\text { structures, wash out bridges } \\
\text { supporting waste transporter, } \\
\text { disrupt power. }\end{array}$ \\
\hline 5 Debris avalanching & $\begin{array}{l}\text { The sudden and rapid movement of debris } \\
\text { (soil, vegetation and weathered rock) down } \\
\text { steep slopes resulting from intensive rainfall. }\end{array}$ & Similar to Avalanche \\
\hline 6 Denudation & $\begin{array}{l}\text { The sum of the processes that result in the } \\
\text { wearing away or the progressive lowering of } \\
\text { the surface of the earth by weathering, mass } \\
\text { wasting, and transportation. }\end{array}$ & $\begin{array}{l}\text { [And so on. .... Analyst to } \\
\text { identify issues related to } \\
\text { preclosure safety.] }\end{array}$ \\
\hline 7 Dissolution & $\begin{array}{l}\text { A process of chemical weathering by which } \\
\text { mineral and rock material passes into } \\
\text { solution. }\end{array}$ & \\
\hline 8 Eperogenic displacement & $\begin{array}{l}\text { Geomorphic processes of uplift and } \\
\text { subsidence that have produced the broader } \\
\text { features of the continents and oceans. }\end{array}$ & \\
\hline 9 Erosion & $\begin{array}{l}\text { The slow wearing-away of soil and rock by } \\
\text { weathering, mass wasting, and the action of } \\
\text { streams (denudation), glaciers, waves, wind. }\end{array}$ & \\
\hline 10 Extreme wind & $\begin{array}{l}\text { Wind is a meteorological term for air that } \\
\text { moves parallel to the surface of the earth. } \\
\text { Extreme wind conditions for nuclear plants } \\
\text { are defined in NUREG-0800 (NRC 1987) and } \\
\text { ASCE 7-98 (ASCE 2000). }\end{array}$ & \\
\hline $\begin{array}{l}11 \text { Extreme weather } \\
\text { fluctuations }\end{array}$ & $\begin{array}{l}\text { Various types of weather fluctuations that } \\
\text { exceed expected operational ranges of } \\
\text { repository processes. }\end{array}$ & \\
\hline 12 Range fire & $\begin{array}{l}\text { The combustion of natural vegetation external } \\
\text { to the repository that propagates to } \\
\text { combustible materials within the repository } \\
\text { operations area. }\end{array}$ & \\
\hline $\begin{array}{l}13 \text { Flooding (storm, river } \\
\text { diversion) }\end{array}$ & $\begin{array}{l}\text { The covering or causing to be covered with } \\
\text { water. }\end{array}$ & \\
\hline
\end{tabular}


Table 6-1. Generic External Events (Continued)

\begin{tabular}{|c|c|c|}
\hline $\begin{array}{l}\text { External } \\
\text { Category }\end{array}$ & Definition & $\begin{array}{l}\text { Potential Concern for } \\
\text { Preclosure Safety }\end{array}$ \\
\hline $\begin{array}{l}14 \text { Fungus, bacteria, and } \\
\text { algae }\end{array}$ & $\begin{array}{l}\text { Fungus and bacteria are part of a general } \\
\text { class of microorganisms that may be } \\
\text { present in the subsurface environment. } \\
\text { Algae are aquatic plants that may be } \\
\text { present in spent fuel storage and staging } \\
\text { water-filled pools. }\end{array}$ & \\
\hline 15 Glacial erosion & $\begin{array}{l}\text { Reduction of the surface of the earth as a } \\
\text { result of grinding and scouring by glacier ice } \\
\text { armed with rock fragments. }\end{array}$ & \\
\hline 16 Glaciation & $\begin{array}{l}\text { The formation, movement, and recession of } \\
\text { glaciers or ice sheets. }\end{array}$ & \\
\hline 17 High Lake Level & $\begin{array}{l}\text { Any inland body of standing water occupying } \\
\text { a depression in the surface of the earth, } \\
\text { generally of appreciable size and too deep } \\
\text { to permit vegetation to take root completely } \\
\text { across the expanse of water with potential } \\
\text { for overflow or flooding. }\end{array}$ & \\
\hline 18 High Tide & $\begin{array}{l}\text { Tides are the rhythmic, alternate rise and fall } \\
\text { of the surface of the ocean, and bodies of } \\
\text { water connected with the ocean with the } \\
\text { potential for flooding inland areas. }\end{array}$ & \\
\hline 19 High river stage & $\begin{array}{l}\text { A river is a natural freshwater permanent or } \\
\text { seasonal surface stream of considerable } \\
\text { volume with a potential for flooding }\end{array}$ & \\
\hline 20 Hurricane & $\begin{array}{l}\text { An intense cyclone that forms over the } \\
\text { tropical oceans and ranges } 100 \text { to } 1000 \mathrm{~km} \\
\text { in diameter. }\end{array}$ & \\
\hline $\begin{array}{l}21 \text { Inadvertent future } \\
\text { intrusions (man-made) }\end{array}$ & $\begin{array}{l}\text { Man-made inadvertent future intrusions with } \\
\text { regard to the } 100 \text {-year operational period } \\
\text { involving undetected surface access into } \\
\text { repository facilities. }\end{array}$ & \\
\hline $\begin{array}{l}22 \text { Industrial activity induced } \\
\text { accident }\end{array}$ & $\begin{array}{l}\text { An accident resulting from industrial or } \\
\text { transportation activities unrelated to the } \\
\text { repository. }\end{array}$ & \\
\hline $\begin{array}{l}23 \text { Intentional future intrusions } \\
\text { (man-made) }\end{array}$ & $\begin{array}{l}\text { Man-made intentional future intrusions with } \\
\text { regard to preclosure involving undetected } \\
\text { surface access or sabotage to repository } \\
\text { facilities. Sabotage may also include events } \\
\text { such as bombings and missile attacks. }\end{array}$ & \\
\hline 24 Landslides & $\begin{array}{l}\text { A general term covering a wide variety of } \\
\text { mass-movement land forms and processes } \\
\text { involving the downslope transport, under } \\
\text { gravitational influence, of soil and rock } \\
\text { material. }\end{array}$ & \\
\hline 25 Lightning & $\begin{array}{l}\text { The flashing of light produced by a } \\
\text { discharge of atmospheric electricity between } \\
\text { an electrically charged cloud and the earth. }\end{array}$ & \\
\hline $\begin{array}{l}26 \text { Loss of offsite or onsite } \\
\text { power }\end{array}$ & $\begin{array}{l}\text { The loss of electrical power either generated } \\
\text { or controlled by persons outside of the } \\
\text { repository site or a loss of power within the } \\
\text { repository. }\end{array}$ & \\
\hline
\end{tabular}


Table 6-1. Generic External Events (Continued)

\begin{tabular}{|c|c|c|}
\hline $\begin{array}{l}\text { External } \\
\text { Category }\end{array}$ & Definition & $\begin{array}{l}\text { Potential Concern for } \\
\text { Preclosure Safety }\end{array}$ \\
\hline 27 Low lake level & $\begin{array}{l}\text { A lake is any inland body of standing water } \\
\text { occupying a depression in the surface of the } \\
\text { earth, generally of appreciable size and too } \\
\text { deep to permit surface vegetation to take } \\
\text { root completely across the expanse of water } \\
\text { where the lake level must be maintained for } \\
\text { cooling purposes. }\end{array}$ & \\
\hline 28 Low river level & $\begin{array}{l}\text { A river is a natural freshwater permanent or } \\
\text { seasonal surface stream of considerable } \\
\text { volume where river level must be maintained } \\
\text { for cooling purposes. }\end{array}$ & \\
\hline 29 Meteorite impact & $\begin{array}{l}\text { The impact of any meteoroid that has } \\
\text { reached the surface of the earth without } \\
\text { being completely vaporized. }\end{array}$ & \\
\hline $\begin{array}{l}30 \text { Military activity induced } \\
\text { accident }\end{array}$ & $\begin{array}{l}\text { An accident resulting from military activities } \\
\text { on the Nevada Test Site or Nellis Air Force } \\
\text { Range. }\end{array}$ & \\
\hline 31 Orogenic Diastrophism & $\begin{array}{l}\text { Movement of the crust of the earth produced } \\
\text { by tectonic processes in which structures } \\
\text { within fold-belt mountainous areas were } \\
\text { formed, including thrusting, folding, and } \\
\text { faulting. }\end{array}$ & \\
\hline 32 Pipeline accident & $\begin{array}{l}\text { Industrial pipeline containing hazardous } \\
\text { materials (e.g., oil and gas). }\end{array}$ & \\
\hline 33 Rainstorm & $\begin{array}{l}\text { A rainstorm of concern is one that produces } \\
\text { the } 100 \text {-year or greater maximum rainfall } \\
\text { rate occurring for one day. }\end{array}$ & \\
\hline 34 Sandstorm & $\begin{array}{l}\text { Extreme wind capable of transporting sand } \\
\text { and other unconsolidated surficial materials. }\end{array}$ & \\
\hline 35 Sedimentation & $\begin{array}{l}\text { The process of forming or accumulating } \\
\text { sediment (solid fragmental material that } \\
\text { originates from weathering of rocks) in } \\
\text { layers. }\end{array}$ & \\
\hline 36 Seiche & $\begin{array}{l}\text { A free or standing-wave oscillation of the } \\
\text { surface of water in an enclosed or semi- } \\
\text { enclosed basin (as a lake, bay, or harbor). }\end{array}$ & \\
\hline $\begin{array}{l}37 \text { Seismic activity, uplifting } \\
\text { (tectonic) }\end{array}$ & $\begin{array}{l}\text { A structurally high area in the crust, } \\
\text { produced by positive movements over a } \\
\text { long period of time that result in faults giving } \\
\text { rise to the upthrust of rocks. }\end{array}$ & \\
\hline $\begin{array}{l}38 \text { Seismic activity, } \\
\text { earthquake }\end{array}$ & $\begin{array}{l}\text { Pertaining to earthquake or earth vibrations, } \\
\text { including those that are artificially induced. }\end{array}$ & \\
\hline $\begin{array}{l}39 \text { Seismic activity, surface } \\
\text { fault displacement }\end{array}$ & $\begin{array}{l}\text { A fracture or a zone of fractures along which } \\
\text { there is potential for displacement of the } \\
\text { sides relative to one another parallel to the } \\
\text { fracture. }\end{array}$ & \\
\hline $\begin{array}{l}40 \text { Seismic activity, } \\
\text { subsurface fault } \\
\text { displacement }\end{array}$ & $\begin{array}{l}\text { A fracture or a zone of fractures along which } \\
\text { there is potential for displacement of the } \\
\text { sides relative to one another parallel to the } \\
\text { fracture. }\end{array}$ & \\
\hline
\end{tabular}


Table 6-1. Generic External Events (Continued)

\begin{tabular}{|c|c|c|}
\hline $\begin{array}{l}\text { External } \\
\text { Category }\end{array}$ & Definition & $\begin{array}{l}\text { Potential Concern for } \\
\text { Preclosure Safety }\end{array}$ \\
\hline 41 Static Fracturing & $\begin{array}{l}\text { Any break in a rock due to mechanical } \\
\text { failure by stress (includes cracks, joints, and } \\
\text { faults). }\end{array}$ & \\
\hline 42 Stream Erosion & $\begin{array}{l}\text { The progressive removal, by a stream, of } \\
\text { bedrock, overburden, soil, or other exposed } \\
\text { matter, from the surface of its channel. }\end{array}$ & \\
\hline 43 Subsidence & $\begin{array}{l}\text { The sudden sinking or gradual downward } \\
\text { settling of the surface of the earth with little } \\
\text { or no horizontal motion. }\end{array}$ & \\
\hline 44 Tornado & $\begin{array}{l}\text { A small-scale cyclone generally less than } \\
500 \mathrm{~m} \text { in diameter and with very strong } \\
\text { winds. Intense thunderstorms that are } \\
\text { present in the desert southwest have the } \\
\text { capability of producing tornadoes. }\end{array}$ & \\
\hline 45 Tsunami & $\begin{array}{l}\text { A gravitational sea wave produced by a } \\
\text { large-scale, short-duration disturbance on } \\
\text { the ocean floor. Wave heights of up to } 30 \mathrm{~m} \\
\text { may impact coastal regions. }\end{array}$ & \\
\hline $\begin{array}{l}46 \text { Undetected past intrusions } \\
\text { (man-made) }\end{array}$ & $\begin{array}{l}\text { Past intrusions involve mining activities } \\
\text { where deep shafts, drill holes, or tunnels } \\
\text { may have been excavated. }\end{array}$ & \\
\hline $\begin{array}{l}47 \text { Undetected Geologic } \\
\text { features }\end{array}$ & $\begin{array}{l}\text { Geologic features of concern to the } 100 \text {-year } \\
\text { operational period include natural event } \\
\text { such as faults and volcanoes. }\end{array}$ & \\
\hline $\begin{array}{l}48 \text { Undetected Geologic } \\
\text { processes }\end{array}$ & $\begin{array}{l}\text { Geologic processes of concern to the } 100- \\
\text { year operational period include natural } \\
\text { events such as erosion, tectonic and seismic } \\
\text { processes. }\end{array}$ & \\
\hline 49 Volcanic Eruption & $\begin{array}{l}\text { The process by which magma and its } \\
\text { associated gases rise into the crust and are } \\
\text { extruded onto the surface of the earth and } \\
\text { into the atmosphere. }\end{array}$ & \\
\hline $\begin{array}{l}50 \text { Volcanism, intrusive } \\
\text { magmatic activity }\end{array}$ & $\begin{array}{l}\text { The development and movement of magma } \\
\text { and mobile rock material underground. }\end{array}$ & \\
\hline $\begin{array}{l}51 \text { Volcanism, ashflow } \\
\text { (extrusive magmatic } \\
\text { activity) }\end{array}$ & $\begin{array}{l}\text { A highly heated mixture of volcanic gases, } \\
\text { magma, mobile rock material, and ash } \\
\text { traveling down the flank of a volcano or } \\
\text { along the surface of the ground (silacic } \\
\text { volcanism). }\end{array}$ & \\
\hline 52 Volcanism, ashfall & $\begin{array}{l}\text { Airborne volcanic ash falling from an } \\
\text { eruption cloud. }\end{array}$ & \\
\hline 53 Waves (aquatic) & $\begin{array}{l}\text { An oscillatory movement of water } \\
\text { manifested by alternating rise and fall of the } \\
\text { water surface. }\end{array}$ & \\
\hline $\begin{array}{l}54 \text { Onsite Surface } \\
\text { Construction Activities }\end{array}$ & $\begin{array}{l}\text { Construction of some surface operations } \\
\text { buildings may proceed while waste is being } \\
\text { received and process. Such construction } \\
\text { will be phased out over time. In addition, } \\
\text { there will surface operations that support } \\
\text { subsurface construction over a longer time. }\end{array}$ & \\
\hline
\end{tabular}


Table 6-1. Generic External Events (Continued)

\begin{tabular}{|c|l|c|}
\hline $\begin{array}{l}\text { External } \\
\text { Category } \quad \text { Hazard }\end{array}$ & \multicolumn{1}{c|}{ Definition } & $\begin{array}{c}\text { Potential Concern for } \\
\text { Preclosure Safety }\end{array}$ \\
\hline $\begin{array}{c}55 \text { Onsite Subsurface } \\
\text { Construction Activities }\end{array}$ & $\begin{array}{l}\text { Construction of repository emplacement and } \\
\text { access drifts will proceed while waste is } \\
\text { being emplaced. Hazards unique to } \\
\text { underground construction will include } \\
\text { blasting, potential rockfall-concussion, and } \\
\text { rock burst. }\end{array}$ & \\
\hline
\end{tabular}

\subsubsection{General Description of the Repository Site}

A site description should be prepared to establish a basis for screening natural phenomena. Section 5 of this guide provides guidance for gathering site-related information to support the EEHA (and the PSA). The EEHA analysts should advise the preparer of the PSA site description of the particular needs and degree of detail required to support the EEHA screening process. A summary of the relevant site description information should be provided in the EEHA documentation.

The site description should include summaries of pertinent site information, including the following:

$\begin{array}{ll}\text { - } & \text { Geography } \\ \text { - } & \text { Demography } \\ \text { - } & \text { Heteorology } \\ \text { - } & \text { Geology } \\ \text { - } & \text { Nearby facilities (industrial and military) } \\ \text { - } & \text { Transportation routes (public, industrial, and military). }\end{array}$

The description should be as complete as necessary to support the PSA and the EEHA. Similarly, the description might continue with a summary of climatological and meteorological characteristics of the region and site to establish perspective for the screening analysis descriptions.

The preclosure safety analysts will incorporate relevant portions of site as necessary to document the safety analysis. Other sections of the licensing application documents will provide the details of site information required by the YMRP (NRC 2003). For example, Section 2.1.1 of the YMRP (NRC 2003) identifies types of site information, including regional climatology, regional and local ground-water hydrology, site geology, etc., (see Section 5 of this guide).

\subsubsection{General Description of the Repository Facilities}

The EEHA should provide a brief summary of the repository operational areas that are potentially vulnerable to external event hazards. This summary can be simplistic in describing the types and locations of radioactive materials (and operations involving those materials) that 
could be potentially vulnerable to a credible external event. This summary and the associated assumptions establish a portion of the bases for the evaluation of external hazards.

\subsubsection{Application of Screening Criteria}

A generic list of external hazards is presented in Table 6-1 with definitions sufficient to establish the potential impact on the repository based on site and facility descriptions. The screening criteria previously discussed must be applied sequentially with supporting rationale. Whenever the response to any criterion is negative, the analysis of that hazard ceases. Therefore, the rationale for negative responses must be defensible. As appropriate, qualitative arguments or calculations are provided to support the negative response. If the rationale is affected by a design-specific or site-specific assumption or condition, then the rationale must document the source of the assumption or condition according to the procedures for documenting qualityaffecting work.

If a hazard cannot be screened out through the application of screening criteria, then it is retained on the EEHL for further disposition, either by including the hazard in the facility design bases or by recommending the initiation of additional analyses of frequency or potential impact (consequences).

For clarity of presentation and to ensure completeness, the EEHA should be documented in a standard format to indicate the response to each criterion and to provide the supporting rationale, even if the rationale seems obvious. The following format is used in Section 6.1.3.5 to document the screening analysis of each external event:

Definition-Establishes the explanation of the event to be analyzed.

Required Condition-States what has to occur for the event or events to exist and result in a potential release of radioactive material or exposure to radioactivity.

Evaluation-States what must occur for the event to be considered a potential initiator of a radiological release, exposure to radiation, or a criticality condition during the preclosure period.

Applicability-States the conclusion of the screening (i.e., whether the hazard is or is not applicable to the repository preclosure period.

An event is considered to be a potential initiator of a radiological release event sequence if, and only if, all of the screening criteria presented in Section 6.1.2 are determined to be applicable. If any statement is indeterminate (its validity cannot be determined without further analysis), then the hazard is not eliminated through the screening process. If any of the criteria discussed in Section 6.1.2 is not applicable for any external event, then the event is not considered applicable to the hazards list for the repository and all the statements that follow are not applicable. 
The following notes provide conditions to be considered for the consideration of the criteria.

1. The potential hazard exists and is applicable to the repository site.

NOTE: If the event cannot exist in the Yucca Mountain region, e.g., because it pertains to an ocean or near-ocean phenomenon, then the statement is labeled as False. Similarly, if the event pertains to features that must exist in the immediate vicinity of the repository site to be considered a hazard, but do not actually exist at or near the repository, then the statement is also labeled as False.

2. The rate of the physical process of the hazard can produce undesired effects during the repository preclosure period (e.g., up to 325 years).

NOTE: Long-term phenomena are defined as those that require thousands of years for perceptible changes to take place. Potential hazards including Erosion, Glaciation, Glacial Erosion, Oroge nic Diastrophism, Sedimentation, Seismic Activity Uplifting [Tectonic], and Stream Erosion are such phenomena. These phenomena are not applicable to the repository during the preclosure period even if it is extended to 325 years. Although supporting information may be included, the information is not required for disposition of the phenomena.

3. The consequences of the hazard are significant enough to affect operations or storage during the preclosure period.

NOTE: The response to this criterion must consider the characteristics of the repository operations that are potentially vulnerable to a release of radioactivity, exposure to radioactivity, or potentially criticality condition as a consequence of the hazard interacting with the facility. This evaluation requires knowledge of the design of the facility, including the intended operations where radioactive material or potential fissile materials are to be handled or stored. This evaluation applies analysis elements similar to a "what if?" analysis or a Failure Modes and Effects Analysis to determine the manner in which direct or indirect consequences of the external hazards could potentially interact with the facility.

4. The event frequency is greater than $1 \times 10^{-6}$ events per year.

NOTE: The event cutoff frequency of $1 \times 10^{-6}$ events per year is based on a 100 -year operational period. This screening criterion is stated in 10 CFR Part 63 as a chance of one in 10,000 in the period before permanent closure. If a different time period is appropriate (e.g., 30 years for surface operations or 325 years for preclosure subsurface operations and storage), then the frequency screening criteria will be adjusted appropriately to the hazard and the potentially vulnerable operations area. 
The following section provides examples of how the screening analysis is applied to a range of hazard types.

\subsubsection{Examples of Application of Screening Criteria}

The following sections are presented in a format that can be used to document the external event hazards screening process. The formatted material may be presented in a table if preferred.

These examples were selected from a previous EEHA (CRWMS M\&O 1999) to include several various types of hazards and to represent the application of each of the primary screening criteria. Table 6-2 summarizes the application of the screening process for these examples. Table 6-3 illustrates the EEHL, which is the principal product of the EEHA. Table 6-4 lists the hazards that have been eliminated through the screening process.

Table 6-2. Example Summary of External Events Hazards Analysis Screening

\begin{tabular}{|c|c|c|c|c|c|}
\hline \multirow[b]{2}{*}{$\begin{array}{c}\text { External Hazard } \\
\text { Name }\end{array}$} & \multicolumn{5}{|c|}{ Summary of Screening } \\
\hline & $\begin{array}{c}1 . \\
\text { Potential } \\
\text { exists and } \\
\text { the event } \\
\text { is } \\
\text { applicable } \\
\text { to the } \\
\text { repository } \\
\text { site. }\end{array}$ & $\begin{array}{l}\text { 2. The rate } \\
\text { of the } \\
\text { hazard } \\
\text { process is } \\
\text { sufficient } \\
\text { to affect } \\
\text { the } 100- \\
\text { year } \\
\text { operational } \\
\text { period. }\end{array}$ & $\begin{array}{l}\text { 3. Undesired } \\
\text { effects of the } \\
\text { hazard are } \\
\text { large enough } \\
\text { to affect } \\
\text { operations or } \\
\text { storage during } \\
\text { the preclosure } \\
\text { period. }\end{array}$ & $\begin{array}{l}\text { 4. The event } \\
\text { frequency is } \\
\text { greater than } \\
10^{-6} \text { events } \\
\text { per year. }\end{array}$ & $\begin{array}{c}\text { Applicability } \\
\text { (Included in } \\
\text { EEHL?) }\end{array}$ \\
\hline Aircraft crash & TRUE & TRUE & TRUE & TRUE & YES \\
\hline Avalanche & FALSE & NA & NA & NA & $\mathrm{NO}$ \\
\hline Coastal Erosion & FALSE & NA & NA & NA & $\mathrm{NO}$ \\
\hline Dam Failure & FALSE & NA & NA & NA & $\mathrm{NO}$ \\
\hline $\begin{array}{l}\text { Eperogenic } \\
\text { Displacement }\end{array}$ & TRUE & FALSE & NA & NA & NO \\
\hline Extreme Wind & TRUE & TRUE & TRUE & TRUE & YES \\
\hline Range Fire & TRUE & TRUE & TRUE & TRUE & YES \\
\hline $\begin{array}{l}\text { Inadvertent future } \\
\text { intrusions (man- } \\
\text { made) }\end{array}$ & TRUE & TRUE & TRUE & TRUE & YES \\
\hline $\begin{array}{l}\text { Loss of offsite or } \\
\text { onsite power }\end{array}$ & TRUE & TRUE & TRUE & TRUE & YES \\
\hline Meteorite Impact & TRUE & TRUE & TRUE & FALSE & NO \\
\hline $\begin{array}{l}\text { Seismic activity, } \\
\text { earthquake }\end{array}$ & TRUE & TRUE & TRUE & TRUE & YES \\
\hline
\end{tabular}

NOTE: NA = Not applicable 
Table 6-3. Example External Events Hazards List

\begin{tabular}{|l|l|}
\hline \multicolumn{1}{|c|}{ External Hazard Name } & \multicolumn{1}{c|}{ Comments } \\
\hline Loss of offsite or onsite power & Design bases to mitigate release \\
\hline Seismic activity, earthquake & Design bases to mitigate release \\
\hline Aircraft crash & Probabilistic analysis required \\
\hline Extreme Wind & Group with wind/tornado \\
\hline Range Fire & Group with other fire analyses \\
\hline Inadvertent future intrusions (man-made) & Additional analysis required \\
\hline
\end{tabular}

Table 6-4. Example External Events Hazards Screened Out

\begin{tabular}{|l|l|}
\hline \multicolumn{1}{|c|}{ External Hazard Name } & \multicolumn{1}{c|}{ Principal Basis for Screening Out } \\
\hline Avalanche & 1. Not present at site \\
\hline Coastal Erosion & 1. Not present at site \\
\hline Dam Failure & 1. Not present at site \\
\hline Eperogenic Displacement & 2. Process too slow to affect preclosure \\
\hline Meteorite Impact & 4. Frequency below $1 \times 10^{-6}$ per year \\
\hline
\end{tabular}

Examples of the rationale applied in the screening are presented in the following format, using the format described in Section 6.1.3.4. However, the analyst may employ other formats.

\section{External Hazard 1, Aircraft Crash}

Definition-Accidental impact of an aircraft on the site.

Required Condition-Periodic presence of aircraft over or near the site.

\section{Evaluation-}

1. Potential exists and is applicable to the repository site. TRUE.

Rationale-The statement is true because of the potential for commercial aircraft over-flights and the proximity of the repository site to the flight path of military aircraft flying from Nellis Air Force Base to their practice range (CRWMS M\&O 1999).

2. The rate of the process of the hazard is sufficient to affect the 100 -year operational period. TRUE.

Rationale-The effect of an aircraft crash is immediate. 
3. The consequences of the hazard are significant enough to affect operations or storage during the preclosure period. TRUE.

Rationale-Potential effects of aircraft crash are readily identified as potential direct impact on radioactive waste and an indirect impact on safety-related structures, as well as a source of fire initiation. If deemed necessary, available evidence or analyses can be referenced. For example, a prior EEHA (CRWMS M\&O 1999) referred to an analysis of the potential consequences that was performed in 1990.

4. The event frequency is greater than $1 \times 10^{-6}$ events per year. TRUE.

Rationale-Insufficient evidence exists to support a negative response without detailed analyses. Furthermore, the response to this criterion is subject to change if there are changes in site layout, site usage, or frequency and types of aircraft in the vicinity.

Applicability-Yes. This event is applicable to the EEHL for the repository site.

\section{External Hazard 2, Avalanche}

Definition-A large mass of snow, ice, soil, or rock, or mixtures of these materials, falling, sliding, or flowing under the force of gravity.

Required Condition-Steeply sloped terrain found in high mountain ranges must exist.

\section{Evaluation-}

1. Potential exists and is applicable to the repository site. FALSE.

Rationale-The required condition (high mountain ranges) does not exist. Therefore, it is not applicable on this basis alone.

It is also noteworthy that temperature and precipitation levels at the repository site do not support the build-up of large masses of snow, ice, or soil required to produce an avalanche (except, potentially, a debris avalanche). If deemed necessary, references may be provided to justify that historical evidence for temperatures and precipitation preclude this event.

Criteria 2 through 4 are not applicable because the analysis stops with first not applicable evaluation.

Applicability-No. This event is not applicable to the EEHL for the repository site.

\section{External Hazard 4, Dam Failure}

Definition-Failure of a large man-made barrier that creates and restrains a large body of water.

Required Condition-A dam must exist in the vicinity of the site. 


\section{Evaluation-}

1. Potential exists and is applicable to the repository site. FALSE.

Rationale-This event requires a dam of sufficient size and proximity to the repository site. Since the required condition does not exist in the vicinity of the repository site, this event is eliminated from further consideration.

Criteria 2 through 4 are not applicable because the analysis stops with first negative evaluation.

Applicability-No. This event is not applicable to the EEHL for the repository site.

Applicability-No. This event is not applicable to the EEHL for the repository site.

\section{External Hazard 10, Extreme Wind}

Definition-Wind is a meteorological term for that component of air that moves parallel to the surface of the earth. In the Standard Review Plan for the Review of Safety Analysis Reports for Nuclear Power Plants (NRC 1987, Sections 2.3.1, 3.3.1, and 4.3) it is stated that the 100-year return period "fastest mile of wind" including vertical velocity distribution and gust factor should be used and be based on the standard published by the American National Standards Institute with suitable corrections for local conditions. The current standard published by the American National Standards Institute is ANSI/ASCE7-98, Minimum Design Loads for Buildings and other Structures (ASCE 7-98 2000, Section 4.3). The basic wind speed is defined as a 3 second gust with annual probability of 0.02 of being equaled or exceeded (for a 50 year mean recurrence interval) (ASCE 7-98 2000, p. 13).

Required Condition-Meteorological conditions conducive to wind generation must exist at the site.

\section{Evaluation-}

1. Potential exists and is applicable to the repository site. TRUE.

Rationale-Extreme winds do occasionally occur in southern Nevada (Eglinton and Dreicer 1984, Coats and Murray 1985), making this event applicable for consideration during the 100-year operational period.

2. The rate of the hazard process is sufficient to affect the 100-year operational period. TRUE.

Rationale-The impact is immediate. Wind effects could initiate event sequences and cause collapse or failure of SSCs that house radioactive materials.

3. The consequences of the hazard are significant enough to affect the 100-year operational period. TRUE. 
Rationale-Wind effects could initiate event sequences and cause collapse or failure of SSCs that house radioactive materials. However, without engineering analyses, this statement is viewed as indeterminate. Since the response to this criterion is indeterminate (i.e., its validity cannot be determined at this time), it is treated as equivalent to TRUE.

4. The event frequency is greater than $1 \times 10^{-6}$ events per year. TRUE.

Rationale-Some credible extreme wind conditions exist for all sites. The design basis determination will establish the wind parameters for the repository facilities.

Applicability-Yes. This event is not applicable to the EEHL for the repository site.

\section{External Hazard 26, Loss of Offsite or Onsite Power}

Definition-This event includes the loss of electrical power either generated or controlled by persons outside the repository site as well as a loss of power within the repository.

Required Condition-The need and provision for electrical power at the site.

\section{Evaluation-}

1. Potential exists and is applicable to the repository site. TRUE.

Rationale-The repository operations will rely primarily on offsite power from a commercial grid. Such grids are vulnerable to outages from many causes. As appropriate to sustain required safety functions, onsite power supplies will be provided for selected SSCs ITS.

2. The rate of the hazard process is sufficient to affect the 100-year operational period. TRUE.

Rationale-The impact is immediate. Loss of power effects could initiate event sequences.

3. The consequences of the hazard are significant enough to affect the 100-year operational period. TRUE.

Rationale-Loss of power effects could initiate event sequences. Design bases and event sequence analyses are required to evaluate this event. Because this statement is indeterminate (its validity cannot be determined at this time), the statement is treated as equivalent to true.

4. The event frequency is greater than $1 \times 10^{-6}$ events per year. TRUE.

Rationale-The rate of occurrence of a loss of offsite power is known to be on the order of 0.1 per year for nuclear plants. Site-specific analysis is required for the repository offsite power supply reliability and design-specific reliability analysis of 
onsite safety-related power supplies are required as well. Because the response to this criterion is indeterminate (its validity cannot be determined at this time), it is treated as equivalent to TRUE.

Applicability-Yes. This event is applicable to the EEHL for the repository site.

\section{External Hazard 38, Seismic Activity, Earthquake}

Definition-This event pertains to earthquake or earth vibrations, including those that are artificially induced.

Required Condition-Natural seismic activity or seismic-like man-induced events such as weapons testing on Nevada Test Site.

\section{Evaluation-}

1. Potential exists and is applicable to the repository site. TRUE.

Rationale-Earthquakes have occurred as recently as 1993 in the region (National Research Council 1995, p. 92), making this event applicable for consideration during the 100-year operational period. The Preclosure Seismic Design Methodology for a Geologic Repository at Yucca Mountain (YMP 1997) describes the strategy for the 100-year operational period seismic design methodology. Further, there is a potential for resumption of nuclear weapon testing at the Nevada Test Site.

2. The rate of the hazard process is sufficient to affect the 100-year operational period. TRUE.

Rationale-The impact is immediate. Earthquake effects could initiate event sequences and cause collapse or failures of SSCs that house radioactive materials.

3. The consequences of the hazard are significant enough to affect the 100-year operational period. TRUE.

Rationale-Earthquake effects could initiate event sequences and cause collapse or failures of SSCs that house radioactive materials. Design criteria for selected SSCs will have to be defined to prevent adverse consequences. Without engineering analyses, the response to this criterion is viewed as indeterminate and is treated as equivalent to TRUE.

4. The event frequency is greater than $1 \times 10^{-6}$ events per year. TRUE.

Rationale-The repository will use mean annual probabilities of $1 \times 10^{-3}$ and $1 \times 10^{-4}$ as reference values in determining the frequency category 1 and frequency category 2 design basis vibratory ground motions (YMP 1997, p. iii). The SSCs ITS will be designed to withstand a design basis earthquake (frequency category 1 or frequency category 2), as appropriate. 
Applicability-Yes. This event is applicable to the EEHL for the repository site.

\subsubsection{External Events Hazards List}

Documentation of the EEHA will summarize the process and present results in the EEHL. The EEHL is a listing of external hazards that will be addressed either as initiating events for event sequences or will be dealt with otherwise. Table 6-3 is an example of an EEHL using the examples presented in Section 6.1.3.5. In addition, the EEHA will provide a summary table of those hazards that were eliminated through the screening process, including a statement of the primary rationale for the elimination of the hazard. Table 6-4 illustrates these hazards.

\subsection{INTERNAL EVENTS HAZARDS ANALYSIS}

\subsubsection{Introduction}

The purpose of this analysis is to identify and document the internal hazards and preliminary events as part of the PSA. Internal hazards are those hazards presented by operation of the facility and its associated processes. These hazards are in contrast to external hazards, which involve natural phenomena and external man-made hazards. The hazard analysis methodology used in this analysis provides a systematic means to identify facility hazards and associated event sequences that may result in adverse radiological consequences to the public and facility workers during the repository preclosure period. The events are documented in a preliminary internal event hazards list and are intended to be used as input to the repository initiating event selection process. It is expected that the results from this analysis will undergo further screening and analysis based on the criteria that apply to the performance of event sequence analyses for the preclosure period of repository operation. As the repository design progresses, this analysis will be reviewed to ensure that no new hazards are introduced and previously evaluated hazards have not increased in severity.

\subsubsection{Overview of Basic Approach}

This analysis is performed utilizing the hazard analysis methodologies described in the System Safety Analysis Handbook (Stephans and Talso, eds. 1997) and addresses the repository internal hazards and associated events that could result in radiological consequences to the public or facility workers during the preclosure period. The list of preliminary events is generated by applying a checklist of potential generic events (see Section 6.2.3.3) to each functional area within the repository. A description of the process steps is provided in the following sections.

\subsubsection{Define Repository Functional Areas}

To facilitate identification of repository hazards, the repository is divided into functional areas. These functional areas are defined by a specific function, physical boundaries of the facility, or both. Repository functional areas are listed in Section 6.2.3.1 and described in Section 6.2.4. For the purposes of this guide, the functional areas are described generically. As the design progresses, names of buildings and operations areas may change. 


\subsubsection{Define Repository Design Configuration and Operations}

Following the definition of functional areas, facility design configuration and operations within those areas are established and documented prior to hazard identification activities. Functional area design configuration and operations are discussed in Sections 6.2.3.2 and 6.2.4.

\subsubsection{Develop Generic Event Checklist}

Once the repository functional areas, design configuration, and facility operations are defined, a list of generic internal events is developed that, if determined to be applicable, could result in adverse radiological consequences to the public or facility workers. This generic list is not project-specific and attempts to identify all potentially hazardous event sequences. A comprehensive list will ensure a thorough treatment of all possible events. The development of generic events will make maximum use of existing repository documents where similar work has been performed. A list of generic events is provided in Section 6.2.3.3.

\subsubsection{Determine the Repository Applicability of Internal Events}

This portion of the analysis includes a review of the repository functional areas, including facility design and operations, to determine the applicability of generic events that could potentially result in adverse radiological consequences.

Specific criteria will be developed for each of the generic events to support the applicability determination. If the criteria are satisfied, the generic event has the potential for adverse radiological consequence and specific preliminary events will then be identified.

It is noted that unintentional human actions may be the initiator of, or contributor to, the occurrence of one or more of the generic event categories. Rather than create "human actions" as a separate category of event, the internal events hazards analyst should consider how and where human actions could come into play in association with one or more of the generic event categories.

A general review of previously performed safety evaluations of repository operations has been conducted to determine the preliminary events applicable to the repository. These evaluations included:

- $\quad$ Preliminary Worst-Case Accident Analysis to Support the Conceptual Design of a Potential Repository in Tuff(Jackson et al. 1984)

- $\quad$ Site Characterization Plan Conceptual Design Report - Volume 4 Appendices $F$ - $O$ (MacDougall et al. 1987)

- $\quad$ Yucca Mountain Site Characterization Project Identification of Structures, Systems, and Components Important to Safety at the Potential Repository at Yucca Mountain (Hartman and Miller 1991)

- $\quad$ Preclosure Radiological Safety Analysis for Accident Conditions of the Potential Yucca Mountain Repository: Underground Facilities (Ma et al. 1992) 
- $\quad$ Preclosure Radiological Safety Evaluation: Exploratory Studies Facility (Schelling and Smith 1993).

The following approach should be used to document the analysis of preliminary events presented in Section 6.2.4.

Area Description-Establishes the baseline description of the repository functional area. Information will be used to gain an understanding of the expected use of the area.

Generic Event Category Applicability-Summarizes results from the applicability assessment for each of the following generic events:

- $\quad$ Collision/Crushing

- $\quad$ Chemical Contamination/Flooding

- $\quad$ Explosion/Implosion

- $\quad$ Fire

- $\quad$ Radiation/Magnetic/Electrical/Fissile

- Thermal.

Where applicable, the internal events hazards analyst should consider how and where human actions could come into play in association with one or more of the generic event categories. For example, a collision/crushing event might occur by dropping a fuel assembly. The cause of the drop could be a mechanical failure or a human action. Details of the effects of human actions will be developed as part of the event sequence analyses described in Section 7 and Section 7.3, in particular.

Reference-Identifies the source of the preliminary design data used to conduct the analysis. Preliminary Events-Identifies specific events based on the potential for interaction.

\subsubsection{Approach for Evaluating Applicability of Generic Internal Events to Repository Functional Areas}

The basic input used in the performance of this analysis consists of repository process and design information and includes system description documents, process flow diagrams, mechanical flow diagrams, and a conceptual description of repository operations. Additional design input to this analysis is described in the following sections.

\subsubsection{Repository Functional Areas}

The following functional areas have been defined to facilitate the identification of the repository hazards and events associated with preclosure operations. A description of each functional area is provided in Section 6.2.4.

- Waste Receipt and Carrier or Cask Transport

- Carrier Preparation

- $\quad$ Waste Handling - Transport Cask Handling

- Waste Handling - Canister Transfer 
- Waste Handling - Assembly Transfer

- Waste Handling - Waste Package Handling and Waste Package Remediation

- $\quad$ Subsurface Transport, Emplacement, and Monitoring

- $\quad$ Site-Generated Waste Treatment - Liquid Low-level Waste

- $\quad$ Site-Generated Waste Treatment - Solid Low-level Waste

- Waste Aging.

\subsubsection{Repository Design Configuration and Facility Operation}

Prior to performing repository hazards analysis, facility design configuration and operations as well as the function of facility SSCs are established. This analysis is based upon the repository design and functions. A brief description of operations for each functional area is provided in Section 6.2.4.

\subsubsection{Generic Internal Event Checklist}

The development of the generic internal event checklist is based on the following hazard evaluation techniques:

- $\quad$ Energy Analysis (Stephans and Talso, eds. 1997, p. 3-77)

- $\quad$ Energy Trace Barrier Analysis (Stephans and Talso, eds. 1997, p. 3-79)

- $\quad$ Energy Trace Checklist (Stephans and Talso, eds. 1997, p. 3-85).

The generic list is based upon the lists provided in these three approaches that have been reorganized for convenience and applicability to repository preclosure operations. The resulting comprehensive checklist contains a series of questions for each generic hazard. Applicability to a functional area of design is determined by a positive response to all questions.

\subsection{Collision/Crushing}

\section{A. Categories-}

1. Uncontrolled Mass/Force-Examples include: excessive velocity or acceleration of mass, inadvertent operation of appendage, failure of primary or secondary structure, tumbling (or tipped-over) mass, uncontrolled robot, or uncontrolled fixed rotating equipment, falls, drops.

2. Protrusions into Pathways-Examples include: extended appendages, protruding structural elements, or improperly placed equipment.

\section{B. Applicability to Functional Area of Design-}

1. Is kinetic or potential energy present?

2. Can the kinetic or potential energy be released in an unplanned way? 
3. Can the release of kinetic or potential energy interact with the waste form?

6.2.3.3.2 Chemical Contamination/Flooding (not normally a direct potential threat to the waste form-usually a contributing cause of another threat category)

\section{A. Categories-}

1. Reactions-Examples include: release of chemicals or materials that react with system materials causing system deterioration. The released materials could foster electrolytic, galvanic, or stress corrosion, or oxidation.

2. Off-Gassing-Example: release of volatile or condensable materials.

3. Venting-Examples include: leaking or venting of materials, gases, or liquids.

4. Debris/Leaks-Examples include: small loose or free parts, flaking, leaking fluids or flooding, or dirt and dust, oxidized materials (e.g., metal rust).

5. Flooding-Examples include: water, water leading to the potential for criticality.

\section{B. Applicability to Functional Area of Design-}

Category 1-Reactions:

1. Are corrosive or reactive chemicals or materials present?

2. Can these chemicals or materials be released?

3. Can the chemicals or materials interact with the waste form?

Category 2-Off-Gassing:

1. Are volatile or condensable materials present?

2. Can these materials be released?

3. Can these materials interact with the waste form?

Category 3-Venting:

1. Is there potential for venting materials in the area?

2. Can the materials interact with the waste form?

Category 4-Debris and Leaks:

1. Is there potential for debris or leaks in the area?

2. Can the debris or fluids interact with the waste form? 


\section{Category 5-Flooding:}

1. Are sources of water present in the area?

2. Is there a potential to release the water?

3. Can the released water interact with the waste form with potential for criticality?

6.2.3.3.3 Explosion/Implosion (This event is normally accompanied by shrapnel or other high velocity debris.)

\section{A. Categories-}

1. Pressure Energy Release-Examples include: damage, failure, and rupture of pressurized containers or components and release of gases, or implosion of containers, vessels, or enclosed structural volume.

2. Electrical Energy Release-Examples include: faults, arcs, static charge, electrical component failure, battery overcharge or overdischarge, or out of phase source connection.

3. Chemical Energy Release-Examples include: chemical dissociation or reactions, fire internal to confined volumes, adiabatic detonation, or ignition of confined flammable gases.

4. Mechanical Equipment-For example: rotating equipment disintegration due to overspeed.

\section{B. Applicability to Functional Area of Design-}

1. Is pressure, electrical, chemical, or mechanical energy present?

2. Can an event occur that results in an explosion or implosion energy release?

3. Can the released energy impact the waste form directly?

\subsection{Fire}

Must have ignition, fuel, and oxidizer sources.

Ignition Sources-Examples include: electrical faults, shorts, arcs, chemical reactions, hot surfaces, small flames, or catalytic reaction (see Explosion/Implosion).

Fuel and Oxidizer Sources-Examples include: flammable materials (solids and liquids) and flammable atmospheres (gases), in addition to the presence of an 
oxidizing environment from ambient atmosphere or other chemical agents (see Contamination).

\section{A. Categories-Not Applicable}

\section{B. Applicability to Functional Area of Design-}

1. Are fuel, oxidizers, and ignition sources present?

2. Is there sufficient fuel and oxidizer to sustain fire?

3. Can fire interact with the waste form?

\subsection{Radiation/Magnetic/Electrical/Fissile}

\section{A. Categories-}

1. Ionizing-Examples include radioactive materials, x-rays, or high voltage radio frequency equipment.

2. Non-Ionizing-Examples include electromagnetic interference, radio frequency, or corona.

3. Magnetic-Examples include permanent magnets and electromagnetic devices.

4. Nuclear Particles-Examples include ion and electron beams or radioactive materials.

5. Laser Light-For example, high-energy laser beams and accompanying energy forms such as heat.

6. Fissile Material-Examples include uranium-233, uranium-235, and plutonium-239.

\section{B. Applicability to Functional Area of Design-}

1. Are radiation, magnetic, or electrical energy sources present external to the waste form? Is fissile material present?

2. Is a mechanism present to release radiation, magnetic, or electrical energy?

3. Can the release of radiation, magnetic, or electrical energy interact with the waste form?

4. Can fissile material be arranged in such a manner as to result in criticality? 


\subsection{Thermal (also see Fire)}

\section{A. Categories-}

Heat-This category accommodates any thermal energy source with sufficient energy to have an impact on the waste form.

\section{B. Applicability to Functional Area of Design-}

1. Are external thermal energy sources present?

2. Can thermal energy be released?

3. Can the thermal energy affect the waste form?

\subsubsection{Examples of Evaluating the Applicability of Generic Events to Repository Function Areas}

The following sections provide selected examples of application of internal hazard analysis. The examples represent the main operations that handle or transport high-level radioactive waste forms.

\subsubsection{Example 1: Waste Receipt and Carrier or Cask Transport}

Area Description-Transportation casks containing spent nuclear fuel (SNF) and high-level radioactive waste (HLW) and associated carriers are received at the repository waste entry point or security gate. The SNF and HLW are contained in casks equipped with impact limiters and personnel barriers. At the security gate, the cask carrier and offsite prime mover are inspected for contraband, sabotage, and radioactive contamination. Following inspection, the offsite prime mover is decoupled and an onsite diesel-driven prime mover is used to transport the carrier and cask to a carrier preparation area. Following preparation of the carrier and cask, the system moves the carrier and cask to the cask staging pad or a waste handing building for cask unloading.

These operations are carried out on the surface at the North Portal and consist of security inspection and radiation monitoring equipment, required road and rail systems, and onsite prime movers. The system also transports empty transportation casks and associated carriers back through the carrier preparation area and on to the repository security gate for dispatch from the site.

\section{Generic Events Applicability-}

- $\quad$ Collision/Crushing-Yes

- Chemical Contamination/Flooding- None identified

- $\quad$ Explosion/Implosion-None identified

- $\quad$ Fire-Yes - diesel fuel fire

- $\quad$ Radiation/Magnetic/Electrical/Fissile-Yes - Radiation, Fissile

- $\quad$ Thermal-Yes (see Fire) 
Reference-Jackson et al. 1984, MacDougall et al. 1987, Hartman and Miller 1991, and applicable system description and design documents.

\section{Preliminary Events-}

- Collision/Crushing-Cask collision, railcar derailment involving transportation cask, overturning of truck trailer involving transportation cask

- $\quad$ Fire, Thermal-Diesel fuel fire

- $\quad$ Radiation-Radiation exposure of facility worker

- $\quad$ Fissile-Criticality associated with cask collision, railcar derailment, or overturned truck trailer and rearrangeme nt of cask internals

\subsubsection{Example 2: Carrier Preparation}

Area Description-Transportation casks containing SNF and HLW and associated carriers are delivered to the carrier preparation area by the onsite diesel-driven prime mover. Within the area, the carriers and casks are prepared for entering the carrier bay of a waste handling facility. The primary operations include:

- $\quad$ Measure external carrier and cask radiation levels

- $\quad$ Remove and retract personnel barriers

- Inspect carriers and casks for radiation contamination

- $\quad$ Measure external cask temperature

- $\quad$ Remove and retract impact limiters.

The carrier preparation system also functions to prepare empty carriers and casks for dispatch from the repository. Specifically, the carriers and casks are inspected for radiation contamination and the impact limiters and personnel barriers are installed. The empty carriers and casks are removed from the carrier preparation area for dispatch by the onsite prime mover. The system performs these functions utilizing remotely operated cranes and manipulators; however, some local operator actions may be required.

\section{Generic Events Applicability-}

- Collision/Crushing-Yes

- Chemical Contamination/Flooding-None identified

- Explosion/Implosion-None identified

- $\quad$ Fire-Yes

- Radiation/Magnetic/Electrical/Fissile-Yes, Radiation/Fissile

- $\quad$ Thermal-Yes (see Fire).

Reference-Applicable system description and design documents. 


\section{Preliminary Events-}

- Collision/Crushing-Handling equipment drops on transportation cask, cask collision

- $\quad$ Fire, Thermal-Diesel fuel fire

- $\quad$ Radiation-Radiation exposure of facility worker

- $\quad$ Fissile-Criticality associated with cask collision and rearrangement of cask internals.

\subsubsection{Example 3: Waste Handling - Transport Cask Handling}

Loaded transportation casks and associated carriers are transported from the carrier preparation area or cask staging area to a waste handling facility by the onsite dieseldriven prime mover (rail and road). Incoming carriers and casks are prepared for waste removal by upending the cask on the carrier, lifting the cask from the carrier and lowering the cask onto a cask transfer cart. The system also functions to load empty transportation casks and non-disposable canisters onto carriers for shipment from the repository. The system performs these functions utilizing remotely operated cranes and manipulators; however, some local operator actions may be required.

\section{Generic Events Applicability-}

- $\quad$ Collision/Crushing-Yes

- Chemical Contamination/Flooding-None identified

- $\quad$ Explosion/Implosion-None identified

- $\quad$ Fire-Yes

- $\quad$ Radiation/Magnetic/Electrical/Fissile-Yes, Radiation/Fissile

- $\quad$ Thermal-Yes (see Fire).

Reference-Applicable system description and design documents.

\section{Preliminary Events-}

- Collision/Crushing-Transportation cask drop, transportation cask slap down, cask collision, isolation door closes on transportation cask, handling equipment drops on transportation cask

- $\quad$ Fire, Thermal-Diesel fuel fire

- $\quad$ Radiation-Radiation exposure of facility worker

- $\quad$ Fissile-Criticality associated with ask collision or drop and rearrangement of cask internals.

\subsubsection{Example 4: Waste Handling - Canister Transfer}

Transportation casks containing large and small disposable canisters are transferred from the carrier bay to the canister transfer area by means of cask transfer carts. In the canister transfer area, canisters are unloaded from casks, stored as required, and loaded into waste packages 
(WPs). Empty casks are also prepared for shipment from the repository. Cask unloading begins with cask inspection, sampling, and lid bolt removal operations. The cask lids are removed and the canisters are unloaded. Small canisters are loaded directly into a waste package (WP), or are stored until enough canisters are available to fill a WP. Large canisters are loaded directly into a WP. Transportation casks and related components are decontaminated as required, and empty casks are prepared for shipment from the site.

Multiple independent and remotely operated canister transfer lines may be provided in the waste handling facility. The lines are operated independently to handle disposable canisters and load them into WPs. Each canister transfer line contains an airlock, cask preparation and decontamination area, and a canister transfer cell. Each cask preparation and decontamination area includes a cask preparation station and a cask decontamination station. Remote handling equipment consists of cask transfer carts, cask preparation manipulators, and equipment required to perform sampling, cask unbolting, lid removal, and decontamination. The canister transfer cells include a canister transfer station and WP transfer cart supported by remote handling equipment including a bridge crane (sized to handle the largest canisters), WP loading manipulator, and an array of large and small canister lifting fixtures. A canister staging rack is provided for the accumulation of small canisters in a shielded area.

\section{Generic Events Applicability-}

- $\quad$ Collision/Crushing-Yes

- $\quad$ Chemical Contamination/Flooding-None identified

- $\quad$ Explosion/Implosion-None identified

- $\quad$ Fire-None identified

- $\quad$ Radiation/Magnetic/Electrical/Fissile-Yes, Radiation/Fissile

- Thermal-None identified.

Reference-Applicable system description and design documents.

\section{Preliminary Events-}

- Collision/Crushing-Transportation cask slapdown, WP slapdown, canister drop, canister slap down, canister collision, canister drops onto WP, canister drop on sharp object, canister drop onto another canister at small canister staging rack, shield door closes on transportation cask, shield door closes on WP, handling equipment drops on transportation cask, canister or WP

- $\quad$ Radiation-Radiation exposure of facility worker

- $\quad$ Fissile-Criticality associated with small canister staging rack, criticality associated with collision or drop of casks or canisters, and rearrangement of container internals.

\subsubsection{Example 5: Waste Handling - Assembly Transfer}

Area Description-Transportation casks containing uncanistered spent nuclear fuel (SNF) assemblies or duatpurpose canisters (DPCs) are transferred to the assembly transfer area by 
means of cask transfer carts. Alternative concepts include transfer of SNF or DPCs in (1) a dry environment, such as a shielded transfer cell, or (2) a wet environment using a cask unloading pool. For illustration, this guide assumes that a transfer pool is used. Casks are lifted from the transfer cart and placed into a cask preparation pit. The cask interiors are sampled for radioactivity, vented, cooled down with compressed gas, and then filled with water. The cask lid bolts are then detensioned and removed. The cask is lifted and placed in the cask unload pool, where the cask lid is removed and the assemblies are removed and placed directly into a transfer cart or a staging rack. Assemblies contained in a dual purpose canister (DPC) involve the additional steps of removing the DPC from the cask and DPC opening prior to assembly removal. Following assembly removal, empty transportation casks and DPCs are removed from the pool and prepared for dispatch from the repository site.

Following removal from the cask or DPC, the SNF assemblies are transferred to the assembly cell (either directly or from the staging rack) by an inclined transfer cart. In the assembly cell, the SNF assemblies are placed in the assembly drying station for water removal and then transferred to WP. The WP is then fitted with a temporary seal, decontaminated, evacuated, and backfilled with nitrogen and moved to the WP cell for lid welding.

The system utilizes remotely operated equipment to perform these functions including, a bare fuel assembly transfer machine, fuel assembly grapples, container transfer carts, contamination barriers, inspection instruments, and low-level radioactive waste (LLW) removal subsystems.

\section{Generic Events Applicability-}

- Collision/Crushing-Yes

- Chemical Contamination/Flooding-Yes, Flooding

- $\quad$ Explosion/Implosion-None identified

- $\quad$ Fire-Yes

- $\quad$ Radiation/Magnetic/Electrical/Fissile-Yes, Radiation/Fissile

- Thermal-Yes.

Reference-Applicable system description and design documents.

\section{Preliminary Events-}

- Collision/Crushing-Transportation cask drop, transportation cask slap down, cask collision, SNF assembly drop onto pool floor, SNF assembly drop onto SNF assembly staging rack, SNF assembly drop onto assembly cell floor, SNF assembly drop onto assembly dryer, SNF assembly drop onto WP, SNF assembly collision, loaded SNF assembly basket drop onto pool floor, loaded SNF assembly basket drop onto SNF assembly staging rack, loaded SNF assembly basket drop onto assembly cell floor, loaded SNF assembly basket drop onto assembly dryer, loaded SNF assembly basket collision, uncontrolled descent of loaded incline basket transfer cart

- $\quad$ Flooding-Uncontrolled pool water draindown or filling resulting in flooding 
- Fire, Thermal-SNF overheating due to loss of pool water resulting in excessive clad temperature and possible zircaloy cladding fire, SNF overheating in an assembly transfer basket or dryer resulting in excessive clad temperature and possible zircaloy cladding fire

- Radiation-Uncontrolled pool water draindown or filling resulting in flooding and radioactive contamination of adjoining Waste Handing Building (WHB) areas, increased radiation levels in the assembly transfer area and potential uncovering of fuel assemblies, radiation exposure of facility worker

- $\quad$ Fissile-Criticality associated with a cask collision or drop and the rearrangement of cask internals, criticality associated with SNF assembly staging rack, criticality associated with misload of assembly dryer, criticality associated with misload of waste package.

\subsubsection{Example 6: Waste Handling - Waste Package Handling and Waste Package Remediation}

Area Description-Within the WP handling area, empty WPs are prepared for loading. WPs are transferred to and from the assembly and canister transfer systems, the WP lids are welded, and WPs may be stored temporarily. WPs are also loaded into the WP transporter and transferred to and from the WP remediation system. An empty WP consists of the container barriers, pacing structures or baskets, shielding integral to the container, and packing contained with the container. A sealed or loaded WP consists of the WP and waste form(s) after the outer lid welds are completed and accepted.

The process begins with the preparation of an empty WP, which includes staging, installing lifting collars, tilting the WP upright and outfitting the container, and transferring it to WP transfer operations. WP transfer operations include staging WP lids for the weld stations and transferring the WPs to or from the assembly or canister transfer systems for loading and welding. The WP welding operation receives loaded WPs directly from the waste handling lines or from interim lag storage for welding. The welding operations include positioning the WP in the welding station, removing lid seals, and installing and welding the inner and outer lids. The weld process for each lid includes non-destructive examination. Following examination and weld acceptance, the sealed WP is either staged or transferred to a tilting station. At the tilting station, the WP is tilted to horizontal, the collars are removed, and the WP is transferred to WP transporter loading operations. The WP transporter loading operations include survey and decontamination, and lifting and loading the WP into the WP transporter. WPs that do not meet the welding examination criteria are transferred to the WP remediation system for inspection or repair.

The WP handling area is contained within a waste handling facility that includes areas for empty WP preparation, welding, staging, loaded WP staging, WP transporter loading, and the associated operating galleries and required equipment maintenance areas. The empty WP preparation area is located in an unshielded structure.

Waste package hand ling equipment includes a bridge crane, tilting station, and transfer carts. The welding area includes welders, staging stations, and a tilting station. Welding operations are supported by remotely operated equipment including transfer carts, a bridge crane and hoists, 
welder jib cranes, and manipulators. WP transfer includes a transfer, decontamination, and transporter load area. The operations are supported by a remotely operated horizontal lifting system, decontamination system, decontamination and inspection manipulator, and a WP horizontal transfer cart. Handling operations are supported by a suite of fixtures including yokes, lift beams, and lid attachments. Remote equipment is designed to facilitate decontamination and maintenance, and interchangeable components are provided where appropriate. Set-aside areas are included as required for fixtures and tooling to support off-normal and recovery operations. Semi-automatic, manual, and backup control methods support normal, maintenance, and recovery operations.

\section{Generic Events Applicability-}

- Collision/Crushing-Yes

- Chemical Contamination/Flooding-None identified

- Explosion/Implosion-None identified

- $\quad$ Fire-Yes

- Radiation/Magnetic/Electrical/Fissile-Yes, Radiation/Fissile

- Thermal-Yes.

Reference-Applicable system description and design documents.

\section{Preliminary Events-}

- Collision/Crushing-WP drop, WP slap down, WP drop onto sharp object, WP collision, equipment drops onto WP. Similar events are identified for both the sealed WP and unsealed/open WPs. Release of radiation is more likely for events involving unsealed/open WPs.

- $\quad$ Fire, Thermal-Fuel damage by burn through during welding process, SNF overheating in a WP resulting in excessive clad temperature and possible zircaloy cladding fire

- $\quad$ Radiation-Radiation exposure of facility worker

- $\quad$ Fissile-Criticality associated with the staging area, criticality associated with collision or drop of and rearrangement of container internals.

\subsubsection{Example 7: Subsurface Transport, Emplacement, and Monitoring}

Area Description-The waste emplacement system transports the loaded and sealed WP from the waste handling facility to the subsurface emplacement area. This system operates on the surface between the north portal and the WHB, and in the underground ramps, access mains, and emplacement drifts. This system receives the WP into the shielded transporter, transports the WP to the emplacement area, and emplaces the WP in the emplacement drift. The operation cycle is completed when the transport equipment returns to the surface to receive another WP. 
Major items and sub-systems of the waste emplacement system consist of the following:

- A shielded transporter with a transfer mechanism for accepting a WP. The transporter requires transport locomotives for move ment.

- Transport locomotives for the transporter movement and control functions between the surface waste handling facility and the subsurface repository.

- A remotely controlled emplacement gantry for the WP emplacement functions in the emplacement drifts. The gantry is self-powered through a direct current third rail system.

- A gantry carrier for gantry transfer between the emplacement drifts and the maintenance facilities. The gantry carrier requires a transport locomotive for the carrier movement and control functions.

The sequence of the subsurface WP handling process is described in the following paragraphs:

The WP is positioned on a transfer mechanism and is moved into the shielded transporter in a waste handling facility. A remotely controlled loading mechanism moves the transfer mechanism into and out of the transporter. The loading mechanism will be an integral part of the transporter.

One (or more) transport locomotive(s) is used to move the transporter from a waste handling facility, into and down the north ramp, into a main access drift, and to the vicinity of the designated emplacement drift. At the pre-selected emplacement drift location the locomotive pushes the transporter into the emplacement drift turnout. Before the transporter is pushed into the turnout, the locomotive operators leave the locomotive, and the following functions of the emplacement sequence are performed remotely. Once the transporter is partway in the turnout, the transporter doors and the drift isolation doors open remotely, then the transporter is pushed into contact with the subsurface emplacement transportation system drift transfer dock.

Once the transporter is docked, the transfer mechanism moves the WP out of the transporter and onto the transfer dock. The emplacement gantry moves into position over the WP and raises the WP off the transfer mechanism. The gantry carries the WP into the emplacement drift, stopping at a pre-determined emplacement position. The WP is lowered to a specific location in the emplacement drift. The WP is supported by a pedestal or pallet. The gantry disengages from the WP and moves back to its waiting position at the transfer dock. These operations are reversible to support moving an emplaced WP to another location.

The transporter retracts the transfer mechanism and is pulled away from the drift entrance doors by a locomotive. The transporter doors and the drift doors are then closed, and the transporter returns to the surface for another transport and emplacement operation. The transporter may also receive a WP from the emplacement gantry to move the WP to another emplacement drift or to the surface (e.g., for remediation).

Following emplacement, the WPs are monitored between the time the WP is emplaced and the time the repository is closed. Concurrent with the emplacement and monitoring of WPs, 
construction is underway on the development of additional emplacement drifts. Physical separation of emplacement and development activities is provided by isolation air locks. When a predetermined number of newly excavated emplacement drifts are ready for waste emplacement, the isolation airlocks are moved to include the newly developed drifts in the emplacement area.

\section{Generic Events Applicability-}

- Collision/Crushing-Yes

- Chemical Contamination/Flooding-Yes, Flooding

- Explosion/Implosion-No

- $\quad$ Fire-Yes

- Radiation/Magnetic/Electrical/Fissile-Yes, Radiation/Fissile

- $\quad$ Thermal-Yes, see Fire.

Reference-Jackson et al. 1984, MacDougall et al. 1987, Hartman and Miller 1991, Ma et al. 1992, Schelling and Smith 1993, and applicable system description and design documents.

\section{Preliminary Events-}

- Collision/Crushing-Transporter derailment outdoors, transporter derailment on ramp or in main drift, transporter collision with other stationary or moving equipment, WP reusable rail car rolls out of transporter, runaway transporter, rockfall onto transporter, loaded emplacement gantry derailment, WP drop from emplacement gantry, WP or emplacement gantry collision with equipment or another WP, rockfall onto WP, steel set drop onto WP, failure of isolation air locks due to rockfall, equipment collision, or other impacts as a result of development operations

- $\quad$ Flooding-Flooding from water pipe break originating on development or emplacement sides

- Fire, Thermal-Fire associated with WP transporter, locomotive, or development equipment

- Radiation-Radiation exposure of facility worker, early or juvenile WP failure and resultant release of radioactive material

- $\quad$ Fissile-Criticality associated with collision or drop of WP and rearrangement of package internals.

\subsubsection{Internal Events Hazards List}

The product of the analysis described in Section 6.2 is a compilation of tables that list the potentially credible internal events hazards that cannot be screened out by the process. 


\subsection{REFERENCES}

\subsubsection{Documents Cited}

AIChE (American Institute of Chemical Engineers) 1992. Guidelines for Hazard Evaluation Procedures. 2nd Edition with Worked Examples. New York, New York: American Institute of Chemical Engineers. TIC: 239050.

ASCE 7-98. 2000. Minimum Design Loads for Buildings and Other Structures. Revision of ANSI/ASCE 7-95. Reston, Virginia: American Society of Civil Engineers. TIC: 247427.

Coats, D.W. and Murray, R.C. 1985. Natural Phenomena Hazards Modeling Project: Extreme Wind/Tornado Hazard Models for Department of Energy Sites. UCRL-53526, Rev. 1.

Livermore, California: Lawrence Livermore National Laboratory. ACC: MOL.20010405.0048.

CRWMS M\&O 1999. MGR Design Basis Extreme Wind/Tornado Analysis. ANL-MGR-SE000001 REV 00. Las Vegas, Nevada: CRWMS M\&O. ACC: MOL.19991215.0461.

Eglinton, T.W. and Dreicer, R.J. 1984. Meteorological Design Parameters for the Candidate Site of a Radioactive-Waste Repository at Yucca Mountain, Nevada. SAND84-0440/2. Albuquerque, New Mexico: Sandia National Laboratories. ACC: NNA.19870407.0048.

Hartman, D.J. and Miller, D.D. 1991. Identification of Structures, Systems, and Components Important to Safety at the Potential Repository at Yucca Mountain. SAND89-7024.

Albuquerque, New Mexico: Sandia National Laboratories. TIC: 203536.

Jackson, J.L.; Gram, H.F.; Hong, K-J.; Ng, H.S.; and Pendergrass, A.M. 1984. Preliminary Worst-Case Accident Analysis to Support the Conceptual Design of a Potential Repository in Tuff. SAND83-1787C. Albuquerque, New Mexico: Sandia National Laboratories.

TIC: 229295.

Ma, C.W.; Sit, R.C.; Zavoshy, S.J.; and Jardine, L.J. 1992. Preclosure Radiological Safety Analysis for Accident Conditions of the Potential Yucca Mountain Repository: Underground Facilities. SAND88-7061. Albuquerque, New Mexico: Sandia National Laboratories. ACC: NNA.19920522.0039.

MacDougall, H.R.; Scully, L.W.; and Tillerson, J.R., eds. 1987. Nevada Nuclear Waste Storage Investigations Project, Site Characterization Plan Conceptual Design Report. SAND84-2641. Volume 4, Appendices F-O. Albuquerque, New Mexico: Sandia National Laboratories. ACC: NN1.19880902.0017.

National Research Council 1995. Technical Bases for Yucca Mountain Standards. Washington, D.C.: National Academy Press. TIC: 217588.

NRC (U.S. Nuclear Regulatory Commission) 1987. Standard Review Plan for the Review of Safety Analysis Reports for Nuclear Power Plants. NUREG-0800. LWR Edition.

Washington, D.C.: U.S. Nuclear Regulatory Commission. TIC: 203894. 
NRC (U.S. Nuclear Regulatory Commission) 2003. Yucca Mountain Review Plan, Final Report. NUREG-1804, Rev. 2. Washington, D.C.: U.S. Nuclear Regulatory Commission, Office of Nuclear Material Safety and Safeguards. TIC: $\underline{254568}$.

Schelling, F.J. and Smith, J.D. 1993. Preclosure Radiological Safety Evaluation: Exploratory Studies Facility. SAND92-2334. Albuquerque, New Mexico: Sandia National Laboratories. TIC: 207076.

Solomon, K.A.; Erdmann, R.C.; and Okrent, D. 1975. "Estimate of the Hazards to a Nuclear Reactor from the Random Impact of Meteorites." Nuclear Technology, 25, 68-71. La Grange Park, Illinois: American Nuclear Society. TIC: 241714.

Stephans, R.A. and Talso, W.W., eds. 1997. System Safety Analysis Handbook. 2nd Edition. Albuquerque, New Mexico: System Safety Society. TIC: 236411.

YMP (Yucca Mountain Site Characterization Project) 1997. Preclosure Seismic Design Methodology for a Geologic Repository at Yucca Mountain. Topical Report YMP/TR-003-NP, Rev. 2. Las Vegas, Nevada: Yucca Mountain Site Characterization Office.

ACC: MOL.19971009.0412.

\subsubsection{Codes, Standards, Regulations, and Procedures}

10 CFR 63. 2002. Energy: Disposal of High-Level Radioactive Wastes in a Proposed Geologic Repository at Yucca Mountain, Nevada. Readily available. 


\section{SECTION 6 APPENDIX}

\section{BIBLIOGRAPHY FOR DOCUMENTS POTENTIALLY RELEVANT TO EXTERNAL EVENTS HAZARDS ANALYSIS}

ANS 1988. Design Criteria for an Independent Spent Fuel Storage Installation (Water Pool Type). ANSI/ANS 57.7-1988. La Grange Park, Illinois: American Nuclear Society. TIC: 238870.

ANS 1992. Determining Design Basis Flooding at Power Reactor Sites, an American National Standard. ANSI/ANS 2.8-92. La Grange Park, Illinois: American Nuclear Society. TIC: 236034.

Braithwaite, J.W. and Nimic, F.B. 1984. Effect of Host-Rock Dissolution and Precipitation on Permeability in a Nuclear Waste Repository in Tuff. SAND84-0192. Albuquerque,

New Mexico: Sandia National Laboratories. ACC: MOL.19980622.0579.

Coats, D.W.; and Murray, R.C. 1985. Natural Phenomena Hazards Modeling Project: Extreme Wind/Tornado Hazard Models for Department of Energy Sites. UCRL-53526, Rev. 1.

Livermore, California: Lawrence Livermore National Laboratory. TIC: 225881.

Coe, J.A.; Glancy, P.A.; and Whitney, J.W. 1995. Volumetric Analysis and Hydrologic Characterization of a Modern Debris Flow Near Yucca Mountain, Nevada. Denver, Colorado: U.S. Geological Survey. ACC: MOL.19950307.0140.

Crowe, B.; Perry, F.; Geissman, J.; McFadden, L.; Wells, S.; Murrell, M.; Poths, J.; Valentine, G.A.; Bowker, L.; and Finnegan, K. 1995. Status of Volcanism Studies for the Yucca Mountain Site Characterization Project. LA-12908-MS. Los Alamos, New Mexico: Los Alamos National Laboratory. ACC: HQO.19951115.0017.

CRWMS M\&O (Civilian Radioactive Waste Management System Management and Operating Contractor) 1996. Preliminary MGDS Hazards Analysis. B00000000-01717-0200-00130 REV 00. Las Vegas, Nevada: CRWMS M\&O. ACC: MOL.19961230.0011.

CRWMS M\&O 1996. Probabilistic Volcanic Hazard Analysis for Yucca Mountain, Nevada. BA0000000-01717-2200-00082 REV 00. Las Vegas, Nevada: CRWMS M\&O. ACC: MOL.19971201.0221.

CRWMS M\&O 1997. Engineering Design Climatology and Regional Meteorological Conditions Report. B00000000-01717-5707-00066 REV 00. Las Vegas, Nevada:

CRWMS M\&O. ACC: MOL.19980304.0028.

CRWMS M\&O 1997. Final Report Waste Package Degradation Expert Elicitation Project. Rev. 0. Las Vegas, Nevada: CRWMS M\&O. ACC: MOL.19980218.0231.

CRWMS M\&O 1998. Retrievability Strategy Report. B00000000-01717-5705-00061 REV 01. Las Vegas, Nevada: CRWMS M\&O. ACC: MOL.19980723.0039. 
CRWMS M\&O 1999. MGR Aircraft Crash Frequency Analysis. ANL-WHS-SE-000001 REV 00. Las Vegas, Nevada: CRWMS M\&O. ACC: MOL.19981221.0203.6.2.6.

DOE (U.S. Department of Energy)1988. Site Characterization Plan, Yucca Mountain Site, Nevada Research and Development Area. DOE/RW-0199. Eight volumes. Washington, D.C: U.S. Department of Energy, Office of Civilian Radioactive Waste Management. ACC: HQO.19881201.0002.

Eglinton, T.W. and Dreicer, R.J. 1984. Meteorological Design Parameters for the Candidate Site of a Radioactive-Waste Repository at Yucca Mountain, Nevada. SAND84-0440/2. Albuquerque, New Mexico: Sandia National Laboratories. ACC: NNA.19870407.0048.

Lipman, P.W.; and Mullineaux, D.R. 1981. The 1980 Eruptions of Mount St. Helens, Washington - Geological Survey Professional Paper 1250, Aerial Distribution, Thickness, Mass, Volume, and Grain Size of Air-fall Ash From the Six Major Eruptions of 1980.

Denver, Colorado: U.S. Geological Survey. TIC: 218260.

Ma, C.W.; Sit, R.C.; Zavoshy, S.J.; and Jardine, L.J. 1992. Preclosure Radiological Safety Analysis for Accident Conditions of the Potential Yucca Mountain Site Repository: Underground Facilities. SAND88-7061. Albuquerque, New Mexico: Sandia National Laboratories. ACC: NNA.19920522.0039.

Ma, C.W.; Zavoshy, S.J.; Jardine, L.J.; and Kiciman, O.K. 1991. An Analysis of Scenarios and Potential Radiological Consequences Associated with U.S. Military Aircraft Crashes for The Yucca Mountain Site Repository. SAND 90-7051. Albuquerque, New Mexico: Sandia National Laboratories. TIC: 222207.

NRC (U.S. Nuclear Regulatory Commission) 1974. Design Basis Tornado for Nuclear Power Plants. Regulatory Guide 1.76. Washington, D.C: U.S. Nuclear Regulatory Commission. TIC: 2717.

NRC 1988. Evaluation of Station Blackout Accidents at Nuclear Power Plants. NUREG-1032. Washington, D.C: U.S. Nuclear Regulatory Commission. TIC: 225880.

Perry, F.V. and Crowe, B.M. 1987. Preclosure Volcanic Effects: Evaluations for a Potential Repository Site at Yucca Mountain, Nevada. Los Alamos, New Mexico: Los Alamos National Laboratory. ACC: NNA.19900112.0341.

Squires, R.R.; and Young, R.L. 1984. Flood Potential of Fortymile Wash and its Principal Southwestern Tributaries, Nevada Test Site, Southern Nevada. Water-Resources Investigations Report 83-4001. Carson City, Nevada: U.S. Geological Survey. ACC: HQS.19880517.1933.

Uniform Building Code 1997, Volume 2, Structural Engineering Design Provisions. International Conference of Building Officials (ICBO), Whittier, California. TIC: 233818. 
YMP (Yucca Mountain Site Characterization Project) 1993. Evaluation of the Potentially Adverse Condition "Evidence of Extreme Erosion During the Quaternary Period" at Yucca Mountain, Nevada. YMP/92-41-TPR. Las Vegas, Nevada: Yucca Mountain Site Characterization Office. ACC: NNA.19930316.0208.

YMP 1995. Site Atlas 1995. Deliverable OE10. Two volumes. Las Vegas, Nevada: Yucca Mountain Site Characterization Office. ACC: MOL.19960311.0262.

YMP 1995. Technical Basis Report for Surface Characteristics, Preclosure Hydrology, and Erosion. YMP/TBR-0001, Rev. 0. Las Vegas, Nevada: Yucca Mountain Site Characterization Office. ACC: MOL.19951201.0049.

YMP 1997. Preclosure Seismic Design Methodology for a Geologic Repository at Yucca Mountain. YMP/TR-003-NP, Rev. 2. Las Vegas, Nevada: Yucca Mountain Site Characterization Office. ACC: MOL.19971009.0412. 


\section{INTENTIONALLY LEFT BLANK}




\section{EVENT SEQUENCE FREQUENCY ANALYSIS}

This section presents details of the methodology for using sequence analyses in the Preclosure Safety Analysis (PSA), including:

- $\quad$ Event Tree Analysis

- $\quad$ Fault Tree Analysis

- Human Reliability Analysis

- $\quad$ Common-Cause and Dependent Failures Analysis

- $\quad$ Event Sequence Frequency Binning.

\subsection{EVENT TREE ANALYSIS}

\subsubsection{Purpose}

This sectiondefines the bases and methodology for the construction and use of event tree analysis (ETA) in support of the PSA. This analysis technique is applied when:

- Identifying and structuring sequences of events that could potentially result in radiological releases or exposures

- Identifying and quantifying dependencies between events in a sequence

- Identifying the degree or magnitude of system failure or damage that correlates to the magnitude of potential releases and exposures

- Quantifying the frequency (or annual probability) of various event sequences by combining probabilities of initiating and enabling events

- $\quad$ Providing a structure for including and propagating uncertainty factors in sequence quantification.

\subsubsection{Scope}

This section is a cursory, focused guide to the construction, application, and evaluation of event trees (ETs). While some concepts are universal to all ETA, the applications in this Section are focused on the support of the PSA. This section is not meant to be a textbook or exhaustive in scope. Where appropriate, reference is made to literature for additional information.

\subsubsection{Overview of Approach}

An event tree (ET) is a graphical logic model that identifies the possible outcomes following an initiating event (IE). ETs are similar to decision trees in depicting the manner in which a chain of alternative outcomes can occur.

Potential accident scenarios (or event sequences) may be displayed in the form of ETs. ETs include an IE (from an identified hazard) and one or more enabling events that must occur to result in a release of radioactivity, a criticality, or an abnormal radiological exposure of the 
public or a worker. The ET format may also be used to analyze scenarios involving chemical exposures, fires, or explosions (see AIChE 1989, Figure 3.10). The enabling events generally represent the success or failure of some safety features that mitigate the effects of the IE alone or in combination with other events. The enabling events may also represent specific human actions (HAs) or physical conditions (i.e., a temperature) that could affect the progression of an event sequence (or scenario).

The ET format provides a framework for estimating the likelihood of event sequences by displaying the frequency of the IE and the conditional probabilities of contributing (enabling) events. An ET generally represents a chronological sequence of events. However, in many cases an ET can be simplified (i.e., have fewer limbs or branches) by rearranging events such that the more likely or more significant events are addressed first.

ETs can be used in deterministic and qualitative analyses to display alternative possible sequences, to examine the levels of protection that are present in a design concept, or both.

Further, an ET may be simplified by assuming that some events will occur with a probability of one (e.g., all fuel cladding breaches in a dropped fuel assembly). This assumption may be appropriate if insufficient data exist to quantify the probability of a failure, if a conservative analysis is being performed, or if regulatory policy demands it.

The construction of ETs in the PSA will build, primarily, on the IEs or event categories identified in the internal events hazards analysis (see Section 6.2). In addition, ETs may be constructed as required for the events identified by the External Events Hazards Analysis (see Section 6.1). The following discussion primarily addresses the application of ETA for internal events. Section 10.1 describes the use of ETA for seismic event sequences.

IEs are identified in the internal events hazards analysis for each repository surface and subsurface operation that could directly or indirectly impact the various radioactive waste forms. IEs in a given operation may include one or more opportunities for drops, collisions, tipovers/slapdowns, fires, explosions, flooding, criticality; exposure to chemical, radiation, thermal effects; or human failure events (HFEs). In general, system design and good practices will provide features (one or more structures, systems, and components (SSCs)), administrative controls, or human intervention) that will serve as physical or functional barriers that prevent or mitigate the release of radioactivity or the exposure of individuals. The proper functioning and availability of such features provide success paths such that an IE does not lead to an undesired consequence. Depending on the number of features that are unavailable when challenged by the occurrence of a given IE, undesirable event sequences can be described that represent failure paths, abnormal occurrences, or accidents that are usually differentiated by the degree of undesired consequences that characterize the end state of a given failure path. The ET is a useful tool to define the manner in which failure paths may occur, as well as a framework for quantifying the frequencies of the various success and failure paths.

\subsubsection{Example of Event Tree}

Figure 7-1 shows an example of a simple ET structure for a hypothetical sequence of events associated with the handling of a canister containing radioactive waste. The ET was designed to 
display several of the types of events and dependencies that may come to play in realistic situations. Section 7.1.4 describes the processes for developing ETs and provides a more complex, hypothetical example for instructional purposes. Section 10.1 describes applications of ETs in seismic sequences.

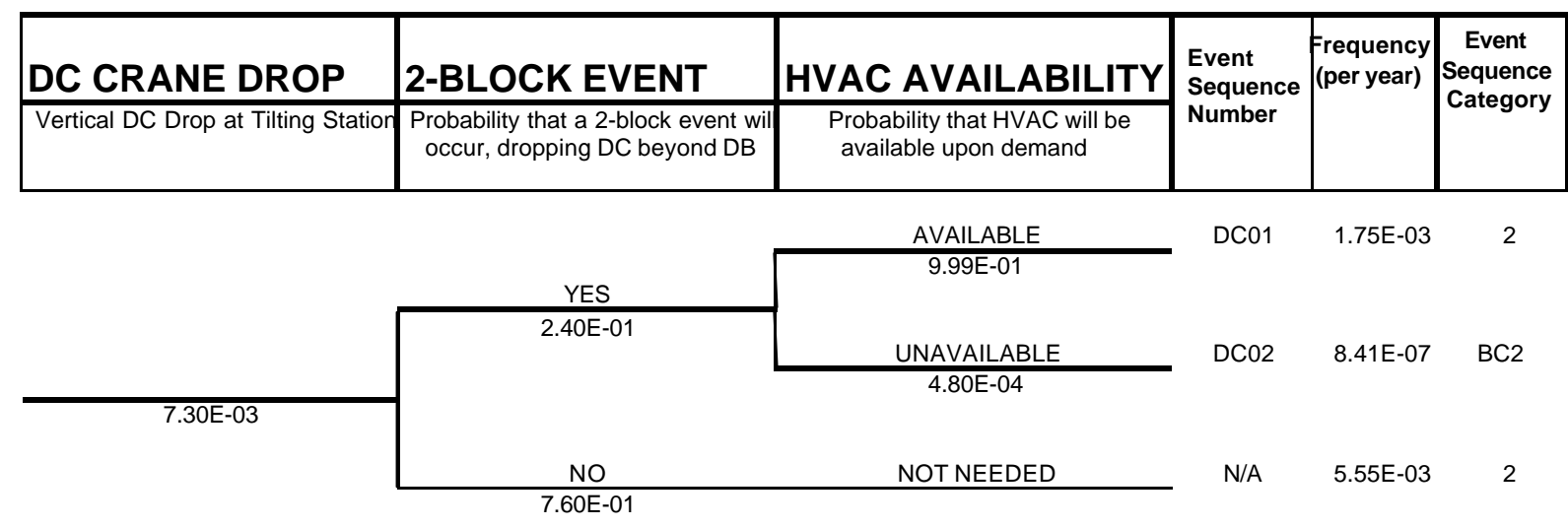

Figure 7-1. Example of a Fork Style Event Tree for a Hypothetical Waste Handling System

The ET in Figure 7-1 includes three events spaced across the top of the figure. The event labels are known as the event headings. This logic diagram depicts a single line for the IE, but allows for (generally) two branches under each of the contributing (or enabling) event headings. The definitions in the event headings are defined to describe a success, as shown for the event heading "HVAC Availability". The upward branch under the heading "HVAC Availability" represents a success (yes or TRUE). The downward branch under each event heading represents a FALSE (no) event (e.g., the HVAC function fails or is not available. But, the convention is sometimes reversed, as shown under the heading 2-Block Event, in which case the upward branch means that the undesired event occurs. The success (or failure) criteria for each safety function must be precisely defined so that the meaning of the "yes" and "no" branches are unambiguous. In binary logic, partial successes or failures are not permitted. Each pathway through the ET, from the IE toward the right, terminates at an "End State" when a fork is encountered in the path. Each event sequence is labeled with a sequence number. The frequency under the heading HVAC Availability and the frequency category (per 10 CFR 63.2 definitions) for each event sequence are shown.

The format for displaying the branches in Figure 7-1 is termed the fork style because the TRUE and FALSE branches both diverge from the incoming path. This style of ET is used by SAPHIRE (Russell et al. 1994). By contrast, Figure 7-2 illustrates an ET in the stair-step style. This style is easier to generate by hand (e.g., using the Microsoft Excel spreadsheet program).

Tracing through the branches in Figure 7-2, a particular path defines an event sequence that ends at an "End State." Each End State represents the severity of the consequences associated with a particular event sequence expressed as the absence of, or the release of, radioactivity to the environment. The following describe the events represented in the figure, and the results:

- $\quad$ The IE is Drop of Waste Form (onto an unyielding surface). The cause of the drop may be a mechanical failure or HFE (human error). As shown in Note 1, the frequency of the 
IE is estimated from generic crane data fr drops-per-lift (14 drops per 1,000,000 lifts) and the handling rate of the hypothetical operation (524 lifts per year). The IE frequency for drops of the waste form is estimated to be $7.3 \times 10^{-3}$ per year.

- The first enabling event heading is titled "Waste Form Maintains Containment." Since the waste form container will be designed to sustain certain handling stresses and impacts (i.e., those within its design basis, most or all of the possible drop heights could be within the design basis of the waste form and no release of radioactivity would occur). Unless there is absolutely no possible physical means for the operation to result in a breach of the waste form, there is a finite probability that a breach may occur. In the example of Figure 7-2. However, it is estimated that there is a rather high probability per lift of 0.25 (i.e., one chance in four) that if a drop occurs, it will exceed the design basis of the waste form. This probability value could represent the experience data from commercial nuclear power plants (NPPs), independent fuel storage facilities, or other cranes where cases of two-blocking may have occurred. Two-blocking is a term used to describe situation in which lifting continues to a maximum allowable travel height until the strain against a dead pull results in a drop from a high point. The probability value of 0.25 per lift would represent all causes of drops, including hardware failure, software failure, and HFEs. It is expected that repository design and operations will not allow such a large conditional probability. In this example, the conditional probability of the NO branch is, therefore, 0.25 and the probability of the YES branch is 0.75 . The sum of probabilities for each branch point under each heading must equal 1.0.

- The second enabling event heading is titled "HVAC/HEPA [heating, ventilation, and airconditioning/high-efficiency particulate air] Filter Available." Since there are two exit paths from the event "Waste Form Maintains Containment," the probability of the HVAC and HEPA filter being available is conditioned on the need, operational conditions, or both, that are present in each path. In the case of the YES branch for "Waste Form Maintains Containment," there is no need for the HVAC/HEPA filter and a single path labeled "Not Needed" is shown under the heading "HVAC/HEPA Filter Available." (For quantification purposes described in the following paragraph, a conditional probability of success of 1.0 is ascribed to dependent events that are not needed. By contrast, a conditional probability of failure of 1.0 is ascribed for dependent or deterministic events that are guaranteed failure.)

In the case of the NO branch exiting event titled "Waste Form Maintains Containment," however, there is a need to mitigate the amount of radioactivity that can escape from the operations building. A reliability analysis (e.g., a fault tree analysis (FTA)) may show that the conditional probability of $5 \times 10^{-4}$ of the HVAC/HEPA filter failing during a certain mission time (for example, 24 hours). The probability that the system is available (i.e., the system does not fail during the 24-hour mission time) is 0.9995 (i.e., $1-5 \times 10^{-4}$ ). The success criteria for the HVAC/HEPA filter branch must include conditions such as: effectively remove 99 percent of particular matter greater than 0.3 microns for a period not less than 24 hours, when called upon. Recall the sum of probabilities at each branch point under each heading must equal 1.0. 
- The structure of the ET now provides the means of identifying various event sequences, the means to quantify the frequency of each sequence, and a means of classifying the degree of damage, or amount of release, associated with each sequence.

The path from the IE, through YES on containment, and NOT NEEDED for the HVAC/HEPA filter is a success path. It is identified in Figure 7-2 as Sequence No. 1. The End States for the example in Figure 7-2 represent the source term (labeled Release Severity) associated with each event sequence. Success paths may be labeled "OK" (as is typical in ETA) or "N/A" (for not applicable). The non-success event sequences result in some releases is described qualitatively in the column labeled Release Severity.

\begin{tabular}{|c|c|c|c|c|c|}
\hline DROP OF WASTE FORM & $\begin{array}{c}\text { WASTE FORM MAINTAINS } \\
\text { CONTAINMENT }\end{array}$ & HVAC/HEPA AVAILABLE & \multirow[b]{2}{*}{$\begin{array}{l}\text { Sequence } \\
\text { Identifier }\end{array}$} & \multirow[b]{2}{*}{$\begin{array}{c}\text { Frequency } \\
\text { (per year) }\end{array}$} & \multirow[b]{2}{*}{$\begin{array}{l}\text { Release } \\
\text { Severity }\end{array}$} \\
\hline $\begin{array}{c}\text { Drop of Waste Form onto } \\
\text { Unyielding Surface }\end{array}$ & $\begin{array}{l}\text { Cond. Probability: drop height within } \\
\text { design basis of Waste Form Container }\end{array}$ & $\begin{array}{l}\text { Probability that HVAC/HEPA is } \\
\text { available upon demand }\end{array}$ & & & \\
\hline Initiating Event ${ }^{(1)}$ & YES $^{(2)}$ & NOT NEEDED & \multirow[t]{2}{*}{1} & \multirow[t]{2}{*}{$5.5 \mathrm{E}-3$} & \multirow[t]{2}{*}{ OK (or N/A) } \\
\hline \multirow[t]{4}{*}{$7.3 \mathrm{E}-03$} & 0.75 & & & & \\
\hline & $\mathrm{NO}^{(3)}$ & YES & \multirow[t]{2}{*}{2} & \multirow[t]{2}{*}{$1.8 \mathrm{E}-3}$. & \multirow[t]{2}{*}{ Low, gases } \\
\hline & 0.25 & 9.99E-01 & & & \\
\hline & & $\frac{\mathrm{NO}}{48 \mathrm{~F}-04}$ & 3 & $8.8 \mathrm{E}-7$ & Moderate \\
\hline
\end{tabular}

Notes:

(1) Initiating event is due to unspecified failure in the lifting crane. From generic data, the frequency

of initiating event is estimated to be 524 lifts/yr $\times 14$ drops/million lifts

(2) Drop from normal height or less than design basis.

(3) Drop exceeds design basis due to 2-block event. Conditional probability of 2-block event is assumed to be 0.25 for this illustration.

(4) Unavailability of HVAC/HEPA derived from fault-tree analysis of HVAC/HEPA system.

Figure 7-2. Example of a Stair-Step Style ET for a Hypothetical Waste Handling System

The frequency (or annual probability of occurrence) is estimated for each event sequence that results in a release of radioactivity or abnormal worker exposure. The framework of the ET is used to display the frequency of the initiator and the conditional probabilities of each enabling event in a sequence. The frequency of each event sequence is calculated as the product of the initiator frequency and the probabilities of all success and failure branches that comprise a given event sequence. The ET permits display of dependencies between the IE and enabling events, dependencies between enabling events, or both. Therefore, if there are sequence-dependent couplings between events, different sequences could have different probability values assigned to any given enabling event.

\subsubsection{Quantification of Event Probabilities and Sequence Frequencies}

The frequencies of IEs for internal hazards are estimated from the annual frequency of each operation multiplied by the probability per opportunity (or per operation) that the IE occurs. For example, the frequency of a canister drop is estimated by the product of the frequency of canister 
lifts (i.e., the number per year) and the conditional probability of dropping the canister per lift. The annual frequencies of each operational step are determined from programmatic information regarding the number of transport casks, spent fuel assemblies, spent fuel canisters, high-level radioactive waste canisters, and waste packages (WPs) that are expected to be processed each year during the preclosure operations.

The conditional probability of each enabling event (usually a failure of some preventive or mitigative feature), such as a drop of a waste form, is estimated from facility-specific data (if available) or generic data for similar operations. Section 7.5 describes the sources and techniques for defining appropriate event probabilities and their uncertainties for use in the PSA. Section 9 describes how uncertainties are applied and propagated. In many cases for the preliminary event sequence screening analyses, conservative probabilities are assumed for the conditional events (e.g., assuming a probability of 1.0 that all fuel rods breach in a drop sequence). This conservatism is warranted in most cases in early screening analyses because complete design criteria and design details are not available.

A quantitative screening analysis applies the 10 CFR 63.2 definition of Category 2 Event Sequence to screen out event sequences whose estimated frequency results in a probability of less than one chance in 10,000 of occurring during the preclosure operations. Such event sequences are termed Beyond Category 2 (BC2) Event Sequences and are screened out (see Section 4, Figure 4-1). Because of uncertainties, the frequency screening is conservatively applied initially so that event sequences within one or two orders of magnitude of the threshold are considered as potential event sequences until additional design or pheno menological data, or detailed analyses including quantitative treatment of uncertainties, demonstrate that the event sequences have frequencies that are $\mathrm{BC} 2$. In the preliminary binning, frequencies of IEs and probabilities of enabling events are conservatively estimated and multiplied to estimate the frequencies of event sequences. The conservatisms are thereby stacked. The screening criterion ensures that no credible event sequences are likely to be screened out prematurely. By contrast, event sequences having frequencies within an order of magnitude of the Category 1 lower limit (i.e., down to $1 \times 10^{-3} / \mathrm{yr}$ ) are considered Category 1 until more refined analysis shows otherwise. The one order of magnitude screening margin is considered adequate and ensures that the complications of aggregating Category 1 consequences will not be unduly cumbersome. As for all PSA activities, the preliminary event sequence binning will be documented according to Project procedures.

In the refined analyses, probability distributions are defined for the IE frequencies and event probabilities to represent uncertainties and are propagated, and described in Section 9, to derive probability distributions for sequence frequencies. The mean value of frequencies of event sequences will be used for binning the results as Category 1 or Category 2 event sequences as described in Section 7.6. The mean value must be less than the frequency of the respective thresholds for Category 1 or 2, as appropriate, to provide the desired level of confidence (see Section 7.6). As for all PSA activities, the refined event sequence binning will be documented according to Project procedures. The results of the refined binning will provide the bases for preparing the LA. 


\subsubsection{Alternative Forms and Analysis of Event Trees}

It is not feasible to list, by inspection, the important event sequences for a complex nuclear power plant or chemical facility. The ET format provides a systematic and orderly approach to understand and accommodate the many factors that could influence the course of potential accidents. For simpler operations, such as many of the repository operations, the ET display may not be necessary; however, it does provide a powerful and convenient communication tool.

As described in the US. Nuclear Regulatory Commission (NRC) PRA Procedures Guide, A Guide to the Performance of Probabilistic Risk Assessments for Nuclear Power Plants (NRC 1983), there are two main analytical formats for using ET and fault trees (FTs) in accident sequence delineation: small ET/large FT versus large ET/small FT. The small ET/large FT technique is recommended for virtually all of the PSA and is described in the remainder of this section.

Small ET quantification employs the use of FT linking. In this technique individual FTs that represent the respective event headings in the ET are linked through a sequence FT. Each of the function or system FTs is modeled to represent various basic events and dependencies on support systems. Evaluation of interdependencies between the heading events, such as common support systems or common HAs, is accommodated via the Boolean algebra in the analysis of the sequence FT.

In the large ET method, by contrast, all of the dependencies and system boundary conditions are explicitly represented in the many headings and branches of the ET. The supporting FTs are small because they represent very specific conditions on the systems or HAs that are represented in the ET headings. In some cases, it is not necessary to use an FT per se, and tabulated probabilities suffice.

There is considerable latitude in the definition of event headings, even in the small ET approach. The same tree may use headings that represent functions, systems, components, and HAs. ET headings may also be used to establish conditions that could ameliorate or exacerbate potential sequences (e.g., the presence of an extreme ambient temperature or the presence of an oversized and overweight load on a lifting device).

ETA can be used in two types of applications to describe potential accident sequence evolution:

1. The first application of ETA is described in the PRA Procedures Guide (NRC 1983) for analyzing potential alternative responses of a complex system to a given IE. This method is sometimes referred to as a pre-incident (or pre-accident) analysis because it models sequences up to the point of having undesired damage states or releases (see AIChE 1989). In this application, a particular IE is postulated and an ET is constructed by listing across the top of the ET the various event possibilities that represent the safety functions or systems that are necessary to prevent or mitigate the potential consequences following the IE. For example, in a typical nuclear reactor ET, the IE is a loss of coolant accident and the functions listed across the top of ET would include reactor subcritical, containment overpressurization, and core cooling. 
This type of application is appropriate for dealing with repository operational event sequences. This approach is appropriate for either initiators from internal or external events (including natural phenomena) that are directly associated with the repository operations (e.g., random failures of lifting devices) or those events that are tightly coupled to those operations (e.g., earthquake directly shakes the lifting device).

2. The second application of an ETA is used to examine how events and conditions that could exacerbate a potential accident (see AIChE 1989). Such ETs are sometimes termed post-incident (or post-accident) analyses to identify incident outcomes. For example, an ET developed for a large leakage of pressurized flammable material from an isolated liquid propane gas storage tank might include event headings such as immediate ignition, delayed ignition, flash fire, ignited jet point at liquid propane gas tank, and wind to populated area. Similarly, phenomenological ETs are used to describe the possible modes of containment behavior in the post-core-damage phase of nuclear reactor plants.

This type of application is appropriate for dealing with potential event sequences initiated by events originating offsite or outside of the repository operational areas such as range fires, toxic releases from transportation accidents, military or industrial hazards, or aircraft crashes that are not tightly coupled to the repository operational functions. The first part of the ETA involves the probability that a harmful agent interacts with the facility or repository operational equipment.

The remaining discussion applies the pre-incident style of ETs as the primary application in the PSA.

The placement of event headings across the top of the ET can represent either the time sequence in which the events occur, proceeding left to right, or some other logical order reflecting operational dependencies (or conditions, as noted previously). Initially, the analyst may order the event headings by temporal, functional, or hardware relationships, but may re-order the headings to determine the best way to simplify the analysis or to clarify the presentation. Typically, a temporal ordering is used initially based on a process flow diagram, an operational description, or a pre-analysis such as the use of an Event Sequence Diagram (see Section 10.1). However, functional or hardware dependencies should be considered, as in cases in which a given failure mode may imply the guaranteed failure of one or more other events in the headings.

For a given IE, the analyst must identify the safety functions that must be performed to control the sources of energy and radiation hazards in the facility. Such safety functions can be provided by active systems through automatic or manual actuation, by passive systems that provide barriers or containment, or from the natural or inherent feedback in the facility. As noted, the success criteria for each function must be unambiguously defined.

Starting with the IE, the analyst must postulate the success or failure of each function or system in the context of boundary conditions established by the states of the functions or systems in the ET headings. As noted, an event heading may connote the presence or absence of an enabling condition (e.g., temperature exceeds normal operating range or operator by-passes interlock). When the analyst considers a succeeding event, such as crane prevents lift beyond prescribed height, the probability of failure may depend on the operating temperature (i.e., one probability 
of failure based on random hardware failure rate or human error probability (HEP) is used when temperatures are normal, but perhaps a higher failure rate or HEP is assigned when the temperature is abnormally high). This method models the dependency on prior conditions. For conservatism an ET may be constructed such that the abnormal temperature guarantees failure (i.e., has a probability of 1.0 that the crane lift height exceeds the limit). (Section 10.1 provides examples of ET having dependent failures in the context of seismic initiators.)

\subsubsection{Details of Approach}

\subsubsection{Constructing an Event Tree}

Figure 7-3 summarizes the tasks in required to construct and evaluate an ET. The steps are described in Section 7.1.4.2.

ETs can be constructed at either a functional level or a system level.

Functional level ETs are developed at a relatively high level and serve to identify and order the safety functions according to the mitigating requirements of a given IE. The functional ET can also be used to depict contingent events that may result only if a precursor or conditioning event occurs (e.g., fire occurs after waste form is dropped). Functional ETs are generally simple or short, but each event heading in the functional ET can be supported by a complex FT. FT linking is used to quantify the sequence frequencies. Dependencies between functions, or their supporting systems, are flushed out when the minimal cutsets are determined (see Section 7.2) for the sequence FT.

If there are potential dependencies between the functional event headings (e.g., two or more functional events depend on the same source of electrical power or the same human action [HA]), then a system level ET may be required to understand the dependencies. A complete system level ET that depicts all of the conditional probabilities and dependencies can be very complex or long.

One or more functional ETs should be developed for each credible IE that has been selected for analysis from the respective Internal or External Events Hazards Analysis. The ET is a primary tool for defining potential accident sequences. As noted, for some complex operations it may be necessary to draw an intermediate diagram known as an Event Sequence Diagram (see Section 10.1) to help simplify the ET.

As noted in Figure 7-3, before starting an ET, the analyst must understand the system. This familiarization should be done with the help of personnel from design and operations, radiological consequence analysts, a radiation protection program, and safety-specific analyses (e.g., fire hazards, criticality). The description and results of the Internal (or External) Events Hazards Analysis are a starting place. When design or operational details are available, the functional ET should be developed accordingly to refine the discussion of potential events and consequences that may be speculative in the hazards analysis.

If necessary to understand the operations and how potential accidents could evolve, the ET analyst must acquire or draw a process flow diagram that shows each operation that interacts 
with the waste form (e.g., lifts, moves, lowers). An analysis of failure modes and effects (FMEA), performed by design personnel may aid in understanding potential mishaps.

Become familiar with design and operation of the system.Using results of hazards analysis as guide. Identify safety functions and features that mitigate identified hazards. If necessary, develop functional diagrams and/or process flow diagrams to help identify where initiating events may occur and how event sequences may develop.

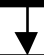

1. Identify Initiating Event. Identify all initiating events for a given system. A separate event tree will be developed for each initiating event. Several operations in a given system may admit an initiating event that be a potential hazard to a waste form. A list of all specific initiating events is generated. The hazards analysis will have provided a list of initiating events for each operational area.

\section{Identify Safety functions and Conditioning Factors (Event Tree Headings)}

Event tree headings are defined primarily to represent the safety features that have to succeed or fail to propagate an event sequence. Event tree heading may also define conditioning events such as the presence of extreme temperature, fire, or human action that could affect the need for, or conditional probability of, a subsequent event in a sequence. Phrase event headings as "success" of safety feature or as presence of "favorable" conditioning events or human actions.

\section{Construct/Edit Event Tree}

Starting with initiating event, construct initial event tree by listing event headings from left to right. Generally, headings are listed in chronological order. Conditioning events may be inserted where appropriate. Draw branches by connecting nodes under each event heading. Account for dependence on preceding events and conditions. After examination of results after Steps 4 or 5 , it may be possible or preferable to edit tree by rearranging order of headings, deleting headings, or adding new headings, as appropriate.

\section{Classify Outcomes, System States, or Consequences of Each Sequence \\ The end states represent conditions that affect the consequences associated with a given sequence. Categories may be qualitative, but generally are defined by quantitative measures of radioactivity available for release. The consequence classification establishes initial conditions for consequence analyses. The outcome of each sequence is defined by consideration of the various successes and failures of safety functions (or conditioning events) occur between the initiating event and the end point.}

\section{Quantify Initiating Event Frequency and Probabilities of Branches}

Estimate frequency of each initiating event from the annual frequency of each operation times the conditional probability of the initiating event per operation. The conditional probability of each branch under a heading in an event tree (other than the initiating event) corresponds to a probability of the outcome (i.e., the event is TRUE or FALSE) that is conditional on the occurrence of the preceding event. The sum of the probabilities of the two branches of each limb must total to 1.0. Usually the probability of the TRUE (or YES) branch is close to 1.0 by itself since it is the expected successful availability of a safety function or a nominal environment. The FALSE (o NO) branches are usually low probability events (small fractions). The probability of the failure of a safety feature an undesirable human action, or a less desirable condition is estimated from generic data for similar operations o from experience data if available. Total dependencies such as "guaranteed failure," "guaranteed success," and "not needed" are assigned conditional probabilities of 1.0 .

\section{Quantify Sequence Frequencies}

For each sequence defined by a pathway from initiating event to end state in the event tree, quantify the sequence frequency by multiplying the initiating frequency by the conditional probabilities of all events in a sequence.

\section{Review Results}

Review the results of the event tree analysis to ensure that the outcomes are physically possible, accurately defined and quantified, and complete. Review team includes event tree analyst and cognitive personnel (e.g., from design, operations, radiological consequence analysts, radiation protection program, and safety-specific areas.)

Figure 7-3. Steps in Event Tree Construction 
If necessary, an Event Sequence Diagram should be completed (see Section 10.1) to indicate success paths in the operations and how various event sequences may develop:

- $\quad$ For each operation in the system whose malfunction could impact the waste form, define an IE (e.g., crane drops waste form; shield door closes on waste form).

- From an inspection of the flow diagram, system layout, event sequence diagram, and FMEA (if available), list and order the subsequent events that could possibly happen after the IE has occurred. Since the event sequences that lead to release of radioactive material to the environment are the events of importance to the repository PSA, the analyst must consider all possibilities. Subsequent screening and analyses will filter out impossible, not credible, or insignificant events. Some events that may come to play in one or more sequences at the repository include:

- Waste form containment is breached

- $\quad$ Fire occurs concurrently

- Waste form releases mass of radioactive material (amount may differ with or without concurrent fire).

The graphical development of the ET may be constructed by hand (using pencil and paper), as a spreadsheet program (e.g., Microsoft Excel), or semi-automatically using special-purpose software such as a probabilistic risk analysis (PRA) workstation (e.g., SAPHIRE). Pencil and paper are recommended for initial conceptualization and ET simplification. A more refined ET can be constructed in a spreadsheet format that can also be used for quantifying sequences involving simple or moderately complex cases. If FT linking is to be used, then the final ET has to be constructed and quantified using a computer program such as SAPHIRE (Russel et al. 1994).

The following section presents more detailed guidance on the development of an ET.

\subsubsection{Steps in ET Construction}

\subsection{Identify the Initiating Event}

The IE for each ET should be identified from a hazards analysis as an event that has the possibility of leading to an exposure to, or release of, radioactivity. In addition, the event must have been quantitatively screened in (found credible) in the hazards analysis. The IE will usually be an internal event that can impact energy or damage a waste form (e.g., crane drops spent nuclear fuel (SNF) canister). The IE could also be a fire (external or internal) or another external event (man-made or natural phenomena) such as loss of offsite power, aircraft crashes into waste handling building, or earthquake at waste handling building site.

The external hazards analysis will have generated a list of general categories of IEs that are applicable to a given repository operations area. The list of IEs will be as complete as possible within the level of design detail available at the time that the hazards analysis is performed. 
In general, it is necessary at the outset to define the specific purpose of the ET analysis since concerns associated with the possible outcomes (e.g., public doses versus worker exposures) will influence the event headings, success criteria, and structure of the tree.

\subsection{Identify Safety Functions and Conditioning Factors (ET Headings)}

For each particular IE that is postulated to occur in a given operational area, an ET is constructed by listing the event headings across the top of the page. Event headings primarily represent the various event possibilities that represent the safety functions or systems that are necessary to mitigate the potential consequences following the IE. Such event headings may represent passive barriers, automatic safety systems, or alarms to alert operators. Thus, in the case of crane drops SNF canister, maintaining the integrity of the canister provides the safety function of containment of radioactivity. The ET heading could be canister is not breached (conditional on being dropped). Another safety function could be HVAC/HEPA filters exhaust air.

However, the headings may also represent conditioning events such as "building containment intact," which, when placed ahead (to the left) of "HVAC/HEPA filters exhaust air," provide a structure for conditioning the probability of failure of "HVAC/HEPA filters exhaust air." That is, if the event titled "building containment intact" is false (NO branch), then the conditional probability is 1.0 (guaranteed failure) that "HVAC/HEPA filters exhaust air" is false. Otherwise, when "building containment intact" is true (YES branch), then the probability that "HVAC/HEPA filters exhaust air" is false depends on the reliability of the HVAC/HEPA filter system. Other conditioning events may represent environmental factors such as temperature anomalies caused by an upstream event or consequential fire.

In some systems there may be a mutual dependence of all active safety functions on a single support active system, such as an onsite power supply. The ET for such a situation should use the conditioning event "electric power available" early in the event headings. The FALSE branch would then result in a series of guaranteed failures and a simplified ET. Otherwise, the vulnerability posed by the power supply may not be realized until after the FT linking and Boolean reduction is performed. If the safety functions and support systems have been designated a priori to be highly-reliable, single-failure proof, or both, then the event heading titled "electric power available" need not be included in the ET since the combinations of dependent failures may be too complex and best handled through FT linking.

The event heading may also represent a human interaction such as an explicit kind of conditioning event such as "operator installs proper lifting yoke" or an operational condition such as "operator maintains air seals on building containment."

\subsection{Construct or Edit the Event Tree}

An ET is constructed conventionally left to right, beginning with the IE. Under each event heading, one or more sequence branch points (or nodes) are included to represent the two alternative pathways. Some ETs may use multiple branches, but multiple branches are not discussed here. The branch points may be drawn with two-pronged forks at each node, as illustrated in Figure 7-1, or as stair-steps, as illustrated in Figure 7-2. 
The labels for the event headings are conventionally phrased such that an upward branch in the fork style (the convention to be used herein with the SAPHIRE computer software) represents that the heading is TRUE (branch labeled YES) indicates that the function is successful. For conditioning events, the upward breach represents (usually) the more favorable condition, tending toward successful mitigation or reduced consequences. The downward branch (labeled NO) represents the complementary situation (and probability) that is defined in the event heading, thus representing failure of the function or presence of the less desirable condition.

Although the example shown in Figure 7-1 was created with Microsoft Excel, the fork style is difficult to create by hand because changes and branching requires much re-drawing and re-positioning of lines on a page. However, fork-style ETs are very easily created and edited with a computer program such as SAPHIRE.

In the stair-step format (which is easy to implement in the Microsoft Excel spreadsheet program), the YES paths are represented by horizontal lines and the NO paths branch downward (see Figure 7-2).

One advantage of the fork style is the clearer depiction of dependent events (e.g., "guaranteed failure" or "not needed" are shown as horizontal paths that pass through a node without branching up or down). By contrast, in the stair-step style, dependent events resemble success branches unless they are labeled as "guaranteed failure" or "not needed," or are depicted by a dotted line rather than a solid line.

In some instances, the analyst may restructure the headings of the ET to better represent dependencies on conditional or precursor events, or to simplify the ET. This process may occur iteratively after Step 4 in Figure 7-3 is performed.

If the outcomes (i.e., system states, or amounts of material released) of several sequences are the same or nearly the same, some event headings may be seen to be irrelevant to understanding and quantifying the risk. Even though the headings may introduce branching and extra sequences that could occur, the overall frequency of an exposure or release of a given magnitude would be the sum over these sequences. If some of the headings are deleted or subsumed in other headings, a simpler, but sufficient representation of the risk is achieved (see examples in Section 7.1.5).

\subsection{Classify the Outcomes, System States, or Consequences of Each Sequence}

The endpoint of each event sequence represents a potential state of the system. In ETs for nuclear reactor plants, the end points of the system analysis (i.e., the level 1 PRA) are called plant damage states. For the repository PSA, the endpoints will be termed system states or consequence categories. The end states represent conditions that affect the consequences associated with a given sequence.

For example, for an ET that addresses potential releases to the public, categories of consequences can be very qualitative in preliminary or scoping analyses (e.g., no release, small release - gases only, and small release - gases and particulates). Alternatively, the qualitative consequence categories can be more explicitly tied to the material at risk (e.g., no release, one fuel assembly 
breached, and basket of 8 fuel assemblies breached). The end states that result in no consequences of interest are usually labeled $\mathrm{OK}$ as shorthand.

The outcome of each sequence is defined by consideration of the various successes and failures of safety functions (or conditioning events) that must occur between the IE and the end point. For example, in a sequence where one spent fuel assembly has dropped and breached and the conditioning event "building containment intact" is FALSE, the release of radioactivity (gases, volatiles, and particulates) can escape to the atmosphere unimpeded and without the benefit of being filtered or released from an elevated stack. In a different sequence in which one spent fuel assembly has dropped and breached, the conditioning event "building containment intact" is TRUE and the "HVAC/HEPA filters exhaust air" is TRUE, so the release of radionuclides is limited to gases.

The consequence classification establishes the conditions for the consequence analyses described in Section 8. The source terms, leak path factors, and atmospheric dispersion factors, including credit for stack height (appropriate to the consequence category) are used in the consequence analyses.

\subsection{Quantify Initiating Event Frequency and Probabilities of Branches}

The frequencies of IEs for internal hazards are estimated from the product of the annual frequency of each operation and the conditional probability of the IE per operation. For example, the frequency of a canister drop is estimated by the product of the freque ncy of canister lifts (i.e., the number per year) and the conditional probability of dropping the canister per lift. The annual frequencies of each operational step are determined from programmatic information that quantifies the number of transport casks, spent fuel assemblies, spent fuel canisters, high-level radioactive waste canisters, and WPs that are expected to be processed each year during the preclosure operations. Per 10 CFR 63.112, the PSA will assume maximum throughput rate in these analyses.

Unless the ET is to be quantified using FT linking, branch point probabilities must be specified directly in the ET to aid in sequence quantification (see Step 6 in Figure 7-3).

The conditional probability of each enabling event (usually a failure of some preventive or mitigative feature such as a drop of a waste form) is estimated from the failure rates and repair times applicable to the event represented in the heading. Since little, or no, repository-specific data on equipment reliability is available, the ET and FT analyses will use generic data for similar operations. In many cases for the preliminary event sequence screening analyses, conservative probabilities are assumed for the conditional events (e.g., assuming a probability of 1.0 that all fuel rods breach in a drop sequence). This conservatism may be warranted in the early screening process because design criteria or design details are not in place.

Each branch under a heading in an ET (other than the IE) corresponds to a probability of the outcome (i.e., the event is TRUE or FALSE) that is conditional on the occurrence of the preceding event. The sum of the probabilities of the branches under each event heading in a given event sequence must total to 1.0. Usually the probability of the YES (or TRUE) branch is close to 1.0 by itself since it is expected to be available to successfully perform a safety function 
or to ensure a nominal operating environment. The FALSE (or NO) branches are usually low probability events (small fractions).

The branch-point probability values may be developed from databases of experience data) from qualified estimates of similar systems or events (see Section 7.5), from human reliability analysis (HRA, as described in Section 7.3), or from FTA as described in Section 7.2. If the probabilities are independent of the preceding event, the application of data or analyses is relatively straightforward. If the probabilities are dependent (conditional) on the outcome of the preceding event, then appropriate adjustments must be made. If experience data or estimates from similar systems are available for the specific condition, the dependency analysis is straightforward. Otherwise, it may be necessary for the analyst to make reasoned estimates depending on previous events. In such cases, the analyst must provide justification for the adjustment. Even human failure probabilities may be dependent on outcomes of previous events. For example, in the aftermath of an earthquake, repository operators may experience extra emotional stress that may lead to a higher probability of human error (see Section 7.3).

Some event branching may represent split fractions of highly likely events (e.g., 0.5 and 0.5 for equally likely conditions or 0.75 and 0.25 for cases where one branch is more likely than the other branch). For example, a conditioning event might represent the mix of waste forms being processed that possess different source term characteristics. In this example, 75 percent of the canisters may contain intact spent fuel assemblies and 25 percent of the canisters may contain fuel rod segments. Depending on what these conditions imply, the event heading "canister contains intact assemblies" might be found late or early in the tree. If the condition affects only the final consequence, then the event would be placed late and the number of release sequences would double. If the condition could affect the likelihood of a breach given a drop (e.g., the canisters containing fuel rod segments may be designed to withstand all credible drops without a breach), then the event heading would be placed earlier in the tree.

\subsection{Quantify Sequence Frequencies}

The frequency of each sequence on the ET is determined by the multiplication of the frequency of the IE times all of the conditional probabilities appearing in the sequence of events. For example, if the frequency of the IE is $2 \times 10^{-2}$ per year, the conditional probability of breach is 0.01, and the conditional probability of the HVAC/HEPA filter being unavailable is 0.001 , the frequency of a sequence involving the release of gases, volatiles, and particulates is $2 \times 10^{-7}$ per year (i.e., $\left.2 \times 10^{-2} \times 0.01 \times 0.001\right)$. The frequency of a sequence involving a drop, a breach, and a release of gases and volatiles through the HVAC/HEPA filter is event is $1.99 \times 10^{-4}$ per year (i.e., $\left.2 \times 10^{-2} \times 0.01 \times 0.999\right)$. The frequency of a sequence involving a drop, no breach, and, therefore, no release is $1.98 \times 10^{-2}$ per year (i.e., $2 \times 10^{-2} \times 0.99 \times 1.00$ ). Note that the sum of the frequencies of all of the event sequences equals the IE frequency:

$$
2 \times 10^{-7}+1.99 \times 10^{-4}+1.98 \times 10^{-2}=2 \times 10^{-2}
$$

Event sequence frequencies may be calculated by hand using a calculator or with spreadsheet formulas (e.g., the Microsoft Excel spreadsheet program). When ET event headings are represented as top events in fault trees, then FT linking is used to quantify event sequences. 
A sequence FT is created for each event heading by linking all of the event-heading FTs into a single FT. The sequence frequency is quantified by solving the sequence FT using a computer program like SAPHIRE. The Boolean algebra routine interval to the code (e.g. SAPHIRE) reduces a complex sequence expression to a table of minimal cutsets (see Section 7.2). Any dependencies between basic events modeled in the respective FTs for the event headings are revealed in the minimal cutsets. Because the ETs and systems used in the MGR operations are not complex, FT linking is unlikely to be necessary in the repository PSA, particularly in the LA for CA. When more design details are available, FT linking may be necessary to quantify event sequences and to support other analyses such as importance or sensitivity studies.

The results of the event sequence frequency analysis are used to classify event sequences as Category 1, Category 2, or BC2 Event Sequences (see Section 7.6). The ET page layout can include a column that indicates the category of each event sequence in the tree.

\subsection{Review of Results}

The ET analyst and cognitive associates should review the results of the analysis to ensure that the outcomes are physically possible, accurately defined and quantified, and complete (this is an ideal, but omissions should be noted even if done deliberately for modeling purposes). As with FTA, poor input data or erroneous information will lead to wrong and usually worthless ETs. The review team should include an ET analyst and cognizant personnel (e.g., personnel from design, operations, radiological consequence analysis, radiation protection programs, and safety-specific areas).

\subsubsection{Examples of Applications of Event Tree Analysis}

This section presents a series of ETs that were developed for instructional purposes. The three example ETs described each involve a hypothetical uncontrolled descent of a WP transporter train. The example variations between the three trees are constructed to illustrate one or more of the factors to be considered.

The hypothetical situation involves the transport of a WP from the surface facilities to the subsurface repository. The WP is enclosed in a shielded transporter car and hauled by one or more locomotives. The locomotives and transporter car are equipped with one or more brake systems, control and actuation systems that monitor and control the speed, and automatic and manual actuation systems for the brakes. During a trip down the North Ramp, an uncontrolled descent is initiated.

For illustration purposes, cases are illustrated for three different IEs. In the first case an undefined random failure in a mechanical, electrical, electronic, or software system causes the initiation of the event. In the second instance, an on-board fire on the controlling locomotive is assumed to result in an uncontrolled descent. In the third case, a HFE is assumed to initiate the sequence of events leading to an uncontrolled descent.

\subsubsection{ET Example 1: Random Event Initiates Uncontrolled Descent}

Figure 7-4 illustrates how a hypothetical sequence of events, initiated by a random failure, can lead to or exacerbate the release of radioactive material. The event headings shown in the figure 
are essentially self-explanatory, but are elaborated as necessary. Recall that definitions of event headings must include unambiguous success criteria.

\subsection{Event Tree Construction}

The event headings in Figure 7-4 are arranged essentially in chronological order. They represent safety functions and conditioning events, as will be explained below. For completeness, one or more of the event headings could be defined to represent the successful operation of the mechanical, air, or hydraulic equipment of the brake system(s). For simplicity, it is assumed that these failure modes are included in the two headings that involve stopping the train. Alternatively, it may have been shown in a preliminary scoping analysis that the probability of a brake system failure is very small and only contributes to an event sequence that is not credible. Therefore, the revised tree is simplified.

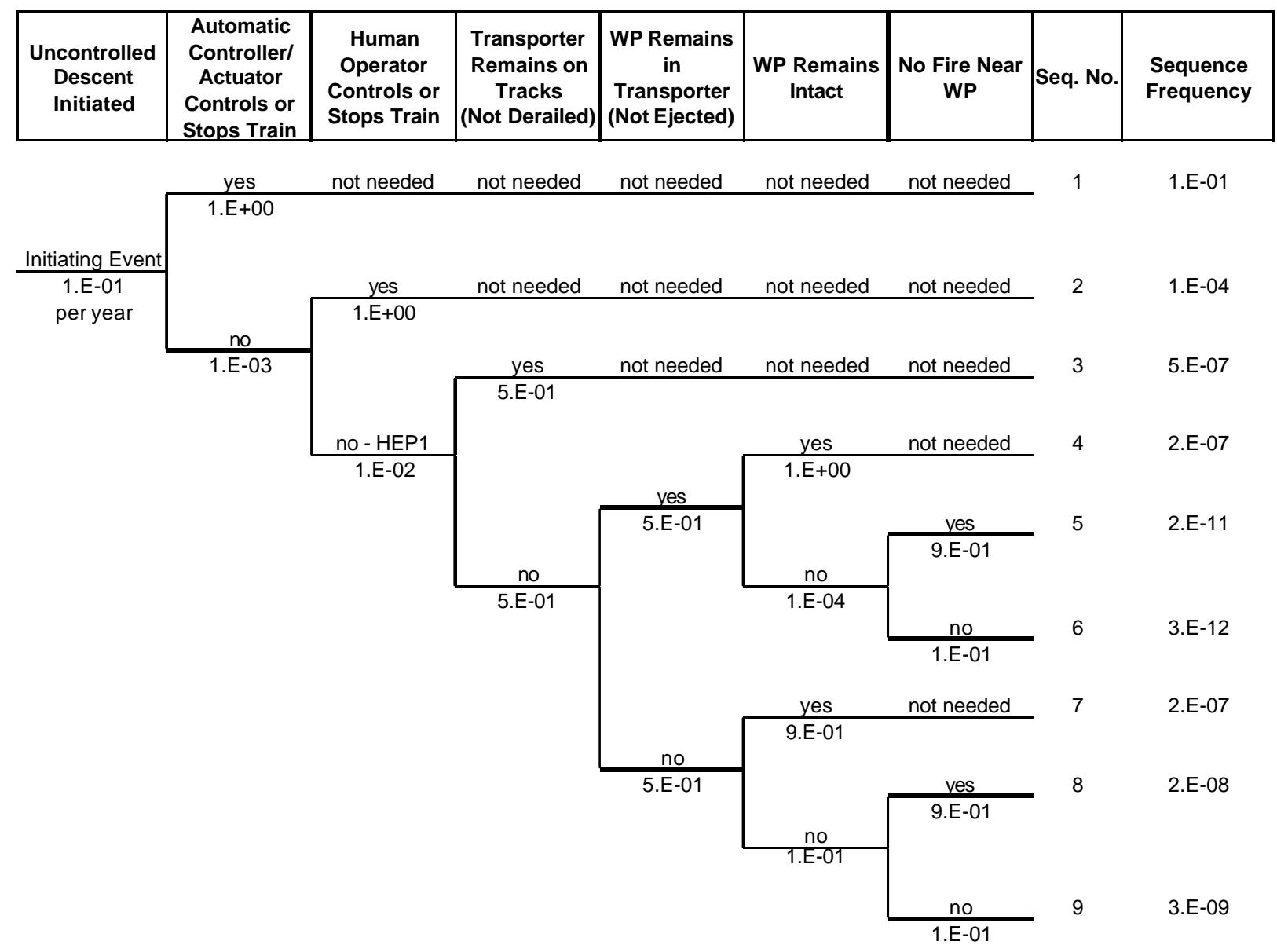

Figure 7-4. ET for Hypothetical Uncontrolled Descent Due to Random-Failure Initiator

Uncontrolled Descent Initiated-A random failure in a mechanical, electrical, electronic, or software system on-board the controlling locomotive causes the train to speed up.

Automatic Controller/Actuator Controls or Stops Train-In this example it is assumed that the initiating failure has not disabled the automatic control system that monitors 
speed and sends signals to slow down or to apply emergency brakes when needed. This heading represents a safety function.

Human Operator Controls or Stops Train-In this example, it is assumed that the initiating failure has not disabled the manual control system that permits a human operator, as a backup to the automatic system, to decrease the train speed or to apply emergency brakes. This heading represents a safety function.

Transporter Remains on Tracks (not derailed)-There is a curve in the track at the bottom of the North Ramp. If the runaway train attains sufficient speed, it will be expected to derail and hit the tunnel walls. If the transporter train remains on the track (even at high speed) it will eventually slow down and will not experience any hard impacts. This heading represents a conditioning event.

WP Remains in Transporter (not ejected)-The WP will be restrained inside the transporter. In the event of a derailment during the runaway, the impact on the WP is expected to be reduced by energy absorption by the transporter car. If the WP is ejected, however, it could impinge on ground support structures, track rails, rock protrusions, and other items, and all of the kinetic energy would be imparted to the WP. This heading represents a conditioning event. The response to this heading affects the probability of breaching the WP. Although not developed in this example, the response to this heading could also affect the assumed source term if the number of fuel rods breached is correlated to the impact energy.

WP Remains Intact-This is the key event heading with respect to a radioactive release. If the WP is not breached, then it is assumed that no radioactivity is released. Otherwise, depending on the degree of breaching, varying amounts of radioactivity may be released.

The WP is designed to withstand credible impacts. The repository safety strategy is to demonstrate that impact on a WP from an uncontrolled transporter is not credible. The event analysis will provide support to that conclusion.

Nevertheless, it is possible for the WP involved in the derailment to have a manufacturing defect or out-of-specification welded lid seal. At some probability, such defective WPs may breach in an impact that is within the design basis of the WP.

No Fire Near WP-This heading is included in this example to illustrate the modeling of a post-accident environment that could exacerbate consequences. In the example the heading is applied only to sequences where the WP is already breached. The presence of a fire near the WP might increase the fraction of radionuclides that are released from the spent fuel rods inside the breached WP. The source of the fire is not defined in this example, but could result from an electrical fire initiated when the transporter crashes into an electrical supply cabinet. In other ET development involving intense fires, it may be appropriate to order the fire event ahead of the WP Remains Intact event to enable the fire to be a cause of the WP breach as well as a mechanism for exacerbating the release. 
The ET is constructed with consideration given to dependencies and conditioning events. The construction leads to the defining of the nine sequences, as labeled in "Seq. No." in Figure 7-4. The sequence numbers are used to describe the bases for the construction.

- $\quad$ Sequence 1-The automatic system responds correctly to the IE. None of the other event headings come into play and are labeled "not needed." There is no radioactive material released in this sequence.

- $\quad$ Sequence 2-After the automatic system fails to respond to the IE, the train operator correctly intervenes. None of the remaining event headings come into play in mitigating the event sequence and are labeled "not needed." There is no radioactive material released in this sequence.

- $\quad$ Sequence 3-After the automatic system and the train operator fail to respond to the IE, the train descends uncontrolled to the bottom of the North Ramp without derailing. Because no impact results, the remaining event headings do not come into play and are labeled "not needed." There is no radioactive material released in this sequence.

- Sequence 4-The transporter derails and impacts the tunnel walls. The WP remains inside the transporter and is not breached. The fire issue is not relevant (see the previous discussion) and is labeled "not needed." There is no radioactive material released in this sequence.

- $\quad$ Sequences 5 and 6-The transporter derails and impacts the tunnel walls. The WP remains inside the transporter and is breached. In Sequence 5 no fire is present; Sequence 6 includes a fire. Both sequences result in a release. Because of the fire, the amount of radioactive material released in Sequence 6 may be greater than the amount released in Sequence 5.

- $\quad$ Sequence 7-The transporter derails and impacts the tunnel walls. The WP is ejected from the transporter and may impact walls, rails, or other items, but is not breached. The fire issue is not relevant (see the previous discussion) and is labeled "not needed." There is no radioactive material released in this sequence.

- $\quad$ Sequences 8 and 9-The transporter derails and impacts the tunnel walls. The WP is ejected from the transporter and may impact walls, rails, or other items and is breached. In Sequence 8 no fire is present; Sequence 9 includes a fire. Both sequences result in a release of radioactive material. Because of the fire, the amount of radioactive material released in Sequence 9 may be greater than the amount released in Sequence 8.

After constructing the ET, the analyst proceeds with sequence frequency quantification, as described in the following section. 


\subsection{Event Tree Quantification}

For illustration purposes arbitrary values are assigned to the IE and the branch points in Figure 7-4. Rationale statements are provided for the parameters used in the example.

The values provided in the Figure use scientific notation with one significant digit. Therefore, the probabilities of most of the success branches are shown as 1.0. The value of each success branch is actually the complement of the probability of the failure branch (i.e., if $\mathrm{p}$ (failure) $=1 \times$ $10^{-3}$, then the $\mathrm{p}($ success $)=[1-\mathrm{p}($ failure $)]=\left[1-\left(1 \times 10^{-3}\right)\right]=9.99 \times 10^{-1}$ [which is rounded to $1.0])$.

If more than one branch node appears under a given event heading because they appear in different event sequences, then the probabilities of the event may be different in the respective branches to reflect dependencies on events as conditions occurring earlier in the sequence. Specific instances are described in the following paragraphs.

Uncontrolled Descent Initiated-A frequency of $1 \times 10^{-1}$ per year is assigned. The emplacement rate for WPs is assumed to be approximately 500 per year. Based on actuarial data (if available) or analysis (such as FT), if it is determined that an uncontrolled descent could be initiated 2 times in 10,000 trips; the probability would be 2 $\times 10^{-4}$ per demand. Therefore, the assumed frequency is calculated as the product of 500 per year and $2 \times 10^{-4}$ per demand, or $1 \times 10^{-1}$ per year.

Automatic Controller/Actuator Controls or Stops Train-Based on actuarial data (if available) or analysis (such as FTA), it is determined that the failure rate of the control system is $1 \times 10^{-3}$. The complementary probability is $\left(1-1 \times 10^{-3}\right)=9.99 \times 10^{-1}$ (which is rounded to $1 \times 10^{0}$ ).

Human Operator Controls or Stops Train-Using HRA (see Section 7.3) that take into consideration the situational factors (performance shaping factors) that account for such factors as available instrumentation, control layout, and time pressure on the human, the HEP, labeled HEP1, is estimated to be $1 \times 10^{-2}$ per demand. The complementary probability is $\left(1-1 \times 10^{-2}\right)=9.9 \times 10^{-1}$ (which is rounded to $\left.1 \times 10^{0}\right)$.

Transporter Remains on Tracks (not derailed)-Calculations (hypothetical) indicate that the train may achieve the critical speed for derailing near the middle of the curve if the runaway starts more than halfway up the ramp. Therefore, a probability of derailment of 0.5 is assumed.

The complementary probability is $(1-0.5)=0.5$.

WP Remains in Transporter (not ejected)-No analyses are available for the response of the transporter car and WP to a crash into a tunnel wall. Therefore, it is assumed that there is equal chance of success and failure. Therefore, a probability of WP ejection of 0.5 is assumed and a probability of derailment of 0.5 is assumed. The complementary probability is $(1-0.5)=0.5$. 
WP Remains Intact-The WP is designed to withstand credible impacts. It is possible for the WP involved in the derailment to have a manufacturing defect or out-ofspecification welded lid seal. These weak WPs may breach in an impact that is within the WP design basis. It is assumed that the probability of WP breach is correlated with the relative impacts of the WP ejection and non-ejection cases.

The probability of WP breach when the WP remains in the transporter is assumed to be $1 \times 10^{-4}$ per demand. The complementary probability is $\left(1-1 \times 10^{-4}\right)=9.999 \times 10^{-1}$ (which is rounded to $1 \times 10^{0}$ ).

The probability of WP breach when the WP is ejected from the transporter is assumed to be $1 \times 10^{-1}$ per demand. The complementary probability is $\left(1-1 \times 10^{-1}\right)=9.9 \times 10^{-1}$ (which is rounded to $1 \times 10^{0}$ ).

No Fire Near WP-No analysis is available to evaluate whether or not the construction material in the transporter car, or other sources, will ignite on impact with the wall. It is assumed that the probability is $1 \times 10-1$ per demand. The complementary probability is $(1-1 \times 10-1)=9.9 \times 10-1$ (which is rounded to $1 \times 100)$.

Using the (hypothetical) values described above, and presented in Figure 7-4, each sequence is quantified by multiplying the frequency of the IE and the probabilities of each event that occurs in that sequence. For example, the frequency of Sequence 1 is simply the product of the probability of the IE $(1 \times 10-1$ per year $)$ and the probability that the automatic control system functions (approximately 1.0). The result is $1 \times 10-1$ per year.

The frequency of Sequence 9 is more complex, involving the product of the IE frequency and six probability values.

The example in Figure 7-4 was constructed and quantified using the Microsoft Excel spreadsheet program.

Note that the values used for preliminary ET analyses may be viewed as point estimates and are generally assumed to be the median values. As described in Section9, median values propagate through multiplication; thus, the sequence frequencies shown in Figure 7-4 are median values. For sequence frequency binning, however, the mean value of frequencies will be used. To obtain the mean values, uncertainties are quantified as described in Section9. The IE frequency and each probability value will have a probability distribution function (PDF) assigned to it that is usually assumed to be a $\log$ normal distribution defined by its median value and an error factor (EF). The PDFs are then combined analytically or using a Monte Carlo routine (for more complex problems).

\subsection{Interpretation of Event Tree}

The event sequences of interest are those that result in a release of radioactivity, i.e., those involving a breach of the WP, such as sequences 5, 6, 8, and 9 in Figure 7-3. None of these sequences have a median frequency greater than $1 \times 10^{-6}$ per year, so all of the examples have 
frequencies that are $\mathrm{BC} 2$. If it were desired to show margins to regulatory limits, consequence analyses would be performed for these sequences using methods described in Section 8.

\subsection{Simplification of Event Trees}

Consequence Binning-Consequence analyses may indicate that the release fractions from a breached WP do not vary significantly, regardless of whether or not a credible fire is present. A credible fire, in this case, is defined as one that could be initiated as a result of the runaway rather than an independent fire initiated by petroleum-based fuels. If this is the case, the ET heading "No Fire Near WP" can be eliminated because the resulting dose consequences are not different enough to warrant carrying the distinction forward in the ET. In this situation, Sequences 5 and 6 in Figure 7-4 would merge into one sequence (call it sequence 5A) and Sequences 8 and 9 would merge (call it sequence $8 \mathrm{~A}$ ). The frequency of Sequence $5 \mathrm{~A}$ is essentially the same as the former Sequence 5 and the frequency of Sequence 8A is essentially the same as that for Sequence 8. The simplified ET would now have only 7 outcome sequences and only two sequences that have radioactive material releases. The modified tree is not shown.

This simplification is applied in the other examples presented in Sections 7.1.5.2 and 7.1.5.3.

Event Heading Definitions/Success Criteria-Suppose the design criteria for the WP will not withstand the potential maximum impact during the runaway. Here one or more branches under the heading "WP Remains Intact" may be candidates for simplification or deletion. The discussion of this situation starts with the original ET presented in Figure 7-4.

In the first simplification of Figure 7-4, the WP may breach whenever it is ejected from the transporter at the runaway speed. In this case the "yes" branch is eliminated (Sequence 7 is noted as deleted in Figure 7-5) and the probability of the "no" branch becomes 1.0 (dependent failure guaranteed by the ejection). This modification would increase the frequencies of Sequences 8 and 9 by a factor of 10 (the inverse of $1 \times 10^{-1}$ per demand). The probability of WP failure when it remains in the transporter might also be increased (e.g., to $1 \times 10^{-2}$ per demand), thus affecting the frequencies of Sequences 5 and 6. This modified (simplified) ET is presented in Figure 7-5.

In a second simplification of Figures 7-4 and 7-5, where it is assumed that it does not matter whether or not the WP is ejected from the transporter, the heading "WP Remains in Transporter (not ejected)" is irrelevant and can be deleted from the tree. Therefore, Sequences 4 through 7 are eliminated from the original ET (Figure 7-4). The frequencies of the releases in Sequences 8 and 9 increase. The heading "WP Remains Intact" could be merged with "Transporter Remains on Tracks (not derailed)" to further simplify the analysis (under these circumstances any derailment results in a release) or the headings could be retained to enhance communication of the events in the sequence and gain insights. This modified (simplified) ET is presented in Figure 7-6. 


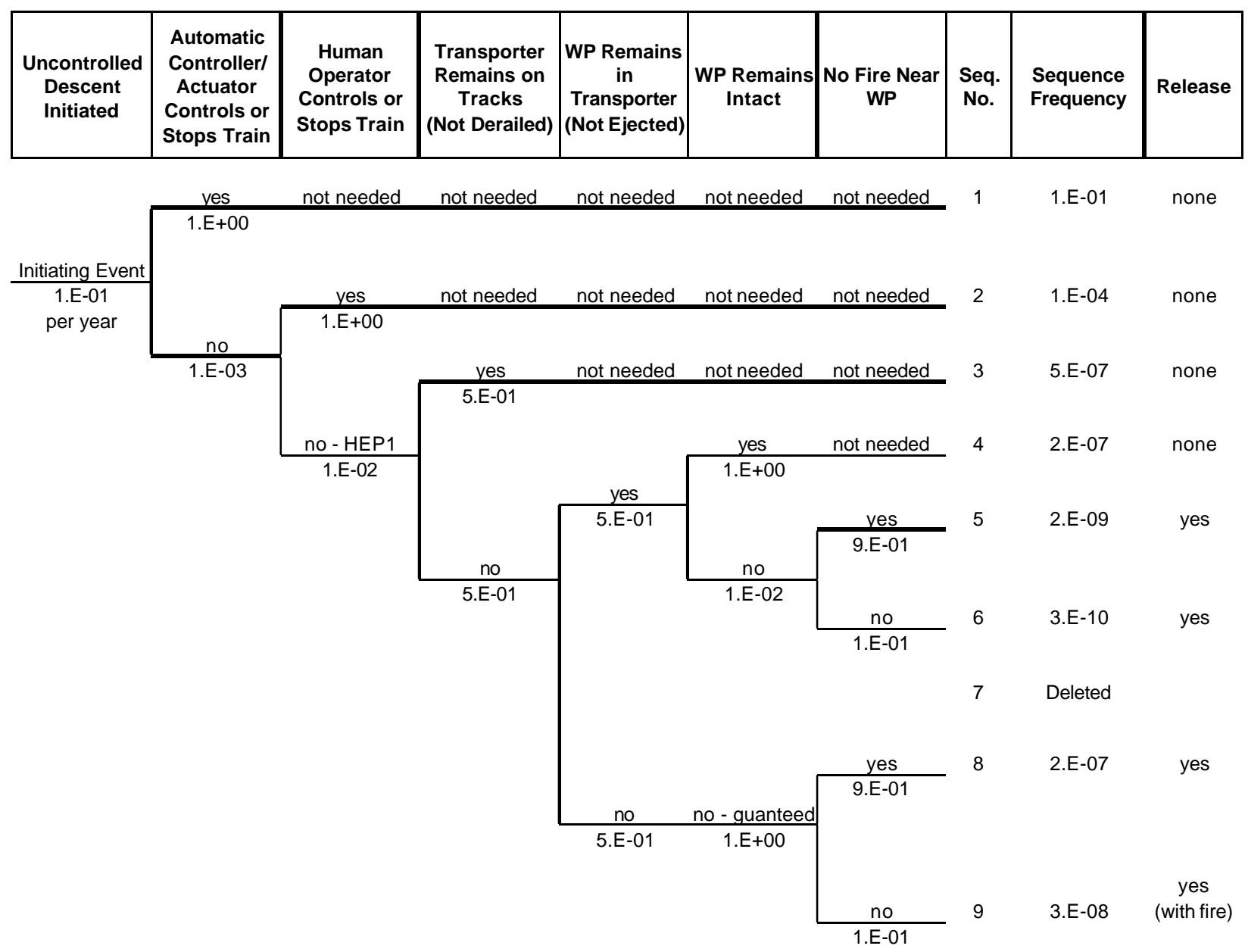

Figure 7-5. Simplified ET for Hypothetical Uncontrolled Descent (First Example) 


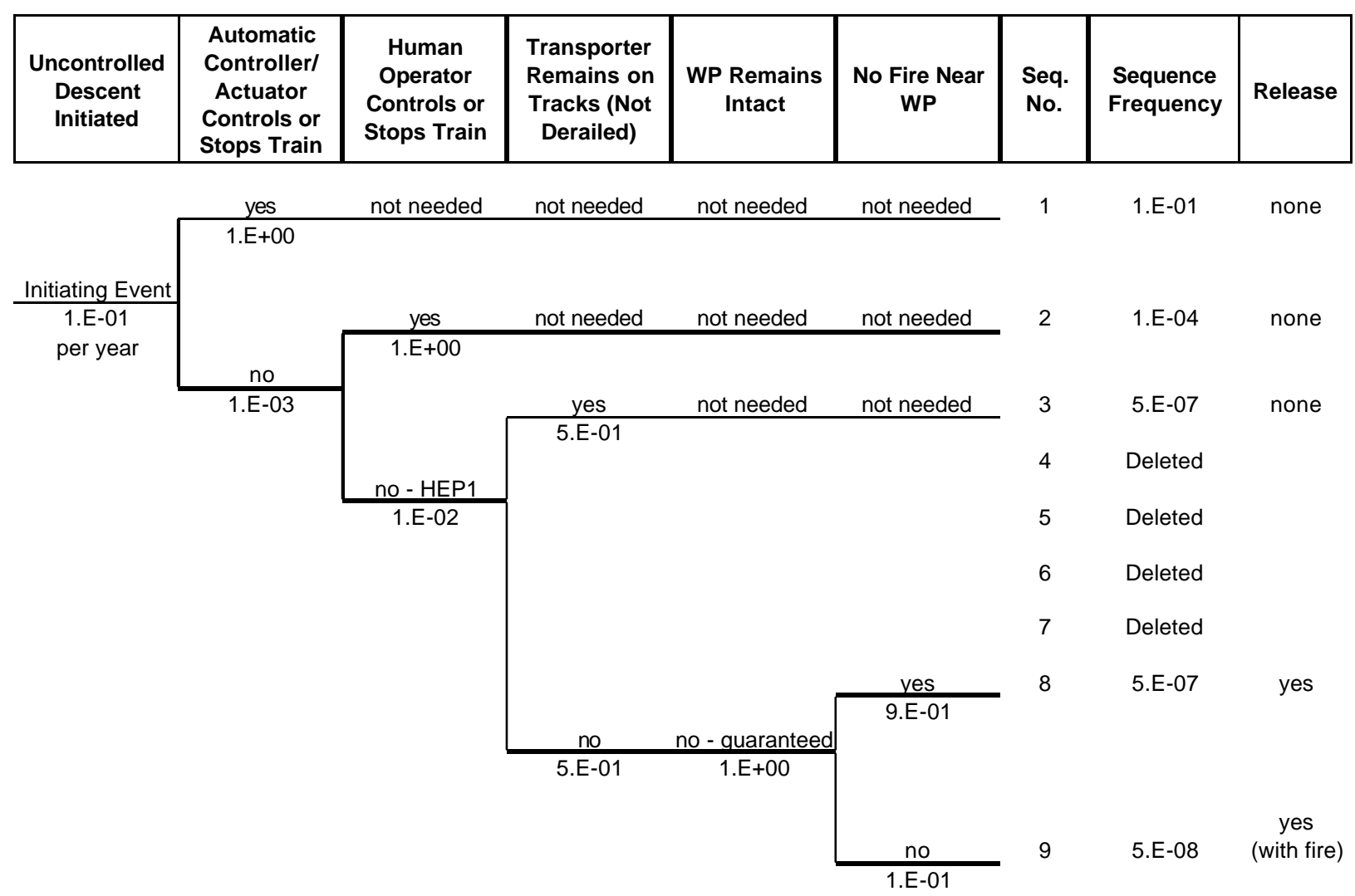

Figure 7-6. Simplified ET for Hypothetical Uncontrolled Descent (Second Example)

\subsubsection{ET Example 2: On-board Fire Initiates Uncontrolled Descent}

This example is presented to illustrate how a previously developed ET may be modified to represent other initiators. In particular, this example illustrates how the ET for the uncontrolled transporter descent, initiated by a random failure internal to its operational systems, can be modified to represent potential events initiated by a fire. Figure 7-7 illustrates this example.

\subsection{Event Tree Construction}

The ET depicted in Figure 7-4 and the event descriptions in Section 7.1.5.1.1 are used with modifications, as described in the following text. The ET is initially simplified by assuming that the event heading "No Fire Near WP" is irrelevant (see Section 7.1.5.1.4). The IE titled "Uncontrolled Descent Initiated" is not shown explicitly in this ET; it is a potential consequence precipitated by the initiating fire and subsequent failure events.

The following event headings are used:

Fire Initiated in Transporter Locomotive-This IE represents a fire that could occur in any of the electrical components and wiring in the controlling locomotive.

Fire Suppression System Extinguishes Fire-The transporter locomotives will be equipped with automatic fire-suppression systems in accordance with the need defined 
through a fire hazards analysis. The successful operation of this system influences dependent events, as described below.

Automatic Controller/Actuator Controls or Stops Train-In this example, two different pre-conditions are modeled. In the first case, shown in the upper portion of Figure 7-7, the fire suppression system is successful in extinguishing the fire before it causes failure of the automatic control system. However, the automatic control system could fail for independent causes not related to the fire. Should such a failure occur, given that a runaway was initiated by the initial fire, then the "no" branch is developed in the same manner as the ET depicted in Figure 7-4.

In the case where "Fire Suppression System Extinguishes Fire" is unsuccessful (the no branch), it is assumed that there is a dependent failure of the function titled "Automatic Controller/Actuator Controls or Stops Train." This failure is a type of common-cause failure (CCF) and is given as "guaranteed failure (GF) (CCF/Fire)" in Figure 7-7 to indicate a guaranteed failure due to the $\mathrm{CCF}$.

Human Operator Controls or Stops Train-For illustration it is assumed in this example that the human-actuated controls are not failed by the fire; however, the probability of human error is affected. In the upper portion of the ET depicted in Figure 7-7, following the independent failure of the automatic control system, the probability of human error is assumed to be the same as in Figure 7-4 (labeled as HEP1). In the lower portion of the ET representing the aftermath of the fire that progresses far enough to cause failure of the automatic control system, the operator may react with lower reliability because of the extra distractions and stresses. This probability is labeled as HEP2 in Figure 7-7.

Transporter Remains on Tracks (not derailed)-Same as in Section 7.1.5.1.1.

WP Remains in Transporter (not ejected)-Same as in Section 7.1.5.1.1.

WP Remains Intact-Same as in Section 7.1.5.1.1.

\subsection{Event Tree Quantification}

This example will discuss the features of Figure 7-7 that are different than Figure 7-4.

Fire Initiated in Transporter Locomotive-For illustration, an arbitrary frequency of $1 \times 10-1$ per year is specified. An actual analysis would apply actuarial data for electric locomotives.

Fire Suppression System Extinguishes Fire-An estimate of the failure probability is developed from FTA or from actuarial data, supported by a fire-propagation analysis. 


\begin{tabular}{|c|c|c|c|c|c|c|c|c|}
\hline $\begin{array}{l}\text { Fire Initiated in } \\
\text { Transporter } \\
\text { Locomotive }\end{array}$ & $\begin{array}{c}\text { Fire Suppression } \\
\text { System } \\
\text { Extinguishes Fire }\end{array}$ & $\begin{array}{c}\text { Automatic } \\
\text { Controller/ Actuator } \\
\text { Controls or Stops } \\
\text { Train }\end{array}$ & $\begin{array}{c}\text { Human Operator } \\
\text { Controls or } \\
\text { Stops Train }\end{array}$ & $\begin{array}{c}\text { Transporter } \\
\text { Remains on } \\
\text { Tracks (Not } \\
\text { Derailed) }\end{array}$ & $\begin{array}{l}\text { WP Remains in } \\
\text { Transporter (Not } \\
\text { Ejected) }\end{array}$ & $\begin{array}{l}\text { WP Remains } \\
\text { Intact }\end{array}$ & $\begin{array}{l}\text { Seq. } \\
\text { No. }\end{array}$ & $\begin{array}{l}\text { Sequence } \\
\text { Frequency }\end{array}$ \\
\hline
\end{tabular}

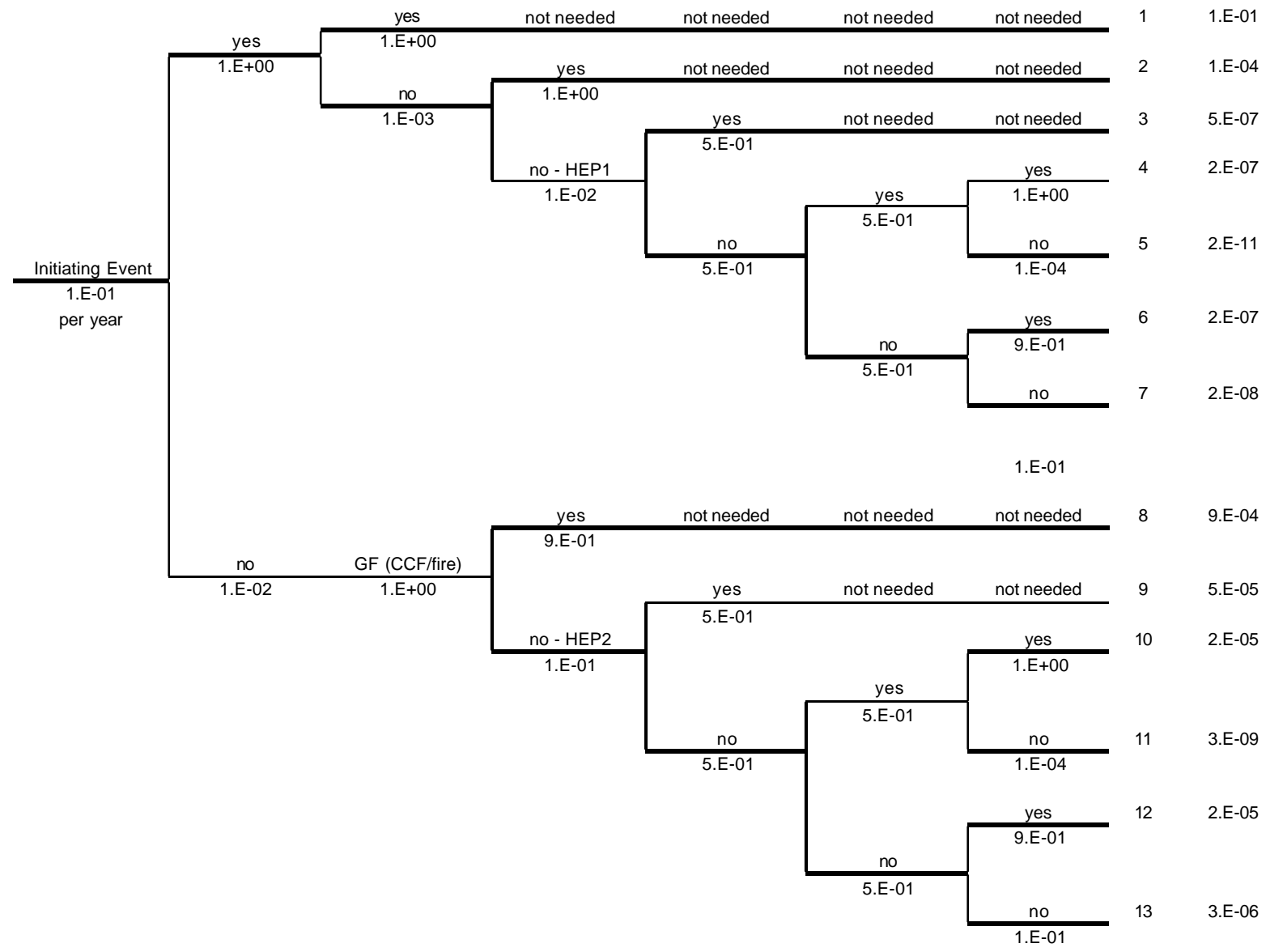

NOTE: $G F=$ guaranteed failure .

Figure 7-7. ET for Hypothetical Fire Initiated Uncontrolled Descent

Automatic Controller/Actuator Controls or Stops Train-If the fire suppression system is successful in extinguishing the fire before it causes failure of the automatic control system, the same value for independent failure from Figure 7-4 is used (i.e., $1 \times$ 10-3 per demand).

In the case where "Fire Suppression System Extinguishes Fire" is unsuccessful, the automatic system fails due to a CCF. This is given as "GF (CCF/Fire)" in Figure 7-7, and the conditional probability is 1.0 .

Human Operator Controls or Stops Train-In the upper portion of the tree (Figure 7-7) following the independent failure of the automatic control system, the probability of 
human error is assumed to be same as in Figure 7-4, labeled as HEP1. It is quantified as $1 \times 10-2$ per demand.

In the lower portion of the tree, in the aftermath of the fire that progresses far enough to cause failure of the automatic control system, the operator may react with lower reliability because of extra distractions and stresses. This probability is labeled HEP2 (Figure 7-7). Using HRA (see Section 7.3) that accounts for the situational factors (performance shaping factors) that account for such factors as available instrumentation, control layout, and time pressure on the human, the HEP, labeled HEP2, is estimated to be higher by an order of magnitude (i.e., $1 \times 10$ - 1 per demand).

Transporter Remains on Tracks (not derailed)-Same as in Section 7.1.5.1.2.

WP Remains in Transporter (not ejected)-Same as in Section 7.1.5.1.2.

WP Remains Intact-Same as in Section 7.1.5.1.2.

The quantification of sequence frequencies proceeds the same as described in Section 7.1.5.1.2.

\subsubsection{ET Example 3: Human Operator Initiates Uncontrolled Descent}

This example is presented to further illustrate how dependent events affect the construction and quantification of ETs.

In this example, it is assumed that an operator on the control locomotive or in a central control room commits an erroneous action that not only initiates an uncontrolled descent, but also disables all of the systems that can be used to control the speed or apply emergency brakes.

The quantification of the remaining events in Figure 7-7 is the same as in Figure 7-4.

\subsection{Event Tree Construction}

The example ET is shown in Figure 7-8. The event descriptions in Section 7.1.5.1.1 are used, with modifications as described in the following paragraphs. The tree is simplified by assuming that the event heading "No Fire Near WP" is irrelevant (see Section 7.1.5.1.4). The IE titled "Uncontrolled Descent Initiated" is not shown explicitly in this tree; it is a potential consequence of subsequent failure events. The following event headings are used:

Uncontrolled Descent Initiated by Operator Error-An operator on the control locomotive or in a central control room, commits an erroneous action that initiates an uncontrolled descent.

The event frequency is estimated to be $1 \times 10-3$ per year based on actuarial data or HRA. 


\begin{tabular}{|c|c|c|c|c|c|c|c|}
\hline $\begin{array}{c}\text { Uncontrolled } \\
\text { Descent } \\
\text { Initiated by } \\
\text { Operator Error }\end{array}$ & $\begin{array}{c}\text { Automatic } \\
\text { Controller/ } \\
\text { Actuator } \\
\text { Controls or } \\
\text { Stops Train }\end{array}$ & $\begin{array}{l}\text { Human } \\
\text { Operator } \\
\text { Controls or } \\
\text { Stops Train }\end{array}$ & $\begin{array}{l}\text { Transporter } \\
\text { Remains on } \\
\text { Tracks (Not } \\
\text { Derailed) }\end{array}$ & $\begin{array}{l}\text { WP Remains } \\
\text { in Transporter } \\
\text { (Not Ejected) }\end{array}$ & $\begin{array}{l}\text { WP Remains } \\
\text { Intact }\end{array}$ & $\begin{array}{l}\text { Seq. } \\
\text { No. }\end{array}$ & $\begin{array}{l}\text { Sequence } \\
\text { Frequency }\end{array}$ \\
\hline
\end{tabular}

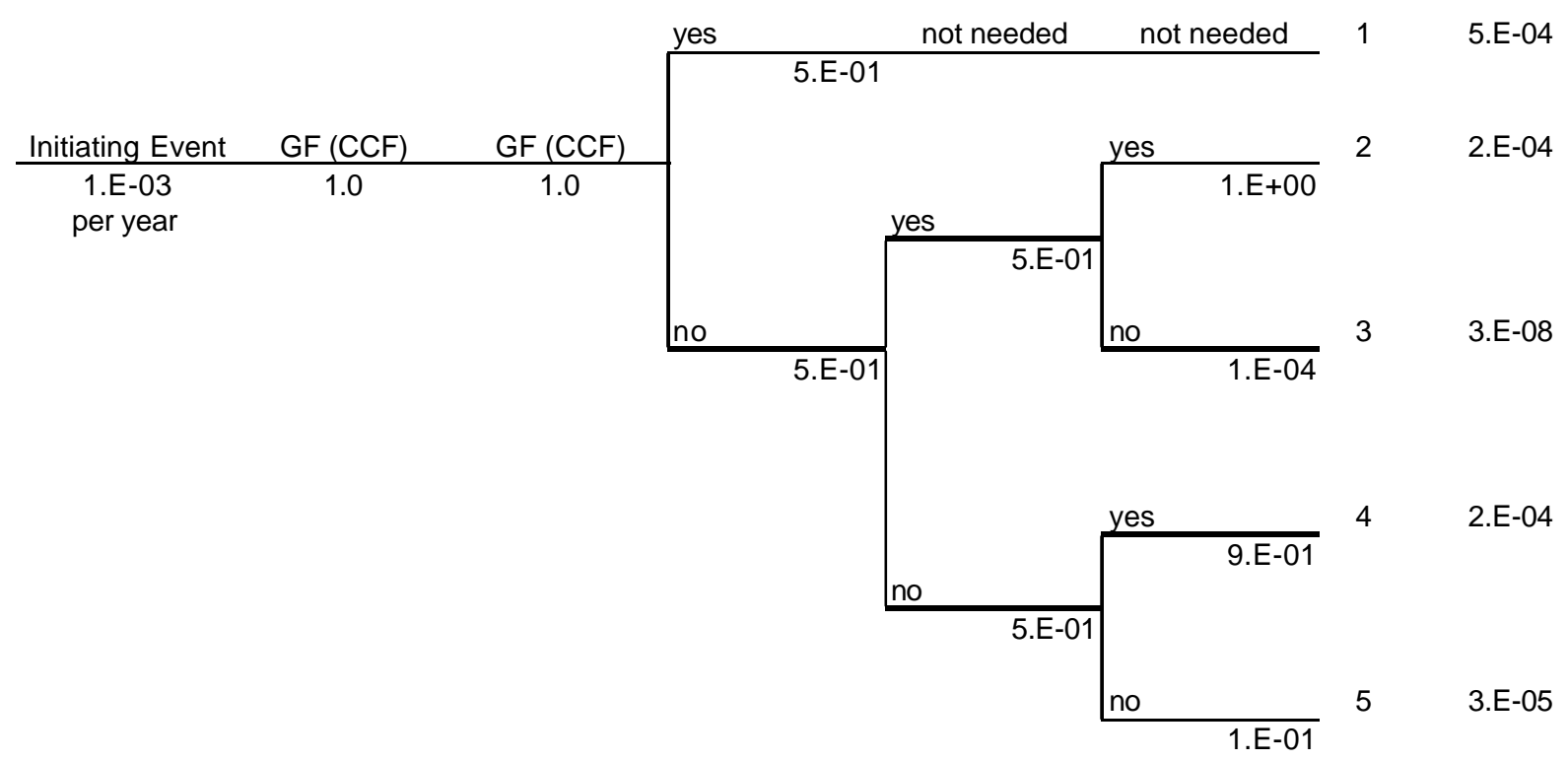

NOTE: GF = guaranteed failure .

Figure 7-8. ET for Hypothetical Human Error Initiated Uncontrolled Descent

Automatic Controller/Actuator Controls or Stops Train-In this example, it is assumed that the initial operator error also causes a dependent (common-cause) failure of the automatic controller. This dependent guaranteed failure deletes the chance for a success (yes) branch under this event heading. It is labeled "GF (CCF)" in Figure 7-8.

The conditional failure probability is 1.0 .

Human Operator Controls or Stops Train-This event may be considered to be the same event as the IE and could be deleted from the tree structure. However, it could also be a true dependency where the initial operator error disables the system that an operator (not necessarily the same one) would attempt to use as an emergency action.

For this example, a CCF is assumed, and no success branch is shown. The "no" branch is labeled "GF (CCF)" in Figure 7-8 with a conditional failure probability is 1.0.

In other constructions, the probability of operator recovery might be included to generate a success branch under this event.

The definitions and quantification of the remaining events in Figure 7-8 are the same as in Figure 7-4. 
Transporter Remains on Tracks (not derailed)-Same as in Section 7.1.5.1.1.

WP Remains in Transporter (not ejected)-Same as in Section 7.1.5.1.1.

WP Remains Intact-Same as in Section 7.1.5.1.1.

\subsection{Quantification}

The quantification of sequence frequencies proceeds the same as described in Section 7.1.5.1.2.

\subsection{FAULT TREE ANALYSIS}

\subsubsection{Introduction}

This section defines the bases and methodology for the construction and use of FTA in support of the PSA. Logic models of physical system are applied in FTA for the purpose of quantifying the probabilities of top events based on combinations of basic events that represent mechanical failures, human failure events (HFEs), or computer/control system failures (including software failures described in Section 7.7). The use of FTA has applications in:

- $\quad$ Quantifying the frequency of IEs as well as the conditional probability of enabling events that contribute to event sequences

- $\quad$ Explicit modeling and quantifying of dependencies between primary (front-line) safety systems and support systems

- Top-down modeling of combinations of events that lead to an undesired outcome, including development of master logic diagrams

- Defining how operation-specific controls and management measures can be used to prevent or mitigate releases of radioactivity

- $\quad$ Providing a structure for propagating uncertainties in basic events to the top event.

This section provides a cursory, focused guide to the construction, application, and evaluation (both qualitative and quantitative) of FT models. While some concepts are universal to all FTAs, the applications in this section are focused on support of the PSA for a repository. The guide is not meant to be a textbook or exhaustive. Where appropriate, reference is made to literature for additional information.

\subsubsection{Overview of Approach}

The use of FTAs is a special branch of systems analysis. The goal of FTA, similar to other systems analysis, is to effect a structured analysis of complex systems using abstractions and approximations to support decision-making in safety and engineering. FTA is used to synthesize information from which to infer potential vulnerabilities as well as to estimate the probabilities of undesired events. 
General Description-An FT model maps physical systems into a logic model based on deductive logic. The deductive model begins with a defined undesired event (or consequence), such as release of radioactivity from surface facility, and identifies (deduces) the causes of the undesired event. The undesired event is termed the "top event" in FTA and must be defined precisely. The model is developed downward from the top event through the various levels of assembly and usually stops at the basic event level. For example, an FTA for the top event, "release of radioactivity from surface facility," would proceed downward in levels of assembly from facility to building to operation to system to subsystem to the basic events. The basic events represent failures in specific hardware components, software, electronic control or logic elements, HFEs, or loss of essential support functions, such as loss alternating current (AC) electrical power. The FT can include the loss of, or circumvention of, design and administrative controls. The basic events for a given component, therefore, may represent independent failures, CCFs, a dependent failures (see Section 7.5 for more information on CCFs and dependent failures).

Master Logic Diagram-An FT developed for a top event such as "release of radioactivity from surface facility" is sometimes termed a master logic diagram (MLD) as a framework for identifying and organizing all of the hazards at a given facility. In this application, the top event is defined broadly but explicitly. The causes and probability of a given accident or class of accidents for a specific facility are also analyzed with FT logic. In this application, the top event might be "release of radioactivity from transport cask unloading facility resulting in dose greater than 5 rem at site boundary." The FT logic is applied to identify locations in the MGR where a large dose could be generated.

The MLD can be developed further to identify fault combinations that must occur to result in the defined top event. Various paths from the top event down to the fundamental or basic events (e.g., HFEs, equipment failures, and earthquakes) comprise alternative event sequences (or accident scenarios). Thus, the FT logic will usually capture the same scenarios as identified in ET analysis. However, individual sequences of events may be difficult to define in complex FTs.

System Analyses/ET Headings-Most applications of FTA, however, involve evaluations of the vulnerabilities within a given system or of the unreliability (or unavailability) of that system. The system unavailabilities are needed, for example, to quantify the probabilities of event headings in ETs and support quantification of event sequence frequencies. For example, an ET for the waste handling building might have an event heading "HVAC/HEPA filter starts and runs for 24 hours," expressed as a success criterion. An FTA of the HVAC/HEPA filter system is developed to reveal how failures of the system may occur (the vulnerabilities), and to estimate the probability of the failure branch under that ET heading.

Selection of Top Event and Success Criteria-The FT top event for a system is generally defined as a complete, or catastrophic, failure of the system resulting in the unavailability of the desired safety function. It is important to be careful in choosing the top event and its success criterion. If the definition is too general, the analysis will be unmanageable. On the other hand, the analysis will not provide a sufficiently wide view of the system and its interfaces if the top event is too specific. 
Qualitative Evaluation/Cutset Generation-The FT model is solved qualitatively using the rules of Boolean algebra to reveal the number of combinations of basic events that can result in the occurrence of the top event. Section 7.2.4.1 presents basic Boolean algebra as background material for the FT analyst. A summary of Boolean algebra is presented in Section VII of the Fault Tree Handbook (Vesely et al. 1981).

The combinations of basic events that lead to the top event are termed cutsets. Through complete Boolean reduction, the least number of unique cutsets that result in the top event are determined and are termed the minimal cutsets. The occurrence of at least one of the minimal cutsets will result in the occurrence of the top event. Some minimal cutsets may contain a single basic event, but most will represent the logical intersection (i.e., AND logic, or arithmatic product) of two or more basic events. The probability that the top event will occur is the union (or OR logic, or arithmetic sum) of the probabilities represented by the minimal cutsets.

The results of a qualitative FTA provide insights into potential system vulnerabilities that may, in some cases, be prevented or reduced in probability through design or operational modifications. For example, if the cutset analysis reveals that the system is very vulnerable to a human error by the facility operator (e.g., to ensure building air-tightness) then an interlock switch could be introduced into the design such that the system failure requires the concurrent failure of the interlock and the operator error.

Stated another way, qualitative FTA also serves to demonstrate the defense-in-depth of a system. A simple FT can determine if a potential accident condition or a system performance is defended against a single failure (or single contingency). A hand-drawn FT also can be a useful tool for the safety analyst.

In applications of an FTA program such as SAPHIRE (Russell et al. 1994), the analyst can develop and solve very complex FTs. The results are made manageable by truncating the qualitative analysis by specifying the maximum order of cutsets to be generated. The order is the number of basic events included in a minimal cutset. A singlet cutset includes one basic event (i.e., it represents a single-point failure) and may include a known and unlikely passive failure such as the collapse of a shield wall or may reveal the key human error, as discussed previously. In reliable mechanical or electrical systems, it is unusual to have a single minimal cutset unless it is a CCF or a HFE. A doublet cutset represents the concurrent occurrence, or intersection (or AND logic, or arithmetic product) of two basic events. In the previous example, a design modification that added an interlock to prevent the human error single point failure would produce a doublet in a revised FTA: the human error is ANDed with failure of the interlock. The cutset ordering continues through triplet, quadruplet, and so forth. In practical terms, it is seldom necessary to go beyond doublets or triplets unless the system is very complex.

Quantitative Evaluation/Top Event Probability-The FT model may be solved quantitatively after the minimal cutsets have been derived. The probability of the top event is represented by the union (or OR logic, or arithmetic sum) of all of the minimal cutsets. Quantitative probabilities are inserted for all of the basic events that appear in the minimal cutsets. The symbolic Boolean operations of intersection (AND) is replaced with the arithmetic operation of multiplication and the union (OR) is replaced by summation. The basic event probabilities are derived as described in Section 7.3, Section 7.4, and Section 7.5. Quantitative FTA is used in the 
quantification of event sequence frequencies (i.e., by direct or indirect linking to ETs) and categorization of event sequences.

The probability of each minimal cutset is quantified by the multiplication of the probabilities of all of the basic events appearing in it. The top event probability is calculated by adding the probabilities of all of the minimal cutsets.

The analyst can truncate the quantitative analysis by specifying the minimum cutset probability to be generated in an FTA application program such as SAPHIRE. Thus, if the analyst is interested in finding the dominant contributors to a total system unavailability that is on the order of $10^{-3}$ per demand, a minimum cutset probability of perhaps $10^{-4}$ to $10^{-5}$ might be specified since 10 to 100 cutsets are required to produce the top event probability range. On the other hand, if a top event probability of $10^{-6}$ is needed, the cutoff probability for individual cutsets might be set at $10^{-8}$ to $10^{-9}$, at least initially, to ensure that all significant contributors are accounted for. Several iterations are usually required to settle in at an appropriate cutoff probability for a given system.

The results of a quantitative FTA provide a different degree of insight into potential system vulnerabilities than is provided by the qualitative FTA. For example, by maintaining the discrete probabilities of individual cutsets, it is revealing to rank their contribution to the top event probability. This methodology provides visual insights into the dominant contributors as well as a means for formal importance ranking. Knowledge of the relative importance of various cutsets and the basic events that contribute to the top event (e.g., hardware failures, software failures, HFEs, and CCFs) can be used to prioritize design alternatives, importance to safety classifications, and other risk-informed analyses. There are seve ral standard forms of importance measures (e.g., Birnbaum, Fussell-Veseley) that can be generated automatically using a program like SAPHIRE.

\subsubsection{Details of Approach}

This section presents a brief introduction to the fundamental elements of FTA. The PSA analyst should consult the Fault Tree Handbook (Vesely et al. 1981), the PRA Procedures Guide (NRC 1983), and the SAPHIRE users manual (Russell et al. 1994) for more information.

\subsubsection{Essential Boolean Algebra}

It is not necessary for the FT analyst to understand Boolean algebra unless it is required to solve an FT by hand. The FT programs such as SAPHIRE (Russell et al. 1994) provide all of the manipulations of Boolean expressions for the analyst. In many cases, simple FTs can be solved by hand using the rudimentary elements of Boolean algebra. The following discussion (Table 7-1) presents the Boolean operations, their arithmetic (engineering) equivalent notations and equations, and their corresponding probability expressions. The examples represent the occurrence of event $\mathrm{C}$ after operating on events $\mathrm{A}$ and $\mathrm{B}$, and their respective probabilities (i.e., $\mathrm{p}(\mathrm{A}), \mathrm{p}(\mathrm{B})$, and $\mathrm{p}(\mathrm{C}))$. 
Table 7-1. Boolean Operations

\begin{tabular}{|c|c|c|}
\hline $\begin{array}{l}\text { Union [OR logic, } \\
\text { sum of event } \\
\text { probabilities] }\end{array}$ & $C=A \cup B ; C=A O R B ; p(C)=p(A)+p(B)-[p(A) p(B)]$ & (Eq. 7-1) \\
\hline $\begin{array}{l}\text { Intersection [AND } \\
\text { logic, multiplication } \\
\text { of event } \\
\text { probabilities] }\end{array}$ & $C=A \cap B ; C=A$ AND $B ; p(C)=p(A) p(B)$ & (Eq. 7-2) \\
\hline $\begin{array}{l}\text { Absorption } \\
\text { (reduce condition } \\
\text { for TRUE } \\
\text { expression to } \\
\text { minimum), for } \\
\text { example, }\end{array}$ & $\begin{array}{l}C 1=A \cup(A \cap B)=A ; C 1=A O R(A \text { AND } B)=A ; p(C 1)=p(A)+(p(A) p(B))=p(A) \\
C 2=A \cap(A \cup B)=A ; C 2=A \text { AND }(A \text { OR } B)=A ; p(C 1)=p(A)(p(A)+p(B))=p(A) \\
\text { Note that if } A \text { is TRUE then } C \text { is TRUE no matter whether } B \text { is TRUE or FALSE. } \\
\text { The sub-expressions involving } B \text { has been absorbed by those expressions involving } A \text {. }\end{array}$ & $\begin{array}{l}\text { (Eq. 7-3) } \\
\text { (Eq. 7-4) }\end{array}$ \\
\hline $\begin{array}{l}\text { Complementation } \\
\text { [Event NOT A (or } \\
\text { A) is the } \\
\text { complement of } \\
\text { event } A \text { ] }\end{array}$ & $\begin{array}{l}C 3=A \cup \underline{A}=1 ; C 3=A+\underline{A}=1 ; p(C 3)=p(A)+p(\underline{A})=1 \\
C 4=A \cap \underline{A}=\varnothing[n u l l] ; C 4=A \underline{A}=0 ; p(C 4)=p(A) p(\underline{A})=0\end{array}$ & $\begin{array}{l}\text { (Eq. 7-5) } \\
\text { (Eq. 7-6) }\end{array}$ \\
\hline
\end{tabular}

The Boolean logic of AND and OR form the basic building blocks of an FT structure. Specialized adaptations of the AND logic have been introduced into FT symbology as described below. The rule of Boolean logic, especially ABSORPTION and COMPLEMENTATION are used in solving an FT (i.e., finding the minimal cutsets among all the possible combinations of basic events).

\subsubsection{Fault Tree Symbols}

The symbols used in FT construction are illustrated in Figure 7-9. These symbols have been standardized and have been incorporated into the graphics and logic of programs such as SAPHIRE. It is unlikely that FTA performed for preclosure safety will use all of the symbols and their associated logic, but all are presented for completeness.

\subsection{Top Events and Intermediate Events}

A rectangle used to enclose the precise statement about the top event or an intermediate event. The event described in the rectangle represents a fault event that occurs because of the occurrence of one or more antecedent events acting through logic gates. A rectangle is usually opened by specifying a logic gate (an AND or OR gate) as a place to enter the textual description of the top or intermediate event in a program such as SAPHIRE. But, intermediate event descriptions are often included in rectangles in a tree structure as clarifying descriptions with pass through logic (i.e., no AND or OR).

Several symbols are used to indicate the types of primary or fundamental events that act as antecedents or conditioning events for faults higher in a tree. 


\section{PRIMARY EVENT SYMBOLS}

BASIC EVENT - A basic initiating fault requiring no further development

CONDITIONING EVENT - Specific conditions or restrictions that apply

to any logic gate (used primarily with PRIORITY AND and INHIBIT gates)

UNDEVELOPED EVENT - An event which is not further developed either because it is of insufficient consequence or because information is unavailable

EXTERNAL EVENT — An event which is normally expected to occur

\section{INTERMEDIATE EVENT SYMBOLS}

INTERMEDIATE EVENT - A fault event that occurs because of one or more antecedent causes acting through logic gates

\section{GATE SYMBOLS}

AND - Output fault occurs if all of the input faults occur

OR - Output fault occurs if at least one of the input faults occurs

EXCLUSIVE OR - Output fault occurs if exactly one of the input faults occurs

PRIORITY AND - Output fault occurs if all of the input faults occur in a specific sequence (the sequence is represented by a CONDITIONING EVENT drawn to the right of the gate)

INHIBIT - Output fault occurs if the single fault occurs in the presence of an enabling condition (the enabling condition is represented by a CONDITIONING EVENT drawn to the right of the gate)

\section{TRANSFER SYMBOLS}

TRANSFER IN - Indicates that the tree is developed further at the occurrence of the corresponding TRANSFER OUT (e.g., on another page)

TRANSFER OUT - Indicates that this portion of the tree must be attached at the corresponding TRANSFER IN

Figure 7-9. Standard Fault-Tree Symbols 


\subsection{Primary Events}

Basic Event-A basic event is a fault that requires no further development; it is represented by a circle. The circle signifies that the appropriate limit of resolution has been reached. It signifies that the stopping rule for the analysis scope has been satisfied. A basic event may be a component failure, a system failure, software failures, a human error, or a CCF. The probability or failure rate of a basic event, along with its uncertainty distribution, represents the fundamental input to a quantitative FTA.

Undeveloped Event-An undeveloped event is represented by a diamond. This symbol represents an event that could be developed further toward basic events. However, it is not further developed because it does not cause significant consequences, sufficient information is not available to warrant decomposition, information is available for faults at the higher level, or the analyst wants a placeholder. For example, an event titled "loss of AC power supply 'Train A' to HVAC/HEPA filters" might be shown as a diamond on an FT as an input to "HVAC/HEPA filter fails to start and run for 24 hours." The analyst may either quantify the probability of the loss of AC "Train A" or later change the diamond to a TRANSFER (definition to follow) to a detailed FT for the AC power system.

Conditioning Event-A conditioning event is represented by an ellipse (oval). This symbol represents a restriction or condition that can be applied to any logic gate but is used primarily with PRIORITY and INHIBIT gates. For example, an FT for a potential criticality event might have a conditioning event titled "moderator is present" as an input to an AND gate that also includes "misload of WP" and "neutron absorber omitted from WP."

External Event-An external event is represented by a house. This symbol does not represent a fault; it represents an event that is expected to occur. It may play the role of a conditioning event or a contingency event. For example, an FT might model an event such as "AC applied to motor startup sequencer" due to an out-of-sequence relay operation whose primary fault be "relay contacts fail closed." An EXTERNAL EVENT titled "AC power available to motor start sequencer" would show the need for the presence of the additional event or condition before the fault could occur.

\subsection{Gate Symbols}

The gate symbols and the logic they represent provide the backbone of an FT structure. The operational aspect of a gate is to define whether the output of the gate is TRUE or FALSE depending on the status of several inputs to the gate. When the output of a gate is TRUE in an FT, the fault described in the event box occurs (exists). The logical operation of each kind of gate is described as follows:

AND-The AND gate is represented by a flat-bottomed arch (or mailbox). The OUTPUT fault occurs if, and only if, all of the input events or faults occur.

OR-The OR gate is represented by an arch-bottomed barn roof (or bishop's hat). The OUTPUT fault occurs if at least one of the input events or fault occurs. This gate is sometimes called the INCLUSIVE OR to distinguish it from the EXCLUSIVE OR (description to follow). However, most FTAs encountered in the PSA for the repository will use the basic (or inclusive) OR. 
Exclusive OR-The exclusive OR is represented by a modified OR symbol that has an archbottomed triangle inside the "barn. The output fault occurs if exactly one of the input events or faults occurs. Alternatively, this logic could be represented by an OR gate with a conditioning event specifying a required order of the inputs or exclusion statement "A not B, or B not A." It is noted in the Fault Tree Handbook (Vesely et al. 1981) that the quantitative difference between the inclusive and exclusive OR events is generally insignificant.

Priority AND-Priority AND is represented by an AND gate with an inscribed triangle (caution: it looks similar to the exclusive OR gate but has a flat bottom). The output fault occurs only if all of the inputs occur (like the AND gate) in the prescribed sequence order. If $\mathrm{A}, \mathrm{B}$, and $\mathrm{C}$ are three inputs to the PRIORITY AND, read left to right, the output occurs only if A occurs before $\mathrm{B}, \mathrm{B}$ occurs before $\mathrm{C}$, and $\mathrm{C}$ occurs. Alternatively, this logic could be represented by an AND gate with a CONDITIONING EVENT specifying the required order of the inputs (as "A before $\mathrm{B}, \mathrm{B}$ before C").

Inhibit-An INHIBIT is represented by a hexagon. The INHIBIT is a special kind of AND gate that propagates a fault in the presence of an enabling condition. The single input fault is shown as the only input into the bottom apex of the hexagon and the enabling condition as a CONDITIONING EVENT connected to the side of the hexagon. For example, an INHIBIT event might be defined as "fire protection system fails to prevent control system failure" with the only input fault being "fire protection system fails" while the conditioning event is "fire greater than Z degrees occurs in control area." There is little distinction in this example between the fires as conditioning events, rather than external (house) event, except in the specificity of fire severity.

K-out-of-N-K-out-of- $\mathrm{N}$ is represented by an OR gate with an attached oval. This gate symbol states the condition for occurrence of the intermediate event, which requires failure of $\mathrm{K}$ components out of $\mathrm{N}$ total to cause the described intermediate fault event. This gate symbol is a shortcut for the actual Boolean logic, which is a combination of AND gates with combinations of the basic events as inputs. Here the AND gates are input to the OR gate of the intermediate event. This gate symbol is often used in modeling the failure logic of safety-related instrumentation and control systems in which safety is balanced against trip avoidance. It is unlikely that instrumentation and control systems for a repository will use such logic; however, other systems having multiple levels of redundancy, such as the HVAC system of a wastehandling building, may use this type of gate.

\subsection{Transfer Symbols}

The transfer symbols serve several purposes:

1. Assist the analyst in controlling the complexity and graphic scale of an FT so text remains legible (e.g., to put a complex tree on multiple pages),

2. Allow modularization to direct the flow of fault to repeated elements without redrawing portions of the FT (e.g., a fault in a motor-control center may be a common input to several fans in a complex HVAC system), and 
3. Permit linking of trees of main systems to subsystems or to support systems (e.g., the main HVAC FT may link to subsystems in primary and secondary isolation zones to portions of an AC power supply system).

The TRANSFER IN and TRANSFER OUT symbols work together usually as pairs. For each TRANSFER IN, there must be a corresponding TRANSFER OUT in another page of the FT or in an FT for the corresponding subsystem or support system. It is possible for multiple TRANSFER INs to be linked to a single TRANSFER OUT.

A TRANSFER IN is indicated by a triangle with a connection from its top apex to an EVENT BOX. The TRANSFER IN indicates that the event defined is developed further at the occurrence of the corresponding TRANSFER OUT. For example, two inputs to the event "HVAC/HEPA filter system fails to start and run for 24 hours" through an AND gate might be "Train A of HVAC/HEPA filter system fails to start and run for 24 hours" and "Train B of HVAC/HEPA filter system fails to start and run for 24 hours." Each of the latter events could be shown as a TRANSFER IN events. The corresponding TRANSFER OUT events would be attached to the top events of FTs representing, respectively, "Train A ..." and "Train B ..."

A TRANSFER OUT is indicated by a triangle with connection out of its side to an EVENT BOX. The TRANSFER OUT symbol indicates that the tree structure represented below the top event is effectively a part of one or more other FTs that have faults at higher levels of assembly.

The application of the various symbols will be described later in several examples.

\subsubsection{Guidance on Fault Tree Construction}

This section describes how FT models are constructed using deductive logic. The discussion is oriented toward logic modeling to support the PSA of a repository at relatively high level of design detail.

Actual applications of FTA to the repository PSA are provided in Subsurface Transporter Safety Systems Analysis (CRWMS M\&O 2000) and Application of Logic Diagrams and CommonCause Failures to Design Basis Events (CRWMS M\&O 1997). The FT logic models were based on a limited amount of design detail but were quite extensive in defining the potential HFEs and CCFs that lead to the top events that were modeled. Portions of those applications are used as examples in the following discussion.

The necessary ingredients in FT construction include an understanding of the systems and an understanding of how things may go wrong. The Fault Tree Handbook (Vesely et al. 1981) has attempted to make FT construction more systematic, by developing rules for FT construction. The analyst is referred to Chapter V of the Fault Tree Handbook (Vesely et al. 1981) for a discussion on the fundamentals of FTA of complex systems. The following material is provided as background information and terminology that is useful in helping the PSA team gain experience as FT analysts.

Each event (e.g., top event, gates, basic event) in an FT has a name and a description. The name is an abbreviated set of letters, numbers, or characters that is used as a unique label on graphics, in databases, and reports. The rame is generally recognizable by key letters, although not in 
complex trees or if system-specific identification tags are used. The description may be a verbose, full definition of the event that may be tabulated with the event name, or it may be an abbre viated version that fits conveniently into the graphic displays and printouts.

This section adapts several of the rules of the Fault Tree Handbook (Vesely et al. 1981) in examples that are more appropriate to the PSA.

Rule 1 - Top Event Definition-The top event is defined as precisely as it can be expressed. It is an undesired event (e.g., an entire accident sequence) or a description of specific events that contribute to an accident sequence (e.g., the IE, the failure of a specific safety function or system, or a particular human error). The FTs will represent the failure or unavailability of an event defined in an ET model of potential accident sequences in most cases. As noted, the headings of an ET are defined in terms of specific success criteria that must be achieved to take credit for the safety function. The corresponding FT models the complement of the event heading success criteria; that is, the top event of the FT represents the condition (and the probability) that the success criteria are not met.

For any events described in an FT model, precision is the key factor to proper logic development. The statements entered in the top event (and other event boxes) are expressed as a fault (or a failure). The fault (WHAT condition) and when it occurs (WHEN condition) should be precisely stated. The WHAT condition describes the relevant failed (or undesired operating) state of the function, structure, system, or component (SSC). The WHEN condition describes the condition of the system that makes the WHAT condition a fault. For example, if the success criterion for the HVAC/HEPA requires only that it be available for 24 hours. The analyst should be as verbose as necessary to precisely define the fault condition. The event box in the tree diagram should not dictate the event description. Words, but not ideas, should be abbreviated if necessary.

An example of an undesired event sequence involves a runaway transporter train on the North Ramp during a descent to emplace a WP. After the occurrence of an event that initiates a runaway, automatic systems and human operators are called upon to arrest the runway before a derailment or impact on the WP occurs. The success criteria would be "runaway is controlled before train attains derailment speed on the North Ramp (during descent of the North Ramp)." The first part of the description defines the WHAT condition, and the phrase in parentheses defines the WHEN condition. The phase in parentheses might be omitted for brevity in the FT, but must be clearly stated in the definition of the condition of interest. The corresponding top event of an FT model would be "failure to control runaway before train achieves derailment speed during descent of the North Ramp," as illustrated in Figure 7-10. The name given to the top event is CONTRUN.

The specification of the WHEN condition during descent of the North Ramp may serve to identify the event, by contrast, to a similar event (e.g., during an ascent or the North Ramp, or during the descent of a different portion of the main tunnel, such as a North Ramp Extension). The WHEN condition may also assist in the definition of a specific time span, or mission time, during which success is required. 
Deductive logic is then applied successively at lower and lower levels of decomposition until the model is sufficient to support the analysis or has reached the lowest level of detail (e.g., at the component level).

Rule 2 - Development of Immediate Cause-The next step in FT development is to define the immediate, necessary, and sufficient causes for the top event. These causes are not the basic causes, but are immediate causes or immediate mechanisms. If all of the immediate causes are independent of each other and each fit definition of immediate, necessary, and sufficient to result in the top event, the top event is developed as an OR gate. If the top event occurs only if two or more causal events occur concurrently, then the top event is developed as an AND gate. The top event is often developed as an AND gate to represent some conditioning event that must be present for the fault to occur.

In the example "failure to control runaway before train achieves derailment speed during descent of the North Ramp," the immediate causes might be identified as "human operators fail to apply brakes in timely manner" and "failure of brake system to apply sufficient braking force upon demand." Since the occurrence of either event will result in the occurrence of the top event, the two events are input through an OR gate to the top event. At this stage of FT development, the definition of the immediate cause can be general or universal and does not require specific design details.

The development can be made more general, or inclusive, by replacing the causal event "human operators fail to apply brakes in timely manner" with "failure to detect runaway initiation and failure to apply brakes in a timely manner," which is illustrated in Figure 7-10 by the event named DETAPPL. This definition allows for flexibility in further development if it $\dot{\$}$ not known, or decided at the time of the analysis, whether human operators or automatic systems will be the primary means of detecting an initiation of runaway and actuating brakes. One application of the FTA is to assist in the determination of the design requirements needed to achieve the necessary functional reliability. The event DETAPPL is depicted as an undeveloped event by the use of a diamond under the event description box.

The timely manner phrase is a reminder that restrictions may be placed on the definitions of the causal events that correspond to the WHEN portion of the top event criteria. The mission-time parameters can be used in the event descriptions if they are known. For example, if the rate of acceleration and distance to the "point of no return" are known, a minimal response time can be specified (e.g., 30 seconds). The causal event might then be defined as "failure to detect runaway initiation and failure to apply brakes within 30 seconds." The probability of failing to respond could potentially be calculated from a time-dependent reliability model for the respective electronic and human systems and the required response time of 30 seconds.

The name BRKFORC is given to the event titled "failure of brake system to apply sufficient braking force upon demand," as illustrated in Figure 7-10. The event titled BRKFORC is depicted as an undeveloped event by the use of a diamond under the event description box. An explicit mission time could also be applied to the causal event titled BRKFORC. In this case, however, the mission time is defined as the "time on the ramp" during each descent operation (e.g., 30 minutes). The probability of failure on demand may be estimated from the system 
failure rate and the potential exposure time of 30 minutes. These matters are described further in the discussion of basic event quantification in Section 7.2.4.5.

All descriptive (causal) events located below the top event are termed Intermediate Events.

Rule 3 - Complete the Gate-All inputs to a particular gate (i.e., a boxed event description with an event name) should be completely defined before any of them are analyzed (decomposed) further. This rule is important for maintaining discipline in the deductive logic decomposition of a top event down to lower level events. All of the causal (input) events must be precisely defined, as described previously.

Rule 4 - No Miracles-The logical development of causal events is based on the occurrence of faults or failures in which the normal or expected functions do not take place. A corollary to this logical development is the No Miracles rule, as defined in the Fault Tree Handbook (Vesely et al. 1981). That is, if the normal functioning of a system, component or HAs propagate a fault sequence, it is assumed that the normal function occurs (i.e., there is no miraculous interdiction of the fault propagation). By contrast, if the normal functioning of a component blocks the fault propagation, then faults must be introduced into the tree to defeat the blocking function. This situation usually results in the introduction of an AND-gate: primary fault sequences are propagated upward in the tree and connected with the failure of the fault blocking function with an AND gate.

Rule 5 - Development of Intermediate Events-The immediate causes of the top event are each, in turn, treated like a top event and the immediate, necessary, and sufficient causes for each event are defined. This process is essentially a sequential application of Rule 2 that is continued down through the levels of assembly, continually transferring the point of view from failure mode (result) to the failure mechanism (cause). The process stops when the lowest level of resolution is reached, usually at the failure mode level of individual compone nts or subsystems. These are then represented as basic events.

This discussion continues with the example shown in Figure 7-10.

If it is possible in the system design for either a human or an electronic system to detect the need for applying brakes, and then to apply them, an event named DETAPPL is developed as an AND gate with two inputs. These inputs are titled AUTOSPD (the failure of autospeed controller to detect overspeed and apply brakes) and HASPEED (the failure of operator to detect overspeed and apply brakes), which is not illustrated in Figure 7-10. 


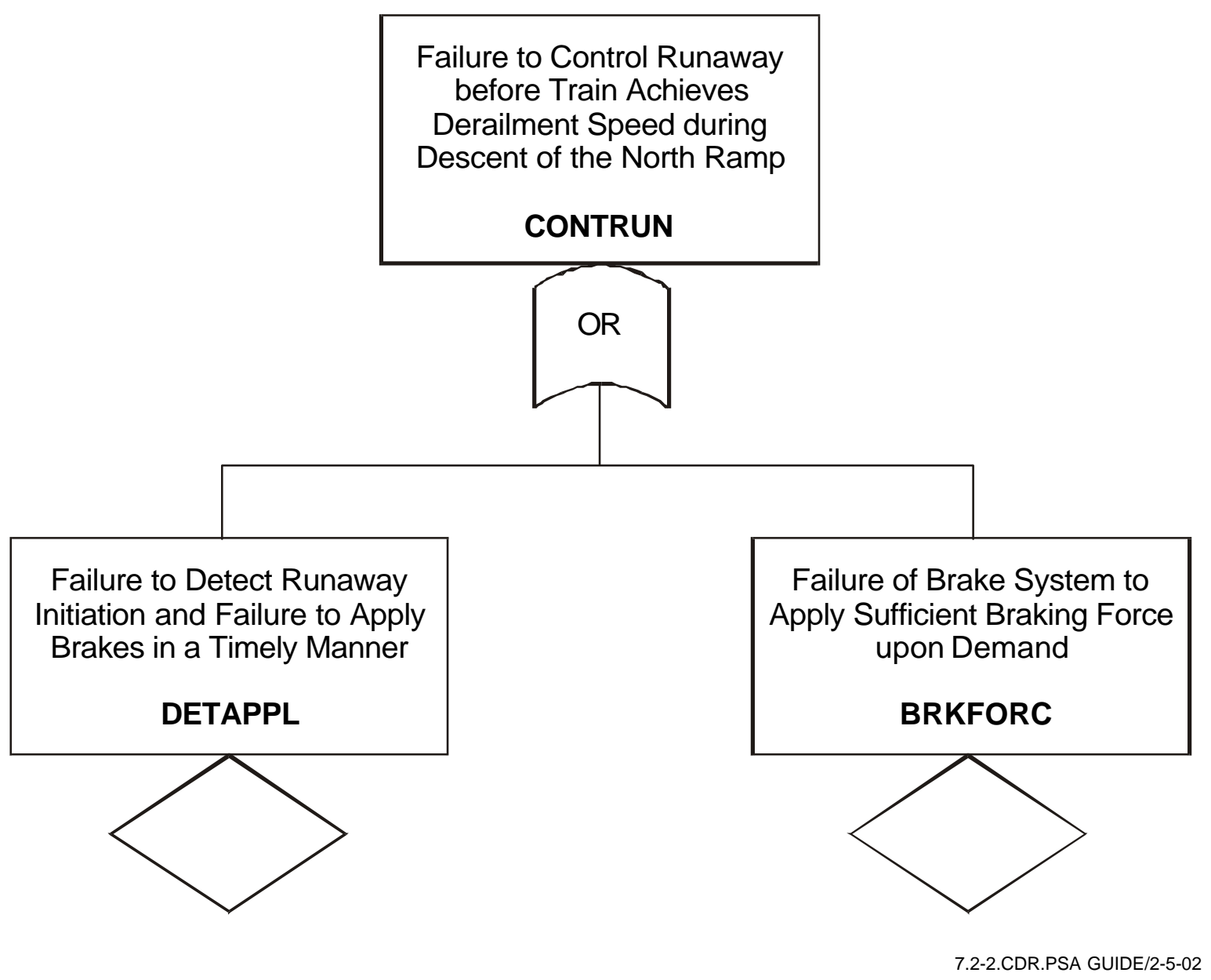

Figure 7-10. Illustration of Fault Tree Development

The event BRKFORC is developed as an OR gate since (in this hypothetical example) a failure of either a brake control system (the event titled BRKCONT) or a failure of the brake mechanisms (the event titled BRKMECH) will result in the event titled BRKFORC, which is not illustrated in Figure 7-10).

Rule 6 - Identify Potential Dependent or Common-Cause Failures-Note that the Fault Tree Handbook does not have a rule to explicitly identify and model common-cause or dependent failures. For emphasis, this PSA guide adds this rule to ensure that the PSA analyst does not overlook these important mechanisms (see Section 7.4).

\subsubsection{Basic Event Quantification}

Quantitative data are input at the lowest level of resolution of each branch of an FT. The analyst must ensure that the data are appropriate to the precise definition of the basic event. In the analysis of system reliability, the lowest level is usually the failure probability for a specific failure mode of a component. For example, in an FT for a fluid system, one or more branches would terminate in basic events such as "pump A fails to start," "pump A fails to run 6r eight hours," or "pump A out of service for maintenance." 
If the top event is quantified as a probability (e.g., probability that system fails to supply adequate cooling flow for 24 hours), then all input data must be expressed as probabilities (as unitless or per demand).

If the top event is quantified as a frequency of an undesired event (e.g., radioactive release from canister transfer system), however, then input data must be a mixture of probabilities and event frequencies or rates that become joined through AND gate(s). For example, there may be two scenarios that lead to the top event (filtered release and unfiltered release). The top event is shown as an OR gate. Under each of the intermediate events titled "filtered release" and "unfiltered release," respectively, there would be an AND gate. One input to each AND gate would be an IE (such as crane drops canister a distance further than design height) quantified as a frequency or rate of occurrence (i.e., per unit time) and an event representing the conditional probability of a "radioactive release given drop of canister further than design height" (unitless as per demand or per opportunity).

If the top event is quantified as a failure rate (e.g., "the system fails to supply adequate cooling flow" at a rate of ? [e.g., failures per million hours]) and only OR logic appears, then the basic input data generally are expressed as failure rates (units of inverse time). However, if the top event requires combinations of failures of subsystem or components (i.e., using AND gates), then all but one of the inputs to each AND gate must be expressed as a conditional probability (i.e., probability of failure per demand conditioned on the occurrence of the first, or triggering, event).

The product of a frequency and one or more probability terms is a frequency. It is never appropriate to multiple a frequency (or rate) by another frequency (or rate) because the resulting units are not physical (i.e., units of hours ${ }^{-2}$ have no meaning).

Section 7.5 provides guidance on developing input information for preclosure safety analyses. This section provides a brief discussion for continuity.

Available historical (actuarial) event data for the actual SSCs of a repository should be used to define the quantitative probabilities and frequencies used in FTA and ETA. Since there will be no repository operational data prior to the LA submittal, other sources of information are needed. Again, when available, performance data for SSCs of the same design and operational environment as that intended for each operation in a repository should be used. The analysis must otherwise proceed with the best available data for SSCs that closest resemble those to be used in the repository design, such as data from other fuel handling facilities. In many cases, especially for the LA-CA submittal, it will be necessary to use generic tabulated data (e.g., electrical data, electronic data, and various mechanical systems and components data used in many PRAs). In other cases, it will be necessary to use surrogate data (i.e., railroad accident statistics) to estimate the probabilities of events during WP transport. Except for direct data from repository operations, it may be necessary to modify the probabilities to account for conditions at the repository that are different from those for which the data represent. In some instances, the probabilities may be higher (e.g., a more severe operating environment). However, these probabilities could also be smaller in other cases because additional quality assurance or administrative controls would preclude or reduce the likelihood of some of the causes of failure in the surrogate database. See Section 7.5 for an additional discussion on this process. 
Basic event probabilities or failure rates are derived from experience data, as described in Section 7.2.3.4.1.

\subsection{Basic Event Probability}

An event probability is a pure number ranging from 0 to 1.0. As a probability, it is physically unitless. Component faults are characterized as one of the following probabilities:

- $\quad$ Failure on demand - the probability of a failure per demand

- $\quad$ Standby failure - the probability of a failure on demand after a given non-operational period, usually given as time-between-inspections

- $\quad$ Operational failure - the probability of failing to run or operate (provide required function) during a specified time period (i.e., the mission time).

The symbol used for the probability in discussions, tables, or qualitative FTA is very often a "p." However, in many cases the symbol "q" is used to connote the probability of failure (per demand), or unavailability (i.e., the probability of being unavailable when called upon for the time required).

The value of q may be derived directly from demand-based experience data, or indirectly from rate (or frequency) based experience data, as described in the following definitions.

Demand-Based Experience Data-K failures are observed in $\mathrm{N}$ challenges (demands) on components in records or test data. Demand-based data analysis would estimate the failure rate (or probability per demand), also termed the component unavailability, to be:

$$
\mathrm{q}=\mathrm{K} / \mathrm{N} \text { failures per demand }
$$

When a component or system failure probability is needed for quantifying an input to a basic event in an FT, q has the proper characteristic.

Rate Based Experience Data-M failures are observed in exposure (operational or test) time $\mathrm{T}$ for components in records or test data. Rate-based data analysis would estimate the failure rate in units of numbers of failures per unit time, also termed the component failure frequency, to be:

$$
?=\mathrm{M} / \mathrm{T} \text { failures per hour }
$$

When a component or system failure rate is needed for quantifying an input to a basic event in an FT, ? has the proper rate-based characteristic.

If the probability of failure (unavailability) of a component or system is needed, however, the rate data must be used to calculate an appropriate unavailability factor. 
Operational Unavailability (No-repair Model)-The unavailability of a component or system in the exponential reliability model without repair is calculated as:

$$
\mathrm{q}=1-\exp \left(-? * \mathrm{t}_{\mathrm{M}}\right)
$$

Where $t_{M}$ is the mission time and $q$ is the probability that that the component or system will not perform its safety function for at least a time $\mathrm{m}$ when it is needed. The expression for $q$ is usually approximated as

$$
\mathrm{q} \cdot ? * \mathrm{t}_{\mathrm{M}}
$$

when ?, $\mathrm{t}_{\mathrm{M}}$, or both are small values.

Standby Unavailability (with-repair or renewal)-The average unavailability of a system that is on standby but is periodically inspected at a time interval $\left(\mathrm{t}_{\mathrm{I}}\right)$ and repaired, if necessary, is given by

$$
\mathrm{q} \cdot\left(? * \mathrm{t}_{\mathrm{I}}\right) / 2
$$

where it is assumed that the component or system is as good-as-new after inspection or repair.

Common-Cause Failures-A more complete discussion of dependent failures and CCFs is presented in Section 7.4.

In developing FT models that include redundant components or subsystems, it is generally recognized that the joint probability of concurrent failure of two or more redundant components may not be the product of independent failure probabilities. That is, the failures of the individual components or subsystems may be dependent (i.e., coupled). This possibility is modeled in the FT when the construction rules are applied.

The probabilities of the CCFs are quantified using demand-based or rate-based parameters, as appropriate, for the event being quantified. In FTA for repository preclosure safety, it is expected that most CCF quantifications will apply the beta factor method (see Section 7.4) in a repository preclosure safety FTA. 


\subsection{Initiating Event Frequency}

When the purpose of an FTA is to quantify the frequency of an event sequence, the frequency of the IE must be scaled to match the operational load of the system. For example, the IE definition may be "crane drops SNF canister" and the quantification required would be " $F_{D}$ drops per year." The operational throughput of the system may be Zcanisters per year. Demand-based and rate-based data can be used to calculate the frequency of the IE, as explained in the following examples:

Demand Based: Experience data could show that the probability of dropping any given canister during a lift is $Q_{D}$ drops per lift (i.e., more precisely defined as the probability of a canister drop per lifting operation). If the frequency of lifting the canisters is $\mathrm{Z}$ per year, then the frequency of the postulated IE is:

$$
\mathrm{F}_{\mathrm{D}}=\mathrm{Z} * \mathrm{Q}_{\mathrm{D}} \text { (drops per year) }
$$

Rate Based: Experience data could show that the rate of dropping any given canister during operational time is $?_{\mathrm{D}}$ drops per hour (e.g., this rate might be derived from related information such as a crane failure rate). In this situation, the exposure time (or mission time) must be defined for each lift operation to derive the probability of drop per lift. The estimated time that each canister is suspended in a vulnerable condition during each operation is $\mathrm{T}_{\mathrm{L}}$ minutes. The probability of canister drop per lift is calculated as

$$
\mathrm{Q}_{\mathrm{D}}=?_{\mathrm{D}} * \mathrm{~T}_{\mathrm{L}} \text { (drops per lift) }
$$

The time units must be converted, as appropriate, in these examples.

Proceeding in the same manner as for the demand-based case, the frequency of the postulated IE is calculated as:

$$
\mathrm{F}_{\mathrm{D}}=\mathrm{Z} * \mathrm{Q}_{\mathrm{D}} \text { (drops per year) }
$$

\subsection{Human Error Probabilities or Rates}

Many basic events in FTs may represent human actions in operations or maintenance. In FTA, human actions are modeled to include the failure to perform some needed function or the commission of some erroneous action. These events are termed human failure events (HFEs). Special techniques have been developed for estimating the probabilities of various types of HFEs, as described in Section 7.3. In some instances, success events are modeled to include the positive effects of human actions (recoveries or interventions). The term "human failure event" is preferred over the term "human error" because the basic causes of an undesired event involving a human may be situational (contextual) and not a true human error. The techniques of human reliability analysis (HRA) are used to analyze situations where an HFE causes failure of a given safety function of a SSC and/or a human recovery action restores a failed safety function. HRA also includes the process of quantifying the probability of each human failure or recovery event. Section 7.3 describes the recommended approach for the support of the PSA HRAs for the respective phases of LA submittals. This section provides a brief guide to application of HRA in FTA. 
Quantification of the probability of an HFE is often described as human error probability (HEP), which is usually quantified in terms of the probability per opportunity (or exposure). The HFE is treated in FT logic as a mode of failure for a given component or system. It is sometimes helpful to examine each situation to identify the potential errors of commission, in which a human acts improperly (spuriously or induced by the contextual situation) to initiate an unwanted state or response of the system. It is also helpful to identify potential errors of omission in which the human fails to perform a required act that would prevent an unwanted state or response of the system. Such HFEs may occur during maintenance activities (including test, inspection, and calibration), leaving a system or component in an unavailable or failed state. They also may occur during on-line maintenance thereby initiating an unwanted event sequence or during operations also as an IE of an unwanted sequence, or as the failure to respond to, and recover from, an unwarranted condition.

\subsubsection{Examples of Application}

This section provides an example of the process for creating an FT logic model for the specific failure mode of a relatively simple system. The example is derived from the Fault Tree Handbook (Vesely et al. 1981, Section VIII) for the Pressure Tank System (Figure 7-11). The system is not necessarily similar to any repository systems.

\subsubsection{System Familiarization}

The first step in any FTA is to define the system and understand how it functions. This step is the necessary prerequisite for FT analyses as well as for hazards analyses, CCF analyses, and ET analyses.

Several operating modes are possible for the system configuration:

- $\quad$ Dormant mode

- $\quad$ Pumping mode

- $\quad$ Ready mode

- $\quad$ Emergency shutdown.

The function of each component of the system varies according to the operating mode. The function of the control system is to regulate operation of the pump. The pump brings in fluid from an infinite reservoir. Ten seconds are normally required to pressurize the tank.

The pressure switch contacts are closed when the tank is empty but open when the threshold pressure is reached. The opening of the pressure switch contacts de-energize the coil of relay $\mathrm{K} 2$, whose contacts then open to stop the power to the pump and cease pumping. The tank is fitted with an outlet valve that drains the tank; however, there is no pressure relief valve on the tank. When the tank is emptied, the pressure switch closes, thereby energizing relay $\mathrm{K} 2$ and the pump to repeat the cycle.

Switch S1 contacts are open in the dormant state, which de-energizes the coils of relays K1 and $\mathrm{K} 2$ and, thereby, opens the contacts of both relays. Relay K1 is self-latching and closes, and remains closed, after switch S1 is pressed momentarily to startup the system. The timer contacts 
remain closed in the dormant state (and during system startup) for up to 60 seconds of continuous energization. The timer is reset every time the power to the timer is interrupted by the opening of the pressure switch contacts. The timer provides an emergency shutdown function in case the pressure switch fails. If the pressure switch fails to break the pump control circuit, the timer contacts open to de-energize relay $\mathrm{K} 2$, whose contacts then open to stop the power to the pump.

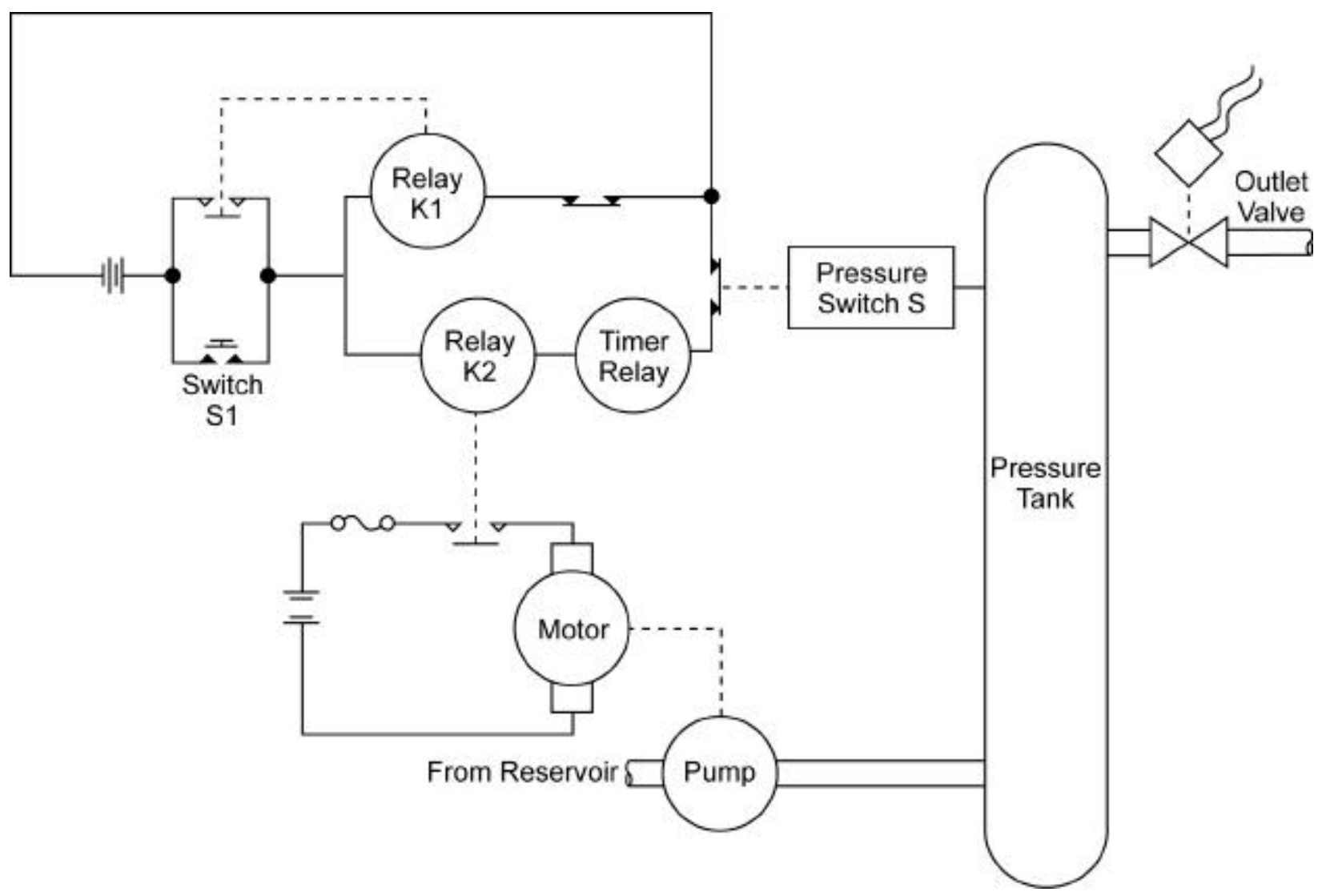

Source: modified from Vesely et al. (1981, Figure VIII-1).

Figure 7-11. Pressure Tank System

This system description is applied to an example of FT construction using the rules and definitions in the Fault Tree Handbook (Vesely et al. 1981). A skilled FT analyst may not go through the steps mechanically but would use such rules intrinsically.

\subsubsection{Fault Tree Construction for Pressure Tank Example}

It was decided in this example to resolve the FT down to the component level. Figure 7-12 shows the fault tree developed to the component level as described in the following paragraphs. 
The first step in the FT construction is to define the top event as a precise statement of the undesired system effect and a system failure mode of interest. This is an application of Rule 1.

Write a statement in the top event box as a fault. State precisely WHAT the fault is and WHEN it occurs.

For the example, the top event is defined as: Rupture of Pressure Tank After the Start of Pumping. The next step is application of Rule 2 and the immediate cause principle. The analyst identifies three immediate and necessary causes for the top event and adds an OR gate below the top event. One cause is identified as "Tank Rupture (Primary Failure)" to indicate the possibility of a random failure of a tank operating under normal, expected environmental conditions. This fault is shown on the FT diagram as a circle (i.e., a basic event). See Figure 7-12.

Two other immediate faults are identified. The first is named "tank ruptures due to improper selection or installation," which disqualifies the tank for the operating conditions. This fault is shown in the FT diagram as a diamond to indicate that it will remain undeveloped. As noted in the Fault Tree Handbook (Vesely et al. 1981), under the ground rules set for the analysis, this fault may be introduced for completeness and then immediately pruned from the tree as being outside the scope of the analysis. It is noted that the potential mechanisms are potentially related to a HFE in this example.

The other secondary fault is simply identified as such (i.e., tank ruptures (secondary failure)) to acknowledge that there may be several fault paths that can cause the top event by creating an environment or operating condition that is beyond the qualification basis of the tank.

Rule 3 is applied to complete the gate by explicitly diagramming the three faults under the top event.

Rule 2 is now applied to the event titled "tank ruptures (secondary failure)." Because this is a component fault, an OR gate is added under the event box and immediate causes are identified. In the example, two faults are identified. One is an undeveloped event titled "Secondary Tank Failure from Other Out-of-Tolerance Conditions (Thermal, mechanical);" the other input fault is titled "Tank Rupture due to Over Pressure Caused by Continuous Pump Operation >60 sec." This fault description is seen to be a precise statement of a fault that addresses the fault effect, mode, and mechanism in a single statement. It is concluded that this is not a component fault and therefore must be a system fault. The input to a system fault event box may be an OR gate, an AND gate, an INHIBIT gate, or no gate at all. In this case, motor running is a normal condition and results in a fault mechanism for the tank only if it runs for more than 60 seconds. Therefore, the fault is represented as an INHIBIT gate in which the input event is "pump operates continuously for $>60 \mathrm{sec}$ " and the conditioning event is "if pump runs $>60 \mathrm{sec}$ tank will rupture (probability $=1.0$ )." The conditioning event is not developed further; it is a statement of the condition or assumption.

The event titled "pump operates continuously for $>60 \mathrm{sec}$ " is developed further to identify the basic causal faults. The application of Rule 2 (principle of immediate cause), the analyst cannot identify the need for a gate because there is a unique event titled "pump motor runs for $>60 \mathrm{sec}$ " that is tightly coupled to the pump impeller. An application of Rule 3 (No Miracles) indicates 
that it cannot be assumed that the pump shaft will break or that the motor winding will burn out to avoid the undesired pumping time. The event titled "pump motor runs for $>60 \mathrm{sec}$ " is coupled directly to the event titled "power applied to pump motor $>60 \mathrm{sec}$," which is not shown in Figure 7-12. There are no miracles to interrupt the power; therefore, a "no gate" input is appropriate.

Applying Rule 5, the process is repeated for the event titled "power applied to pump motor $>60 \mathrm{sec}$ " (not shown in Figure 7-12). Using Rule 2 indicates that the immediate cause is "K2 relay contacts remain closed $>60$ sec." Thus, the FT structure below the INHIBIT gate input to "Tank Rupture due to Over Pressure Caused by Continuous Pump Operation $>60$ sec" appears as a series of intermediate events without any gates. This structure is typical of initial FT construction. As will be described later, the series of pass through fault descriptions do not contribute to FT evaluations either in qualitative or quantitative analyses. This series is usually collapsed into as few fault statements as possible without losing information.

Rule 2 is next applied to the fault titled "K2 relay contacts remain closed $>60 \mathrm{sec}$." This component fault requires the addition of an OR-gate. Three faults are defined as immediate causes. The fault "K2 relay contacts fail to open" is a primary failure. It is implied in the primary failure that all other portions of the relay unit are functioning properly; however, the relays do not open (perhaps because of corroded contacts or broken springs if the contacts are to open when the coil is de-energized). The secondary failure titled "K2 relay (secondary failure)" is included for completeness, but is not developed further. The command fault is titled "EMF [electromagnetic force] applied to K2 relay coil >60 sec;" it is developed further for defining the basic causes.

An examination of the control circuit indicates that the immediate cause is a condition that requires the concurrence of two events: "Pressure switch contacts closed >60 sec" AND "EMF remains on pressure switch when pressure switch closed $>60$ sec." An AND gate is added below "K2 relay contacts remain closed $>60 \mathrm{sec}$ " and the event boxes for the two input events are also added.

The development of the event titled "EMF remains on pressure switch when pressure switch closed >60 sec" proceeds in a similar manner. The development continued per Rule 5. The discussion of this example is terminated, however, because the process is repeated until every path down the tree from the top event is terminated at primary or secondary faults of components or command faults that are not developed further. The complete FT for the example is presented in Figure 7-12. The reader should consult the Fault Tree Handbook (Vesely et al. 1981, Section VIII) for the full description of the development of this FT example for the pressure tank system, as well as other examples.

Rule 6 should now be applied to examine the system for potential dependent or CCFs. Since the example system has nonredundant components, there are no CCFs to include. The FTA could be expanded to show explicit dependence on an external electric power supply. 


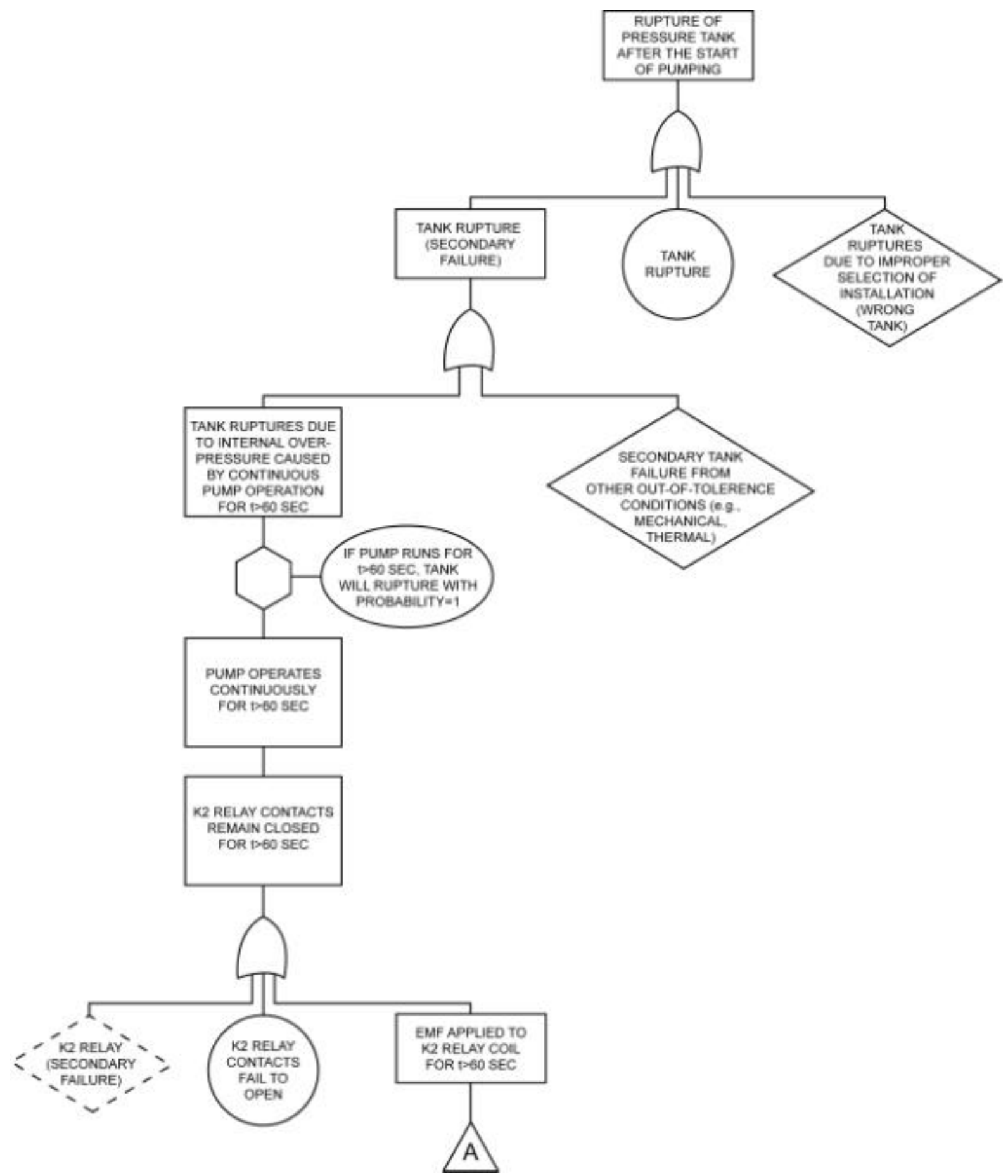

Source: modified from Fault Tree Handbook (Vesely et al. 1981, Section VIII).

Figure 7-12. Fault Tree Example for Pressure Tank Rupture (1 of 2) 


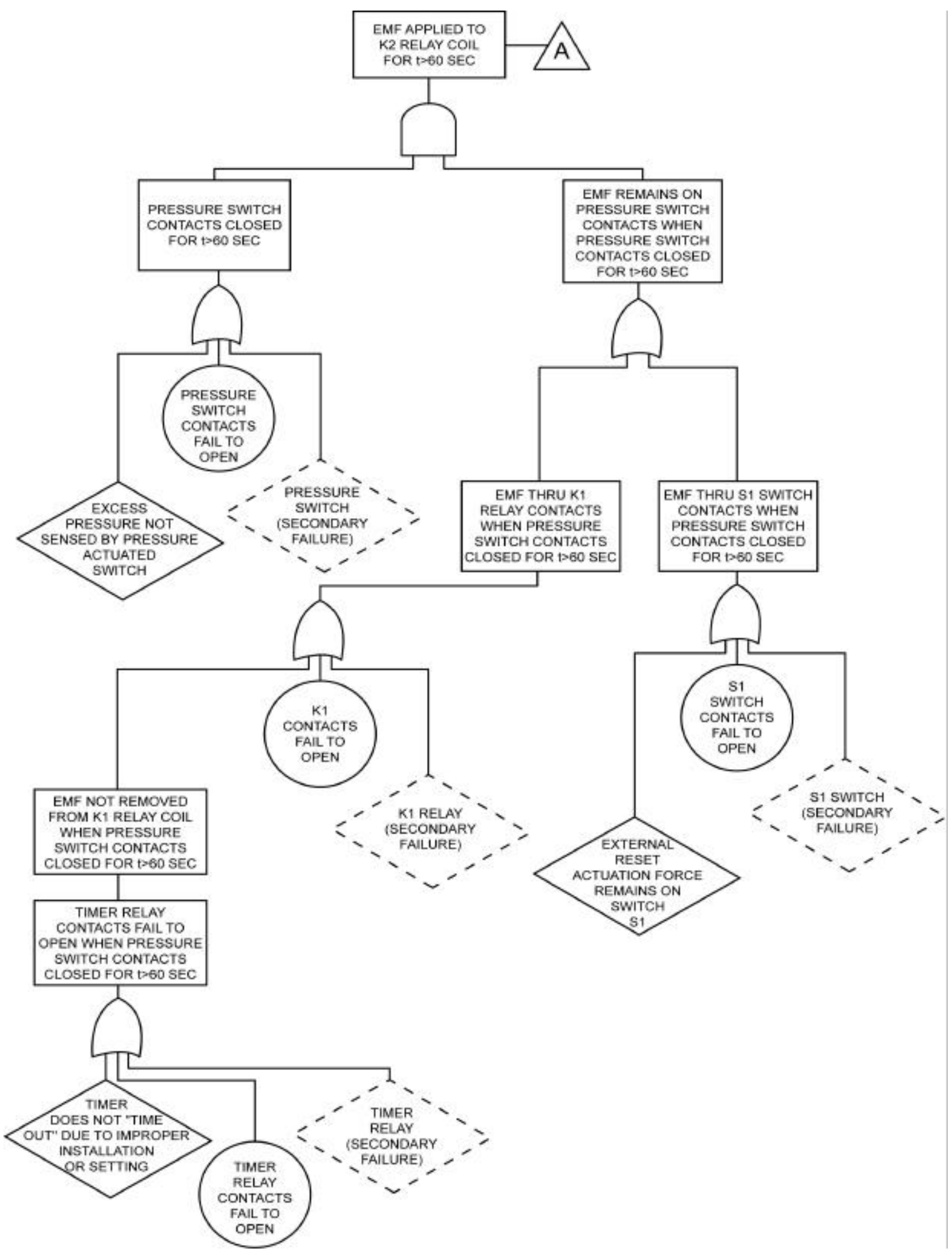

Figure 7-12. Fault Tree Example for Pressure Tank Rupture (2 of 2) 
The complete fault tree should be examined and simplified if it is too complete (i.e., contains events that do not contribute to the understanding of the basic causal factors or do not contribute to the analysis of minimal cutsets or quantification). The Fault Tree Handbook (Vesely et al. 1981), for example, deletes many of the secondary faults. As noted previously, many of the intermediate events can be deleted or merged with other event descriptions. The simplified FT, illustrated in Figure 7-13 terminates with primary failures. The primary failures are indicated by circles and are, therefore, treated as basic events in the FT structure.

Simplification of an FT is not necessary when using a program such as SAPHIRE to solve the FT for the minimal cutsets or for quantification. However, it may be advisable to simplify a complex FT for reporting. Documentation of complex trees may run from 10 to 50 pages if legible font sizes are desired. Such a presentation adds numerous TRANSFER IN and TRANSFER OUT symbols to the FT, making the FT very difficult to follow, especially for readers not familiar with FTs. Detailed trees are appropriate for documenting the analysis. However, simplification of an FT to a few (one to four) pages is recommended for summary reports, including those supporting an LA submittal.

\subsection{HUMAN RELIABILITY ANALYSIS}

\subsubsection{Purpose}

This section defines the bases and methods for the application of HRA in support of the PSA for a repository. The section defines the methodology for the treatment of human interactions in operational, administrative, and maintenance activities that are explicitly incorporated into the ET or FT logic models for the PSA.

\subsubsection{Scope}

This section presents a cursory, focused guide to the construction, application, and evaluation (both qualitative and quantitative) of HRA models. While some concepts are universal to all HRAs, the application in this section is focused on the support of the repository PSA. This section is not meant to be a textbook or exhaustive in scope. Where appropriate, reference is made to literature for additional information.

The HRA methods presented in this section provide a systematic process for identifying and evaluating human interactions that can affect the risk associated with preclosure operations of a repository and quantifying their probabilities.

\subsubsection{Overview of Approach}

An HRA is primarily an engineering discipline developed in support of system safety analyses, but may involve a multi-disciplinary team. HRA is frequently called human factors in PRAs or safety reports. While HRA is related to disciplines of Human Factors and Ergonomic Engineering, there are important differences. Human factors specialists, educated in the fields of ergonomics or behavioral science, are engaged at complex facilities, like NPPs or chemical processing plants, to design work situations that reduce the likelihood of errors by providing unambiguous instrumentation, logical arrangements of controls, ease of access, and ease of communications. 


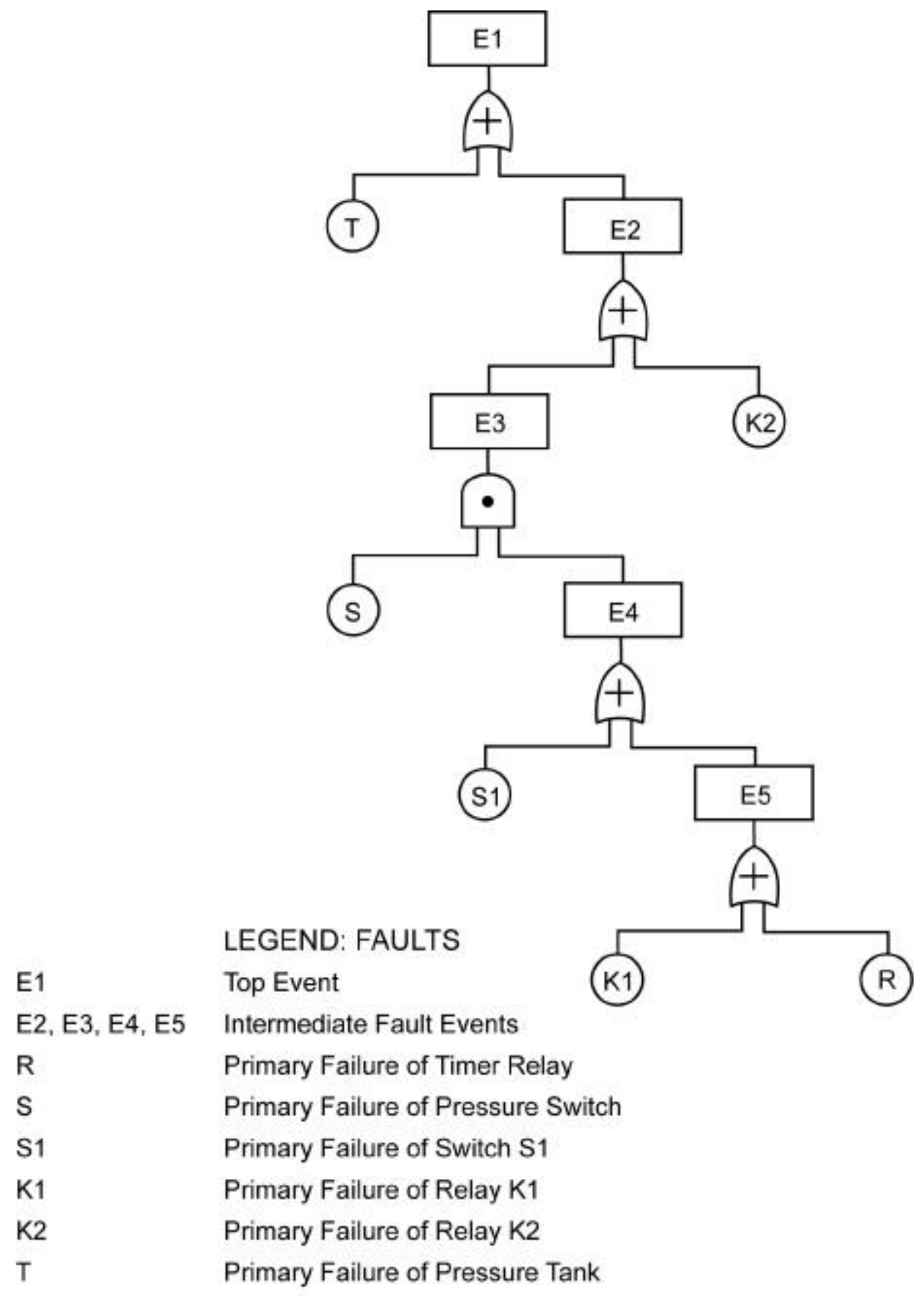

Figure 7-13. Simplified Fault Tree for Pressure Tank Example 
The human reliability analyst, by contrast, is usually an engineer or system safety analyst who can identify potential human events that can affect system safety. The human reliability analyst identifies where and how human interactions can influence the progression of event sequences, estimates the probability that a particular human action (HA) will be performed correctly and in a timely manner, and evaluates the effect on the frequencies of alternative event sequences. The HRA analyst can often estimate the probability of a human failure event (HFE) (i.e., performing a given HA incorrectly) using generic information. In more complex instances, unique to a particular operation, the human reliability analyst may be assisted by a Human Factors Specialist to identify and quantify the effects of performance shaping factors and error-forcing conditions, or to prepare a detailed task analysis as a framework for quantifying the probability of performing the task correctly and timely.

The HAs of interest to PSA are operational, maintenance, or administrative actions that can increase or decrease the probability of an unwanted event sequence. The important HAs are identified through the process of ET construction and the supporting FT construction. The ET or FT construction applies information provided by the Repository Design Project on such matters as operations and applicable operating procedures, system functions and layouts, instrumentation and controls, and throughput rate. Significant HAs may be modeled as event headings in ET construction.

This section presents a discussion of the HRA techniques that are to be applied in the PSA.

\subsubsection{Details of Approach}

Background-Advances in HRA were initiated as part of the evolution of PRA methodology. Early PRA studies during the 1970s (e.g., the Reactor Safety Study: An Assessment of Accident Risks in US Commercial Nuclear Power Plants (NRC 1975)) demonstrated the uses of ET and FT modeling of accident sequences for complex nuclear reactor power plants, and identified instances in which human interactions with the plant systems could hinder (exacerbate) or help (ameliorate) the initiation or propagation of event sequences. The Reactor Safety Study (NRC 1975) was supported by an early version of the Handbook of Human Reliability Analysis with Emphasis on Nuclear Power Plant Operations (Swain and Guttmann 1983). The early PRAs also served to identify areas where HRA methodology was weak and in need of improvement to adequately model the interactions and to quantify the probability of such actions.

During the past 30 years, research and data-gathering operations sponsored by the U.S. Nuclear Regulatory Commission (NRC), the Electric Power Research Institute, the Institute of Nuclear Power Operations, and others have produced many insights into the underlying causes of HFEs. The underlying causes include "unsafe acts" performed by humans that may be induced by "error-forcing conditions." Several methods for representing and quantifying the probabilities of HFEs have been developed (see Moieni for a review of many methods). The most recent attempt to improve upon HRA methodology is the ATHEANA study (NRC 2000).

Much of the HRA methodology has been developed to support PRAs for complex systems represented by NPPs and chemical process plants. Although the operations of a repository are not as potentially challenging to human operators as one of the more complex systems, and as 
not as susceptible to catastrophic results in the event of HFE, most of the HRA methods can be applied to the PSA, albeit with some simplifications.

Anatomy of an Accident-Post-event evaluations of many industrial accidents have shown that a high proportion can be attributed to some form of human error or human failure event (HFE). The term "human failure event" is preferred over "human error" because causes of an undersized event involving an HA may be situational (contextual) that virtually guarantees that the human fails to succeed (NRC 2000). Evaluations have shown that the type of HFEs involved in many catastrophes are caused by faulty diagnosis, flawed or missing communications, failure to perceive a signal or warning, decisions taken too late, and violations of procedure or rule. Hidden (latent) HFEs (e.g., faulty maintenance, or failure to return a system or component to service) can contribute to the progression or severity of an accident.

By comparing accidents across industries and performing an evaluation of their root causes, various authors (e.g., Joksimovich et al. 1993) have defined the anatomy of an accident in terms of "the four Ms:"

- Machine-The system design with basic flaws, control characteristics, and operator friendliness

- Milieux (Media)-Operating conditions (context), commercial and regulatory pressures, natural phenomena

- Man-Operator reliability in preventing accidents and controlling systems in emergency conditions; maintenance reliability

- Management-Flaws in safety culture, organizational influences, quality of procedures, training, and resources provided; reactions to political and regulatory pressures.

The evolution of PRA methodology has addressed each of the four Ms sequentially. Early PRAs concentrated on the effects associated with non-human influences (i.e., machine and milieux). The HRA research conducted over the past two decades concentrated on the human influences; first at the individual (man) level, and most recently, on the organizational influences (management) level.

As noted, the most recent attempt to improve upon HRA methodology was the ATHEANA study (NRC 2000). The term HFE was introduced in that study to eliminate the element of blame, which is viewed as implicit in the older term of human error. The basic premise of ATHEANA is that many HFEs are caused by contextual, or situational, conditions that virtually guarantee that the human operator will make the wrong decision or perform an unsafe act that results in an undesired plant state. The ATHEANA study provides a framework for identifying the causal factors that underlie an HFE. The ATHEANA study is oriented toward the post-accident responses of NPP operators.

This section describes the me thods that are appropriate to the PSA.

HRA Process and Structure-The processes of HRA may be addressed (via the risk triplet) by asking: what can happen, what are the consequences, and how likely is it? These questions are 
applied at any point in the development of an ET or FT whenever there is a known or potential human interaction with the systems or processes. Several methods have been developed to provide a structured process for addressing these questions. This section adapts the principal elements of the SHARP process (Section 7.3.4.1).

The answers to "what can happen?" identify where potential errors of commission can initiate or exacerbate an event sequence, where errors of omission can potentially occur (in which a human fails to take appropriate action to mitigate the sequence), or where the human can ameliorate the effects of prior HFEs or equipment failures by performing a recovery action. Refinements of this identification process take into account the operational context (e.g., the availability of instrumentation, crew size, the occurrence of a precursor event such as equipment failure, or prior HFEs). This evaluation is similar to the dependency analysis for events in an event sequence as described in Section 7.1.

The answers to "what are the consequences?" require the knowledge of the likely system response given the HFE or human recovery event. If a human closes a switch in the wrong system, or in the right system at the wrong time, how does the facility respond? Does this action require rapid recovery to avoid a significant release of radioactivity, or is it benign? If the consequences are deemed significant in quantifying the frequencies or radiological consequences of event sequences, then the third question will be addressed.

The answer to "how likely is it?" may be easy to answer for some well-known, generic HAs, or could involve an extensive analysis. In some applications, it is efficient to perform a conservative quantitative screening by assigning a high probability to the HFE, such as 1.0. If the HFE is not revealed as a significant contributor to the FT top event probability, or a sequence frequency, then the HFE can be eliminated and is not subjected to a detailed analysis.

There are several different methods for representation and quantification of probabilities of HFEs, as well as for human successes and recovery actions. Many of these methods are aimed at particular types of HAs. As part of the structured approach to HRA, potential HAs are categorized as one of three types:

Type A (Pre-Initiator HAs)-Type A characterizes HAs that occur before the IE of an event sequence. Type A HAs are typically are related to errors made during test and maintenance (T\&M) activities wherein a system is left in a state of unavailability or under-capacity. Both errors of commission and errors of omission can occur. This type of HA may be termed latent because its effect on the progression of an accident is unrevealed until the system is called upon. The potential effects of Type A HAs on system unavailability are usually modeled in system FTs.

Type B (HAs contributing to IEs)-Type B characterizes HAs that cause the initiation of an event sequence. Such events are not usually analyzed in PRAs for nuclear plants for which experience data exist for IEs. The human-related causes are considered to be implicit in the historical data For example, in estimating the frequency of crane load drops, the historical data may represent both mechanical failures and HFEs, but are not reported as separate causes. In general, Type B events may require construction of an HRA model for identifying HFE related 
IEs for a first-of-a-kind facility such as a repository. Type B HAs are usually errors of commission. Type B events are modeled in system FTs to quantify the likelihood of an IE.

Type C (Post-Initiator HA)-Type C characterizes HAs that occur after an IE as part of the process of mitigating an event sequence. Errors of commission and errors of omission can occur. The influence of Type $\mathrm{C}$ events on event sequences is modeled primarily in ETs. For some HRA quantification, it is appropriate to sub-divide Type $\mathrm{C}$ into:

- $\quad$ Type CP (Procedure Driven HAs)-This subtype refers to HAs that are procedurally driven by formal procedures (written emergency operating) or by informal procedures (learned training) that guide the human operator in performing a series of steps. The HFE may involve an Error of Omission wherein steps in a procedure are skipped, or an Error of Commission wherein the wrong procedure is applied, procedural steps of the correct procedure are performed in the wrong order or applied to the wrong system, or ignored in favor of an alternative (ineffective) strategy.

- $\quad$ Type CR (Recovery)-This subtype refers to recoveries of unavailable systems and of prior human errors. Such HAs may not be part of a procedure, but they rely on the knowledge of the operating crew. The human failure rate in this case is the failure to recover a given safety function within a limited time window.

\subsubsection{Structured and Systematic Approach for Incorporating HRA into PSA}

One approach for structuring the responses to the risk-triplet questions is termed SHARP (Hannaman and Spurgin 1984). The SHARP1 process (Wakefield et al. 1992) enhances SHARP, but this effort primarily is a rebundling of the seven steps into the first two of four stages (the other two stages are recovery analysis and internal review). These enhancements are not deemed relevant to the purposes of this guide.

The SHARP process defined seven steps for a structured systematic approach for incorporating HRA into a PRA. It was developed originally as a means to augment an existing PRA so as to improve its treatment of HRA. Pre-existing ETs and FTs are examined for HAs. For the PSA of a repository, however, HAs will be addressed as part of iterative development of ETs and FTs as the design details evolve. Much of the SHARP guidance fits well. Step 7 is a re-statement of the outputs of Sections 7.1 and 7.2, respectively. When all of the probabilities (and uncertainties) of HFEs and recoveries have been quantified, they are incorporated into the ET and FT logic models. Since all PSA analyses, including HRA, will be performed and documented according to Yucca Mountain Project procedures, the SHARP Step 7, Documentation, is not addressed in this section. 
Therefore, the remaining six steps of the SHARP process were combined to form a framework for conducting the HRA portion of the PSA. The following sections define the activities of each of the following steps:

1. Identification and Logic Modeling

2. Screening

3. Task Analyses

4. Representation, Models, and Quantification.

\subsection{Identification and Logic Modeling (Step 1)}

This step may be regarded as integral to the development ET or FT logic models as described in Sections 7.1 and 7.2, respectively. In general, Type A and B HAs will be included in system FT models as basic events that contribute to the top event expression for SSC unavailability. Figure 7-14 illustrates the manner in which a Type A HA is incorporated into a system FT. Figure 7-15 illustrates the use of a Type B HA as a contributor to an IE. The shaded boxes in the respective figures indicate the HAs.

A Type C HA (after an IE) will usually be modeled in ETs, but could be modeled in an FT in the same manner as a Type A HA. As noted in Section 7.1, HAs may be included as one of the event headings that define the logic structure of the ET. Potential dependencies between the HA and a precursor event can be identified as described in Section 7.1. Figure 7-16 illustrates how a Type C HA is included in an ET. The shaded event heading in the figure indicates the HA.

Step 1 also covers situations where preliminary ET or FTs have to be modified to include HAs. For example, preliminary logic models may be high-level or functional. After design decisions are made regarding the selection of specific types of equipment to accomplish the functions (the selection of, for example, manual versus automatic controls), there will be a better understanding of where and how humans can interact with the operational systems. The logic models will be updated accordingly.

The output of Step 1 is a comprehensive list of all of the potential HAs that affect the event sequences.

The quantification of the conditional probability of the HFE uses an appropriate method, as described in section 7.3.4.

\subsection{Screening (Step 2)}

The purpose of Step 2 is to reduce the number of HAs that require a detailed HRA. This step was developed as part of SHARP (Hannaman 1984) as a means for managing the HRA for complex event sequences and detailed system FT analyses that are experienced in the PRAs associated with nuclear reactor plants. If only a few HAs are identified, which is expected to be the case for the repository PSA, the screening process may not be required. Nevertheless, it is useful to survey the list of identified HAs to identify those that are likely to be most important to risk reduction.

Screening may be performed qualitatively or quantitatively. 


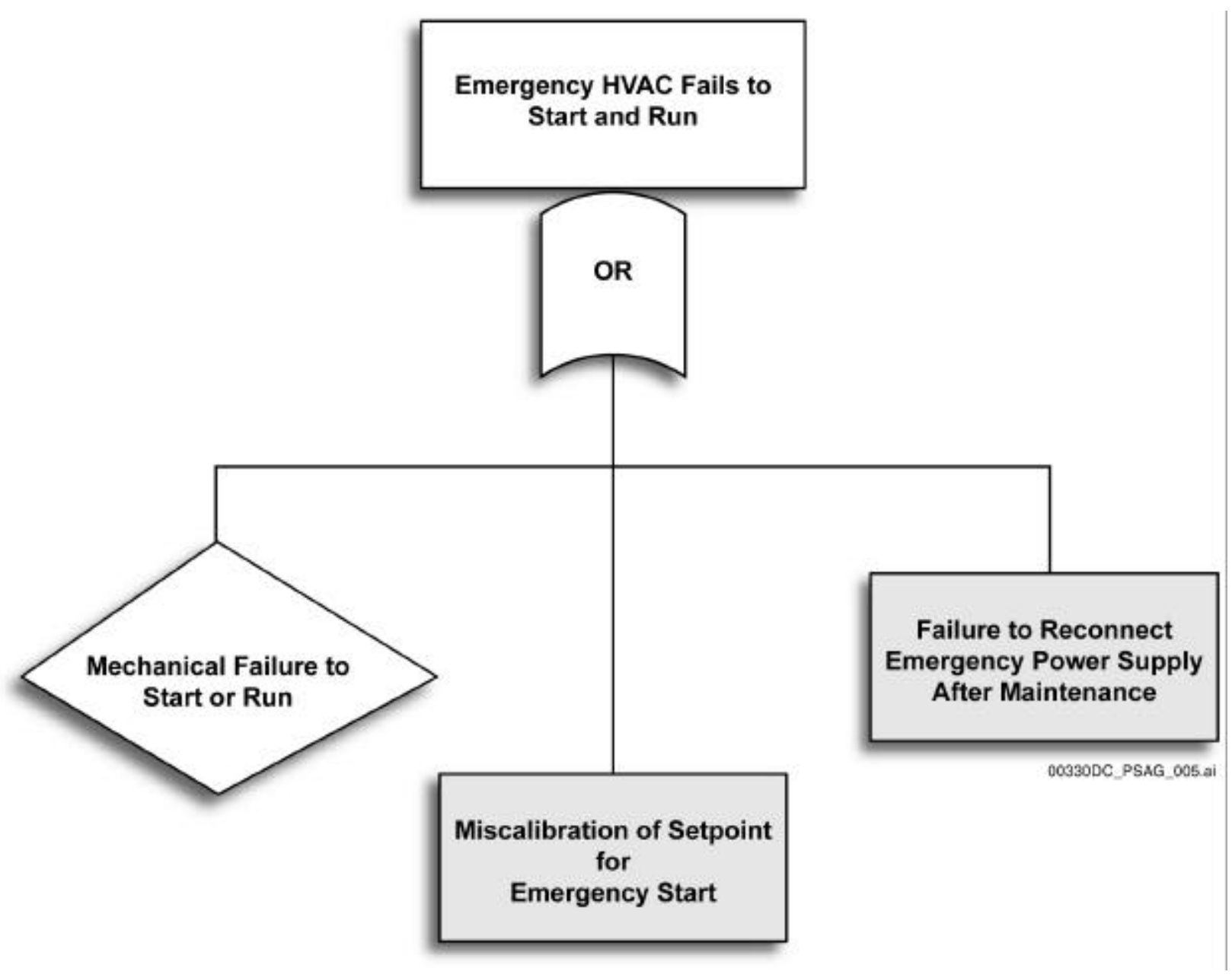

Figure 7-14. Example of FT Containing Type A Human Actions 


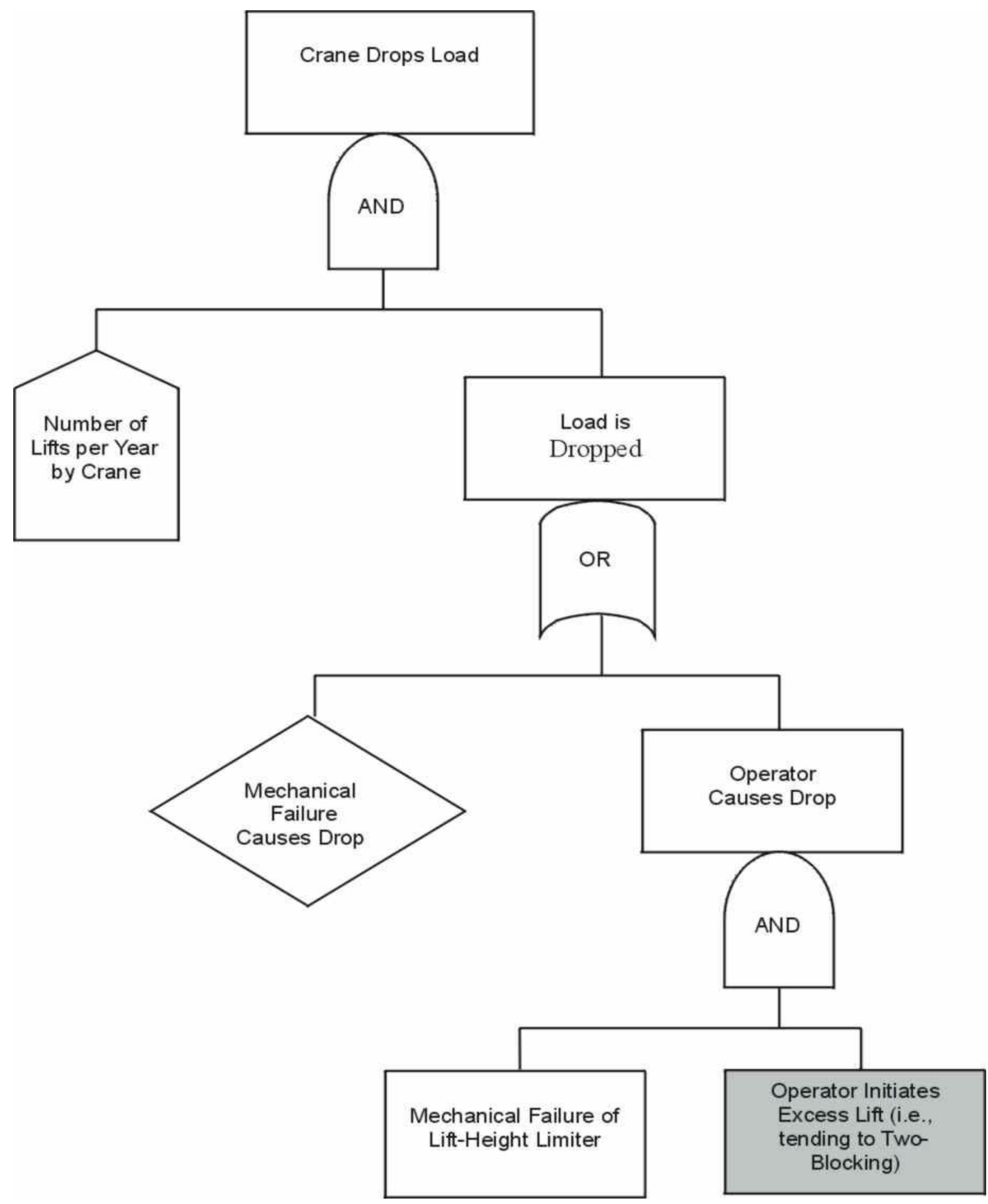

Figure 7-15. Example of FT Containing Type B Human Actions 
Example of Event Tree with Human Action in Event Headings

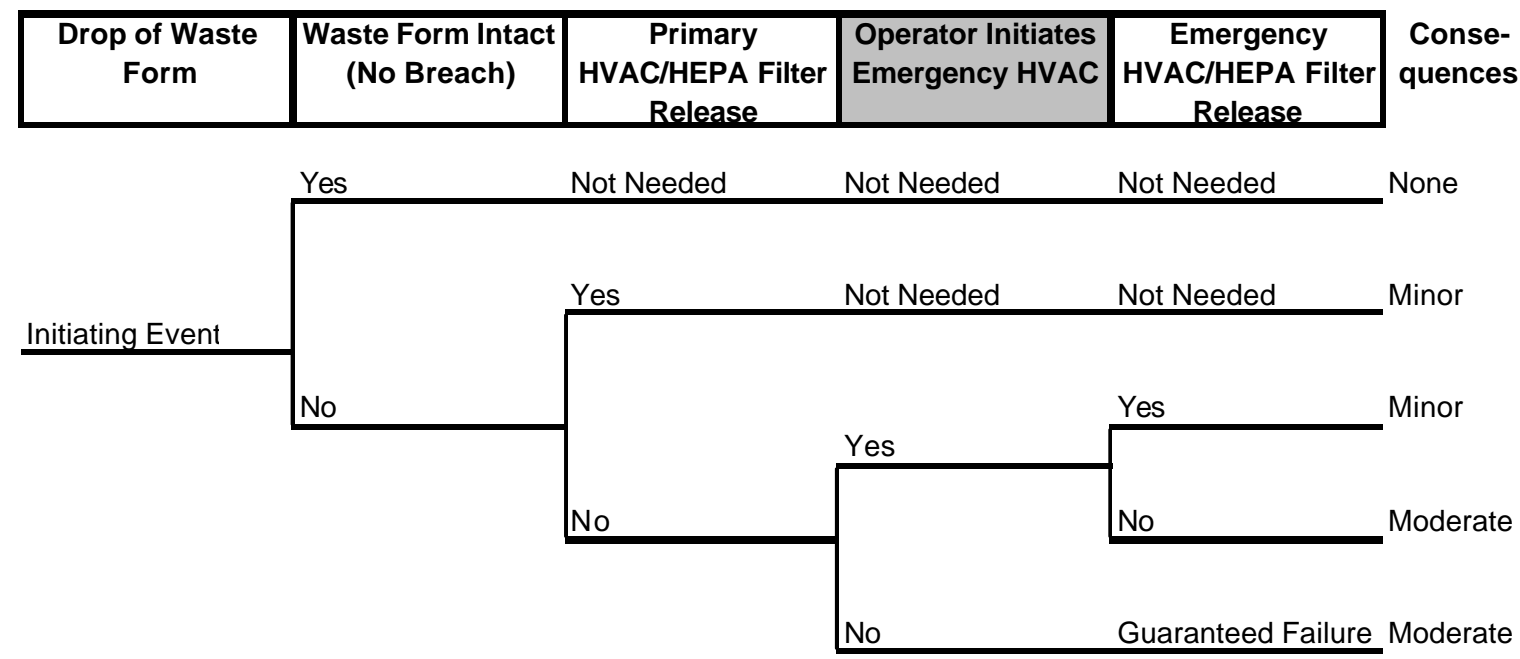

Figure 7-16. Example of ET with Type C Human Action in Event Headings

Qualitative screening rules are to be developed to fit the purpose of the PSA. The screening rules must be tailored to fit the safety function and the system characteristics of the MGR. Examples of qualitative screening rules for Type A (pre-IE) or Type B (part of IE) HAs include:

- $\quad$ Analyze (retain) miscalibration events because of potential CCFs

- $\quad$ Eliminate from consideration mis-alignment events where there is

- $\quad$ Automatic realignment on demand signal

- Interlocks to prevent operation with mis-alignment

- $\quad$ System status indicated in control panel, and

- $\quad$ The hardware is judged to have adequate reliability.

Examples of qualitative screening rules for Type C HAs include:

- Eliminate the HA from the logic model if the success or failure of the action has no influence on progression of an event sequence

- $\quad$ Retain a HA in the logic model if it changes the state of equipment that is required to respond to (mitigate) sequence progression

- Eliminate the HA from the logic model if physical limitations prevent action (e.g., requires access to radioactive or hostile environment, or if the time required is too short for a realistic HA). This means that no credit is taken for success of a recovery action in such a situation.

Quantitative screening is performed as a pre-test to determine the potential significance of a given HA to the unavailability of an SSC or to event sequence frequencies. Quantitative screening should be applied to Type A HAs because these events compete with hardware and 
software failures in system logic models and may only serve as backups to automatic actions. A coarse screening is performed in such cases by setting the probability of the human failure alternatively to 1.0 and 0.0 and comparing the top event probabilities in the two cases. If the difference is judged insignificant, then that HA does not need detailed analysis.

Quantitative screening of a HA in Type B HAs is similar to that of Type A. If non-human initiated causes dominate the probability of the initiating event, then the particular Type B HA does not require detailed analysis.

Since a Type C HA is judged important enough to explicitly model in ET headings, a probability screening may not rule out the need for a detailed analysis. On the other hand, the radiological consequences of performing a particular HA (e.g., restoring offsite power within " $X$ " hours) may be insignificant. In this case, that HA may also be excluded from a detailed analysis.

\subsection{Task Analyses (Step 3)}

This step is the initial step of detailed HRA. In the SHARP methodology (Hannaman and Spurgin 1984), this step is termed Breakdown. The objective of this step is to identify as specifically as possible within the level of available detail on design and operations, the tasks or actions that the particular human is required to perform, including any time restrictions. The human may be, for example, an equipment operator, a central control room operator, a T\&M technician, a health physicist, or a supervisor.

There may be detailed procedures for the specific task in mature designs that are applied in the task analysis. In earlier stages of design, before such procedures are available, the HR analyst will have to consult with the design and operations staff to define the principle tasks to be performed, the time restraints, and the man-machine interface that will be used (including the types and locations of controls, instrumentation, or other source of information).

A human-factors evaluation is then performed to identify the conditions and contextual environment associated with each task. The conditions and context are then used to identify the specific performance shaping factors and error-forcing conditions that will be used in the representation and quantification steps. The ATHEANA methods (NRC 2000) may be applicable in this part of the analysis.

Table 7-2a and Table 7-2b present an example of a task analysis for a hypothetical transfer of an SNF assembly that affects the IE and the emergency response.

It may be possible to identify and take credit for recovery actions to reduce the importance of the initial HFE as part of this step or after the quantification of the FT or ET.

Further, the results of a task analysis can provide guidance to the design and operations staffs to help develop procedures for normal and emergency operations, and/or to help improve the design (or requirements for) instrumentation and controls as means of reducing the probability of human error. 
Table 7-2a. Example of Task Analysis

Part A: Task Description and Context

\begin{tabular}{|c|c|c|c|c|c|c|}
\hline $\begin{array}{c}\text { Task } \\
\text { Number }\end{array}$ & $\begin{array}{c}\text { Task } \\
\text { Description }\end{array}$ & $\begin{array}{c}\text { Subtask } \\
\text { Description }\end{array}$ & $\begin{array}{l}\text { Location and } \\
\text { Environment }\end{array}$ & Indications & $\begin{array}{l}\text { Time } \\
\text { Factor }\end{array}$ & Other Factors \\
\hline 1 & $\begin{array}{l}\text { Transport } \\
\text { block to pickup } \\
\text { location }\end{array}$ & $\begin{array}{l}\text { Move bridge, } \\
\text { trolley, or both } \\
\text { into position }\end{array}$ & $\begin{array}{l}\text { Control Room } \\
\text { and Manual } \\
\text { Control }\end{array}$ & $\begin{array}{l}\text { Visual - coarse } \\
\text { position; CRT - } \\
\text { computer-aided } \\
\text { positioning }\end{array}$ & $\begin{array}{l}\text { Normal } \\
\text { speed for } \\
\text { throughput }\end{array}$ & $\begin{array}{l}\text { Procedures for } \\
\text { entire } \\
\text { operation } \\
\text { cycle; } \\
\text { extensive } \\
\text { training }\end{array}$ \\
\hline 2 & $\begin{array}{l}\text { Lower block to } \\
\text { height for } \\
\text { engaging load }\end{array}$ & & & $\begin{array}{l}\text { CRT - } \\
\text { computer aided }\end{array}$ & & \\
\hline 3 & Engage load & $\begin{array}{l}\text { Operate } \\
\text { remote grapple } \\
\text { to mate with } \\
\text { lifting lugs on } \\
\text { load }\end{array}$ & & $\begin{array}{l}\text { Panel lights for } \\
\text { limit-switch } \\
\text { position }\end{array}$ & & $\begin{array}{l}\text { Faulty lifting } \\
\text { lugs on } \\
\text { package may } \\
\text { prevent full } \\
\text { mating }\end{array}$ \\
\hline 4 & $\begin{array}{l}\text { Raise block to } \\
\text { transport } \\
\text { height (e.g., so } \\
\text { bottom of load } \\
\text { is six inches } \\
\text { above floor) }\end{array}$ & & & $\begin{array}{l}\text { Visual - coarse } \\
\text { position; CRT - } \\
\text { computer-aided } \\
\text { height monitor }\end{array}$ & & \\
\hline 5 & $\begin{array}{l}\text { Transport load } \\
\text { (supported by } \\
\text { cable and } \\
\text { block) to } \\
\text { transfer } \\
\text { location (move } \\
\text { bridge, trolley, } \\
\text { or both into } \\
\text { position) }\end{array}$ & & & & & \\
\hline 6 & $\begin{array}{l}\text { Lower block } \\
\text { until load is } \\
\text { supported by } \\
\text { target location }\end{array}$ & & & & & \\
\hline 7 & $\begin{array}{l}\text { Disengage } \\
\text { load }\end{array}$ & $\begin{array}{l}\text { Operate } \\
\text { remote grapple } \\
\text { to release } \\
\text { lifting lugs on } \\
\text { load }\end{array}$ & & $\begin{array}{l}\text { Panel lights for } \\
\text { limit-switch } \\
\text { position }\end{array}$ & & $\begin{array}{l}\text { Faulty lifting } \\
\text { lugs on } \\
\text { package may } \\
\text { prevent } \\
\text { release }\end{array}$ \\
\hline 8 & $\begin{array}{l}\text { Raise block to } \\
\text { transport } \\
\text { height (repeat } \\
\text { cycle) }\end{array}$ & & & & & \\
\hline
\end{tabular}


Table 7-2b. Example of Task Analysis (Continued)

Part B: Identification of Influence Factors and Potential Unsafe Acts

\begin{tabular}{|c|c|c|c|c|c|}
\hline $\begin{array}{c}\text { Task } \\
\text { Number }\end{array}$ & $\begin{array}{c}\text { Task } \\
\text { Description } \\
\end{array}$ & $\begin{array}{c}\text { Potential } \\
\text { Influence Factors }\end{array}$ & $\begin{array}{c}\text { Potential Unsafe } \\
\text { Acts } \\
\text { (Mistakes/Slips) }\end{array}$ & $\begin{array}{c}\text { Consequences of } \\
\text { Mistake/Slip }\end{array}$ & $\begin{array}{l}\text { Recovery } \\
\text { Potential } \\
\end{array}$ \\
\hline 1 & $\begin{array}{l}\text { Transport } \\
\text { block to pickup } \\
\text { location }\end{array}$ & $\begin{array}{l}\text { Computer } \\
\text { positioning } \\
\text { miscalibrated }\end{array}$ & $\begin{array}{l}\text { Mis-alignment of } \\
\text { grapple with lifting } \\
\text { lugs }\end{array}$ & $\begin{array}{l}\text { No engagement (not } \\
\text { a safety problem) }\end{array}$ & $\begin{array}{l}\text { Manual- halt } \\
\text { operation to } \\
\text { calibrate } \\
\text { computer }\end{array}$ \\
\hline 2 & $\begin{array}{l}\text { Lower block to } \\
\text { height for } \\
\text { engaging load }\end{array}$ & & & & \\
\hline 3 & Engage load & $\begin{array}{l}\text { Faulty lifting lugs; } \\
\text { failure of } \\
\text { engagement } \\
\text { indicators, } \\
\text { interlocks, or both }\end{array}$ & $\begin{array}{l}\text { Inadequate } \\
\text { engagement of lugs }\end{array}$ & $\begin{array}{l}\text { Uneven load; single } \\
\text { lug engaged; slap- } \\
\text { down of load }\end{array}$ & \\
\hline 4 & $\begin{array}{l}\text { Raise block to } \\
\text { transport } \\
\text { height (e.g., so } \\
\text { bottom of load } \\
\text { is six inches } \\
\text { above floor) }\end{array}$ & $\begin{array}{l}\text { Operator } \\
\text { distracted - too } \\
\text { routine; computer } \\
\text { aided height } \\
\text { control fails or not } \\
\text { used }\end{array}$ & $\begin{array}{l}\text { Raises load higher } \\
\text { than procedure } \\
\text { calls for }\end{array}$ & $\begin{array}{l}\text { Potential damage to } \\
\text { load - Contingent } \\
\text { upon subsequent } \\
\text { drop }\end{array}$ & $\begin{array}{l}\text { Lower back to } \\
\text { normal }\end{array}$ \\
\hline 5 & $\begin{array}{l}\text { Transport load } \\
\text { (supported by } \\
\text { cable and } \\
\text { block) to } \\
\text { transfer } \\
\text { location (move } \\
\text { bridge, trolley, } \\
\text { or both into } \\
\text { position) }\end{array}$ & $\begin{array}{l}\text { Operator } \\
\text { distracted - too } \\
\text { routine; computer } \\
\text { aided position and } \\
\text { speed control fails } \\
\text { or not used }\end{array}$ & & & \\
\hline 6 & $\begin{array}{l}\text { Lower block } \\
\text { until load is } \\
\text { supported by } \\
\text { target location }\end{array}$ & & & & \\
\hline 7 & $\begin{array}{l}\text { Disengage } \\
\text { load }\end{array}$ & & & & \\
\hline 8 & $\begin{array}{l}\text { Raise block to } \\
\text { transport } \\
\text { height (repeat } \\
\text { cycle) }\end{array}$ & & & & \\
\hline
\end{tabular}

Note: $\mathrm{CRT}=$ cathode ray tube (i.e., a computer monitor). 


\subsection{Representation, Models and Quantification (Step 4)}

The representation is the method (or logical framework) for organizing the information developed in Step 3. Selection of a representation method for a particular HA depends on the quantification method used for HA Type A, Type B, or Type C. The model is the equation(s) that result from the representation. Quantification is the process of assigning values to the parameters used in the model. Representation methods include:

- $\quad$ Simple success-failure

- $\quad$ HRA ET

- $\quad$ HRA FT

- $\quad$ Operator action tree (OAT).

The representation and models recommended for the PSA are described in the following sections.

\section{Type A (Pre-Initiator Human Actions)}

Type A HAs are typically test and maintenance (T\&M) errors (e.g., leaving an SSC in an unavailable or degraded state) or calibration errors (e.g., resulting in failure to actuate automatic safety functions when the conditions require). The methods described in Swain and Guttmann (1983), known as THERP, are applicable to a repository. THERP provides tables of human error probability (HEP) for many operational situations that are typical of NPP operations.

Figure 7-14 illustrates a simple FT that includes two Type A HAs (the FT is developed as part of Step 1). The top event is titled "Emergency HVAC Fails to Start and Run." Three causes of the top event are shown as inputs to an OR gate. One input is titled "Mechanical Failure to Start or Run." This event is shown as diamond indicating that the logic is undeveloped (see Section 7.2). One Type A HA is titled "Miscalibration of Setpoint for Emergency Start," and the other is titled "Failure to Reconnect Emergency Power Supply After Maintenance." The top event describes a probability to start or run, $\mathrm{q}_{\mathrm{SR}}$, which is termed the unavailability of the HVAC in a sequence frequency quantification. Therefore, all of the input events in Figure 7-14 must be represented as probabilities.

A representation of system or component unavailability due to a Type A maintenance or calibration error accounts for several factors:

- $\quad$ Initial HEP (Ei)

- $\quad$ Probability of non-recovery of initial error by self, crew, or supervisor (R)

- $\quad$ Single component or multiple components

- Whether or not the system or component availability is checked or monitored between T\&M intervals (announced versus unannounced unavailability) 
- The fractional time that the component or system is out-of-service (or miscalibrated) between periodic T\&M.

The generalized model for a Type A HA is:

$$
\begin{gathered}
\mathrm{q}_{\mathrm{SR}}=\left(\mathrm{p}_{\mathrm{HE}} * \mathrm{~d}\right) / \mathrm{T} \\
\mathrm{p}_{\mathrm{HE}}=\mathrm{E}_{\mathrm{i}} * \mathrm{R}
\end{gathered}
$$

where

$$
\begin{aligned}
& \mathrm{d}=\begin{array}{l}
\text { mean equipment downtime (or time in a miscalibrated state), in hours, between } \\
\text { scheduled } T \& M \text { with regular interval }(T) \text { hours }
\end{array} \\
& \mathrm{E}_{\mathrm{i}}=\text { initial HEP } \\
& \mathrm{R}=\text { probability of non-recovery of } \mathrm{E}_{\mathrm{i}}
\end{aligned}
$$

If the equipment outage or miscalibration is not checked or monitored between scheduled $\mathrm{T} \& \mathrm{M}$, the mean downtime is equal to the T\&M interval, and

$$
\mathrm{d}=\mathrm{T}
$$

and

$$
\mathrm{q}_{\mathrm{SR}}=\mathrm{p}_{\mathrm{HE}}=\mathrm{E}_{\mathrm{i}} * \mathrm{R}
$$

where

$$
\begin{aligned}
& \mathrm{d}=\text { mean equipment downtime (or time in a miscalibrated state), in hours, between } \\
& \text { scheduled T\&M with regular interval (T) hours } \\
& \mathrm{E}_{\mathrm{i}}=\text { initial HEP } \\
& \mathrm{R}=\text { probability of non-recovery of } \mathrm{E}_{\mathrm{i}}
\end{aligned}
$$

If the equipment outage or miscalibration is checked or monitored between scheduled $\mathrm{T} \& \mathrm{M}$, the mean downtime is a function of the efficiency of the checking (monitoring) function. Here efficiency is defined as the probability $\left(\mathrm{C}_{\mathrm{i}}\right)$ of detecting a prior error during the $\mathrm{f}^{\text {th }}$ check that occurs at an interval $\left(\mathrm{H}_{\mathrm{i}}\right)$ within the interval $(\mathrm{T})$. In this case, the mean outage (miscalibration) of the system or component is represented as the following:

$$
\mathrm{d}=\mathrm{H} 1+\mathrm{C} 1 * \mathrm{H} 2+\mathrm{C} 2 * \mathrm{H} 3+\mathrm{C} 1 \mathrm{C} 2 * \mathrm{H} 3+\ldots
$$

Values for $\mathrm{E}, \mathrm{R}$, and $\mathrm{C}_{\mathrm{i}}$ are estimated from experience data (if available) or from Swain and Guttmann (1983), or other appropriate source of information. Table 7-3 presents examples of the form of information contained in Swain and Guttmann (1983). 
The initial error, $\mathrm{E}_{\mathrm{i}}$, may be either an error of commission or an error of omission. Estimates of the parameters account for factors affecting the quality of T\&M, such as:

- T\&M procedures

- Training

- Use of independent checkers

- $\quad$ Tagging system (e.g., to avoid T\&M and calibration of wrong equipment)

- $\quad$ Administrative controls

- Safety culture.

The presence and quality of these factors will have to be assumed and documented for the PSA. The application in the quantification (Step 4) accounts for these factors.

Table 7-3. Example Probabilities of Errors of Commission in Operating Manual Controls

\begin{tabular}{|c|c|c|c|}
\hline Item & \multicolumn{1}{|c|}{ Potential Errors } & HEP & $\begin{array}{c}\text { Error } \\
\text { Factor }\end{array}$ \\
\hline & Select wrong control on a panel from an array of similar-appearing controls. & & \\
\hline$(2)$ & identified by labels only & 0.003 & 3 \\
\hline$(3)$ & arranged in well-defined functional groups & 0.001 & 3 \\
\hline$(4)$ & which are part of a well-defined mimic layout & 0.0005 & 10 \\
\hline & Turn rotary control in wrong direction (for two-position switches, see item 8): & & \\
\hline$(5)$ & when there is no violation of population stereotypes & 0.0005 & 10 \\
\hline$(6)$ & $\begin{array}{l}\text { when design violates a strong population stereotype and operating } \\
\text { conditions are normal }\end{array}$ & 0.05 & 5 \\
\hline$(7)$ & $\begin{array}{l}\text { when design violates a strong population stereotype and operation is } \\
\text { under high stress }\end{array}$ & 0.5 & 5 \\
\hline$(8)$ & Turn a two-pos ition switch in wrong direction or leave it in the wrong setting & c & \\
\hline
\end{tabular}

Source: Modified from Swain and Guttmann (1983, Table 20-12)

NOTES: ${ }^{a}$ The HEPs are for errors of commission only and do not include any error of decision as to which controls to activate.

${ }^{\mathrm{b}}$ If controls or circuit breakers are to be restored and are tagged, adjust the tabled HEPs according to Swain and Guttmann (1983, Table 20-15).

${ }^{\mathrm{c}}$ Divide HEPs for rotary controls (Items 5 through 7) by 5 (use same EFs).

\section{Type B (HAs Contributing to IEs)}

Type B HAs are typically operational or T\&M errors that cause a system or component to change state, and thereby initiate an abnormal operating condition that could propagate to a sequence of events leading to release or exposure to radioactivity.

Figure 7-15 illustrates a simple FT that includes a Type B HA (the FT is developed as part of Step 1). The top event is titled "Crane Drops Load" in a FT representation to estimate the frequency of the event. The house event represents the frequency of opportunities for the operator to err; it is titled "Number of Lift per Year." 
Two causes of the intermediate event titled "Load is Dropped" are shown as inputs to an OR gate. One input is titled "Mechanical Failure Causes Drop." This event is shown as a diamond indicating that the logic is undeveloped (see Section 7.2). The other intermediate event is titled "Operator Causes Drop." These two events will be quantified as probabilities per lift.

The event titled "Operator Causes Drop" is developed through an AND gate to represent that the event can happen only if both input events occur (i.e., that "Operator Initiates Excess Lifts (i.e., tending to Two-Blocking)" and "Mechanical Failure of Lift-Height Limiter" occur).

A representation for the HA titled "Operator Causes Drop" is illustrated next. The information from Step 2, Table 7-2, indicates that the operation is manually controlled. Table 7-2 defines the tasks to be performed by the operator:

- $\quad$ Transport the block to the pickup location (move the bridge, trolley, or both into position)

- $\quad$ Lower the block to the height for engaging the load

- $\quad$ Engage the load (e.g., operate the remote grapple to mate with the lifting lugs on the load)

- $\quad$ Raise the block to the transport height (e.g., so that the bottom of load is six inches above the floor)

- Transport the load (supported by a cable and block) to the transfer location (move the bridge, trolley, or both into position)

- Lower the block until the load is supported by the target location

- $\quad$ Disengage the load (e.g., operate the remote grapple to release the lifting lugs on load)

- $\quad$ Raise the block to the transport height (repeat the cycle).

The analyst now asks "what can happen?" with respect to dropping the load; that is, what erroneous actions could the operator take to cause the load to drop? While there may be several opportunities for the operator to cause the drop, this illustration will examine the task titled "Raise block to transport height." This task has the potential for causing a two-blocking event that can result in the overstressing and breaking of the lifting cable(s), resulting in a load drop from a height exceeding the normal transport height.

The operator is trained to raise the load only to the normal transport height (e.g., six inches) but the controller permits the operator to raise it higher, subject to a control interruption by an interlock that prevents the raising of the load to the two-blocking height. Each time that the operator performs the routine lift (that has been performed hundreds of times previously) a probability exists that the attention of the operator can be diverted. An initial error of commission is committed by holding the lift control too long and raising the load too high.

If the operator or other crew member realizes the commission of the initial error in a timely manner, the event can be recovered (i.e., the lift can be stopped and the load lowered). If there is 
no height-limiting device and no recovery, then the initial error will result in two-blocking event followed by a load drop.

The FT (Figure 7-15) leads to the following model (i.e., the Boolean expression for the FT events) for estimating the frequency of the IE:

$$
\mathrm{f}_{\mathrm{OD}}=\mathrm{f}_{\mathrm{LL}} * \mathrm{q}_{\mathrm{HL}} * \mathrm{E}_{\mathrm{O}} * \mathrm{R}
$$

where

$$
\begin{aligned}
& f_{\mathrm{OD}}=\text { frequency that load drops are initiated by operator error, drops per year } \\
& \mathrm{f}_{\mathrm{LL}}=\text { frequency of load lifts using crane (calculated from throughput), lifts per year } \\
& \mathrm{q}_{\mathrm{HL}}=\text { probability that lift-height limiter fails on demand, probability per demand } \\
& \mathrm{E}_{\mathrm{O}}=\begin{array}{l}
\text { probability of initial error that the operator attempts to raise the load to excessive } \\
\text { height probability per opportunity (probability per routine lifting operation) }
\end{array} \\
& \mathrm{R}=\text { probability that the operator fails to recover from the initial error }
\end{aligned}
$$

As in the case of a Type A HAs, the parameters $\mathrm{E}_{\mathrm{O}}$, and $\mathrm{R}$ are estimated from experience data (if available) or from Swain and Guttmann (1983). Table 7-3 presents examples of the form of information contained in Swain and Guttmann. Estimates of the hardware unavailability ( $\mathrm{q}_{\mathrm{HL}}$ ) are obtained from experience (see Section 7.5) or through FTA (see Section 7.2). Since Type B HAs may involve errors of commission induced by error-forcing conditions, the ATHEANA methods (NRC 2000) may provide an alternative approach for analysis.

\section{Type C (Post-Initiator HA)}

Type C HAs are actions taken by an operator in response to an IE or another event. The HAs of interest are those taken to a) prevent an event sequence from progressing toward a worse state, b) to mitigate the consequences of an event sequence, or c) that could worsen the situation. Generally, such HAs are included in the event headings of the ET for a given IE. It is important to show the HA in ET headings when (1) there are dependencies between the success of the HA and prior events in the ET (either an equipment failure or prior HFE) or (2) the success or failure of the HA represents a significant turning point in the evolution of event sequences (see Section 7.1).

For example, an ET heading in Figure 7-16 titled "Operator Initiates Emergency HVAC" might be an important action that would prevent a significant release of radioactivity following the drop and breach of a waste form. This action warrants its inclusion in an ET heading. The operator may be prompted early in the sequence to initiate the action by an alarm (e.g., radiation alarm, or loss of normal HVAC alarm), an operator, or (later) by secondary indications (e.g., radiation alarms in stack monitors). In addition there may be no secondary prompt; instead, the indication may rely solely on the attentiveness of the operator (and other staff). The success or failure of the alarm or prompts to alert the operator represent alternative conditions that affect the 
probability of the success or failure of the operator performing the HA. Thus, the representation of the HFE must account for the dependency on the alarm.

The probability of failure for some Type C HAs may be sensitive to the maximum allowable response time for the operator (or operating crew). Even if the response is correct but not timely, a HFE is said to have occurred. Special analytic techniques have been developed to evaluate the probability of human success (or failure) in time-limited situations.

In other cases, a Type C HA may be modeled as part of an FT for a system failure event that is represented in an ET heading. This is the case, for example, for a backup operator action to manually actuate a system that is supposed to start automatically. The ET heading represents the operation of the system; for example, a heading titled "Emergency AC power is available." The system is supposed to start automatically on the loss of the primary power supply. The system FT for the failure event titled "Emergency AC power is unavailable" would include events representing the failure of components, including the failure of the automatic backup actuation function. The backup operator action titled "Operator fails to actuate emergency AC power" would be ANDed with the automatic actuation event in the FT.

The following sections describe respective cases of Type C HAs.

\section{Type C HAs in Event Tree Headings}

This type of Type C HA has been the subject of a considerable amount of research and development, as well as the subject of a considerable amount of controversy.

The principal research on this HA has been directed toward a better understanding, representation, and quantification of the reliability of the operators of NPPs in preventing and mitigating severe accidents. Severe accidents for NPPs are event sequences that progress to undesired plant damage states that exceed the design basis accidents; namely, core damage and, possibly, loss of secondary containment. Because the probability of a HFE involves cognitive processes, this research has involved various multi-disciplinary teams of system-safety and PRA practitioners, behavioral scientists, human-factors specialist, NPP operators and operations supervisors, and operator training personnel.

The HAs of most interest to NPP risk assessment are, typically, time-critical and are performed when the operators are under extreme stress because they understand the severity of the evolving situation. However, there are other Type $\mathrm{C}$ HAs that are risk-significant for NPPs that are not as time-critical. These differences have led to different types of representations for the two classes of Type C HAs.

The hazards and operations associated with a repository do not pose demands on the operators with the severity of those associated with NPPs. In addition, the risk profile of a repository is not expected to be very sensitive to operator reliability for Type C HAs. Nevertheless, the efforts of the past three decades have led to advances in the understanding and development of alternative methods for the representation and quantification that can be applied in the PSA, where appropriate, to Type C HAs. The ATHEANA method was recently developed to deal primarily with Type C HAs (NRC 2000). 


\section{Operator Action Tree}

The Operator Action Tree (OAT) shown in Figure 7-17 is a generalized representation of Type C HAs. There are two main phases of operator response that are indicated across the top of the figure: detection, diagnosis, and decision phase, as well as Manual Action. The OAT, as shown, represents both time critical and non-time critical HAs. Two ET headings comprise the detection, diagnosis, and decision phase: Cognitive Processing/Procedural Mistakes and Failure to Process Information in a Timely Manner.

The event heading titled "Cognitive Processing/Procedural Mistakes" covers all of the information gathering and diagnosis that the operator performs (e.g., through the instrumentation or through phone or radio communications with from local operators) that make the operator aware of an off-normal situation. The indications are symptoms that are indicative of an event. Operators are trained to use the symptoms to diagnose the event and initiate appropriate actions.

As shown in the OAT, the failure to diagnose the event leads to a failure to perform the Type $\mathrm{C}$ $\mathrm{HA}$, as indicated by the " $F$ " at the endstate. The probability of this failure is shown as $\mathrm{p}_{1}$ in Figure 7-17. The representation, modeling, and quantification of $p_{1}$ have been the principal subjects of HRA research. Most recently, it was the primary motivation for the ATHEANA project (NRC 2000). Methods for quantifying $\mathrm{p}_{1}$ are discussed in a following section.

The event heading titled "Failure to Process Information in a Timely Manner" means that there is a finite time window within which the manual action must be started; if not, the action is performed too late. This non-action results in a failure to perform the Type C HA, as indicated by the " $F$ " at the endstate. The probability of this failure is shown as $\mathrm{p}_{2}$ in the Figure 7-17. Representation, modeling, and quantification of $\mathrm{p}_{2}$ have also been subjects of HRA research (e.g., Moieni et al. 1993). If the particular HA is not time-critical, this event heading, sequence branch, and endstate are deleted from the OAT.

The event heading in the Manual Action phase of the OAT is labeled "Manipulative Slips." The probability of the slip is indicated by $\mathrm{p}_{3}$ in Figure 7-17. The term slips is used to denote that at this point, the operator knows what to do and moves to the appropriate control to execute the desired action. For various reasons, including poor ergonomic design, the operator selects the wrong control or moves it to the wrong position. In addition, $\mathrm{p}_{3}$ includes the probability that all steps in a control action are not completed, or not completed within a required time window. The result is a failure to perform the Type C HA, as indicated by the " $F$ " in the endstate.

The probabilities, $\mathrm{p}_{1}$ and $\mathrm{p}_{3}$, (Figure 7-17) represent non-recovered mistakes and slips. In most cases, the final probability for $\mathrm{p}_{1}$ or $\mathrm{p}_{3}$ represents a product

$$
\mathrm{p}_{\mathrm{i}}=\mathrm{E}_{\mathrm{i}} * \mathrm{R}_{\mathrm{i}}
$$

where

$$
\begin{aligned}
& E_{i}=\text { probability of initial mistake (or slip) } i \\
& R_{i}=\text { probability of non-recovery of initial mistake (slip) } i
\end{aligned}
$$

The probability, $\mathrm{p}_{2}$, includes an implicit failure to recover within the allowed time. 
The probability of failing to perform the particular Type C HA is the sum of the three failure branches of the OAT (labeled F):

$$
\mathrm{p}_{\mathrm{HA}}=\mathrm{p}_{1}+\mathrm{p}_{2}+\mathrm{p}_{3}
$$

The $\mathrm{p}_{2}$ contribution to $\mathrm{p}_{\mathrm{HA}}$ is usually dominant when the time available of a given HA is of the same order as the time taken by a crew carrying out the response. However, $p_{1}$ can become dominant if the time available is greatly in excess of the time required to perform the task and conditions for forcing an error exist (Moieni et al. 1993).

The following sections describe the representations and models for the respective probabilities $\left(\mathrm{p}_{1}, \mathrm{p}_{2}\right.$, and $\left.\mathrm{p}_{3}\right)$. This is an elaboration of Step 4. These sections also describe the bases for quantifying the probabilities in Step 4.
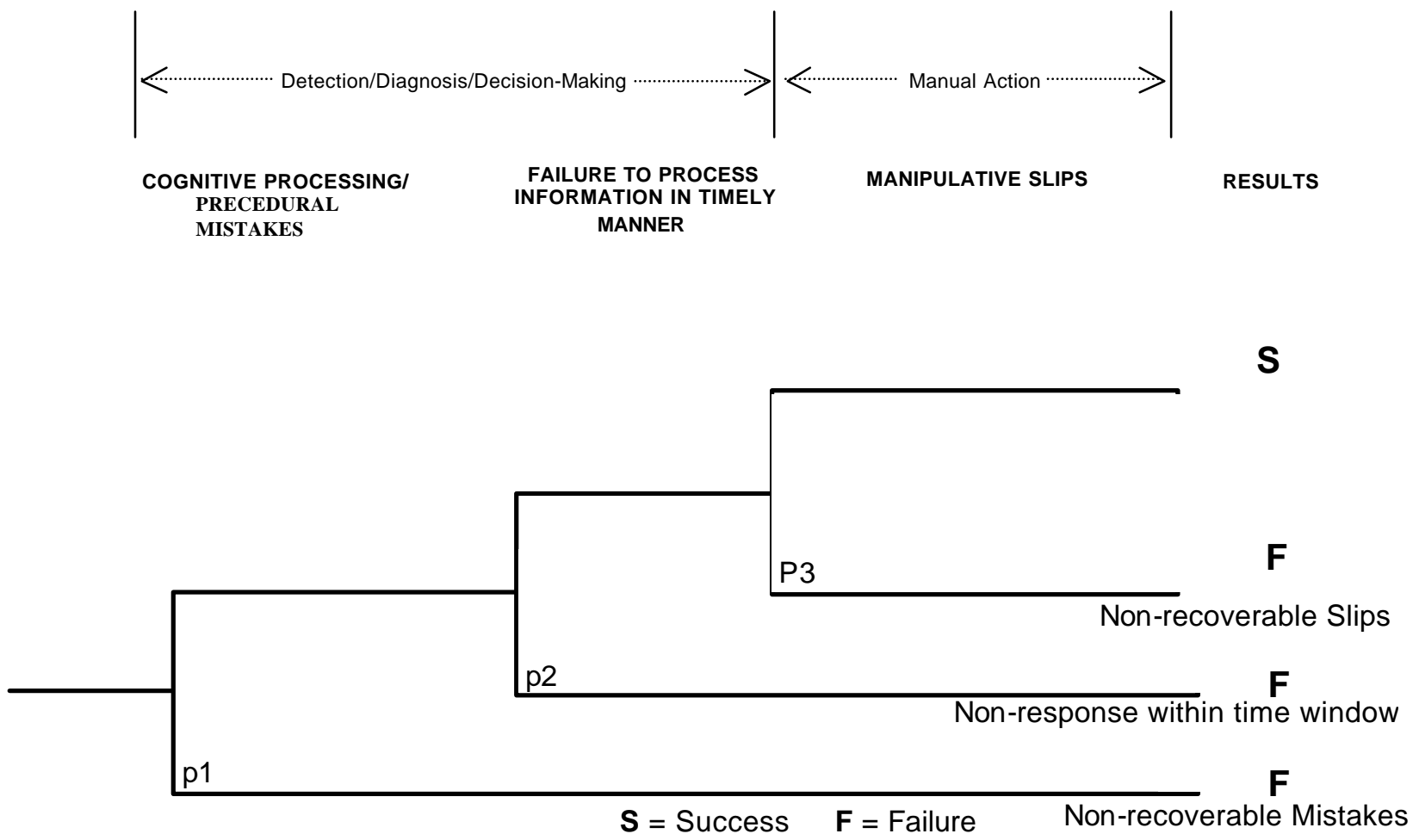

Figure 7-17. Operator Action Tree: A Generalized Representation of Type C HAs

\section{Representation, Modeling, and Quantifying $\mathbf{p}_{1}$}

Several methods have been developed for defining $p_{1}$ for NPP applications (e.g., Moieni et al. 1993). This portion of the detection, diagnosis, and decision phase for NPPs typically involves the use of emergency operating procedures that the operators follow to diagnose and respond to the event. Currently, NPPs use symptom-based emergency operating procedures that support decision making with cascading IF-THEN statements. While a repository will have emergency operating procedures, it is unlikely that they will be as complex as those of NPPs. 
All of the methods provide some means of identifying and quantifying the effects of causal factors (or error forcing conditions) and Performance Shaping Factors that affect the probability. Typical causal factors might be:

- $\quad$ Erroneous or incomplete procedures (e.g., have inadequate validation and verification)

- Inadequate training to help diagnose, or apply procedures

- Inadequate instrumentation or alarms

- $\quad$ Miscommunication among crew members.

Alternative approaches for quantifying p1 include:

- $\quad$ Swain and Guttmann (1983, Chapter 20)

- $\quad$ Decision tree (Moieni et al. 1993)

- $\quad$ ATHEANA (NRC 2000).

Some of the approaches for quantifying p1 may be inappropriate for representing the types of emergency operator actions expected in a repository. These alternative methods will be reviewed and adapted as appropriate to the PSA.

\section{Representation, Modeling, and Quantifying $\mathbf{p}_{2}$}

As noted in Moieni (1994), the $\mathrm{p}_{2}$ contribution to the total failure probibility, $\mathrm{p}_{\mathrm{HA}}$ (Equation 7-22) is normally dominant when the time available for a given HA is of the same order as the time taken by the crew in carry out the response. However, $\mathrm{p}_{1}$ can become dominant if the time available is greatly in excess of the task response time and error-causing conditions exist. In general, both $\mathrm{p}_{1}$ and $\mathrm{p}_{2}$ contribute to the non-success probability.

The heading of Figure 7-17, "Failure to Process Information in a Timely Manner," means that $\mathrm{p}_{2}$ must be represented by some kind of time-reliability correlation (or TRC). Such a representation is similar to a repair-time model wherein the analyst calculates the probability that a given set of repair actions are completed within a time "T."

The primary concept of a time-reliability model is that the probability of success increases with the amount of time available to complete a diagnosis and to perform the required action. The time available to perform a given diagnosis and perform an action is termed the "time window." The "time window" may be very short for some responses required in plant operation and quite long for other actions. If the time is short and an action is unlikely to be unsuccessful when performed by human, usually an automatic system is provided such that the human's role becomes a backup function (if time permits). The probability of success of human response in a time-limited situation becomes a joint function of the time window and the expected response time for an operator (or an operating crew). 
A simple exponential model has been applied as human reliability TRC in some early PRA studies (analogous to an exponential repair model) and may be an appropriate model for some HAs expected in the MGR operations. The exponential model for $\mathrm{p}_{2}$ is expressed as the following:

$$
\mathrm{p}_{2}\left(\mathrm{~T}_{\mathrm{W}}\right)=\exp \left(-\mathrm{T}_{\mathrm{W}} / \mathrm{t}\right)
$$

where

$\mathrm{p}_{2}\left(\mathrm{~T}_{\mathrm{W}}\right)=$ the probability that the HA fails to be performed within the allowable time,

$\mathrm{T}_{\mathrm{W}}=$ the maximum response time permissible ("time window") for the human operator,

and

$\mathrm{t}=$ the mean time for performing the required $\operatorname{task}(\mathrm{s})$.

It is observed in this model that the probability of failure tends to 1.0 if $\mathrm{T}_{\mathrm{W}}$ becomes very short, or if $t$ is significantly longer than $\mathrm{T}_{\mathrm{W}}$. Estimates of the mean response time, $\mathrm{t}$, can be developed from task analyses in association with the physical layout of the operations area. In this process, the location of controls of each task and subtask is noted. If the operator has to walk to another control panel at the other side of the room, or has to pick up a phone to call a local operator, has to take a meter reading before proceeding, has to reset an interlock, etc., the mean time for the operator to arrive at the control and take action can be estimated by cognizant operation personnel, human factors analysts, or from a human factors handbook.

For example, suppose the mean time to go a back panel to start a second train of the HVAC system is 10 seconds (i.e., $t=10$ ). If the time allowable for this action in a given event sequence is 60 seconds $\left(\mathrm{T}_{\mathrm{W}}\right)$, the value of $\mathrm{p}_{2}$ is calculated as follows:

$$
\mathrm{p}_{2}\left(\mathrm{~T}_{\mathrm{W}}\right)=\exp \left(-\mathrm{T}_{\mathrm{W}} / \mathrm{t}\right)=\exp (-60 / 10)=\exp (-6)=0.0025
$$

which means "the probability that the operator fails to perform the task within allowed response time $\mathrm{T}_{\mathrm{W}}$ is 0.0025 ." If the time window is only 30 seconds, then $\mathrm{p}_{2}\left(\mathrm{~T}_{\mathrm{W}}=30\right)=0.05$.

The uncertainties in the exponential model include uncertainties in both $\mathrm{T}_{\mathrm{W}}$ and $\mathrm{t}$. The uncertainties in $\mathrm{T}_{\mathrm{W}}$ stem from the uncertainties in the plant system model (e.g., how much time is available before an event sequence reaches a "point of no return"). The uncertainties in t depend on many factors including the ergonomic design of the human-machine interface, the operator training, and other contextual factors that may influence the operator's (or crew's) mean response time.

This model may suffice for MGR PSA, but there are other TRC models that have been developed to predict the reliability of reactor operators during their response to off-normal situations, sometimes aided by symptom-based emergency operating procedures (EOPs). 
One version of such an approach is the Human Cognitive Reliability (HCR) model that fits measurements of operator-crew response times to a Weibull distribution. Further research performed EPRI in the Operator Reliability Experiments (ORE) program resulted in a modification of that model to the HCR-ORE that shows that a log-normal distribution fits the data better than a Weibull or exponential distribution. (Moeini et al. 1993)

In the HCR-ORE model, the median crew response time $\left(\mathrm{T}_{1 / 2}\right)$ and the logarithmic standard deviation $\left(\mathrm{s}_{\mathrm{L}}\right)$ are the key measured variables derived from observations of several crews performing the same series of tasks. The ORE, in particular, collected response time data for crews responding to reactor accidents simulated on full-scale training simulators. The operators were compelled to follow written emergency operating procedures (EOPS) and work as a crew wherein the senior operator reads the procedures and directs the actions of two or more assistants. The median response time and logarithmic standard deviation for each of several tasks were quantified. In the HCR-ORE model, the $\mathrm{p}_{2}\left(\mathrm{~T}_{\mathrm{R}}\right)$ is calculated as follows:

$$
\mathrm{p}_{2}\left(\mathrm{~T}_{\mathrm{R}}\right)=\quad \operatorname{Pr}\left(\mathrm{T}_{\mathrm{R}}>\mathrm{T}_{\mathrm{W}}\right)=1-\mathrm{F}\left[\ln \left(\mathrm{T}_{\mathrm{W}} / \mathrm{T}_{1 / 2}\right) / \mathrm{s}_{\mathrm{L}}\right]
$$

where

$$
\begin{aligned}
& \mathrm{F}[.]=\text { standard normal cumulative distribution function } \\
& \mathrm{T}_{\mathrm{R}}=\text { response time of a given crew } \\
& \mathrm{T}_{\mathrm{W}}=\text { allowable response time based on event sequence progression, } \\
& \mathrm{T}_{1 / 2}=\text { median crew response time based on measurements of several crews, and } \\
& \mathrm{s}_{\mathrm{L}}=\begin{array}{l}
\text { logarithmic standard deviation }\left(\mathrm{s}_{\mathrm{L}}\right) \text {, based on measurements of several } \\
\text { crews. }
\end{array}
\end{aligned}
$$

$\mathrm{p}_{2}\left(\mathrm{~T}_{\mathrm{R}}\right)$ gives the probability that the response time of a crew, selected at random, will exceed the allowable response time, thereby resulting in a failure to respond in time. In this approach, the analyst must estimate the parameters $T_{1 / 2}$ and $s_{L}$. The original HCR/ORE produced values derived from measured response times. For general application, the analyst must develop reasonable estimates of $\mathrm{T}_{1 / 2}$ and $\mathrm{s}_{\mathrm{L}}$ based on task analyses. The value of $\mathrm{s}_{\mathrm{L}}$ is estimated from the situational factors, described in Moieni et al. (1993), that relate to the kinds of alarms and indictors that prompt the operators. Uncertainties in the crew response times are embodied in $\mathrm{s}_{\mathrm{L}}$. Uncertainties in $\mathrm{T}_{\mathrm{W}}$ stem from the uncertainties in the plant system model (e.g., how much time is available in a given event sequence.

As an example, assume there is an event sequence where the operator has to diagnose a situation that (1) a fuel assemble has been dropped and breached and (2) the HVAC with HEPA filtration is not functioning properly because the transfer cell confinement is not secured so that radioactive releases are bypassing the HEPA filter. Assume the following values are applicable:

$$
\begin{array}{ll}
\mathrm{T}_{\mathrm{W}} & =30 \text { minutes, } \\
\mathrm{T}_{1 / 2} & =12 \text { minutes, and }
\end{array}
$$




$$
\begin{array}{ll}
\mathrm{s}_{\mathrm{L}} & =0.5 \\
\mathrm{p}_{2}\left(\mathrm{~T}_{\mathrm{R}}\right)= & \operatorname{Pr}\left(\mathrm{T}_{\mathrm{R}}>\mathrm{T}_{\mathrm{W}}\right)=1-\mathrm{F}\left[\ln \left(\mathrm{T}_{\mathrm{W}} / \mathrm{T}_{1 / 2}\right) / \mathrm{s}_{\mathrm{L}}\right]=1-\mathrm{F}[\ln (30 / 12) / 0.5]=1-\mathrm{F}[\ln (5)] \\
& =1-\mathrm{F}[1.609]=1-0.946=0.054 .
\end{array}
$$

This model fits the general requirements for a TRC because $\mathrm{F}$ [.]:

- Increases with a larger time window, TW, so p2 decreases, and

- $\quad$ Decreases with larger median response time, T1/2, so p2 increases.

In addition, $\mathrm{F}$ [.] also decreases with larger logarithmic standard deviation, $\mathrm{s}_{\mathrm{L}}$, so $\mathrm{p}_{2}$ increases.

Another format of TRC is presented in Section 12 of Swain and Guttman (1983). The methods consider response times on the order of one minute to 1,000 minutes. Tables and figures are provided with descriptions of their applicability.

\section{Representation, Models, and Quantification of $p_{3}$}

The $\mathrm{p}_{3}$ probability represents the chance of a non-recovered slip by control operators. This type of HA is generally viewed as non-cognitive and the requirements are well known to the trained operator.

Alternative representations of $\mathrm{p}_{3}$ depend on the complexity of the manual actions to be performed. If the action is simple, such as changing the position of a single switch or controller, then a binary, success or failure, representation suffices. If the action requires multiple steps then either a HR FT or Swain and Guttmann HRA tree can be us ed to delineate the various steps and the conditional probabilities of the sequential steps. These representations include dependencies between steps.

The representation, modeling, and quantification must include the effects of performance shaping factors (e.g., quality of ergonomic interface of indicators, controls, communications, training, and the complexity of task).

The basic source of information on quantification is The Handbook of Human Reliability Analysis with Emphasis on Nuclear Power Plant Operations (Swain and Guttmann 1983). This document, called THERP, has extensive tables of generic error types. For example, Table 7-2 illustrates the kind of information found in THERP, such as an error titled "Select wrong control on a panel from an array of similar-appearing controls" (Swain and Guttmann 1983, Table 20-12). As illustrated in Table 7-2, THERP provides recommended values for the HEP and EF for lognormal (LN) distribution. The analyst must provide justification for applying any of the THERP values to the PSA. See Section 7.6 and Section 9 for discussions of uncertainties and EFs.

The HEP values and EFs in THERP are given for various configurations and operating conditions. For the example previously quoted, the HEP and EF are 0.003 and 3, respectively, if controls are identified by labels only. If the control is part of a panel where controls are arranged 
in well-delineated functional groups, then the HEP is given as 0.001 with an EF of 3 . Further, several ancillary tables provide adjustments for various performance-shaping factors and operating conditions. Again, for the example quoted, a footnote reads, "if controls are to be restored and are tagged, adjust the tabled HEPs according to Table 20-15." (Swain and Guttmann 1983)

For a single step HA, such as "Start emergency HVAC with Switch No. 1234," located in a well-delineated functional group and there are no performance shaping factors outside the nominal range, the representation and quantification are given as:

$$
\begin{aligned}
\mathrm{p}_{3}= & \mathrm{HEP} \text { (tabulated for conditions, adjusted for performance } \\
& \text { shaping factors) with EF } \\
= & 0.001(\mathrm{EF}=3)
\end{aligned}
$$

The representation for multiple-step HAs is a compounding of the single action case with consideration of dependencies. That is, if the operator slips on the first action without recovery, the execution of the second and subsequent actions may be missed because the operator is executing a practiced, but erroneous, series of manipulations. The representation may be an HRA tree or a human-reliability FT, depend ing on the HA to be modeled.

As an example, a HRA tree is illustrated in Figure 7-18. HRA trees are introduced by Swain and Guttmann (1983). The control action consists of two steps: A - "Start emergency HVAC with Switch No. 1234," which is located in a well-delineated functional group; and B - "Close HVAC damper between Zones 2 and 3 with switch D56." This action requires that the switch be held in the closed position until the damper completely closes. Swain and Guttmann (1983, Table 20-12, Item 10) gives this HEP as $0.003(\mathrm{EF}=3)$.

Following the convention of Swain and Guttmann (1983), the branches in Figure 7-18 are labeled with capital letters represent failure to execute and small letters are the success branches. If there are no recoveries, the representation for $\mathrm{p}_{3}$ is:

$$
\mathrm{p}_{3}=\mathrm{A}+\mathrm{B}
$$

and the quantification is:

$$
\begin{aligned}
\mathrm{p}_{3} & =\mathrm{HEP}_{\mathrm{A}}+\mathrm{HEP}_{\mathrm{B}}(\text { with composite EF }) \\
& =0.001+0.003=0.004(\mathrm{EF}>3)
\end{aligned}
$$

where $\mathrm{HEP}_{\mathrm{A}}$ and $\mathrm{HEP}_{\mathrm{B}}$ are the human error probabilities for actions $\mathrm{A}$ and $\mathrm{B}$, respectively.

If recoveries are possible at Step 1 or Step 2 (illustrated by dashed lines in Figure 7-18), the probabilities of non-recovery $\left(\mathrm{R}_{\mathrm{A}}\right.$ and $\left.\mathrm{R}_{\mathrm{B}}\right)$ are inserted into the representation as follows:

$$
\mathrm{p}_{3}=\mathrm{HEP}_{\mathrm{A}} * \mathrm{R}_{\mathrm{A}}+\mathrm{HEP}_{\mathrm{B}} * \mathrm{R}_{\mathrm{B}} \text { (with composite } \mathrm{EF} \text { ) }
$$




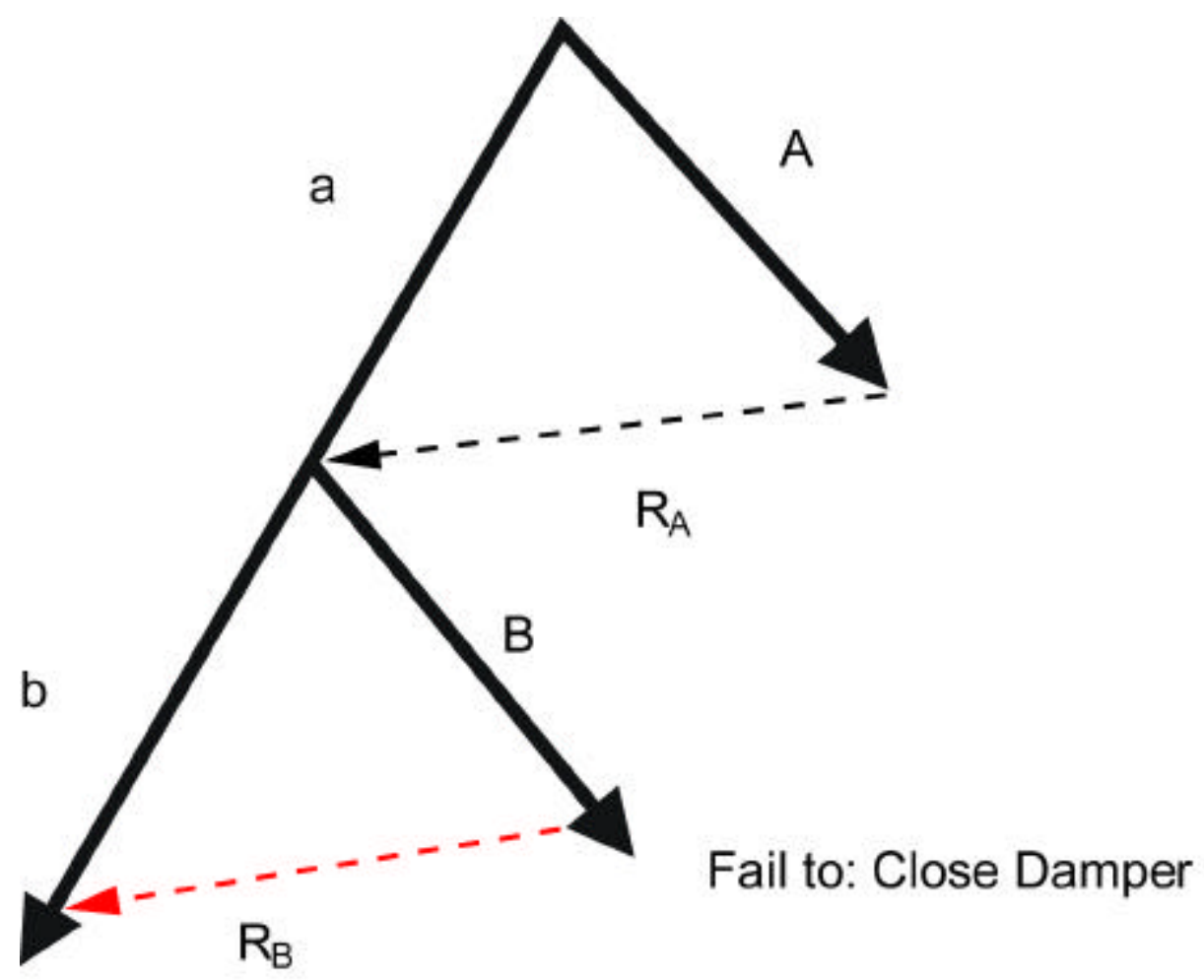

\section{Probability of Human Failure to Start Emergency $\mathrm{HVAC}=\mathrm{A}+\mathrm{B}$}

O0330DC PSAG 008. \&

Figure 7-18. Example of Human Reliability Analysis Tree

For example, if $\mathrm{R}_{\mathrm{A}}=0.1$ and $\mathrm{R}_{\mathrm{B}}=1$ (non-recoverable) the quantification becomes:

$$
\mathrm{p}_{3}=(0.001) *(0.1)+(0.003) *(1.0)=0.0031 \text { (with composite EF) (Eq. 7-27) }
$$

The representation must also consider if the order of execution is important because of potential dependencies. For example, suppose the HVAC damper has to be fully closed before the emergency HVAC can be started (i.e., an interlock prohibits starting the HVAC). In this particular example, the representation is further complicated by the dependency on the reliability of the hardware (interlock) as well as the human reliability:

$$
\mathrm{p}_{3}=\operatorname{HEP}_{\mathrm{B}}+\operatorname{HEP}_{\mathrm{A}} *\left(1-\mathrm{q}_{\mathrm{IL}}\right)+\mathrm{q}_{\mathrm{IL}}, \text { (no recovery) }
$$

where

$$
\mathrm{q}_{\mathrm{IL}}=\text { probability of failure of interlock, failures per demand }
$$


If $\mathrm{q}_{\mathrm{IF}}=0.0001$, for example, $\mathrm{p}_{3}$ is quantified as:

$$
\begin{aligned}
\mathrm{p}_{3} & =0.003+0.001 *(1-0.0001)+0.0001 \\
& =0.0032
\end{aligned}
$$

\subsection{COMMON-CAUSE AND DEPENDENT FAILURES ANALYSIS}

\subsubsection{Purpose}

This guide defines the bases and methods for identifying and analyzing common-cause and dependent failures in support of the PSA. These CCFs and dependent failure analyses support event sequence analyses through applications in ETA and FTA. In addition, this section provides a link to HRA, which is an important contributor to CCFs and dependent failures.

\subsubsection{Scope}

This section is a guide to the systematic identification and analysis of common-cause and dependent failures. While some concepts and methods are universal to safety and risk analyses of nuclear, chemical, and other facilities, the approaches and examples are focused on the support of a repository PSA. The guide provides methods that are expected to be acceptable to the NRC. The guide is not meant to be a textbook or exhaustive. Where appropriate, reference is made to literature for additional information. The systematic identification of potential CCFs and dependent failures is part of the development of event sequence logic models, i.e., ETs described in Section 7.1, FTs described in Section 7.2, and external events analyses described in Section 10. Examples of CCF applications are described in Sections 7.1, 7.2, and 10.1, Seismic Analysis.

In particular, this section will provide guidance in the following areas:

- Method(s) used to identify and screen important dependent failures in SSCs that affect preclosure safety

- $\quad$ Application of qualitative versus quantitative evaluations, where qualitative analysis is used to postulate, identify, and eliminate potential dependent failures through a screening process

- Quantitative methods for use when evaluating FTs, ETs, and event sequence frequencies

- Data requirements and sources

- $\quad$ Treatment of external events as potential common-cause IEs and how dependent failures of SSCs are conditionally linked to external hazard frequency

- $\quad$ Differences in approach and level of design detail and operational detail considered for the LA-CA submittal in contrast to the LA submittal to receive and possess nuclear materials 
- $\quad$ Application of software packages (e.g., SAPHIRE, and the Microsoft Excel spreadsheet program).

\subsubsection{Overview of Approach}

The term common cause events refers to a specific class of dependent events that must be considered in reliability analyses of safety systems in support of a PSA or PRA. CCFs are encountered when considering the causes of, and probabilities of, basic events at the component level in system logic models (e.g., FTs).

"Explicit" dependent failure is used to define those dependent events that can be directly attributed to physical phenomena and identifiable causal factors. Causal factors include inter-system dependencies that are hard-wired inter-connections; physical interactions between components or systems, such as missiles or sprays; environmental factors such as extreme temperatures or humidity; and HAs, including miscalibration of instruments or T\&M. System analysts include the explicit dependent failures in the system or plant logic models. That is, functional dependencies can be indicated in ETs to impose boundary conditions on event probabilities for events that occur later in the ET. In addition, functional dependencies of front line systems on support system are directly modeled in FTs as either basic (or undeveloped) events or as a transfer to the FT model of the support system. Likewise, cascading or propagating failures and operator actions to respond to events are modeled explicitly. Identified maintenance errors are modeled directly in the FTs.

The probabilities of such dependent events are quantified with appropriate equipment failure rates, T\&M intervals, and human-error probabilities. In some cases, physical interaction probabilities can be explicitly calculated, such as the probability of a spray or missile from the first failed component causing a failure in two or more additional components in the same or different systems.

By contrast, the term "implicit" dependent failures is used to define the potential occurrence of unidentified specific causal factors that can defeat the independence between redundant systems or components. Such dependencies are modeled in ET and FT logic as basic events as "pseudo-components" that are not physically present in the system design. The probabilities of such events are quantified using "implicit" or "parametric" analyses in which the failure rate information for various components is partitioned into independent and dependent rates.

Initially the plant or system logic model (e.g., FT) is developed with the basic events considered to be independent failures. Explicit intersystem dependencies are modeled as described above. Potential dependencies among components (basic events) that have not been explicitly modeled in the logic model are identified and modeled as pseudo-events in the FT models to represent CCFs. The probabilities of the CCFs are quantified with methods described in NUREG/CR-4780 (Mosleh et al. 1988). Only a brief acknowledgement of alternative methods is provided here since the simplest model for CCF analysis, the beta factor model, suffices for most preclosure safety analyses of a repository. If deemed appropriate, this desktop guide can be revised to include more advanced methods of treating CCFs. 


\subsubsection{Definitions}

The following definitions taken from NUREG/CR-4780 (Mosleh et al. 1988) are of the principal terms used in this section.

Independent Event-This is an event in which a component state occurs causally unrelated to any other component state. Two events, A and B, are independent if and only if:

$$
\mathrm{p}(\mathrm{A} \mid \mathrm{B})=\mathrm{p}(\mathrm{A}) \text {, and } \mathrm{p}(\mathrm{B} \mid \mathrm{A})=\mathrm{p}(\mathrm{B})
$$

such that

$$
\mathrm{p}(\mathrm{A} \text { and } \mathrm{B})=\mathrm{p}(\mathrm{A}) * \mathrm{p}(\mathrm{B})
$$

where

$\mathrm{p}(\mathrm{x} \mid \mathrm{y})=$ probability of occurrence of event $\mathrm{x}$ given the occurrence of event $\mathrm{y}$, $\mathrm{p}(\mathrm{x})=$ probability of occurrence of event $\mathrm{x}$, and $\mathrm{x}$ or $\mathrm{y}$ refer to events A or B in Equation 7-29a and Equation 7-29b.

Dependent Event-This event does not satisfy the definition of an independent event. Two events, A and B, are dependent if and only if:

$$
\mathrm{p}(\mathrm{A} \text { and } \mathrm{B})=\mathrm{p}(\mathrm{A}) * \mathrm{p}(\mathrm{B} \mid \mathrm{A})=\mathrm{p}(\mathrm{B}) * \mathrm{p}(\mathrm{A} \mid \mathrm{B}) \neq \mathrm{p}(\mathrm{A}) * \mathrm{p}(\mathrm{B})
$$

and more importantly

$$
\mathrm{p}(\mathrm{A} \text { and } \mathrm{B})>\mathrm{p}(\mathrm{A}) * \mathrm{p}(\mathrm{B})
$$

Common Cause Event-In the context of system modeling, common cause events are a subset of dependent events in which two or more component failure states exist at the same time or in a short time interval and are a direct result of a shared cause. NUREG/CR-4780 (Mosleh et al. 1988) does not attempt to provide a clear and unambiguous definition of common cause events for all purposes. It is implied that the shared cause is not another component state because such cascading failures are modeled explicitly in the system models. The common cause is termed a root cause applied at the component level.

- Hardware and software-inherent defects

- Human failure events (HFEs) - operations, T\&M, design, construction

- Environmental-events external to the equipment but internal to the facility or operation that result in abnormal stresses in the equipment

- Externalevents external to the facility that result in abnormal stresses in the equipment. 
Coupling Mechanism-A coupling mechanism is a means by which a root cause propagates to involve multiple components or subsystems. Three broad categories of coupling mechanisms are identified:

- $\quad$ Functional Couplings

- $\quad$ Spatial Couplings

- Human Couplings.

Table 7-4 describes some examples of each of these coupling mechanisms for three types of dependent events.

Common Cause Component Group-This is a group of components (usually similar) that are considered to have a high potential of failing due to the same cause.

Defensive Strategy-A defensive strategy is a measure taken to diminish the probability and consequences of CCFs. Operations, maintenance, design, and surveillance are areas where defensive strategies can be applied.

Table 7-4. Types of Dependent Events Based on their Impact on Preclosure Safety of a Repository

\begin{tabular}{|c|c|c|c|}
\hline $\begin{array}{c}\text { Dependent Event } \\
\text { Type } \\
\end{array}$ & Characteristics & $\begin{array}{c}\text { Subtypes } \\
\text { (Coupling Mechanism) }\end{array}$ & Examples \\
\hline 1. Common Cause IE & $\begin{array}{l}\text { Causes challenge to facility } \\
\text { design or operations, and } \\
\text { concurrently increases } \\
\text { likelihood that one or more } \\
\text { prevention or mitigation SSCs } \\
\text { will fail }\end{array}$ & $\begin{array}{l}\text { Functional } \\
\text { Spatial } \\
\text { Human }\end{array}$ & $\begin{array}{l}\text { Loss of Offsite Power } \\
\text { Earthquake or fire } \\
\text { Maintenance error in main control } \\
\text { room }\end{array}$ \\
\hline $\begin{array}{ll}\text { 2. } & \text { Intersystem } \\
\text { Dependency }\end{array}$ & $\begin{array}{l}\text { Causes a dependency in a } \\
\text { joint event probability } \\
\text { involving two or more } \\
\text { systems }\end{array}$ & $\begin{array}{l}\text { Functional } \\
\text { Spatial } \\
\text { Human }\end{array}$ & $\begin{array}{l}\text { Two trains of instrumentation and } \\
\text { control fail because electric power } \\
\text { supply fails } \\
\text { Fire in one instrument cluster causes } \\
\text { failure in others in proximity } \\
\text { Operator error causes loss of two or } \\
\text { more systems }\end{array}$ \\
\hline $\begin{array}{ll}\text { 3. Intercomponent } \\
\text { (Intrasystem) } \\
\text { Dependency }\end{array}$ & $\begin{array}{l}\text { Causes a dependency in a } \\
\text { joint event probability } \\
\text { involving two or more } \\
\text { components }\end{array}$ & $\begin{array}{l}\text { Functional } \\
\text { Spatial } \\
\text { Human }\end{array}$ & $\begin{array}{l}\text { Crane cable(s) break after two-block } \\
\text { prevention features fail } \\
\text { Failure of one of two crane cables } \\
\text { allows rigging to tilt and sever second } \\
\text { cable } \\
\text { Installation of wrong lifting fixture } \\
\text { permits crane two blocking and break } \\
\text { of cables }\end{array}$ \\
\hline
\end{tabular}

Source: Modified from NUREG/CR-4780 (Mosleh et al. 1988, Table 2-1)

Explicit Analyses-Explicit analyses of dependent or CCF failures are identified from specific potential root causes and coupling mechanisms. Inter-component or inter-system dependencies are shown explicitly in logic models (e.g., ETs and FTs). Conditional probabilities of dependent events are evaluated from consideration of vulnerabilities in the target component or system and 
opportunities for the coupling mechanism to link the root cause (triggering event) to failure of the target.

Implicit (or Parametric) Analyses-Implicit analyses of dependent or CCF failures are used when the possibility of dependent failure is known (or suspected) to exist but specific root causes and coupling mechanisms cannot be identified or quantified. Inter-component or inter-system dependencies are shown explicitly in the system logic models (principally FTs) to represent implicit events. Conditional probabilities of dependent failure are estimated using various parametric approaches such as the beta factor method.

Parametric Analyses-See the definition of implicit analyses.

Primary (Front-Line) System-A primary system is one that provides a direct function in the handling, packaging, or transporting a high-level radioactive waste form. Of particular importance are the front-line systems that prevent or mitigate potential unwanted sequences of events. Such front-line safety systems may be slated for single-failure-proof-, or fail-safe, design principles. The HVAC/HEPA filter system in the waste handling building of the surface facility is an example of an important front-line system (although consequence analyses may show that this system is not ITS). The AC power supply and perhaps a cooling-water system are support systems to the HVAC/HEPA system. Analyses of dependent and CCFs can help to provide assurance that such systems perform their intended safety functions with adequate reliability.

Support (Secondary) System-A support system is one that provides an indirect function in the handling, packaging, or transporting of a high-level radioactive waste form by providing essential support to the front-line systems. An important support system for the safety of repository operations is the electrical supply system. Virtually every operation in a repository is dependent on electric power. Although many devices can be designed to halt in a safe mode on the loss of a power supply, other devices (i.e., HVAC/HEPA filters, instrumentation, or control systems) cannot. Thus, there is an explicit coupling (dependency) between the front-line system and the support system.

\subsubsection{Background Discussion}

A CCF (sometimes called common-mode failure, although there is a distinction) can be considered to be a special case of dependent failures. Dependent failures, as a class, are so-named to distinguish them from independent failures. Independent failures are sometimes termed random failures, but this is a misnomer since dependent failures can also occur randomly in time.

Common-cause and dependent failures are important considerations in the analysis of SSCs that are intended to be highly reliable in preventing or mitigating the effects of potential hazards. Considerations of common-cause and dependent failures are important whenever redundant components or subsystems (or alternative success paths) have been provided for safety and reliability. The treatment of common-cause and dependent failures contrasts with traditional reliability analyses and single-failure-proof design approaches that implicitly assume that only independent failures can occur among two or more redundant components or subsystems. 
Dependent failures result from the coexistence of two factors: a susceptibility for components to fail or be unavailable from a particular root cause and a coupling mechanism.

Figure 7-19 (based on Mosleh et al. 1988) illustrates the general model for consideration of dependent failures or CCFs. A root cause interacts with each of the multiple components labeled A through $\mathrm{N}$ by the means of a coupling mechanism. A defense strategy may be employed to prevent dependent failures or reduce their likelihood. A defense strategy attacks any or all of the elements in the figure by eliminating or reducing the root cause, eliminating or reducing the coupling mechanism, or by making each component less susceptible to the root cause or the coupling mechanism (one means of achieving the latter might be to use diverse components). Table 7-4 illustrates several typical root causes and coupling mechanisms.

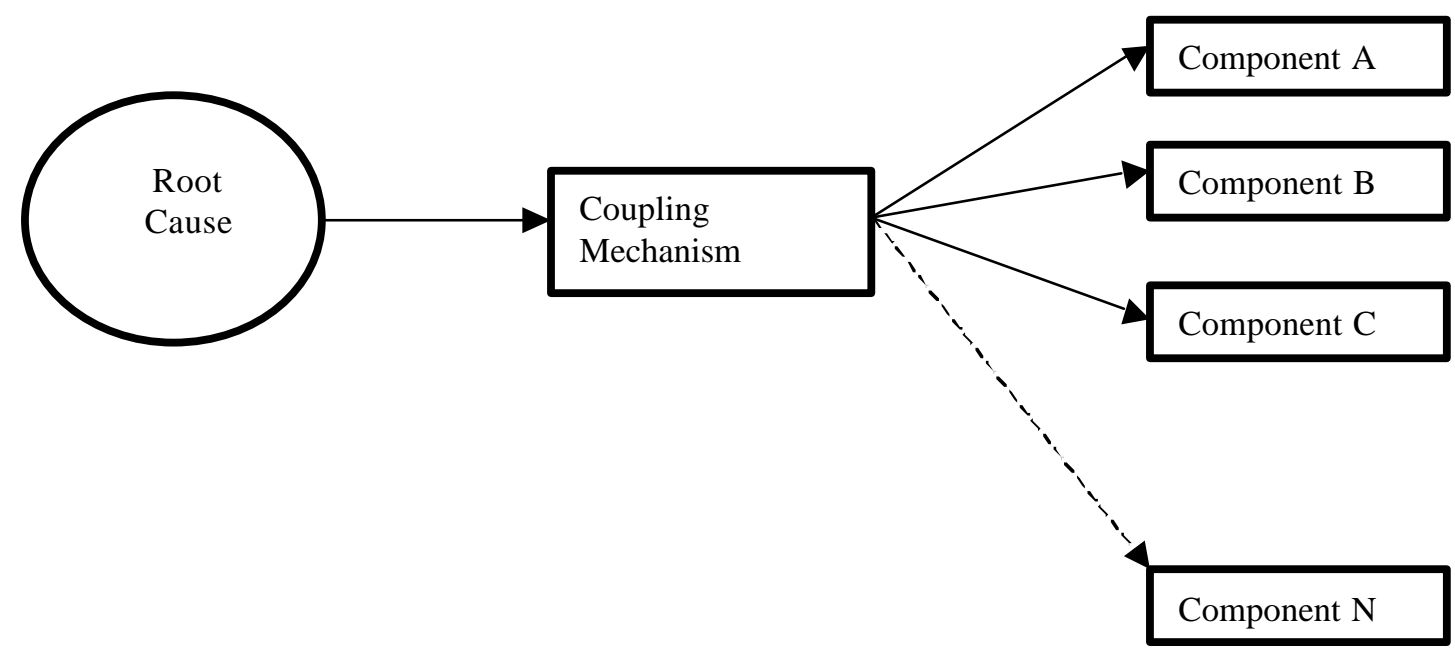

Source: modified from NRC (1987)

Figure 7-19. Physical Elements of Dependent Events

For example, two components located in the same room might be susceptible to failure if the humidity exceeds some level. An event such as a rupture of a hot water or steam pipe would result in extreme humidity and induce a dependent failure of the two components. High humidity from the steam break would be the root cause of the component failure. The fact that the components are situated in the same room where there is a source of water or steam is the coupling mechanism.

Design errors can also result in dependent failures. For example, the redundant safety injection system at one NPP failed because the motor-operated valves in both of the redundant pump trains were undersized and unable to open against the pressure. The root cause was the design process and the coupling mechanism was the use of identical valves and common demand conditions in addition to the lack of adequate surveillance tests. An analogous situation could occur in a repository. For example, if the braking power of each of two redundant and diverse brake systems on the emplacement transporter was designed to be inadequate, then the effect of having a redundant backup system might be negligible. Or, the design might be such that the primary brake system fails in such a way to cause a fluid spray or missile to induce failure of the backup system. Generally, CCFs due to system design flaws are eliminated through design 
reviews, including FTA and quality assurance. As the design of a repository evolves, PSA specialists can help in design reviews to eliminate potential CCFs. Potential design flaws must be evaluated implicitly as one of the non-specific common causes during the preliminary design phases.

Another type of dependent failure among redundant SSCs occurs when two or more components or subsystems are dependent on the same support system. For example, if all of the fan motors in a HVAC/HEPA filter system are connected to the same power bus, all fans will fail to run if the power system fails. Design features can eliminate such dependencies or displace them a lower level (e.g., by providing redundant offsite and onsite power distribution systems).

In addition, human actions can be a coupling event for CCFs. Such CCFs may arise from common maintenance errors, common calibration errors, inadequate design (capacity), abnormal loads, or other situations that result in multiple components (or systems) failing in response to a given demand or during a given mission time.

Insights from the PRAs of nuclear plants and chemical process plants, and events such as the Three Mile Island incident and Challenger explosion, have revealed the significance of CCFs. The identification and elimination of potential CCFs are now part of safety system design and operations analyses.

In addition, studies have shown that CCFs (identified or unidentified) limit the practical reliability that is achievable in engineered systems. Even with the use of redundant and diverse channels (trains), there appear to be limits on the lowest probability of failure that can be achieved. Table 7-5 summarizes s commentary in Watson (1987) on the reliability achievable with various system configurations employing varying degrees of redundancy and diversity.

It is noted that the lowest limit for fully diverse and redundant systems is approximately $10^{-6}$ per demand. Therefore, any system analysis for active repository systems that yields a failure probability less than $10^{-6}$ should be challenged and reviewed to ensure that all potential causes of $\mathrm{CCF}$ and dependent failures have been identified. This does not mean that lower probabilities are to be categorically dismissed, but only that the analysis is subject to scrutiny if major safety decisions are based on such analyses.

\subsubsection{Details of Approach}

The analysis of CCFs and dependent failures may take many forms. In explicit analyses, potential dependent or CCF failure models are identified from specific potential root causes and probabilities of common-cause events are evaluated from a consideration of vulnerabilities and opportunities for coupling via spatial, functional, environmental, or human interactions. In implicit analyses (also termed parametric modeling), it is assumed that a small fraction of the total failure probability of a component or system is attributed to CCFs of indeterminate or non-specific causes. The small fraction of CCFs is included in system reliability models though parameters derived from experience data or through judgement. The well-known beta-factor method is an example of an implicit or parametric model. 


\subsection{Explicit Dependencies in Event Trees}

The framework of the ET is used to display the frequency of the initiator and the conditional probabilities of each enabling event in a sequence. The frequency of each event sequence is calculated as the product of the initiator frequency and the probabilities of branch nodes that appear in the event sequence. The ET permits analysis of the dependencies between the IE and enabling events, dependencies between enabling events, or both. This means that if there are sequence-dependent couplings between events, there may be different probability values for a given enabling event in different sequences.

Table 7-5. A Guide to Unreliability of Various System Arrangements with Consideration of Dependent Failures

\begin{tabular}{|c|c|c|}
\hline $\begin{array}{c}\text { System } \\
\text { Arrangement }^{\mathrm{a}}\end{array}$ & Description and Features & $\begin{array}{l}\text { Range of } \\
\text { Unreliability } \\
\text { Factors }^{b}\end{array}$ \\
\hline $\begin{array}{l}\text { Single Channel } \\
\text { System }\end{array}$ & $\begin{array}{l}\text { The simplest form of a system having a single input module and single processor } \\
\text { or output module. The lower limit of probability of failure is about } 10^{-2} \text {. Adding a } \\
\text { redundant channel can improve the reliability to about } 10^{-4} \text { if only independent } \\
\text { failures can occur. But the effects of CCF become apparent. }\end{array}$ & 0.2 to $10^{-2}$ \\
\hline $\begin{array}{l}\text { Partly } \\
\text { Redundant } \\
\text { System }\end{array}$ & $\begin{array}{l}\text { A system having redundancy in its input channels only might have a failure } \\
\text { probability in a range of } 5 \times 10^{-2} \text { to } 10^{-3} \text {. The inference is that the most } \\
\text { significant contributors to system failure have been determined to be in the input, } \\
\text { although redundancy could be extended to other modules for further reduction in } \\
\text { failure probability. CCF }\end{array}$ & $5 \times 10^{-2}$ to $10^{-3}$ \\
\hline $\begin{array}{l}\text { Partly Diverse } \\
\text { System }\end{array}$ & $\begin{array}{l}\text { The logical development in the quest for higher system reliability is to reduce the } \\
\text { CCF probability by introducing diversity into those parts of the system where } \\
\text { redundancy was previously considered, as in the Partly Redundant System, and } \\
\text { to introduce redundancy where there was none previously. In this example, the } \\
\text { input modules apply diverse designs while the processor or output applies } \\
\text { redundant modules. One arrangement could be isolated channels where the } \\
\text { channel fails if either its input or its processor or output fails. Alternatively, cross } \\
\text { ties may be included to permit either input channel to connect to either } \\
\text { process/output channel. It is cautioned that such cross ties may themselves } \\
\text { introduce other CCF paths. The Partly Diverse System is capable of a failure } \\
\text { probability in a range of } 10^{-2} \text { to } 10^{-4} \text {. }\end{array}$ & $10^{-2}$ to $10^{-4}$ \\
\hline $\begin{array}{l}\text { Fully Diverse } \\
\text { System }\end{array}$ & $\begin{array}{l}\text { For further reduction in system failure probability, the independence between } \\
\text { redundant channels must be improved by using diverse designs for input } \\
\text { modules and for processor/output modules, and eliminating any cross ties } \\
\text { between the channels. Systems have evolved to provide a failure probability in a } \\
\text { range from } 10^{-3} \text { to less than } 10^{-5} \text {. }\end{array}$ & $10^{-3}$ to $<10^{-5}$ \\
\hline $\begin{array}{l}\text { Two Diverse, } \\
\text { Redundant } \\
\text { Systems }\end{array}$ & $\begin{array}{l}\text { The final stage in this example of system design evolution is to provide diverse } \\
\text { input channels each being two-fold redundant in addition to redundant and } \\
\text { diverse processor/output modules (i.e., four input channels, two each connected } \\
\text { to one of two redundant and diverse processor/output modules). For practical } \\
\text { reasons it is unlikely that more than two-fold redundancy can be applied to each } \\
\text { subsystem. There are, therefore, completely diverse and separate systems } \\
\text { throughout and would be expected to provide an overall system failure } \\
\text { probability in a range of } 10^{-4} \text { to } 10^{-6} \text {. }\end{array}$ & $10^{-4}$ to $10^{-6}$ \\
\hline
\end{tabular}

Source: $\quad$ Modified from Watson (1987, Figure 9)

NOTES: $\quad{ }^{a}$ Examples are primarily active electronic systems that have input, and processing/output modules.

b Per Watson (1987, Figure 10). 
A dependent event in an ET has to be inserted into the tree after (to the right of) a precursor event upon which it is dependent. In extreme cases of dependency, the occurrence of the precursor event may guarantee the occurrence of the dependent event; that is, there is complete dependence between the events.

Figure 7-20A and Figure 7-20B illustrate how dependent failures can alter the structure of ETs and affect the outcomes of event sequences. Figure 7-20A illustrates a simple (baseline) ET containing only independent events. The IE is a drop of a waste form that causes a release inside the transfer cell. When the HVAC/HEPA filter system functions properly, the filtered release is small. This is indicated by a "Yes" under the event heading titled "HVAC/HEPA Filters Release" leading to Sequence No. 2. If the HVAC/HEPA filter fails (by independent failure), as represented by the "No" branch, the release is large, as represented by Sequence No. 3. Because this failure is independent of the IE, the frequency of Sequence No. 3 is equal to the frequency of the IE multiplied by the independent failure probability of the HVAC/HEPA filter.

Figure 7-20B, by contrast, illustrates the case in which the initiator is a fire inside the transfer cell. In this example, it is assumed that there is a dependency between the IE (fire) and the HVAC/HEPA filter system. In this case, there is no "Yes" (or success) branch under the heading titled "HVAC/HEPA Filters Release," which leads to Sequence No. 3 and a large release. Note that the sequence numbers are different in Figures 7-20A and Figure 7-20B.

The origin of the fire is not defined in this example. In addition, the probability of success or failure of a fire suppression system is not modeled in this example. See Section 10.5.1 for a discussion of such ETs.

Similarly, events may be dependent on the availability of a support system. In an ET having an IE titled "loss of offsite power," an event heading might be titled "backup power system is available." Events that are dependent on having AC or DC electrical power are positioned under other event headings after "backup power system is available." For example, the HVAC/HEPA filter requires $\mathrm{AC}$ power for its fan motors, but the control and instrumentation systems may require DC electric power to perform their safety functions. In drawing the loss-of-offsite-power ET, in the "no" branch under the heading titled "backup power system is available," no success branch would be shown under the event heading titled "HVAC/HEPA filter operates." This indicates a "guaranteed failure" because the HVAC/HEPA filter is dependent on the AC and DC power. In the "yes" branch, by contrast, a branching node would be included to represent the independent failure of the HVAC/HEPA filter system when AC and DC power are available. The other examples would be similarly modeled.

Dependencies on key HAs can be modeled in an ET in the same manner. If an operator is supposed to take an action to prevent or mitigate a potentially unsafe situation (e.g., activate a filtration system, a backup power supply, or close an isolation barrier), the branching nodes under the event headings in the ET are developed to show these dependencies. The dependencies may be total (or complete), giving a guaranteed failure (as in the examples previously mentioned), or partially dependent resulting in conditional probabilities that are higher than the independent failure probability for the heading event.

The analyst must justify the conditional probabilities assigned in such circumstances. 
Fire Initiated Inside
Transfer Cell

Crane Retains Load (No Drop)
Waste Form Remains Intract (No Release to Transfer Cell)

Yes Initiating Event Not Needed
HVAC/HEPA Filters Release

Amount

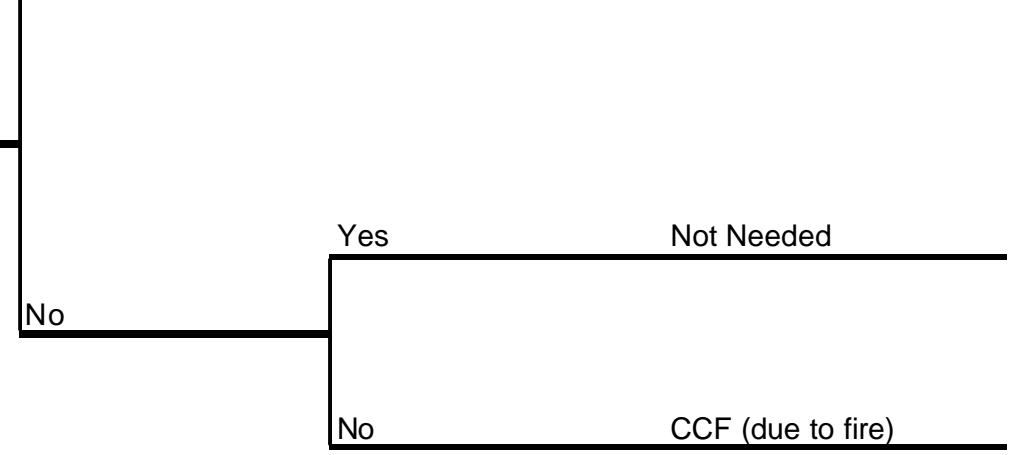

No CCF (due to fire)

Figure 7-20A. Baseline Event Tree Without CCFs
No. Released

1 None

2 None

3 Large

\begin{tabular}{|c|c|c|c|c|c|}
\hline $\begin{array}{l}\text { Fire Initiated Inside } \\
\text { Hot Cell }\end{array}$ & $\begin{array}{l}\text { Crane Retains Load } \\
\text { (No Drop) }\end{array}$ & $\begin{array}{l}\text { Waste Form Remains } \\
\text { Intract (No Release to } \\
\text { Hot Cell) }\end{array}$ & $\begin{array}{l}\text { HVAC/HEPA Filters } \\
\text { Release }\end{array}$ & $\begin{array}{l}\text { Seq. } \\
\text { No. }\end{array}$ & $\begin{array}{l}\text { Amount } \\
\text { Released }\end{array}$ \\
\hline
\end{tabular}

Initiating Event

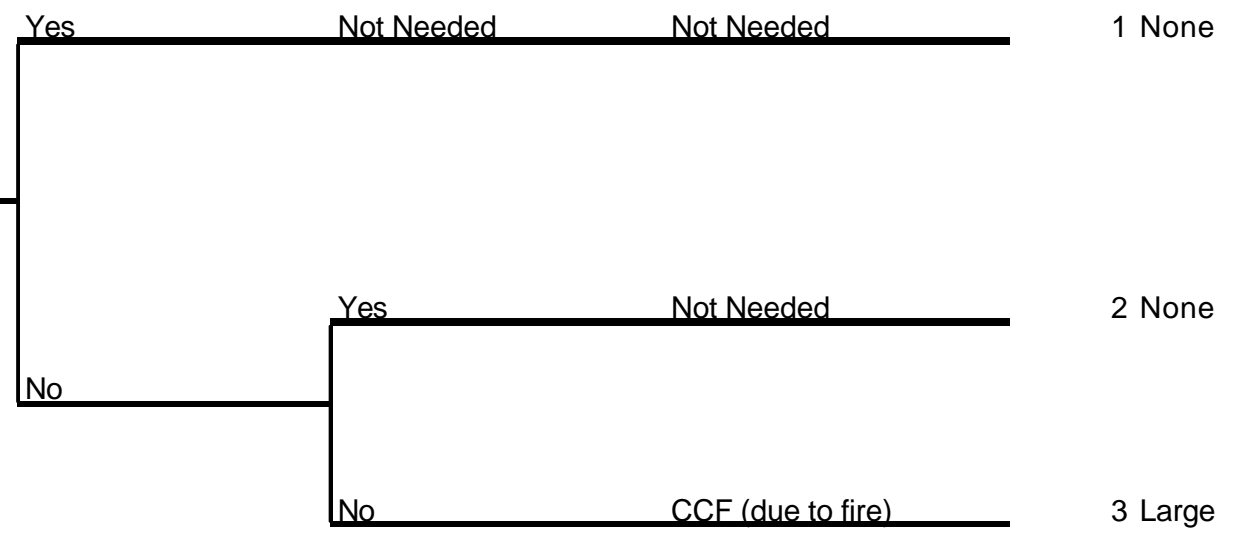

Figure 7-20B. ET with Fire-Initiated Common-Cause Failure of a Heating, Ventilation, and Air-Conditioning, and High-Efficiency Particulate Air Filter System 


\subsection{Explicit Dependencies in Fault Trees}

To a certain degree, accounting for explicit dependencies in FT modeling is almost automatic if the analyst is thorough. The top-down decomposition of the top event to subsystems, components, and basic events leads to the identification of virtually all explicit dependencies.

For example, in an FT for a multi-train HVAC/HEPA filter system, the analyst resolves the failure of one of the trains (an event titled "HVAC/HEPA filter Train A fails to start and run") through an OR gate that includes as inputs: failure of the motor to start and run, failure of HEPA filter element, and failure of the fan. These inputs represent failures within the hardware of the primary system. Other events that could cause Train A to be unavailable (e.g., Train A out of service for maintenance, No electric power available to Train A, or Operator fails to actuate Train A) must be included to complete the FT. These inputs are examples of explicit dependencies that are incorporated into the logic model for the system.

In a multi-train system (such as the HVAC/HEPA filter system in the example), several of the modeled dependencies may be found to be CCFs. For example, if Train A and Train B (and other trains) all depend on a single train of electric power, then loss of the power supply would result in a loss of all HVAC/HEPA filters. In FT analyses, such dependencies might be identified through inspection in a simple system. Otherwise, in the determination of the minimal cutsets for the system failure, the singlet representing the failure of the electric power supply would be identified automatically through the Boolean algebra.

\subsection{Common-Cause Initiating Events}

IEs such as earthquakes, floods, fires, and loss of offsite power (previously discussed) can be important contributors to the risk of a facility unless design bases prevent dependent failures. These topics are addressed in more detail in Section 10 this guide.

\subsubsection{Use of Software}

Dependent events and CCFs are readily handled in both ETs and FTs with computer programs such as SAPHIRE. A Microsoft Excel spreadsheet can be used to draw ETs that include dependent events and can be used to quantify event sequences.

\subsubsection{Implicit (or Parametric) Modeling and Quantification of Common-Cause Failure}

A CCF analysis can be applied to systems containing several levels of redundancy and diversity, including systems having various success criteria (e.g., 1 out of 2,2 out of 3 , and so on). The simplest example for introducing CCF analyses is illustrated in Figure 7-21A. This figure presents a reliability block diagram for a system having two-fold redundancy. The success criterion is one out of two: if either component A or B is available, the system safety function is achieved. Figure 7-21B illustrates the FT logic model for the system assuming that all failures of $\mathrm{A}$ and $\mathrm{B}$ are independent. 
The top event (failure of safety function) will occur when A and B fail, as represented by the AND gate. The probability of the top event is given as:

$$
\mathrm{p}_{\mathrm{S}}=\mathrm{p}_{\mathrm{A}} * \mathrm{p}_{\mathrm{B}}
$$

If

$$
\mathrm{p}_{\mathrm{A}}=\mathrm{p}_{\mathrm{B}}=0.01
$$

then

$$
\mathrm{p}_{\mathrm{S}}=0.01 * 0.01=0.0001
$$

The potential for $\mathrm{CCF}$ is introduced into the reliability block diagram by inserting a pseudo-component that is in series with the physical components (or systems), $\mathrm{A}$ and $\mathrm{B}$, as shown in Figure 7-22A. The pseudo component is labeled $\mathrm{CCF}_{\mathrm{AB}}$. Figure 7-22B illustrates the FT logic model for the system in the reliability block diagram. The top event (failure of safety function) will occur when $\mathrm{A}$ and $\mathrm{B}$ fail independently $\mathrm{OR}$ if they fail by the $\mathrm{CCF}_{\mathrm{AB}}$. The top event is resolved into an OR gate having event "System Fails Due to Common Cause Failure" as one input and the event titled "System Fails Due to Independent Failures" as the other input.

The probability of the top event is given as:

$$
\mathrm{p}_{\mathrm{S}}=\mathrm{p}_{\mathrm{A}, \mathrm{I}} * \mathrm{p}_{\mathrm{B}, \mathrm{I}}+\mathrm{p}_{\mathrm{CCF}}
$$

where

$\mathrm{p}_{\mathrm{A}, \mathrm{I}}$ and $\mathrm{p}_{\mathrm{B}, \mathrm{I}}$ are the probabilities of independent failures of A and B, respectively, and $\mathrm{p}_{\mathrm{CCF}}$ is the probability of $\mathrm{CCF}_{\mathrm{AB}}$.

The expression in Equation 7-35 is valid for any appropriate values of the parameters $\mathrm{p}_{\mathrm{A}, \mathrm{I}}$, $\mathrm{p}_{\mathrm{B}, \mathrm{I}}$, and $\mathrm{p}_{\mathrm{CCF}}$. A determination of the value of $\mathrm{p}_{\mathrm{CCF}}$ is required. The beta-factor method, described in Section 7.4.4.3.1, is applied as one method for estimating $\mathrm{p}_{\mathrm{CCF}}$.

\subsection{Beta Factor Approach}

The beta factor method assumes that a fraction $B$ of the reported failures of components is due to CCFs with the remainder due to independent failures.

If, in Figure 7-21,

$$
\mathrm{p}_{\mathrm{A}}=\mathrm{p}_{\mathrm{B}}=\mathrm{p}_{\mathrm{Tot}}
$$

where

$$
\mathrm{p}_{\mathrm{Tot}}=\text { total failure probability of either component } \mathrm{A} \text { or } \mathrm{B} \text {, taken alone, then }
$$

the probability of both components failing due to CCF is defined as: 


$$
\mathrm{p}_{\mathrm{CCF}}=\beta * \mathrm{p}_{\mathrm{Tot}}
$$

and the probability of independent failure of either component is given by:

$$
\mathrm{p}_{\mathrm{A}, \mathrm{I}}=\mathrm{p}_{\mathrm{B}, \mathrm{I}}=(1-\beta) * \mathrm{p}_{\mathrm{Tot}}
$$

A typical value (e.g., a rule of thumb often used in screening analyses) is to assume $\beta=0.1$. Using this value in the example presented in Section 7.4.4.3 gives the following values:

$$
\begin{aligned}
& \mathrm{p}_{\mathrm{CCF}}=\beta * \mathrm{p}_{\mathrm{Tot}}=0.1 * 0.01=0.001 \\
& \mathrm{p}_{\mathrm{A}, \mathrm{I}}=\mathrm{p}_{\mathrm{B}, \mathrm{I}}=(1-\beta) * \mathrm{p}_{\mathrm{Tot}}=(1-0.1) * 0.01=0.9 * 0.01=0.009 \\
& \mathrm{p}_{\mathrm{S}}=\mathrm{p}_{\mathrm{A}, \mathrm{I}} * \mathrm{p}_{\mathrm{B}, \mathrm{I}}+\mathrm{p}_{\mathrm{CCF}}=0.009 * 0.009+0.001=0.000081+0.001
\end{aligned}
$$

The contribution from the CCF dominates the system failure probability. This is a typical result from the beta factor approach when $\beta$ is 0.1 or higher. For the two-fold redundancy case, it may be shown that a CCF will dominate the system failure probability until $\beta \approx$ p $_{\text {Tot. }}$. It should be noted that the beta factor method gives essentially the same numerical result for any redundancy of two or higher. More complex, multi-parameter models may be used, as described in Section 7.4.4.3.7.

These results demonstrate that even a small contribution from CCFs can seriously degrade the reliability of a safety system. Designer and safety analysts must be cautioned against overconfidence and complacency when redundancy or single-failure proof designs are specified.

The beta factor method is perhaps the most useful technique for including CCFs in the PSA, especially for the LA-CA, when complete design detail is not yet available. Moreover, the beta factor is suitable when only two-fold redundancy is used. The value chosen for beta may be less than, or more than, the generic beta of 0.1 . The analyst must determine whether design, operational controls, and environmental controls affect the susceptibility and opportunity for CCFs and justify an appropriate beta factor or factors.

\subsection{Using the Beta Factor with Component Failure Rate and Event Frequencies}

The development of the methodology in Section 7.4.4.3 used the probability of a component failure as the parameter of interest. The same development can be based on a failure rate using the beta factor. The original development of the beta factor was based on component failure rates because experience data (from which beta is derived) are expressed in terms of failure rates (either in units of time or per demand). 
A. Reliability Block Diagram of Redundant System

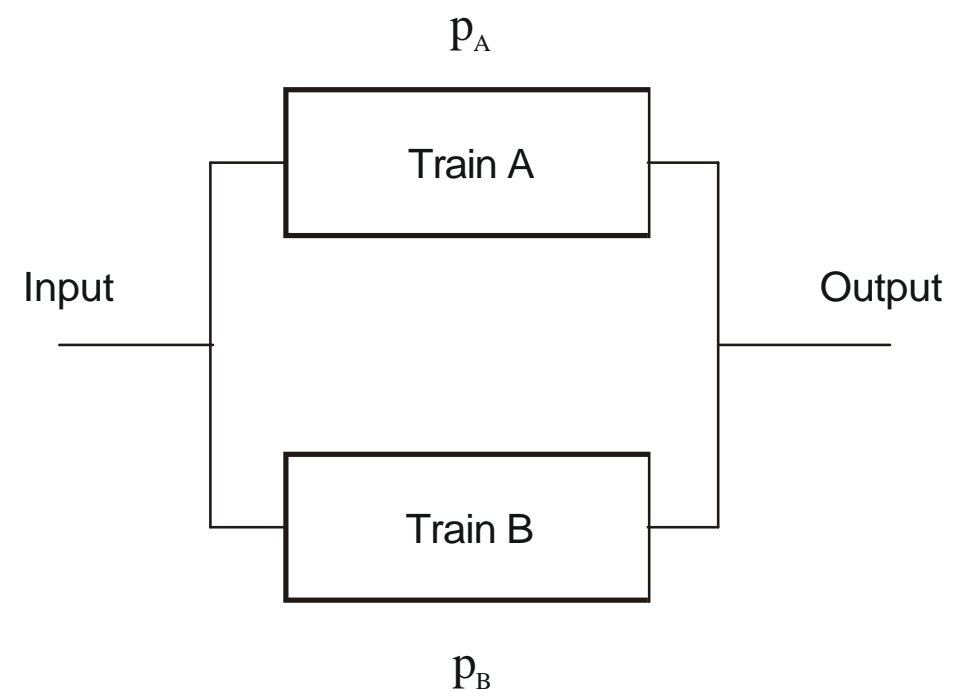

B. Fault Tree Logic Model of Redundant System

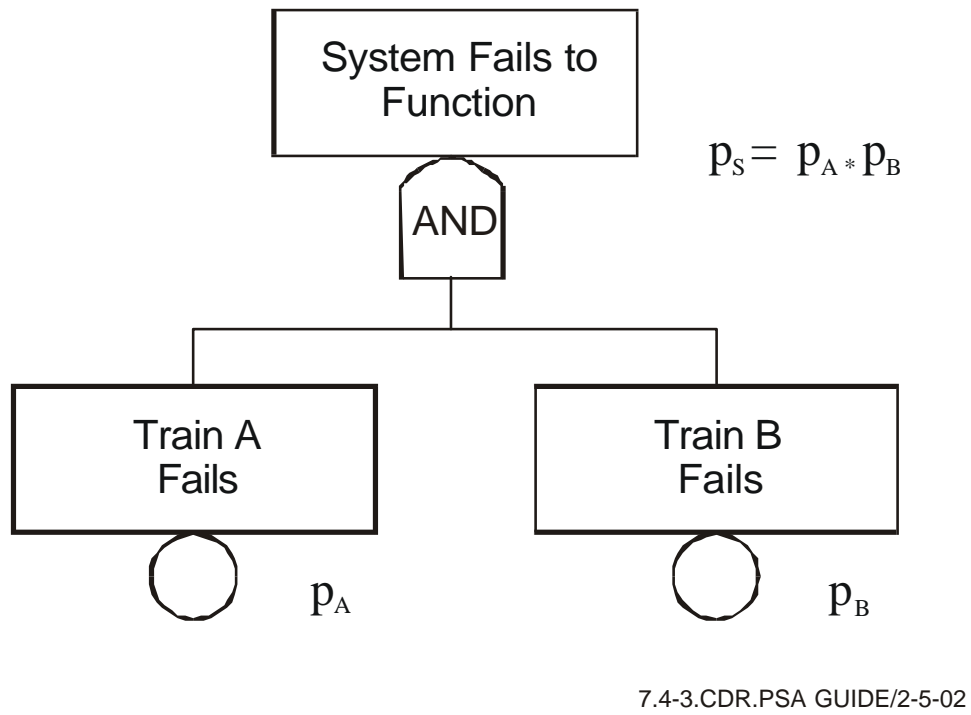

Figure 7-21. Illustration of Logic Models for Independent Failures 
A. Reliability Block Diagram of Redundant System with Pseudo Series Element CCF

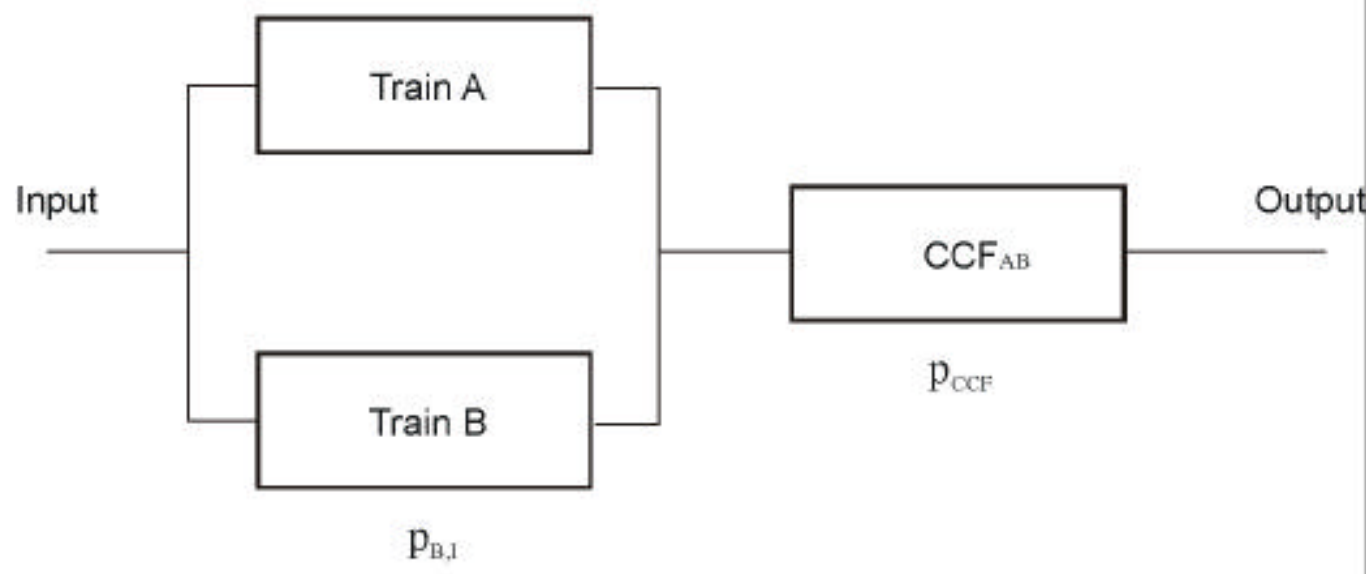

B. Fault Tree Logic Model with CCF of Redundant System

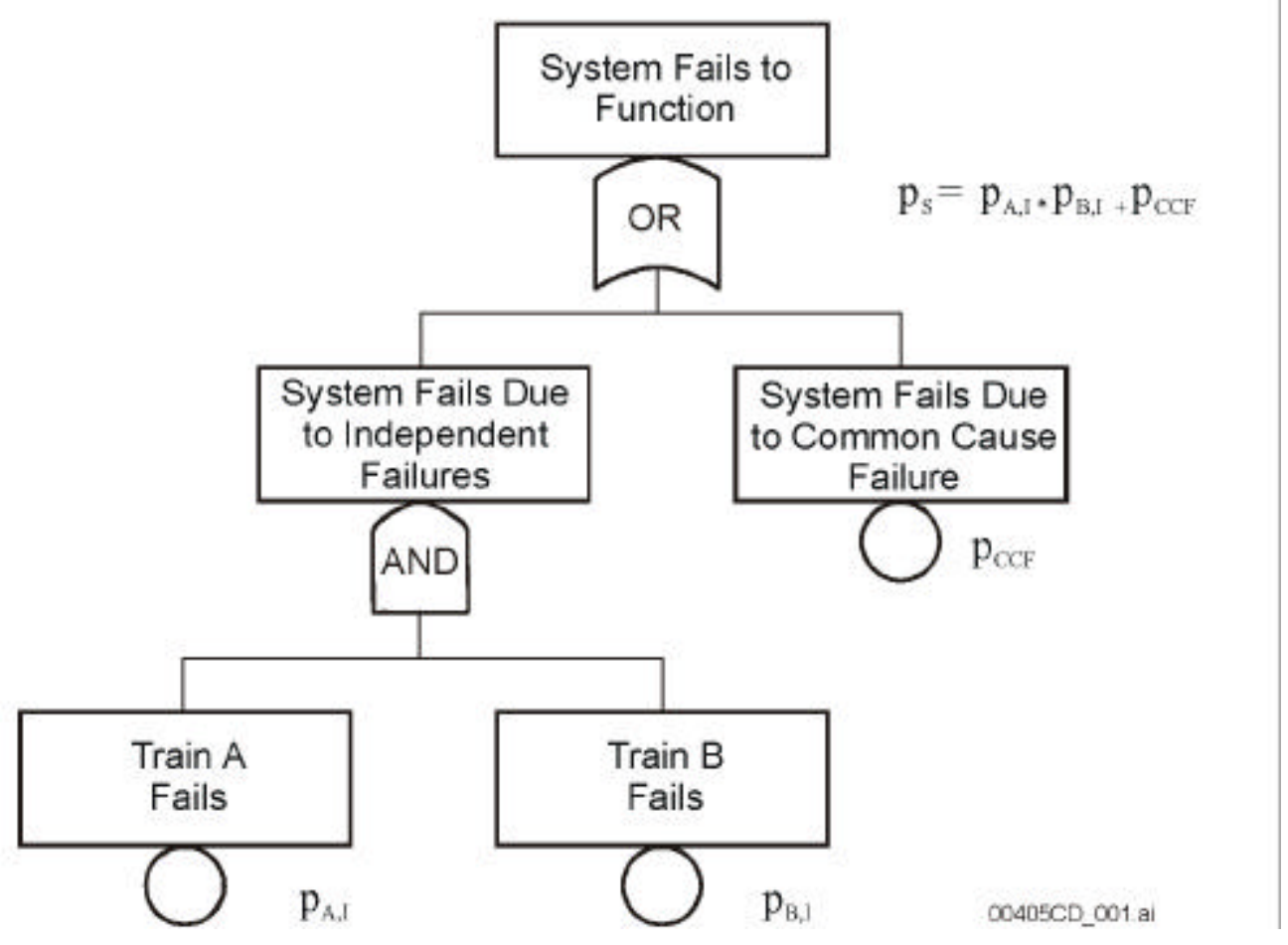

Figure 7-22. Illustration of Logic Models for Common-Cause Failures 
Experience data are expressed in one of the following forms:

Demand Based-K failures are observed in $\mathrm{N}$ challenges (demands) on components in records or test data. In this basis, data analysis would estimate the failure rate (or probability per demand). The total failure rate, also termed the component unavailability, is calculated as:

$$
\mathrm{q}=\mathrm{K} / \mathrm{N} \text { failures per demand }
$$

CCF Contribution, Beta Factor Estimation:

The analysts examine the database(s) to identify what fraction of all recorded failures can be attributed to CCFs. It is determined that a portion $\mathrm{k}_{\mathrm{CCF}}$ of the $\mathrm{K}$ failures are attributed to CCFs. This defines the beta factor as:

$$
\beta_{\mathrm{q}}=\mathrm{k}_{\mathrm{CCF}} / \mathrm{K}
$$

So that

$$
\begin{gathered}
\mathrm{q}_{\mathrm{I}}=\left(1-\beta_{\mathrm{q}}\right) \mathrm{q} \\
\mathrm{Q}_{\mathrm{CCF}}=\beta_{\mathrm{q}} \mathrm{q}
\end{gathered}
$$

where

$\mathrm{q}_{\mathrm{I}}=$ probability of independent failures, per demand

$\mathrm{Q}_{\mathrm{CCF}}=$ Probability of CCF failure, per demand

Rate Based-M failures are observed in exposure (operational or test) time $\mathrm{T}$ for components in records or test data. In this basis, data analysis would estimate the failure rate (in units of numbers of failures per unit time, also termed the component failure frequency) as:

$$
\lambda=\mathrm{M} / \mathrm{T} \text { failures per hour }
$$

CCF Contribution, Beta Factor Estimation:

The analysts examine the database(s) to identify the fraction of all recorded failures that can be attributed to CCFs. It is determined that a portion $\mathrm{m}_{\mathrm{CCF}}$ of the $\mathrm{M}$ failures are attributed to CCFs. This defines beta as:

$$
\beta_{?}=\mathrm{m}_{\mathrm{CCF}} / \mathrm{M}
$$

The failure rate for independent failures becomes:

$$
\lambda_{I}=\left(1-\beta_{?}\right) \lambda
$$

and the expression for the failure rate for CCFs is:

$$
\lambda_{\mathrm{CCF}}=\beta_{?} \lambda
$$


The unavailability of a component or system in the exponential reliability model is expressed as:

$$
P_{F}=1-\exp \left(-\lambda t_{M}\right)
$$

Here $t_{M}$ is the mission time and $P_{F}$ is the probability that that the component or system will not perform its safety function for at least a time $t_{\mathrm{M}}$ when it is needed. The expression for $\mathrm{P}_{\mathrm{F}}$ is usually approximated as

$$
\mathrm{P}_{\mathrm{F}} \approx \lambda \mathrm{t}_{\mathrm{M}}
$$

and $\mathrm{P}_{\mathrm{F}}$ is the probability of failure for all causes (i.e., the total of independent and CCFs) for the mission time, $\mathrm{t}_{\mathrm{M}}$.

The independent failure and CCF contributions to the component or system unavailability can be separated using Equations 7-45 and 7-46.

The probability of independent failure is

$$
\mathrm{P}_{\mathrm{F}_{I}} \approx \lambda_{I} \mathrm{t}_{\mathrm{M}} \approx\left(1-\beta_{?}\right) \lambda \mathrm{t}_{\mathrm{M}} \approx\left(1-\beta_{?}\right) \mathrm{P}_{\mathrm{F}}
$$

and the probability of $\mathrm{CCF}$ is:

$$
\mathrm{P}_{\mathrm{FCCF}} \approx \lambda_{\mathrm{CCF}} * \mathrm{t}_{\mathrm{M}} \approx \beta_{?} \mathrm{t}_{\mathrm{M}} \approx \beta_{?} * \mathrm{P}_{\mathrm{F}}
$$

\subsection{Other Methods for Common-Cause Failure quantification}

When diversity is also present in addition to redundancy and in cases where three-fold or higher redundancy is used, other methods such as the Multiple Greek Letter or the alpha factor should be used. If the need arises, the analyst should consult a source such as NUREG/CR-4780 for instructions.

\subsubsection{Steps in Performing Dependent Failure Analysis for a Repository}

The following steps are presented to guide the analyst. The steps are based on those presented in NUREG/CR-4780 (Mosleh et al. 1988) but are less detailed since some of the steps are not relevant to the preclosure safety of a repository. The first two steps are general systems analysis tasks that are performed in conjunction with ET and FT analyses.

\subsubsection{Step 1-System Logic Model Development}

System Familiarization-The specific system or operation of a repository is examined for preclosure safety issues. The analyst becomes familiar with the design, environment, and operational characteristics of the system. This step is a common starting point and common activity for the entire PSA. For dependent failure analysis, attention must be given to the following points: 
- The results of external and internal event hazards analyses are used to develop event sequence descriptions (e.g., using ET logic models) and FT logic models of SSCs that are relied upon for prevention or mitigation of particular sequences of events.

- The analyst must understand the intended function of each front-line SSC, what it is composed of (i.e., construction, kinds of components), what kinds of procedures will govern its operation, and its requirements for T\&M.

- The analyst must also understand which support systems are required for proper functioning of each frontline SSC (i.e., does it require electrical power, cooling water or air, temperature or humidity control?).

- $\quad$ The analyst should consider the location of each SSC in relation to other operations that may pose hazards of spatial interaction.

Problem Definition-In this step, the analyst translates information from the familiarization step into specific considerations and constraints that will influence the logic model development. Particular points to be considered include:

- $\quad$ Specific success (performance) criteria that are defined for each SSC that prevents or mitigates an undesired sequence

- $\quad$ Boundaries of the specific system being considered (i.e., what it includes and what it does not)

- $\quad$ Dependencies between frontline (primary) system and support systems or functions (for complex systems, a support matrix may be constructed to define direct and indirect dependencies between primary, secondary, and tertiary systems and components or HAs)

- $\quad$ Ground rules imposed on the analyses to focus on the problems of interest (e.g., coarse modeling and conservative rules might be applied to preliminary analyses, and them more detailed modeling and more realistic rules might be applied in later analyses)

- Identify those root causes of dependent failures that will be explicitly modeled (e.g., earthquakes, fires, T\&M, HFEs).

The last point is important; in later modeling of implicit (parametric) dependencies care must be taken to not introduce double counting.

Logic Model Development-Explicit dependencies are incorporated into ET or FT logic models. Implicit (or parametric) dependencies are treated in FT models that permit the analyst to relate (decompose) a system state (such as HVAC/HEPA filter system is unavailable) to lower, component level states. The dependent failure events are then treated as one cause of component failure alongside independent component failure events. 


\subsubsection{Step 2-Identification and Screening of Common-Cause Failure Component Groups}

The objectives of this step include qualitative and quantitative screening to:

- Identify the groups (or types) of components to be included in, or excluded from, the $\mathrm{CCF}$ analysis

- $\quad$ Prioritize the groups to allocate resources and time

- $\quad$ Provide engineering arguments to aid data analysis

- $\quad$ Provide engineering insights for later formulation of CCF defense alternatives.

Qualitative Analysis-The analyst searches for common attributes and mechanisms of failure that can lead to common cause events. This step relies on past experience and an understanding of system and component behavior in the intended operational environment for signs of potential dependence among redundant components as well as consideration of defenses that may be included in the design. If necessary, a root-cause analysis is performed to substantiate and improve the initial identification of potential CCFs.

Quantitative Screening-This step is applied in the CCF analysis of complex systems to identify dominant contributors to system unavailability or event sequence frequencies. In this step, conservative values are assigned to each basic event in the system FT for both independent and CCF modes. If several potential CCFs are associated with a given system, this step will help to identify the dominant contributors and to prioritize further analyses.

\subsubsection{Step 3-Common Cause Modeling and Data Analysis}

A CCF model that best fits the situation being modeled is then selected. NUREG/CR-4780 (Mosleh et al. 1988) several methods are presented. For most repository analyses that involve two-fold redundancy, the beta-factor method is the recommended approach. However, the appropriate beta factor must be applied.

The analysis of appropriate CCF factors is similar to the general problem of parameter estimation and selection, as discussed in Section 7.5. If information sources are available for systems or components similar to those of a repository and are located in an environment similar to a repository application, the analyst should attempt to extract CCF factors. Otherwise a generic beta factor should be used. Although a beta factor of 0.1 is a good value for use in preliminary analyses of high quality components, the analyst should consider whether a smaller or larger value is more suitable for the quality of component, the environment, and the degree of uncertainty in the root causes and coupling mechanisms for the CCFs.

Table 7-6 (based on Table 3-7 of NUREG/CR-4780 (Mosleh et al. 1988)) lists generic beta factors for several components used in nuclear reactor plants. The generic factor ranges from 0.03 for various pumps to 0.22 for various safety and relief valves. The average value is 0.1 for all components. 
Table 7-6. Generic Beta Factors

\begin{tabular}{|l|c|}
\hline \multicolumn{1}{|c|}{ Component } & Generic Beta Factor $^{\mathrm{a}}$ \\
\hline Reactor Trip Breakers & 0.19 \\
\hline Diesel Generators & 0.05 \\
\hline Motor Operated Valves & 0.08 \\
\hline Safety or Relief Valves & \\
Pressurized Water Reactor & 0.07 \\
Boiling Water Reactor & 0.22 \\
\hline Check Valves & 0.06 \\
\hline Pumps & \\
Safety Injection & 0.17 \\
Residual Heat Removal & 0.11 \\
Containment Spray & 0.05 \\
Auxiliary Feedwater & 0.03 \\
Service Water & 0.03 \\
\hline Chillers & 0.11 \\
\hline Fans & 0.13 \\
\hline All & $0.10^{\mathrm{b}}$ \\
\hline
\end{tabular}

Source: $\quad$ Modified from NUREG/CR-4780 (Mosleh et al. 1988)

NOTES: ${ }^{a}$ Based on classification of 3000 events from experience data. Dependent failure types were classified. Generic common cause events included potential as well as actual events. See Table 3-7 and the explanation in NUREG/CR-4780 (Mosleh et al. 1988, Section 3).

${ }^{\mathrm{b}}$ Average of all component beta factors.

\subsubsection{Step 4-System Quantification, Sensitivity Analysis, and Interpretation of Results}

The probability of system failure is quantified (e.g., using the SAPHIRE code) after: (1) all of the CCF elements in the system logic model have been assigned appropriate CCF parameters (e.g., an appropriate beta factor) and (2) parameters have been assigned to all independent failure modes and explicit dependencies (such as human error probabilities or T\&M unavailability). Examination of the dominant cutsets from the FT analysis identifies the key contributors to system unavailability. These contributors are expected to be one or more CCF events. The initial results may point to potential recovery actions that can reduce the impact of the CCFs and identify defenses against the CCFs.

At this stage, it may be desirable to perform a sensitivity analysis by varying the beta factors in the various CCF elements to gain insight into the significance of uncertainty in the CCF parameters.

The analyst should also perform a review of the results at this point to determine if the system unavailability factor appears to be extraordinarily small or large.

\subsubsection{Step 5-Reporting/Documentation}

Although the dependent failure/CCF analysis is an integral part of the event sequence analyses, it is important that the analyst clearly document this portion of the analyses with respect to 
assumptions, modeling approximations, and parameter selection. NUREG/CR-4780 (Mosleh et al. 1988, Section 3) presents a detailed explanation of the activities in Step 1 through Step 5.

\subsubsection{Examples of Application}

An example application of a CCF analysis was developed to examine the likelihood of having an uncontrolled descent of a waste-package transporter train during travel to the subsurface. An FTA was performed to examine the reliability of the brake system(s) of the WP transporter train. The most recent analysis is reported in Subsurface Transporter Safety Systems Analysis (CRWMS M\&O 2000) based on FT models developed in Application of Logic Diagrams and Common-Cause Failures to Design Basis Events (CRWMS M\&O 1997). The logic model made extensive use of CCF modeling.

The train was theoretically comprised of two locomotives and a shielded waste-package transporter car. Each vehicle had air-actuated tread brakes and hydraulic actuated disk brakes. Each of the vehicles had elements of redundancy within each of the respective brake systems. The actuation of the transporter brakes was controlled by the counterpart brake system on the primary locomotive. Thus, one mode of failure of transporter brakes was dependent on failure of the locomotive brake actuation system. This dependency was modeled explicitly in the FTA. Actuation of the brakes, however, could be initiated from either locomotive or from a central control room.

The beta factor method in this analysis was used at three levels: intra-vehicle (i.e., among redundant components on either of two locomotives or the transporter), inter-locomotive (i.e., among redundant and like components on both locomotives), and inter-vehicle (among redundant and like components on both locomotives and the transporter car).

The standard generic beta factor of 0.1 was used for the intra-vehicle level. This beta factor was applied to mechanical and electronic components in redundant configurations. Thus, the two channels of brake actuation signals were modeled as two paths of independent failures in series with one path of CCF. Redundant air-brake system components were modeled similarly.

A second level of CCF was introduced for the inter-locomotive CCFs using a beta factor of 0.01 (using the argument that the probability is less likely than the intra-vehicle situation) to allow for the possibility that there may be mechanisms for $\mathrm{CCF}$ among components on the two locomotives (e.g., root causes of common erroneous maintenance, calibration, and installation) that are less probable than CCFs between components located on the same vehicle. Similarly, a third level of CCF was introduced using a beta factor of 0.001 to allow for CCFs among components on all three vehicles. By using three beta factors that differ by orders of magnitude, the issue of double counting of some of the failure modes is less important.

The analysis indicated, as expected, that use of diverse and redundant brake systems on multiple vehicles reduce the probability of failure by independent failures or intra-vehicle CCFs. The assumed inter-vehicle CCFs are seen to be potentially significant contributors (even when a beta factor of 0.001 was used). The insights gained from such analyses indicate that programmatic controls should be put into place to eliminate or reduce the lkelihood of such CCFs. The 
numerical results must not be taken too literally or used to infer that brake systems cannot be made sufficiently reliable.

\subsection{TECHNICAL INFORMATION}

\subsubsection{Introduction}

This section defines the bases and methods for gathering and quantifying technical information that is used in the quantification of FTs and ETs. The technical information needs for ET and FT quantification consist generally of IE frequencies, failure rates and probabilities, CCF parameters, HEP, mission times, repair times, inspection intervals, and demand rates. Because of the precise use of the term "data" on the Yucca Mountain Project, this section uses the term "technical information" for the sources of information described.

This section will concentrate on the bases and methods for gathering and quantifying failure rates and probabilities for hardware and software along with associated mission times, repair times, inspection intervals, and demand rates. Information needs for common-cause and dependent failure analyses are presented in Section 7.4. Information needs for human reliability analyses are discussed in Section 7.3.

This section also includes methods for combining various sources of generic databases and for combining generic databases with repository-specific information. The bases for estimating uncertainty factors in parameters are described, as well as reference to the concepts presented in Section 9.

\subsubsection{Overview of Approach}

Other sections of this guide present methods for modeling and analyzing ETs, FTs, CCFs, and HFEs. All of those methods require inputs of various kinds. Most of these input parameters will be used to quantify the probabilities of basic events in FT models or the probabilities of event headings in ETs. Another application of the information is for use in quantifying the frequency of IEs (i.e., the frequency is expressed as probability per unit time). The fundamental input parameters for ET and FT quantification are in the form of failure rates (i.e., number of failures per unit time) and failure probability on demand (e.g., number of failures per number of trials).

This section follows the presentation in Section 5 of the PRA Procedures Guide (NRC 1983) for the following five elements:

1. Selection and Use of Event Models

2. Information (Data) Gathering

3. Estimation of Model Parameters

4. Uncertainties in Information and Event Probabilities

5. Documentation.

The Selection and Use of Event Models refers to the mathematical expression used to quantify a specific failure probability, the unavailability of SSC, or the frequency of an initiator. In many cases, the mathematical expression will be time-based to express the probability that a given failure will occur within some mission time or the probability that a particular SSC will be 
unavailable because it is out of service for T\&M or inspection. Each of these time-based situations has a rigorous mathematical formula for calculating the desired probability. Furthermore, each of the rigorous expressions is often approximated by simpler mathematical expressions.

For example, the exponential formula is used to calculate the probability that a component will not be available for a mission time, $\mathrm{T}$, when the failure rate, ?, is constant in time. The probability is expressed as $\mathrm{q}=1-\exp (-? * \mathrm{~T})$. When ?, $\mathrm{T}$, or both are small, the expression is approximated as q. ?* T. The exponential and other models are described in Section 7.5.3.

Information (Data) Gathering involves the selection and acquisition of generic databases, generic incident reports, and repository-specific event data, when available. Because a repository is a first-of-kind and will not have any operational experience prior to licensing, repository-specific equipment failure rate information will not be available. Therefore, the PSA must rely heavily on generic information, principally information from generic databases developed for PRAs, but also from experience data for equipment and systems similar to those that will be used in a repository. For some parameters, site-related information such as the frequency of natural phenomena, nearby hazardous activities, and historical information is available for components used in the Exploratory Studies Facility (ESF) (e.g., ground support maintenance $\log$ ).

A qualified database of equipment failure rates and human reliability factors will be compiled, under QA procedures, to support the PSA for LA. The PSA database will apply failure rate data in a manner that is consistent with the state-of-the-art in PRA and risk-informed, performance-based regulation. As such, the most representative failure rate information for a given SSC will be generated and applied in the PSA quantification. The failure rate information will include estimates of the mean values and uncertainty ranges. As appropriate, information from non-nuclear facilities will be adjusted to account for differences in quality assurance and maintenance programs that will apply to the repository and uncertainty factors that express the degree of confidence in the failure rates will be applied. Section 9 describes the process for applying uncertainty and sensitivity analyses in the process of screening and binning of event sequence frequencies.

Where ge neric failure rate data from NPP experience for safety-related SSCs, or from other NRC regulated facilities subject to a nuclear quality assurance program is used to estimate the failure rate of repository SSC ITS, that SSC will be required to have levels of control and quality assurance classifications consistent with the quality level of the facility from which the failure rate data is adopted.

Estimation of Model Parameters is the process of assigning a value to each of the parameters. If generic databases are used, the parameters of interest are already processed into the proper form giving a failure rate and its uncertainty. Therefore, the estimation of the counterpart parameter for the repository SSC may involve adjustment factors to alter the generic failure rate to account for repository-specific conditions (such as operational environments or quality assurance program). In some cases, there may be several pieces of generic information (and their uncertainty ranges) that are combined in specified ways to arrive at the best values for repository application. 
If a database of processed information is not available, then the failure rates have to be derived from event data. The number of observed failures must be divided by the number of trials or by the length of exposure time. The associated uncertainty factors are also derived. See Sections 7.2.3.4.1, 7.5.3.1.1, and 7.5.3.1.2. The Bayesian approach is the generally accepted method for parameter estimation in PRAs, including uncertainty factors. It is based on subjective probabilities applied with empirical information (see Section 7.5.3.3). In many reliability analyses, however, the classical or frequentist approach is used. When enough information is available, the two approaches give essentially the same numerical results. The Bayesian approach has some advantages, however, when less information is available (e.g., when the number of observed failure events is zero).

Uncertainties in Information and Parameters are the sources of uncertainty that are accounted for, and propagated in, the event sequence quantification (as described in Section9). The uncertainty derives from issues such as the amount of information available (e.g., number of trials), variability between sources (e.g., the failure rate for similar components vary significantly between two or more compilations), and the potential inaccuracies in the reported values. The uncertainty distributions ascribed to basic parameters (e.g., failure rates and repair times) are propagated through FT, HRA, and ET models and result in uncertainty distributions for event sequence frequencies.

\subsubsection{Details of Approach}

This section provides the essential methods and sources that are expected to be applied in performing the PSA. It is not intended to be exhaustive. In some cases, the analyst may find a need for alternative approaches that can be found in PRA and reliability literature.

\subsubsection{Selection and Use of Event Models}

Section 7.2.3.4.1, FTA, describes the event models most likely to be used in a PSA, but the mathematical formulas are repeated here for clarity. The analyst must determine the appropriate model to apply to a particular basic event. These models are summarized in Table 7-7. PRA or FTA programs, such as SAPHIRE (Russell et al. 1994) permit the user to specify which event model to use for quantifying a given basic event probability.

Except when quantifying IE frequencies, the purpose of an event model is to quantify a probability (that ranges from 0 to 1.0). The probability evaluation may be time-based or demand-based. Component or system faults are characterized as one of the following probabilities:

- $\quad$ Failure on demand - probability of failure per demand

- $\quad$ Standby failure - probability of failure on demand after a given no n-operational period, usually given as time-between-inspection

- $\quad$ Operational failure - probability of failing to run or operate (provide required function) during a specified time period (i.e., the mission time) 
Table 7-7. Sources of Facility-Specific and Operations-Specific Experience Information

\begin{tabular}{|l|l|l|}
\hline \multicolumn{1}{|c|}{ Parameter } & \multicolumn{1}{|c|}{ Information Requirements } & \multicolumn{1}{c|}{ Potential Sources $^{\text {a }}$} \\
\hline Probability of failure on demand & $\begin{array}{l}\text { Number of failures } \\
\text { Number of demands }\end{array}$ & $\begin{array}{l}\text { Repository and ESF inspection and } \\
\text { T\&M reports } \\
\text { Surrogate and generic reports }\end{array}$ \\
\hline Standby failure rate & $\begin{array}{l}\text { Number of failures } \\
\text { Time in standby }\end{array}$ & Same as above \\
\hline Operating failure rate & $\begin{array}{l}\text { Number of failures } \\
\text { Time in operation }\end{array}$ & Same as above \\
\hline Repair-time distribution parameters & $\begin{array}{l}\text { List of kinds of repairs (principally on- } \\
\text { line) of interest to PSA } \\
\text { Repair times }\end{array}$ & $\begin{array}{l}\text { Preliminary hazards and event } \\
\text { sequence analyses } \\
\text { Sources as above }\end{array}$ \\
\hline Unavailability due to T\&M & $\begin{array}{l}\text { List of kinds of T\&M of interest to } \\
\text { PSA } \\
\text { Frequencies and length of T\&M }\end{array}$ & $\begin{array}{l}\text { Preliminary hazards and event } \\
\text { sequence analyses } \\
\text { Sources as above }\end{array}$ \\
\hline Recovery & $\begin{array}{l}\text { List of kinds of recovery actions of } \\
\text { interest to PSA } \\
\text { Recovery times }\end{array}$ & $\begin{array}{l}\text { Preliminary hazards and event } \\
\text { sequence analyses } \\
\text { Sources as above }\end{array}$ \\
\hline HFEs, or HEP & $\begin{array}{l}\text { Lists of human interactions of } \\
\text { interest to PSA } \\
\text { Number and categories of HFEs } \\
\text { Number of opportunities } \\
\text { Recovery }\end{array}$ & $\begin{array}{l}\text { Preliminary hazards and event } \\
\text { sequence analyses } \\
\text { Detailed HRA for PSA } \\
\text { Sources as above }\end{array}$ \\
\hline
\end{tabular}

NOTE: a When available, parameters should be estimated from repository, ESF, or other Yucca Mountain specific sources. Otherwise, the best available and applicable surrogate sources should be used. Surrogate sources represent operations, equipment, and environments similar to a repository.

The causes of failures may be random faults in hardware or software, or may be human-caused, such as:

- Human failure events in T\&M that leave the equipment or software in a disabled state - Human failure events during operation that cause a loss of the safety function.

Finally, there may be cases where a system or subsystem is taken out of service for scheduled maintenance. The maintenance unavailability may be modeled in the system FTA. The unavailability for this case is a function of a scheduled maintenance interval and the expected time duration for the maintenance and does involve an estimate of failure rate of components.

In Section 7.5, the symbol "q" is used to connote the probability of failure (per demand), or the probability of being unavailable when needesd. The value of "q" may be calculated directly from demand-based experience data or derived from time-based (or rate/frequency) experience data, as described in the following sections.

\subsection{Time-Based Event Models}

Unless special cases dictate the use of a different model, it is generally assumed that, all timebased failures are governed by a failure rate that is constant in time. This produces the wellknown exponential failure model, which is expressed as 


$$
q(t)=1-\exp (-? t)
$$

where

$\mathrm{q}(\mathrm{t})$ is the probability that the component or system will fail within a time, $\mathrm{t}$; and ? is the constant failure rate.

A graph of $q(t)$ is illustrated in Figure 7-23.

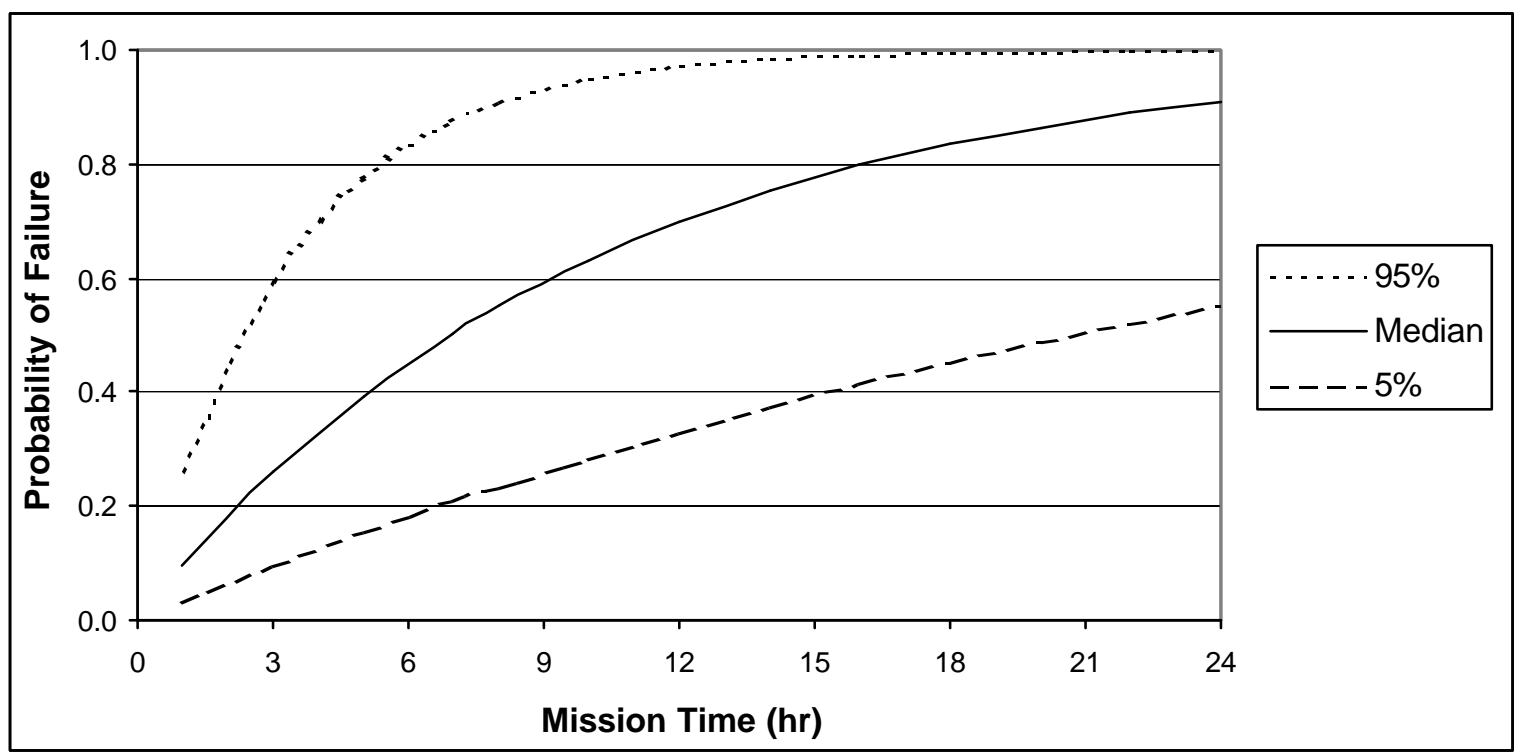

Figure 7-23. Exponential Probability of Failure

The PDF for $\mathrm{q}(\mathrm{t})$ is given as:

$$
\mathrm{f}(\mathrm{t}) \mathrm{dt}=? \exp (-? \mathrm{t}) \mathrm{dt}
$$

where

$\mathrm{f}(\mathrm{t}) \mathrm{dt}$ is the probability of a component or system failing within a time interval dt about $t$. Using the PDF, the mean-time-to-failure is evaluated as:

$$
\underline{\mathrm{t}}=\int_{0}^{\infty} ? \mathrm{t} \exp (-? \mathrm{t}) \mathrm{dt}=1 / ?
$$

This is an important relationship that is used in parameter estimation. The mean-time-to-failure is the inverse of the constant failure rate ? in an exponential model. 
There is an uncertainty distribution (i.e., a PDF) associated with the parameter $\lambda$ that will result in an uncertainty distribution for $\mathrm{q}(\mathrm{t})$. If the $5^{\text {th }}$ percent lower bound and the $95^{\text {th }}$ percent upper bound are expressed as ? ${ }_{\mathrm{LB}}$ and ${ }_{\mathrm{LB}}$, the corresponding expressions for the event probability are:

$$
\begin{aligned}
& \mathrm{q}_{\mathrm{LB}}(\mathrm{t})=1-\exp \left(-?_{\mathrm{LB}} \mathrm{t}\right) \\
& \mathrm{q}_{\mathrm{UB}}(\mathrm{t})=1-\exp \left(-?_{\mathrm{UB}} \mathrm{t}\right)
\end{aligned}
$$

These probabilities are illustrated in Figure 7-23. The methods for quantifying ?B $_{\mathrm{LB}}$ and $?_{\mathrm{LB}}$ are described in Section 7.5.3.3. Several time-based event models are derived from the exponential failure model (Equation 7-51), as defined in the following section.

Operational Unavailability (No-repair Model)-The unavailability of a component or system in the exponential reliability model without repair is:

$$
\mathrm{q}\left(\mathrm{t}_{\mathrm{M}}\right)=1-\exp \left(-? \mathrm{t}_{\mathrm{M}}\right)
$$

where $t_{M}$ is the mission time. The term $\mathrm{q}\left(\mathrm{t}_{\mathrm{M}}\right)$ is the probability that that the component or system will not perform its safety function for at least a time $t_{M}$ when it is needed. The longer the mission time, the higher the probability $\mathrm{q}\left(\mathrm{t}_{\mathrm{M}}\right)$ for the failure event modeled in the ET or FT.

Because the failure rate for highly reliable components is usually small, (i.e., such that ? $t_{M}<0.1$ ) the expression for $\mathrm{q}\left(\mathrm{t}_{\mathrm{M}}\right)$ can usually be approximated as:

$$
\mathrm{q}\left(\mathrm{t}_{\mathrm{M}}\right) \approx ? \mathrm{t}_{\mathrm{M}}
$$

This event model is applied to the failure-upon-demand of standby components that are not inspected or repaired. It is often applied to failure-to-run of a normally operating system or to a standby system after successful starts- upon-demand.

Standby Unavailability (With-Repair or Renewal, Unannuciated)-This unavailability applies to a system or component that is on standby, but whose condition is not known between periodic inspections or tests (i.e., failures are unanunciated). If a system is found to be failed or not performing to specification, the system or component is repaired. It is assumed that after repair, the component or system becomes good-as-new with a failure rate of ? $\mathrm{s}$, and the failure probability between inspections/tests follows the exponential function. This function is presented in Equation 7-51 (in Equation 7-51, ? is replaced by the standby failure rate of ?s).

The average unavailability of a system that is on standby but is periodically inspected, tested, and repaired, is given by:

$$
\mathrm{q}(\tau) \approx ?_{\mathrm{S}} \tau / 2
$$

Here $\tau$ is the inspection or test interval.

Figure 7-24 illustrates the time behavior of the exponential function between inspection intervals of varying length (calculated with Equation 7-56) and the corresponding average unavailability (calculated with Equation 7-58). The figure illustrates how the average unavailability increases 
with the inspection or test interval. In addition, the maximum failure probability can be significantly higher than the average unavailability and occurs just before the inspection or test.

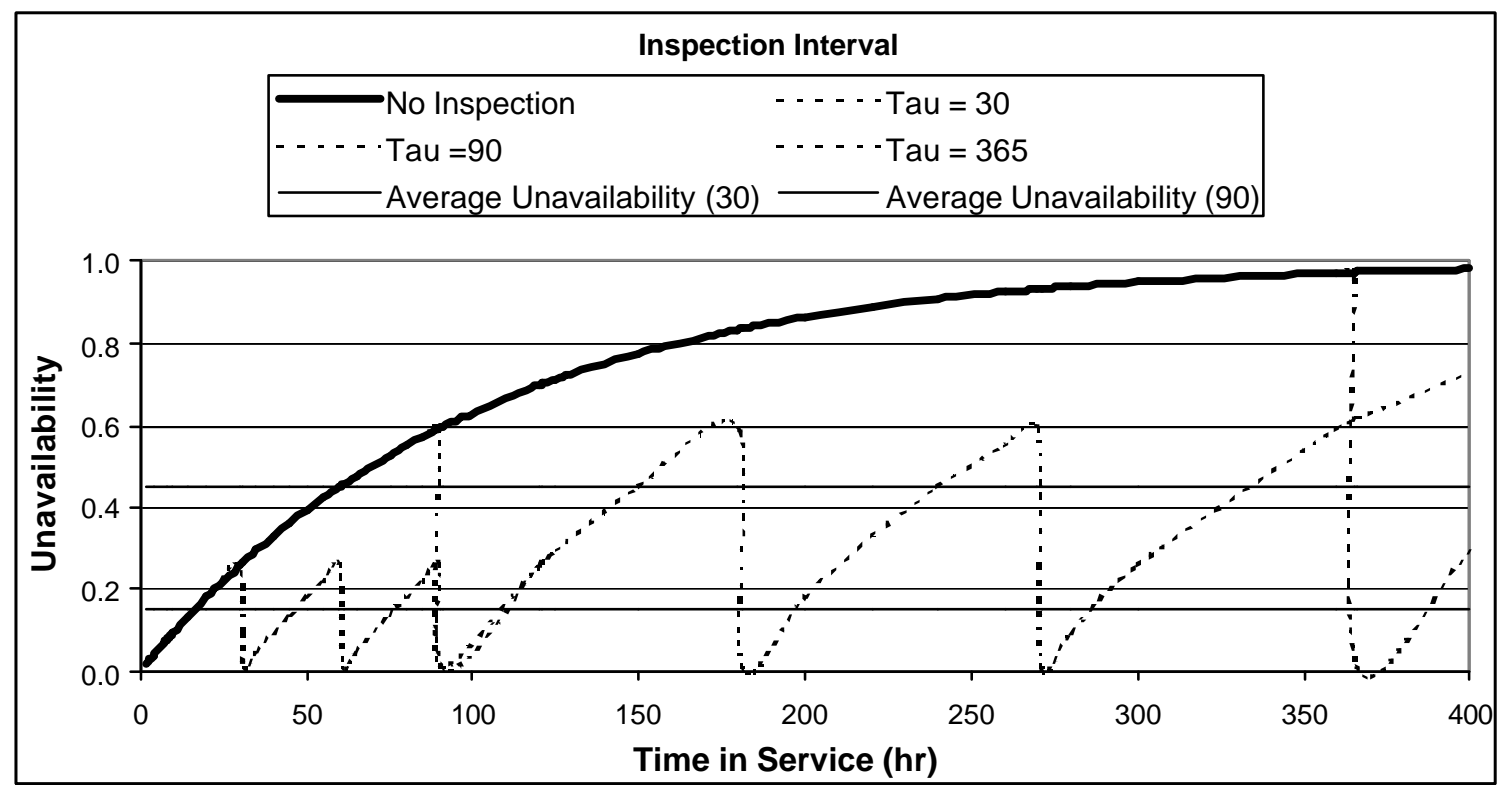

Figure 7-24. Unavailability with Inspection and Test

Standby Unavailability (With-Repair or Renewal, Annuciated)-This unavailability applies to a system or component that is on standby, but whose condition is known continuously due to instrumentation or some performance characteristic that indicates when the item is unavailable. The event model becomes that of the operational unavailability. Here it is assumed that repair or restoration begins immediately and that normal operations continue without having the item available.

The average unavailability of a system that is on standby but is periodically inspected, tested, and repaired, is given by:

$$
\mathrm{q}(\tau) \approx ? \mathrm{~T} /(1+? \mathrm{~T})
$$

Here $\mathrm{T}$ is the average total time to respond to the failure indication, repair, and return the item to service.

As above, if $\lambda \mathrm{T}$ is small compared to unity, the expression is approximated as:

$$
\mathrm{q}(\tau) \approx ? \mathrm{~T}
$$


Recovery within Required Time-This case represents an event that is represented in a logic model as an intersection (AND logic) with a primary failure (unavailability) event. It may be applied to failures during mission time, to failures to start-and-run on demand, and to IEs such as loss-of-primary power source.

In many instances, the exponential function (Equation 7-51) is applied as an exponential repair model, given as:

$$
\mathrm{p}_{\mathrm{R}}\left(\mathrm{t}_{\mathrm{C}}\right)=1-\exp \left(-\mathrm{t}_{\mathrm{C}} / \tau_{\mathrm{R}}\right)
$$

where

$\tau_{\mathrm{R}}$ is the mean-time-to-restore,

$\tau_{\mathrm{R}}$ is the required recovery time, and

$\mathrm{p}_{\mathrm{R}}\left(\mathrm{t}_{\mathrm{C}}\right)$ is the probability that the unavailable item is recovered (returned to functionality) within a required time $\mathrm{t}_{\mathrm{C}}$

Figure 7-25 illustrates the behavior of this function for a range of $\tau_{\mathrm{R}}$. It is observed that the probability of successful restoration for a given required time, $\mathrm{t}_{\mathrm{C}}$, is closer to 1.0 for small values of $\tau_{R}$. In quantifying an event for an ET or FT application, a value of $t_{C}$ is specified, based on safety functional requirements. If $\mathrm{t}_{\mathrm{C}}$ were 1.0 hours, the probability of success would be 0.982 for a mean-time-to-restore $\tau_{R}$ of 0.25 hours, but only 0.632 for $\tau_{R}$ of 1.0 hours.

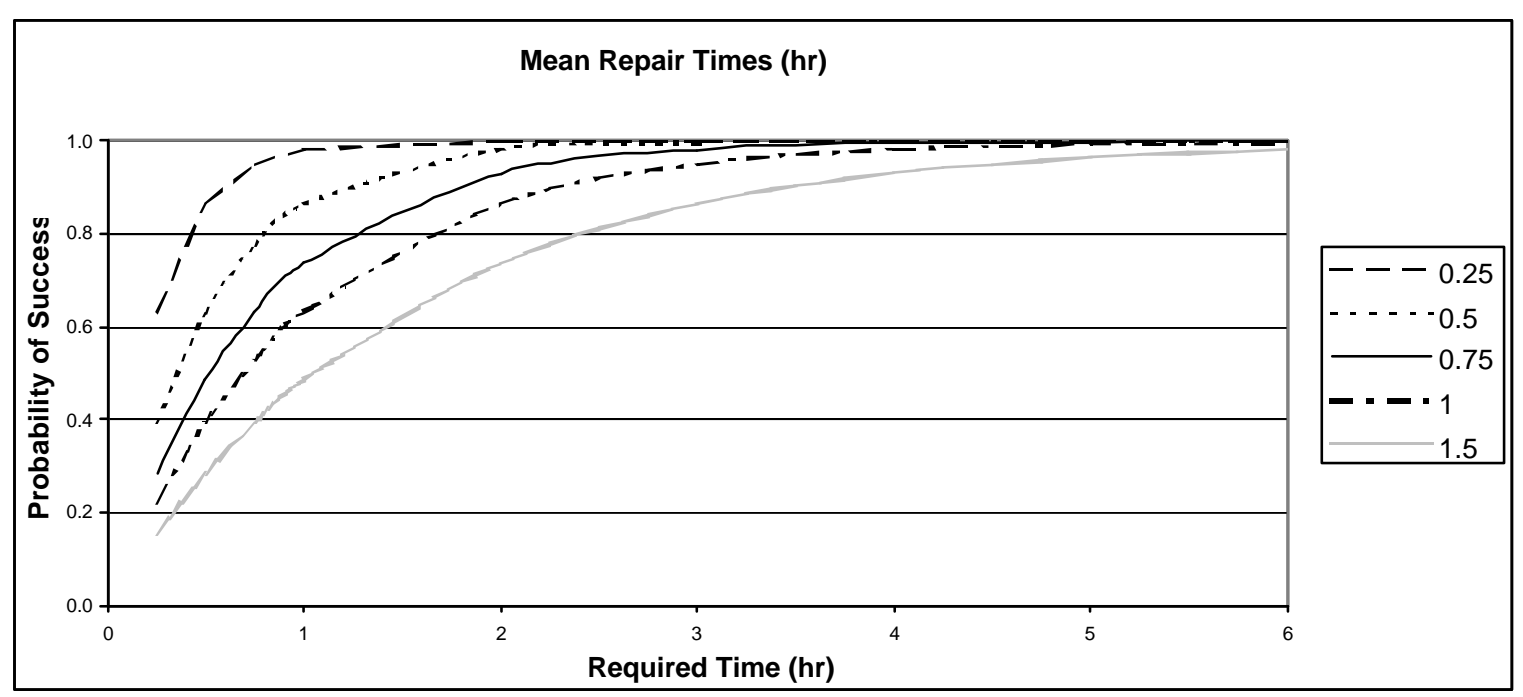

Figure 7-25. Probability of Restoration - Exponential Repair Model

This failure probability is applied in the event seque nce modeling. For the examples cited previously, where $t_{C}$ is 1.0 hours, the probability of failure is small i.e., $0.018=(1-0.982)$ for a mean-time-to-restore $\tau_{R}$ of 0.25 hours, but 0.3680 for $\tau_{R}$ of 1.0 hours. 
The joint probability of having the item unavailable to provide its safety function is the product of the primary failure probability and the probability of non-recovery in the required time. If the primary failure probability is $\mathrm{q}_{\mathrm{P}}=0.01$ and $\tau_{\mathrm{R}}$ is 0.25 hours, then the joint probability of having an SSC failure and not be recovered within the critical period ( $\mathrm{t}_{\mathrm{C}}=1.0$ hours) is calculated as:

$$
\mathrm{q}=\mathrm{qP}_{\mathrm{P}} * \mathrm{p}_{\mathrm{R}}\left(\mathrm{t}_{\mathrm{C}}\right)=0.01 * 0.018=0.00018
$$

Estimates of the mean-time-to-restore, $\tau_{R}$, are developed for each situation, where required. This parameter is also subject to uncertainty analysis. The lognormal distribution has been shown to be a good representation of the repair and restoration times.

\subsection{Specifying Mission Times and Allowable Recovery Time}

The analyst must specify a mission time when the non-repairable time-based model is used. The specification must be defensible to the NRC as being adequate for a specific safety function. The specified mission time may be based on an engineering analysis or dictated by a regulatory requirement or precedent. However, the mission time may be somewhat arbitrary a long as the performance is shown to meet $10 \mathrm{CFR}$ Part 63 requirements. For example, requiring that a waste-handling building HVAC/HEPA filter system must function for at least 24 hours following a release of radioactivity from a breached waste form may be based, initially, on the qualitative argument that most of the important filtration will have occurred in that period. Should offsite doses indicate that a longer filtration period is required, however, the mission time would have to be extended.

The analyst must provide similar justification for allowable recovery times for repairable systems. The logic is similar to the specification of a mission time, but asks the complementary question of "how long can we be without this safety function before the 10 CFR Part 63 performance criteria cannot be met?" Using the example of the HVAC/HEPA filter system, it may be allowable for components of the secondary or tertiary zones to be out of service for many hours without compromising the negative pressure that ensures that airflow is inward toward the primary zone. The allowable time would set the limit on the recovery time in the repairable event model.

\subsection{Specifying Time between Tests or Inspections}

The probability of a failure-on-demand of standby SSCs is assumed to increase between inspections or tests, at which time they are restored to good-as-new. The probability of failure on demand must be low enough to ensure that a repository can meet the risk-informed performance requirements. It may be required to specify a shorter inspection interval or developing a more reliable standby system having a lower standby failure rate. This activity may be iterative.

The analyst may initially specify a reasonable typical interval such as one year, three months, one month, or a week, depending on how important it is to ensure the availability of a given system or component. If a specific inspection interval is essential to demonstrate compliance with the requirements of 10 CFR Part 63, then the specified interval may become part of the licensing specifications. If the performance is unacceptable, then shorter testing and inspection 
intervals may be explored or alternative system designs (e.g., having more redundancy or diversity) may be considered.

\subsection{Demand-Based Event Models}

The failure-on-demand event model, as described in the PRA Procedures Guide (NRC 1983), is also termed the constant-failure-rate-per cycle model in the Fault Tree Handbook (Vesely et al. 1981).

The failure-on-demand model applies to a component or system that is in a dormant state until the instant there is a demand for it. This concept applies to standby components, as described previously. The failure-on-demand model also applies to structural and passive components that may never be challenged during their operational lifetime or are not amenable to testing, inspection, or refurbishing after the initial installation or construction. The weld on a WP is an example of such a component.

A point estimate of the failure on demand is the value of the constant probability for a given situation, calculated as:

$$
\mathrm{q}_{\mathrm{D}}=\mathrm{p}_{\mathrm{D}}=\mathrm{r} / \mathrm{n}
$$

where

$\mathrm{p}_{\mathrm{D}}$ is derived from tests or event reports for $\mathrm{r}$ failures in $\mathrm{n}$ trials.

The expression for $\mathrm{q}_{\mathrm{D}}$ is a limiting case (for $\mathrm{r} \geq 1$ failure) of the binomial probability distribution.

The constant-failure-rate-per cycle model is also applicable for operating equipment that may be required to perform several, repeated operations (demands) for which there is a fixed probability of failure per demand.

When the event involves a cycling of a system or component during some operational time span (or mission time), the expected number of cycles (demands) during the time interval is important. If $\mathrm{N}$ cycles are expected during a mission time $\mathrm{T}$ and the probability of failure per demand is $\mathrm{p}_{\mathrm{D}}$, then the probability of failure during $\mathrm{T}$ is estimated as:

$$
\mathrm{q}_{\mathrm{T}}=\mathrm{N} * \mathrm{p}_{\mathrm{D}}
$$

If the failure on demand is modeled as a conditional probability of failure to respond in an ET event sequence or as a basic event in a system FT model, then the probability form is used exactly as shown in Equation 7-63. The event modeling will specify the number of demands that will be expected. For example, a pressure relief damper may be required to cycle $\mathrm{N}$ times during a transfer cell purging operation following a drop and breach of an SNF assembly; the probability of failure, then, is $\mathrm{q}_{\mathrm{T}}=\mathrm{N} * \mathrm{p}_{\mathrm{D}}$.

Equation 7-63 can be modified to quantify IE frequencies. Event modeling will specify an operational frequency for demands (e.g., $\mathrm{N}$ is the number of lifts per year of SNF assemblies). If 
$\mathrm{p}_{\mathrm{D}}$ represents the probability per lift of dropping a SNF assembly, then the frequency of dropping $\mathrm{SNF}$ assemblies becomes $\mathrm{f}_{\mathrm{T}}=\mathrm{N} * \mathrm{p}_{\mathrm{D}}$ drops per year; here, $\mathrm{f}_{\mathrm{T}}$ is used in place of $\mathrm{q}_{\mathrm{T}}$.

Section 7.5.3.3 presents methods for estimating probability distributions and confidence intervals for time-based and demand-based failure rates.

\subsection{Binomial Distribution}

The binomial distribution is a discrete form of a PDF:

$$
\mathrm{b}(\mathrm{x} ; \mathrm{n}, \mathrm{p})=\left(\begin{array}{l}
\mathrm{n} \\
\mathrm{x}
\end{array}\right) \mathrm{p}^{\mathrm{x}}(1-\mathrm{p})^{\mathrm{n}-\mathrm{x}}
$$

This expression gives the probability that exactly $x$ number of failures will be observed in $n$ independent trials, given a constant probability per trial, p. The parameter needed in this model is $\mathrm{p}$. The expression for $\mathrm{b}(\mathrm{n} ; \mathrm{n}, \mathrm{p})$ is a built-in function in the Microsoft Excel spreadsheet program.

The binomial form of the cumulative probability function is expressed as:

$$
\mathrm{B}(\mathrm{r} ; \mathrm{n}, \mathrm{p})=?\left(\begin{array}{l}
\mathrm{n} \\
\mathrm{s}
\end{array}\right) \mathrm{p}^{\mathrm{s}}(1-\mathrm{p})^{\mathrm{n}-\mathrm{s}} ; \text { sum from } \mathrm{s}=0 \text { to } \mathrm{s}=\mathrm{r}
$$

This expression gives the probability that $\mathrm{x}$, the number of failures observed in $\mathrm{n}$ independent trials, will be less than or equal to $r$, given a constant probability per trial, $p$. The statistical average of the binomial distribution is $n p$ and the variance is $n p(1-p)$. The expression for $\mathrm{B}(\mathrm{r} ; \mathrm{n}, \mathrm{p})$ is a built-in function in the Microsoft Excel spreadsheet program.

If the binomial PDF is taken to the limit as $\mathrm{n}$ goes to infinity for the product, $\mathrm{m}=\mathrm{np}$ is constant and finite reduces to the Poisson distribution that is expressed as:

$$
\mathrm{p}(\mathrm{x})=\left[\mathrm{m}^{\mathrm{x}} / \mathrm{x} !\right] \exp (-\mathrm{m})
$$

This expression gives the probability that exactly $x$ number of failures will be observed in a large number (effectively infinite) of independent trials having a small probability per trial, $\mathrm{p}$. The parameter needed in this model is $\mathrm{m}=\mathrm{np}$. The mean value is $\mathrm{m}$, and the variance is also $\mathrm{m}$. The probability that $x$ is less than or greater than $r$ is the summation of Equation 7-66 over $x$, from 0 to $r$. The Poisson distribution of Equation 7-66 is the basis for the exponential failure models, described in the following paragraphs.

The Poisson distribution is a good approximation for the binomial, even for rather large values of $\mathrm{p}$ and small values of n. As an example, the Fault Tree Handbook (Vesely et al. 1981) asks, "what is the probability of finding exactly one defective unit in a random lot of 10 , given $\mathrm{p}=$ 0.1?" The exact value using the binomial distribution is 0.3874; the Poisson formula gives 0.3679 . This estimation may be adequate for many probability estimates in light of other uncertainties. When the lot size is increased to 20, the respective values are 0.2702 and 0.2707 ; thus, in excellent agreement. 
It is further noted that for most ET and FT analyses, the probability of interest is that exactly 0 failures occur, i.e., success. Setting $x=0$ in Equation 7-66 gives:

$$
\mathrm{p}(0)=\exp (-\mathrm{m})=\exp (-\mathrm{np})
$$

The available failure event data are given as time-based data, (i.e., a failure is observed to occur with an average interval of $\mathrm{t}$ hours). Expressed another way, if the mean arrival interval of failures is t a number $R$ failures would be expected in some time interval $T$, where $R=T / \mathrm{t}$ ). Since $\mathrm{m}$, (Equation 7-66) is the number of failures, replacing $\mathrm{M}$ with $\mathrm{R}=T / \mathrm{t}$, gives:

$$
\mathrm{p}(0)=\exp (-R)=\exp (-T / \mathrm{t})=\exp (-? T)
$$

Here $?=1 / \mathrm{t}$ is a constant failure rate. This expression is observed to be the exponential event model, thus demonstrating the similarities between the demand-based and time-based event models. Equation 7-68 gives the probability of having exactly zero failures in the time $T$. The probability of having at least one failure is a time period, $T$, is given by $\mathrm{P}_{\mathrm{F}}=1-\mathrm{p}(0)=1-\exp (-? T)$.

\subsection{Dependent and Common-Cause Failures}

A more complete discussion of dependent failures and CCFs is presented in Section 7.4.

In developing FT models that include redundant components or subsystems, it is generally recognized that the joint probability of the concurrent failure of two or more redundant components may not be the product of two independent failure probabilities. That is, the failures of the individual components or subsystems may be dependent (i.e., coupled). This possibility is modeled in the FT when the construction rules are applied. Similarly, two or more events modeled in an ET may not be independent (i.e., the success or failure of one system may influence the probability of failure of a system, component or human, that occurs later in the sequence).

The probabilities of the dependent or CCFs are quantified using demand-based or rate-based parameters, as appropriate for the event being quantified. It is expected that most CCF quantification will apply the beta factor method (see Section 7.4).

\subsection{Initiating Event Frequency}

To quantify the frequency of an event sequence (or accident scenario), the frequency of the IE has to be scaled to match the operational load of the system. For example, the IE definition may be "crane drops SNF canister" and the quantification may require the frequency specified or " $F_{D}$ drops per year." The operational throughput of the system may be Z canister lifts per year and the basic failure parameter is given as " $\mathrm{Q}_{\mathrm{D}}$ drops per lift." Demand-based and rate-based data can be used to calculate the frequency of the IE, as follows: 
Demand-Based Data-Experience data indicate that the probability of dropping any given canister during a lift is $\mathrm{Qb}$ drops per lift (i.e., more precisely defined as the probability of a canister drop per lifting operation). If the frequency of lifting canisters is $\mathrm{Z}$ per year, then the frequency of the postulated IE is calculated as:

$$
\mathrm{F}_{\mathrm{D}}=\mathrm{Z} * \mathrm{Q}_{\mathrm{D}} \text { drops per year }
$$

Rate Based Data-Experience data show that the rate of dropping any given canister during operational time is $\lambda_{D}$ drops per hour (e.g., this rate might be derived from related information like a crane failure rate). In this situation, the exposure time (or mission time) must be defined for each lift operation to derive the probability of a drop per lift. The estimated time that each canister is suspended in a vulnerable condition during each operation is $T_{L}$ minutes. The probability of canister drop per lift is derived as:

$$
\mathrm{Q}_{\mathrm{D}} \approx \lambda_{D} * \mathrm{~T}_{\mathrm{L}} \text { drops per lift }
$$

The time units must be converted, as appropriate, from hours to years.

Proceeding in the same manner as in the demand-based case, the frequency of the postulated IE is calculated as:

$$
\mathrm{F}_{\mathrm{D}}=\mathrm{Z} * \mathrm{Q}_{\mathrm{D}} \text { drops per year }
$$

\subsection{Human Error Probabilities or Rates}

Many basic events in ET or FT models represent HFEs in operations or maintenance. Special techniques have been developed for estimating the probabilities of various kinds of HFEs. The probability values may be expressed as human error probability (HEP) using tables from Swain and Guttman (1983) or developed in a more complex HRA model, such as that of ATHEANA (NRC 2000). HRA is the process of analyzing situations where human errors (or human recovery actions) may occur and quantifying the probability of those actions. Section 7.3 describes a method for HRA for support of the PSA.

\subsubsection{Information (Data) Gathering}

A repository is a first-of-a-kind facility. Therefore, there is no facility-specific operational experience to draw from to support the PSA for LA-CA. Estimates of event probabilities or failure rates will be based on surrogate experience or generic information. Since the operational portions of the facility will employ many systems and components that are common in general industry, mining, and the nuclear industry, there are many potential sources of information that can be applied in the PSA. This section identifies some of the known sources and describes the kind of information that is available in each. Guidance is provided on how to employ such information in the PSA development.

One concern raised by the NRC suggests that perhaps SSCs screened out in event sequences that are deemed not credible may be based on use of failure rate data for SSCs subject to QA programs at nuclear plants. Once the sequence is screened out and the SSC is deemed not ITS 
for the MGR, there would not be a comparable QA program applied to the SSC in the MGR to ensure its reliability for the safety function credited. While this issue will be guarded against in the PSA, the following paragraphs provide guidance on the application of surrogate failure rate data.

Traditionally, reliability engineers have applied "quality factors" or "environmental factors" to failure rate data whenever the service environment in the system of interest is not exactly the same as that of the information source. For example, the failure rates of some electronic components are increased or decreased by "K-factors" that relate to the temperature, humidity, vibration, etc., of environments of the application relative to the environment present in the failure rate tests. In the same vein, failure rates and their uncertainty factors for various systems or components of the repository can be adjusted up or down, with proper rationale, to represent the differences between the operating conditions and quality-assurance controls at the source of the information and that expected at the repository.

For example, information on failure rates of commercial rail locomotives, rail, and control/instrumentation, or commercial shipyard cranes, may be judged applicable to the repository waste package transporter and handling system, if certain adjustments are made. Through scrutiny of the breakdown of failure causes in the commercial operations (e.g., iced rail, open rail switch, crane rigging error, etc.), the number of observed failures can be reduced by crediting: (1) MGR operating conditions conducted inside of buildings (2) operations conducted in tunnels that are out of the weather, and (3) design features that preclude the kinds of failures reported.

If failure rate and uncertainty information for specific systems are derived from nuclear facilities and represent SSCs that are subject to a nuclear QA program (or similar QA program), then the failure rates may have to be used with care to ensure that they are not applied inappropriately. If the information is applied to a given SSC that is classified as ITS and retains that designation after event sequence frequency screening and/or consequence analyses, then the application of the failure rates and uncertainties may be deemed appropriate. If the frequency screening or consequence analysis indicates that the SSC is not ITS and is therefore exempt from the nuclear QA controls, then it may be necessary to increase the failure rates and uncertainty factors by an appropriate factor to account for quality and to reevaluate the SSC for ITS considerations. This section does not recommend a single definitive database as a mandatory input to the PSA. However, information that is used to support the design of SSCs ITS will be developed and controlled according to the Project quality assurance program. The processes and procedures for establishment, maintenance, and configuration control of such a database are outside of this guide.

The two primary categories of information are operational experience and tabulated generic data.

\subsection{Operational Experience}

Operational experience provides raw data on the number, modes, and causes of failures of systems, components, and software and a baseline that quantifies the time-in-service or number of demands represented in the reporting. A failure rate (or failure probability) of a given failure mode is derived from the ratio of the number of failures during the operational time (or number 
of demands). While it is relatively easy to find reports on the number and modes of failures in reports from many industries (i.e., to quantify the numerator), it is usually difficult to determine the baseline (i.e., to quantify the denominator). The analyst must often make assumptions on the baseline, estimating the time-in-service or number of demands based on throughput rates of the surrogate facility, preferably with input from operating personnel at that facility.

As previously noted, the analyst may have to adjust the raw information to make it applicable to a particular repository operation. For example, if information is available on commercial railway locomotive derailments per mile traveled, and the causal breakdown shows that 25 percent are due to bad weather, the analyst might reduce the raw number of derailments per year by 25 percent as an estimate for subsurface transporter locomotives to account for the fact that there is no weather underground.

In applications of surrogate data, the analyst must provide a rationale to support selection of the source and how the information is applied.

Representative sources of operational information sources are described in the following paragraphs.

- $\quad$ Exploratory Studies Facility-The ESF experience can be applied where appropriate. For example, records on ground support system installation, maintenance, and inspections may provide bases for estimating the reliability of the repository ground support system.

- U.S. Department of Transportation, Federal Railway Association-Statistics and analysis of causal factors of accidents on commercial railways may provide bases for estimating derailment, brake failure, and human error rates.

- British Mining Locomotive Data (U.K. Health and Safety Executive)-Statistics and analysis of causal factors of accidents on commercial mining locomotives may provide bases for estimating derailment, brake failure, and human error rates.

- U.S. Nuclear Regulatory Commission-The NRC maintains databases of licensee event reports for cranes, fuel handling equipment, instrumentation and controls, electrical distribution, emergency diesel generators, HVAC systems, and other systems that will be used in a repository.

- Waste Isolation Pilot Project-Experience information accumulated on this project should be examined and incorporated into event probability estimates.

- Institute of Nuclear Power Operations-Performance information has been collected for many years, but for confidentiality, the Institute and the participating utilities closely held the information. Some summary information has been published, but access to compiled reliability databases has been restricted. Available information should be examined for applicability to the PSA for a repository. 


\subsection{Tabulated Generic Data}

There are many tabulations of generic information that may be applicable for the PSA. A bibliography of generic data sources is provided in the Section 7 Appendix. The following paragraphs describe some of the principal databases.

- Savannah River Site Generic Data Base (Blanton and Eide 1993)-This document describes a project for improving the component failure rate database at the Savannah River Site. It provides a representative list of components and failure modes, approximately 75 percent of which are based on actual events. Many sources of generic data are noted, but a major generic source was NUCLARR (see below), but also incorporated data from the INEEL chemical processing plant. A Bayesian approach was used for estimation. The information was aggregated to obtain generic failure rate distributions (given as mean and $\mathrm{EF}$ of $\mathrm{LN}$ ) for each component failure mode. $\mathrm{EF}$ is the ratio of 95 percent upper bound to median (50 percentile).

- Savannah River Site Human Error Rate Database (Benhardt et al. 1994)-A counterpart of the Savannah River Site component database. This report tabulates HEP for 35 representative HAs in Savannah River Site safety analyses: 16 are based on generic information, and 19 are based on site-specific information.

- IEEE Recommended Practice for the Design of Reliable Industrial and Commercial Power Systems (IEEE 1998)-This document provides a limited summary of equipment reliability data (see also IEEE 1984).

- NUCLARR, NUREG/CR-4639 (INEEL 1989)-This database, sponsored by the NRC, is a compilation of event data extracted from many PRA and individual plant examinations. Not all of the information is independent, especially some of the generic information that is replicated in several studies. The entries are categorized as 1,2 , and 3 to indicate the degree of independence and quality so the user may reject some entries, or use them with caution or weighting. Access to the NUCLARR database requires a subscription.

- $\quad$ Eide et al. (1993)-This paper presents failure rates for fluid system components to support internal flooding PRAs for NPPs. The basic information was gathered from licensee event reports reported in Nuclear Power Experience. Rupture probabilities and leakage frequencies were estimated using Bayesian update with a noninformative prior. Component exposure times were estimated if they were not explicitly given in the information base. 
- $\quad$ Eide and Calley (1993)-This paper presents a comprehensive tabulation of generic component failure rates developed for light-water reactor PRAs. NUCLARR was used, so that most of the failure rates are based on actual plant experience. Failure rates and their EFs are given for several failure modes of each component. The EFs are the ratio of the 95th percentile to the 50th percentile. NUCLARR has automatic aggregation routines to pool information from different sources. Table 7-8 illustrates the format of the information in that paper.

Table 7-8. Example of Generic Component Failure Rates Database

\begin{tabular}{|c|c|c|c|c|c|c|c|}
\hline \multirow[b]{2}{*}{ Component/Failure Mode } & \multirow[b]{2}{*}{$\begin{array}{c}\text { Recommend-ed } \\
\text { Failure Rate, } \\
\text { Mean }\end{array}$} & \multirow[b]{2}{*}{$\begin{array}{c}\text { Error } \\
\text { Factor, } \\
95 / 50\end{array}$} & \multicolumn{4}{|c|}{ NUCLARR Component Failure Information } & \multirow[b]{2}{*}{$\begin{array}{l}\text { NUCLARR } \\
\text { Source }\end{array}$} \\
\hline & & & Sources & Failures & Demand & Hours & \\
\hline \multicolumn{8}{|l|}{ Mechanical Components } \\
\hline \multicolumn{8}{|l|}{ Valve - Motor Operated } \\
\hline Fail to open/close & $3.0 \mathrm{E}-03 / \mathrm{d}$ & 5 & 13 & 480 & 141474 & & Category 1 \\
\hline Spurious operation & $5.0 \mathrm{E}-08 / \mathrm{h}$ & 10 & 4 & 1 & & $2.00 \mathrm{E}+07$ & Category 1 \\
\hline $\begin{array}{l}\text { Plug } \\
\text { Internal leakage }\end{array}$ & 5.0E-09 /h & 10 & & 0 & & $1.24 \mathrm{E}+08$ & $\begin{array}{l}\text { Category } 2 \\
\text { None }\end{array}$ \\
\hline Interanal rupture & $1.0 \mathrm{E}-07 / \mathrm{h}$ & & & & & & Other \\
\hline . & . & . & . & . & . & . & . \\
\hline . & . & . & . & . & . & . & . \\
\hline . & . & . & . & . & . & . & . \\
\hline \multicolumn{8}{|l|}{ Pump - Motor Driven } \\
\hline Fail to start & $3.0 \mathrm{E}-03 / \mathrm{d}$ & 5 & 17 & 137 & 48459 & & Category 1 \\
\hline Fail to run & $3.0 \mathrm{E}-05 / \mathrm{h}$ & 10 & 16 & 216 & & $7.46 \mathrm{E}+06$ & Category 1 \\
\hline . & . & . & . & . & . & . & . \\
\hline . & . & . & . & . & . & . & . \\
\hline . & . & . & . & . & . & . & . \\
\hline \multicolumn{8}{|l|}{ Electrical Components } \\
\hline \multicolumn{8}{|l|}{ Battery } \\
\hline $\begin{array}{l}\text { Failure } \\
\text { Battery charger }\end{array}$ & $1.0 \mathrm{E}-05 / \mathrm{h}$ & 5 & 6 & 8 & & $9.44 \mathrm{E}+05$ & Category 1 \\
\hline $\begin{array}{l}\text { Failure } \\
\text { Switch-General }\end{array}$ & $1.0 \mathrm{E}-05 / \mathrm{h}$ & 5 & 7 & 29 & & $1.62 \mathrm{E}+06$ & Category 1 \\
\hline Failure to open/close & $1.0 \mathrm{E}-05 / \mathrm{d}$ & 5 & & & & & Other \\
\hline Spurious operation & $1.0 \mathrm{E}-06 / \mathrm{h}$ & 10 & & & & & Other \\
\hline Switch-Limit & & & & & & & \\
\hline Failure to open/close & $3.0 \mathrm{E}-05 / \mathrm{d}$ & 5 & 1 & 0 & 12550 & & Category 1 \\
\hline Spurious operation & $1.0 \mathrm{E}-06 / \mathrm{h}$ & 10 & 1 & 7 & & $8.10 E+06$ & Category 1 \\
\hline$\cdot$ & $\cdot$ & . & $\cdot$ & . & . & . & . \\
\hline . & . & . & . & . & . & . & . \\
\hline rce. Fide and Calle & . & . & . & . & . & . & . \\
\hline
\end{tabular}


- IEEE Guide to the Collection and Presentation of Electrical, Electronic, and Sensing Component Reliability Data for Nuclear-Power Generating Station (IEEE 1984)This document contains failure rate point values and intervals for electronic, electrical, and sensing components. The values reported were elicited from about 200 experts and pooled using geometric averaging. Some of the information is based on operational and test information, but the user cannot tell which information has this basis versus that based purely on expert opinion.

- $\quad$ Rome Air Force Base, NPRD-2, Nonelectronic Parts Reliability Data (Arno 1981) This document is intended to complement MIL-HNBK-217F (DOD 1991) by providing information on mechanical, fluid, and air-handling system components. For example, the table includes failure modes and rates for vehicle brakes in various applications. The tables provide rates (mean and confidence interval) for various failure modes, and where available, it provides raw data (number of failures and number of trials or operational time).

- AIChE Guidelines for Process Equipment Reliability Data with Data Tables (AIChE 1989)-This source contains information on components used in non-nuclear facilities. Tables include failure rates for different modes of failure and the lower bound, mean, and upper bound.

- MIL-HDBK-217F, Military Handbook Reliability Prediction of Electronic Equipment (DOD 1991)-This document is a compilation of baseline failure rates for a wide variety of electronic components, and it includes adjustment factors to account for the environment, duty or load, quality factor, and similar items. This document should be considered a prime source of information for the PSA because it is applied widely in government-supported activities.

- Waste Isolation Pilot Project Safety Analysis-This source should be examined for potential use in the PSA.

- Reactor Safety Study (WASH 1400) (NRC 1975)-This work was compiled in the mid-1970s. It has tabulations of component and system failure rates and probabilities applicable to NPPs. The tabulations include data on pumps, valves, and reactor protection systems, which are not relevant to PSA; however, information on electrical components and instrumentation may be applicable. Parts of this report are still quoted and are embedded in some of the other generic databases (e.g., NUCLARR [INEEL 1989]). For PSA, preference should be given to more recent sources, provided they are applicable and reliable.

- Government Industry Data Exchange Database (GIDEP)-Primarily oriented toward aerospace and defense industries. Generic failure rate information is similar to that presented in the Rome Air Force Base (Arno 1981) and MIL-HDBK-217F (DOD 1991) documents. Subscribers pay no fees, but must contribute data.

- $\quad$ Plant-Specific PRAs and Individual Plant Examinations-Every PRA and individual plant examination submitted to the NRC contains a tabulation of basic event data. These 
will be a mixture of generic and plant-specific information. If other generic sources do not support a particular facet of the PSA, the analyst may have to use this source.

- $\quad$ Foreign Databases-NPP component failure rate data have been compiled by foreign nuclear programs such as those in France and Sweden.

\subsubsection{Estimation of Model Parameters}

This section describes the methods for quantifying event probabilities and frequencies using the models described in Section 7.5.3.1. Two general classes of methods are described that are known, respectively, as classical (or frequentist) estimation and Bayesian (or subjectivist) estimation.

The classical approach relies on statistical theories that equate probability to the frequency of observed outcomes, usually invoking hypothetical runs of many trials. The classical approach has been applied in traditional reliability engineering. The classical approach has limitations in trying to estimate the probability of events that have never occurred, but which are believed to be possible.

The Bayesian approach is probability based, not statistical based. In this concept, probability is related to the state of knowledge or degree of belief of the analyst, hence the notion of subjectivity. However, the method is not entirely subjective because there is a robust theoretic foundation for incorporating empirical evidence into the estimation of event probabilities. Notably, there is a technique for Bayesian updates of facility-specific reliability databases. Further, Bayesian concepts are applied in the pooling, or aggregating, of information from several sources. Although the approach was fostered in the development of PRA methods, it has been adapted in modern reliability engineering.

Both the classical and Bayesian methods provide for estimating the uncertainties or in the model parameters. These are termed confidence intervals in classical estimation, and probability intervals or EFs in Bayesian estimation. In all cases, the intervals represent the range about the point estimate of a given parameter where the integral of the PDF is the fraction $\alpha$ of possible values reported from a large number of observations (i.e., the interval is expected to include the true value of the parameter with probability of $100 \alpha$ percent. The respective limits on the confidence interval are calculated as the area in the upper and lower tails of the particular PDF. The intervals are expressed as the value of the parameter that represents the upper $100\left(1-\frac{a}{2}\right)$ percent and lower $100\left(1-\frac{a}{2}\right)$ percent values of the parameter.

The following sections are based, in large measure, on the PRA Procedures Guide (NRC 1983).

\subsection{Classical Parameter Estimation}

The classical approach is presented for point estimates and confidence intervals for the binomial, Poisson and LN distributions. The information requirements for quantifying each distribution are also presented. 


\section{Binomial Distribution}

The fundamental parameter is $\mathrm{p}$, the probability of failure on demand (unitless) (see Section 7.5.3.1). It is derived from test or experience information as follows:

Point Estimate: $\quad p^{*}=f / n$

where information needs are:

$$
\begin{aligned}
& \mathrm{f}=\text { number of observed or recorded failures in } \mathrm{n} \text { demands or trials } \\
& \mathrm{n}=\text { number of recorded demands or trials in reporting period. }
\end{aligned}
$$

Confidence Interval: The exact method for interval estimation for the binomial distribution is to use the expression $\mathrm{B}(\mathrm{f} ; \mathrm{n}, \mathrm{p})$ for the cumulative distribution solving for $\mathrm{p}_{\mathrm{U}}$ and $\mathrm{p}_{\mathrm{L}}$, respectively, that give the upper and lower $100(1-\alpha)$ percent confidence limits:

$$
\begin{aligned}
& \alpha=\mathrm{B}\left(\mathrm{f} ; \mathrm{n}, \mathrm{p}_{\mathrm{U}}\right)=\sum\left(\begin{array}{l}
\mathrm{n} \\
\mathrm{s}
\end{array}\right) \mathrm{p}_{\mathrm{U}}^{\mathrm{s}}\left(1-\mathrm{p}_{\mathrm{U}}\right)^{\mathrm{n}-\mathrm{s}} ; \text { sum from } \mathrm{s}=0 \text { to } \mathrm{s}=\mathrm{f} \\
& \alpha=\mathrm{B}\left(\mathrm{f} ; \mathrm{n}, \mathrm{p}_{\mathrm{L}}\right)=\sum\left(\begin{array}{l}
\mathrm{n} \\
\mathrm{s}
\end{array}\right) \mathrm{p}_{\mathrm{L}}^{\mathrm{s}}\left(1-\mathrm{p}_{\mathrm{L}}\right)^{\mathrm{n}-\mathrm{s}} ; \text { sum from } \mathrm{s}=\mathrm{f} \text { to } \mathrm{s}=\mathrm{n}
\end{aligned}
$$

These expressions may be solved using standard tables or by using built-in formulas in a spreadsheet (e.g., the Microsoft Excel spreadsheet program).

For small $\mathrm{f}$ and large $\mathrm{n}$, the interval may be approximated using:

$$
\begin{gathered}
P_{U}(1-a)=\left[\chi^{2}(2 f+2, \alpha)\right] / 2 n \\
P_{L}(1-a)=\left[\chi^{2}(2 f, 1-\alpha)\right] / 2 n
\end{gathered}
$$

where $\chi^{2}(\mathrm{~m}, \gamma)$ is the value of the Chi-Squared distribution for the $100 \gamma$-percentile fr $\mathrm{m}$ degrees of freedom. The interval between $\mathrm{P}_{\mathrm{L}}(1-\alpha)$ and $\mathrm{P}_{\mathrm{U}}(1-\alpha)$ constitutes a confidence interval. For example, $2 \alpha=0.1$, the range constitutes a 90 percent confidence interval and $\alpha=0.05$ in Equations 7-75 and 7-76.

These expressions may also be solved using standard tables or by using built-in formulas in a spreadsheet (e.g., the Microsoft Excel spreadsheet program).

\section{Poisson Distribution}

The fundamental parameter is $\lambda$, the probability of failure per unit time (see Section 7.5.3.1). It is derived from test or experience information as follows:

Point Estimate:

$$
?^{*}=\mathrm{f} / \mathrm{T}
$$


where the information needs are

$\mathrm{f}=$ number of observed or recorded failures (or an IE) in a time interval $\mathrm{T}$.

$\mathrm{T}=$ time duration in reporting period.

Confidence Interval: The interval estimation for the Poisson distribution is to solve for $\lambda_{U}$ and $\lambda_{\mathrm{L}}$ using the following expressions:

$$
\begin{gathered}
?_{\mathrm{L}}(1-\mathrm{a})=\left[\chi^{2}(2 \mathrm{f}+2,1-\mathrm{a})\right] / 2 \mathrm{~T} \\
?_{\mathrm{U}}(1-\mathrm{a})=\left[\chi^{2}(2 \mathrm{f}, \mathrm{a})\right] / 2 \mathrm{~T}
\end{gathered}
$$

where

$\chi^{2}(\mathrm{~m}, \gamma)$ is the value of the Chi-Squared distribution for the $100 \gamma$-percentile for $\mathrm{m}$ degrees of freedom

These expressions may also be solved using standard tables or by using built-in formulas in a spreadsheet (e.g., the Microsoft Excel spreadsheet program). These expressions are similar to the above approximate interval estimate for $\mathrm{p}$ in the binomial case, except that $\mathrm{T}$ replaces $\mathrm{n}$.

\section{Lognormal Distribution}

Parameter estimation for the LN distribution is different than the prior two in two respects: 1) it describes a transformed variable rather than the fundamental parameter of interest, and 2) it requires two-parameters, the sample mean, $\mu^{*}$, and the sample variance and $\sigma^{2 *}$. Further discussions of the properties of the very important LN distribution are provided in Section 9, Uncertainty Analysis.

The fundamental parameter might be an observable quantity like a repair time for some component or system, $\tau$, which is to be estimated from experience records.

In this example, the information needs are $\mathrm{N}$ independent observations such as of repairs time, say $\mathrm{t}_{1}, \mathrm{t}_{2}, \ldots \mathrm{t}_{\mathrm{N}}$. The transformed variable is $\mathrm{x}_{\mathrm{i}}=\ln \left(\mathrm{t}_{\mathrm{i}}\right) ; \mathrm{i}=1,2, \ldots \mathrm{N}$.

The parameters of the PDF of the transformed variable $\mathrm{x}_{\mathrm{i}}$ are calculated as follows:

$$
\begin{gathered}
\mu^{*}=S x_{i} / N \text { sum for } \mathrm{i}=1 \text { to } \mathrm{n} \text {, for the sample mean } \\
\mathrm{s}^{2^{*}}=\mathrm{S}\left(\mathrm{x}_{\mathrm{i}}-\mu^{*}\right)^{2} /(\mathrm{N}-1) \text {, sum for } \mathrm{i}=1 \text { to } \mathrm{n} \text {, for the sample variance }
\end{gathered}
$$

Confidence Intervals: Because the distribution requires two parameters, confidence intervals are calculated for $\mu$ and $\mathrm{s}^{2}$.

For $\mu$, the upper and lower $100(1-$ a) percent confidence limits are:

$$
\mu_{\mathrm{L}}=\mu *-\mathrm{t}(\mathrm{n}-1,1-\mathrm{a})\left[\mathrm{s} * / \mathrm{n}^{0.5}\right]
$$




$$
\mu_{U}=\mu^{*}+t(n-1,1-a)\left[s^{*} / n^{0.5}\right]
$$

where $t(d, ?)$ is the ?-percentile of Student's t distribution with d degrees of freedom.

For $\sigma^{2}$, the upper and lower $100(1-\alpha)$ percent confidence limits are:

$$
\begin{gathered}
\mathrm{s}_{\mathrm{L}}^{2}=\left[(\mathrm{n}-1) \mathrm{s}^{2 *}\right] / \chi^{2}(\mathrm{n}-1,1-\mathrm{a}) \\
\mathrm{s}{ }_{\mathrm{U}}^{2}=\left[(\mathrm{n}-1) \mathrm{s}^{2^{*}}\right] / \chi^{2}(\mathrm{n}-1, \mathrm{a})
\end{gathered}
$$

where $\chi^{2}(\mathrm{~m}, \gamma)$ is the value of the Chi-Squared distribution for the $100 \gamma$-percentile for $\mathrm{m}$ degrees of freedom.

These expressions involving ? and Students $\tau$ distributions may also be solved using standard tables or by using built-in formulas in a spreadsheet (e.g., the Microsoft Excel spreadsheet program).

\subsection{Bayesian Parameter Estimation}

The Bayesian approach also yields point estimates and interval estimates to represent the range where the analyst is confident that the true parameter lies. Its basis is different than the classical estimation, however, in that it permits incorporation of analysts' belief and information not contained in observed data. Such belief and information are incorporated by assigning a probability distribution, termed the prior distribution that describes the analyst's belief about the parameter. The prior describes the best estimate point value, uncertainty range, and an assumed shape (e.g., normal, LN, or binomial). In cases where the analyst has no information or weak belief in the value of a parameter, the Bayesian approach permits use of a noninformative prior (see discussion below). By applying evidence that exists (e.g., test results, experience data from surrogate systems, or facility-specific experience data), a posterior probability distribution is generated using the Bayes theorem (NRC 1983). The posterior distribution yields a revised (updated) estimate of the best estimate (median or mean) and the uncertainty ranges.

As will be shown, the Bayesian approach uses integration over the joint distribution of the prior distribution and over a likelihood function. It has been shown that the integration can be performed in closed form if the priors are represented by conjugate distributions, and each primary distribution has a natural conjugate (see PRA Procedures Guide (NRC 1983, Section 5) for more information). When the prior distribution is not described by a standard probability distribution, it is usually approximated with a discrete (rather than continuous) distribution, where a summation over the joint distribution of prior and likelihood function is used.

After a summation of concepts that are common to all Bayesian estimates, this section provides the methods for applying the approach to point estimates and confidence intervals for the binomial, Poisson (including exponential), and LN distributions. The information requirements for quantifying each distribution are also presented. 


\section{Basic Elements of Bayesian Estimation}

Bayesian Point and Interval Estimation-The prior distribution summarizes the uncertainty in a parameter based on judgement or generic information sources. Similarly, the posterior distribution summarizes the uncertainty in the facility-specific or surrogate information.

Two commonly used values of point estimates are used, the mean and the median, which are based on the properties of PDFs. For example, if a failure rate ? is the parameter of interest, and its uncertainty is described by a PDF $\mathrm{f}($ ?), the respective point estimates are calculated as follows:

$$
\mu_{?}=\int_{0}^{\infty} ? \mathrm{f}(?) \mathrm{d} ?, \text { is the mean }
$$

while the median, $\mathrm{m}(?)$, is the solution to the integral equation:

$$
\mathrm{F}(?)=\int_{0}^{m(\lambda)} \mathrm{f}(\mathrm{t}) \mathrm{dt}=0.5
$$

where $\mathrm{F}(?)$ is the cumulative distribution function.

The point estimate definitions are applied to both the prior and the posterior distribution, as needed.

The Bayesian interval estimate uses the probability distribution for the parameter. The range of integration is set so that the range includes the desired probability that the range contains the true value. If the desired probability is given as $(1-\gamma)$, the respective upper $\left(\lambda_{U}\right)$ and lower $\left(\lambda_{L}\right)$ interval limits are calculated from the following definitions:

$$
\begin{aligned}
& \int_{0}^{\lambda_{u}} \mathrm{f}(?) \mathrm{d} ?=\gamma / 2 \\
& \int_{\lambda_{L}}^{\infty} \mathrm{f}(?) \mathrm{d} ?=\gamma / 2
\end{aligned}
$$

The interval definitions are applied to both the prior and the posterior distribution, as needed.

If the desired probability of success $(1-\gamma)$ is 0.90 , then $?=0.10$, so $\gamma / 2=0.05$.

The application of the point and interval calculations is demonstrated below for the parameter of the binomial, Poisson, and LN distributions. 


\section{Steps in Bayesian Estimation Approach}

The PRA Procedures Guide (NRC 1983) identifies the following steps for applying the Bayesian approach to information processing. These steps are listed here in abbreviated form as applicable to the PSA.

- Identify sources and forms of generic information to be used in generating an appropriate prior distribution

- $\quad$ Select a prior distribution family if none has been specified in the generic information

- $\quad$ Define a particular prior distribution from parameters derived from generic information by reducing or combining, as appropriate

- Plot the prior distribution and characterize it: mean, median, variance, and summary percentiles (e.g., upper and lower 95 percent limits)

- If generic estimates are to be used, generate from the prior

- If facility or application-specific estimates are required, additional sub-steps are used:

- $\quad$ Obtain specific information

- $\quad$ Identify appropriate form for the likelihood function

- $\quad$ Apply the Bayes theorem to generate the posterior distribution:

- Plot posterior on same graph as prior to observe effect of specific information (e.g., shift in central measure, change in distribution shape)

- $\quad$ Characterize posterior distribution: mean, median, variance, and summary percentiles (e.g., upper and lower 95 percent limits).

\section{Defining Prior Distributions}

Unless a noninformative prior is selected, a prior distribution is developed from generic information. When estimating a parameter such as the failure rate of a given component, the analyst usually has available generic information consisting of engineering knowledge about the design, construction, expected performance, and expected operating environment associated with the component, and the past performance and reliability of similar components. Section 7.5.3.2 describes some of the sources of generic information. When little or no generic prior information is available, a noninformative prior may be used.

In many instances, a natural conjugate distribution is used in Bayesian estimation to permit closed form integration. For a given likelihood function, such as the exponential, a natural conjugate function has the property that the posterior and prior distributions are member of the same family of distributions (i.e., a $\mathrm{LN}$ prior distribution on $\lambda$ yields $\mathrm{LN}$ posterior distribution on $\lambda$ ). 
Sometimes in practice, a particular distribution may be mapped into its conjugate by moments matching, and after performing the Bayesian integration over the conjugate and likelihood function, the posterior distribution is mapped back to its conjugate (Blanton and Eide 1993).

Generic information may be obtained from single or multiple sources to ensure sufficient information to generate the distribution parameters of the priors. For example, at least two independent pieces of information are required to generate the parameters needed to define a LN prior distribution for $\lambda$. Thus, pairs of information like (1) upper and lower limits, (2) mean and variance, or (3) median and EF must be defined by the analyst. The information may be derived from tabulated failure rates, reported experience, or expert judgement.

For much of the PSA analysis, tabulated data that have been applied in various PRA studies or in MIL-HDBK-217F (DOD 1991) will suffice, particularly when there is a clear match between a repository component or system and a component or system represented in the tabulation. In other cases, the analyst may not be able to clearly establish the direct applicability of one or more tabulated items and must resort to multiple information sources. Such sources are combined using one of the methods described in the following section.

\subsection{Pooling and Combining Information from Multiple Sources}

Since the PSA will be based in large measure on surrogate information, there may be instances where two or more sources provide event data or failure rates for systems or components that are judged to be representative of those in a repository, thus, prior multiples distributions are available. For purposes of event probability estimation, a prior distribution is needed. Numerous methods are available, but the PRA Procedures Guide (NRC 1983) describes three processes for pooling multiple information sources to arrive at a prior distribution. One process, termed the mixture method, is judged to be too cumbersome for PSA application, so two of the methods are presented here.

The first, based on a geometric mean, is simple to apply and is believed to be sufficient for the PSA for the LA-CA. This method is noted to underestimate the uncertainties. The second method, a two-stage Bayesian, has been applied in numerous PRA studies. It is based on developing a prior distribution that is grounded in generic information before updating the distribution with facility-specific information. Since a repository will have little specific information to apply, this method is not developed in detail in this edition of the PSA guide.

Martz and Waller (1978) examined several methods of pooling information sources. They concluded that simple averaging techniques are satisfactory when a small number of sources are to be pooled, but more sophisticated methods are required when 15 or more sources are to be combined. 


\section{Geometric Mean Method}

If there are $\mathrm{M}$ sources of information for a failure rate $?_{i}$ and each source provides a point estimate and interval estimate, the composite values for the prior distribution are calculated as geometric means, as

$$
\begin{aligned}
<?_{0}> & =\left(\prod_{i=1, m} ?_{0, \mathrm{i}}\right)^{1 / \mathrm{M}} ; \text { where } \mathrm{i}=1 \ldots \mathrm{m} \text { for the composite point value } \\
\left\langle ?_{\mathrm{LB}}>\right. & =\left(\prod_{i=1, m} ?_{\mathrm{LB}}, \mathrm{i}\right)^{1 / \mathrm{M}} ; \text { where } \mathrm{i}=1 \ldots \mathrm{m} \text { for the composite lower bound } \\
\left\langle ?_{\mathrm{UB}}>\right. & =\left(\prod_{i=1, m} ?_{\mathrm{UB}}, \mathrm{i}\right)^{1 / \mathrm{M}} ; \text { where } \mathrm{i}=1 \ldots \mathrm{m} \text { for the composite lower bound }
\end{aligned}
$$

where

$?_{0, \mathrm{I}}$ is the point value from the $i^{\text {th }}$ information source

$?_{\mathrm{LB}, \mathrm{i}}$ and $?_{\mathrm{UB}}, \mathrm{i}$, respectively, are lower and upper bounds of the $\mathrm{i}^{\text {th }}$ information source

With the composite point estimate treated as a mean or median, as deemed appropriate for the assumed family of the prior distribution, the available experience data (evidence) can be applied to derive the posterior distribution, as described in Section 7.5.3.3.4, Bayesian Estimation of Failure-on-Demand Probabilities.

\section{Two -Stage Bayesian Method}

The analyst is referred to the PRA Procedures Guide (NRC 1983).

\subsection{Applications of Bayesian Estimation to Event Quantification}

For PSA purposes, important techniques for parameter estimation have been extracted from reference material. The first application is for estimating failure-on-demand probabilities, and the second is for estimating constant failure rates. The presentations give the mathematical formulas for distribution parameters when noninformative and conjugate distributions are used.

\section{Bayesian Estimation of Failure-on-Demand Probabilities}

The binomial distribution, given in Equation 7-64, gives the probability of observing exactly $r$ failures in $n$ trials, given a probability of failure per trial of $p$. That equation is used as the likelihood function. The purpose of the Bayesian estimation is to determine the best estimate for $\mathrm{p}$ and its uncertainty distribution.

The first case is application of a noninformative prior. The form of noninformative prior given in Section 5.5.2.3.2 of the PRA Procedures Guide (NRC 1983) is

$$
[\mathrm{q}(1-\mathrm{q})]^{-0.5} / \pi ; \text { for }(0 \leq \mathrm{q} \leq 1)
$$

where it may be shown that 


$\begin{array}{llll}\text { Prior mean: } & \mathrm{q}_{0} & = & 0.5 \\ \text { Prior median: } & \mathrm{q}_{0,0.5}= & 0.5 \\ \text { Prior variance: } & \sigma_{0}^{2}= & 0.125\end{array}$

and the 100(1 - $\gamma$ ) percent (e.g., 95 percent) symmetric probability is a function of the F-distribution with a and $b$ degrees of freedom, $F_{1-\gamma / 2}(a, b)$, as follows:

Prior lower bound:

$$
\begin{gathered}
\mathrm{q}_{0, \mathrm{~L}}=0.5 /\left[0.5+0.5 \mathrm{~F}_{1-\gamma / 2}(1,1)\right] \\
\mathrm{q}_{0, \mathrm{U}}=0.5 \mathrm{~F}_{1-\gamma / 2}(1,1) /\left[0.5+0.5 \mathrm{~F}_{1-\gamma / 2}(1,1)\right]
\end{gathered}
$$

The posterior distribution is shown to have the form of a beta distribution as follows:

$$
[?(n+1) / ?(r+0.5) ?(n-r+0.5)]\left[q^{r-0.5}(1-q)\right]^{n-r-0.5} ; \text { for }(0=q=1)
$$

where

$\mathrm{G}(\mathrm{x})$ is the gamma function

The parameters of the posterior distribution are the following:

Posterior mean: $\quad \underline{q}=(r+0.5) /(n+1)$

Posterior median: $\mathrm{q}_{0.5}=(\mathrm{r}+0.5) /\left[(\mathrm{r}+0.5)+(\mathrm{n}-\mathrm{r}+0.5) \mathrm{F}_{0.5}(2 \mathrm{n}-2 \mathrm{r}+1,2 \mathrm{r}+1)\right]$

Posterior variance: $\quad \sigma^{2}=(r+0.5)(n-r+0.5) /\left[(n+1)^{2}(n+2)\right]$

and the $100(1-\gamma)$ percent symmetric probability is a function of the F-distribution with a and $\mathrm{b}$ degrees of freedom, $\mathrm{F}_{1-\gamma / 2}(\mathrm{a}, \mathrm{b})$, as follows:

Posterior lower bound:

$$
\mathrm{q}_{\mathrm{L}}=(\mathrm{r}+0.5) /\left[(\mathrm{r}+0.5)+(\mathrm{n}-\mathrm{r}+0.5) \mathrm{F}_{1-\gamma / 2}(2 \mathrm{n}-2 \mathrm{r}+1,2 \mathrm{r}+1)\right]
$$

Posterior upper bound:

$\mathrm{q}_{\mathrm{U}}=\left[(\mathrm{r}+0.5) \mathrm{F}_{1-\gamma / 2}(2 \mathrm{r}+1,2 \mathrm{n}-2 \mathrm{r}+1)\right] /\left[(\mathrm{n}-\mathrm{r}+0.5)+(\mathrm{r}+0.5) \mathrm{F}_{1-\gamma / 2}(2 \mathrm{r}+1,2 \mathrm{n}-2 \mathrm{r}+1)\right]($ Eq. $7-101)$

The noninformative prior is very useful when the available performance records show zero failures for a finite number of trials. In this instance, the classical estimation must assert at least one failure has occurred, or the estimation interval on $\mathrm{p}$ becomes indeterminant (see Section 7.5.3.4.1).

The second application assumes a beta prior that is derived from information available prior to the analysis. Such prior information may be derived from generic sources. The beta prior has the form:

$$
\left[?\left(\mathrm{n}_{0}\right) / ?\left(\mathrm{r}_{0}\right) ?\left(\mathrm{n}_{0}-\mathrm{r}_{0}\right)\right]\left[\mathrm{q}^{r_{o}-1}(1-\mathrm{q})\right]^{n_{o}-r_{o}-1} ; \text { for }(0=\mathrm{q}=1)
$$


where the values of $\mathrm{m}_{\mathrm{b}}$ and $\mathrm{r}_{0}$ are the parameters of the assumed beta prior distribution, but may also be interpreted as information derived from the prior information, where $\mathrm{n}$ represents the number of trials, and $r_{0}$ the number of failures. ?(x) is the gamma function. The parameters of this distribution are:

Prior mean: $\quad \underline{\mathrm{q}}_{0}=\mathrm{r}_{0} / \mathrm{n}_{0}$

Prior median: $\quad \mathrm{q}_{0,0.5}=\mathrm{r}_{0} /\left[\mathrm{r}_{0}+\left(\mathrm{n}_{0}-\mathrm{r}_{0}\right) \mathrm{F}_{0.5}\left(2 \mathrm{n}_{0}-2 \mathrm{r}_{0}, 2 \mathrm{r}_{0}\right)\right]$

Prior variance: $\quad \sigma_{0}^{2}=\mathrm{r}_{0}\left(\mathrm{n}_{0}-\mathrm{r}_{0}\right) / \mathrm{n}_{0}^{2}\left(\mathrm{n}_{0}+1\right)$

and the $100(1-\gamma)$ percent symmetric probability is a function of the F-distribution with $a$ and $b$ degrees of freedom, $\mathrm{F}_{1-\gamma / 2}(\mathrm{a}, \mathrm{b})$, as follows:

Prior lower bound: $\quad \mathrm{q}_{0, \mathrm{~L}}=\mathrm{r}_{0} /\left[\mathrm{r}_{0}+\left(\mathrm{n}_{0}-\mathrm{r}_{0}\right) \mathrm{F}_{1-\gamma / 2}\left(2 \mathrm{n}_{0}-2 \mathrm{r}_{0}, 2 \mathrm{r}_{0}\right)\right]$

Prior upper bound: $\left.\mathrm{q}_{0, \mathrm{U}}=\mathrm{r}_{0} \mathrm{~F}_{1-\gamma / 2}\left(2 \mathrm{r}_{0}, 2 \mathrm{n}_{0}-2 \mathrm{r}_{0}\right)\right] /\left[\left(\mathrm{n}_{0}-\mathrm{r}_{0}\right)+\mathrm{r}_{0} \mathrm{~F}_{1-\gamma / 2}\left(2 \mathrm{r}_{0}, 2 \mathrm{n}_{0}-2 \mathrm{r}_{0}\right)\right]$

Posterior mean: $\quad \underline{\mathrm{q}} \quad=\left(\mathrm{r}+\mathrm{r}_{0}\right) /\left(\mathrm{n}+\mathrm{n}_{0}\right)$

Posterior median:

$$
\mathrm{q}_{0.5}=\left(\mathrm{r}+\mathrm{r}_{0}\right) /\left[\left(\mathrm{r}+\mathrm{r}_{0}\right)+\left(\mathrm{n}-\mathrm{r}+\mathrm{n}_{0}-\mathrm{r}_{0}\right) \mathrm{F}_{0.5}\left(2 \mathrm{n}-2 \mathrm{r}+2 \mathrm{n}_{0}-2 \mathrm{r}_{0}, 2 \mathrm{r}+2 \mathrm{r}_{0}\right)\right]
$$

Posterior variance:

$$
\sigma^{2}=\left(r+r_{0}\right)\left(n-r+n_{0}-r_{0}\right) /\left[\left(n+n_{0}\right)^{2}\left(n+n_{0}+1\right)\right]
$$

and the $100(1-$ ?) percent symmetric probability is a function of the F-distribution with a and $b$ degrees of freedom, $\mathrm{F}_{1-\gamma / 2}(\mathrm{a}, \mathrm{b})$, as follows:

Posterior lower bound:

$$
\mathrm{q}_{\mathrm{L}}=\left(\mathrm{r}+\mathrm{r}_{0}\right) /\left[\left(\mathrm{r}+\mathrm{r}_{0}\right)+\left(\mathrm{n}-\mathrm{r}+\mathrm{n}_{0}-\mathrm{r}_{0}\right) \mathrm{F}_{1-\gamma / 2}\left(2 \mathrm{n}-2 \mathrm{r}+2 \mathrm{n}_{0}-2 \mathrm{r}_{0}, 2 \mathrm{r}+2 \mathrm{r}_{0}\right)\right]
$$

Posterior upper bound:

$$
\begin{gathered}
\mathrm{q}_{\mathrm{U}}=\left[\left(\mathrm{r}+\mathrm{r}_{0}\right) \mathrm{F}_{1-\gamma / 2}\left(2 \mathrm{r}+2 \mathrm{r}_{0}, 2 \mathrm{n}-2 \mathrm{r}+2 \mathrm{n}_{0}-2 \mathrm{r}_{0}\right)\right] /\left[\left(\mathrm{n}-\mathrm{r}+\mathrm{n}_{0}-\mathrm{r}_{0}\right)+\right. \\
\left.\left(\mathrm{r}+\mathrm{r}_{0}\right) \mathrm{F}_{1-\gamma / 2}\left(2 \mathrm{r}+2 \mathrm{r}_{0}, 2 \mathrm{n}-2 \mathrm{r}+2 \mathrm{n}_{0}-2 \mathrm{r}_{0}\right)\right] .
\end{gathered}
$$

The third application assumes a LN prior distribution on q. This distribution is often used for failure rates, especially for low rates like $10^{-6}$ per demand or unit time. The LN is so named because the random variable represented by the distribution, $\mathrm{x}$, is the logarithmic transform of a random variable of interest (i.e., the failure rate per demand, $q$ ). Thus, $x=\ln (q)$ is the random variable, and $\mathrm{x}$ is assumed to follow a normal (or Gaussian) distribution. All the well-known statistical properties and tabulations of the normal distribution can then be applied. The transformation between moments of the transformed variable and the failure rate are shown below. 
The LN distribution requires two parameters, $\mu$ and $\sigma$, the mean and standard deviation of a normal distribution on $x$. These distribution parameters are derived from the assumed LN distribution on $q$, as follows.

The analyst estimates or specifies two symmetric percentiles for the interval containing $q$ with a given probability, $1-\gamma$, where $0<\gamma<0.5$ (usually, $\gamma$ is 0.1 or 0.05 ). The respective percentiles are labeled $\mathrm{q}_{\gamma}$ (or $\mathrm{q}_{\mathrm{L}}$, lower bound) and $\mathrm{q}_{1-\gamma}$ (or $\mathrm{q}_{\mathrm{U}}$, upper bound), and are symmetrical, giving:

$$
\mathrm{p}\left(\mathrm{q}<\mathrm{q}_{\gamma}\right)=\mathrm{p}\left(\mathrm{q}>\mathrm{q}_{1-\gamma}\right)=?
$$

The median value of $\mathrm{q}$ is the geometric mean of the interval limits, that is:

$$
\mathrm{q}_{0.5}=\left(\mathrm{q}_{\gamma} \mathrm{q}_{1-\gamma}\right)^{1 / 2}
$$

and the $\mathrm{EF}$ is defined as:

$$
\mathrm{EF}=\left(\mathrm{q}_{1-\gamma} / \mathrm{q}_{\gamma}\right)^{1 / 2}
$$

and a useful property of the EF is its relationship to the median, as follows:

$$
\mathrm{EF}=\left(\mathrm{q}_{0.5} / \mathrm{q}_{\gamma}\right)=\left(\mathrm{q}_{1-\gamma} / \mathrm{q}_{0.5}\right)
$$

The parameters of the associated $\mathrm{LN}$ distribution, $\mu$ and $\sigma$, become:

$$
\begin{gathered}
\mu=\ln \left(\mathrm{q}_{0.5}\right) \\
\sigma=\ln (\mathrm{EF}) / \mathrm{z}_{1-\gamma}
\end{gathered}
$$

where $\mathrm{z}_{-\gamma}$ is the $100(1-\gamma)^{\text {th }}$ percentile of a normal (Gaussian) distribution. Values of $\mathrm{z}_{-\gamma}$ are tabulated in virtually all statistics books and can be obtained from the normal distribution function that is built into the Microsoft Excel spreadsheet program.

The moments of the fitted $\mathrm{LN}$ are derived from the parameters as follow:

Mean:

$$
\underline{q}=\exp \left(\mu+\sigma^{2} / 2\right)
$$

Mode:

$$
\mathrm{q}_{\mathrm{Md}}=\exp \left(\mu-\sigma^{2}\right)
$$

Median:

$$
\mathrm{q}_{0.5}=\exp (\mu)
$$

Variance:

$$
\sigma_{\mathrm{q}}^{2}=\left[\exp \left(2 \mu+\sigma^{2}\right]\left[\exp \left(\sigma^{2}\right)-1\right]\right.
$$

The variance $\sigma_{\mathrm{q}}{ }^{2}$ is for the distribution of the failure rate $\mathrm{q}$, while $\sigma^{2}$ is the variance of the transformed random variable $x=\ln (\mathrm{q})$.

The evidence in the form of $r$ failures in $n$ trials is incorporated into the Bayesian analysis. Since the LN does not allow a closed-form integral solution, numerical integration is used as described in Section 5.5.2.3.4 of the PRA Procedures Guide (NRC 1983). 
An alternative method, applied at the Savannah River Site (described in Blanton and Eide 1993), converts the prior LN into a beta distribution, applies the specific evidence (number of failures, $r$, and number of trials, $\mathrm{n}$ ) in the Bayesian integration, which in turn produces a beta posterior distribution. The beta posterior distribution is then converted to a LN.

\section{Bayesian Estimation of Constant Failure Rates}

The methods for estimating constant failure rates are very similar to those for failure-on-demand with two primary differences. First, the likelihood function is the Poisson distribution, rather than the binomial. Second, the natural conjugate for the Poisson distribution is the gamma distribution, rather than the beta distribution. A third difference, demonstrated below, is the form of the noninformative prior that is recommended.

The method is aimed at deriving a best estimate and probability interval for a constant failure rate, $\lambda$, given information on the number of failures, $r$, in a given test-time duration, $T$. The failure on demand uses $r$ and the number of trials, $n$, rather than the time.

The likelihood function for constant failure rates is the Poisson distribution, expressed as:

$$
\mathrm{L}(\mathrm{E} \mid ?)=(? \mathrm{~T})^{\mathrm{r}} \exp (-? \mathrm{~T}) / \mathrm{r} !(\mathrm{r}=0,1,2, \ldots)
$$

The estimation methods are presented for three cases using different prior distributions: noninformative, gamma, and LN.

The first case is the application of a noninformative prior. The form of noninformative prior given in Section 5.5.2.4.2 of the PRA Procedures Guide (NRC 1983) is:

Prior density: $\quad \mathrm{f}_{0}(?)=?^{-0.5}($ an improper distribution $)(?>0)$

Posterior density: $\quad \mathrm{f}(?)=\left[\mathrm{T}^{\mathrm{r}+0.5} / ?(\mathrm{r}+0.5)\right] ?^{\mathrm{r}-0.5} \exp (-? \mathrm{~T})(?>0)$

Posterior mean: $\quad \underline{?}=(2 \mathrm{r}+1) / 2 \mathrm{~T}$

Posterior median: $\quad ?_{0.5}=?^{2}{ }_{0.5}(\mathrm{r}+0.5) /(2 \mathrm{~T})$

where

$?^{2}{ }_{1-\gamma}(\mathrm{x})$ is the $100(1-\gamma)$ percent (e.g., 95 percent) percentile of a chi-square distribution.

The symmetric probability interval is given by:

Posterior lower bound:

$$
?_{\mathrm{L}}=\mathrm{X}^{2} \gamma / 2(2 \mathrm{r}+1) /(2 \mathrm{~T})
$$

Posterior upper bound:

$$
?_{\mathrm{U}}=\mathrm{X}_{1-\gamma / 2}^{2}(2 \mathrm{r}+1) /(2 \mathrm{~T})
$$

The noninformative prior is very useful when the available performance records show zero failures for a finite time at test. In this instance, the classical estimation must assert at least one failure has occurred, or the estimation interval on $\lambda$ becomes indeterminant. In the 
noninformative prior, the analyst asserts that the probability of failure per demand is somewhere in the range of $(0,1)$ with equal likelihood, giving the prior mean of 0.5 as the best estimate (i.e., the analyst asserts that the item is equally likely to succeed or fail in any given trial.) The effect of 0 failures in $n$ trials is to adjust the denominator so that the posterior gives the probability of 0.5 that the device will fail in $n+1$ trials.

The second application assumes a gamma distribution prior that is derived from information available prior to the analysis. Such prior information may be derived from generic sources. The gamma prior has the form:

$$
\mathrm{f}_{0}(?)=\left[\beta_{0} \mathrm{a}_{0} / ?\left(\mathrm{a}_{0}\right)\right] ?^{\alpha 0-1} \exp \left(-\beta_{0} ?\right) ;(\text { for } ?>0)
$$

where the parameter a $a_{0}$ (shape factor) can be interpreted as the prior number of failures in $\beta_{0}$ prior total operating time ( $\beta_{0}$ is the scale factor). The parameters of the gamma distribution are:

Prior mean:

$$
\begin{gathered}
\stackrel{?}{0}_{0}=\mathrm{a}_{0} / \beta_{0} \\
?_{0,0.5}=\chi_{0.5}^{2}\left(2 \mathrm{a}_{0}\right) /\left(2 \beta_{0}\right) \\
\mathrm{s}_{0}^{2}=\mathrm{a}_{0} / \beta_{0}^{2}
\end{gathered}
$$

Where

$$
\chi_{1-\gamma}^{2}(\mathrm{x}) \text { is the } 100(1-\gamma) \text { percent percentile of a chi-square distribution. }
$$

The prior $100(1-\gamma)$ percent (e.g., 95 percent) symmetric probability interval is given by:

Prior lower bound:

Prior upper bound:

$$
\begin{gathered}
?_{0, \mathrm{~L}}=\chi_{\gamma / 2}^{2}\left(2 \mathrm{a}_{0}\right) /\left(2 \beta_{0}\right) \\
?_{0, \mathrm{U}}=\chi_{1-\gamma / 2}^{2}\left(2 \mathrm{a}_{0}\right) /\left(2 \beta_{0}\right)
\end{gathered}
$$

The posterior distribution is also a gamma distribution given as:

$$
f(?)=\left[\left(\beta_{0}+\mathrm{T}\right)^{\mathrm{a} 0+\mathrm{r}} / \Gamma\left(\alpha_{0}+\mathrm{r}\right)\right] ?^{\alpha 0+\mathrm{r}-1} \exp \left[-\left(\beta_{0}+\mathrm{T}\right) ?\right] ;(\text { for } ?>0)
$$

The parameters of the posterior distribution are:

Posterior mean:

$$
\underline{\lambda}=\left(\mathrm{a}_{0}+\mathrm{r}\right) /\left(ß_{0}+\mathrm{T}\right)
$$

Posterior median:

$$
\begin{gathered}
?_{0.5}=\chi_{0.5}^{2}\left(2 \mathrm{a}_{0}+2 \mathrm{r}\right) /\left(2 \beta_{0}+2 \mathrm{~T}\right) \\
\sigma^{2}=\left(\mathrm{a}_{0}+\mathrm{r}\right) /\left(\beta_{0}+\mathrm{T}\right)^{2}
\end{gathered}
$$

and the prior $100(1-\gamma)$ percent symmetric probability interval is given by:

Posterior lower bound: $\quad ?_{\mathrm{L}}=\chi_{\gamma / 2}^{2}\left(2 \mathrm{a}_{0}+2 \mathrm{r}\right) /\left(2 \beta_{0}+2 \mathrm{~T}\right)$ 
Posterior upper bound: $\quad ?_{\mathrm{U}}=\chi_{1-\gamma / 2}^{2}\left(2 \mathrm{a}_{0}+2 \mathrm{r}\right) /\left(2 \mathrm{~B}_{0}+2 \mathrm{~T}\right)$

The third application assumes a LN prior distribution on $\lambda$. The presentation in Section 7.5.3.4.1 applies by replacing $\mathrm{q}$ with $\lambda$ in all of the expressions. As previously noted, there are two difficulties in using for the LN prior distribution, and the Bayesian integration cannot produce a closed form posterior distribution. Numerical solutions are required.

An alternative method, applied at the Savannah River Site (described in Blanton and Eide 1993), converts the prior $\mathrm{LN}$ on $\lambda$ into a gamma distribution, applies the specific evidence (number of failures, $r$, and time on test, T) in the Bayesian integration, which in turn produces a gamma posterior distribution. The gamma posterior distribution is then converted to a $\mathrm{LN}$.

\subsection{Uncertainties in Information and Event Probabilities}

Section 9 provides a full discussion of treatment of uncertainties in event sequence quantification, including the propagation of uncertainties through the sequence freque ncies. Part of the uncertainty stem from uncertainties in the probabilities and frequencies of events. This section (Section 7.5) discusses the sources of uncertainties contained in the information sources and its application in estimation of parameters and event probabilities.

The PRA Procedures Guide (NRC 1983) identifies two categories of uncertainties in event probabilities: modeling uncertainty and information (data) uncertainty. These sources are evaluated differently, as described below.

Modeling Uncertainty-No physical occurrence exactly fits a mathematical model such as having a constant failure rate, adherence to a Poisson time to failure, or failure on demand fitting a binomial with constant probability per demand. In Bayesian estimation, the selection of the prior distribution is another source of modeling uncertainty. So, the selection of the event model by the analyst introduces uncertainty. Different values for the point estimate, the PDF family, and different 90 percent confidence interval can result with different event models. Such uncertainty is evaluated with a sensitivity analysis. The event probability is re-evaluated with alternative models.

Information Uncertainty-Uncertainty in estimated event probabilities and their associated distribution parameter arise from several sources: (1) amount of information (i.e., number of trials, duration, number of failure events), (2) diversity of information sources when pooling (i.e., various kinds of equipment, vendors, applications and environments) (3) accuracy of information sources (i.e., quality of tests or record keeping), and (4) applicability to repository facilities.

The uncertainty due to the amount of data is treated explicitly in the event estimation techniques described in Section 7.5.3.3. The amount of data affects the variance, the mean, and the confidence (classical) or probability (Bayesian) interval. The greater the number of trials (or duration), the tighter the distribution of the estimated parameters and event probabilities.

The uncertainties in the diversity or accuracy of information (which may be forced on the analyst if sufficient and relevant information is not available) can be alleviated by the application of the 
pooling procedures described in Section 7.5.3.3.3, but this requires judgement by an analyst. If all sources are judged equally representative of the system or component of interest, all information is weighted equally and the uncertainties in the respective source are propagated through the pooling formulas to give composite mean, medium, variance, and intervals that reflect the overall uncertainty. Otherwise, the analyst may want to assign weights to the various sources in proportion to their respective applicability or accuracy.

Likewise, if multiple sources are judged equally accurate, the equal-weight pooling can be used.

The uncertainty in the applicability of a particular information source to an event in the PSA for a repository is also treated by analyst judgement. In some instances, this may require increasing an estimated event probability derived from a given source to account for repository operating environment or duty. In other instances, the probability may be decreased for the same reasons, or to take credit for quality assurance, expected tests, and inspections. For example, crane failure rates derived from general industrial sources may be judged to be too high for repository cranes that are designed to nuclear industry standards. The analyst must decide on whether to increase (decrease) the point estimate, the upper or lower uncertainty bounds, or both, to account for the application. Section 9 provides guidance to the analyst on such treatment of uncertainties.

\subsection{Documentation of Parameters and Event Probabilities}

To support the PSA for LA, the analyst must provide a clear, auditable record. For each event identified in the PSA event sequence analyses, an event probability (or frequency) will be tabulated.

The tabulation will be annotated to point to, for each event probability, the following:

- $\quad$ Event Model Used

- Information Source(s) Used

- $\quad$ Calculation File for Estimation of Model Parameters and Event Probability

- Treatment and Bases for Uncertainties.

Such documentation will be prepared and checked in accordance with the applicable procedure.

\subsubsection{Examples of Parameter Estimation - Contrast of Classical and Bayesian Methods}

This section presents a simple application of the estimation methods described in Sections 7.5.3.3.1 and 7.5.3.3.2. The example is a failure-on-demand model using both classical and Bayesian approaches. For the latter, applications of noninformative and other prior distributions are illustrated.

The basic information assumed is either repository-specific (or ESF-specific) performance records, if available, or representative surrogates (e.g., records of events related to failures of spent fuel handling equipment at NPPs). The information sets are used in the example below is:

Failure on Demand-Crane drop of load - 0 failures in 47,400 lifts (surrogate information; Lloyd 2001). 
This information will be augmented with alternative information in the demonstration of pooling information.

Constant Failure Rate-Failure of steel sets in ESF ground support system; experience gives 0 failures in 9,200 steel-set years (BSC 2001).

\subsection{Estimation of Parameters - Failure on Demand}

\section{Classical Estimation}

Point Estimate:

$$
\mathrm{p}^{*}=\mathrm{f} / \mathrm{n}
$$

where

$\mathrm{f}=$ number of observed or recorded failures in $\mathrm{n}$ demands or trials, $\mathrm{n}=$ number of recorded demands or trials in reporting period.

For small $\mathrm{f}$ and large $\mathrm{n}$, the $5^{\text {th }}$ to $95^{\text {th }}$ percentile interval $(\alpha=0.05)$ may be approximated using the following:

$$
\begin{gathered}
\mathrm{p}_{\mathrm{U}}(1-\alpha)=\left[\chi^{2}(2 \mathrm{f}+2,1-\alpha)\right] / 2 \mathrm{n}=\left[?^{2}(2 \mathrm{f}+2,0.95)\right] / 2 \mathrm{n} \\
\mathrm{p}_{\mathrm{L}}(1-\alpha)=\left[\chi^{2}(2 \mathrm{f}, \alpha)\right] / 2 \mathrm{n}=\left[?^{2}(2 \mathrm{f}, 0.05)\right] / 2 \mathrm{n}
\end{gathered}
$$

Basis: Crane drop of load (0 failures in 47,400 lifts) or:

$$
\begin{aligned}
& \mathrm{f}=0 \\
& \mathrm{n}=47,400
\end{aligned}
$$

Initial Trial: Insert information into formulas:

$$
\begin{aligned}
& \mathrm{p}_{1} *=\mathrm{f} / \mathrm{n}=0 / 47,400=0, \text { which is not credible, while } \\
& \mathrm{p}_{\mathrm{U}}=6.3 \times 10^{-5} \text {, and }
\end{aligned}
$$

$\mathrm{p}_{\mathrm{L}}$ is indeterminant, that is, $\chi^{2}(0,0.05)$ cannot be determined.

Second Trial: Assume that there will be a failure on the next demand, so adjust input to:

$$
\mathrm{f}^{\prime}=\mathrm{f}+1 \text {, and } \mathrm{n}^{\prime}=47,400+1
$$

using Equations 7-75 and 7-76 the estimation gives:

$$
\mathrm{p}^{*}=\mathrm{f}^{\prime} / \mathrm{n}^{\prime}=1 / 47,401=2.1 \times 10^{-5}(\text { point estimate) }
$$

and the 90 percent confidence interval is given by

$$
\begin{aligned}
& \mathrm{p}_{\mathrm{U}}=\left[\chi^{2}\left(2 \mathrm{f}^{\prime}+2,0.05\right)\right] / 2 \mathrm{n}^{\prime}=\left[\chi^{2}(4,0.05)\right] / 94802=9.49 / 94802=1.0 \times 10^{-4} \\
& \mathrm{p}_{\mathrm{L}}=\left[\chi^{2}\left(2 \mathrm{f}^{\prime}, 0.95\right)\right] / 2 \mathrm{n}^{\prime}=\left[\chi^{2}(2,0.95)\right] / 94802=0.71 / 94802=1.08 \times 10^{-6}
\end{aligned}
$$


By examining at least one failure, the point estimate $\mathrm{p}^{*}$ is more useful (i.e., not equal to 0 ) and appears more credible (i.e., no equipment is perfect), and the point estimate falls within and interval that has a very low lower bound and a conservative upper bound.

\section{Bayesian Estimation}

The first case is application of a noninformative prior:

$$
[\mathrm{q}(1-\mathrm{q})]^{-0.5} / \pi ; \text { for }(0=\mathrm{q}=1)
$$

The evidence gives:

$$
\begin{aligned}
& \mathrm{f}=0 \text {, number of observed or recorded failures in } \mathrm{n} \text { demands or trials, and } \\
& \mathrm{n}=47,400 \text {, number of recorded demands or trials in reporting period. }
\end{aligned}
$$

Using Equation 7-97 through Equation 7-101, the Bayesian estimation gives:

Posterior mean: $\quad \underline{q}=(f+0.5) /(n+1)=(0.5) / 47,401=1.05 \times 10^{-5}$

Posterior median: $\mathrm{q}_{0.5}=(\mathrm{f}+0.5) /\left[(\mathrm{f}+0.5)+(\mathrm{n}-\mathrm{f}+0.5) \mathrm{F}_{0.5}(2 \mathrm{n}-2 \mathrm{f}+1,2 \mathrm{f}+1)\right]$

$$
\begin{aligned}
& =(0.5) /\left[(0.5)+(47,400+0.5) \mathrm{F}_{0.5}(94801,1)\right. \\
& =2.32 \times 10^{-5}
\end{aligned}
$$

and the 90 percent symmetric probability is a function of the F-distribution with a and b degrees of freedom, $F_{1-\gamma / 2}(a, b)$, as follows:

Posterior lower bound:

$$
\mathrm{q}_{\mathrm{L}}=(0.5) /[(0.5)+(47400.5) \mathrm{F} 0.05(94801,1)]=4.15 \times 10^{-8}
$$

Posterior upper bound:

$$
\mathrm{qU}=[(\mathrm{f}+0.5) \mathrm{F} 0.05(1,94801)] /[(47400.5)+(0.5) \mathrm{F} 0.05(1,94801)]=4.05 \times 10^{-5}
$$

The non-informative prior is very useful when the available performance records show zero.

The Bayesian approach shifts the estimation toward lower points values and intervals. This result may be viewed as a better result given that no failures were observed. By selecting the noninformative prior, the analyst says "The probability of failure, $\mathrm{q}$, is between 0 and 1 . I am confident that q can not be 0 , because nothing is perfect, and I am confident that it can not be approaching 1.0, because then there would be many observed failures."

Using the evidence of zero failures for the large number of trials gives a point estimate that is approximately half of the classical estimate with one assumed failure (the Bayesian approach does not require this arbitrary assumption). Moreover, the upper $95^{\text {th }}$ percent limit is $4.05 \times 10^{-5}$ versus $1.0 \times 10^{-4}$ from the classical estimation. The lower $5^{\text {th }}$ percent limit is $4.15 \times 10^{-8}$, which can be regarded as approaching 0 versus the larger value of $1.08 \times 10^{-6}$ from the classical approach. 


\subsection{Estimation of Parameters - Constant Failure Rate}

For a constant failure rate model, the point estimate is:

$$
?^{*}=\mathrm{f} / \mathrm{T}
$$

where

$$
\begin{aligned}
& \mathrm{f}=\text { number of observed or recorded failures in time } \mathrm{T}, \\
& \mathrm{T}=\text { time duration of reporting period. }
\end{aligned}
$$

The parameter estimation proceeds as described in Section 7.5.3.3.4, Bayesian Estimation of Constant Failure Rates. For example, if the information on steel set performance from the ESF is applied, $\mathrm{f}=0$ failures and $\mathrm{T}=9,200$ steel-set years. The classical approach assumes at least one failure, gives a point estimate of $?=.1 \times 10^{-} / \mathrm{yr}$.

The Bayesian approach, using a non-informative prior and $\mathrm{f}=0$, gives a posterior mean of:

$$
?=(2 \mathrm{f}+1) / 2 \mathrm{~T})=1 /(2 \mathrm{~T})=1 / 18000=5.4 \times 10^{-5} / \mathrm{yr} .
$$

The uncertainty bounds are readily calculated using Equation 7-123 and Equation 7-124.

\subsection{Estimation of Parameters - Pooling Information}

Table 7-9 presents crane failure on demand rates as derived from three different sources. The Bayesian approach with noninformative prior was applied, independently, to each set of the raw information to get the posterior parameters shown in the table. These three set of parameters were processed this way to simulate how the analyst might find different sets of processed data (e.g., in the generic databases described in Section 7.5.3.2.2). The purpose here is to demonstrate the result of combining tabulated information sources. When the source provides the raw information, it may be more appropriate to apply a successive Bayesian update, as shown below.

For demonstration information is pooled using the geometric mean (see Section 7.5.3.3.3, Geometric Mean Method)

$$
\begin{aligned}
& \left\langle\mathrm{q}_{0}\right\rangle=\left(\pi \mathrm{q}_{0, i}\right) 1 / \mathrm{M} ; \text { for the composite point value } \\
& \left\langle\mathrm{q}_{\mathrm{LB}}\right\rangle=\left(\pi \mathrm{q}_{\mathrm{LB}, \mathrm{i}}\right) 1 / \mathrm{M} \text {; for the composite lower bound } \\
& \left\langle\mathrm{q}_{\mathrm{UB}}\right\rangle=\left(\pi \mathrm{q}_{\mathrm{UB}, \mathrm{i}}\right) 1 / \mathrm{M} \text {; for the composite upper bound }
\end{aligned}
$$

Where $\mathrm{q}_{0, \mathrm{i}}, \mathrm{q}_{\mathrm{LB}, \mathrm{i}}$, and $\mathrm{q}_{\mathrm{UB}, \mathrm{i}}$ are the point value, lower bound, and upper bound, respectively from the $i^{\text {th }}$ information source.

In this example, $\mathbf{M}=3$. 
Using the mean values in Table 7-9 gives the following composite parameter estimates:

$$
\begin{aligned}
& \left\langle\mathrm{q}_{0}\right\rangle=\left[\left(1.44 \times 10^{-5}\right)\left(4.97 \times 10^{-5}\right)\left(1.05 \times 10^{-5}\right)\right] 1 / 3 \\
& \left\langle\mathrm{q}_{\mathrm{LB}}\right\rangle=\left[\left(8.6 \times 10^{-6}\right)\left(3.80 \times 10^{-5}\right)\left(4.15 \times 10^{-5}\right)\right] 1 / 3 \\
& \left\langle q_{U B}>=\left[\left(2.14 \times 10^{-5}\right)\left(6.27 \times 10^{-5}\right)\left(4.05 \times 10^{-5}\right)\right] 1 / 3\right. \\
& \begin{array}{l}
=1.96 \times 10^{-5} \\
=2.38 \times 10^{-6} \\
=3.79 \times 10^{-5}
\end{array}
\end{aligned}
$$

\begin{tabular}{|c|c|c|c|c|c|}
\hline Source & Failures & Trials & \multicolumn{3}{|c|}{$\begin{array}{c}\text { Posterior } \\
\text { Using Noninformative Prior }\end{array}$} \\
\hline \multicolumn{3}{|l|}{ Event: Drop of Load by Crane } & Mean & Lower $5 \%$ & Upper 95\% \\
\hline Newport News (CRWMS M\&O 1998, Attachment X) & 13 & 939,000 & $1.44 \mathrm{E}-5$ & $8.60 \mathrm{E}-6$ & $2.14 \mathrm{E}-5$ \\
\hline NUREG-0612 (NRC 1980) & 43 & $8.75 \mathrm{E}+5$ & 4.97E-5 & $3.80 \mathrm{E}-5$ & $6.27 \mathrm{E}-5$ \\
\hline Lloyd (2001) & 0 & 47,400 & $1.05 \mathrm{E}-5$ & $4.15 \mathrm{E}-8$ & 4.05E-5 \\
\hline
\end{tabular}

Table 7-9. Crane Failure Demand Rates

\subsection{EVENT SEQUENCE FREQUENCY BINNING}

\subsubsection{Purpose}

This guide defines the bases and methods for applying the results of ET sequence quantification to categorize (or bin) credible event sequences as Category 1 or Category 2 according to the definitions of 10 CFR 63.2. Potential radiological consequences of the event sequences are then subject to the performance criteria of 10 CFR 63.111. Event sequences that are not Category 1 or Category 2 are categorized as "Beyond Category 2" (BC2) and are not subjected to performance criteria. Since there are various degrees of uncertainty associated with the quantification of event sequence frequencies, this guide recommends means for dealing with uncertainty factors in categorizing sequences.

\subsubsection{Scope}

This section provides guidance on interpreting and using the results of ET analyses performed in accordance with Section 7.1, considerations of uncertainties per Section 9, and the overall PSA process described in Section 4. This section does not describe ET construction or analysis.

\subsubsection{Overview of Approach}

The results of ET analyses, in addition to the graphical display of the alternative sequences (or scenarios) that can result following a particular IE, include calculations of the frequency (or annual probability of occurrence) of all sequences that are modeled. The sum of the frequencies of all sequences equals that of the IE frequency.

The endpoint of each pathway through the ET represents a particular state of the system being analyzed, termed the "endstate". Each endstate has a measure of radiological consequence (or performance) associated with it; in most instances, the radiological consequences are nil (all consequences prevented or mitigated) or very small (mitigation features are effective). The frequency and consequence analyses of Category 1 and Category 2 event sequences form the bases for defining the 10 CFR 63.2 design basis for a repository, and in classifying the SSCs ITS 
that are credited with prevention and mitigation of events that make up the various event sequences.

For event sequences that are below the threshold frequency category (seismic) (FC-2) event sequences (i.e., BC2 event sequences), there are no radiological performance requirements in 10 CFR Part 63. However, any SSCs that are credited in the frequency analyses of BC2 event sequences may be subject to classification as important to safety.

Since there are various degrees of uncertainty associated with the quantification of event sequence frequencies, it is necessary to deal with uncertainty factors in categorizing sequences. For example, if a point estimate (or best estimate) of an event frequency results in a value that is slightly below the threshold of Category 2, should the sequence be declared a BC2 or Category 2 event sequence in view of the degree of uncertainty in the frequency analysis? Similarly, if another sequence frequency is slightly below the breakpoint between Categories 1 and 2, should the sequence be categorized as Category 1 or Category 2? This guide provides a basis for answering such questions.

\subsubsection{Details of Approach}

\subsubsection{Fundamental Screening Criteria}

Event sequence Category 1 and Category 2 are defined by 10 CFR 63.2 (see Sections 2 and 3). If a100-year period before permanent closure is used as a basis, then frequency bounds can be defined for the respective event sequence categories as:

$$
\begin{aligned}
& \text { Category 1: } \mathrm{f}(\text { event sequence }) \geq 1 \times 10^{-2} \text { per year } \\
& \text { Category 2: } 1 \times 10^{-2}>\mathrm{f}(\text { event sequence }) \geq 1 \times 10^{-6} \text { per year }
\end{aligned}
$$

This guide will use these definitions as Fundamental Screening Criteria in the context of event sequence frequency binning.

It is noted, however, that other preclosure time periods may be defined for all or portions of operations, but the principles described herein are to be applied to those time bases, nevertheless. See Section 3.4 for a discussion of preclosure time periods.

This guide is based on quantitative evaluations of event sequence frequencies. However, it may be preferable to use the probability of occurrence of a sequence rather than the preclosure period. This approach eliminates the need to assume a preclosure period (e.g., 100 years) for direct comparison to the definitions of Category 1 and Category 2 per 10 CFR 63.2.

\subsubsection{Screening Criteria with Consideration of Uncertainties}

Section 9 describes methods for identifying sources of uncertainty in event sequence modeling and Section 7.5 discusses uncertainty in probabilities of basic events that are input to FTA (Section 7.2) and HRA (Section 7.3). 
In formal analysis of uncertainties, results of event sequence quantification are expressed in the form of a probability distribution function (PDF). The complementary cumulative probability distribution represents the probability between 0 and 1 that the frequency of a given sequence of events is less than or equal to a particular value. Unless otherwise noted, the point estimates derived in preliminary sequence quantification will fall near the middle of the distribution, often being the true median (i.e., the frequency corresponding to a probability of 0.5 ). To evaluate the mean of sequence frequency, the form of the PDF must be specified. For PSA purposes, many parameters are assumed to be lognormally distributed (see Section 9).

The PSA that supports the LA-CA will categorize event sequences based on the mean value of the sequence frequencies. The mean is a probability-weighted measure of an event-sequence frequency over the range and distribution of uncertainties. Section 9 describes the general treatment of uncertainties and illustrates the significance of the mean as a measure of the true value of an event-sequence frequency. If the mean is less than the threshold frequency for Category 1 event sequences, the sequence is designated Category 2 . If the mean is less than the threshold frequency for Category 2 event sequences, the sequence is designated BC2.

\subsubsection{Beyond Category 2 Event Sequences: Quantitative Screening}

During event sequence evaluation, as many sequences as possible are screened out of further analysis. Such event sequences are termed BC2. A BC2 event sequence consists of an IE and one or more additional events whose joint frequency is less than $1 \times 10^{-6}$ per year. However, if $\mathrm{f}($ sequence $)=1 \times 10^{-6}$ per year, then the test fails and the sequence must be included as a Category 2 event sequence. The test is applied to the frequencies of every sequence modeled in an ET.

\subsection{Consideration of Uncertainties in Beyond Category 2 Event Sequences: Screening and Stopping Rules}

10 CFR 63.112(d) requires that the PSA include the technical basis for either inclusion or exclusion of specific, naturally occurring and human-induced hazards in the safety analysis. This requirement has been interpreted to mean that the NRC expects the PSA to tabulate sequences that have been declared BC2 and to provide the bases. To avoid having an infinitely long list of sequences to pedigree that includes sequences of extremely small frequencies, it is necessary to define a lower limit on sequence frequency to be documented, which is termed the stopping rule. The definition and application of the stopping rule must be compatible with considerations of uncertainties.

The stopping rule recommended for the PSA is:

No event sequence having a point estimate frequency less than $1 \times 10^{-8}$ per year will be included in the list of BC2 event sequences.

No uncertainty analysis will be applied in executing the stopping rule. This stopping rule provides two orders of magnitude below the Category 2 lower threshold, which is a wide margin. The stopping rule can be applied during ET construction and preliminary quantification as a means of simplifying the ETs. Tree branches that are readily seen to be on the order of $10^{-8}$ per year can be pruned from the tree. As design evolves and uncertainties are reduced, or formal 
uncertainty analyses are applied to obtain mean values of event sequence frequency. The BC2 cutoff frequency for the mean may be raised to $1 \times 10^{-7}$ per year.

\subsection{Identifying Controls Credited for Prevention or Mitigation of Beyond Category 2 Event Sequences}

Except for event sequences that are below $1 \times 10^{-8}$ per yr (i.e, per the stopping rule), the events comprising each of the documented $\mathrm{BC} 2$ event sequences must be examined to identify items important to safety.

The primary evaluation assesses the credit taken in event sequence frequency for each SSC event or HFE in the sequence, other than the IE. The assessed probability of failure for each SSC or HFE is set equal to 1.0 and the frequency of the event sequence is recalculated. If the recalculated mean sequence frequency is greater than the Category 2 threshold $\left(10^{-6}\right.$ per year) for any one item (e.g., an SSC, or a specific human interaction), then a coarse estimate of potential consequences is made. If the consequences appear to exceed the regulatory limits, then the item represented by that event may be subject to classification as an potential item important to safety and appropriate controls (e.g., quality assurance controls). If the consequences appear to be within regulatory limits for Category 2, then no such classification is necessary (see Section 12 for the discussion of the classification process).

When the event probability within an event sequence is set equal to 1.0 for a given item and the recalculated mean sequence frequency remains below the Category 2 threshold $\left(10^{-6}\right.$ per year) with sufficient margin, then no further action is required.

\subsection{SOFTWARE RELIABILITY}

There are two kinds of software that could influence the preclosure safety of the MGR. One kind of software refers to the instruction sets that control digital computers and automated systems. This "computer software" comprises operating systems, programming languages, and the coding (the actual instructions, logic, and computations) that produces a desired output for a given set of input parameters (e.g., temperatures, or status of interlock switches). Another kind of software is the instruction sets that control the actions of humans who interface with the MGR operating systems. This software comprises the normal and emergency operating procedures, maintenance procedures, technical specification (including test and inspection intervals and instructions), and even training material. Imbedded errors (or "bugs") in either kind of software may be a causal factor that leads to the initiation of, or inability to mitigate, an undesired event sequence.

If an FT model for estimating the probability of failure of a given SSC includes the automatic response of a programmable device as a fault, a failure cause, then the logic model must include faults generated by the software as well as faults caused by a physical failure of the electronic device. Although software developers and extremely careful, and the software is subject to an extensive verification and validation $(\mathrm{V} \& \mathrm{~V})$ process, some "bugs" may slip through undetected and remain as a residual cause of system failure. The effects, in many cases, would be the same as an undetected maintenance error that leaves a safety system unable to respond. The probability of having undetected and uncorrected "bugs" is a potential issue that could affect the preclosure safety of the MGR. The probability can be used to quantify the basic event appearing 
in the system FT. Special techniques (discussed in Section 7.7.1) are being developed by the NRC and others to estimate the probability that such errors are present that will be adapted to the MGR preclosure safety analyses, as appropriate.

Similarly, if the success of a particular safety function depends on the correct action by a human operator or maintenance technician, the probability of success depends in turn on the correctness of the procedures and/or training materials. The quality (structure of decision-making logic statements, correctness of instructions relative to the plant state being controlled, and "userfriendliness") are represented in human reliability analyses (see Section 7.3) as "error producing contexts" (or "performance shaping factors"). The quality of such (non-computer) software is generally ensured through an extensive $V \& V$ process, similar to that used to ensure quality of computer software. Section 7.7.2 briefly summarizes the elationship software reliability to HRA.

\subsubsection{Computer Software Reliability Analysis in PSA}

The application of event-tree and fault-tree logic models can identify where software flaws have the potential to affect the initiation or propagation of event sequences. For example, in a fault-tree model the basic events that are identified as causes (input to an OR gate) of the Top Event might include (1) hardware failures (both mechanical or electrical systems and electronic control hardware), (2) HFEs, and (3) software failure. The probability of the Top Event is the sum of probabilities of the three basic events. A challenge is to quantify the probabilities of the basic events. Methods for quantifying hardware failures are many decades old and use wellknown tools of reliability engineering, as described in Section 7.4 and 7.5. Methods for quantifying human failure are somewhat newer and have been developing over about two decades as described in Section 7.3. Methods for quantifying software failure, however, are relatively new having been developing for only about one decade.

The NRC has sponsored a significant amount of research on software reliability. In large measure this research is related to digital control of reactor protection systems. Much of the research has emphasized the means to prevent or obviate the effects of a failure. On one hand, the methods relate to the quality assurance programmatic issues that seek to prevent initial coding errors supported by thorough review and testing. The NRC has sponsored a significant amount of research to develop effective tools to evaluate such systems, including design codes and standards, analytical techniques, design methods, and computer-aided systems for ferreting out "bugs."

For the PSA of the MGR, it is premature to provide explicit guidance for evaluating the effects of software reliability, but general guidance is presented here to ensure that this area will be considered during the preparation of the PSA. The general guidance is summarized in the following: 
- Apply the logic structure of ETs and FTs to systematically identify where software reliability could be a contributor to event sequence probability

- Review the current NRC guidance on evaluating software reliability and apply the appropriate techniques to the kind of computerized systems that will be used in a given application for the MGR.

In many cases, the effects of software reliability will not result in a significant risk because: (1) there may be redundant and diverse channels of the computerized control so that the potential of common-case software error is reduced, and/or (2) there may be an opportunity for a human operator to intervene and take manual control. In these situations, it may be appropriate to take no credit for reliability for the software (i.e., assume a failure probability of 1.0), or apply some generic software failure probability value based on coding of similar complexity.

In cases (if any in the MGR) where software reliability has a high risk significance, then quantification of the failure probability must be performed by a method appropriate to the specific computerized task, using evaluation techniques acceptable to the NRC.

The preclosure safety analyst should review the NRC guidance and advances made in the state of the art.

\subsubsection{Non-computer Software Reliability in PSA}

Non-computer software comprises the operating procedures (both normal and emergency), maintenance procedures, radiation protection procedures, and technical specifications. Although the procedures may have logical flaws and other "bugs," there are no hidden coding errors like there could be with computer software. The reliability of such non-computer software is ensured by validation and verification programs. The process for ensuring such reliability is beyond the scope of this PSA guide. The reliability of such documents is not generally accounted for in PSA frequency or consequence analyses except in instances where the quality of procedures may affect the reliability of human operators and maintenance technicians. The effects of procedure quality are considered accounted for in HRA as part of the "performance shaping factors" or "error causing factors," as described in Section 7.3.

\subsection{REFERENCES}

\subsubsection{Documents Cited}

AIChE (American Institute of Chemical Engineers) 1989. "Partial List of External Events." Table 3.13 of Guidelines for Chemical Process Quantitative Risk Analysis. New York, New York: American Institute of Chemical Engineers. TIC: 241701.

Arno, R.G. 1981. Noneletronic Parts Reliability Data. NPRD-2. 24, 25. Griffiss Air Force Base, New York: Reliability Analysis Center. TIC: 245435.

Benhardt, H.C.; Eide, S.A.; Held, J.E.; Olsen, L.M.; and Vail, R.E. 1994. Savannah River Site Human Error Data Base Development for Nonreactor Nuclear Facilities (U). WSRC-TR-93581. Aiken, South Carolina: Westinghouse Savannah River Company. 
Blanton, C.H. and Eide, S.A. 1993. Savannah River Site, Generic Data Base Development (U). WSRC-TR-93-262. Aiken, South Carolina: Westinghouse Savannah River Company. TIC: 246444.

BSC (Bechtel SAIC Company) 2001. Analysis of Preclosure Design Basis Rock Fall onto Waste Package. ANL-EBS-MD-000061 REV 00. Las Vegas, Nevada: Bechtel SAIC Company. ACC: MOL.20011127.0110.

CRWMS M\&O (Civilian Radioactive Waste Management Systems Management and Operating Contractor) 1997. Application of Logic Diagrams and Common-Cause Failures to Design Basis Events. BCA000000-01717-0200-00018 REV 00. Las Vegas, Nevada: CRWMS M\&O.

ACC: MOL.19980206.0272.

CRWMS M\&O 1998. Preliminary Preclosure Design Basis Event Calculations for the Monitored Geologic Repository. BC0000000-01717-0210-00001 REV 00. Las Vegas, Nevada: CRWMS M\&O. ACC: MOL.19981002.0001.

CRWMS M\&O 2000. Subsurface Transporter Safety Systems Analysis. ANL-WER-ME000001 REV 00. Las Vegas, Nevada: CRWMS M\&O. ACC: MOL.20000225.0052.

DOD (U.S. Department of Defense) 1991. Military Handbook, Reliability Prediction of Electronic Equipment and Production. MIL-HDBK-217F. Washington, D.C.: U.S. Department of Defense. TIC: 232828.

Eide, S.A. and Calley, M.B. 1993. "Generic Component Failure Data Base.” PSA '93, Proceedings of the International Topical Meeting on Probabilistic Safety Assessment, Clearwater Beach, Florida, January 26-29, 1993. 2, 1175-1182. La Grange Park, Illinois: American Nuclear Society. TIC: 247455.

Hannaman, G.W. and Spurgin, A.J. 1984. Systematic Human Action Reliability Procedure (SHARP). EPRI-NP-3583. Palo Alto, California: Electric Power Research Institute.

IEEE Std 500-1984. IEEE Guide to the Collection and Presentation of Electrical, Electronic, Sensing Component, and Mechanical Equipment Reliability Data for Nuclear-Power Generating Stations. New York, New York: Institute of Electrical and Electronics Engineers. TIC: 240502.

IEEE Std 493-1997. 1998. IEEE Recommended Practice for the Design of Reliable Industrial and Commercial Power Systems. New York, New York: Institute of Electrical and Electronics Engineers. TIC: 243205.

INEEL (Idaho National Engineering and Environmental Laboratory) 1989. Nuclear Computerized Library for Assessing Reactor Reliability. NUREG/CR-4639. Washington, D.C.: U.S. Nuclear Regulatory Commission.

Lloyd, R.L. 2001. Technical Assessment Generic Issue 186 Potential Risk and Consequences of Heavy Load Drops in Nuclear Power Plants. Pre-Draft NUREG-Xxxx (ML012620352). Washington, D.C.: U.S. Nuclear Regulatory Commission. 
Martz, H.F. and Waller, R.A. 1978. An Exploratory Comparison of Methods for Combining Failure-Rate Data from Different Data Sources. LA-7556-MS. Los Alamos, New Mexico: Los Alamos Scientific Laboratory.

Moieni, P., Spurgin, A.J., and Singh, A. 1994. "Advances in Human Reliability Analysis Methodology." Reliability Engineering and System Safety, 44, (1994), 27-55, 57-66. Dublin, Northern Ireland: Elsevier Science Limited.

Mosleh, A.; Fleming, K.N.; Parry, G.W.; Paula, H.M.; Worledge, D.H.; and Rasmuson, D.M. 1988. Procedural Framework and Examples. Volume 1 of Procedures for Treating Common Cause Failures in Safety and Reliability Studies. NUREG/CR-4780. Washington, D.C.:

U.S. Nuclear Regulatory Commission. TIC: 221775.

NRC (U.S. Nuclear Regulatory Commission) 1975. Reactor Safety Study: An Assessment of Accident Risks in U.S. Commercial Nuclear Power Plants. WASH-1400. Washington, D.C.: U.S. Nuclear Regulatory Commission. TIC: 236923.

NRC 1980. Control of Heavy Loads at Nuclear Power Plants. NUREG-0612. Washington, D.C.: U.S. Nuclear Regulatory Commission. TIC: 209017.

NRC 1983. PRA Procedures Guide, A Guide to the Performance of Probabilistic Risk Assessments for Nuclear Power Plants. NUREG/CR-2300. Two volumes. Washington, D.C.: U.S. Nuclear Regulatory Commission. TIC: 205084.

NRC 2000. Technical Basis and Implementation Guidelines for a Technique for Human Event Analysis (ATHEANA). NUREG-1624. Washington, D.C.: U.S. Nuclear Regulatory Commission.

Russell, K.D.; Kvarfordt, K.J.; Skinner, N.L.; Wood, S.T.; and Rasmuson, D.M. 1994. Integrated Reliability and Risk Analysis System (IRRAS) Reference Manual. Volume 2 of Systems Analysis Programs for Hands-On Integrated Reliability Evaluations (SAPHIRE), Version 5.0. NUREG/CR-6116. Washington, D.C.: U.S. Nuclear Regulatory Commission. TIC: 249497.

Swain, A.D. and Guttmann, H.E. 1983. Handbook of Human Reliability Analysis with Emphasis on Nuclear Power Plant Applications Final Report. NUREG/CR-1278. Washington, D.C.: U.S. Nuclear Regulatory Commission. TIC: 246563.

Vesely, W.E.; Goldberg, F.F.; Roberts, N.H. ; and Haasl, D.F. 1981. Fault Tree Handbook. NUREG - 0492. Washington, D.C.: U.S. Nuclear Regulatory Commission. TIC: 208328.

Wakefield, D.J.; Parry, G.W.; Spurgin, A.J.; and Moieni, P. 1992. Systematic Human Action Reliability Procedure (SHARP) Enhancement Project: SHARP1 Methodology Report. EPRI-RP-3206-01. Palo Alto, California: Electric Power Research Institute.

Watson, I.A. 1987. "Analysis of Dependent Events and Multiple Unavailabilities with Particular Reference to Common Cause Failures." The SRS Quarterly Digest, 1987, (February), 
Warrington, United Kingdom: Systems Reliability Service, National Centre of Systems Reliability.

\subsubsection{Codes, Standards, Regulations, and Procedures}

10 CFR 63. 2002. Energy: Disposal of High-Level Radioactive Wastes in a Proposed Geologic Repository at Yucca Mountain, Nevada. 


\section{SECTION 7 APPENDIX}

\section{BIBLIOGRAPHY OF INFORMATION SOURCES}

AIChE. Guidelines for Process Equipment Reliability Data with Data Tables. Center for Chemical Process Safety of the American Institute of Chemical Engineers. New York, NY. 1989.

Arno, R.G. 1981. Noneletronic Parts Reliability Data. NPRD-2. 24, 25. Griffiss Air Force Base, New York: Reliability Analysis Center. TIC: 245435.

Blanton, C.H. and Eide, S.A. 1993. Savannah River Site, Generic Data Base Development (U). WSRC-TR-93-262. Aiken, South Carolina: Westinghouse Savannah River Company. TIC: 246444.

Dexter, A. H. and W. C. Perkins. Component Failure-Rate Data with Potential Applicability to a Nuclear Fuel Reprocessing Plant. E.I. du Pont de Nemours, Savannah River Laboratory. July 1982.

DOD (U.S Department of Defense) 1991. Military Handbook, Reliability Prediction of Electronic Equipment and Production. MIL-HDBK-217F. Washington, D.C.: U.S. Department of Defense. TIC: 232828.

Eide, S.A. and Calley, M.B. 1993. "Generic Component Failure Data Base.” PSA '93, Proceedings of the International Topical Meeting on Probabilistic Safety Assessment, Clearwater Beach, Florida, January 26-29, 1993. 2, 1175-1182. La Grange Park, Illinois: American Nuclear Society. TIC: 247455.

Eide, S.A. , S.T. Khericha, M.B. Calley, and D. A. Johnson (1993). Component External Leakage and Rupture Frequency Estimates. Proceedings Probabilistic Safety Assessment and Management, PSA'93. American Nuclear Society, Clearwater Beach, Florida, January, 1993.

IEEE Std 493-1997. 1998. IEEE Recommended Practice for the Design of Reliable Industrial and Commercial Power Systems. New York, New York: Institute of Electrical and Electronics Engineers. TIC: 243205.

IEEE 1983. IEEE Guide to the Collection and Presentation of Electrical, Electronic, and Sensing Component Reliability Data for Nuclear-Power Generating Station. IEEE Std 5001984. The Institute of Electrical and Electronic Engineers, Inc.

INEEL (Idaho National Engineering and Environmental Laboratory) 1989. Nuclear Computerized Library for Assessing Reactor Reliability. NUREG/CR-4639. Washington, D.C.: U.S. Nuclear Regulatory Commission.

NRC 1975. Reactor Safety Study: An Assessment of Accident Risks in U.S. Commercial Nuclear Power Plants. WASH 1400/NUREG75/014. U.S. Nuclear Regulatory Commission.

WIPP Safety Analysis. 


\section{INTENTIONALLY LEFT BLANK}




\section{CONSEQUENCE ANALYSES}

This section describes the approach and methods for analysis of radiological consequences. Consequence analyses include routine releases from normal operations and for Category 1 and Category 2 event sequences. This section is organized as follows:

- $\quad$ Section 8.1 presents the performance objectives and exposure standards that determine compliance with 10 CFR Part 63, and provides definitions of the radiological dose terms that appear in the regulations.

- Section 8.2 describes the information that must be input to dose calculations (e.g., source terms, release fractions, and atmospheric dispersion factors). In many cases, the information is common to both Category 1 and Category 2 dose calculations.

- $\quad$ Section 8.3 presents the approach and methodology for calculating Category 1 doses, and addresses both public (offsite) and worker (onsite) exposures resulting from direct radiation and from airborne radionuclides. This section also describes computer codes used for calculating doses from direct radiation and airborne releases.

- $\quad$ Section 8.4 presents the approach and methodology for calculating Category 2 doses to the public (offsite) exposures to direct radiation and to airborne radionuclides.

The MACCS2 code is used to calculate doses from airborne releases for Category 1 and Category 2 event sequences, but there are differences in input and treatment of the outputs. The treatment of uncertainties in dose calculations is described for Category 1 and Category 2, respectively, in Sections 8.3 and 8.4.

As defined in 10 CFR 63.2, Category 1 event sequences are those event sequences, that are expected to occur one or more times before permanent closure of the GROA. Doses associated with Category 1 are evaluated as annual occurrences. Category 2 event sequences, by contrast, are other human-induced event sequences that have at least one chance in 10,000 of occurring before permanent closure. Doses associated with Category 2 are evaluated as single occurrences within a given event sequence. The results of consequence analyses are compared against the preclosure performance objectives specified in 10 CFR 63.111 to ensure that the repository design meets the regulations for preclosure operations.

Sections 4, 6, and 7, describe the processes for identifying radiological hazards and Category 1 and Category 2 event sequences. The description of a given event sequence specifies the type and quantity of waste form involved in the release or exposure scenario, and the conditions of structures, systems, and components that can lead to exposures to, and releases of, radioactivity. This information is used as input to consequence analyses. Routine releases from repository operations are quantified and are also used as input to consequence analyses.

\subsection{PERFORMANCE OBJECTIVES AND EXPOSURE STANDARDS}

Radiation dose limits for Category 1 and Category 2 event sequences are specified in 10 CFR Part 63.111. Paragraph 63.111(a)(1) incorporates 10 CFR Part 20 by reference while Paragraph 63.111(a)(2) references Section 63.204, the Preclosure Standard that limits releases 
from the Yucca Mountain Site to the general environment. Per Paragraph 63.111(b)(1), Paragraph 63.111(a) applies only to Category 1 event sequences. A complicating feature of 63.111(b)(1) is the requirements that "the aggregate radiation exposures and aggregate radiation levels in both restricted and unrestricted areas, and the aggregate releases of radioactive materials to unrestricted areas, will be maintained within the limits specified in paragraph (a) of this section."

The requirement for aggregation leads to the process of frequency-weighed dose analysis for Category 1 event sequences, as described further in Section 8.3. Regulations specify the offsite and worker dose limits during normal operations and for Category 1 event sequences. Units of the performance objectives are expressed as annual doses (e.g., mrem per year). The performance objectives (dose standard) for normal operations and Category 1 event sequences are summarized in Table 8-1.

Table 8-1. Dose Standard for Normal Operations and Category 1 Event Sequences

\begin{tabular}{|c|c|c|c|}
\hline \multirow{2}{*}{$\begin{array}{l}\text { Event Sequence } \\
\text { Type }\end{array}$} & \multirow[b]{2}{*}{ Dose Type } & \multicolumn{2}{|c|}{ Dose Standard } \\
\hline & & Worker $^{\mathrm{a}}$ & Offsite \\
\hline Category 1 & $\begin{array}{l}\text { 1. Annual TEDE during normal operations and for } \\
\text { Category } 1 \text { event sequences } \\
\text { 2. Aggregate TEDE for Category } 1 \text { event sequences }\end{array}$ & --- & $15 \mathrm{mrem} / \mathrm{yr}^{\mathrm{b}}$ \\
\hline Category 1 & TEDE & $5 \mathrm{rem} / \mathrm{yr}$ & $100 \mathrm{~m} \mathrm{rem} / \mathrm{yr}^{\mathrm{c}}$ \\
\hline Category 1 & The highest of the CDE plus the DDE & $50 \mathrm{rem} / \mathrm{yr}$ & --- \\
\hline Category 1 & LDE & $15 \mathrm{rem} / \mathrm{yr}$ & --- \\
\hline Category 1 & SDE & $50 \mathrm{rem} / \mathrm{yr}$ & --- \\
\hline Category 1 & External dose: Highest of DDE, LDE, or SDE & --- & $\begin{array}{l}2 \text { mrem in any } \\
\text { one hour }\end{array}$ \\
\hline \multicolumn{4}{|l|}{ a 10 CFR 20.1201} \\
\hline \multicolumn{4}{|l|}{ b 10 CFR 63.204} \\
\hline \multicolumn{4}{|c|}{${ }^{\mathrm{c}} 10$ CFR 20.1301 (a)(1) } \\
\hline \multicolumn{4}{|c|}{${ }^{\mathrm{d}} 10$ CFR $20.1301(\mathrm{a})(2)$} \\
\hline
\end{tabular}

By contrast, Paragraph 63.111(b)(2) specifies numerical guides for Category 2 performance objectives that apply only to public doses, specifically to an individual located on or beyond the boundary of the site. For Category 2, no consideration of worker doses is required nor is aggregation of doses required. Units are expressed as dose per occurrence of an event sequence, termed here as dose per event (i.e., rem per event). The performance objectives for Category 2 event sequences are presented in Table 8-2.

There are four dose measures applicable to normal operations and Category 1 and Category 2 event sequences, as follows:

Total Effective Dose Equivalent (TEDE)-For purposes of assessing doses to workers, the TEDE is equal to the sum of the deep-dose equivalent (DDE) for external exposures and the committed effective dose equivalent (CEDE) for internal exposures (10 CFR 63.2). For purposes of assessing doses to members of the public, TEDE is equal to the sum of the effective dose equivalent (EDE) for external exposures and CEDE (10 CFR 63.2). CEDE is calculated 
using the effective inhalation dose conversion factor (DCF). EDE is calculated using the effective air submersion DCF. For normal operations and Category 1 and Category 2 event sequences, TEDE also includes ingestion and groundshine doses in addition to inhalation and submersion doses. In assessing compliance with the individual radiation protection standard, DDE is replaced by EDE per NRC guidance on the use of DDE and EDE for external exposure (66 FR 55732).

Table 8-2. Dose Standard for Category 2 Event Sequences

\begin{tabular}{|l|l|l|l|}
\hline \multirow{2}{*}{$\begin{array}{l}\text { Event Sequence } \\
\text { Type }\end{array}$} & \multirow{2}{*}{ Dose Type } & \multicolumn{2}{|l|}{ Dose Standard } \\
\cline { 3 - 4 } & TEDE & Worker & Offsite $^{\text {a }}$ \\
\hline Category 2 & --- & 5 rem/event \\
\hline Category 2 & The highest of the CDE plus the DDE & --- & 50 rem/event \\
\hline Category 2 & LDE & --- & $15 \mathrm{rem} /$ event \\
\hline Category 2 & SDE & --- & $50 \mathrm{rem} / \mathrm{event}$ \\
\hline
\end{tabular}

${ }^{\mathrm{a}} 10$ CFR $63.111(\mathrm{~b})(2)$

The Highest of Committed Dose Equivalents plus Deep-Dose Equivalent (CDE+DDE)-The organs evaluated to determine the highest committed dose equivalents (CDE) are the lungs, breasts, gonads, red marrow, bone surface, thyroid, and remainder. The remainder is not an organ, but rather a weighted combination of the five remaining organs or tissues (liver, kidneys, spleen, and brain, but excluding skin, lens of the eye, and the extremities) receiving the highest doses (Eckerman et al. 1988). DDE, which is added to the highest CDE, is equal to that used to calculate TEDE. In assessing compliance with the individual radiation protection standard, DDE is replaced by EDE per NRC guidance on the use of DDE and EDE for external exposure (66 FR 55732).

Lens Dose Equivalent (LDE)-Lens dose equivalents (LDEs) are not calculated using lens of the eye DCFs because Federal Guidance Report 11 (Eckerman et al. 1988) DCFs are incomplete; lenses of the eye DCFs are given for only one radionuclide, (i.e., $\mathrm{Kr}-83 \mathrm{~m}$ ). However, NUREG1567 (NRC 2000a) states that compliance with lens of the eye dose limit is achieved if the sum of the skin dose equivalent (SDE) and the TEDE does not exceed 15 rem.

Skin Dose Equivalent (SDE)-Dose to the skin is due to air submersion and groundshine pathways. SDEs are calculated using DCFs for air submersion in Federal Guidance Report 12 (Eckerman and Ryman 1993) and the groundshine dose from MACCS2 (ORNL 1998).

\subsection{INPUTS TO CONSEQUENCE ANALYSES}

\subsubsection{Source Terms}

Source terms for spent nuclear fuels (SNFs) and waste forms to be received and handled at the MGR are needed to perform consequence analyses. Source terms are a function of the initial fuel enrichment, fuel compound, cladding type, moderator type, and reactor operating history. Source terms are usually calculated using a computer program that performs a point depletion and decay calculation. 
The same source terms for crud, U.S. Department of Energy (DOE SNF), naval SNF, and vitrified high-level radioactive waste (HLW) are used for both Category 1 and Category 2 event sequences as well as for normal operations. The source terms for commercial spent nuclear fuel (CSNF) are different for Category 1 and Category 2 event sequences as described in Section 8.2.1.1. Source terms are defined as concentrations or inventories of radionuclides in SNFs or waste forms to be received and handled at the repository. The concentration or inventory of each radionuclide in SNF or waste form is usually expressed as curies per fuel assembly, per unit weight of waste form, or per canister.

\subsubsection{Commercial Spent Nuclear Fuel}

Source terms for pressurized water reactor (PWR) and boiling water reactor (BWR) Commercial Spent Nuclear Fuel (CSNF) assemblies are based on actual fuel parameters that are submitted in the License Application (LA). The preclosure consequence analyses consider source terms for four combinations of initial enrichment, burnup, and decay time by assembly category: Average PWR, Maximum PWR, Average BWR, and Maximum BWR. Table 8-3 presents examples of the specification of the combinations of fuel parameters and their designations.

Table 8-3. Average and Maximum PWR and BWR CSNF Assemblies

\begin{tabular}{|l|c|c|c|}
\hline \multicolumn{1}{|c|}{ Assembly Category } & Percent & GWd/MTU & Years \\
\hline Average PWR & 4.0 & 48 & 25 \\
\hline Maximum PWR & 5.0 & 75 & 5 \\
\hline Average BWR & 3.5 & 40 & 25 \\
\hline Maximum BWR & 5.0 & 75 & 5 \\
\hline
\end{tabular}

Source: CRWMS M\&O 1999a; CRWMS M\&O 1999b.

Application of the four assembly categories are described for Category 1 and Category 2 Event Sequences as follows:

Category 1 Event Sequences-Both the Average PWR fuel or the Average BWR fuel are used to calculate mean doses, which are then used to determine which source term results in the highest dose. Average PWR fuel is selected for consequence analysis of all Category 1 event sequences because, in previous analyses (BSC 2001), Average PWR fuel was found to result in a higher offsite dose consequence as compared to Average BWR fuel. This result is generally attributed to a higher enrichment, burnup, and concentration of long-lived radionuclides in PWR fuel.

Category 2 Event Sequences-Both the Maximum PWR fuel or the Maximum BWR fuel are used to calculate maximum doses, which are then used to determine which source term results in the highest dose. For Category 2 event sequences, mean doses are also calculated using the Average PWR or Average BWR fuel.

Examples of radionuclide inventories in curies per fuel assembly (Ci/FA) for each nuclide and fuel type evaluated are presented in Table 8-4 for the fuels characterized in Table 8-3. As noted, the source terms used in the PSA are based on actual fuel parameters submitted in the LA. 
Table 8-4. Example of PWR and BWR CSNF Radionuclide Inventories

\begin{tabular}{|c|c|c|c|c|}
\hline Nuclide & $\begin{array}{c}\text { Average PWR } \\
(\mathrm{Ci} / \mathrm{FA})\end{array}$ & $\begin{array}{c}\text { Maximum PWR } \\
(\mathrm{Ci} / \mathrm{FA})\end{array}$ & $\begin{array}{c}\text { Average BWR } \\
(\mathrm{Ci} / \mathrm{FA})\end{array}$ & $\begin{array}{c}\text { Maximum BWR } \\
(\mathrm{Ci} / \mathrm{FA})\end{array}$ \\
\hline Ac-227 & $1.61 \mathrm{E}-05$ & $0.00 \mathrm{E}+00$ & $0.00 \mathrm{E}+00$ & $0.00 \mathrm{E}+00$ \\
\hline Am-241 & $1.98 \mathrm{E}+03$ & $8.71 \mathrm{E}+02$ & $5.58 \mathrm{E}+02$ & $2.66 \mathrm{E}+02$ \\
\hline $\mathrm{Am}-242 \mathrm{~m}$ & $6.39 \mathrm{E}+00$ & $1.02 \mathrm{E}+01$ & $2.17 \mathrm{E}+00$ & $3.40 \mathrm{E}+00$ \\
\hline Am-243 & $2.20 \mathrm{E}+01$ & $5.22 \mathrm{E}+01$ & $5.35 E+00$ & $1.93 \mathrm{E}+01$ \\
\hline C-14 & 3.32E-01 & 4.89E-01 & $1.75 \mathrm{E}-01$ & $3.16 \mathrm{E}-01$ \\
\hline $\mathrm{Cd}-113 \mathrm{~m}$ & $7.66 \mathrm{E}+00$ & $3.82 \mathrm{E}+01$ & $2.26 \mathrm{E}+00$ & $1.39 \mathrm{E}+01$ \\
\hline $\mathrm{Cl}-36$ & $6.80 \mathrm{E}-03$ & $9.69 \mathrm{E}-03$ & $2.93 \mathrm{E}-03$ & 4.99E-03 \\
\hline $\mathrm{Cm}-242$ & $5.27 \mathrm{E}+00$ & $3.43 E+01$ & $1.79 \mathrm{E}+00$ & $1.13 E+01$ \\
\hline $\mathrm{Cm}-243$ & $1.03 \mathrm{E}+01$ & $3.83 E+01$ & $2.48 \mathrm{E}+00$ & $1.12 \mathrm{E}+01$ \\
\hline $\mathrm{Cm}-244$ & $1.36 \mathrm{E}+03$ & $1.12 \mathrm{E}+04$ & $2.56 \mathrm{E}+02$ & $3.95 E+03$ \\
\hline $\mathrm{Cm}-245$ & 3.07E-01 & $1.41 \mathrm{E}+00$ & 4.04E-02 & 3.54E-01 \\
\hline $\mathrm{Cm}-246$ & $1.04 \mathrm{E}-01$ & $8.38 \mathrm{E}-01$ & $1.45 \mathrm{E}-02$ & $2.97 \mathrm{E}-01$ \\
\hline Co-60 & $3.13 E+02$ & $5.66 \mathrm{E}+03$ & $4.40 \mathrm{E}+01$ & $8.56 \mathrm{E}+02$ \\
\hline Cs-134 & $2.52 \mathrm{E}+01$ & $3.72 E+04$ & $6.32 \mathrm{E}+00$ & $1.16 \mathrm{E}+04$ \\
\hline Cs-135 & $3.50 \mathrm{E}-01$ & 5.99E-01 & 1.39E-01 & 2.82E-01 \\
\hline Cs-137 & $4.11 \mathrm{E}+04$ & $9.87 E+04$ & $1.39 E+04$ & $3.87 E+04$ \\
\hline Eu-154 & $6.71 \mathrm{E}+02$ & $5.77 \mathrm{E}+03$ & $1.80 \mathrm{E}+02$ & $1.83 \mathrm{E}+03$ \\
\hline Eu-155 & $5.16 \mathrm{E}+01$ & $1.68 \mathrm{E}+03$ & $1.64 \mathrm{E}+01$ & $6.37 \mathrm{E}+02$ \\
\hline $\mathrm{Fe}-55$ & $3.47 \mathrm{E}+00$ & $6.84 \mathrm{E}+02$ & $1.09 \mathrm{E}+00$ & $2.35 \mathrm{E}+02$ \\
\hline $\mathrm{H}-3$ & $1.14 \mathrm{E}+02$ & $4.72 E+02$ & $3.95 E+01$ & $1.76 \mathrm{E}+02$ \\
\hline I-129 & $2.20 \mathrm{E}-02$ & 3.38E-02 & 7.43E-03 & 1.36E-02 \\
\hline $\mathrm{Kr}-85$ & $1.13 \mathrm{E}+03$ & $5.63 \mathrm{E}+03$ & $3.81 \mathrm{E}+02$ & $2.03 E+03$ \\
\hline $\mathrm{Nb}-93 \mathrm{~m}$ & $1.30 \mathrm{E}+01$ & $4.54 \mathrm{E}+01$ & $4.74 \mathrm{E}-01$ & $1.22 \mathrm{E}+00$ \\
\hline $\mathrm{Nb}-94$ & 8.39E-01 & $1.27 \mathrm{E}+00$ & 1.87E-02 & 3.39E-02 \\
\hline $\mathrm{Ni}-59$ & $2.09 E+00$ & $2.78 \mathrm{E}+00$ & 5.03E-01 & 7.80E-01 \\
\hline $\mathrm{Ni}-63$ & $2.52 E+02$ & $4.16 \mathrm{E}+02$ & $5.87 E+01$ & $1.16 \mathrm{E}+02$ \\
\hline $\mathrm{Np}-237$ & 2.47E-01 & $3.85 \mathrm{E}-01$ & 6.89E-02 & 1.33E-01 \\
\hline $\mathrm{Pa}-231$ & $2.97 \mathrm{E}-05$ & $4.25 \mathrm{E}-05$ & $1.39 \mathrm{E}-05$ & $2.94 \mathrm{E}-05$ \\
\hline $\mathrm{Pb}-210$ & $0.00 \mathrm{E}+00$ & $0.00 \mathrm{E}+00$ & $0.00 \mathrm{E}+00$ & $0.00 \mathrm{E}+00$ \\
\hline $\mathrm{Pd}-107$ & 8.41E-02 & $1.45 \mathrm{E}-01$ & 2.65E-02 & 5.70E-02 \\
\hline $\mathrm{Pm}-147$ & $1.19 \mathrm{E}+02$ & $2.34 \mathrm{E}+04$ & $3.98 \mathrm{E}+01$ & $7.46 \mathrm{E}+03$ \\
\hline Pu-238 & $2.29 \mathrm{E}+03$ & $6.16 \mathrm{E}+03$ & $5.85 E+02$ & $2.11 \mathrm{E}+03$ \\
\hline Pu-239 & $1.77 \mathrm{E}+02$ & $1.85 \mathrm{E}+02$ & $5.35 \mathrm{E}+01$ & $5.36 \mathrm{E}+01$ \\
\hline Pu-240 & $3.18 \mathrm{E}+02$ & $3.90 \mathrm{E}+02$ & $1.14 \mathrm{E}+02$ & $1.48 \mathrm{E}+02$ \\
\hline Pu-241 & $2.47 E+04$ & $7.91 \mathrm{E}+04$ & $6.78 \mathrm{E}+03$ & $2.25 E+04$ \\
\hline Pu-242 & $1.64 \mathrm{E}+00$ & $3.01 E+00$ & $5.09 \mathrm{E}-01$ & $1.26 \mathrm{E}+00$ \\
\hline
\end{tabular}


Table 8-4. Example of PWR and BWR CSNF Radionuclide Inventories (Continued)

\begin{tabular}{|c|c|c|c|c|}
\hline Nuclide & $\begin{array}{c}\text { Average PWR } \\
(\mathrm{Ci} / \mathrm{FA})\end{array}$ & $\begin{array}{c}\text { Maximum PWR } \\
(\mathrm{Ci} / \mathrm{FA})\end{array}$ & $\begin{array}{c}\text { Average BWR } \\
(\mathrm{Ci} / \mathrm{FA})\end{array}$ & $\begin{array}{c}\text { Maximum BWR } \\
(\mathrm{Ci} / \mathrm{FA})\end{array}$ \\
\hline Ra-226 & $0.00 \mathrm{E}+00$ & $0.00 \mathrm{E}+00$ & $0.00 \mathrm{E}+00$ & $0.00 \mathrm{E}+00$ \\
\hline Ra-228 & $0.00 \mathrm{E}+00$ & $0.00 \mathrm{E}+00$ & $0.00 \mathrm{E}+00$ & $0.00 \mathrm{E}+00$ \\
\hline Ru-106 & 1.23E-02 & $1.27 \mathrm{E}+04$ & 3.00E-03 & $3.29 E+03$ \\
\hline Sb-125 & $9.71 \mathrm{E}+00$ & $2.05 \mathrm{E}+03$ & $2.89 \mathrm{E}+00$ & $6.21 \mathrm{E}+02$ \\
\hline Se-79 & 4.57E-02 & 6.95E-02 & 1.59E-02 & $2.89 \mathrm{E}-02$ \\
\hline Sm-147 & $0.00 \mathrm{E}+00$ & $0.00 \mathrm{E}+00$ & $0.00 \mathrm{E}+00$ & $0.00 \mathrm{E}+00$ \\
\hline Sm-151 & $2.11 \mathrm{E}+02$ & $3.13 E+02$ & $5.39 \mathrm{E}+01$ & $8.22 \mathrm{E}+01$ \\
\hline Sn-126 & 3.85E-01 & $6.28 \mathrm{E}-01$ & $1.27 \mathrm{E}-01$ & $2.52 \mathrm{E}-01$ \\
\hline Sr-90 & $2.72 \mathrm{E}+04$ & $6.30 \mathrm{E}+04$ & $9.54 \mathrm{E}+03$ & $2.52 \mathrm{E}+04$ \\
\hline Tc-99 & $8.99 \mathrm{E}+00$ & $1.28 \mathrm{E}+01$ & $3.20 \mathrm{E}+00$ & $5.35 \mathrm{E}+00$ \\
\hline Th-229 & $0.00 \mathrm{E}+00$ & $0.00 \mathrm{E}+00$ & $0.00 \mathrm{E}+00$ & $0.00 \mathrm{E}+00$ \\
\hline Th-230 & $1.48 \mathrm{E}-04$ & 3.56E-05 & $6.09 \mathrm{E}-05$ & $2.05 \mathrm{E}-05$ \\
\hline Th-232 & $0.00 \mathrm{E}+00$ & $0.00 \mathrm{E}+00$ & $0.00 \mathrm{E}+00$ & $0.00 \mathrm{E}+00$ \\
\hline U-232 & 2.05E-02 & 5.31E-02 & 4.64E-03 & 2.00E-02 \\
\hline U-233 & 4.07E-05 & 2.42E-05 & 1.14E-05 & $0.00 \mathrm{E}+00$ \\
\hline U-234 & 6.77E-01 & 5.46E-01 & 2.49E-01 & 2.26E-01 \\
\hline U-235 & 7.36E-03 & 4.15E-03 & 2.62E-03 & $9.40 \mathrm{E}-04$ \\
\hline U-236 & 1.72E-01 & 2.24E-01 & 6.26E-02 & 9.55E-02 \\
\hline U-238 & $1.48 \mathrm{E}-01$ & $1.43 \mathrm{E}-01$ & $6.32 \mathrm{E}-02$ & 6.07E-02 \\
\hline Zr-93 & $8.94 \mathrm{E}-01$ & $1.33 \mathrm{E}+00$ & $3.38 \mathrm{E}-01$ & $6.03 \mathrm{E}-01$ \\
\hline
\end{tabular}

Source: CRWMS M\&O 1999a; CRWMS M\&O 1999b.

PWR and BWR source terms for selected fuel assemblies as a function of assembly average burnup and cooling time are calculated using the SAS2H sequence in the SCALE V4.3 computer program (ORNL 1997). The prime functional module of the SAS2H code sequence utilized is the ORIGEN-S code. This code performs a point depletion and decay calculation of a selected fuel type with user-specified irradiation conditions and decay times. The resulting source terms are then extracted from the SAS2H output and used as input to consequence analyses.

\section{Crud Source Term}

Crud is a corrosion product found on the exterior surface of SNF assemblies due to irradiation and imperfect water chemistry control in the reactor coolant system. Crud can be potentially released to the environment in the unlikely event of an accident involving CSNF at the repository. The nuclide species with significant surface activity in crud after decaying for five years are Iron-55 (Fe-55) and Co-60. Table 8-5 lists the initial crud surface activities at the time when fuel assemblies are discharged from a reactor. 
Table 8-5. CSNF Assembly Initial Crud Activities

\begin{tabular}{|l|c|c|}
\hline Radionuclide & PWR $(\mu \mathrm{Ci} / \mathbf{c m} 2)$ & BWR $(\mu \mathbf{C i} / \mathbf{c m} 2)$ \\
\hline Co-60 & 140 & 1254 \\
\hline Fe-55 & 5902 & 7415 \\
\hline
\end{tabular}

Crud surface activities listed in Table 8-5 are bounding estimates based on the analysis of measured crud activity data entitled Commercial SNF Accident Release Fractions (BSC 2003). Crud surface activity for a given assembly is a function of time after discharge from a reactor. Time-dependent crud surface activity is based on the radioactive decay equation Equation 8-1 (CRWMS M\&O 1999a, Section 5.6):

$$
\mathrm{N}(\mathrm{t})=\mathrm{N}(0) \exp \left(-\mathrm{t} * \ln 2 / \mathrm{t}_{1 / 2}\right)
$$

where

$$
\begin{array}{ll}
\mathrm{N}(\mathrm{t}) & =\text { crud activity at time } \mathrm{t}, \\
\mathrm{N}(0) & =\text { crud activity at time } 0, \\
\mathrm{t}_{1 / 2} & =\text { radionuclide half- life in years, and } \mathrm{t} \text { is the decay time in years. }
\end{array}
$$

The crud source term (Ci/FA) released to the environment, on a per assembly basis, is calculated as follows:

$$
S T_{\text {crud }}=S A_{\text {crud }} \times A_{S F A} \times \text { conv }
$$

where

$$
\begin{aligned}
& S T_{\text {crud }}=\text { Crud source term }(\mathrm{Ci} / \mathrm{FA}) \\
& S A_{\text {crud }}=\text { Crud surface activity }\left(\mu \mathrm{Ci} / \mathrm{cm}^{2}\right) \\
& A_{S F A}=\text { Surface area per assembly }\left(\mathrm{cm}^{2} / \mathrm{FA}\right) \\
& \text { conv }=\text { Conversion factor }\left(10^{-6} \mathrm{Ci} / \mu \mathrm{Ci}\right)
\end{aligned}
$$

CSNF assemblies have the following surface areas, $A_{S F A}$ :

$$
\begin{aligned}
& \mathrm{PWR}=449,003 \mathrm{~cm}^{2} / \text { assembly } \\
& \mathrm{BWR}=168,148 \mathrm{~cm}^{2} / \text { assembly }
\end{aligned}
$$

The surface areas calculated for PWR and BWR assemblies are bounding estimates based on two assemblies with the highest known surface areas: a South Texas PWR assembly (CRWMS M\&O 1999a) and an ANF $9 \times 9$ JP-4 BWR assembly (CRWMS M\&O 1999b). 
Category 1-Crud source terms for Category 1 event sequences are based on Average PWR with a 25-year decay time (BSC 2001). Table 8-6 provides examples of Category 1 crud source terms (25-yr decay) using Equation 8-1, Equation 8-2, and CSNF surface areas, $A_{S F A}$.

Table 8-6. Examples of Category 1 Crud Source Terms (25-year decay)

\begin{tabular}{|l|l|}
\hline $25-$ Year Crud Source & $(\mathrm{Ci} / \mathrm{FA})$ \\
\hline Fe-55 PWR & $4.64 \mathrm{E}+00$ \\
\hline Fe-55 BWR & $2.18 \mathrm{E}+00$ \\
\hline Co-60 PWR & $2.35 \mathrm{E}+00$ \\
\hline Co-60 BWR & $7.87 \mathrm{E}+00$ \\
\hline
\end{tabular}

Category 2-Crud source terms for Category 2 event sequences are based on the Maximum PWR fuel with a 5-year decay time. Table 8-7 provides examples of Category 2 crud source terms (5-year decay) using Equation 8-1, Equation 8-2, and CSNF surface areas, $A_{S F A}$.

Table 8-7. Examples of Category 2 Crud Source Terms (5-year decay)

\begin{tabular}{|l|c|}
\hline \multicolumn{1}{|c|}{ 5-year Crud Source } & (Ci/FA) \\
\hline Fe-55 PWR & $7.45 \mathrm{E}+02$ \\
\hline Fe-55 BWR & $3.50 \mathrm{E}+02$ \\
\hline Co-60 PWR & $3.26 \mathrm{E}+02$ \\
\hline Co-60 BWR & $1.09 \mathrm{E}+02$ \\
\hline
\end{tabular}

\subsubsection{DOE Spent Nuclear Fuel}

DOE SNF is shipped in two types of disposable canisters: the DOE standardized canister and the multi-canister overpack (MCO). DOE SNF is received at the repository in transportation casks containing the sealed disposable canisters.

Revision 1 of Interim Staff Guidance No. 5 (ISG-5) (NRC 2003) states that detailed consequence analyses are not necessary for storage casks having closure lids designed and tested to be leak tight as defined in ANSI N14.5-1997. DOE standardized canisters and MCOs are designed and tested to the ANSI N14.5-1997 leak-tight standard. Tests demonstrate that a DOE canister or MCO will not breach after being dropped from a design basis drop height. Because design bases for canister handling and equipment prevent drops from heights greater than the design bases of the canisters, this ensures that drop and breach of a canister is a $\mathrm{BC} 2$ event sequence. Therefore, detailed consequence analyses are not necessary for LA submittal per ISG-5 (NRC 2003). 
In the event that dose calculations must be performed for a $\mathrm{BC} 2$ event sequence (e.g., in support of a seismic risk analysis as described in Section 10.1), realistic source terms need to be generated, as appropriate, for damage states that are defined for particular event sequences. The following considerations are noted:

The National Spent Nuclear Fuel Program is developing average and bounding source terms for over 250 DOE fuel types using a template methodology (INEEL 2003). The bases for the template methodology are templates consisting of radionuclide inventories that are precalculated using validated calculational methodologies for specific reactor types, fuel types, burnups, and decay times. The templates are first segregated by reactor and fuel type, including reactor moderator type, fuel cladding, fuel enrichment, and the beginning-of-life heavy metal constituents. For each reactor and fuel type, a family of templates is developed by parametrically varying burnup and decay times. Each template is based on a depletion calculation with a given set of input conditions and assumptions conservatively mapped to reactor moderator type, fuel type, burnup value, and decay time. After choosing a template family, based on reactor and fuel type, a specific template is selected that bounds the burnup and decay time. Radionuclides in the emplate are then scaled to account for fuel mass and, if necessary burnup, to conservatively estimate the radionuclide inventories for the fuel.

Appropriate release fractions are developed for source terms, fuel types, fuel conditions, and release scenarios.

\subsubsection{Naval Spent Nuclear Fuel}

Source terms for naval SNF is assumed to be crud deposited on fuel assemblies. Crud loading for a naval canister is determined by summing the crud loading of each individual assembly in the canister. A generic approach is used in the PSA for naval SNF in which calculations and measurements from expended cores provide a basis for the amount and composition of the tightly adherent crud layer at the time of shutdown. Each isotope in the crud is decayed based on the time difference between core shutdown and emplacement in the repository. The calculated bounding crud loading for a naval canister is based on information provided by the Navy and is reproduced in Table 8-8.

\subsubsection{Vitrified High-Level Radioactive Waste}

Vitrified HLW forms from the Savannah River Site, the Hanford Site, West Valley, and the Idaho National Engineering and Environmental Laboratory, are received at the repository in sealed HLW canisters inside transportation casks.

Revision 1 of ISG-5 (NRC 2003) states that detailed consequence analyses are not necessary for storage casks having closure lids designed and tested to be leak tight as defined in ANSI N14.51997. DOE standardized canisters and MCOs are designed and tested to the ANSI N14.5-1997 leak-tight standard. Tests demonstrate that a DOE canister or MCO will not breach after being dropped from a design basis drop height. Because design bases for canister handling and equipment prevent drops from heights greater than the design bases of the canisters, this ensures that drop and breach of a canister is a BC2 event sequence. Therefore, detailed consequence analyses are not necessary for LA submittal per ISG-5 (NRC 2003). 
Post-irradiated isotopic concentrations for HLW forms may be obtained from the Savannah River Site, the Hanford Site, West Valley, and the Idaho National Engineering and Environmental Laboratory as shown in Table 8-8. Prior analyses (CRWMS M\&O 1999c, Attachment VI) compiled source term and release scenario data for application in the Project site recommendation public and worker dose calculations for which appropriate release fractions will be developed.

Table 8-8. Radionuclide Content of HLW Canisters

\begin{tabular}{|c|c|c|c|c|}
\hline Isotope & SRS (Ci) & Hanford (Ci) & West Valley (Ci) & INEEL (Ci) \\
\hline Ac-227 & $0.00 \mathrm{E}+00$ & $0.00 \mathrm{E}+00$ & 9.07E-03 & $0.00 \mathrm{E}+00$ \\
\hline Am-241 & $2.28 \mathrm{E}+01$ & $5.72 \mathrm{E}+02$ & $2.10 \mathrm{E}+02$ & $2.61 \mathrm{E}+00$ \\
\hline Am-242m & $0.00 \mathrm{E}+00$ & $0.00 \mathrm{E}+00$ & 1.23E+00 & $0.00 \mathrm{E}+00$ \\
\hline $\mathrm{Am}-243$ & $0.00 \mathrm{E}+00$ & $0.00 \mathrm{E}+00$ & $1.36 \mathrm{E}+00$ & $0.00 \mathrm{E}+00$ \\
\hline Cd-113m & $0.00 \mathrm{E}+00$ & $1.18 \mathrm{E}+01$ & $6.75 \mathrm{E}+00$ & $0.00 \mathrm{E}+00$ \\
\hline Ce-144 & $1.16 \mathrm{E}+02$ & $3.50 \mathrm{E}+02$ & $0.00 \mathrm{E}+00$ & $1.23 \mathrm{E}+02$ \\
\hline $\mathrm{Cm}-243$ & $0.00 \mathrm{E}+00$ & $0.00 \mathrm{E}+00$ & 4.67E-01 & $0.00 \mathrm{E}+00$ \\
\hline $\mathrm{Cm}-244$ & $8.89 \mathrm{E}+01$ & $1.03 \mathrm{E}+01$ & $2.48 \mathrm{E}+01$ & 5.48E-01 \\
\hline Co-60 & $8.80 \mathrm{E}+01$ & $0.00 \mathrm{E}+00$ & $1.57 \mathrm{E}+00$ & $0.00 \mathrm{E}+00$ \\
\hline Eu-154 & $4.14 \mathrm{E}+02$ & $2.24 \mathrm{E}+02$ & $2.51 \mathrm{E}+02$ & $1.54 \mathrm{E}+02$ \\
\hline Eu-155 & $2.40 \mathrm{E}+02$ & $0.00 \mathrm{E}+00$ & $0.00 \mathrm{E}+00$ & $0.00 \mathrm{E}+00$ \\
\hline Np-237 & $0.00 \mathrm{E}+00$ & 2.00E-01 & 9.22E-02 & $0.00 \mathrm{E}+00$ \\
\hline $\mathrm{Pa}-231$ & $0.00 \mathrm{E}+00$ & $0.00 \mathrm{E}+00$ & 5.97E-02 & $0.00 \mathrm{E}+00$ \\
\hline Pm-147 & $6.46 \mathrm{E}+03$ & $1.06 \mathrm{E}+04$ & $0.00 \mathrm{E}+00$ & $4.09 \mathrm{E}+03$ \\
\hline Pu-238 & $1.43 \mathrm{E}+03$ & 7.40E-01 & $3.14 \mathrm{E}+01$ & $8.60 \mathrm{E}+01$ \\
\hline Pu-239 & $1.29 \mathrm{E}+01$ & $1.41 \mathrm{E}+00$ & $6.38 \mathrm{E}+00$ & 8.92E-01 \\
\hline Pu-240 & $8.70 \mathrm{E}+00$ & $5.46 \mathrm{E}-01$ & $4.67 \mathrm{E}+00$ & 8.27E-01 \\
\hline $\mathrm{Pu}-241$ & 1.32E+03 & $2.03 E+01$ & $2.50 \mathrm{E}+02$ & $1.61 \mathrm{E}+02$ \\
\hline Th-228 & $0.00 \mathrm{E}+00$ & $0.00 \mathrm{E}+00$ & 3.43E-02 & $0.00 \mathrm{E}+00$ \\
\hline U-232 & $0.00 \mathrm{E}+00$ & $0.00 \mathrm{E}+00$ & 2.68E-02 & $0.00 \mathrm{E}+00$ \\
\hline I-129 & $0.00 \mathrm{E}+00$ & 1.63E-05 & $0.00 \mathrm{E}+00$ & $0.00 \mathrm{E}+00$ \\
\hline Cs -134 & $6.28 \mathrm{E}+01$ & $2.23 \mathrm{E}+02$ & $3.78 \mathrm{E}+00$ & $7.85 \mathrm{E}+02$ \\
\hline Cs -137 & $3.87 \mathrm{E}+04$ & $4.54 \mathrm{E}+04$ & $2.52 \mathrm{E}+04$ & $1.48 \mathrm{E}+04$ \\
\hline Ru-106 & $7.40 \mathrm{E}+01$ & $1.64 \mathrm{E}+02$ & 1.82E-03 & 4.07E+01 \\
\hline Sr-90 & $4.28 \mathrm{E}+04$ & $3.82 \mathrm{E}+04$ & $2.41 \mathrm{E}+04$ & $1.52 \mathrm{E}+04$ \\
\hline Y-90 & $4.28 \mathrm{E}+04$ & $3.82 \mathrm{E}+04$ & $2.41 \mathrm{E}+04$ & $1.52 \mathrm{E}+04$ \\
\hline
\end{tabular}

Source: DOE High-Level Vitrified Waste Dose Calculation (CRWMS M\&O 1999d), page III-1.

\subsubsection{Source Terms for Mixed-Oxide Waste Forms}

Appropriate source terms are developed should waste-stream characteristics encompass mixedoxide SNF or other waste forms that contain actinides. 


\subsubsection{Meteorological Data and Site Boundary Distance for Determination of Atmospheric Dispersion Factors}

Atmospheric dispersion factors are calculated internally from input of hourly meteorological data, from year 1998 through 2002 gathered at the Yucca Mountain site, to the MACCS2 code. Output from MACCS2 is a mean, 50-percentile, 95-percentile, or 99.5-percentile, value of the atmospheric dispersion factor, which is evaluated at a given site boundary distance. The current design of surface facilities includes more than one location and building for waste handling operations, which affects site boundary distances. Similarly, current design concepts for the subsurface repository footprint and ventilation designs also affect site boundary distances. The PSA will apply site boundary parameters established by the DOE before the LA is submitted to the NRC.

For example, site boundary distances of 8 kilometers for subsurface releases and 11 kilometers for surface releases were used in previous analyses, based on the location of a single dry transfer facility that defined the minimal distance to the site boundary (DTN: MO0001YMP00001.00). The site boundary distance of 11 kilometers corresponds to the distance from the dry transfer facility ventilation exhaust shaft to the nearest point of public access (determined to be the Project Withdrawal Area boundary to the West); the distance was used to calculate atmospheric dispersion factors due to radiological releases from the surface facility. Similarly, the site boundary distance of 8 kilometers was used to calculate atmospheric dispersion factors, due to radiological releases from the subsurface repository, having a distance that corresponded to the approximate distance between the ventilation shaft opening at the surface and the nearest point of public access.

Airborne releases from normal operations and from Category 1 event sequences that are to be aggregated (i.e., frequency weighted to obtain annualized releases) are modeled as "chronic" releases. The chronic exposure is based on the annual average, best-estimate exposure at the site boundary, in accordance with Regulatory Guide 1.111. On the other hand, releases for single Category 1 event sequences and for Category 2 event sequences are modeled as "acute" releases. The acute exposure atmospheric dispersion factor is based on a 2-hour exposure at the respective site boundary distances defined for surface and subsurface operations in accordance with Regulatory Guide 1.145. Ground- level releases are conservatively assumed in either the acute or chronic exposures.

\subsubsection{Dose Conversion Factors}

For dose calculations for Category 1 and Category 2 event sequences, inhalation DCFs are derived by the MACCS2 code based on the dosimetric methodology from International Commission on Radiological Protection Publication 30 (ICRP 1979).

DCFs for inhalation are dependent on the chemical form of the radionuclide, which is represented by the lung clearance class $(\mathrm{D}=$ daily, $\mathrm{W}=$ weekly, $\mathrm{Y}=$ yearly) and the fractional uptake from the small intestine to blood (f1). Some isotopes have only one lung clearance class (e.g., H-3), whereas others have multiple lung clearance classes (e.g., Pu-239). For the inhalation dose assessment of radionuclides with multiple lung clearance classes, the lung clearance class corresponding $\mathbf{b}$ the oxide form of the radionuclide (Eckerman et al. 1988) is 
assumed. The inhalation DCFs utilized for the dose assessment are from Table 2.1 of Federal Guidance Report No. 11 (Eckerman et al. 1988). The air submersion DCFs for gonads, breast, lungs, red marrow, bone surface, thyroid, remainder, effective (i.e., whole body), and skin for the dose assessment are taken from Table III.1 of Federal Guidance Report No. 12 (Eckerman and Ryman 1993). The remainder category is a weighted combination of the five remaining organs or tissues (e.g., liver, kidneys, spleen, and brain, but excluding skin, lens of the eye, and the extremities) receiving the highest doses (Eckerman et al. 1988).

\subsubsection{Radionuclide Release Fractions}

Although a given waste form may contain a significant quantity of radioactive material, only a small fraction of the total inventory is able to become airborne during the types of credible preclosure event sequences. The various waste forms exhibit different release characteristics and different approaches are used to estimate the fraction of airborne release from the various waste forms. The following sections describe the bases and approaches for estimating release fractions.

\subsubsection{Commercial Spent Nuclear Fuel Release Fractions}

The Category 1 and Category 2 event sequence total release fraction is defined as the fraction of total inventory of a given radionuclide that is released to the environment from a CSNF element following an event sequence (e.g., drop of a fuel element). The release fraction for CSNF is primarily a measure of the inventory of fuel particulates, gases, and volatile species present in a breached fuel element.

The total release fraction for calculating the source term released from Category 1 event sequences is a function of the cladding damage fraction (DF), cladding release fraction (CR), airborne release fraction (ARF), respirable fraction (RF), and the local deposition factor (DEP):

$$
\text { Total Release Fraction }=\mathrm{DF} \times \mathrm{CR} \times \mathrm{ARF} \times \mathrm{RF} \times \mathrm{DEP} \times \mathrm{MF}
$$

The DF is the fraction of fuel rods that are assumed to fail by cladding breach during an event sequence. The CR is the fraction of the total radionuclide inventory in the gap between fuel elements and cladding. The ARF is the fraction of the total radionuclide inventory in damaged fuel rods that is released from breached cladding and is suspended in air as an aerosol following an event. The RF is the fraction of airborne radionuclide particles having an aerodynamic equivalent diameter of $10 \mu \mathrm{m}$ and less, which can be transported through air, inhaled into the human respiratory system, and contributes to the inhalation dose. The DEP is the fraction of the ARF that reaches the ventilation system after local deposition (i.e., plate-out and gravitational settling) within the waste handling building. The mitigation factor (MF) is the fraction of radionuclides that is released to the environment after escaping from the high efficiency particulate air (HEPA) filters in the ventilation system of the Dry Transfer Facility \#1 or Dry Transfer Facility \#2 (see Section 8.2.5).

For Category 1 and Category 2 event sequences, the DF, CR, and DEP are assumed to be unity. This is a conservative assumption since each of these factors is expected to provide some degree of radionuclide release mitigation. 
For CSNF releases in air, ARF, and RF parameters (BSC 2002) for the Category 1 and Category 2 inhalation dose assessment are shown in Table 8-9, based on Commercial SNF Accident Release Fractions (BSC 2003). For the Category 1 and Category 2 ingestion dose assessment, an RF of 1.0 is conservatively assumed, which means that all particle sizes are included in the dose calculation for the ingestion pathway. Particle sizes larger than respirable sizes could deposit on the ground and contribute to radiation doses through the ingestion pathway (i.e., human consumption of crops, fruits, and vegetables grown on the contaminated soil).

For events occurring in a spent fuel pool, an ARF equal to zero $(A R F=0)$ is assumed for all particulate and volatile species. In these events, only the noble gases are released from the pool.

Table 8-9. Respirable Release Fractions for CSNF

\begin{tabular}{|l|c|c|c|c|c|}
\hline \multirow{2}{*}{ Radionuclide } & \multicolumn{5}{|c|}{$\begin{array}{c}\text { Airborne Release Fraction (ARF) / } \\
\text { Respirable Fraction (RF) }\end{array}$} \\
\cline { 2 - 6 } & $\begin{array}{c}\text { Category 1: } \\
\text { Mechanical/ } \\
\text { Cladding } \\
\text { Damaged }\end{array}$ & $\begin{array}{c}\text { Category 2: } \\
\text { Consolidated/ } \\
\text { Reconstituted }\end{array}$ & $\begin{array}{c}\text { Category 3a: } \\
\text { Fuel Rods with } \\
\text { Intact Cladding }\end{array}$ & $\begin{array}{c}\text { Category 3b: } \\
\text { Other Fuel } \\
\text { Rods, Pieces, } \\
\text { and Debris }\end{array}$ & Intact CSNF \\
\hline${ }^{3} \mathrm{H}$ & $0.3 / 1.0$ & $0.3 / 1.0$ & $0.3 / 1.0$ & $0.3 / 1.0$ & $0.3 / 1.0$ \\
\hline${ }^{85} \mathrm{Kr}$ & $0.3 / 1.0$ & $0.3 / 1.0$ & $0.3 / 1.0$ & $0.3 / 1.0$ & $0.3 / 1.0$ \\
\hline${ }^{129} \mathrm{I}$ & $0.3 / 1.0$ & $0.3 / 1.0$ & $0.3 / 1.0$ & $0.3 / 1.0$ & $0.3 / 1.0$ \\
\hline $\begin{array}{l}{ }^{134} \mathrm{Cs} \& \\
{ }^{137} \mathrm{Cs} \text { (v) }\end{array}$ & $2.0 \mathrm{E}-04 / 1.0$ & $2.0 \mathrm{E}-04 / 1.0$ & $2.0 \mathrm{E}-04 / 1.0$ & $2.0 \mathrm{E}-04 / 1.0$ & $2.0 \mathrm{E}-04 / 1.0$ \\
\hline $\begin{array}{l}{ }^{134} \mathrm{Cs} \& \\
{ }^{137} \mathrm{Cs}(\mathrm{p})\end{array}$ & 0 & 0 & 0 & 0 & 0 \\
\hline${ }^{90} \mathrm{Sr}$ & $3.0 \mathrm{E}-05 / 5.0 \mathrm{E}-03$ & $3.0 \mathrm{E}-05 / 5.0 \mathrm{E}-03$ & $5.8 \mathrm{E}-07 / 1.0^{\mathrm{a}}$ & $5.8 \mathrm{E}-07 / 1.0^{\mathrm{a}}$ & $3.0 \mathrm{E}-05 / 5.0 \mathrm{E}-03$ \\
\hline${ }^{106} \mathrm{Ru}$ & $2.0 \mathrm{E}-04 / 1.0$ & $2.0 \mathrm{E}-04 / 1.0$ & $2.0 \mathrm{E}-04 / 1.0^{\mathrm{a}}$ & $2.0 \mathrm{E}-04 / 1.0^{\mathrm{a}}$ & $2.0 \mathrm{E}-04 / 1.0$ \\
\hline Fuel Fines & $3.0 \mathrm{E}-05 / 5.0 \mathrm{E}-03$ & $3.0 \mathrm{E}-05 / 5.0 \mathrm{E}-03$ & $5.9 \mathrm{E}-07 / 1.0^{\mathrm{a}}$ & $5.8 \mathrm{E}-07 / 1.0^{\mathrm{a}}$ & $3.0 \mathrm{E}-05 / 5.0 \mathrm{E}-03$ \\
\hline $\mathrm{Crud}$ & $1.5 \mathrm{E}-02 / 1.0^{\mathrm{b}}$ & $1.5 \mathrm{E}-02 / 1.0^{\mathrm{b}}$ & $1.5 \mathrm{E}-02 / 1.0^{\mathrm{b}}$ & $1.5 \mathrm{E}-02 / 1.0^{\mathrm{b}}$ & $1.5 \mathrm{E}-02 / 1.0^{\mathrm{b}}$ \\
\hline
\end{tabular}

a These values assume a cask drop from 80 inches $(203.2 \mathrm{~cm})$ for fuel fine and particulate $(p)$ release fractions.

b The crud ARF/RF values are bounding values. RF is conservatively assumed to be 1.0 .

\subsubsection{Naval Spent Nuclear Fuel Release Fractions}

ARFs and RFs for naval SNF for Category 1 and Category 2 event sequences are provided by the U.S. Navy. No credit is taken for a reduction in naval SNF source terms (crud only) due to retention of radionuclides in canisters.

\subsubsection{DOE SNF Release Fractions}

As noted in Section 8.2.1.3, detailed dose calculations will not be required for demonstrating compliance to regulations for Category 1 or Category 2 event sequences because breach of the DOE SNF canisters will be demonstrated to be non-credible. Should the need arise to evaluate the dose consequences of some BC2 event sequence(s) (e.g., to support a limited seismic risk analysis), then release fractions will have to be developed. 


\subsubsection{Vitrified High-Level Waste Release Fractions}

The formation of particulates from an impact breach of an HLW canister is based on Airborne Release Fractions at Non-Reactor Nuclear Facilities (ANSI/ANS-5.10-1998, p. 15). The results are based on empirical measurements of impact tests on $\mathrm{UO}_{2}$, ceramic, and glass- simulated waste forms. Small-scale established correlations for the percentage of respirable size fractions created during impacts. This method used the available results to develop a method to estimate the fractions of HLW canister glass that could be released as airborne particulates.

Based on the methods discussed above, the fraction of respirable airborne particulates or PULF formed following an impact can be estimated as follows:

$$
P U L F=2 E-4 \mathrm{~cm} 3 / \mathrm{Joule} * E / V
$$

where

$$
\begin{aligned}
& \text { PULF }=\quad \text { fraction pulverized into respirable sizes }(\leq \mu \mathrm{m}) \text { from a drop event } \\
& \text { (units }=\text { dimensionless) } \\
& \mathrm{E} / \mathrm{V}=\quad \text { impact energy density in impacted fuel, } ? * \mathrm{~g} * \mathrm{~h} \\
& =\quad 1.0(\text { see CRWMS M\&O 1999d, Section 5.2.7) }
\end{aligned}
$$

where

$$
\begin{array}{rll}
? & = & \text { density of the fuel dropped } \\
\mathrm{g} & = & 2.75 \mathrm{~g} / \mathrm{cm}^{3} \text { (see CRWMS M\&O 1999d, Section 5.2.7) } \\
& = & \text { gravitational constant } \\
& = & 980.7 \mathrm{~cm} / \mathrm{s}^{2} \text { (see CRWMS M\&O 1999d; Attachment V) }
\end{array}
$$

\subsubsection{PULF for HLW Canister Drop}

From Equation 8-4:

$$
\begin{aligned}
\mathrm{PULF}= & 2 \mathrm{E}-4 \mathrm{~cm}^{3} / \mathrm{J} * 2.75 \mathrm{~g} / \mathrm{cm}^{3} * 980.7 \mathrm{~cm} / \mathrm{s}^{2} * 1 \mathrm{E}-7 / \text { dyne }-\mathrm{cm} \\
& * 1 \text { dyne }-\mathrm{cm}-\mathrm{s}^{2} / \mathrm{g}-\mathrm{cm}^{2} *(\text { drop height }) \mathrm{cm}
\end{aligned}
$$

Calculated PULF fractions for selected drop heights are listed below:

$\begin{array}{cc}\text { Drop Height } & \text { PULF Fraction } \\ 80 \text { inches } / 203 \mathrm{~cm} & 1.10 \mathrm{E}-05 \\ 264 \text { inches } / 671 \mathrm{~cm} & 3.62 \mathrm{E}-05 \\ 330 \text { inches } / 838 \mathrm{~cm} & 4.52 \mathrm{E}-05 \\ 448 \text { inches } / 1138 \mathrm{~cm} & 6.14 \mathrm{E}-05\end{array}$




\subsubsection{Mitigation Factor}

The mitigation factor refers to the mitigation of particulates provided by high-efficiency particulate air (HEPA) filters that are present in the Dry Transfer Facility ventilation system. A mitigation factor, usually on the order of 0.0001 , is applied to particulate releases to calculate offsite doses. The mitigation factor selected is justified to be appropriate to the system that will be part of the design bases that supports LA. For example, the system may include a HEPA filtration system that contains a pre-filter and two HEPA filter banks. Each HEPA filter bank is assumed to have a particulate removal efficiency of 99 percent, which is consistent with the NRC-recommended credit for accident dose evaluations in Regulatory Guide 1.140 and Regulatory Guide 1.52 .

If credit for the mitigation factor is necessary to demonistrate complience with 10 CFR 63.111 for either Category 1 or Category 2 event sequences, or both, then the HEPA bank and associated ventilation systems will have to be designated as important to safety. If so, and because compliance does not require credit for the mitigation factor, then the HEPA bank and associated ventilation systems will be considered a non-safety category. The high reliability expected for the ventilation system of the Dry Transfer Facility event sequences that involve a potential failure of the ventilation system is expected to be BC2 event sequences.

\subsection{CALCULATIONS OF DOSES TO WORKERS AND MEMBERS OF THE PUBLIC FROM CATEGORY 1 EVENT SEQUENCES FROM AIRBORNE RELEASES AND EXPOSURES TO DIRECT RADIATION}

For Category 1 event sequences, 10 CFR 63.111 requires evaluation of doses to the public (offsite) and to workers (onsite). Doses received from Category 1 event sequences may derive from airborne releases due to a breach of the confinement barrier(s) of a waste form, or from direct exposures from direct exposures that might occur if an abnormality occurs during waste form handing operations. This section describes the methods (computer codes) and aggregation approach used to calculate doses for Category 1 event sequences. Section 8.4 describes the approach used to calculate doses for Category 2 event sequences.

\subsubsection{Calculations of Doses to Workers and Members of the Public from Airborne Radionuclides}

Section 8.3.1.1 describes computer codes used to calculate potential doses to onsite workers and members of the public from airborne radionuclides as a result of normal operations and Category 1 event sequences. The input parameters used in the dose calculations are presented in Section 8.2. Section 8.3.1.2 discusses the uncertainty analysis for Category 1 dose analyses.

\subsubsection{Computer Codes Used in Dose Calculations for Normal Operations and Category 1 Event Sequences}

MACCS2-Doses to a maximally exposed individual at the repository site boundary due to Category 1 event sequences (and Category 2 event sequences), as well as normal operational releases, are calculated using the MACCS2 (ORNL 1998) computer code (MELCOR Accident Consequence Code System for the Calculation of the Health and Economic Consequences of Accidental Atmospheric Radiological Releases). A maximally exposed individual is an 
individual who is located at a distance that corresponds to the approximate distance between the surface facility or the subsurface repository and the nearest point of public access on the Yucca Mountain Project. Dose calculations consider potential exposure pathways, including inhalation, ingestion, air submersion, and groundshine.

The MACCS2 computer code simulates the impact of accidental atmospheric releases of radiological materials on the surrounding environment. The principal phenomena considered in MACCS2 are atmospheric transport, mitigative actions based on dose projection, dose accumulation by a number of pathways including food and water ingestion, early and latent health effects, and economic costs. MACCS2 contains simple models with analytical solutions. An MACCS2 calculation consists of three phases: input processing and validation, phenomenological modeling, and output processing. The phenomenological models are based mostly on empirical data, and the solutions they entail are usually analytical in nature and computationally straightforward. The modeling phase is divided into three modules: the ATMOS, EARLY, and CHRONC modules. The ATMOS module treats atmospheric transport and dispersion of material and its deposition from the air utilizing a Gaussian plume model with Pasquill-Gifford dispersion parameters. The EARLY module models consequences of the accident to the surrounding area during an emergency action period. The CHRONC module considers the long-term impact in the period subsequent to the emergency action period.

As noted in Section 8.2, meteorological data are input to the MACCS code. Appropriate atmospheric dispersion factors are calculated internally in the code according to whether the calculation is for chronic releases (normal operations and Category 1 event sequences that will be aggregated) or for acute releases (single event sequences, either Category 1 or 2).

Airborne releases from normal operations and from Category 1 event sequences that are to be aggregated (i.e., frequency weighted to obtain annualized releases) are modeled as "chronic" releases. The chronic exposure is based on the annual average best-estimate exposure at the site boundary, in accordance with Regulatory Guide 1.111. On the other hand, releases for single Category 1 event sequences and for Category 2 event sequences are modeled as "acute" releases. The acute exposure atmospheric dispersion factor is based on a 2-hour exposure at the respective site boundary distances defined for surface and subsurface operations in accordance with Regulatory Guide 1.145. Ground-level releases are conservatively assumed in either acute or chronic exposures.

Meteorological, population, and economic and health data are required depending upon the type of analyses to be performed and output required. Model parameters can be provided by the user via input facilitating the analysis of consequence uncertainties due to uncertainties in the model parameters.

ARCON96- This computer program is used to calculate the atmospheric dispersion factors for facility workers who are located less than 100 meters away from the point of Category 1 event sequence releases. The ARCON96 (Ramsdell and Simonen 1997) computer program was developed to calculate relative concentrations in plumes from nuclear power plants at control room air intakes in the vicinity of the release point. ARCON96 implements a straight-line Gaussian dispersion model with dispersion coefficients that are modified to account for low wind meander and building wake effects. Hourly, atmospheric dispersion factors $(\chi / Q)$ are calculated 
from hourly meteorological data. The hourly values are averaged to form atmospheric dispersion factors for periods ranging from 2 to 720 hours in duration. The calculated values for each period are used to form cumulative frequency distributions.

\subsubsection{Uncertainty Analysis}

Consequence analysis performed for normal operational releases and Category 1 event sequences uses either average or best-estimate input parameter values. The reasons for using average or best-estimate values are because normal operations and Category 1 event sequences are expected to occur several times a year. Therefore, each consequence analysis input parameter includes an average value that represents a waste form with different burnup values, a range of waste form damage conditions, or a range of weather conditions over a one-year period. For example, average source terms, annual average, best-estimate atmospheric dispersion factors, best-estimate release fractions, and best-estimate annual food consumption rates for a real member of the public are used for Category 1 event sequences. For these reasons, uncertainty analysis is not performed for normal operational releases and Category 1 event sequences.

\subsubsection{Calculation Doses to Members of the Public and Workers from Normal Operations and Category 1 Event Sequences}

The regulatory requirements for Category 1 event sequences are summarized in Section 8.1. As noted, doses from normal operations and Category 1 event sequences are aggregated and evaluated against annual limits. This section describes how the results of the computer analysis for individual sequences are combined (frequency weighted) to calculate the annualized doses.

\subsection{Doses to Members of the Public - Category 1 Airborne Releases}

The total Category 1 annual dose is based on contributions from three sources: Category 1 event sequences, normal operational (routine) releases from surface facilities, and normal operational releases from the subsurface repository. The total Category 1 annual dose (mrem/yr) is generally described by the following equation:

$$
D_{C a t .1}^{T O T}=D_{C a t .1}+D_{N O}^{D F}+D_{N O}^{S u b}
$$

where
$D_{\text {Cat. } 1}=\quad$ Annual dose due to all Category 1 event releases $(\mathrm{mrem} / \mathrm{yr})$
$D_{N O}^{D F} \quad=\quad$ Annual dose due to normal operational releases from the surface facilities (mrem/yr)
$D_{N O}^{S u b}=$ Annual dose due to normal operational releases from the subsurface repository $(\mathrm{mrem} / \mathrm{yr})$ 
$D_{C a t .1}, D_{N O}^{D F}$, and $D_{N O}^{S u b}$ are calculated using MACCS2 (ORNL 1998). Radiological release (Ci/yr) estimates for each of these three components are input to MACCS2 dose calculations.

Example of Calculating Normal Releases-The term $D_{N O}^{D F}$ represents the annual dose due to normal operational releases from surface facilities. In principle, releases from each operational building of radiological species represented in the source terms is estimated, combined, and input to the MACCS code. However, the total release from surface facilities is estimated to be about 4,010 curies per year and is expected to be entirely $\mathrm{Kr}-85$ released from the waste handling building(s). This release was estimated based on the postulated failure of PWR and BWR SNF assemblies during normal handling operations (CRWMS M\&O 2000a). The (low-level) Waste Treatment Building is not expected to generate significant radiological emissions, based on current best-available information (CRWMS M\&O 2000a).

The term $D_{N O}^{S u b}$ represents the annual dose due to normal operational releases from the subsurface repository. Normal releases from subsurface facilities are more complex than are releases from surface facilities. For example, results of an analysis based on the postulated activation of air and dust in subsurface facilities during normal operations (CRWMS M\&O 2000b) are shown in Table 8-9. Subsurface releases are due to radionuclides generated by activation of air (Ar-41 and $\mathrm{N}-16$ ) and dust (N-16, Na-24, Al-28, Si-31, K-42 and Fe-55). Ni-16, Al-28, and K-42 are not included in the example because their releases and half-lives are so small that their annual offsite dose contributions are insignificant. Fe-55 is the only subsurface radionuclide released that has a half life measured in years $(2.73)$, but its total curie release $\left(1.492 \times 10^{-4}\right)$ is viewed as being insignificant compared to curie releases from Category 1 event sequences (BSC 2001, Attachment IX).

Table 8-9. Example of Annual Releases from the Subsurface Due to Normal Operations

\begin{tabular}{|l|l|l|}
\hline \multicolumn{2}{|c|}{$\begin{array}{l}\text { Routine Release - } \\
\text { Subsurface (Ci/yr) }\end{array}$} & Half Life ( $\left.\mathbf{T}_{\mathbf{1 / 2}}\right)$ \\
\hline Activated Air & \\
\hline $\mathrm{N}-16$ & $2.909 \mathrm{E}-3$ & $7.13 \mathrm{sec}$ \\
\hline Ar-41 & $5.728 \mathrm{E}+1$ & $1.82 \mathrm{hr}$ \\
\hline Activated Dust & \\
\hline $\mathrm{N}-16$ & $1.189 \mathrm{E}-8$ & $7.13 \mathrm{sec}$ \\
\hline $\mathrm{Na}-24$ & $6.471 \mathrm{E}-3$ & $14.96 \mathrm{hr}$ \\
\hline Al-28 & $3.963 \mathrm{E}-3$ & $2.25 \mathrm{~min}$ \\
\hline Si-31 & $7.170 \mathrm{E}-4$ & $2.62 \mathrm{hr}$ \\
\hline K-42 & $8.041 \mathrm{E}-4$ & $12.36 \mathrm{hr}$ \\
\hline Fe-55 & $1.492 \mathrm{E}-4$ & $2.73 \mathrm{yr}$ \\
\hline
\end{tabular}

Example of Calculating Annualized Releases from Category 1 Event Sequences - The term $D_{\text {Cat. } 1}$ represents the annual dose due to Category 1 releases. The analytic approach is to develop annualized source terms for radionuclides that are potentially significant contributors to dose. Dose is calculated using MACCS code and annualized (frequency-weighted) source terms for 
each radionuclide. The annual release due to Category 1 event sequences is calculated using the following equation:

$$
R_{D B E s}^{T O T}=\sum_{i=1}^{n} R_{i} \cdot f_{i}
$$

where

$\begin{array}{lll}I & = & \text { Index for a given Category } 1 \text { event sequence }(\mathrm{i}=1,2, \ldots \mathrm{n}) \\ n & = & \text { Total number of Category } 1 \text { event sequences } \\ R_{i} & = & \text { Radiological releases due to event sequence } \mathrm{i}(\mathrm{Ci} / \mathrm{event}) \\ f_{i} & = & \text { Frequency of event sequence } \mathrm{i} \text { (events/yr) }\end{array}$

For illustration purposes, Table 8-10 uses Category 1 event frequency calculations in BSC 2001 (p. VII-5). For LA submittal, current Category 1 event sequences developed by the methods outlined in Section 7 will be defined and employed in the dose aggregation process. In Table 810 for example, Category 1 event releases are calculated based on event frequencies (events per year) and event source terms (Ci/event) as described in BSC 2001 (Attachments VII and VIII, respectively). The source term for each Category 1 event sequence is annualized by multiplying the expected release of each radionuclide that is released by the event frequency, as indicated in Equation 8-6. An example of annualized release calculations is shown in Table 8-10 for Cesium137 (Cs-137).

Table 8-10. Example of Calculating Annualized Cesium-137 Release for Category 1 Event Sequences

\begin{tabular}{|c|c|c|c|}
\hline $\begin{array}{c}\text { Event No. } \\
(\mathbf{1})\end{array}$ & $\begin{array}{c}\text { Frequency } \\
\text { (events/yr) } \\
(\mathbf{2})\end{array}$ & $\begin{array}{c}\text { Source Term } \\
\text { (Ci/event) } \\
(\mathbf{3})\end{array}$ & $\begin{array}{c}\text { Annualized } \\
\text { Release (Ci/yr) } \\
\mathbf{( 2 )} \times \mathbf{( 3 )}\end{array}$ \\
\hline $1-01$ & $2.34 \mathrm{E}-01$ & 0 & 0 \\
\hline $1-02$ & $3.90 \mathrm{E}-02$ & 0 & 0 \\
\hline $1-03$ & $4.22 \mathrm{E}-02$ & 0 & 0 \\
\hline $1-04$ & $1.92 \mathrm{E}-01$ & 0 & 0 \\
\hline $1-05$ & $4.10 \mathrm{E}-02$ & 0 & 0 \\
\hline $1-06$ & $4.10 \mathrm{E}-02$ & 0 & 0 \\
\hline $1-07$ & $4.10 \mathrm{E}-02$ & 0 & 0 \\
\hline $1-08$ & $4.10 \mathrm{E}-02$ & 0 & 0 \\
\hline $1-09$ & $4.10 \mathrm{E}-02$ & 0 & $1.35 \mathrm{E}-02$ \\
\hline $1-10$ & $4.10 \mathrm{E}-02$ & $3.29 \mathrm{E}-01$ & $2.70 \mathrm{E}-02$ \\
\hline $1-11$ & $4.10 \mathrm{E}-02$ & $6.59 \mathrm{E}-01$ & $3.85 \mathrm{E}-02$ \\
\hline $1-12$ & $2.34 \mathrm{E}-01$ & $1.65 \mathrm{E}-01$ & $1.93 \mathrm{E}-02$ \\
\hline $1-13$ & $2.34 \mathrm{E}-01$ & $8.25 \mathrm{E}-02$ & $3.85 \mathrm{E}-02$ \\
\hline $1-14$ & $2.34 \mathrm{E}-01$ & $1.65 \mathrm{E}-01$ & $1.37 \mathrm{E}-01$ \\
\hline Total & & &
\end{tabular}




\subsection{Dose to Involved and Non-Involved Workers - Category 1 Airborne Releases}

The expected annual dose to an involved worker within a radiation area and a non-involved worker (a worker located 100 meters from the release point and in outside a radiation area) is calculated for Category 1 event releases, including normal operational releases from surface and subsurface facilities.

Calculation of involved worker doses is performed by the Nuclear Engineering group with support of specialists in design engineering and ALARA. Calculations estimate the annual individual and collective doses to workers for each facility area, system, or process involving radioactive material or radiation exposure on site. Dose calculations for the non-involved worker assumes that a single worker receives a chronic exposure at a distance of 100 meters from the release point from potential Category 1 event sequences and normal operational releases in a single year. The methodology for direct radiation exposure is described in Section 8.3.2.1 and the methodology for airborne releases is described in Section 8.3.1.1. Dose calculations are documented in accordance with governing procedures.

Inputs to consequence analyses include radiological conditions identified in facility areas during normal operations, and specification of the number of personnel present and their time of exposure to normal operations. In addition, the PSA group defines radiological conditions in facility areas that result from Category 1 event sequences that are input to the analyses, as discussed in Section 8.3.2.2.

No credit is taken for worker training, administrative controls, or emergency response procedures to minimize worker exposures to Category 1 event sequences. In general, the annualized worker doses are based on the following assumptions:

- $\quad$ Chronic exposure over a period of one year.

- $\quad$ Frequency weighted dose contributions from Category 1 event sequences.

- Only inhalation and submersion pathways are considered. Ingestion and ground contamination pathways are not included because there will be no crops produced onsite and the radiation protection program will prevent worker exposures to contaminated soil.

- $\quad$ Normal - No credit in Category 1 when HEPA is ITS.

- $\quad$ Chronic atmospheric dispersion factor evaluated at a distance of 100 meters or less from the Dry Facility (surface release) or the subsurface facility (subsurface release) to the nearest involved or non-involved worker. 
Occupational dose limits for adults are specified in 10 CFR 20.1201(a)(1) and (2) as follows:

- An annual limit of either (whichever is more limiting): TEDE of 5 rem, or the sum of the $\mathrm{DDE}$ and the CDE of 50 rem to any individual organ or tissue, other than the lens of the eye.

- Annual limits to the lens of the eye and to the skin: an LDE of $15 \mathrm{rem}$, and an SDE of $50 \mathrm{rem}$.

Calculated worker doses are compared with the regulatory dose limits described above and tabulated in Table 8-1.

If the PSA consequence analysis indicates that the regulatory doses are exceeded, then the design, radiation protection, and licensing organizations are notified so that appropriate design or operational modifications are initiated. Designs and operations are also subject to ALARA (as low as is reasonably achievable) considerations, as described in Section 4.6.

\subsubsection{Onsite and Offsite Direct Radiation Exposures during Normal Operations and Category 1 Event Sequences}

Regulations per 10 CFR 63.111(a)(1) require that the GROA meet the requirements of 10 CFR Part 20 for radiation protection. Shielding must take both normal operations and Category 1 event sequences into consideration. The primary objective of shielding is to maintain occupational radiation exposures ALARA, and within the exposure dose limits specified in 10 CFR 20.1201. The controlling dose limit for workers is a TEDE of 5 rem per year as shown in Table 8.1-1 of 10 CFR 20.1201(a)(1).

For ALARA purposes, one-tenth of this limit (i.e., 500 mrem per year) is used as a design goal, consistent with the requirement in 10 CFR 835.1002 and nuclear power industry practice. With this design goal, shielding will be provided to reduce the dose rate to 0.25 mrem per hour in worker areas where continuous occupancy (2000 hours per year or 40 hours per week) is required. Higher dose rates are allowed for areas that require only intermittent personnel access provided that the occupational ALARA design goal of 500 mrem per year is not exceeded.

As illustrated in Section4, shielding calculations are performed by the Nuclear Engineering group as part of design support. The PSA group defines the event sequences whose train of events and damage states may result in direct exposures of workers or the public. This document does not provide guidance on performing shielding calculations, rather it supplies information to preclosure safety analysts for interfacing with shielding analysis, and toward incorporating the results of exposure calculations into the compliance evaluation.

Section 8.3.2.1 describes the computer codes that are commonly used in shielding calculations. Section 8.3.2.2 discusses the inputs to the shielding and exposure calculations. Section 8.3.2.3 describes how direct exposure doses are evaluated against the offsite dose rate limit of 2 mrem in any one hour (see Table 8-1). 


\subsubsection{Computational Methods for Direct Radiation Exposure}

Shielding analysis to support repository design uses nuclear industry standard codes accepted by the NRC. Simple and scoping-type gamma shielding problems are handled with the efficient point-kernel integration codes. Complex or deep-penetration shielding problems require the use of Monte Carlo or deterministic transport codes, especially for problems involving neutron and secondary gamma dose contributions. The following shielding codes have been benchmarked, validated, qualified and baselined in accordance with the project software management procedure to support the repository design:

- $\quad$ MCNP (Monte Carlo n-particle transport code)

- SCALE (a modular code system for standardized computer analysis for licensing evaluation)

- QAD-CGGP (three-dimensional point-kernel gamma shielding computer code)

- $\quad$ PATH (three-dimensional point-kernel gamma shielding computer code)

- $\quad$ MicroSkyshine (air-scattering code).

MCNP (Briesmeister 1997) is a general purpose Monte Carlo code for neutron, photon, or coupled neutron-photon transport problems, suitable for complex three-dimensional geometry and a variety of radiation source types. MCNP represents the best choice for Monte Carlo shielding analysis, as it is currently supported by the code developer, Los Alamos National Laboratory, and is widely used in the nuclear industry for various applications. The NRC also recognizes the acceptance of MCNP in NUREG-1567 (NRC 2000a) and NUREG-1617 (NRC 2000b). Furthermore, Oak Ridge National Laboratory (ORNL) recommended to the DOE that MCNP be a standard code for Monte Carlo analysis (Parks et al. 1988).

SCALE (ORNL 1997) contains the modules for performing source term and shielding calculations. The SCALE package has been developed and maintained by ORNL under the sponsorship of the NRC. For Yucca Mountain applications, SCALE can be used for both source term and shielding calculations. The ability of updating burnup-dependent cross section library in SCALE provides a more accurate determination of the source terms than the ORIGEN code (RSIC 1991). For this reason, plus acceptance by the NRC, SCALE is selected for source term calculations.

QAD-CGGP (CRWMS M\&O 1995) and PATH (Su et al. 1987) are both point-kernel integration codes for gamma shielding problems, capable of treating 3-D source shield configurations explicitly. These two codes are similar in capabilities and produce results in satisfactory agreement. PATH provides additional features to treat multiple sources and various source types in a single run. Successful licensing precedents using these codes lend credence to the acceptability of selecting these codes for Yucca Mountain applications.

MicroSkyshine (Grove 1987) is a microcomputer program to calculate the dose from overhead air-scattered gamma radiation. Because MicroSkyshine is limited to gamma radiation, this code 
was replaced with a new expanded version named SKYSHINE-III (Lampley et al. 1988) from Radiation Safety Information Computational Center at ORNL. SKYSHINE-III calculates the dose contributions from neutron and secondary gamma radiation. The new version is qualified prior to production use. Once qualified, the code is used to calculate the skyshine radiation dose contributions from the waste aging facility at the surface, similar to calculations performed for NRC-certified spent fuel storage cask systems.

\subsubsection{Inputs to Shielding and Exposure Calculations}

Primary inputs to baseline shielding analyses, using the codes previously described, are developed by the Nuclear Engineering group based on the design of waste handling buildings and transport vehicles. Input information includes the geometry, materials of construction, operating environments, and radiation interaction parameters (gamma-ray absorption coefficients and neutron cross sections). Further, isotopic source term information, similar to that described in Section 8, is developed as input. Inputs also include information on staffing levels and staff residence times in radiation zones. However, development of inputs for shielding analysis are beyond the scope of this document.

The Nuclear Engineering group calculates routine exposures as part of the shielding design evaluation based on the baseline input parameters. The group also evaluates changes in potential exposures as part of the ALARA process (see Section 4.6).

However, for Category 1 (and Category 2) event sequences, additional input may be generated by the PSA group in accordance with the plant damage state that is identified for a given event sequence. The plant damage state may involve a waste form stuck in between two safe locations such that abnormal direct radiation shines around or through a shield barrier. Or, the plant damage state may involve damage to a shield such that it loses thickness or is penetrated (e.g., by impact of a tornado missile). In other words, the PSA group defines the "what" that might occur, and "how likely" it may occur, but Nuclear Engineering calculates the consequences. Such consequences may be onsite (worker) doses, offsite (public) doses, or both.

In evaluating complience to 10 CFR Part 63, Table 8-1 illustrates that dose limits for an external dose is 2-mrem-per-hour offsite for Category 1 event sequences.

\subsection{CALCULATIONS OF DOSES TO MEMBERS OF THE PUBLIC FROM CATEGORY 2 EVENT SEQUENCES FROM AIRBORNE RELEASES AND EXPOSURES TO DIRECT RADIATION}

Evaluation of doses to the public (offsite) is required by 10 CFR 63.111 for Category 2 event sequences; worker doses are not part of the compliance requirement for Category 2. Dose limits for Category 2 event sequences are expressed in terms of rems per event in contrast to the annual doses (rems per year) used for Category 1 event sequences. Therefore, Category 2 event sequences do not have to be aggregated unlike Category 1. Doses received from Category 2 event sequences may derive from airborne releases due to a breach of the confinement barrier(s) of a waste form, or from direct exposures that might occur if there is an abnormality in the shielding configuration associated with waste form handing operations. This section describes the methods (computer codes) and approach used to calculate doses for Category 2 event 
sequences. Section 8.3 describes the approach used to calculate doses for Category 1 event sequences.

Section 8.4.1 summarizes the approach used for the MACCS computer code to calculate doses for Category 2 event sequences. Input parameters used in dose calculations are presented in Section 8.2. Section 8.4.2 discusses uncertainty analysis for Category 2 dose analyses.

\subsubsection{Calculations of Doses to the Public from Airborne Radionuclides}

Category 2 event sequences assume that radioactive materials are released as a ground-level radioactive plume, which is dispersed en route to the site boundary and results in a 2-hour acute individual exposure. Category 2 event sequences consider potential radiation doses from inhalation, ingestion, air submersion, and groundshine pathways (Eckerman et al. 1988), which are calculated using the MACCS2 computer code described in Section 8.3.1.1. The ARCON96 computer code is not used for consequence analyses of Category 2 event sequences.

Since Category 2 event releases are modeled as "acute" releases, the maximum sector 99.5 percentile acute ( 0.5 percent exceedance) atmospheric dispersion factor is used to calculate maximum doses, while the 50 percentile acute atmospheric dispersion factor values are used to calculate mean doses.

The maximum sector 99.5 percent atmospheric dispersion factor value was selected based on it being larger than the 95 percent overall site atmospheric dispersion factor value, per Regulatory Guide 1.145. Atmospheric dispersion factor values are based on the 99.5 percentile values at each distance, which corresponds with Wind Sector 14 (West-Northwest to East-Southeast). Maximum doses can be used to account for the uncertainty/variability of input parameters. Mean doses based on the 50 percentile acute atmospheric dispersion factor values are also calculated and used in assessing compliance with 10 CFR 63.111. As noted in Section 8.2, atmospheric dispersion factors are calculated internally in the MACCS code, based on input meteorological parameters.

\subsubsection{Uncertainty Analysis of Category 2 Consequences}

Uncertainty analyses are performed to account for uncertainty and/or variability in input parameter values. Section9 discusses the general concepts and methods for quantitatively assessing uncertainties associated with radiological consequence analyses. Uncertainties in Category 2 offsite doses are analyzed using the Microsoft EXCEL spreadsheet program and the Palisade @ RISK add-in program that provides Monte Carlo and Latin Hypercube routines. Output from the MACCS code is transcribed to the EXCEL spreadsheet and the variability in the input parameters is defined. The @RISK program takes random samples from the distributions in the input parameters and outputs the variability in the offsite doses. 
The TEDE dose measure is expressed as:

$$
T E D E=C E D E+E D E=\sum_{j} D_{j, e f f e c t i v e}^{\text {inh }}+\sum_{j} D_{j, \text { effective }}^{\text {ing }}+\sum_{j} D_{j, \text { effective }}^{\text {ext }}
$$

where

$$
\begin{array}{lll}
T E D E & = & \text { TEDE (rem) } \\
C E D E & = & \operatorname{CEDE}(\mathrm{rem}) \\
E D E & = & \mathrm{EDE}(\mathrm{rem}) \\
D_{j, \text { effective }}^{\text {inh }} & \text { Whole body "effective" inhalation dose from the } \mathrm{j} \text { is isotope (rem) } \\
D_{j, \text { effective }}^{\text {ing }}= & \text { Whole body "effective" ingestion dose from the } \mathrm{j}^{\text {th }} \text { isotope (rem) } \\
D_{j, \text { effective }}^{\text {ext }}= & \text { Whole body "effective" external dose from the } \mathrm{j}^{\text {th }} \text { isotope (rem) }
\end{array}
$$

The CDE+DDE dose measure is expressed as:

$$
C D E_{k}+E D E_{k}=\sum_{j} D_{j, k}^{i n h}+\sum_{j} D_{j, k}^{i n g}+\sum_{\mathrm{j}} D_{j, k}^{e x t} \quad \text { where } \mathrm{k} \neq \text { effective or skin }
$$

where

$$
\begin{aligned}
& C D E_{k}=\quad \mathrm{CDE} \text { to the } \mathrm{k}^{\text {th }} \text { organ (rem) } \\
& D_{j, k}^{i n h}=\text { Radiation dose from the } \mathrm{j}^{\text {th }} \text { isotope to the } \mathrm{k}^{\text {th }} \text { "organ" due to inhalation } \\
& \text { (rem) } \\
& D_{j, k}^{i n g}=\quad \text { Radiation dose from the } \mathrm{f}^{\mathrm{th}} \text { isotope to the } \mathrm{k}^{\mathrm{th}} \text { "organ" due to ingestion } \\
& \text { (rem) } \\
& D_{j, k}^{e x t}=\text { Radiation dose from the } \mathrm{j}^{\text {th }} \text { isotope to the } \mathrm{k}^{\text {th }} \text { "organ" due to external } \\
& \text { exposure (rem) } \\
& k=\text { "Organ" index, where "organs" are gonads, breast, lungs, red marrow, }
\end{aligned}
$$

The external dose is the sum of the groundshine dose and the air submersion dose. The groundshine dose has been shown to be a small contribution to the external dose and therefore the external dose is approximated by the air submersion dose. The ingestion dose is calculated using the MACCS2 code. The calculated ingestion dose is used in Equation 8-7 and Equation 8-8. The previous inhalation and external doses can be further expressed as:

$$
\begin{gathered}
D_{j, k}^{i n h}=S T_{j} \times F A \times \frac{\chi}{Q} \times B R \times \operatorname{conv} \times D C F_{j, k}^{i n h} \\
D_{j, k}^{e x t}=S T_{j} \times F A \times \frac{\chi}{Q} \times \operatorname{conv} \times D C F_{j, k}^{s u b}
\end{gathered}
$$


where

$$
\begin{aligned}
& S T_{j}=\quad \text { Inventory source term release per fuel assembly for the } \mathrm{j}^{\text {th }} \text { isotope }(\mathrm{Ci} / \mathrm{FA}) \\
& F A=\quad \text { Number of fuel assemblies involved in the release (\# FAs) } \\
& \frac{\chi}{Q} \quad=\quad \text { Atmospheric dispersion factor }(\mathrm{s} / \mathrm{m} 3) \\
& B R=\text { Breathing rate }(\mathrm{m} 3 / \mathrm{s}) \\
& D C F_{j, k}^{i n h}=\quad \text { Inhalation DCF of the } \mathrm{j}^{\text {th }} \text { isotope for the } \mathrm{k}^{\text {th }} \text { organ }(\mathrm{Sv} / \mathrm{Bq})(\text { Eckerman et al. } \\
& \text { 1988) } \\
& D C F_{j, k}^{s u b}=\quad \text { Air submersion DCF of the } \mathrm{j}^{\text {th }} \text { isotope for the } \mathrm{k}^{\text {th }} \text { organ }\left[\left(\mathrm{Sv}^{\mathrm{m}} \mathrm{m}^{3}\right) /(\mathrm{Bq}-\mathrm{s})\right] \\
& \text { conv }=\text { DCF unit conversion factor: } 3.7 \times 10^{-12}(\mathrm{rem}-\mathrm{Bq}) /(\mathrm{CiSv})(\text { Eckerman and } \\
& \text { Ryman 1993) }
\end{aligned}
$$

A Microsoft EXCEL spreadsheet model is created to multiply the factors (e.g., inventory source term release per fuel assembly, number of fuel assemblies, airborne release fraction, respirable fraction, breathing rate, dose conversion factor, atmospheric dispersion factor in Equation 8-9 and Equation 8-10). Except for the number of fuel assemblies, each factor is treated as a random variable and an uncertainty distribution is assigned to each factor in the consequence model. The @RISK computer program is then directed to perform a Monte Carlo or Latin Hypercube simulation to propagate the uncertain variables to the output. The results are tabulated giving the mean, median, standard deviation, and percentiles. The results are plotted as probability density functions, cumulative distribution functions, or histograms using EXCEL graphics.

\subsubsection{Evaluation of Doses to Hypothetical Members of the Public from Category 2 Event Sequences Against Regulatory Dose Limits}

Category 2 dose limits are presented in Table 8-2. The mean value of offsite dose for each Category 2 event sequence must be less than the limits given for each dose measure listed in Table 8-2. The mean values are derived from the uncertainty analysis as described in Section 8.4.2.

\subsubsection{Offsite Direct Radiation Exposures from Category 2 Event Sequences}

The methods described in Section 8.3.2 can be applied to direct exposure from Category 2 event sequences, although the need for such analyses is not clearly established, noting that the dose analyses are performed by shielding analyses. Since Category 2 dose limits apply only to members of the public who are located several kilometers from the operations areas, it is unlikely that any direct radiation or even reflected radiation (skyshine) will contribute any significant doses to members of the public from any credible event sequence. Nevertheless, during the identification of Category 2 event sequences and associated plant damage states, the possibility of direct radiation to the site boundary is considered and a rough dose screening analysis is performed to eliminate the need for detailed analysis. If the screening analysis so indicates, a detailed dose analysis is performed following the guidance of Section 8.3.2. 


\subsection{REFERENCES}

\subsubsection{Documents Cited}

Briesmeister, J.F., ed. 1997. MCNP-A General Monte Carlo N-Particle Transport Code. LA-12625-M, Version 4B. Los Alamos, New Mexico: Los Alamos National Laboratory. ACC: MOL.19980624.0328.

BSC (Bechtel SAIC Company) 2001. Design Basis Event Frequency and Dose Calculation for Site Recommendation. CAL-WHS-SE-000001 REV 01 ICN 02. Las Vegas, Nevada: Bechtel SAIC Company. ACC: MOL.20011211.0094.

BSC 2003. Commercial SNF Accident Release Fractions. ANL-WHS-SE-000002 REV 001. Las Vegas, Nevada: CRWMS M\&O. ACC: MOL.20000310.0356.

CRWMS M\&O 1995. Final Version Description Document for the QAD-CGGP Computer Code, Version 1.0. A00000000-01717-2003-10002 REV 00. Las Vegas, Nevada: CRWMS M\&O. ACC: MOV.19951109.0014.

CRWMS M\&O 1999a. PWR Source Term Generation and Evaluation. BBAC00000-017170210-00010 REV 01. Las Vegas, Nevada: CRWMS M\&O. ACC: MOL.20000113.0333.

CRWMS M\&O 1999b. BWR Source Term Generation and Evaluation. BBAC00000-017170210-00006 REV 01. Las Vegas, Nevada: CRWMS M\&O. ACC: MOL.20000113.0334.

CRWMS M\&O 1999c. Source Terms from DHLW Canisters for Waste Package Design. BBA000000-01717-0210-00044 REV 00. Las Vegas, Nevada: CRWMS M\&O. ACC: MOL.19990222.0176.

CRWMS M\&O 1999d. DOE High-Level Vitrified Waste Dose Calculation. CAL-WPS-SE000002 REV 00. Las Vegas, Nevada: CRWMS M\&O. ACC: $\underline{\text { MOL.19990720.0403. }}$

CRWMS M\&O 2000a. Estimated Annual MGR Normal Radiological Release. Input Transmittal RSO-SUF-99389.T.a. Las Vegas, Nevada: CRWMS M\&O.

ACC: MOL.20000125.0174.

CRWMS M\&O 2000b. Estimated Annual Monitored Geologic Repository (MGR) Subsurface Normal Radiological Releases. Input Transmittal RSO-SSR-99412.T. Las Vegas, Nevada: CRWMS M\&O. ACC: MOL.20000105.0146.

Eckerman, K.F.; Wolbarst, A.B.; and Richardson, A.C.B. 1988. Limiting Values of Radionuclide Intake and Air Concentration and Dose Conversion Factors for Inhalation, Submersion, and Ingestion. EPA 520/1-88-020. Federal Guidance Report No. 11. Washington, D.C.:

U.S. Environmental Protection Agency. ACC: MOL.20010726.0072.

Eckerman, K.F. and Ryman, J.C. 1993. External Exposure to Radionuclides in Air, Water, and Soil, Exposure-to-Dose Coefficients for General Application, Based on the 1987 Federal Radiation Protection Guidance. EPA 402-R-93-081. Federal Guidance Report No. 12. 
Washington, D.C.: U.S. Environmental Protection Agency, Office of Radiation and Indoor Air. TIC: 225472.

Grove (Grove Engineering, Inc.) 1987. MicroSkyshine Manual. Grove 92-1. Rockville, Maryland: Grove Engineering, Inc.

ICRP (International Commission on Radiological Protection) 1979. Limits for Intakes of Radionuclides by Workers. Volume 2, No. 3/4 of Annals of the ICRP. Sowby, F.D., ed. ICRP Publication 30 Part 1. New York, New York: Pergamon Press. TIC: 4939.

Lampley, C. M.; Andrews M. C.; and Wells M. B. 1988. The SKYSHINE-III Procedure: Calculation of the Effects of Structure Design on Neutron, Primary Gamma-Ray and Secondary Gamma-Ray Dose Rates in Air. RRA-T8209A. Fort Worth, Texas: Radiation Research Associates.

NRC (U.S. Nuclear Regulatory Commission) 2000a. Standard Review Plan for Spent Fuel Dry Storage Facilities. NUREG-1567. Washington, D.C.: U.S. Nuclear Regulatory Commission. TIC: 247929.

NRC 2000b. Standard Review Plan for Transportation Packages for Spent Nuclear Fuel. NUREG-1617. Washington, D.C.: U.S. Nuclear Regulatory Commission. TIC: 249470.

NRC 2003. "Interim Staff Guidance - 5, Revision 1. Confinement Evaluation." ISG-5, Rev 1. Washington, D.C.: U.S. Nuclear Regulatory Commission. Accessed January 24, 2003. ACC: MOL.20030124.0247. http://www.ncr.gov/reading-rm/doc-collections/isg/spent-fuel.html.

ORNL (Oak Ridge National Laboratory) 1997. SCALE: A Modular Code System for Performing Standardized Computer Analyses for Licensing Evaluation. NUREG/CR-0200, Rev. 5. Washington, D.C.: U.S. Nuclear Regulatory Commission. TIC: 235920.

ORNL 1998. MACCS2 Version 1.12 Melcor Accident Consequence Code System For The Calculation Of The Health And Economic Consequences Of Accidental Atmosphere Radiological Releases (C). ACC: $\underline{\text { MOL.20030204.0225 }}$

Parks, C.V.; Broadhead, B.L.; Hermann, O.W.; Tang, J.S.; Cramer, S.N.; Gauthey, J.C.; Kirk, B.L.; and Roussin, R.W. 1988. Assessment of Shielding Analysis Methods, Codes, and Data for Spent Fuel Transport/Storage Applications. ORNL/CSD/TM-246. Oak Ridge, Tennessee: Oak Ridge National Laboratory. ACC: NN1.19880928.0023.

Ramsdell, J.V. Jr.; and Simonen, C.A. 1997. Atmospheric Relative Concentrations in Building Wakes. NUREG/CR-6331, Rev.1, PNNL-10521, Rev. 1. Richland, Washington: Pacific Northwest National Laboratory.

RSIC (Radiation Shielding Information Center). 1991. ORIGEN 2.1, Isotope Generation and Depletion Code, Matrix Exponential Method. RSIC Computer Code Collection. CCC-371, Oak Ridge, Tennessee: Oak Ridge National Laboratory. ACC: MOV.19970212.0145. 
Su, S.D.; Baylor, K.J.; and Engholm B.A. 1987. PATH Gamma Shielding Code User's Manual. GA-A167721, Rev. 1. San Diego, California: GA Technologies. TIC: 241215.

\subsubsection{Codes, Standards, Regulations, and Procedures}

10 CFR 20. Energy: Standards for Protection Against Radiation. Readily available.

10 CFR 63. Disposal of High-Level Radioactive Wastes in a Proposed Geologic Repository at Yucca Mountain, Nevada. Readily available.

66 FR 55732. Disposal of High-Level Radioactive Wastes in a Proposed Geologic Repository at Yucca Mountain, NV. Final Rule 10 CFR Part 63. Readily available.

ANSI/ANS-5.10-1998. Airborne Release Fractions at Non-Reactor Nuclear Facilities. La Grange Park, Illinois: American Nuclear Society. TIC: 235073.

ANSI N14.5-97. 1998. American National Standard for Radioactive Materials — Leakage Tests on Packages for Shipment. New York, New York: American Nuclear Standards Institute. TIC: $\underline{247029}$.

INEEL (Idaho National Engineering and Environmental Laboratory) 2000. Guide for Estimating DOE Spent Nuclear Fuel Source Terms. DOE/SNF/REP-059 Rev. 0. Washington, D.C.:

U.S. Department of Energy, National Spent Nuclear Fuel Program. TIC: 248604.

INEEL 2003. Source Term Estimates for DOE Spent Nuclear Fuels. DOE/SNF/REP-078 Rev. 0. Washington, D.C.: U.S. Department of Energy, National Spent Nuclear Fuel Program.

Regulatory Guide 1.111, Rev. 1. 1977. Methods for Estimating Atmospheric Transport and Dispersion of Gaseous Effluents in Routine Releases from Light-Water-Cooled Reactors.

Washington, D.C.: U.S. Nuclear Regulatory Commission. Readily available.

Regulatory Guide 1.140, Rev. 1. 1979. Design, Testing, and Maintenance Criteria for Normal Ventilation Exhaust System Air Filtration and Adsorption Units of Light-Water-Cooled Nuclear Power Plants. Washington, D.C.: U.S. Nuclear Regulatory Commission. Readily available.

Regulatory Guide 1.145, Rev. 1. 1982. Atmospheric Dispersion Models for Potential Accident Consequence Assessments at Nuclear Power Plants. Washington, D.C.: U.S. Nuclear Regulatory Commission. Readily available.

Regulatory Guide 1.52, Rev. 2. 1978. Design, Testing, and Maintenance Criteria for Postaccident Engineered-Safety-Feature Atmosphere Cleanup System Air Filtration and Adsorption Units of Light-Water-Cooled Nuclear Power Plants. Washington, D.C.: U.S. Nuclear Regulatory Commission. Readily available. 


\section{INTENTIONALLY LEFT BLANK}




\section{UNCERTAINTY AND SENSITIVITY ANALYSIS, GENERAL CONCEPTS, AND METHODS}

\subsection{INTRODUCTION}

This section provides guidance on methods for identifying, quantifying, propagating, and interpreting uncertainties in event sequence frequency and consequence analyses. The material provides general concepts and methods for qualitatively and quantitatively assessing uncertainties associated with event sequence frequency analysis, or radiological consequence analysis.

\subsection{OVERVIEW OF APPROACH}

Two primary sources were used to develop this section: the PRA Procedures Guide (NRC 1983, Chapter 12) and the CPQRA guidelines (AIChE 1989). Additional information has been incorporated from several sources including Regulatory Guide 1.174, NUREG-0800 (NRC 1987, Chapter 19), and NUREG/BR-0184 (NRC 2001).

Calculations of probabilities, frequencies, source terms, and doses used in preclosure safety are often expressed as single numbers (i.e., point values) for simplicity and convenience of presentation. It is generally understood, however, that virtually every input parameter and every output value has uncertainty associated with it. When the point value represents the mean or expectation value of the quantity, it is often a sufficient parameter for decision making or compliance evaluation because the mean value of a parameter represents a probability-weighted integration of the parameter over the uncertainty range. When the mean of an output quantity like event sequence frequency is far (e.g., an order of magnitude or more) from a decision point like the frequency boundary between Category 1 and Category 2, then the analyst and the NRC has confidence that the sequence is properly categorized. But when the mean is only a factor of two or so from the boundary, the shape and range of the uncertainty distribution come into question. The probability that the true value of the frequency is in the other category may be unacceptable. In either case, an expression of uncertainty distribution is needed to support the decision-making. This section describes the process.

The geologic repository is a first-of-a-kind facility. There is no prototype or repository-specific test facility from to derive equipment performance information. The PSA must rely on generic or surrogate information. The application of such information to the repository introduces uncertainty because the exact equipment represented in information bases may not be used in the MGR and the physical and operational environments at the repository may not be represented in the surrogate information. Further, portions of the facility design may not be mature or finely detailed at the time of LA. Such issues are sources of uncertainty.

Section 7.5 describes the processes for defining the uncertainty distributions for parameters that are inputs to the PSA fault-tree and event-tree modeling. Therefore, these sources of uncertainty are briefly mentioned in this section. This section concentrates on how uncertainties are identified, propagated through the analyses, and examined through sensitivity analyses.

Mathematically, the uncertainty in an input parameter is expressed by a probability distribution that represents the probability that a given value of the parameter, such as a failure rate, is the 
true value. Each input parameter in a FT or ET quantification is expressed in terms of a PDF. The calculation of an event sequence frequency requires the multiplication and addition of many input parameters. The output of the frequency quantification is also represented as a PDF that reflects not only the product or sum of all of the input median (or mean) values, but also the uncertainty distributions of all of the input PDFs. This effect is termed propagation of uncertainties.

The propagation of uncertainties can be performed by hand under certain conditions. Generally, the solution is too complex, however, so computer solutions are used. For the PSA, therefore, the Monte Carlo of Latin Hypercube methods will be used for most of the uncertainty analyses of event sequence frequencies. These techniques are embedded in the SAPHIRE workstation, but can also be performed in a Microsoft Excel spreadsheet using the @ RISK add-in. In this regard, much of the real effort in uncertainty analysis is that of identifying and quantifying the sources of uncertainty and representing it as an appropriate PDF.

In some instances, the source of uncertainty may not be amenable to being expressed as a PDF. For example, there may be uncertainty regarding the presence of a certain operational or environmental condition, or a design feature (e.g., does the power supply system have redundant trains?). In such cases, a sensitivity analysis may be performed to explore the significance of assuming one condition over another (e.g., calculate the event frequency with single-train and with two-train redundancy to evaluate the significance of the alternative design on the results).

Many of the concepts and methods of uncertainty analysis have been developed around the statistical properties of the normal distribution. Section 7.5 describes other distributions that serve significant roles in the ability to quantify and propagate uncertainty. In particular, the lognormal (LN) distribution has become the workhorse for uncertainty analysis in probabilistic risk analysis (PRA) and, likewise, will have substantial application in the PSA.

\subsection{DETAILS OF APPROACH}

This section describes the basic approaches for applying and interpreting measures of uncertainty in the PSA. The discussion will include identification of sources of uncertainty and means to evaluate and interpret uncertainty, both qualitatively and quantitatively. The discussion includes guidance on when to use sensitivity analysis and importance analysis as means to evaluate the significance of sources of uncertainty.

\subsubsection{Background}

The well-known bell curve of the normal distribution is a typical example of an expression of the uncertainty, or variability, that is known to be present in a measured parameter. The bell curve is a PDF. Such variability is known as random or chance errors. There is a true, or most representative, value of some parameter (e.g., the tensile strength) of a certain kind of steel. Results of repeated tensile tests on several specimens are expected to give slightly different values, some above and some below some central value. The statistical analysis produces an expected value (the mean) and a measure of the dispersion, characterized by the variance (or the standard deviation). More recently, such chance variability is termed aleatory uncertainty. 
Most analysts are familiar with basic statistical concepts that express random variability in measured parameters in terms of the number standard deviations from the mean, or the 95 percent confidence level. In risk analysis, the ratio of the 95th percentile to the median (which is also the mean for the normal distribution) is termed the EF. For the LN distribution, the mean is not equal to the median but is readily calculated from the median and the EF.

Similarly, most analysts are familiar with the concept of propagating uncertainties through any calculations that use two or more uncertain parameters (e.g., in adding two quantities, the standard deviation of the sum is calculated value as the root-of-sum-of-squares as the standard deviation of each input parameter, while the mean of the sum is the sum of the means of the input parameters). The greater the number of uncertain variables that are combined, the wider becomes the dispersion (uncertainty) in the output.

In FT and event sequence quantification, however, the end result may involve sums and products of many quantities having different kinds of probability distributions as described in Section 7.5. These facts make the propagation of uncertainty more difficult and usually not amenable to an analytic (i.e., closed form) solution. Therefore, alternative methods must be applied, including approximations and computer simulation (e.g., Monte Carlo analysis).

The concept of epistemic uncertainty and means of dealing with it are not as well known to most analysts. The term encompasses many forms of knowledge uncertainty that can be considered in assessing the frequency and consequences. Epistemic uncertainties include, for example, model uncertainties, applicability of ge neric information and parameters, and effects of environmental factors.

For the PSA, analysts will have to make judgements on how to apply information (e.g., failure rates for equipment, human error rates, and radionuclide release fractions) that are adapted from various sources. In some cases, it may be necessary to adjust the information to fit the operational conditions of the MGR in contrast to that of the source. If so, the analyst must decide on how best to accomplish the adjustment. Alternatives are to adjust the best-estimate value (mean or median) to suit repository conditions, alter the EF, or pool information from multiple sources.

Many of the parameters used in the PSA modeling are not amenable to direct physical measurement as in a laboratory, but are derived from operational (field) data in many instances. The parameters needed include equipment failure rates, human error rates, and equipment repair times. For example, to estimate a failure rate for a component or system like a gantry crane, the kind of information used is 1) a count of the number of failures and 2) the time in which the failures occurred. For most industrial components or systems, the information gathered is imprecise and subject to considerable uncertainties (i.e., the information is not collected during controlled experiments). Gathering the raw information may involve searching through operating logbooks, maintenance records, and estimates of operational time. Generally, there are only a few components of a given type at a given plant in the sample. Results of several different failure modes may be intermixed in the information. The preclosure safety analyst must establish some expression of uncertainty for the derived failure rate and its applicability to repository operations (see Section 7.6). 
In a few cases, component failure rate may be developed from reliability tests conducted by manufacturers or the military. For example, in a typical reliability test, a large number of solidstate devices are subjected to operational tests. The number of failures is precisely known and the time-on-test is precisely known. Further, post-test examinations can reveal the precise mode or cause of each failure. In such instances, the variability in derived failure rate is aleatory uncertainty.

With PDFs defined for all parameters in the event probabilities in fault tree or fault tree models, the uncertainty can be propagated quantitatively by one of the various methods. In this guide, the Monte Carlo-Latin Hypercube computer-based approach is the primary method, but other methods are described.

When the source of uncertainty cannot be described as a PDF, such as uncertainty in a design configuration, then sensitivity analyses may be used to examine the effect of alternative configurations.

\subsubsection{Identifying Sources of Uncertainty in Models and Input Information}

Until the mid-1990s, uncertainty in risk analysis was considered to arise from three sources: parameter uncertainty, model uncertainty, and completeness uncertainty. In more recent risk analysis literature, the terms aleatory (chance) uncertainty, and epistemic (knowledge) uncertainty have been introduced. However, these terms are essentially a re-packaging of the prior concepts. These newer terms are not used in this section unless the distinction is important.

The parameter uncertainty is further divided into 1) randomness inherent in any measured quantity, and 2) applicability uncertainty (e.g., using generic failure rate data to a specific facility). Both of these sources of uncertainty can be quantified and propagated through frequency and consequence analyses. Further, the significance of such uncertainties can be evaluated through sensitivity analyses (e.g., by letting a given parameter go to an extreme value) and importance analyses.

Model uncertainty refers to the fact that models are abstractions of reality. Model uncertainty for PSA includes the use of ETs and FTs that may not realistically model the operational features of the MGR and associated hazards, including dependent failures (e.g., by using a simple betafactor model) or human interactions. Event free and fault free modeling are generally accepted methods and will not be subjected to any uncertainty analysis with respect to alternative models. The logic models will be checked for accuracy. Uncertainties in specific modeling elements, such as mapping the physical configuration of equipment or systems into the logic models and treatment of dependent failures, can be subjected to sensitivity analysis, as needed. Further, use of exponential failure model (constant failure rate) in estimating event probabilities and various human reliability models are abstractions that introduce uncertainty. These methods are generally accepted and are not subjected to uncertainty analysts. Modeling uncertainties in consequences include the source term, damage mechanisms, release fractions, and leak-path mechanisms, as well as environmental transport. These factors can be evaluated by uncertainty or sensitivity analyses described in Section 8. 
Completeness uncertainty refers to the residual, or unknown, that may remain after performing an exhaustive, structured PSA. After examining the preclosure operations using the PSA process (see Section 4) by a cognizant team of safety analysts and designers, such uncertainty should be low. The LA will represent to a high level of confidence that credible Category 1 and Category 2 event sequences have been identified and treated. Further, the LA can discuss event sequences identified as BC2 with respect to modeling assumptions and parameters used. This will provide more transparency to reviewers (e.g., the NRC) who can perform their own sensitivity analysis, if desired, to assure themselves that the list of credible sequences is complete.

Finally, it is possible that differences between analysts introduce another source of uncertainty. The application of this guide, however, and associated Yucca Mountain Project procedures should essentially eliminate this source of uncertainty from the PSA.

\subsubsection{Uncertainties in Input Parameters}

Section 7.5 discusses three sources of uncertainty that are associated with the input information used to quantify event probabilities and frequencies: random variability, uncertainty associated with information source, and uncertainty associated with applicability to repository facilities.

Similar types of parameter uncertainty are associated with consequence analyses.

Other sources of uncertainty in input parameters include the waste stream year-to-year loadings.

Such sources of uncertainty are amenable to quantification and propagation through the event sequence frequency and consequence analyses.

\subsubsection{Uncertainties in Model Inputs and Modeling}

Uncertainty in model inputs relates to the level of detail on design and operations that is available. For the LA for construction authorization, it is anticipated that the level of detail will be limited. Principal operations and associated equipment will be defined, along with the degree of redundancy, dependence on power supplies, spatial relationships, and anticipated human interactions. Therefore, the PSA will require some imagination on the part of analysts, with concurrence of design personnel, to define potential hazards and event sequences, and to synthesize system fault trees and event sequences. This lack of certainty in design and operations becomes a source of modeling uncertainty, described in this section. The PSA to support the LA to Receive and Process will not have this source of uncertainty.

Uncertainties in modeling stem from generic and specific causes. The generic uncertainties stem from use of standard event probability models, such as constant failure rate, repair models, common-cause failure models, and human reliability models. In general, such sources of uncertainty will not be addressed in the PSA unless such modeling effects appear to affect the PSA results. If deemed necessary, sensitivity analyses must be performed to examine the results with alternative models.

Repository-specific modeling uncertainties stem from the representation of reality in the event sequence and fault tree logic models. For example, ETA (Sections 7.1 and 10.1) may include 
dependencies between events whose conditional probabilities are estimated. The presence and nature of the dependency may be uncertain, and the associated conditional probability may be an assumption. Similarly, a fault tree models of a control systems might include a redundant train and might include components like PLCs that are expected to be used, but which have not been completely specified in design documents. Such models may include a CCF model for redundant components. Such modeling is potentially a source of significant uncertainty and stems, in part, from the uncertainty in the model inputs and level of design detail. For these kinds of modeling uncertainties, sensitivity analysis should be performed to demonstrate how significantly they affect the PSA results.

All bases for modeling will be documented so that design-dependent issues and assumption-dependent uncertainties can be identified and appropriate sensitivity analyses performed as necessary.

\subsubsection{Representing Uncertainties in Input and Output Variables}

For the PSA, particularly for the LA for construction authorization, it is recommended that all event probabilities and frequencies be treated as LN distributions, except in cases where a normal distribution is more appropriate. The $\mathrm{LN}$ is a good fit to the distribution that result when several distributions are multiplied, as in an event sequence quantification. As described and illustrated in Section 7.5, the LN in inputs can be converted back and forth to other distributions that are better to work with analytically in event probability estimation (e.g., in an empirical Bayesian analyses). Further, the parameters of the LN are readily associated with the properties and tabulations of the normal distribution. The principal properties of the LN and normal distributions used in the PSA are described in the following sections.

\subsubsection{Uncertainty Interval and Bounds}

The uncertainty in a variable $x$ is described by a PDF that gives the probability $\mathrm{p}(x) \mathrm{dx}$ that the true value of the variable is within the $\mathrm{dx}$ about $x$. The cumulative probability function is given as $\mathrm{P}\left(x_{\mathrm{P}}\right)$, defined as the probability that the true value of the variable is less than or equal to $x_{\mathrm{P}}$. $\mathrm{P}\left(x_{\mathrm{P}}\right)$ is the integral of $\mathrm{p}(x) \mathrm{dx}$ between the lower limit of the distribution and the value $x_{\mathrm{P}}$. The cumulative probability function, $\mathrm{P}\left(x_{\mathrm{P}}\right)$, is used to define the confidence interval, or range, for the input variable or calculated value.

Unless otherwise specified or required, uncertainty on input variables and calculated outputs of event sequence frequencies and consequences will always imply a 90 percent confidence interval (range). This means that 10 percent of the values of inputs or of results can fall outside of the interval. Generally, the PSA will use confidence intervals that span the range from the $5^{\text {th }}$ percentile to the $95^{\text {th }}$ percentile.

The bounding, or limiting, values that define the 90 percent confidence interval of a variable $x$ are the values of $x_{0.05}$ and $x_{0.95}$, where $\mathrm{P}\left(x_{\mathrm{P}}\right)=0.05$ and 0.95 , respectively. The median value of distribution occurs at the value $x_{0.5}$ where $\mathrm{P}\left(x_{\mathrm{P}}\right)=0.5$. The EF is defined as the ratio of the upper 95 percent confidence limit to the median (or $x_{0.95} / x_{0.5}$ ).

These definitions apply irrespective of the particular form of PDF that is used. The following sections describe how these definitions are applied to normal and LN distributions. 


\subsubsection{Properties of the Normal and Lognormal Distributions}

Normal Distribution-For a variable $y$, the properties of the normal distribution apply. The normal distribution is a symmetric ranging from $-\infty$ to $+\infty$. The measures of central tendency are numerical equal: mean $(y)=$ median $(y)=$ mode $(y)$. Dispersion about the mean $(\mu)$ is described by the variance $\left(\sigma^{2}\right)$ or the standard deviation $(\sigma)$.

The normal distribution is often expressed in normalized form in terms of a variable:

$$
\mathrm{z}=[\mathrm{y}-\mu] / \sigma
$$

The PDF for $z$ has a mean value of 0.0 and a standard deviation of 1.0. The cumulative probability of the normal distribution from $-\infty 4$ to a value $z=Z$, sometimes termed the normal curve of error function for $\mathrm{Z}$, is amenable to direct integration and has been extensively tabulated and built into spreadsheet programs like Microsoft Excel. In the normalized form, the percentiles of the cumulative distribution are given as:

\begin{tabular}{|c|c|c|c|}
\hline$Z_{0.5}$ & $=$ & 0 & Median (and mean) \\
\hline$Z_{0.05}$ & $=$ & -1.64 & 5th percentile \\
\hline$Z_{0.84}$ & $=$ & 1.00 & 84th percentile \\
\hline$Z_{0.95}$ & $=$ & 1.64 & 95th percentile \\
\hline$Z_{0.99}$ & $=$ & 2.33 & 99th percentile. \\
\hline ata. & \multicolumn{3}{|c|}{$\begin{array}{l}\text { For brevity, the } Z \text { values are shown only to two } \\
\text { decimal places. For hand calculations, at least } \\
\text { three to four places should be used. When using } \\
\text { Microsoft Excel or SAPHIRE, the functions are } \\
\text { built in and will display as many places as } \\
\text { selected. }\end{array}$} \\
\hline
\end{tabular}

From the definition of $z$, the corresponding values of the variable $y$ are given as:

\begin{tabular}{|l|l|l|l|}
\hline $\mathrm{y}_{0.50}$ & $=$ & $\mu$ & Median (and mean) \\
\hline $\mathrm{y}_{0.05}$ & $=$ & $\mu-1.64 \sigma$ & 5th percentile \\
\hline $\mathrm{y}_{0.84}$ & $=$ & $\mu+1.00 \sigma$ & 84th percentile \\
\hline $\mathrm{y}_{0.95}$ & $=$ & $\mu+1.64 \sigma$ & 95th percentile \\
\hline $\mathrm{y}_{0.99}$ & $=$ & $\mu+2.33 \sigma$ & 99th percentile. \\
\hline
\end{tabular}

The parameters $\mu$ and $\sigma$ characterize the normal distribution. $\mu$ may be considered a location parameter (defines the central value) and $\sigma$ may be considered a shape parameter that describes the degree of spreading or peaking in the distribution of the variable $x$. The larger the value of $\sigma$, the wider the distribution and the greater the uncertainty.

For the normal distribution, the EF, as defined above becomes:

$$
\mathrm{EF}_{\text {normal }}=1+1.64 \sigma / \mu
$$


The EF is not often directly used with the normal distribution. The application of the EF comes when estimating uncertainty ranges and assuming distributions.

For example, the safety analyst (supported by design engineers or equipment vendors) believes that 90 percent of a failure rate for a component lies between a lower bound (LB) of $1 \times 10^{-3}$ and an upper bound (UB) of $5 \times 10^{-3}$, and is normally distributed. Using the relationships above, the statement of belief gives the following:

$$
\begin{aligned}
& \mathrm{LB}=y_{0.05}=1 \times 10^{-3}=\mu-1.64 \sigma \\
& \mathrm{UB}=y_{0.95}=5 \times 10^{-3}=\mu+1.64 \sigma
\end{aligned}
$$

which yield

$$
\begin{aligned}
& \mu=3 \times 10^{-3} \\
& \sigma=1.2 \times 10^{-3}
\end{aligned}
$$

The EF becomes $1.67\left(5 \times 10^{-3} / 3 \times 10^{-3}\right)$, but is a derived quantity in this example. However, the $\mathrm{EF}$ has a more fundamental role for the $\mathrm{LN}$ distribution.

The properties of the normal can be applied to a lognormally distributed variable as described in the following paragraphs.

Lognormal Distribution-The properties of a $\mathrm{LN}$ distribution for a random variable $x$ is developed from the properties of the normal distribution for the transformed variable $y=\ln (x)$, where $\ln ($.$) is the natural logarithm. The LN distribution on x$, the non-transformed variable is not symmetric. It ranges from $x=0$ to $x=+\infty$. The mean value of $x$ is not equal to the median or mode. The transfomed variable y is normally distributed, which is symmetric.

Mathematical expressions for the parameters of the LN are somewhat complex, but they are derived from the properties of the normal distribution for the transformed variable $y$.

To describe a LN distribution, the analyst reeds only two values such as the median value of $x$ and a value for EF, or the median and UB, or the UB and LB. The values of UB and LB define the 90 percent confidence range on $x$. The following relationships apply:

$$
\begin{array}{ll}
\mathrm{M}(x) & =x_{0.50}=\mathrm{UB} / \mathrm{EF}=\mathrm{LB} \times \mathrm{EF}=(\mathrm{UB} \times \mathrm{LB})^{1 / 2} \\
\mathrm{EF} & =\mathrm{UB} / \mathrm{M}=\mathrm{M} / \mathrm{LB}=(\mathrm{UB} / \mathrm{LB})^{1 / 2}
\end{array}
$$


These expressions relate to parameters for the distribution of the non-transformed variable, $x$. When the variable is transformed to $y=\ln (x)$, the parameters for the normal distribution on $y$, are derived as follows:

$$
\begin{aligned}
& \mu_{\mathrm{LN}}=\ln (\mathrm{M}), \text { the location parameter (mean of the } y \text { distribution) } \\
& \sigma_{\mathrm{LN}} \quad=\ln (\mathrm{EF}) / \mathrm{Z}_{0.95}=\ln (\mathrm{EF}) / 1.64
\end{aligned}
$$

With these parameters so defined, the mean of the LN distribution of the non-transformed variable, $x$, becomes:

$$
\operatorname{mean}(x)=\underline{\mathbf{x}} \quad=\exp \left[\mu_{\mathrm{LN}}+1 / 2 \sigma_{\mathrm{LN}}^{2}\right] .
$$

For example, the safety analyst (supported by design engineers or equipment vendors) believes that 90 percent of a failure rate for a component lies between a LB of $1 \times 10^{-4}$ and a UB of $1 \times 10^{-2}$, and it is lognormally distributed (this range covers two orders of magnitude). Using the relationships above for the LN, the statement of belief gives:

$$
\begin{aligned}
& \mathrm{LB}=x_{0.05}=1 \times 10^{-4} \\
& \mathrm{UB}=x_{0.95}=1 \times 10^{-2}
\end{aligned}
$$

which yield

$$
\begin{array}{ll}
\mathrm{M}(x) & =x_{0.50}=(\mathrm{UB} \times \mathrm{LB})^{1 / 2}=\left(1 \times 10^{-2}\right)\left(1 \times 10^{-4}\right)^{1 / 2}=1 \times 10^{-3} \\
\mathrm{EF} & =\mathrm{UB} / \mathrm{M}=1 \times 10^{-2} / 1 \times 10^{-3}=10 \\
\mu_{\mathrm{LN}} & =\ln (\mathrm{M})=\ln \left(1 \times 10^{-3}\right)=-6.907 \\
\sigma_{\mathrm{LN}} & =\ln (\mathrm{EF}) / 1.64=\ln (10) / 1.64=1.40 \\
\underline{\mathbf{x}} & =\exp \left[\mu_{\mathrm{LN}}+1 / 2 \sigma_{\mathrm{LN}}^{2}\right]=\exp \left[-6.907+(1 / 2)(1.40)^{2}\right]=2.7 \times 10^{-3} .
\end{array}
$$

In this case, with an EF of 10, the mean $\underline{x}$ is a factor of 2.7 greater than the median. The UB is a factor of 3.7 above the mean.

The LN distribution is asymmetrical and, because the variable may range over several decades, the distribution presents interesting properties with respect to the relationship of mean to median, and mean to the upper 95 percent confidence limit. Table 9-1 illustrates how the parameter $\sigma_{\mathrm{LN}}$ varies with the EF (note that an EF of 30 indicates a factor of 900 for the ratio of UB/LB). The table also shows how the ratio of mean/median, mean/UB, and $\mathrm{UB} /$ mean vary with $\mathrm{EF}$. The ratio of mean/median ranges from about 1.1 to 8.5 for the range of EF shown, indicating that the mean is within a factor of three or less of the median for EF less than 10 . The ratio of $\mathrm{UB} / \mathrm{mean}$ indicates that the mean is within a factor of about 2 to 4 of the upper bound over the range of EF shown. 
The last column in Table 9-1, CDF (Mean), is the value of the cumulative distribution function (CDF) of the LN evaluated at the mean. This column indicates, somewhat paradoxically, that as the uncertainty increases, characterized by the EF ranging from 2 to 30, the probability that the true value exceeds the mean actually decreases. For example, for an EF of 2, the CDF is 0.58 , meaning that there is 0.58 probability that the true value is less than or equal to the mean, and a probability of 0.42 that the true value exceeds the mean. By contrast, for an EF of 10, the CDF is 0.76 and the complement probability is 0.24 .

Because of the characteristics of the $\mathrm{LN}$, the mean value is a suitable measure for binning event sequence frequencies or for evaluating consequences against regulatory limits.

\subsubsection{Comparison of Output Values with Limits}

The PSA will calculate two kinds of output quantities that must be used in the risk-informed performance-based compliance with 10 CFR Part 63. These variables represent frequency and consequence, respectively. Limits on frequency relate to the boundaries between Category 1 and Category 2, and between Category 2 and Beyond Category 2. Limits on consequences relate to the respective dose limits for the public and workers defined in 10 CFR 63.111.

The PSA will use mean values of frequency and doses. Thus, if the mean value of a dose is 4 rem total effective dose equivalent and therefore less than the limit of $5 \mathrm{rem}$, the result is compliant with the regulations.

Similarly, if the mean value of the frequency of an event sequence is less than $1 \times 10^{-2}$ per yr, the sequence is considered to be Category 2. If the mean value of the frequency of an event sequence is less than $1 \times 10^{-6}$ per yr, the sequence is considered beyond Category 2 .

The uncertainty factors associated with frequency and consequence analyses should be quantified, however. If the PDF for the frequency or consequences of a given event sequence is shown to be lognormally distributed. Table 9-1 illustrates that the mean value is within a factor of 2 to 4 of the 95th percentile upper confidence bound. Therefore, there is confidence that, by using the mean frequency, event sequences will be appropriately categorized with respect to frequency.

As noted is Section 3, the LA for CA will use one-half the regulatory limit as guidance for estimating dose consequences. Therefore, if the mean value of an estimated dose is less than or equal to one-half of the regulatory limit, and the uncertainty in dose is shown to be lognormally distributed, there will be low probability of exceeding the regulatory limits. 
Table 9-1 Properties of the Mean of a Lognormal Distribution

\begin{tabular}{|c|c|c|c|c|}
\hline EF & Mean/Median & Mean/UB & UB/Mean & CDF(Mean) \\
\hline 2 & 1.09 & 0.55 & 1.83 & 0.58 \\
\hline 3 & 1.25 & 0.42 & 2.40 & 0.63 \\
\hline 5 & 1.61 & 0.32 & 3.10 & 0.69 \\
\hline 10 & 2.66 & 0.27 & 3.75 & 0.76 \\
\hline 30 & 8.48 & 0.28 & 3.54 & 0.85 \\
\hline
\end{tabular}

\subsubsection{Propagating Uncertainties in Frequency and Consequence Analyses}

This section describes the principal means for propagating uncertainties. The discussion is based on frequency analyses. Consequence analyses are treated similarly.

The PRA Procedures Guide (NRC 1983) and CPQRA Guidelines (AIChE 2000) describe several methods that could be used for propagating uncertainties. It is noted that direct (analytical) integration of the multivariable probability distribution is generally not possible. The moments method may be used in some situations to combine uncertainties analytically. For complex analyses, the moments methods also appear to be untractable unless the output moments are approximated by using a Taylor series expansion where only second-order terms are retained. Therefore, the favored techniques are numerical integration, which includes the discrete probability method and Monte Carlo simulation.

Since current desktop software like SAPHIRE and Microsoft Excel with an @RISK add-in can perform Monte Carlo simulation, numerical analysis will be the primary technique to be used in frequency and consequence analysis for the PSA. The SAPHIRE workstation permits eleven forms of distribution functions for uncertainty. The analyst must specify the mean and one other parameter, depending on the distribution selected. The following describes the basic steps for sequence uncertainty analysis. The users manual for the particular program (e.g., SAPHIRE) should be consulted.

\subsubsection{Sequence Uncertainty Analysis}

The following are the principal steps for developing an event sequence analysis that includes propagation of uncertainty:

1. Construct the logic models (ET, FT, and human reliability) for the initiating events and systems (see Sections 7.1, 7.2, and 7.3)

2. Obtain and quantify input information for each basic event and initiating event used in the logic models, including quantification of uncertainty distribution (see Section 7.5)

3. Perform sequence quantification analysis to generate minimal cutsets and point estimates (see Section 7.1) 
4. Select method for uncertainty analysis. For simple sequences, it may be appropriate to use Microsoft Excel with the @ RISK add-in. If the event sequence quantification is performed in a program like SAPHIRE (Smith et al. 2000), however, it will be more efficient to use the uncertainty propagation that is built in. The analysis may be performed on individual sequences, group, or family. For example, it may be necessary to add the frequencies of two or more Category 1 sequences for the same or different initiating events for a given repository operations area. For either @ RISK or SAPHIRE, the analyst must select either Monte Carlo or Latin hypercube, number of trials, and random number seed.

5. Obtain tabular and graphical outputs of uncertainty analysis. The output of sequence uncertainty analysis typically includes: mean, median, standard deviation, 5th and 95th percentiles, maximum and minimum (for the run of $\mathrm{N}$ samples), seed number, and sample size.

6. Interpret results. Examine acceptability of results and identify dominant contributors to sequence frequency and uncertainty in results

The sequence uncertainty analysis will be used primarily to generate the mean and EFs to evaluate sequence categorization and to demonstrate compliance with 10 CFR Part 63. Where appropriate, sequence sensitivity analysis will be performed.

\subsubsection{System (Fault Tree Top Event) Uncertainty Analysis}

The steps for evaluating system uncertainty are essentially the same as for the event sequence uncertainty analysis, and are not repeated here.

The system uncertainty analysis will be used primarily to generate insights into the dominant contributors to system reliability and safety performance. Where appropriate, system sensitivity analysis or importance measure (IM) will be obtained.

\subsubsection{Uncertainties in Consequences}

Section 8 describes the approach to consequence analyses for the PSA. Analyses for Category 1, Category 2, and Beyond Category 2 event sequences are described. The bases for identifying and treating uncertainties are discussed, including the use of conservative or bounding values, where appropriate.

\subsubsection{Uncertainty Analysis versus Sensitivity Analysis}

Some sources of uncertainty, especially modeling uncertainties, cannot be analyzed by assigning a PDF, but insights on their significance may be investigated quantitatively through sensitivity analysis. 
A sensitivity analysis for event sequence frequency analysis is performed by changing features of logic models, human reliability models, input parameter values, or the features of the physical facility or operations. In general, a sensitivity analysis examines rather large-scale changes such as:

- $\quad$ Changing the redundancy of a system (i.e., adding a train or deleting a train)

- $\quad$ Changing the probability of a basic event (hardware, software, or human failure) from a best-estimate probability to a bounding value (i.e., to 1.0 or to 0.0 )

- $\quad$ Changing the failure logic by adding or deleting elements, such as adding or deleting an alarm that alert the human operator to take action (e.g., using AND logic).

Such changes are made one at a time in fault tree and event sequence quantification so the output can be compared to the baseline result.

In addition, a sensitivity analysis can be used to evaluate the effect of changing the assumed probability distribution for an input parameter. If it is uncertain, for example, whether to use a LN or a normal distribution for a particular input, the alternative distributions are used and results compared.

A sensitivity analysis of consequences is performed by changing source term parameters (i.e., age and burnup, and fraction of inventory that is released) and the presence of mitigating features (i.e., high-efficiency particulate air filters and deposition). The process is essentially the same as for frequency analysis.

\subsubsection{Importance Measures Analysis}

Importance analysis may be regarded as a special form of sensitivity analys is. There are several standard definitions of importance measures (IMs) that have been applied in PRAs and regulatory evaluations. An importance analysis can be performed on fault trees or event sequence frequency quantification. Analysis of the standard IMs is performed automatically by programs such as SAPHIRE. Therefore, the discussion here is brief.

In fault tree analysis for a system, the top event represents the probability that the defined event will occur (e.g., HVAC fails to run and filter particulates for at least 24 hours). Suppose the fault tree analysis shows the mean probability is $1 \times 10^{-4}$, and lists all of the cutsets (products of basic event probabilities) above a cutoff probability of $1 \times 10^{-7}$. The value for all of the cutset and top event probabilities are subject to the values input for basic event probabilities.

The importance analysis can be used to analyze the sensitivity of the result to the inputs in the following way:

1. The risk-achievement worth (RAW) of every basic event, with respect to output, is calculated by setting the probability of each basic event to 1.0 one-at-a-time while holding the baseline values of probabilities of all of the other basic events. The analysis program then produces a table, which ranks every basic event according to its RAW value. The RAW for a given structure, system, or component (SSC) represents 
the increase in system failure probability if the SSC is removed from the system model. The RAW, like the Birmbaum Importance (BI), may be interpreted as a measure of the margin of safety contributed by proper operation of the model element (e.g., a given SSC).

2. The risk-reduction worth (RRW) of every basic event, with respect to output, is calculated by setting the probability of each basic event to 0.0 one-at-a-time while holding the baseline values of probabilities of all of the other basic events. The analysis program then produces a table, which ranks every basic event according to its RRW value. The RRW for a given SSC represents the decrease in system failure probability if the SSC is perfectly reliable.

3. The BI is calculated, in essence, by taking the difference between the RAW and RRW for each basic event. The analysis program produces a table, which ranks every basic event according to its BI value. The BI is interpreted as a measure of the margin of safety contributed by proper operation of the model elements (e.g., the SSCs). The BI is sometimes interpreted as the maintenance importance for a given SSC (i.e., the importance of keeping it operational). Because the RRW is usually small compared to the RAW, the BI is usually quite close to the RAW numerically.

4. Fussell-Vesely Importance (FV) is calculated, in essence, by taking the product of each basic event probability multiplied by its BI (there are other, more fundamental definitions of FV). The analysis program produces a table, which ranks every basic event according to its FV value. The FV illustrates the fraction of current risk (or top event probability) involving the failure of the model element (i.e., a particular SSC).

Such IMs provide insight to the dominant contributors to system failure and can be used to develop risk-informed maintenance, quality assurance, and training programs. Further, IMs can be used to scope an uncertainty analysis where more attention is given to identifying and quantifying uncertainties in the basic events that have the dominant IMs.

When sequence quantification is performed by the fault-tree linking method (see Sections 7.1 and 7.2), the top event becomes the frequency that the sequence occurs. All of the sequence cutsets include the initiating event frequency times one or more basic event probabilities. Since the initiating event frequency is common to all, it can be set equal to 1.0 and the IMs of the remaining cutsets are evaluated as described above.

The application of IMs has been described in Regulatory Guide 1.174. In those applications, the baseline risk is a measure of integral risk like core-damage frequency of a reactor core damage that stems from multiple event sequences. The change in core-damage frequency is calculated using the RAW, RRW, BI, and FV. 10 CFR Part 63 does not define an integral risk measure for the MGR. Therefore, the application of IMs will be limited to developing insights on SSC risk significance of exceeding dose limits specified in 10 CFR Part 63. 


\subsection{REFERENCES}

\subsubsection{Documents Cited}

AIChE (American Institute of Chemical Engineers) 1989. "Partial List of External Events." Table 3.13 of Guidelines for Chemical Process Quantitative Risk Analysis. New York, New York: American Institute of Chemical Engineers. TIC: 241701.

AIChE 2000. Guidelines for Chemical Process Quantitative Risk Analysis. 2nd Edition. Center for Chemical Process Safety Series. New York, New York: American Institute of Chemical Engineers.

NRC (U.S. Nuclear Regulatory Commission) 1983. PRA Procedures Guide, A Guide to the Performance of Probabilistic Risk Assessments for Nuclear Power Plants. NUREG/CR-2300. Two volumes. Washington, D.C.: U.S. Nuclear Regulatory Commission. TIC: 205084.

NRC 1987. Standard Review Plan for the Review of Safety Analysis Reports for Nuclear Power Plants. NUREG-0800. LWR Edition. Washington, D.C.: U.S. Nuclear Regulatory

Commission. TIC: 203894.

NRC 2001. Regulatory Analysis Technical Evaluation Handbook. Washington, D.C.: U.S. Nuclear Regulatory Commission. NUREG/BR-0184.

Smith, C.L.; Wood, S.T.; Kvarfordt, K.L.; McCabe, P.H.; Fowler, R.D.; Hoffman, C.L.; Russell, K.D.; and Lois, E. 2000. Testing, Verifying, and Validating SAPHIRE Versions 6.0 and 7.0. NUREG/CR-6688. Washington, D.C.: U.S. Nuclear Regulatory Commission. TIC: 249459.

\subsubsection{Codes, Standards, Regulations, and Procedures}

10 CFR 63. 2002. Energy: Disposal of High-Level Radioactive Wastes in a Proposed Geologic Repository at Yucca Mountain, Nevada. Readily available.

Regulatory Guide 1.174, Rev. 01 Draft. 2001. An Approach for Using Probabilistic Risk Assessment in Risk-Informed Decisions on Plant-Specific Changes to the Licensing Basis. Washington, D.C.: U.S. Nuclear Regulatory Commission. Readily available. 


\section{INTENTIONALLY LEFT BLANK}




\section{EXTERNAL EVENTS}

This section of the PSA Guide identifies the methods and steps that will be used to perform safety evaluations for natural phenomena and human induced interacting events that are beyond the direct control of the respository, which are termed "external events." This section provides a bridge between the external events hazards analysis (Section 6.1) and the design bases (Section 13) that will help prevent the occurrence of credible event sequences that do not meet the performance objectives of 10 CFR Part 63. The methodology and steps in this section provide the means to:

- Identify structures, systems, and components (SSCs) that need to withstand credible external events and thereby prevent a radiological release.

- Describe methods to develop controls that prevent credible release scenarios given the occurrence of the initiating event.

External events covered in this section are categorized as:

- Seismic Analysis

- $\quad$ Flooding

- $\quad$ Winds and Tornadoes

- $\quad$ Lightning and Extreme Weather

- $\quad$ Fires

- $\quad$ Other External Events.

The approaches discussed and the scope of information presented herein varies depending on the type of external event.

\subsection{SEISMIC ANALYSIS}

\subsubsection{Introduction}

This section describes the bases and methods for analyzing the design of surface and subsurface repository facilities and waste packages for potential vulnerability to seismically-induced event sequences that could lead to a radiological exposure, radiological release, or criticality. The preclosure safety strategy (see Section 3) includes the prevention of credible scenarios that could lead to potential consequences that exceed the performance requirements of 10 CFR Part 63 . The seismic design strategy for preclosure safety is based on establishing the appropriate combination of design basis ground motion (DBGM) levels and design procedures that will provide reasonable assurance of meeting preclosure safety performance objectives given in 10 CFR 63.111. The bases and methods described herein provide analytic support to the seismic design strategy presented to the NRC in a series of seismic topical reports. 
This section has three main objectives to guide the preclosure safety analyst:

1. To provide a summary of the relevant regulatory bases including their application in Project seismic topical reports and a summary of the preclosure seismic design strategy (Section 10.1.2)

2. To provide guidance and methods for assigning DBGM to SSCs ITS (Section 10.1.3)

3. To provide guidance and methods for evaluating the frequencies and consequences of seismic event sequences, and for demonstrating compliance to 10 CFR Part 63 for seismic event sequences (Section 10.1.4).

\subsubsection{Regulatory Bases and Preclosure Seismic Design Strategy}

\subsubsection{Regulatory Bases, Precedents, and Seismic Topical Reports}

The preclosure seismic safety and design approaches adopt precedents from the regulations and design approaches that have been applied in the licensing of nuclear power plants (NPPs). Such precedents are modified as appropriate for the characteristics of the MGR and the governing regulations (10 CFR Part 63). This section provides perspective to the preclosure safety analyst.

Precedents from Nuclear Power Plants (NPPs)-Commercial NPPs are regulated under 10 CFR Part 50 and 10 CFR Part 100. The licensing basis for an NPP includes the definition of a design basis earthquake, termed a safe shutdown earthquake (SSE), for which ground motion parameters are designed as input to the design of SSCs that are designated as safety related using 10 CFR Part 50 terminology. The regulations require that safety-related SSCs be designed to withstand the vibratory motions associated with the SSE. Safety-related SSCs for nuclear reactor systems are classified as a single category termed Seismic Category 1 SSCs. The list of Seismic Category 1 SSCs for NPPs is prescribed. For NPPs, it is deterministically argued that if an earthquake of intensity greater than the SSE does not occur at the site, then there will be no seismically-induced accident sequences that cannot be prevented or mitigated such that the plant cannot be brought to a safe condition.

Design input parameters for the SSE include the peak ground acceleration (PGA) and other characteristics of the vibratory ground motion, such as spectral acceleration and time-history. Approved regulatory guides and industry codes and standards are applied in the design. Principles and approaches for seismic design are provided in Section 3.7 of the Standard Review Plan for the Review of Safety Analysis Reports for Nuclear Power Plants (NRC 1987).

For NPPs licensed prior to January 1997, the ground motion parameters of the SSE have been defined deterministically, based on the largest historical earthquake for the site in accordance with Appendix A to 10 CFR Part 100. For these licensees, the probability of occurrence of the SSE was not considered or used in the initial licensing basis for most NPPs. For NPPs that applied for licenses after January 1997, probabilistic seismic hazard analysis is used to define the ground motion intensity that corresponds to a mean annual probability of exceedance of $1 \times 10^{-4}$. The regulatory bases for NPPs are provided in 10 CFR 100.23 and Regulatory Guide 1.165. This approach was adapted in Preclosure Seismic Design Methodology for a Geologic Repository at Yucca Mountain (YMP 1997), a.k.a. Seismic Topical Report No. 2, as described in 
the following paragraphs. Seismic probabilistic risk assessments (PRAs) for NPPs of all vintages, such as those performed for existing plants as part of the NRC program for Individual Plant Examination - External Events (IPEEE), use the probabilistic seismic hazard curve (PSHC) as one of the inputs to the risk analysis. The PSHC is a plotted graph depicting the annual probability of exceedance for a range of earthquakes of various intensities. Because of uncertainties, the PSHC is represented by a family of curved lines. In many applications, the mean PSHC suffices.

The seismic risk analysis determines the annual probability (frequency) of a seismically initiated sequence of events for which the NPP cannot be brought to a safe condition. Such sequences may contribute to the overall probability of a severe accident. The seismic PRA expresses results in terms of the core damage frequency (CDF) or large early release frequency (LERF) that is attributed to seismic events.

Regulatory Bases for the Monitored Geologic Repository (MGR)-Seismic Topical Report No. 2 (YMP 1997) adapts the NPP seismic design precedents to the MGR and requires that SSCs that are important to safety (ITS), using 10 CFR Part 63 terminology, must withstand a design basis earthquake. Unlike the prescriptive list of Seismic Category 1 SSCs provided by NPP regulations, SSCs ITS for the MGR have to be identified according to radiological performance criteria as part of the PSA (see Section 4 and Section 12), which leads to a more complex application of NPP precedents.

As described in Section 12, SSCs are designated ITS if they are credited in demonstrating compliance with the dose limits of 10 CFR 63.111. Credit for an SSC ITS may be preventative or mitigative. As noted in Section 4, a compliance evaluation considers both the frequency and the doses associated with any event sequence to which the success or failure of an SSC contributes. A given SSC may be credited for ensuring that the frequency is Category 1, Category 2, or Beyond Category 2 (BC2) and/or for mitigating doses to comply with 10 CFR 63.111. The limiting doses are: (1) offsite dose of 15 mrem worker dose of 5 rem for Category 1, and (2) offsite dose of 5 rem for Category 2. Thus, 10 CFR Part 63 introduces a two-tiered performance basis based on event sequence frequency.

Seismic Topical Report No. 2 (YMP 1997) assigns a corresponding two-tiered seismic design basis that results in the following reference values for design-basis earthquakes:

- Frequency Category 1 refers to a mean annual probability of $1 \times 10^{-3}$ for vibratory ground motions.

- $\quad$ Frequency Category 2 refers to a mean annual probability of $1 \times 10^{-4}$ for vibratory ground motions.

- Frequency Category 1 refers to a mean annual probability of $1 \times 10^{-4}$ for fault displacement.

- Frequency Category 2 refers to a mean annual probability of $1 \times 10^{-5}$ for fault displacement. 
Topical Report No. 2 (YMP 1997) was written and reviewed by the NRC according to the regulations of 10 CFR Part 60. The fundamental approach in Topical Report No. 2 (YMP 1997) can be adapted to address 10 CFR Part 63 since the two-tiered Category 1 and Category 2 event sequence structure was retained in $10 \mathrm{CFR}$ Part 63. However, as described in the following paragraphs, the nomenclature will be modified in seismic analysis and design to support LA. The following paragraphs summarize the impact of moving from $10 \mathrm{CFR}$ Part 60 to 10 CFR Part 63.

Impact of 10 CFR Part 63 on Applicability of Seismic Topical Report No. 2 (YMP 1997)The principal differences between 10 CFR Part 60 and 10 CFR Part 63 are: (1) the change from prescriptive design requirements to risk-informed performance-based requirements, and (2) a quantified basis for limiting credible event sequences per the definition of Category 2 in 10 CFR 63.2. Both 10 CFR Part 60 and 10 CFR Part 63 require consideration of credible natural phenomena in the design of the repository, and both require the use of Category 1 and Category 2 designations for event sequences (or "design basis events" in the case of 10 CFR Part 60). Therefore, until revised or noted otherwise, Topical Report No. 2 is considered to remain applicable for establishing seismic design under 10 CFR Part 63.

For a number of reasons, the nomenclature for the design earthquakes has been modified in this guide. The design earthquakes for SSCs ITS are termed DBGM-1 and DBGM-2, respectively, to represent the two-tiered design bases. DBGM-1 refers to the acceleration and other ground motion parameters associated with a mean annual probability of exceedance of $1 \times 10^{-3}$. The term DBGM-2 refers to the acceleration and other ground motion parameters associated with a mean annual probability of exceedance (MAPE) that is less than $1 \times 10^{-3}$, but may be greater than $1 \times 10^{-4}$. For example, DBGM-2 may be defined as having a MAPE of $5 \times 10^{-4}$. The preclosure seismic safety and design strategy will demonstrate that the MGR designed to withstand DBGM-1 and DBGM-2 ground motions complies with performance requirements of 10 CFR 63.111.

The PSA analyst should be aware of the following when applying Seismic Topical Report No. 2:

- Regulatory references in the report will have to be interpreted as referring to the appropriate sections of 10 CFR Part 63 instead of 10 CFR Part 60. For example, the radiological performance requirements are provided in 10 CFR 63.111.

- $\quad 10$ CFR 63.2 gives a quantitative probability in the definition of Category 2 event sequences while 10 CFR Part 60 gives a qualitative definition. The introduction of the quantitative definition of Category 2 event sequences results in an additional burden in the PSA to demonstrate compliance with 10 CFR Part 63 for seismic event sequences. The means to deal with the compliance issues are discussed in Section 10.1.4.

- $\quad 10$ CFR Part 63 considers seismic events to be just another category of initiating events to be considered in defining Category 1 and Category 2 event sequences.

- $\quad$ Appendix B to Seismic Topical Report No. 2 describes the process for assigning DBGM categories to SSCs ITS. The process assumes the 10 CFR Part 20 dose limit of 100 mrem would be applied to determine which SSCs are assigned the Frequency Category 1 design 
basis earthquake currently termed DBGM-1. However, 10 CFR 63.111 and 10 CFR 63.204 invoke the final Environmental Protection Agency preclosure standard for Category 1 event sequences (e.g., 15 mrem annual dose to the environment). So, applying the process described in Appendix B, in accordance with 10 CFR Part 63, SSCs necessary to prevent or mitigate a dose of 15 mrem must be designed to withstand the DBGM-1 earthquake.

One difficulty in applying Topical Report No. 2 to the 10 CFR Part 63 framework is that the frequency of the initiating earthquake for DBGM-1, at $1 \times 10^{-3}$ per year, is already below the frequency cutoff assumed for Category 1 event sequences in other event sequence analyses.

The change from the qualitative to quantitative definition of Category 2 cutoff probability has an effect on the strategy for preclosure seismic safety. Under the qualitative definition of Category 2 "designed basic events" used in 10 CFR Part 60 and the NPP precedents, it was interpreted that an SSC designed to DBGM-2 would preclude a credible seismic event sequence during the preclosure period. However, the quantitative definition of Category 2 in $10 \mathrm{CFR}$ Part 63 suggests that the seismic design of an SSC must include sufficient margin to ensure a probability of less than one chance in 10,000 in the preclosure period for any seismic event sequence that results in a dose equal to, or greater than, the limits of 10 CFR 63.111. This interpretation is the basis for performing a seismic risk analysis or seismic margins analysis in the compliance demonstration (see Section 10.1.4).

Design Requirements per Seismic Topical Report No. 2 (YMP 1997)-The basis philosophy and approach for adapting NPP seismic design methodology is defined in Topical Report No. 2. The report provides design principles for the following four categories of facilities and SSCs:

1. Surface facilities

2. Underground openings

3. Other underground SSCs

4. Waste packages.

Seismic design principles are provided for both vibratory ground motion and ground fault displacement. In the case of ground fault displacement, event sequence initiation is prevented by the avoidance of ground faults in the design of surface and subsurface facilities.

Underground openings are to be designed in accordance with techniques that are appropriate to mines and tunnels, as described in Section 3.3 of Topical Report No. 2. Waste packages are to be designed in accordance with the structural requirements to sustain confinement of radioactivity in the event of any one of several design-basis drops, slapdowns, and other impacts that may occur during handling operations and seismic loading (see Section 5 of Topical Report No. 2).

As described in Section 3.2 of Topical Report No. 2, SSCs ITS in the surface facilities are to be designed in accordance with the seismic design acceptance criteria in the Standard Review Plan (NRC 1987, Section 3.7.1, Section 3.7.2, Section 3.7.3, and Section 3.7.10). Per Section 3.4 of Topical Report No. 2, SSCs ITS in the subsurface facilities (other underground SSCs) are also to 
be designed accordance with the seismic design acceptance criteria in the Standard Review Plan (NRC 1987, Section 3.7.1, Section 3.7.2, Section 3.7.3, and Section 3.7.10).

The Project will employ a preclosure seismic design strategy as summarized in Section 10.1.2.2.

\subsubsection{Preclosure Seismic Design Strategy}

The preclosure seismic design strategy will include three essential components:

1. Design Basis Ground Motion and Design Procedures-SSCs ITS will be designed to withstand vibratory ground motions associated with specified frequency categories of DBGMs. Such designs will ensure that safety functions credited to a given SSC are available for ground motions up to and including each DBGM. Two DBGMs will be specified in accordance with their respective mean annual exceedance probabilities. DBGM-1 refers to mean annual probability of exceedance of $1 \times 10^{-3}$, and DBGM-2 refers to a lower annual probability of exceedance. The seismic design requirements for SSCs ITS, either DBGM-1 or DBGM-2, are assigned in accordance with the relative importance of a given SSC to preventing or mitigating radiological risk to the public or workers, as described in Section 10.1.3. To ensure adequate levels of conservatism, the codes, standards, and acceptance criteria for design solutions will be those given for NPP design in the Standard Review Plan (NRC 1987; NRC 1997) that are determined to be applicable to SSCs per Topical Report No. 2 (YMP 1997).

The role of the PSA group is to identify SSCs ITS and to designate which of the two DBGMs should be assigned to a given SSC.

2. Structural and Fragility Analyses-Structural analyses are performed to demonstrate that an SSC ITS that is designed for a particular level of DBGMs will respond to higher ground motions within the elastic range, or limited inelastic range, of the materials of construction, thus precluding the loss of its credited safety function even at a beyond-design basis condition. The output of such analyses include the fragility functions (Section 10.1.4.2) and/or the high confidence of low probability of failure (HCLPF) acceleration values (Section 10.1.4.3) for SSCs ITS. Such analyses will support the application of seismic risk and margins analysis methods.

Design engineering personnel will perform the structural analysis and fragility analyses.

3. Demonstration of Regulatory Compliance-Seismic event sequences are analyzed with methods of seismic PRA or seismic margins analysis (SMA) to demonstrate that the probability of exceeding dose limits of 10 CFR 63.111 is not credible.

This portion of the seismic design strategy will be a joint effort by the PSA group and structural engineering personnel.

The remainder of Section 10.1 provides direction on performing the preclosure seismic safety analyses to support the seismic design strategy. Examples presented herein are based on hypothetical situations and the names of the buildings and facilities may not be used in the actual 
LA for CA. None of the hypothetical values of event sequence frequencies or doses used in the following examples should be taken as results applicable to a repository.

\subsubsection{Summary of Preclosure Safety Seismic Analysis to Support Seismic Design and LA}

The seismic analysis portion of the PSA will address potential seismically-induced event sequences through a comprehensive hazards analysis and event sequence analysis as a process to identify SSCs ITS.

The first part of the PSA seismic analysis comprises the assignment of DBGM frequency categories to SSCs ITS. The bases for such analyses are described in this section. Details of approaches for those analyses are presented in Section 10.1.3. The second part comprises the demonstration of regulatory compliance through evaluation of seismic event sequence frequencies and seismic risk analysis. Details of approaches for the latter analyses are presented in Section 10.1.4.

As discussed in Topical Report No. 2 (YMP 1997), acceptable seismic safety is achieved through a combination of using the reference probability level of DBGM and the conservatism in design procedures, acceptance criteria, codes, and standards. The identification of each SSC ITS is made on the basis of the SSC being part of the minimal set of SSCs that are necessary to demonstrate compliance with 10 CFR 63.111 and 10 CFR 63.112. Some SSCs become ITS only because of potential seismically initiated event sequences while other SSCs ITS will be identified from analysis of event sequences initiated by non-seismic events.

All SSCs ITS must be assigned a DBGM. The DBGM that is assigned to a given SSC depends on the dose that would result if the safety function of that SSC were postulated to be lost due to the occurrence of an earthquake. Table 10-1 defines the DBGM assignments in accordance with the dose limits derived from 10 CFR 63. 111.

Table 10-1 Bases for Assigning Design Basis Ground Motions to SSCs IT

\begin{tabular}{|c|c|c|c|c|}
\hline $\begin{array}{c}\text { Consequences of } \\
\text { Loss of Safety } \\
\text { Function of SSC }\end{array}$ & $\begin{array}{c}\text { Worker } \\
\text { Dose } \\
=\mathbf{5} \text { rem }\end{array}$ & $\begin{array}{c}\text { Public Dose } \\
=\mathbf{1 5} \mathrm{mrem}\end{array}$ & $\begin{array}{c}\text { Public Dose } \\
=\mathbf{5} \mathrm{rem}^{(1)}\end{array}$ & $\begin{array}{c}\text { Criticality } \\
\text { Condition }\end{array}$ \\
\hline DBGM for SSC & DBGM-1 & DBGM-1 & DBGM-2 & DBGM-2 \\
\hline
\end{tabular}

Note: ${ }^{(1)}$ Any seismic event sequence that results in a breach of a DOE SNF canister is assumed to exceed $5 \mathrm{rem}$ at the site boundary for the purposes of assigning DBGM-2. As noted in Section 8 , doses from such canister breaches will not be explicitly calculated.

\subsubsection{Methods for assigning Design Basis Ground Motion (DBGM) to SSCs Important to Safety}

The assignment of DBGMs to SSCs ITS must address the following situations:

1. Seismic initiation of event sequences associated with internal events (e.g., drops of waste forms, disruption of power supplies) and concurrent seismically induced failure 
of SSCs in an event sequence (e.g., loss of heating, ventilation, air conditioning, high-efficiency particulate air filtration)

2. Event sequences that can only be initiated by seismic ground motion (e.g., failure of storage racks full of spent-fuel assemblies, collapses of roofs or walls of structures housing radioactive material)

3. Common-cause or correlated seismic effects in event sequences in concurrent operations (e.g., consideration of the simultaneous occurrence of multiple event sequences in the same or different buildings initiated by a seismic event).

\subsubsection{Summary of Process for Assigning DBGMs}

The following steps are applied to assign DBGM levels to SSCs:

1. Review available design descriptions, drawings, and list of SSCs ITS.

2. Review available hazards, event sequences, criticality scenarios, and consequence analyses for events initiated by internal events, internal fires, and internal floods.

3. Define the scenarios by which radionuclides could potentially be released by event sequences initiated by an earthquake. The postulated scenarios include:

a. The failures of SSCs directly associated with the handling, storing, or containment of radioactivity, of HLW forms.

b. SSCs that could interact with SSCs associated with the handling or storage of HLW forms.

c. The failure of fire protection systems.

d. Radioactive waste treatment systems.

4. The analysis may build on prior hazards analyses or event sequence analyses that have been developed for internal events, internal fires, internal floods, and criticality scenarios. Event sequence diagrams (ESDs) and seismic event trees (SETs) may be constructed as described in Section 10.1.3.2, to aid in identifying potential seismic scenarios.

5. Calculate the dose that could result from each postulated failure of a given SSC and the resulting radiological release. Calculate doses with, and without, mitigation features if mitigation is currently used in the design or if mitigation could be applied. If it is known or expected that releases or exposures could exceed the regulatory limit for Category 2 event sequences (or uncertainties in source terms and resulting doses make the doses unquantifiable as is the case of DOE SNF and HLW) then explicit doses will not be calculated (see Section 8, Consequence Analyses). 
6. Subject each SSC to the following dose comparisons, based on the dose limitations derived from 10 CFR Part 63 and listed in Table 10-1.

a. The principal guideline from 10 CFR 63.111(b)(2) is a public dose less than 5 rem total effective dose equivalent (TEDE) for the public. If the individual offsite dose is greater than or equal to 5 rem TEDE or if it cannot be quantified, but is suspected to be unacceptable, then the SCC is assigned DBGM-2

b. If the offsite dose is less than the 5 rem TEDE limit of 10 CFR 63.111(b)(2), but is greater than or equal to the 15 mrem limit specified by 10 CFR 63.204, then the SSC must be designed to withstand at least the vibratory ground motion of DBGM-1. The guidelines of 10 CFR 63.111(a) for Category 1 event sequences include paragraph(1), which requires meeting 10 CFR Part 20 limits. If a given SSC has been designated as ITS because it must function to ensure that worker doses are within the limits of per 10 CFR 20.1201, then the SSC is assigned DBGM-1.

c. If an SSC must function to prevent a criticality condition, then the SSC is assigned DBGM-2.

d. If both the offsite doses and worker doses are less than the 10 CFR 63.111(a) requirements for both workers and the public and no criticality is involved, then the SSC may be designated as non-seismic and designed accordingly (e.g., to the International Building Code).

\subsubsection{Application of Event Sequence Diagrams and Seismic Event Trees}

Section 7.1 describes the techniques used in ET construction and analyses for any initiating event, either an internal event or an external event. Section 7.1 also describes the treatment of dependent failures between ET event headings and initiating events. The ET modeling of dependent failures represents failures that are induced, or made more probable, by the occurrence of a preceding event. Earthquakes, fires, floods, winds and tornadoes, and loss of offsite power (LOSP) are potentially significant because they can act as common-cause initiators that initiate an event sequence and can concurrently induce failure of SSCs included in the design to prevent or mitigate unwanted consequences. The ET format helps to define the potential event sequences and potential common-cause vulnerabilities. Any common-cause vulnerabilities that could result in an unacceptable dose are identified and associated SSCs are designed to withstand the common-cause initiator. In the case of earthquakes, each SSC ITS is required to withstand one of the DBGM levels designated as DBGM-1 or DBGM-2.

Seismic event trees (SETs) are used to model seismically induced sequences. SETs may be built on ETs developed previously for internal or external event initiators. These are termed seismic event trees (SETs). The cause of the initiating event in a previously constructed ET (e.g., fuel assembly drop, LOSP, fire) is assumed in the seismic event tree (SET) to be an earthquake, rather than a random failure $(\mathrm{RF})$ as used in the original ET. 
Construction of an event-sequence diagram (ESD), discussed in Section 10.1.3.2.1, may aid in the creation of a SET. The potential for common-cause failures among SSCs induced by the earthquake can be diagramed on the ESD. These dependencies are accounted for in the structure of the SET.

Initially, the SET is applied qualitatively without the consideration of eve nt frequencies with an assumed total dependence between the initiating earthquake and ET heading for preventive and mitigating safety functions. Total dependency means that the safety function of a given SSC is lost on the occurrence of an earthquake of any intensity. The assumed total dependency helps to define the potential vulnerabilities and consequences and the need for seismic design of SSCs. Consequences associated with each sequence of events are quantified and a DBGM is assigned to each SSC per the guidance outlined in Table 10-1. After a given SSC is designed to withstand a particular DBGM, the total dependency of the SSC with the earthquake initiator is removed from the SET and replaced with a conditional probability of failure, conditioned on the intensity of the earthquake. The conditional probability is termed a fragility function.

The fragility function expresses the probability of failure (loss of safety function) conditioned on the intensity (e.g., peak ground acceleration) of the earthquake. Fragility functions for various SSCs are used in the seismic PRA approach to a demonstration of compliance, described in Section 10.1.4.2. As an alternative to the use of fragilities, the dependent failures of the SSC in the SET can be analyzed by the seismic margins approach described in Section 10.1.4.3.

\subsection{Seismic Event Sequence Diagrams}

An ESD is a less rigid structure than the binary branching structure of an ET. It allows the analyst to respond to the question of what can happen in a brainstorming mode. Several examples of ESDs are described to illustrate how they are constructed and modified to include earthquakes and intermediate events. The example ESDs are simplified whereas detailed ESDs are often used as alternatives to ETs.

Figure 10-1 illustrates an example ESD for a drop of a waste form (e.g., an SNF assembly in the waste handling building (WHB). In this Guide, WHB is used as a functional description and not a particular building name. The hypothetical WHB includes a heating, ventilation, and air conditioning (HVAC) system with a high-efficiency particulate air (HEPA) filter. The initiating event is entitled Drop. In the example, the cause of the drop is not a seismic event (discussed later in the section). The immediate effect of the drop (what can happen) is assumed or known to be a release of radioactivity from breached fuel rod cladding. The assumed safety functions for the example are the confinement and filtering of releases provided, respectively, by the transfer cell structure of the WHB and the HVAC/HEPA system. To develop the ESD, alternative sequences are created for cases where the confinement and/or filtering function(s) are functioning or are not functioning.

If the confinement is not functioning, the radioactivity release may be assumed to go directly to the environment, thereby bypassing the HVAC/HEPA filters. The consequence of this sequence of events (drop-release-not confined) is not mitigated and may not meet the regulatory dose limits. If the confinement is functioning, another answer to the question of "what can happen?" 
is the failure of the HVAC/HEPA to filter the release. The consequences of this sequence (droprelease-confined-not filtered) is also not mitigated and may exceed the regulatory dose limits.

Initial Internal Event

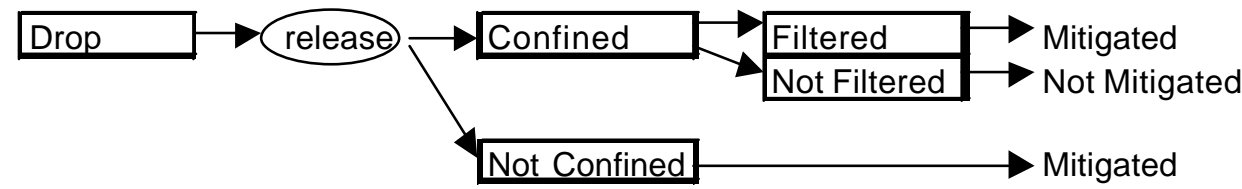

NOTE: All failure events are random.

Figure 10-1. Event Sequence Diagram for Internal Initiated Drop Event

Figure 10-2 illustrates how the example ESD is modified for an earthquake initiator. The top portion of the diagram starting with Drop includes the same events as the non-seismic case illustrated in Figure 10-1. An event entitled No Drop has been added to illustrate that the earthquake may not induce a drop for the particular lifting device, especially if it has been designed to withstand an earthquake of a given ground motion intensity. This diagram also indicates, by dashed lines, the possibility that the earthquake may directly and concurrently induce failure of the safety functions of the confinement structure and the HVAC/HEPA filter system. The consequences for the various sequences are assumed to be the same as for the internally initiated drop, although each situation has to be evaluated for potential exacerbating factors brought about by the earthquake. An example of an exacerbating factor is how previously trapped particulates in the HEPA filter might be released if the HEPA filter is failed by the earthquake, thus giving a higher consequence than the base case.

Another potential exacerbating factor might be an increase in human failure probability brought on by the additional stress on the operator following the earthquake. If credit is taken for an operator action to help in mitigation, for example, the restart of the HVAC/HEPA system, then the likelihood of the loss of that safety function is increased and must be accounted for in the demonstration of compliance analysis.

The SET for this case is described in Section 10.1.3.2.2.

\section{Earthquake initiator}

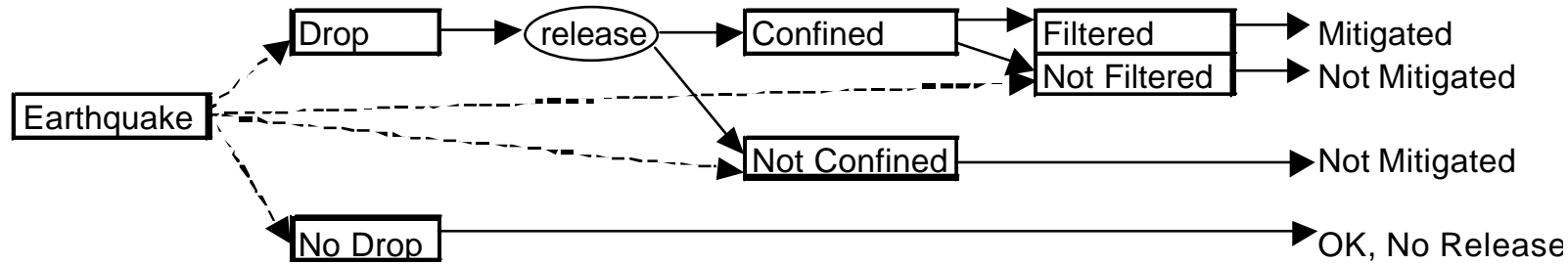

NOTE: Failures events may be random or seismic. Potential seismic interactions/failures indicated by dashed lines.

Figure 10-2. Event Sequence Diagram for Seismic Initiated Drop Event 
More complex seismic scenarios can be modeled in ESDs before developing SETs. Figure 10-3, for example, illustrates an ESD for internal fire-induced sequences. The ESD in Figure 10-3 is seen to have the same structure as the earthquake-only case presented in Figure 10-1. The internal-fire ESD is modified in Figure 10-4 to include an earthquake as an initiating event. The earthquake may cause the fire or several fires and, in turn, the fire(s) may induce the Drop and/or other failures of safety systems, or the earthquake may concurrently cause the Drop and/or other failures as well as initiate the fire. Potential consequences of these hypothetical scenarios could include both radiological and non-radiological releases. Only radiological consequences are considered in the determination of ITS classification of SSCs or assignment of a DBGM. A SET for the earthquake-fire cases is not developed in this guide, as it would be too general and speculative. As necessary, the PSA team will develop SETs specific to the design of the MGR.

Similar ESDs could be developed for LOSP sequences. The ESD would have a similar structure as the earthquake-only case in Figure 10-2, except that there can be no LOSP-induced failures of the confinement. However, depending on the design of the lifting device, HVAC/HEPA filters, and the electrical supply system, it may be possible for a LOSP event to concurrently cause a drop and induce failure of the HVAC/HEPA filters. The earthquake-LOSP case is not developed in this guide, as it would be too general and speculative. As necessary, the PSA team will develop SETs specific to the design of the MGR.

Fire initiator

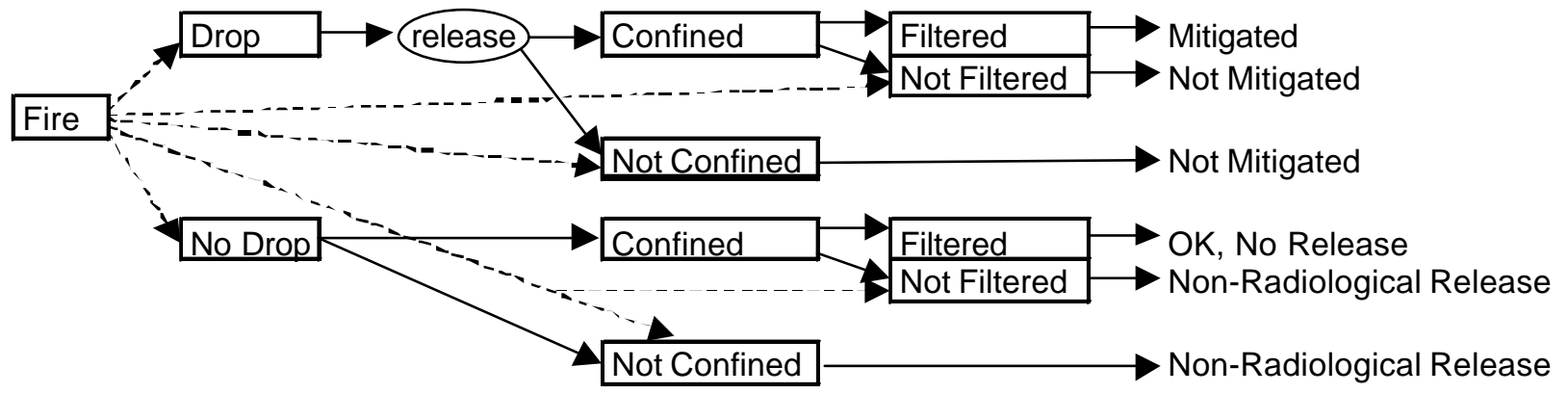

NOTE: Failures events may be random or fire induced. Potential fire induced interactions/failures indicated by dashed lines.

Figure 10-3. Event Sequence Diagram for Fire Initiated Drop Event

Further, an ESD and/or SET could be developed to analyze indirect (or interaction) effects of seismic induced failures of SSCs that are not ITS. Such non-ITS SSCs may be located or function in such a way that a seismic event could cause it to fail (e.g., fall) and interact with one or more other SSCs that are ITS and, thereby, cause a loss of safety function. Such seismic interactions are known as "two-over-one" situations in NPP regulations, meaning that a Seismic Category 1 SSC (safety-related) is vulnerable to a seismic-induced fall or impact by a Non-Seismic-Category 1 component.

Logically, the seis mic ESD is similar to that of the seismic fire-induced case since there is potential spatial interaction between items directly affected by the earthquake and one or more SSC(s) ITS. As necessary, the PSA team will develop SETs specific to the design of the MGR. 


\section{Seismic Initiated Fire}

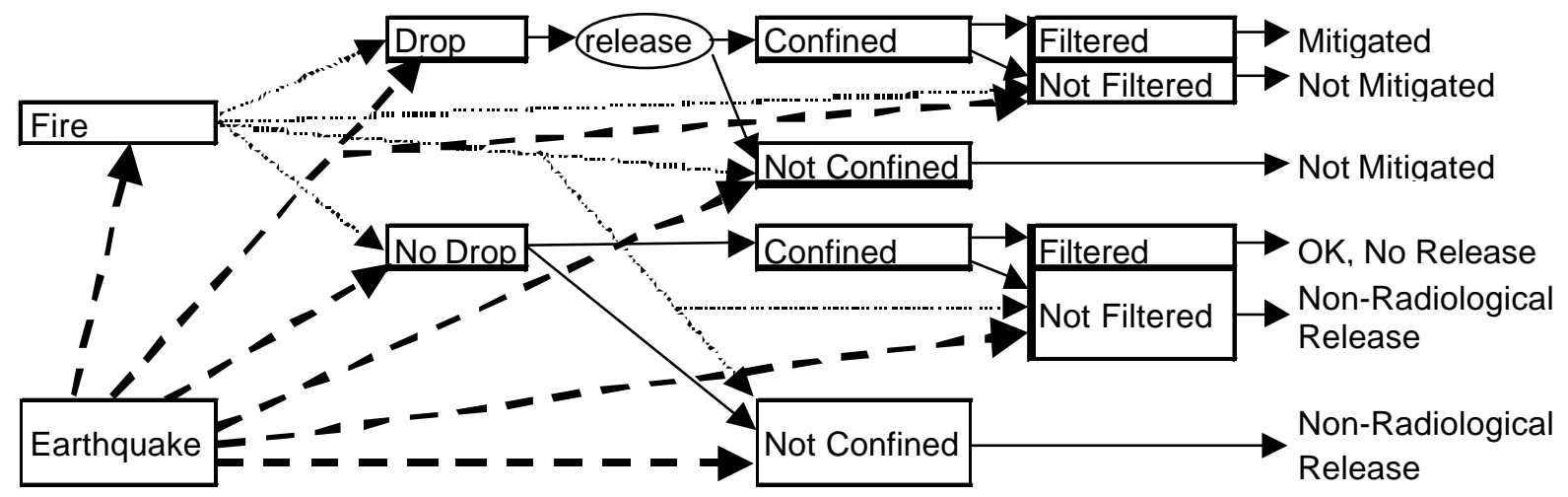

NOTE: $\quad$ Failures events may be random, seismic, or fire induced. Potential fire induced failures indicated by lightdotted lines. Potential seismic induced interactons/failures indicated by heavy-dashed lines.

Figure 10-4. Event Sequence Diagram for Seismic and Fire Initiated Drop Event

\subsection{Seismic Event Trees}

Figure 10-5 is an example of a simplified seismic event tree (SET) for a hypothetical sequence of events associated with a facility that handles a radioactive waste form. The hypothetical operation includes a crane that lifts and transports a particular waste form. Should the crane drop the waste form from a height exceeding its design basis, the waste form shell (its containment barrier) may breach and its contents (e.g., SNF assemblies) may breach, releasing radioactivity to the interior of a transfer cell. If the transfer cell structure remains intact, and if the HVAC ducting and HEPA filter remain intact, then releases are vented in a controlled manner. It is possible, however, that a sequence of undesired events can lead to a release of radioactivity. The sequence of events may result from independent events (e.g., random failures or human errors), seismically induced events, or by a combination of independent and seismically induced failures.

The SET in Figure 10-5 includes five events shown across the top of the figure. These event labels are known as the event headings. The logic diagram shows a single line for the initiating event (earthquake), but allows for two branches for each challenge to one of the event headings. In the tree structure, under each heading event, a horizontal branch labeled "yes" represents success of the function represented in the heading. A downward branch under a heading represents the loss (or failure) of the function. The failure criteria for the function have to be precisely defined so that the meaning of each downward branch is unambiguous. This is important in seismic fragility analysis when defining the conditional failure probability versus ground acceleration. For example, in one sequence of events, failure of the transfer cell structure may be loss of confinement while, in another sequence of events, failure of the transfer cell structure may mean total collapse. These different failure modes have significantly different fragility functions. 


\begin{tabular}{|c|c|c|c|c|c|c|c|c|}
\hline $\begin{array}{l}\text { Initiating } \\
\text { Event: } \\
\text { Earthquake }\end{array}$ & $\begin{array}{l}\text { Crane } \\
\text { Maintains } \\
\text { Functional } \\
\text { (1) }\end{array}$ & $\begin{array}{l}\text { No } \\
\text { Drop or } \\
\text { Breach } \\
\text { of WP } \\
\text { (3) }\end{array}$ & $\begin{array}{c}\text { Spent } \\
\text { Fuel } \\
\text { Remains } \\
\text { Intact (4) }\end{array}$ & $\begin{array}{l}\text { Confine- } \\
\text { ment } \\
\text { Maintained } \\
\text { in Cell } \\
(5)\end{array}$ & $\begin{array}{c}\text { HVAC } \\
\text { Remains } \\
\text { Intact and } \\
\text { Functional } \\
\text { (2) }\end{array}$ & $\begin{array}{l}\text { Seq. } \\
\text { No. }\end{array}$ & Source Term & $\begin{array}{c}\text { Offsite } \\
\text { Conse- } \\
\text { quence } \\
\text { (rem) }\end{array}$ \\
\hline & yes & $\mathrm{NA}$ & $\mathrm{NA}$ & $\mathrm{NA}$ & $\mathrm{NA}$ & 1 & none & 0 \\
\hline & GF or RF & GF & yes & yes & yes & 2 & $\mathrm{C} / \mathrm{SC}$, mitigated & $2.00 \mathrm{E}-03$ \\
\hline & & & & & GF or RF & 3 & $\mathrm{C} / \mathrm{SC}$, not mitigated & 2 \\
\hline & & & & GF or RF & GF - bypass & 4 & $\mathrm{C} / \mathrm{SC}$, not mitigated & 2 \\
\hline & & & no & yes & yes & 5 & SNF inventory, mitigated & $6.00 \mathrm{E}-03$ \\
\hline & & & & & GF or RF & 6 & SNF inventory, not mitigated & 6 \\
\hline & & & & GF or RF & GF - bypass & 7 & SNF inventory, not mitigated & 6 \\
\hline
\end{tabular}

NOTES:

Potential effects of seismic failures in hypothetical factility include:

(1) the failure of a crane lifting an SNF WP inside a WHB,

(2) damage to the building ventilation (filtration) system,

(3) the drop and breach of the WP,

(4) damage to the SNF assembly,

(5) partitioning of a fraction of the radionuclide inventory to the building atmosphere,

(6) release of some radioactive material through the damaged ventilation (filtration) system, and

(7) exposure of an individual (either a worker or a member of the public) to the released radioactive material.

Bypass = failure of transfer cell structure allows airborne radiation to bypass the HVAC ducting and HEPA filters; $\mathrm{C} / \mathrm{SC}=$ crud, surface contamination, or both; $\mathrm{GF}=$ guaranteed failure, dependent on precursor event or on initiating event; HVAC = heating, ventilation, and air conditioning; $\mathrm{N} / \mathrm{A}=$ Not asked, precursor event precludes; $\mathrm{RF}=$ random failure; SNF = Spent Nuclear Fuel; SNF Inventory = radionuclides from inside fuel rods, surface crud, and any contamination from waste package; $\mathrm{WP}=$ waste package .

Figure 10-5. Example of Baseline Seismic Event Tree Derived from Event Sequence Diagram for Load Drop

In Figure 10-5, the causes of the various downward branches are labeled as either RF (random failure), which is independent of the occurrence of the earthquake, or GF (guaranteed failure), which represents total dependence on the occurrence of a preceding eve nt (either a random event or the initiating earthquake). A special case of GF is indicated by GF-bypass to indicate that failure to maintain transfer-cell confinement integrity guarantees failure of the HVAC/HEPA filter function because the radioactive air is vented to the environment by other pathway(s).

Figure 10-5 also displays several branches labeled with NA, used to indicate that the branch-point question regarding the availability of the function represented in the heading is not applicable in that sequence of events. That is, after a certain heading event succeeds, it halts the progression of events toward unwanted consequences. For the example in Figure 10-5, if the Crane Maintains Functional, the succeeding event headings, No Drop or Breach of WP and Spent Fuel Remains Intact, do not come into play and are labeled NA. Since there is no release 
of radioactivity, the headings for confinement structure and HVAC function are irrelevant and are labeled NA.

The cause of the crane failure, as represented in Figure 10-5, may be either GF (dependent on the earthquake) or RF (an independent event). If the crane has been to designed to withstand an earthquake of a given intensity (e.g., DBGM-1) and an earthquake of lesser intensity occurs, then only crane failures due to RF are assumed possible. Conversely, if an earthquake occurs with intensity greater than the DBGM, then a GF is assumed to occur in the initial analysis for assigning DBGMs. However, as discussed later in this section, there is margin in design such that failure of the SSC requires an earthquake of intensity much greater than its design basis. In this example, it is assumed that any drop of the waste form results in its breach, so the breach is labeled as GF. Depending on the assumptions, all or a portion of the SNF assemblies could remain intact. This event could be correlated to the height of the drop, but for this illustration it is assumed to be an independent, random event with "yes" and "no" branches. The probability of the "no" branch can be varied in sensitivity analyses.

Each path from left to right through the SET of Figure 10-5 represents a potential event sequence that could occur as a result of an earthquake. For brevity, these are termed seismic event sequences. It is instructive to trace through the various sequences in Figure 10-5. Each path, or sequence, is labeled in the column entitled Seq. No. and each sequence terminates at an endstate that represents the severity of the consequences associated with that sequence. The consequences of the endstates in the example of Figure 10-5 are releases of radioactivity characterized in the column labeled "Source Term". Event sequences 1 through 7 are described as follows:

Sequence 1-This sequence represents the benign situation where neither seismic nor independent failures occur, so no radioactivity release occurs. An earthquake occurs but the crane maintains its functions ("yes" is indicated under the heading for event number 1). Since the crane is functioning, it does not drop the waste form ("NA" is indicated for event number 3); all other events listed in the headings of the event tree are irrelevant ("NA" is indicated for event numbers 4,5 , and 2). Since there is no radiological release in this sequence, there is mo source term ("none" is indicated for the source term for, sequence number 1). There is no offsite consequence (" 0 " is indicated for offsite consequence (rem) for sequence number 1).

Sequence 2-An earthquake occurs and the crane fails to maintain its functions and the crane drops the waste form. The cause of the crane failure may be GF, dependent on the earthquake, or RF, an independent event. In this sequence, all of the SNF assemblies remain intact and all other events listed in the headings of the event tree function normally ("yes" is indicated for events numbered 4, 5, and 2). The only potential source term in this scenario might be contaminants from inside the breached waste form and/or crud that has been freed from the surfaces of the SNF assemblies. Since the HVAC/HEPA filter is functioning normally, the resulting release would be limited to whatever gaseous contaminant might have been contained in the initial waste form. The magnitude of dose from this source term determines the ITS classification of SSCs involved in the event sequence. Only the failure of the crane's safety function is involved in Seq. No. 2 and results in an offsite dose of $2 \mathrm{E}-03$ rem for the source term designated "C/SC, mitigated" for Seq. No. 2. This result is used to assign a DBGM frequency category to the crane function as described in 10.1.3.4. 
Sequence 3-This sequence is the same as Seq. No. 2 except that the HVAC/HEPA safety function is lost. In this sequence, all of the SNF assemblies remain intact and all other events under the headings function normally ("yes" is indicated for events numbered 4 and 5, and "GF" or "RF" is indicated for event number 2). The HVAC/HEPA filters may fail dependently because of the earthquake (GF) or independently (RF). The potential source term in this scenario might be contaminants from inside the breached waste form and/or crud that has been freed from the surfaces of the SNF assemblies. However, because the HVAC/HEPA filters are not functioning normally, the resulting release could include volatile and particulate matter, as well as gaseous contaminants and/or crud released from surfaces of the SNF assemblies or interior of the waste form. The unmitigated dose would be expected to be higher than that of Seq. No. 2 and is illustrated as 2 rem for the source term designated as "C/SC, not mitigated" for Seq. No. 3. In Seq. No. 3, it may be necessary to assign DBGMs to both the crane and HVAC/HEPA system to prevent the sequence as described in 10.1.3.4.

Sequence 4-This sequence is similar to Seq. No. 2 and Seq. No. 3 except that the confinement function of the transfer cell is lost due to the earthquake (GF) or an independent failure (RF). In this case the failure of the HVAC/HEPA filters is labeled as "GF-bypass," representing the dependency between maintaining the transfer cell confinement geometry and a controlled pathway through the HVAC/HEPA. The only potential source term in this scenario might be contaminants from inside the breached waste form and/or crud that has been freed from the surfaces of the SNF assemblies. Because the HVAC/HEPA filters are not providing filtration, the resulting release could include volatile and particulate matter, as well as gaseous contaminants and/or crud released from surfaces of the SNF assemblies or interior of the waste form. The unmitigated dose would be similar to that of Seq. No. 3 and is illustrated as 2 rem for the source term designated as "C/SC, not mitigated" for Seq. No. 4. In Seq. No. 4, it may be necessary to assign DBGMs to both the crane and the confinement structure to prevent the sequence as described in 10.1.3.4.

Sequence 5-An earthquake occurs and the crane fails to maintain its functions and drops the waste form. The cause of the crane failure may be GF, dependent on the earthquake, or RF, an independent event. In this sequence, the SNF assemblies do not remain intact ("no" is indicated for event number 4). The remaining part of the sequence is similar to Seq. No. 2 ("yes" is indicated for events 5 and 2). The potential source term in this scenario might be the radionuclide contents of the breached fuel rods in addition to contaminants from inside the breached waste form and/or crud that has been freed from the surfaces of the SNF assemblies. Since the HVAC/HEPA filters are functioning normally, the resulting offsite release would be gases. The mitigated dose would be similar to, but larger than that of Seq. No. 2 illustrated as 6E-03 rem for the source term designated as "SNF inventory, mitigated" for Seq. No. 5. Only the failure of the crane's safety function is involved in Seq. No. 5. This result is used to assign a DBGM frequency category to the crane function as described in 10.1.3.4.

Sequence 6-This sequence is similar to Seq. No. 5 except that safety feature of the HVAC/HEPA system (event heading 2) is lost. In this sequence, the SNF assemblies do not remain intact ("no" is indicated for event number 4). The confinement function is maintained ("yes" for event heading 5). The HVAC/HEPA filters may fail because of the earthquake or independently ("GF" or "RF" is indicated for event heading number 2). The potential source term in this scenario might be the radionuclide contents of the breached fuel rods in addition to 
contaminants from inside the breached waste form and/or crud that has been freed from the surfaces of the SNF assemblies. However, because the HVAC/HEPA filters are not functioning normally, the resulting release would be include volatile and particulate matter, as well as gases, contaminants, and/or crud released from surfaces of the SNF assemblies or interior of the waste form. The unmitigated dose would be expected to be higher than that of Seq. No. 5 and is illustrated as 6 rem for the source term designated "SNF inventory, not mitigated" for Seq. No. 6. For Seq. No. 6, it may be necessary to assign DBGMs to both the crane and the confinement structure to prevent the sequence and demonstrate compliance with 10 CFR Part 63 as described in 10.1.3.4.

Sequence 7-This sequence is similar to Seq. No. 5 and Seq. No. 6, except that the confinement function of the transfer cell is lost due to the earthquake (GF) or an independent failure (RF). In this case the failure of the HVAC/HEPA filters is labeled as "GF-bypass," representing the dependency between maintaining the transfer cell confinement geometry and a controlled pathway through the HVAC/HEPA system. In this sequence, the SNF assemblies do not remain intact ("no" is indicated for event number 4). Because the HVAC/HEPA filters are not functioning normally, the resulting release would include volatile and particulate, as well as gases, contaminants, and/or crud released from surfaces of the SNF assemblies or interior of the waste form. The unmitigated dose would be similar to that of Seq. No. 6, illustrated as 6 rem for the source term designated as "SNF inventory, not mitigated" for Seq. No. 7. In Seq. No. 7, it may be necessary to assign DBGMs to both the crane and the confinement structure to prevent the sequence and demonstrate compliance with 10 CFR Part 63 as described in 10.1.3.4.

\subsubsection{Examples of Application of Seismic Analyses to Assign DBGMs}

An earthquake is known as a "common-cause initiator" because similar, and concurrent, event sequences could be initiated in several waste handling, storage, and transport operations. The construction of SETs must include linkage between event sequences for the multiple facilities. The definition of seismic event sequences and consequence analyses are more complex than illustrated in the following examples.

Seismic analyses are applied to the development of a conceptual repository surface facility design. The examples presented herein do not represent any actual design of MGR operations. However, evaluations must be performed in a structured and thorough manner to ensure that potentially significant seismic vulnerabilities are identified for the LA design.

\subsection{Example 1: Hypothetical Seismically Induced Releases in Operations Area}

This example builds on the ESD and SET approaches previously described.

Scenario Description-Within the waste handling facility, a hypothetical assembly transfer system (ATS) uses a crane to unload SNF assemblies from transport casks and transfer them to a waste package. For this operational area, several potential release scenarios will have been identified from hazards analysis and internal event sequence analysis. Each of the non-seismic release scenarios is examined for potential initiation by an earthquake. Event trees may also be available for non-seismic initiating events that can be incorporated in seismic event trees (SETs). 
In addition, each operation within the operational area (e.g., each lift, movement, staging) is examined independently for potential direct or indirect vulnerability to faults induced by the occurrence of an earthquake. The operations area may have several parallel operations that could each contain a maximum inventory when an earthquake occurs, so it can be assumed that parallel operations will fail concurrently during an earthquake of sufficient intensity. The source term is the sum from parallel operations that could have concurrent seismically induced releases.

Development of ESD and SET-The SET defines potentially seismic-initiated or exacerbated event sequences. The source term and resulting consequences for each event sequence determines which SSCs are ITS and their DBGM category. The seismic event sequences are examined one at a time to identify which, if any, of the SSCs associated with the event headings have to be designed to withstand a design basis earthquake. For illustration, hypothetical offsite dose consequences were assumed for the sequences previously defined for Figure 10-5 in Section 10.1.3.2.2. The example SET, shown in Figure 10-5, is used to illustrate the assignment of DBGMs to SSCs ITS, based on offsite doses.

The application of ESDs and/or SETs ensures that a systematic analysis is used to identify SSCs that need to withstand design basis earthquakes.

Assigning DBGMs to SSCs-Hypothetical offsite doses are shown in Figure 10-5 for the seismic-induced failures of SSCs in a representative operations area. The doses are calculated using the same assumptions of conservative release fractions and atmospheric transport factors to the site boundary used for Category 2 doses as described in Section 8, Consequence Analyses. For the example, some of the hypothetical unmitigated doses are made to exceed 5 rem for illustration; therefore, some of the SSCs will be classified as ITS and designed to withstand the DBGM-2.

Table 10-2 presents the assignment of limiting DBGMs to each seismic event sequence based on the consequences assessed for each seismic sequence from Figure 10—5.

Table 10-2. DBGMs Based on Seismic Sequence Consequences

\begin{tabular}{|l|l|l|}
\hline Sequence Number & Offsite Consequences (rem) & Limiting DBGM Assigned \\
\hline 1 & 0 & N/A \\
\hline 2 & 0.002 & N/A \\
\hline 3 & 2 & DBGM-1 \\
\hline 4 & 2 & DBGM-1 \\
\hline 5 & 0.006 & N/A \\
\hline 6 & 6 & DBGM-2 \\
\hline 7 & 6 & DBGM-2 \\
\hline
\end{tabular}

Note: DBGM - design basis ground motion

Sequence 1-SSCs require no seismic classification because the initiating earthquake is not strong enough to cause an SSC failure or a radiological release. 
Sequence 2-The dose is less than the 15 mrem limit for Category 1 event sequences so the crane function and the no-breach function of waste form are not ITS and, therefore, these SSCs do not require assignment of a DBGM.

Sequence 3-The dose is greater than $15 \mathrm{mrem}$, but less than $5 \mathrm{rem}$, so the HVAC/HEPA filter function is ITS and must withstand an DBGM-1 design basis earthquake. With the HVAC/HEPA filter designed as DBGM-1, the crane function may be designated as non-ITS and would not require a DBGM assignment.

Sequence 4-The dose is greater than $15 \mathrm{mrem}$, but less than $5 \mathrm{rem}$, so the transfer cell confinement function is ITS and must withstand at least a DBGM-1 design basis earthquake. With the transfer cell designed as DBGM-1, the crane function may be designated as non-ITS and would not require a DBGM assignment.

Sequence 5-The dose is less than 15 mrem, so the crane function is not ITS and, therefore, does not require assignment of a DBGM.

Sequence 6-The dose is greater than 5 rem, so the HVAC/HEPA filter function is ITS and must withstand an DBGM-2 design basis earthquake. With the HVAC designed as DBGM-2, the crane function may be designated as non-ITS and would not require a DBGM assignment.

Sequence 7-The earthquake causes a failure of the confinement and a bypass of the HVAC/HEPA filter system. The unmitigated dose is greater than $5 \mathrm{rem}$, so the transfer cell confinement function is ITS and must withstand an DBGM-2 design basis earthquake.

At least one of the SSCs whose seismic failure appears in a release sequence must be assigned the limiting DBGM assigned to the sequence endstate. Thus, in Seq. No. 6 and Seq. No. 7, at least one SSC would have to be designated as DBGM-2 and it may be sufficient that only one SSC be designed to the limiting DBGM for the sequence. The selection of the one SSC for the limiting DBGM may depend on the safety strategy that has been assumed for a given operation.

For example, in a confinement-mitigation strategy, it is assumed that the confinement structure and the HVAC system, that includes a HEPA filter, would be designed to withstand the DBGM-2 DBGM. In this case, the seismic classification of waste-handling SSCs (e.g., transfer vehicles, machines, cranes) could be designated as DBGM-1 or non-ITS, depending on the magnitude of the mitigated doses that would result from seismic sequences. Alternatively, in a prevention strategy, it would be required that the handling and staging equipment within the hypothetical assembly transfer system (ATS) be designed to withstand the DBGM-2 DBGM. In this case, no credit would be taken for the mitigation effects of the HVAC/HEPA filter system and the equipment would be classified as non-ITS, unless required to be ITS for reasons other than seismic safety. In addition, the confinement function of the transfer cell structure could be non-ITS. However, in the hypothetical examples illustrated here, the structure of the facility may have to be classified as DBGM-2 DBGM because of the no-collapse requirement in the analysis described in Section 10.1.3.4.2.

In the event that the same transfer cell handles canistered DOE spent nuclear fuel, then actual doses may not be applied in assigning the DBGM categories to SSCs. For example, if the failure of event heading 4 in Figure 10-5 could result in the breach of a DOE canister, then all doses 
mitigated or unmitigated are assumed to exceed 5 rem because explicit doses will not be calculated. In this case, the crane would have to be designed to DBGM-2 to prevent a credible release from the DOE canister.

\subsection{Example 2: Hypothetical Collapse of Waste Handling Building}

Massive structural elements that could fall onto waste forms are examined as potential initiators of release scenarios. This example discusses the bases for assigning the appropriate DBGMs to various structural elements (e.g., roof, walls, foundation).

Scenario Description-The operational and staging areas of a waste handling facility are assumed to be full to maximum capacity to present the potentially largest radiological source term in the event of an earthquake. Where possible, falling structural elements having mass too small to breach a given waste form or to damage staging racks are eliminated from consideration. Otherwise, it is postulated that fragments of the roof or wall fall onto and damage the struck waste form or storage rack.

The source term for the maximum inventory of bare spent nuclear fuel assemblies in the area is used, along with the release factions and atmospheric transport parameters, to calculate the offsite and worker doses. The staging areas are assumed to be full of pressurized water reactor or boiling water reactor spent nuclear fuel assemblies, whichever is shown to produce the maximum source term. If the waste form at risk is in DOE spent nuclear fuel canisters and the canisters could be breached by the impact of collapsing structures, then it is assumed that the airborne release will exceed the 5 rem offsite dose limit without performing dose calculations (see Section 8, Consequence Analyses).

SET and ESD Development-Figure 10-6 and Figure 10-7 illustrate the various ways that event sequences might evolve as a result of an earthquake. The first question to consider is whether the earthquake results in the collapse of the structure. If there is a collapse (i.e., the upper path in Figure 10-6) and the collapse results in an impact on waste with a release of airborne radioactivity, then there is an unmitigated airborne release to the site boundary and environment because of the open confinement structure. If there is no impact on waste, then there is no release results from the structural collapse. If there is no structural collapse (i.e., the lower path in Figure 10-6), then another question is whether there are other seismic induced initiating events inside the structure (e.g., a drop of a waste form) and whether the confinement function of the structure is retained following the earthquake. This lower path is developed and was previously discussed as the subject of Example 1.

The ESD format helps to conceptualize the alternative sequence evolutions. However, the potential dependencies and framework for frequency quantification are more readily displayed in a SET. Figure 10-7 illustrates a SET for structural collapse derived from the upper portion of the ESD shown in Figure 10-6. Only Seq. No. 3 results in an offsite dose. 


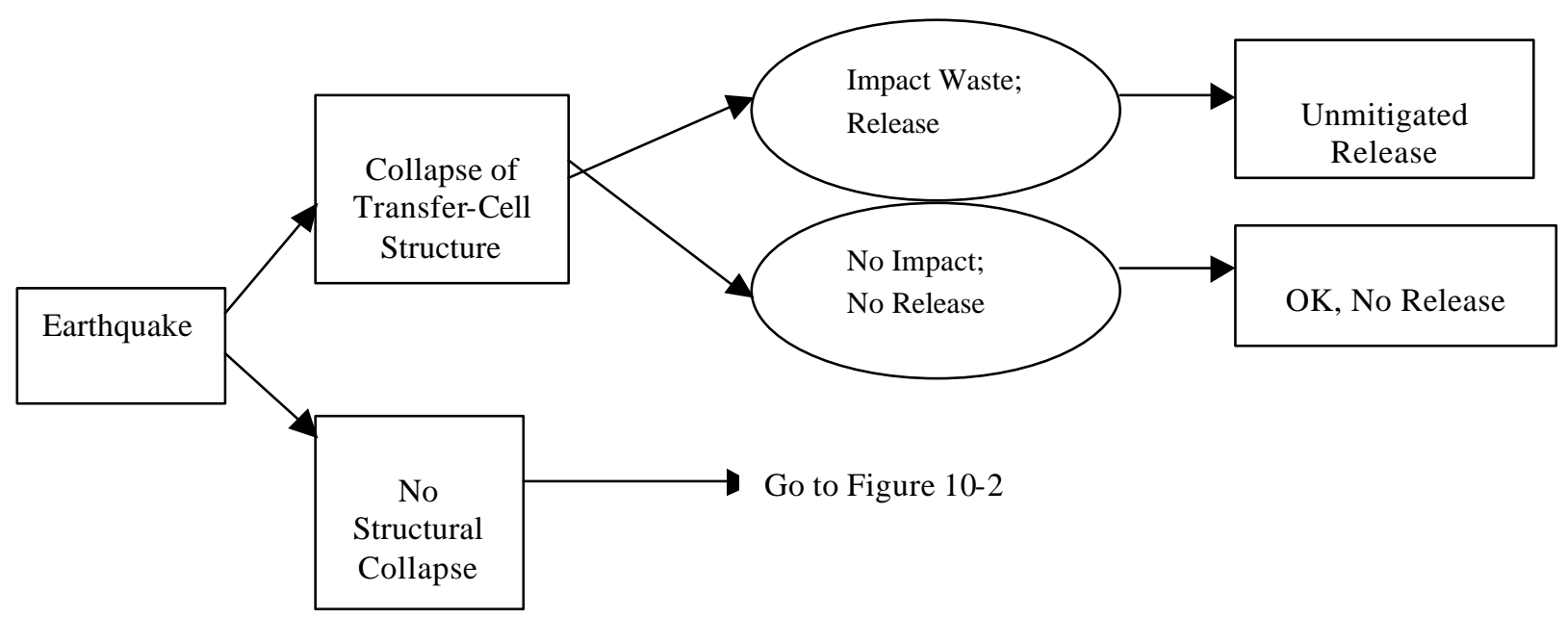

Figure 10-6. Event Sequence Diagram for Collapse of Transfer-Cell Structure

\begin{tabular}{|c|c|c|c|c|c|c|c|}
\hline \multirow[t]{2}{*}{$\begin{array}{l}\text { Initiating } \\
\text { Event } \\
\text { Earhquake }\end{array}$} & $\begin{array}{c}\text { No Collapse } \\
\text { ofTransfer- } \\
\text { Cell Structure } \\
\text { (1) }\end{array}$ & $\begin{array}{l}\text { No Impact on, or } \\
\text { Release from, } \\
\text { Waste Form } \\
\text { (2) }\end{array}$ & $\begin{array}{c}\text { Confinement } \\
\text { Maintained in } \\
\text { Transfer Cell } \\
\text { (3) }\end{array}$ & $\begin{array}{l}\text { HVAC Remains } \\
\text { Intact and } \\
\text { Functional } \\
(4)\end{array}$ & $\begin{array}{l}\text { Seq. } \\
\text { No. }\end{array}$ & $\begin{array}{c}\text { Source } \\
\text { Term }\end{array}$ & $\begin{array}{l}\text { Offsite } \\
\text { Conse- } \\
\text { quences } \\
\text { (rem) }\end{array}$ \\
\hline & yes & NA & NA & NA & 1 & none & 0 \\
\hline & no & yes & NA & $\mathrm{NA}$ & 2 & none & 0 \\
\hline & & no & GF & GF & 3 & $\begin{array}{l}\text { unmitigated, } \\
\text { large } \\
\text { inventory }\end{array}$ & $>5$ rem \\
\hline
\end{tabular}

Note: $\mathrm{GF}=$ guaranteed failure; HVAC = heating, ventilation, and air conditioning; $\mathrm{N} / \mathrm{A}=\mathrm{Not}$ asked, precursor event preclude; rem = the dosage of an ionizing radiation that will cause the same biological effect as one roentgen of X-ray or gamma-ray exposure.

Figure 10-7. Seismic Event Tree for Collapse of Transfer-Cell 
Assigning DBGMs to SSCs - The hypothetical unmitigated doses for Seq. No. 3, shown in Figure 10-7, exceed 5 rem. Therefore, it would be concluded from this hypothetical exercise that the roofs, walls, and foundation must be designed to withstand a DBGM-2. Further, a no-breach design basis has been established for DOE SNF canisters and DOE HLW canisters to avoid having to perform dose calculations for those waste forms (see Section 8, Consequence Analyses). Therefore, any structure used to house a DOE SNF canister or a DOE HLW canister, whose collapse could result in a breach of the canister, must be assigned the DBGM- 2 category.

\subsubsection{Methods for Frequency Quantification and Demonstration of Regulatory Compliance Using Seismic Probabilistic Risk Assessment and Seismic Margins Analyses}

The examples previously described develop a safety case that assumes that SSCs designed to a given design basis earthquake will not fail under earthquake conditions up to, and including, the design basis earthquake as a direct result of the earthquake. As previously noted, the seismic design strategy allows for designing passive structures to DBGM-1 or DBGM-2, subject to demonstration of compliance to 10 CFR Part 63. The demonstration of compliance involves a determination of the frequencies (or annual probability) and dose consequences of seismic event sequences. A seismically induced event sequence may be a composite made up of event sequences initiated concurrently in several handling facilities and/or transport operations.

Section 10.1.4.1 describes how seismic sequence frequencies could be conservatively quantified using a deterministic approach. Section 10.1.4.2 describes the application of seismic PRA methods to demonstrate compliance with 10 CFR Part 63. The seismic PRA approach uses fragility functions to assess the probability of seismic failures of SSCs ITS. Section 10.1.4.3 describes the application of seismic margins analysis (SMA) as an alternative approach to demonstrate compliance with 10 CFR Part 63. The SMA approach uses the HCLPF capacities of SSCs ITS to ensure, with high confidence, that exceedance of the dose limits of 10 CFR Part 63 in a seismic event has a compliant low probability.

\subsubsection{Frequency Quantification of Seismic Sequences Using Deterministic Approach}

This section describes how seismic sequence frequencies could be quantified using a deterministic approach that accounts for the DBGMs assigned to various SSCs appearing in an event sequence. That is, an event sequence resulting in a very conservative estimate of seismic sequence frequencies because the probabilities of a loss of safety function are conservative. Another purpose of a deterministic quantification of seismic event sequence frequencies is to confirm that the DBGMs have been correctly assigned to each SSC, particularly where SSCs having different DBGMs appear in the same event sequence.

The deterministic approach may be viewed as defining a conditional probability of failure of an SSC of: zero (0.0) for earthquakes of intensity less than or equal to the DBGM of that SSC; unity (1.0) for any earthquake that exceeds the DBGM of the SSC where the DBGM is expressed as ground acceleration value (e.g., peak ground acceleration (PGA)). Using a probability of 1.0 is conservative because the conditional probability of failure of an SSC is typically less than 0.01 at multiples of the DBGM accelerations assigned to that SSC. Sections 10.1.4.2 and 10.1.4.3 
describe how seismic sequence frequencies would be quantified more realistically using fragility functions and HCLPF capacities, respectively.

The deterministic approach assumes that SSCs designed to a given design basis earthquake will not fail under earthquake conditions up to, and including, the design basis earthquake as a direct result of the earthquake. If the SSCs do not fail as result of the earthquake, the consequences will be within the consequence regulatory limits. However, it is possible that an independent failure of one or more SSCs (i.e., failures that are not directly related to effects of vibratory ground motions) could occur during an earthquake and lead to doses beyond the regulatory limits. To demonstrate compliance with 10 CFR Part 63, the frequencies of such event sequences will have to be less than $1 \times 10^{-6}$ per year (i.e., BC2 event sequences).

The probability of an event sequence is the product of the probabilities of two or more events. For example, an event sequence annual probability (frequency) would be calculated as the product of the annual probability of exceedance of an earthquake (e.g., $1 \times 10^{-3}$ per year for DBGM-1) and the probability of a failure of one or more SSCs that prevent or mitigate a release within a specified time (e.g., 24 hours) after the earthquake. The probability of failure of the SSC may be independent of the earthquake (i.e., an RF) or dependent on the earthquake. In the deterministic evaluation, the earthquake-dependent failure probability of a given SSC is assigned a value of 0.0 if the ground motions are less than the DBGM for that SSC and assigned a value of 1.0, otherwise. Some examples are presented in the following hypothetical cases.

Case 1-Figure 10-8 presents an ET that illustrates where SSCs are designed to withstand a DBGM-1 design basis earthquake and a DBGM-1 earthquake occurs with a MAPE of $1 \times 10^{-3}$. This means that the crane does not fail as a direct result of the earthquake. However, there is a probability that the crane drops the waste form within a short period of time (i.e., 24 hours after the earthquake) due to an RF, illustrated as a probability of $1 \times 10^{-3}$. Similarly, the probability that the confinement functions of the transfer cell and the HVAC/HEPA filters are unavailable in the release scenarios are illustrated as $1 \times 10^{-6}$ and $1 \times 10^{-5}$, respectively. It is seen that the frequency of the release scenarios resulting in doses of 2 rem or 6 rem is less than approximately $1 \times 10^{-11}$ per year. This frequency is too low to be considered credible. This conclusion is not surprising because the crane, structure, and HVAC/HEPA system of the facility were designed to withstand the DBGM-1. 
Case 2-Figure 10-9 presents a SET that illustrates the same facility represented in Figure 10-8 where the SSCs are designed to withstand a DBGM-1 earthquake. However, an earthquake having accelerations slightly larger than DBGM-1, but having a slightly lower frequency $\left(9 \times 10^{-4}\right.$ per year for illustration purposes $)$ is assumed to occur. Because the accelerations exceed the DBGM-1 design bases of the crane and lifting devices, the confinement structure, and the HVAC/HEPA filters, all of these SSCs are assumed to fail with a conditional probability of 1.0. These GFs (i.e., total dependency on the occurrence of the earthquake) result in the removal of Seq. No. 1, Seq. No. 2, Seq. No. 3, Seq. No. 5, and Seq. No. 6, from Figure 10-8, as shown by the shaded areas in Figure 10-9.

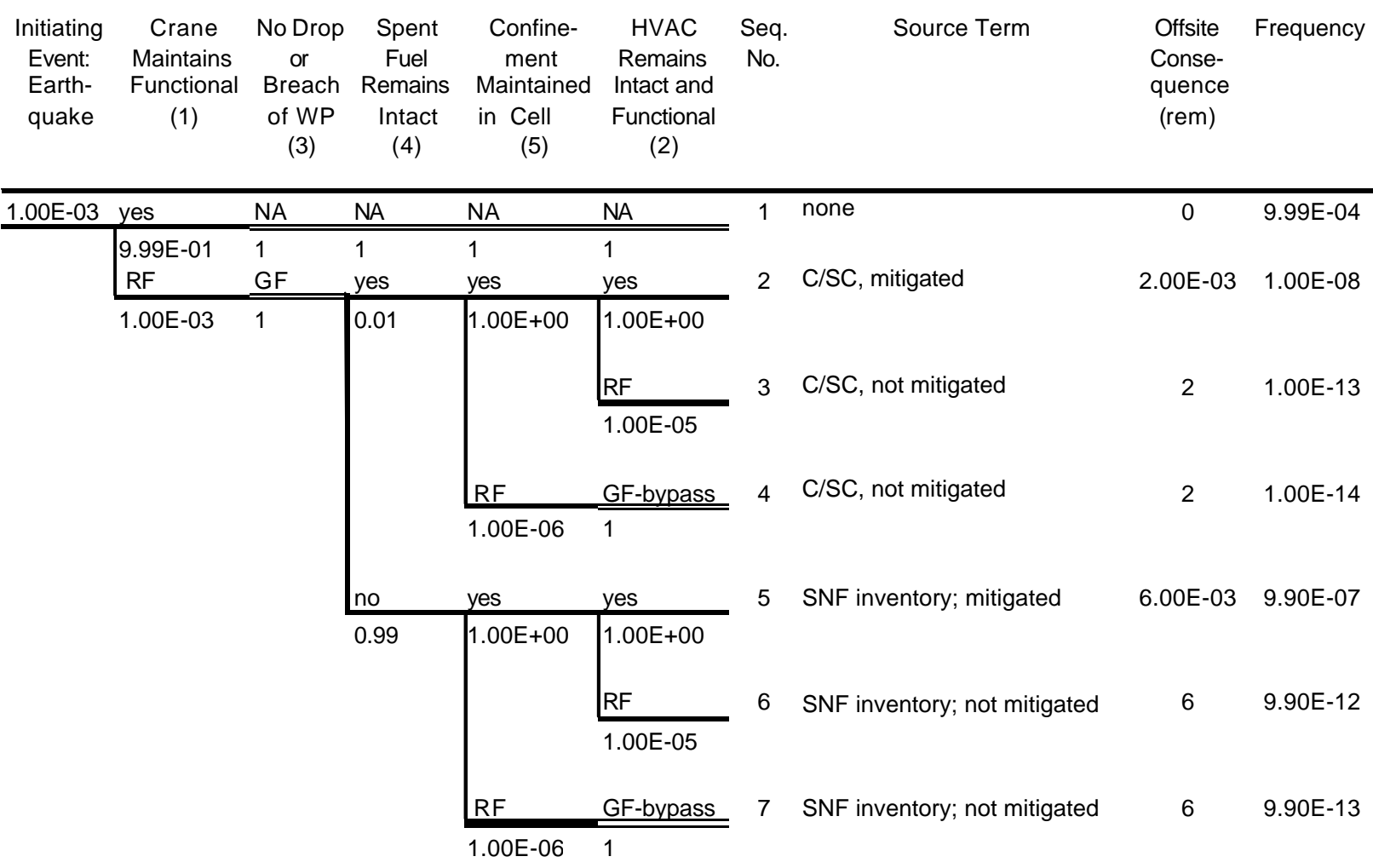

NOTES:

Assume crane and lifting devices, hot-cell structure, and HVAC designed to withstand DBGM-1 earthquake. Bypass = failure of hot-cell structure allows airborne radiation to bypass the HVAC ducting and HEPA filters; C/SC = crud, surface contamination, or both; GF = guaranteed failure, dependent on precursor event or on initiating event; HEPA = high-efficiency particulate air; HVAC = heating, ventilation, and air-conditioning; N/A = Not asked, precursor event preclude; RF = random failure; SNF Inventory = radionuclides from inside fuel rods, surface crud, and any contamination from waste package.

Figure 10-8. Seismic Event Tree - Structures, Systems, and Components Designed to DBGM -1 Earthquake 


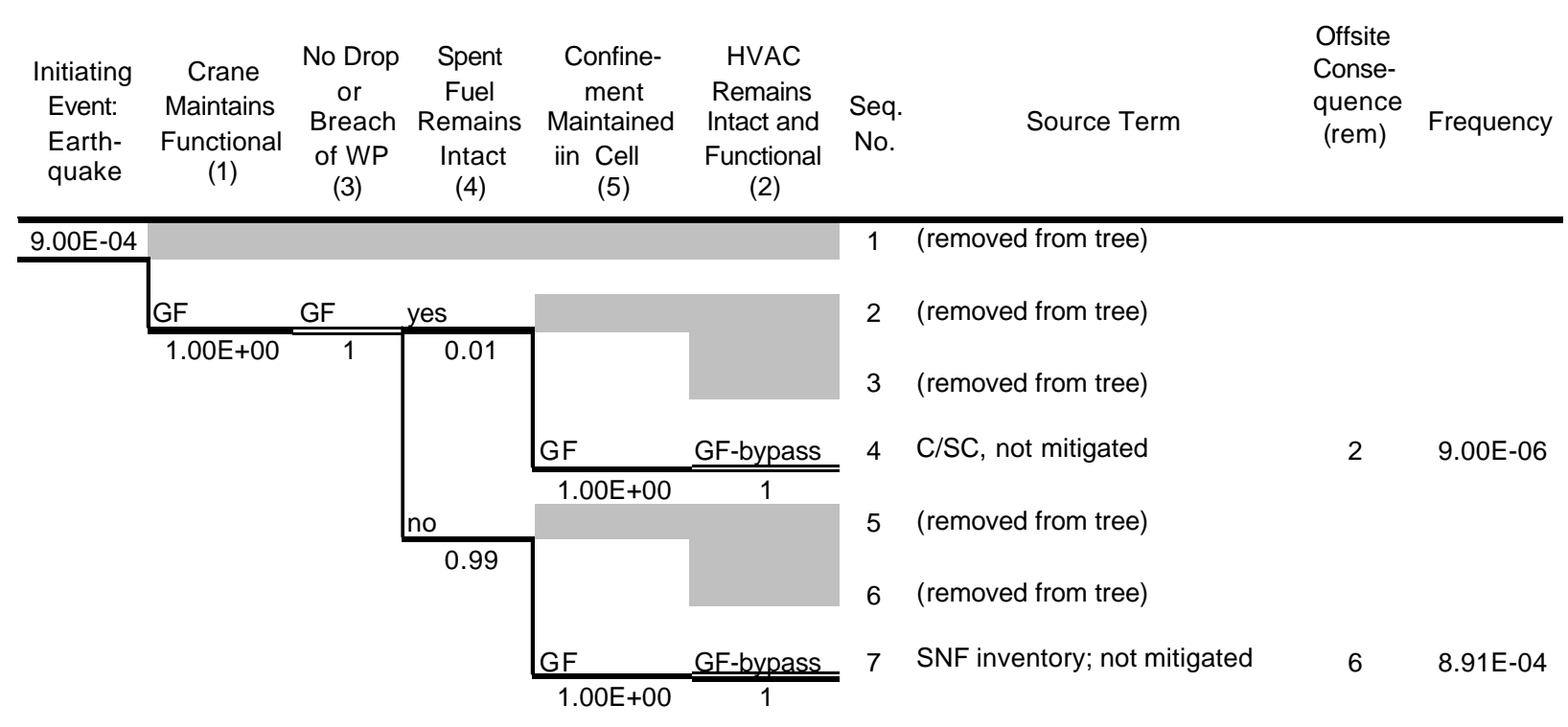

NOTES:

Assume crane and lifting devices, hot-cell structure, and HVAC designed to withstand DBGM-1 earthquake.

Earthquake exceeding DBGM-1 ground motions occurs at $9 \times 10^{-4}$; assume condtional probabiity of failure of 1.0 for SSCs designed to DBGM-1.

Bypass $=$ failure of hot-cell structure allows airborne radiation to bypass the HVAC ducting and HEPA filters; $\mathrm{C} / \mathrm{SC}=$ crud, surface contamination, or both; GF = guaranteed failure, dependent on precursor event or on initiating event; $\mathrm{HVAC}=$ heating, ventilation, and air-conditioning; N/A = Not asked, precursor event preclude; $\mathrm{RF}=$ random failure; SNF Inventory = radionuclides from inside fuel rods, surface crud, and any contamination from WP; WP = waste package.

Figure 10-9. Seismic Event Tree - Structures, Systems, and Components Designed to DBGM-1, but Earthquake Accelerations are Greater than DBGM-1

The consequences of Seq. No. 4 in Figure 10-9 are 2 rem, which exceeds the 15-mrem limit for Category 1 event sequences. However, the frequency of Seq. No. 4 is $9 \times 10^{-6}$ per year. While this is a credible event, its frequency makes it a Category 2 event sequence. However, the dose of the sequence is less than the 5-rem Category 2 limit. As a result, Seq. No. 4 is compliant with 10 CFR Part 63 and it is not necessary to reconsider the DBGMs assigned to the SSCs involved in the sequence.

The frequency of Seq. No. 7 is $9 \times 10^{-4}$ and is, therefore, a Category 2 event sequence. For this example, the hypothetical dose of 6 rem exceeds the Category 2 dose limits. Seq. No. 7 results in an unacceptable dose limit (i.e., it is non-compliant with 10 CFR Part 63), which indicates that some of the SSCs contributing to Seq. No. 7 must be designed to withstand the DBGM-2.

Continuing this process, the SET shown as Figure 10-9 can be modified to examine the effects of designing some components (e.g., crane, HVAC/HEPA filter) to DBGM-1 and the transfer cell confinement to DBGM-2. The result for a $9 \times 10^{-6}$ per year initiating earthquake that exceeds DBGM-1, but less than the accelerations of DBGM-2, would be: (1) Seq. No. 4 has a frequency of $9 \times 10^{-6}$ and a dose of 2 rem as in Figure 10-9, and (2) Seq. No. 7 has a frequency of $9.9 \times 10^{-13}$ and a dose of $6 \mathrm{rem}$ as in Figure 10-8. The evaluation of consequences in association with frequencies of seismic event sequences using deterministic seismic failure 
probabilities illustrates how seismic design bases of SSCs ITS are made to conform with Topical Report No. 2 (YMP 1997) and to demonstrate compliance with 10 CFR Part 63 in a very conservative approach.

\subsubsection{Demonstration of Compliance Using a Seismic PRA Approach}

Another approach for demonstrating compliance with 10 CFR Part 63 for seismic event sequences is to apply the methods of seismic PRA. The product of a seismic PRA is an expression of the annual probability of exceeding some defined risk measure. For NPPs, the risk measure is the core damage frequency $(\mathrm{CDF})$ or the large early release probability (LERF). For the MGR, a risk measure might be a public dose that exceeds the limits of 10 CFR 63.111(b)(2), (i.e., 5 rem TEDE). For purposes of this guide, the 5 rem TEDE public dose is used as the MGR risk measure.

\subsection{Overview of Seismic PRA Method}

A seismic PRA approach combines three separate input analyses, which are:

- $\quad$ Preclosure Safety Seismic Systems Analysis

- $\quad$ SSC Fragility Analysis

- $\quad$ Probabilistic Seismic Hazards Analysis.

The results of these three analyses are combined through a convolution process into a Seismic Risk Analysis to determine the risk (i.e., the annual probability of exceeding 5 rem TEDE) at the YMP site boundary.

Preclosure Safety Seismic Systems Analysis - This analysis develops SETs, as described in Section 10.1.3.2.2, to identify the seismically-induced sequences of events and SSCs. The SETs are supported by fault tree analysis (FTA) to model secismic and independent failure modes of SSCs that come into play under event headings in the SETs. Each basic event that is modeled originally in a fault tree as an independent failure event is modified to include seismically induced and independent events. The fault trees thus include potential common-cause failures, human-induced failures, in addition to the seismic failure events.

In addition to direct seismic failure events, some SSCs ITS in the system fault tree could be vulnerable to failure by secondary system interaction effects. The analysis includes potential interactions between SSCs (i.e., potential failure modes of a given SSC due to the impact of other SSCs in close proximity or overhead). In addition, the analyses will identify any potential seismically initiated fire or flooding scenarios that can propagate into a release sequence or a criticality. These dependencies can be captured in the event-tree logic or fault-tree logic.

A PRA workstation program (e.g., SAPHIRE) (Smith et al. 2000) provides features to model the dependent common-cause failures associated with earthquakes among multiple components in a system. The outputs of such analyses are seismic cutsets that include various combinations of seismically induced failures and RFs.

The Preclosure Safety Seismic Systems Analysis is performed by PSA personnel with the assistance of system/component design personnel. 
SSC Fragility Analysis-The SSC Fragility Analysis is applied to SSCs that appear in seismic event sequences to determine the conditional probability of failure (or loss of safety function) given the occurrence of vibratory ground motion of a given acceleration.

Figure 10-10 is an example of the format of a fragility curve. The fragility function for each SSC is displayed as a set of three S-curves that are plots of probability (ranging from 0 to 1) versus the PGA associated with an earthquake (the acceleration ranges from a fraction of $\mathrm{g}$ to tens of g's). The fragility curves are generated as a family of lognormal distributions represented by a median value of acceleration at which a particular SSC fails to perform its safety function and they are generated through the use of uncertainty factors that represent respectively: (1) the inherent randomness relative to the median (accounts for the sigmoid shape), and (2) uncertainty in the median capacity (accounts for the location of the median capacity at a given confidence level). The two uncertainty factors may be combined into a composite uncertainty factor that, when used, generates a single fragility curve that represents the mean. The mean will be used for much of the PSA for LA

The three curves represent, from top to bottom, the upper 95 percent, median, and lower 5 percent confidence levels. Fragility analysis is performed by structural engineers.

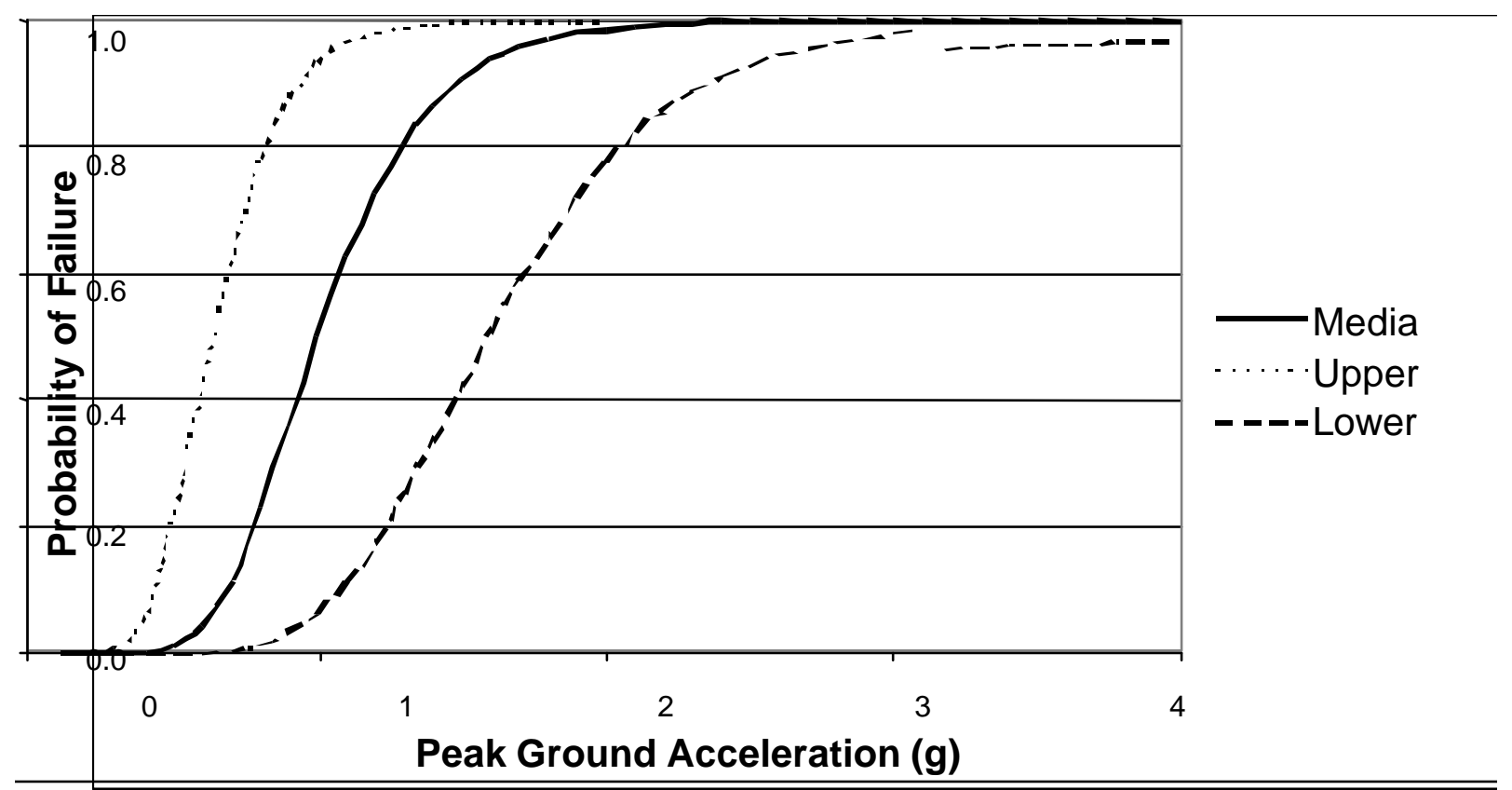

Figure 10-10. Example Fragility Curves 
Probabilistic Seismic Hazards Analysis-This analysis is the subject of Seismic Topical Reports No. 1 (YMP 1995). Topical Report No. 1 describes the method; a planned Topical Report No. 3 provides the results. The probabilistic seismic hazards analysis (PSHA) results are in the form of a family of curves representing the annual probability (or frequency) of exceedance versus an acceleration (e.g., PGA) at the repository site. The probabilistic seismic hazard curves (PSHCs) include the median, mean, 5 percent confidence level, and 95 percent confidence level. H(a) symbolizes the mean PSHC in the following sections.

The PSA analyst should note that the PSHCs represent the annual probability of exceedance, not occurrence, of a particular ground motion acceleration, a. Thus, $\mathrm{H}(\mathrm{a})$ is the mean annual probability of exceedance (MAPE) at acceleration, a. The mean annual probability of occurrence of an earthquake having a ground motion acceleration a in da is the slope of the mean PSHC (i.e., $\mathrm{dH}(\mathrm{a}) / \mathrm{da})$. This distinction is applied in the convolution process.

The specification of the PSHCs is performed by a team of PSHA experts.

Seismic Risk Analysis-The Seismic Risk Analysis combines the three aforementioned analyses (Preclosure Safety Seismic System Analysis, SSC Fragility Analysis, and Probabilistic Seismic Hazards Analysis) through a probabilistic analyses. The probabilistic analysis requires a convolution of the mean seismic hazard, H(a), and the facility system model (SETs and system FTs) that contains the imbedded fragility functions of the SSCs. The convolution integration is performed numerically using a Monte Carlo analysis or a Latin Hypercube analysis. For simple cases, a hand analysis may be performed using an EXCEL spreadsheet.

The goal of the Seismic Risk Analysis is to show that the probability of exceeding 5-rem offsite is less than 0.0001 during the preclosure period. For a 100-year preclosure period, this corresponds to a mean annual probability of $1 \times 10^{-6}$ of exceeding the dose limit.

The linking of SETs and FTA, including convolution with the seismic hazard curve, is performed with the SAPHIRE program. The analyst should refer to the SAPHIRE users manual for guidance on performing such analyses.

\subsection{Details and Example of Seismic PRA Approach}

The annual probability of having a dose that exceeds some value, say 5 rem, is expressed by the convolution integral:

$$
p_{D}=\int_{0}^{\infty}[d H(a) / d a] p_{D}(a)
$$

where

$\mathrm{H}(\mathrm{a})=$ the seismic hazard, mean annual probability of exceedance at ground motion a ,

$\mathrm{dH}(\mathrm{a}) / \mathrm{da}=$ slope of hazard curve, the annual probability of occurrence of ground motions in da about a, 
$\mathrm{p}_{\mathrm{D}}(\mathrm{a})=$ the conditional probability that MGR facilities yield a dose $\mathrm{D}$ or greater, given the occurrence of a seismic ground motion of intensity a, and

$\mathrm{p}_{\mathrm{D}}=$ the mean annual probability that the MGR facilities yield a dose of $\mathrm{D}$ or greater.

The convolution may be performed using discrete arithmetic using the following summation:

$$
p_{D}=\sum_{i=1}^{N}[\Delta H(a) / \Delta a]_{i} p_{D, i}
$$

where

$$
\begin{aligned}
& {[? \mathrm{H}(\mathrm{a}) / ? \mathrm{a}]_{\mathrm{i}}=\text { slope of hazard curve, the annual probability of occurrence of ground }} \\
& \text { motions in ?a about } \mathrm{a}_{\mathrm{i}} \text {, } \\
& \mathrm{p}_{\mathrm{D}, \mathrm{i}}=\text { the conditional probability that MGR facilities yield a dose } \mathrm{D} \text { or greater, given the }
\end{aligned}
$$

The expression $\mathrm{p}_{\mathrm{D}}(\mathrm{a})$ is a shorthand notation that covers the logic of the SET and FT analyses of seismic event sequences and the links to the individual fragility functions of SSCs modeled in the SET and FTs. Because of the complexities of how multiple fragility functions are multiplied together, $\mathrm{p}_{\mathrm{D}}$ (a) may not be an analytic or smooth function of a. For discussion purposes, however, $\mathrm{p}_{\mathrm{D}}(\mathrm{a})$ will be treated as an analytic function.

An example of the seismic PRA approach is presented Section 10.1.4.4

\subsubsection{Demonstration of Compliance Using Seismic Margins Analysis}

An SMA is an alternative method for performing a seismic risk analysis. The goal of an SMA, as developed for NPPs, is to demonstrate that there is a "high confidence of low probability of failure" (HCLPF) to achieve a safe condition after the occurrence of a seismic-margins earthquake (SME). The SME is a special case of a scenario earthquake, which is a seismic event that exceeds the seismic design bases of a hazardous facility that is used to demonstrate sufficient seismic safety. For NPPs, the SME is generally specified to be twice the SSE (i.e., for a $0.1 \mathrm{~g} \mathrm{SSE}$ the SME would be $0.2 \mathrm{~g}$ ). For purposes of illustration, it is assumed that for compliance demonstration purposes, the SME will be the ground motions associated a mean annual exceedance probability of $1 \times 10^{-4}$.

In lieu of a full fragility function, the SMA uses the "HCLPF capacity" of SSCs. The HCLPF capacity for a given SSC is expressed as an acceleration below which the conditional probability of failure (loss of safety function) is 0.01 using the mean fragility, or 0.05 using the 95 percent confidence fragility. The result of the SMA is an expression of the net HCLPF acceleration for the entire MGR. 
SMA has much is common with the seismic PRA, but does not result in an expression of the annual probability of exceeding the 5 rem TEDE. Instead, the SMA results in an expression of high confidence that there is an acceptably low annual probability of exceeding the dose limit. The PSHCs are not directly used in the SMA (i.e., no convolution is performed).

The steps in performing an SMA systems analysis are described in NUREG/CR-5632 (NRC 1990). The SMA employs some of the same analyses used in seismic PRA with some differences as described in the following paragraphs:

- $\quad$ Preclosure Safety Seismic Systems Analysis-The system safety analyst develops SETs and FTs that include seismic-induced failures of SSCs, seismic-influenced HFEs, and independent non-seismic failures of SSCs or HFEs.

- $\quad$ Scenario Earthquake Definition-To demons trate margin beyond the DBGMs of various SSCs and the overall MGR, a SME is defined. The SME may be a multiple of the DBGM-1 or DBGM-2, or chosen on some other basis. For purposes of illustration, it is assumed that for compliance demonstration purposes, the SME will be the ground motions associated a mean annual exceedance probability of $1 \times 10-4$, expressed as acceleration, gSME. The goal of the SMA is to demonstrate that, given the occurrence of the SME, there is a HCLPF capacity for the overall MGR SSCs to ensure compliance with 10 CFR Part 63. This overall, or facility-level, HCLPF capacity expresses confidence that there is a sufficiently low probability that a seismically induced event sequence could result in an offsite dose that exceeds 10 CFR 63.111(b)(2) given the occurrence of an earthquake of intensity of the scenario earthquake.

- $\quad$ SSC Fragility and HCLPF Analysis-The HCLPF analysis uses the mean fragility curve, or an alternative method to determine the HCLPF capacity, for each SSC that appears in a seismic sequence. The HCLPF is defined for each SSC as the ground acceleration (e.g., PGA) that has a probability of less than or equal to 0.01 on the mean fragility curve. It is designated as gH,SSC. Seismic capacity analyses are performed for the SSCs and are combined in the system-safety logic model to determine the limiting capacity for the MGR as a whole, expressed as $\mathrm{gH}, \mathrm{MGR}$. If $\mathrm{gH}, \mathrm{MGR}$ (the overall MGR seismic capacity) exceeds gSME (the acceleration associated SME), then an HCLPF condition exists.

- When the 95 percent confidence limit fragility curve is used, the HCLPF capacity corresponds to 0.05 conditional probability of failure.

Seismic Event Trees-SETs are developed as described in Section 10.1.3.2.2. As in a PRA approach, the systems analysis must define accident sequences for a range of feasible initiating events. Event sequences and consequence analyses may have been performed previously for internal events. The internal events analysis may have treated initiating events (e.g., drops of waste forms, LOSP, fires inside the WHB) as independent events, but each initiating event is further examined to determine if it could also be initiated by an earthquake. In addition, each event heading in the event tree for each initiator is examined for potential vulnerability to an earthquake. The overall probability of an event sequence following an earthquake will account for dependent and independent failures. However, basic events are screened to delete the low 
probability independent events and dependent events that do not contribute significantly to the seismic sequences. Screening rules must be defined that are appropriate to the purpose of the SMA.

System Fault Trees-The fault tree logic models for SSCs that appear in ET headings are modified to include potential seismically induced failures. Each basic event (see Section 7.2) is assumed to be a candidate for both seismically induced and independent failures. The fault trees include potential common-cause failures and human induced failures, as well as seismic failure events. In addition to direct seismic failure, some safety-significant SSCs in the system fault tree could be vulnerable to failure by secondary system interaction effects. If the resulting fault trees are too complex, some screening and/or pruning are performed to simplify the fault trees. If appropriate, an initial seismic screening may apply guidelines developed for SMAs of commercial NPPs that include generic HCLPF capacities given in terms of PGA for various categories of equipment (NRC 1986). However, for an SME greater than $0.5 \mathrm{~g}$, virtually no SSCs can be screened out for the generic commercial NPPs.

The next screening process aims to eliminate low-probability non-seismic events. For example, knowing that the DBGM-2 for the MGR has an annual probability of $10^{-4}$, the occurrence of any random event having a probability of less than approximately $1 \times 10^{-3}$ concurrent with the earthquake would result in a sequence annual probability of less than $1 \times 10^{-7}$ or less (below the Category 2 threshold). Generally, only those equipment failure modes or human interactions with a probability greater than $1 \times 10^{-3}$ that could exacerbate an event sequence are kept in the logic model unless the failure could result in failures of multiple trains in the same or different systems.

The FTA produces a list of minimal cutsets that include combinations of seismic and independent failure events. The union (sum) of the minimal cutsets produces a Boolean expression for the top event of the fault tree. The Boolean expressions for individual system fault trees are combined to produce the overall Boolean expression for the MGR for a damage state that results in doses that exceed 10 CFR Part 63 limits. The cutsets of the simplified system fault trees, including seismic and independent failures, are produced with a fault-tree program (e.g., SAPHIRE) (Smith et al. 2000). Cutsets are quantified using 1.0 for the probibility of seismic failures and actual probabilities for other basic events using the appropriate repository database and mission times for the non-seismic events. Using the fault-tree linking to solve the SET for each initiating event (e.g., the SET for waste-from drop), cutsets are produced in the same way to include both seis mic and independent failures. The cutsets for individual sequences that contribute to a non-compliant dose would be combined into a MGR-wide Boolean expression, as described in the following paragraphs.

Seismic Margins Compliance Evaluation-The objective of the analysis is to demonstrate that there is a suitably low conditional probability of an unacceptable dose given an earthquake of the magnitude of the SME (specified here as vibratory ground motion having PGA of gSME$_{\text {). }}$

The cutsets for individual seque nces that contribute to a non-compliant dose would be combined into a MGR-wide Boolean expression. For example, cutsets for the building collapse sequence would be combined with the drop-load sequence. For the compliance evaluation, the Boolean expression would be developed for the MGR condition that would result in an offsite dose that 
equals or exceeds 5 rem TEDE. The laws of Boolean algebra are applied so that many cutsets containing the same failure event, either seismically induced or independent failures, are absorbed into the lowest order cutset containing that failure event. The result is the final Boolean expression for the top event probability that is being considered. For compliance demonstration, the top event is the probability that a single seismic sequence or the sum of several seismic sequences give the unwanted consequence (i.e., an offsite dose of 5 rem or more). The final Boolean expression is used to calculate the HCFLP acceleration for the MGR as a whole, using HCLPFs of individual SSCs as inputs as described in the following paragraph.

The HCLPF capacity for the MGR is calculated though a maximum-minimum (max-min) treatment of the combinations of HCLPF capacities of the individual SSCs according to how the SSCs appear in the AND and OR logic or the final Boolean expression. When two or more SSC seismic failure events appear in an AND expression (i.e., the intersection of two or more events), the HCLPF acceleration for the expression is the maximum HCLPF acceleration of any among the SSCs that appear in the Boolean expression. When two or more SSC seismic failure events appear in an OR expression (i.e., the union of two or more events), the HCLPF acceleration for the expression is the minimum HCLPF acceleration among the SSCs that appear in the Boolean expression. The PSA analyst should refer to NUREG/CR-5632 (NRC 1990) for additional guidance in applying SMA.

The SAPHIRE program is used to develop the SETs to derive the minimal cutsets for individual sequences and to develop the facility-wide Boolean expression for the top event (a release that exceeds the 10 CFR 63.112 offsite dose limit). The evaluation of the facility-wide HCLPF capacity using the max-min process may be performed by hand, if the expression is simple enough. The result is expressed as the smallest ground motion acceleration that could result in a dose that exceeds the regulatory limits. If all of the SSCs appearing in the MGR-wide Boolean

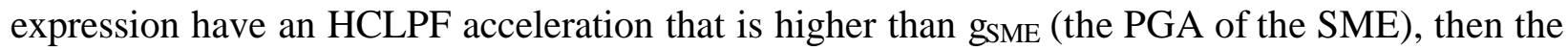
smallest acceleration that could result in a non-compliant dose would also be higher than gSME. The MGR would be deemed to have achieved HCLPF.

Because the annual exceedance probability for the SME would be specified to be $1 \times 10^{-4}$ with PGA denoted by $\mathrm{g}_{\mathrm{SME}}$, and the HCLPF acceleration, $\mathrm{g}_{\mathrm{H}, \mathrm{MGR}}$, is greater than $\mathrm{g}_{\mathrm{SME}}$, it may be stated that the conditional probability of seismic failure is less than or equal to 0.01 . Therefore, the mean annual probability of having of a dose exceeding 5 rem TEDE can be regarded as being less than or equal to $1 \times 10^{-6}$ or at least a suitably low probibility. This satisfies the requirements of 10 CFR Part 63.

An example of a SMA analysis is presented in Section 10.1.4.4.

\subsubsection{Example of Compliance Demons tration Using Seismic PRA and Seismic Margins Approaches}

The SET examples presented in Section 10.1.3.4 are used to illustrate how regulatory compliance can be demonstrated using either the seismic PRA or SMA approaches.

For illustration, assume that the only initiating events due to seismically induced failures are the two cases illustrated previously: (1) a load drop with loss of confinement or mitigation, and (2) a 
building collapse. Only the event sequences that result in (hypothetical) doses that exceed 5 rem are considered. It is assumed that the crane lifting the waste form is designed to withstand DBGM-1 while the transfer cell structure has been designed to withstand DBGM-2 with respect to both the confinement and no-collapse safety functions. The SET in Figure 10-9 represents the first case and shows that only Seq. No. 7 exceeds 5 rem. The SET in Figure 10-7 represents the second case and shows that only Seq. No. 3 exceeds 5 rem. Therefore, the annual probability of exceeding the 5 rem dose limits is derived from the logical (Boolean) union of these two sequences.

For simplicity, the following nomenclature is used for the failure events that appear in the sequences:

$D$ is the event "crane drops waste form," which is the failure event under the heading "Crane Remains Functional" in Figure 10-9:

- $D E Q$ is the event "crane drops waste form due to seismic failure"

- $D_{R F}$ is the event "crane drops waste form due to random failure."

$M$ is the event "loss of confinement/mitigation of transfer cell," which is the failure event under the heading "Confinement Maintained in Transfer Cell" in Figure 10-9:

- $M E Q$ is the event "loss of confinement /mitigation due to seismic failure"

- $M R F$ is the event "loss of confinement /mitigation due to random failure."

$C E Q$ is the event "collapse of transfer cell structure," which is the failure event under the heading "No Collapse of Transfer Cell Structure" in Figure 10-7; no RF is identified for structural collapse:

$E Q$ is the initiating earthquake having ground motion exceeding the design bases of the crane and transfer cell structure. The Boolean expression for the top event "earthquake results in offsite dose in excess of 5 rem" is expressed as the annual probability of non-compliance, $\mathrm{P}_{\mathrm{NC}}$ :

$$
\begin{aligned}
\mathrm{P}_{\mathrm{NC}} & =E Q \cap C_{E Q} \cup E Q \cap D \cap M, \text { or } \\
P_{N C} & =E Q^{*} C_{E Q}+E Q^{*} D^{*} M \\
P_{N C} & =E Q^{*}\left[C_{E Q}+D^{*} M\right]
\end{aligned}
$$


The expression for $\mathrm{D}$ and $\mathrm{M}$ are expanded to include both seismic and RFs:

(Eq. 10-4)

$$
\begin{aligned}
& P_{N C}=E Q^{*}\left[C_{E Q}+D^{*} M\right] \\
& P_{N C}=E Q^{*}\left\{C_{E Q}+\left[D_{E Q}+D_{R F}\right]^{*}\left[M_{E Q}+M_{R F}\right]\right\}
\end{aligned}
$$

If possible, the Boolean expression should be simplified by screening out low probability random events. As a rule of thumb, random events that have a probability of less than approximately $1 E-3$ can be screened out. Per the example in Figure 10-8, the probability of event $M_{R F}$ is $1 E-6$. Therefore, this random event (loss of confinement) can be deleted. Figure 10-8 also gives a value of 1E-3 for the probability of event $\mathrm{D}_{\mathrm{RF}}$. This value may be viewed as borderline for screening out. For purposes of illustrating the respective seismic PRA and SMA approaches, the event $D_{\mathrm{RF}}$ will be retained in the expression until it is shown to be unimportant, giving:

(Eq. 10-5)

$$
P_{N C}=E Q *\left\{C_{E Q}+\left[D_{E Q}+D_{R F}\right] * M_{E Q}\right\}
$$

\subsubsection{Example of Seismic PRA Approach}

The Boolean expression shown in Equation 10-5 is used to illustrate how the quantity $\mathrm{P}_{\mathrm{D}}$ may be evaluated by hand using the discrete form of the convolution expression, shown in Equation 10-2. This process requires fragility functions and seismic hazard functions. For purposes of illustration of the process, arbitrary values of the fragility and hazard curve are assumed. The analysis can be performed in an EXCEL spreadsheet as shown in Table 10-3. The results do not represent a real evaluation of any portion of the MGR.

Table 10-3 illustrates a rather coarse-grained discrete convolution. A fictitious hazard function $\mathrm{H}$ (a) is assumed as shown in columns (1) and (2). Column (3) shows the widths of the acceleration increments and column (4) gives the value of ? H(a) for each acceleration increment. Columns (5) through (8) illustrate hypothetical fragility factors for the three seismic failure modes. Column (9) gives the conditional probability of exceeding the dose limit given the occurrence of an earthquake within the acceleration interval; it is calculated from the Boolean expression shown at the top of the table $[\mathrm{P}=\mathrm{C}+(\mathrm{D}+\mathrm{M})]$. Column (10) is the product of Columns (4) and (9) that gives the contribution to the annual probability of exceeding the dose due to earthquakes within each acceleration interval. 
Table 10-3. Illustration of Convolution Analysis

\begin{tabular}{|c|c|c|c|c|c|c|c|c|c|}
\hline \multicolumn{10}{|c|}{ Fragilities for SSCs } \\
\hline (1) & (2) & (3) & (4) & (5) & (7) & (8) & (9) & (10) & (11) \\
\hline $\begin{array}{l}\mathrm{H}(\mathrm{a}), \\
\text { MAPE }\end{array}$ & PGA, g & $\begin{array}{l}\text { Accera- } \\
\text { tion } \\
\text { Increment }\end{array}$ & $\begin{array}{l}\text { Delta } \\
\mathrm{H}(\mathrm{a})\end{array}$ & $\begin{array}{c}\text { Bldg. } \\
\text { Collapse, } \\
\text { Event, C }\end{array}$ & $\begin{array}{c}\text { Bldg. } \\
\text { Confin't, } \\
\text { Event, MF }\end{array}$ & \begin{tabular}{|c|} 
Crane \\
Drop Load, \\
Event, D
\end{tabular} & $\begin{array}{l}\text { Cond. Prob of } \\
\text { Exceeding Dose } \\
\text { Limit, } P^{*}\end{array}$ & $\begin{array}{l}\text { Annual Prob } \\
\text { of Exceeding } \\
\text { Dose Limit, } \\
\text { P(D) }\end{array}$ & $\begin{array}{l}\text { Fraction } \\
\text { of Total }\end{array}$ \\
\hline $\begin{array}{l}\text { 1.E-03 } \\
\text { 5.E-04 }\end{array}$ & $\begin{array}{l}0.2 \\
0.6\end{array}$ & $\begin{array}{l}0.001-.2 \\
0.2-0.6\end{array}$ & $\begin{array}{l}\text { 9.E-03 } \\
5 . \mathrm{E}-04\end{array}$ & $\begin{array}{r}0 \\
5.00 \mathrm{E}-06\end{array}$ & $\begin{array}{r}0 \\
1.00 \mathrm{E}-05\end{array}$ & $\begin{array}{r}1.00 \mathrm{E}-05 \\
0.05\end{array}$ & $\begin{array}{r}0.00 \mathrm{E}+00 \\
5.50 \mathrm{E}-06\end{array}$ & $\begin{array}{r}0.00 \mathrm{E}+00 \\
2.75 \mathrm{E}-09\end{array}$ & $\begin{array}{l}0.0 \% \\
0.4 \%\end{array}$ \\
\hline 2.E-04 & 0.8 & $0.6-0.8$ & 3.E-04 & $5.00 \mathrm{E}-05$ & $3.00 \mathrm{E}-04$ & 0.1 & $8.00 \mathrm{E}-05$ & 2.40E-08 & $3.5 \%$ \\
\hline 1.E-04 & 1.0 & $0.8-1.0$ & 1.E-04 & $5.00 \mathrm{E}-04$ & $8.00 \mathrm{E}-05$ & 0.8 & 5.64E-04 & $5.64 \mathrm{E}-08$ & $8.1 \%$ \\
\hline 5.E-05 & 1.2 & $1.0-1.2$ & 5.E-05 & $1.00 \mathrm{E}-03$ & $8.00 \mathrm{E}-04$ & 0.99 & $1.79 \mathrm{E}-03$ & 8.96E-08 & $12.9 \%$ \\
\hline 1.E-05 & 1.5 & $1.2-1.5$ & 4.E-05 & $5.00 \mathrm{E}-03$ & $8.00 \mathrm{E}-03$ & 0.999 & $1.30 \mathrm{E}-02$ & $5.20 \mathrm{E}-07$ & $75.1 \%$ \\
\hline tal $f$ & IP & iity of & lir & $e L$ & & & & $6.92 \mathrm{E}-07$ & $100.0 \%$ \\
\hline
\end{tabular}

*Boolean Expression for Exceeding Dose Limit: $\mathrm{P}=\mathrm{C}+\left(\mathrm{D}^{*} \mathrm{M}\right)$

Finally, the rows of Column (10) are summed to produce the total annual probability of exceeding the dose limit that accounts for all credible earthquakes. The latter is sometimes called the "seismic risk," analogous to the core-damage frequency expressed for NPPs because it measures the annual probability (frequency) of having an undesired plant state. In the hypothetical example, the annual probability $\left(6.9 \times 10^{-7}\right)$ is demonstrated to be less than $1 \times 10^{-6}$ and would be deemed to demonstrate compliance since mean values of the seismic hazard and fragility functions were used. However, as in other PSA analyses, a seismic PRA should consider uncertainties.

Table 10-3 is typical of such analyses in that the total annual probability tends to be dominated by seismic failures that occur at higher accelerations that have the lower probabilities. Thus, as the accelerations exceed the design basis of each SSC by a significant amount, the conditional probability of failure of that SSC gets closer to 1.0. Column (11) indicates that 75 percent of the total annual probability, for this hypothetical case, would be due to a seismic hazard on the order of $1 \times 10^{-5}$.

An actual application of the seismic PRA method would involve detailed fault tree models and more complex Boolean expression for the non-compliant plant condition. The SAPHIRE code would be used to perform such detailed systems analyses and an appropriate convolution process.

\subsubsection{Example of SMA Approach}

To illustrate the SMA approaches, the Boolean expression event from Equation 10-5 is applied. The probability of the random failure for the load drop, $\mathrm{D}_{\mathrm{RF}}$ is assumed to be $1 \times 10^{-3}$, as previously. For illustration, the term $D_{\mathrm{RF}}$ is screened out, resulting in Equation 10-6:

$$
P_{N C}=E Q *\left\{C_{E Q}+\left[D_{E Q}+D_{R F}\right] * M_{E Q}\right\}
$$


The SMA is performed using the min-max process, on the basis of the HCLPF capacities of the SSCs that contribute to the event sequence that exceeds the dose limit.

For the purpose of this illustration, it is assumed that the PGA for DBGM-1 is $0.2 \mathrm{~g}$, and the PGA for DBGM-2 is 0.6g. Table 10-4 shows the illustrative seismic design bases assigned to each of the failure modes that appear in Equation 10-7. Table 10-4 also gives hypothetical HCLPF capacities for each failure mode and the symbol assigned to each HCLPF capacity.

The expression for the overall HCLPF for the compliance demonstration is derived from the following expression, based on Equation 10-6:

$$
H=\min \left\{H_{C}, \max \left[H_{D}, H_{M}\right]\right\}
$$

The minimum and maximum operations are performed according to accelerations of the HCLPF capacities of the respective SSCs. Using the HCLPF values from Table 10-4 gives:

$$
\begin{aligned}
& H=\min \{2 g, \max [0.4 g, 1.5 g]\} \\
& H=\min \{2 g, 1.5 g] \\
& H=1.5 g
\end{aligned}
$$

Table 10-4. Assumptions for SMA Example

\begin{tabular}{|l|l|l|l|l|l|}
\hline \multicolumn{1}{|c|}{ Failure Mode } & $\begin{array}{c}\text { Boolean } \\
\text { Expression } \\
\text { Symbol }\end{array}$ & $\begin{array}{c}\text { DBGM } \\
\text { Assigned }\end{array}$ & $\begin{array}{c}\text { DBGM, } \\
\mathbf{g}\end{array}$ & $\begin{array}{c}\text { HCLPF } \\
\text { Symbol }\end{array}$ & $\begin{array}{c}\text { HCLPF } \\
\text { Capacity, } \\
\mathbf{g}\end{array}$ \\
\hline Crane drops waste form due to seismic failure & $\mathrm{D}_{\mathrm{EQ}}$ & $\mathrm{DBGM}-1$ & 0.2 & $\mathrm{H}_{\mathrm{D}}$ & 0.4 \\
Crane drops waste form due to random failure & $\mathrm{D}_{\mathrm{RF}}$ & $\mathrm{N} / \mathrm{A}$ & $\mathrm{N} / \mathrm{A}$ & $\mathrm{N} / \mathrm{A}$ & $\mathrm{N} / \mathrm{A}$ \\
Loss of confinement /mitigation due to seismic failure & $\mathrm{M}_{\mathrm{EQ}}$ & $\mathrm{DBGM}-2$ & 0.6 & $\mathrm{H}_{\mathrm{M}}$ & 1.5 \\
Collapse of transfer cell structure & $\mathrm{C}_{\mathrm{EQ}}$ & $\mathrm{DBGM}-2$ & 0.6 & $\mathrm{H}_{\mathrm{C}}$ & 2 \\
& & & & &
\end{tabular}

Thus, for ground motions up to and including 1.5g PGA, the conditional probability of having a dose that exceeds the limit is less than 0.01 (i.e., 1.5g is the HCLPF capacity for the entire seismic event sequence, which is the composite of the respective drop and collapse seismic sequences).

At this point, the seismic hazard curve may be brought into consideration. In the hypothetical example presented in Table 10-3, the MAPE corresponding to $1.5 \mathrm{~g}$ is $1 \times 10^{-5}$. With consideration of the numerical definition of HCLPF (0.01) and the MAPE of $1 \times 10^{-5}$, it may be concluded that the annual probability of having a seismic event sequence that exceeds the dose limit is less than, or equal to, $1 \times 10^{-7}$. This logic adds additional support to the demonstration of compliance. Again, the example was created for instructional purposes and does not represent any actual seismic hazards or analysis that is applicable to the MGR. 


\subsection{FLOODING}

\subsubsection{Purpose}

This section defines the methods to determine the potential for flooding from external sources and the extent of any flood protection required for SSCs ITS or waste isolation.

\subsubsection{Scope}

This section provides guidance for the interpretation and use of NRC guidance and industry standards to determine for the repository the applicability of flooding from external sources. Areas to be considered include historical flooding, intense precipitation, upper level of possible flood conditions, facility design to determine whether flood effects need to be considered in plant design or emergency procedures, and the extent of any flood protection required for SSCs necessary for preclosure safety and waste isolation.

The analysis of floods initiated from sources internal to MGR operations (e.g., a pipe break, actuation of a fire-suppression system) will be treated similarly as, or part of, the analysis of internal fires as described in Section 10.5.1. If there is a potential for criticality, then the methods of Section 11 will be applied.

\subsubsection{Overview of Approach}

Compliance with 10 CFR 63.21(c)(1)(iii) and NRC guidance provided by NUREG-0800 (NRC 1987, Chapter 2), along with industry standards, are used for guidance for acceptable criteria for LA.

\subsubsection{Details of Approach}

\subsubsection{Potential for Flooding}

The flood history and the potential for flooding are reviewed for applicability. This section provides a summary and identification of the flood-producing phenomena applicable to the site or region considered in establishing the flood design bases for SSCs. Phenomena to be examined include the following:

- $\quad$ Stream flooding (Probable Maximum Flood)

- Surges

- $\quad$ Seiches

- Tsunami

- $\quad$ Seismically induced dam failures

- $\quad$ Flooding caused by landslides

- $\quad$ Ice loadings from water bodies.

Regulatory Guide 1.59, Design Basis Floods for Nuclear Power Plants, provides previous NRC guidance for estimating the design basis for flooding considering the worst single phenomena and combinations of less severe phenomena. Regulatory Guide 1.29, Seismic Design Classification, identifies the SSCs and Regulatory Guide 1.102, Flood Protection for Nuclear 
Power Plants, describes acceptable flood protection to prevent the SSCs from being adversely affected.

\subsubsection{Determination of Maximum Water Level}

ANSI/ANS-2.8-1992, American National Standard for Determining Design Basis Flooding at Power Reactor Sites, defines the Probable Maximum Flood (PMF) as:

The hypothetical flood (peak discharge, volume, and hydrograph shape) that is considered to be the most severe reasonably possible, based on comprehensive hydrometerological application of probable maximum precipitation and other hydrologic factors favorable for maximum flood runoff such as sequential storms and snowmelt.

The same ANSI/ANS standard also defines the probable maximum precipitation as follows:

The estimated depth of precipitation for a given duration, drainage area, and time of year for which there is virtually no risk of exceedance. The probable maximum precipitation for a given duration and drainage area approximates the maximum that is physically possible within the limits of contemporary hydrometeorological knowledge and techniques.

These definitions describe events that are the most severe or the greatest physically possible for a specific site. The probability of occurrence of these events should be extremely low. By conservatively assuming the occurrence frequency is greater than $1 \times 10^{-6}$, rainfall-related flooding events will be evaluated as Category 2 event sequences. The following steps should be followed to perform a flood analysis:

- $\quad$ Review and comply with the Yucca Mountain Review Plan (NRC 2003).

- Identify flooding events that are applicable to the site or operating facilities. Candidate events are documented in the MGR External Events Hazards Analysis (CRWMS M\&O 2000a) and Monitored Geologic Repository Internal Hazards Analysis (CRWMS M\&O 2000b). The list of applicable internal and external events was screened at a high level for gross credibility, applicability to preclosure, radiological safety, and applicability to the Yucca Mountain location. Stream flooding, surges, seiches, tsumani, seismically induced dam failures, flooding caused by landslides, and ice loadings from water bodies are to be considered as required by NUREG-0800 (NRC 1987, Section 2.4.2).

- Identify historical flooding at the site and the region of the site. Identify the types of flood-producing phenomena that are considered in establishing the flood design bases for ITS design features (e.g., stream flooding, surges, seiches, tsunami, dam failure, flooding caused by landslides, ice loadings from water bodies).

- $\quad$ Consider 10 CFR Part 50, Appendix A, General Design Criterion 2, Design Bases for Protection Against Natural Phenomena, as it relates to SSCs ITS being designed to withstand the effects of applicable external flooding initiating events. 
- Consider 10 CFR Part 100, Reactor Site Criteria, as it relates to identifying and evaluating specific criteria for flood history, flood design considerations, effects of local intense precipitation.

- $\quad$ Consider Regulatory Guide 1.29, Seismic Design Classification, for estimating design basis flooding considering the worst single phenomena and combinations of less severe phenomena. The guide identifies SSCs ITS and Regulatory Guide 1.102, Flood Protection for Nuclear Power Plants, describes acceptable flood protection to prevent ITS facilities from being adversely affected.

- $\quad$ Consider publications of the U.S. Geological Survey, National Oceanic and Atmospheric Administration, Soil Conservation Service, Corps of Engineers, applicable State and river basin authorities, and other similar agencies relating to hydrological characteristics and extreme events in the region.

- A sample statement of an NRC evaluation of water level findings is provided in NUREG0800 (NRC 1987, Section 2.4.2.IV). This sample statement will provide a sample of the results the NRC must be able to confirm.

\subsubsection{Probable Maximum Flood on Streams and Rivers}

The Probable Maximum Flood (PMF) as defined in Regulatory Guide 1.59, Design Basis Floods for Nuclear Power Plants, should be evaluated to establish the stream and river flooding design basis referred to in 10 CFR Part 50, Appendix A, General Design Criterion 2. The probable maximum precipitation should also be evaluated for the roofs of ITS structures. One of the following three conditions must be met:

1. The elevation attained by the PMF establishes a required protection level to be used in the design of the facility.

2. The elevation attained by the PMF is not controlling; the design basis flood protection level is established by another flood phenomenon (e.g., the probable maximum hurricane).

3. The site is dry (i.e., the site is well above the elevation attained by a PMF).

For condition 3, the site grade must be well above the PMF water levels defined in Regulatory Guide 1.59 and determined by hydrologic engineering studies. The evaluation of the adequacy of the margin (difference in flood and site elevations) is generally a matter of engineering judgment. This judgement is based on the confidence in the flood level estimate and the degree of conservatism in each parameter used in the estimate.

The following documents may be used as appropriate to determine the PMF data acceptability:

- $\quad$ Regulatory Guide 1.59 provides guidance for estimating the PMF design basis. 
- $\quad$ Regulatory Guide 1.29 identifies the safety-related SSCs for reactors.

- $\quad$ Regulatory Guide 1.102 describes acceptable flood protection to prevent ITS facilities from being adversely affected.

\subsubsection{Potential Dam Failures, Surge, Seiche, and Tsunami Flooding}

Justify the conclusion, as found in the MGR External Events Hazards Analysis (CRWMS M\&O 2000a) that there is no water control failure, surge, seiche, or tsunami flooding to evaluate for the site.

\subsubsection{Flooding Protection Requirements}

Review and consider, as appropriate, SSCs relied upon for plant flood protection whose failure could result in uncontrolled release of significant radioactivity to ensure conformance with 10 CFR Part 63.

If flood protection is required for any SSCs ITS, consider, as appropriate, 10 CFR 50.55a requirements for SSCs to be designed and constructed to quality standards commensurate with the importance of the safety function to be performed.

NUREG-0800 (NRC 1987) requires a determination as to which SSCs are ITS and should be protected against floods or flooded conditions. An analysis of failure modes and effects may be performed to determine whether the flooding consequences resulting from failures of such liquid-containing systems located close to essential equipment will not preclude required functions of safety systems.

\subsubsection{Consequence Analysis}

For each applicable credible event, either individually or in combination with other events in an accident sequence, perform:

1. A frequency analysis that demonstrates the event is not credible.

2. A nuclear safety analysis that demonstrates a radiological release does not occur as a result of the event.

3. A consequence analysis that demonstrates that the radiological consequences of the event are within regulatory requirements or a consequence analysis that identifies required preventative or mitigative SSCs to ensure that the radiological consequences are within regulatory requirements.

For each of the credible events identified, dose assessments will be performed to show compliance to 10 CFR Part 63 requirements as applicable.

The frequency analysis of an event determines if the event is credible. If not credible, no quantitative dose limits are promulgated by 10 CFR Part 63 and there is no impact to other repository design or licensing organizations, therefore no further analysis is required. Event 
sequences that are beyond Category 2 will be tracked to show safety design margin. If the event is determined to be credible, it is categorized based on the 10 CFR Part 63 definition and an analysis is performed to determine if the dose limits associated with the applicable event category can be met.

Category 1 event sequences (i.e., frequency greater than $1 \times 10^{-2}$ events per year) require that the sum of annual doses, exposures, and releases do not exceed limits specified in 10 CFR Part 63 for the public and 10 CFR Part 20 for occupational workers. Category 2 event sequences (i.e., frequency less than $1 \times 10^{-2}$ and greater than $1 \times 10^{-6}$ events per year) require that the consequences of a specific Category 2 event sequence not exceed dose limits as specified in 10 CFR Part 63 for the public beyond the preclosure controlled area.

The consequence analysis determines if the calculated doses are within the applicable regulatory limits. If the calculated dose exceeds applicable limits, SSCs ITS are designated, new requirements are allocated to the system, assumptions are revised, the design configuration is revised (if necessary), and the dose is recalculated and again compared to applicable regulatory dose limits.

\subsection{WINDS AND TORNADOES}

\subsubsection{Purpose}

This section of the guide defines the methods to determine the design basis wind speed, design basis tornado wind speeds and characteristics, and tornado- and straight-wind generated missiles. These analyses are used to define design requirements for SSCs ITS. Primarily, such design requirements are intended to mitigate the effect of design basis wind, tornado, and missiles (if credible) on the structural stability of the repository surface facilities. The primary systems that will contain requirements developed from this section include the structures that house the handling of high-level radioactive waste that are part of the surface facilities. The requirements may also be applicable to other SSCs ITS that are exposed to winds, tornadoes, and credible missiles. A preliminary hazard analysis performed in 1996 for the repository screened out the majority of the postulated external storm events (CRWMS M\&O 1996). The analysis was unable to screen out extreme winds and tornado-related events.

\subsubsection{Scope}

This section provides guidance on the interpretation and use of NRC guidance and industry standards to determine the applicability of external windstorm and missile generation events for the repository. The approach is risk-informed in accordance with 10 CFR Part 63 but adopts, where appropriate for the MGR, precedents developed for NPPs in the Short Range Plan, NUREG-0800 (NRC 1987) and associated regulatory guides.

\subsubsection{Overview of Approach}

10 CFR 63.21(c)(1)(iii) and 10 CFR 63.112, along with NUREG-0800 (NRC 1987, Chapter 3) and industry standards, are used for guidance for acceptable design basis/requirements for the LA. Furthermore, application of risk-informed methods and approaches used in PRAs for reactor sites are applied in the evaluation of credible missiles. 


\subsubsection{Details of Approach}

\subsubsection{Methodology}

10 CFR Part 63 permits the DOE to develop risk-informed performance-based design bases for SSCs ITS. Wind- and tornado-initiated event sequences can be treated like any other event sequence if desired. However, the design strategy is to preclude the initiation of credible event sequences where possible. As for other initiators, a demonstration that the frequency of less than $10^{-6}$ per year for the occurrence of a wind condition, a tornado, or a missile is a basis for screening out the initiating event. When a particular wind, tornado, or missile initiator cannot be screened out, then design requirements are specified following the precedents from other nuclear facilities, namely the guidance from NUREG-0800 and associated regulatory guides and industry standards.

\subsubsection{Extreme Winds}

The typical method for demonstrating compliance of the design of structures that have to withstand the effects of extreme winds is provided in NUREG-0800 (NRC 1987, Sections 2.3.1 and 3.3.1). This NUREG states that the 100-year return period "fastest mile of wind," including the vertical velocity distribution and gust factor should be used as the design and operating bases (NRC 1987, Section 2.3.1) and be based on applicable ANSI building code requirements, with suitable corrections for local conditions. The current standard published by the American National Standards Institute is ASCE 7-98, Minimum Design Loads for Buildings and Other Structures (2000). The basic wind speed defined in ASCE 7-98 is a three-second gust with an annual probability of 0.02 of being equaled or exceeded (50-year mean recurrence interval). Regional data can be used to determine the basic wind speed. The return periods of 100 and 50 years represent winds that are clearly credible since they represent mean frequencies of $10^{-2}$ and $5 \times 10^{-2}$ per year, respectively.

The most recent site-specific wind speed data must be used in PSA. Wind speed data was collected near the repository site from 1993 to 1996, which includes observed maximum daily one-second gust and one-minute wind speed at nine locations (CRWMS M\&O 1997). The magnitudes of the 50-year and 100-year return wind speeds were also estimated from this site-specific data. The example data shown in Table 10-5 corresponds to the location with the highest value in the meteorological monitoring network.

Table 10-5. Example Maximum Estimated and Observed Wind Speeds near Yucca Mountain, Nevada

\begin{tabular}{|l|c|c|}
\hline \multirow{2}{*}{} & \multicolumn{2}{|c|}{ Wind Speed in Miles per Hour [Meters per Second] } \\
\cline { 2 - 3 } & 50-year (3 second gust) & 100-year (1 minute) \\
\hline Observed & $90[40.22]$ & $74[33.16]$ \\
\hline Estimated & $121[54.11]$ & $109[48.47]$ \\
\hline
\end{tabular}

Source: CRWMS M\&O 1997 


\subsubsection{Tornado}

Tornadoes are not considered to be a significant hazard for the Yucca Mountain site. Available site experience data, or near-site experience data, tend to suggest that the probability of a tornado being initiated might be screened out, but the application of regulatory precedent analyses do not permit a tornado strike from being screened out. In general, those analyses tend to be conservative because they apply tornado intensity distributions to a small region that contains the Yucca Mountain site, but were developed for an extremely large homogenized region (the entire western United States). The following discussion summarizes the approach used for the PSA.

Regulatory Guide 1.76, Design Basis Tornado for Nuclear Power Plants, provides guidance for the selection of a design basis tornado for the three regions applicable to the continental U.S. The design basis tornado characteristics for the applicable region can be used in the design of SSCs ITS. A design basis tornado with less conservative parameter values than the regional values given in Regulatory Guide 1.76 can be selected. If the less conservative design basis tornado is selected for use of the MGR, a comprehensive analysis must be performed to justify the selection. The subjects in the following paragraphs should be considered when determining the design basis tornado for the Yucca Mountain site.

The method for demonstrating compliance of the design of structures that have to withstand the effects of design basis tornadoes is provided in NUREG-0800 (NRC 1987). This guide states that facilities must be designed so that facilities remain in a safe condition in the event of the most severe tornado that can reasonably be predicted to occur at a site as a result of severe meteorological conditions. The design strategy for the MGR is to comply with the intent of NUREG-0800 given an appropriate prediction of the design-basis tornado.

The design basis tornado characteristics provided by Regulatory Guide 1.76 are shown in Table 10-6. Using these properties, it is possible to develop a definition for a design basis tornado in terms of the six tornado parameters and use analytical techniques for estimating values of these parameters for purposes of design with an adequate level of conservatism.

The design basis tornado characteristics in Table 10-6 are based on a tornado that has a probability of occurrence of $10^{-7}$ per year (Ramsdell and Andrews 1986).

Table 10-6 also shows Regulatory Guide 1.76 pressure terms corresponding to the wind speeds given for the three tornado regions of the U.S. The table lists maximum tornado wind speeds, rotational speeds, maximum and minimum translation speeds, an assumed vortex radius of 150 feet, and the corresponding pressure drop and rate of pressure drop. The maximum pressure drop (pounds-force per square-inch) values can be calculated from the total and translation speeds using the methodology presented in ANSI/ANS-2.3-1983, Standard for Estimating Tornado and Extreme Wind Characteristics at Nuclear Power Sites.

However, based on a screening value of $10^{-6}$ per year probability of occurrence, the values in Table 10-6 are not applicable to the MGR. Therefore, an alternative basis is needed to predict the design basis tornado. Two alternatives are discussed in the following paragraphs. 
Table 10-6. Design Basis Tornado Characteristics

\begin{tabular}{|c|c|c|c|c|c|c|c|}
\hline \multirow[b]{2}{*}{ Region** } & \multirow{2}{*}{$\begin{array}{c}\text { Maximum } \\
\text { Speed }^{*} \\
\left(\mathrm{mph}^{2}\right)\end{array}$} & \multirow{2}{*}{$\begin{array}{c}\text { Rotational } \\
\text { Speed }^{*} \\
\text { (mph) }\end{array}$} & \multicolumn{2}{|c|}{$\begin{array}{c}\text { Translational } \\
\text { Speed } \\
\text { (mph) }\end{array}$} & \multirow{2}{*}{$\begin{array}{c}\text { Radius of } \\
\text { Maximum } \\
\text { Rotational } \\
\text { Speed (feet) } \\
\end{array}$} & \multirow{2}{*}{$\begin{array}{c}\text { Pressure } \\
\text { Drop } \\
\text { (psi) } \\
\end{array}$} & \multirow{2}{*}{$\begin{array}{c}\text { Rate of } \\
\text { Pressure } \\
\text { Drop } \\
\text { (psi/sec) }\end{array}$} \\
\hline & & & Max & Min & & & \\
\hline 1 & 360 & 290 & 70 & 5 & 150 & 3.0 & 2.0 \\
\hline II & 300 & 240 & 60 & 5 & 150 & 2.25 & 1.2 \\
\hline III & 240 & 190 & 50 & 5 & 150 & 1.5 & 0.6 \\
\hline
\end{tabular}

Source: Regulatory Guide 1.76

Note: $\mathrm{mph}=$ miles per hour; Max = maximum; Min = minimum; psi = pounds -force per square inch; $\sec =$ seconds.

* The maximum wind speed is the sum of the rotational speed component and the maximum translational speed component.

${ }^{* *}$ Region refers to the three tornado intensity regions within the contiguous United States as listed in Figure 1 of Regulatory Guide 1.76. Region III applies to the area surrounding Yucca Mountain.

The first alternative was presented in 1983 when, subsequent to the issuance of Regulatory Guide 1.76, the American Nuclear Society, through the American Nuclear Standards Institute, published ANSI/ANS-2.3-1983. This publication established guidelines to estimate the frequency of occurrence and the magnitude of parameters associated with tornadoes, hurricanes, and other extreme winds. Figures were presented that illustrated the regionalized tornado wind speed corresponding to a given probability. The information is summarized in Table 10-7. Although this publication expired in 1993, it represented the current state of knowledge on tornado and extreme wind characteristics at the time of publication (ANSI/ANS-2.3-1983). Since the Yucca Mountain site is located in tornado Region III, the credible $\left(10^{-6}\right.$ per year) maximum tornado wind speed based on the ANSI standard wo uld be 140 miles per hour.

Table 10-7. Tornado Wind Speed (miles per hour) by Region

\begin{tabular}{|c|c|c|c|}
\hline \multirow{2}{*}{ Region * } & \multicolumn{3}{|c|}{ Probability of Occurrence per Year } \\
\cline { 2 - 4 } & $\mathbf{1 0}^{-5}$ & $\mathbf{1 0}^{-6}$ & $\mathbf{1 0}^{-\mathbf{7}}$ \\
\hline I & 200 & 260 & 320 \\
\hline II & 150 & 200 & 250 \\
\hline III & 100 & 140 & 180 \\
\hline
\end{tabular}

Source: Standard for Estimating Tornado and Extreme Wind Characteristics at Nuclear Power Sites (ANSI/ANS-2.3-1983)

* Region III applies to the area surrounding Yucca Mountain.

The second alternative was presented in 1986, when the NRC issued new guidance on tornado strike and intensity probabilities in NUREG/CR-4461, Tornado Climatology of the Contiguous United States (Ramsdell and Andrews 1986). The new guidance was based on 30 years of data contained in the National Severe Storms Forecast Center tornado database from the period of January 1, 1954, through December 31, 1983. The report contains tornado characteristics 
including the number of occurrences, frequencies of occurrence, and average dimensions. Values are provided for 5-degree and 1-degree latitude and longitude boxes for the contiguous United States.

The probability of occurrence $\left(\mathrm{p}_{\mathrm{occ}}\right)$ of a tornado of a given intensity associated with the Fujita classification of maximum wind speeds is the product of two factors:

$$
\mathrm{p}_{\mathrm{occ}}=\mathrm{p}_{\mathrm{s}} * \mathrm{p}_{\mathrm{i}}
$$

where

$$
\begin{aligned}
& \mathrm{p}_{\mathrm{s}}=\text { point strike probability for a tornado of any intensity } \\
& \mathrm{p}_{\mathrm{i}}=\text { conditional probability that tornado is of intensity } \mathrm{i} \text { or less. }
\end{aligned}
$$

The study applies this formula to derive the critical value $\mathrm{p}_{\mathrm{ic}}$ that leads to selection of the maximum wind speed for a credible tornado. For example, using $p_{\text {occ }}=10^{-6}$ per year as the cutoff for credible initiating events gives:

$$
\text { pic }=10^{-6} \text { (per year) } / \mathrm{p}_{\mathrm{s}} \text { (per year) }
$$

The point strike probability is developed from statistics of reported tornadoes within a specified observation area. Because tornadoes are very rare events in the region near the Yucca Mountain site, it is necessary to use the data compiled for a rather large area defined by a 5-degree latitude-longitude box.

Using curve-fitting techniques, Ramsdell and Andrews (1986) developed a complementary cumulative probability distribution was developed for $p_{s}$ for the entire Western Region of the United States. The result is a correlation of maximum wind speed to the $p_{i}$ factor. This representation of tornado intensities for the Western region may be viewed as conservative for the Yucca Mountain site because it predicts credible occurrences of Fujita Classes greater than $\mathrm{F} 3$ at the site whereas the most severe tornado reported within 50 miles of the site was F0.

After selecting a probability of occurrence for screening, (i.e., $10^{-6}$ per year) the critical intensity factor is derived by dividing $p_{\text {occ }}$ by the point strike probability $p_{s}$. The critical value of $p_{i c}$ then defines the correlated maximum speed associated with that relative probability.

This approach was used to develop maximum credible tornado speeds as shown in Table 10-8, which lists example wind speeds provided for $10^{-5}, 10^{-6}$, and $10^{-7}$ per year probabilities of occurrence for the 5-degree latitude and longitude box containing the repository site. Both the nominal (expected) value and the value associated with the upper end of the 90 percent confidence interval for strike probabilities are shown. Statistically, this latter value is interpreted as the maximum value in a range that has a 90 percent chance of containing the true strike probability. Based on this approach, the credible $\left(10^{-6}\right.$ per year $)$ design-basis tornado wind speed becomes 189 miles per hour. 
Table 10-8. Example Tornado Wind Speed for 5-Degree Latitude and Longitude Box Containing Yucca Mountain, Nevada

\begin{tabular}{|c|c|c|c|}
\hline & \multicolumn{3}{|c|}{ Strike Probability of Occurrence per Year } \\
\hline & $10^{-5}$ & $10^{-6}$ & $10^{-7}$ \\
\hline Nominal Wind Speed $(\mathrm{mph})$ & - & 131 & Not provided \\
\hline Upper $90 \%$ Wind Speed* (mph) & 151 & 189 & 189 \\
\hline
\end{tabular}

Source: Ramsdell and Andrews (1986)

Note: $\mathrm{mph}=$ miles per hour.

* Wind speed is the sum of the translational and rotational components.

\subsubsection{Tornado-Generated Missiles}

As indicated in the previous section, the point strike probability for any tornado is marginally credible for the Yucca Mountain site. Additional probability factors are associated with the generation of a missile and the strike of a missile on a SSC ITS. Therefore, the preferred approach is to demonstrate that tornado generated missile strikes are not credible for the MGR and can be screened out. If this can be demonstrated, the missiles generated by credible straightwinds may have to be included in the design bases.

If tornado missiles cannot be screened out, then design bases will consider precedents from other nuclear facilities.

Tornado-Missile Screening-The probability that a tornado-generated missile initiates an event sequence resulting in a release of, or exposure to, radioactivity is dependent on several factors. The first factor is the probability of having a tornado strike at the site. The point-strike probability factor is discussed in previous paragraphs. The other factors represent the conditional probability of having an event sequence given a tornado strike.

The conditional probability depends on such factors as: the number and kinds of objects in the vicinity that could become missiles (both free objects and objects that could be torn from their normal attachments), the probability distribution of wind speeds given a tornado (the intensity factor related to $\mathrm{p}_{\mathrm{i}}$ as previously discussed), the target area of a potentially vulnerable SSCs, and the susceptibility of SSCs to damage given a strike by a missile of given speed and mass. In general, a physical analysis of such factors is a complex problem. Therefore, the PSA will apply missile-generation factors that have been previously developed.

For example, computer analyses have been performed based on potential missile locations and numbers, velocities based on wind drag and missile masses, directions, and the geometric factors between the missile generation site and the target area. The analyses are repeated for a spectrum of initial tornado wind speeds and results are weighted by the relative probability of having winds or a given speed. 
The result may be expressed as a "missile-strike probability factor" defined as follows:

$$
\Psi=\quad \begin{aligned}
& \text { probability of a missile strike per unit target area per missile generated per point } \\
& \text { strike probability. }
\end{aligned}
$$

The probability of a missile striking a target is calculated as follows:

$$
\mathrm{p}_{\mathrm{mis}}=\mathrm{p}_{\mathrm{s}} * \Psi * \mathrm{~A}_{\mathrm{T}} * \mathrm{~N}_{\mathrm{mis}}
$$

where

$$
\mathrm{A}_{\mathrm{T}}=\text { area of target of } \mathrm{SSC} \text { containing radioactive waste, }
$$

$\mathrm{N}_{\text {mis }}=$ number of missiles of all types available in the vicinity of the site, and

$\mathrm{p}_{\mathrm{s}}=$ point strike probability for a tornado of any intensity.

If the product $\mathrm{p}_{\mathrm{mis}}$ is shown to be less than $10^{-6}$ per year for a given $\mathrm{SSC}$, then a tornado missile is screened out as a non-credible initiator for that SSC.

If a tornado missile cannot be screened out of the SSCs ITS of the surface facilities of the MGR, then design bases based on precedents must be applied, as described in the following paragraphs.

Precedents for Design-Basis Tornado Missiles-The typical method for demonstrating compliance with the design of structures that have to withstand the effects of tornado-generated missiles is provided in Sections 3.5.1.4, Missiles Generated By Natural Phenomena, and 3.5.3, Barrier Design Procedures, of NUREG-0800 (NRC 1987). ITS equipment must be protected, as required, against damage from missiles that might be generated by the design basis tornado.

NUREG-0800 (NRC 1987, Section 3.5.1.4) requires that at least three objects (missiles) must be postulated: a massive high kinetic energy missile that deforms on impact, a rigid missile to test penetration resistance, and a small rigid missile of a size sufficient to just pass through any openings in protective barriers.

The NUREG identifies two missile spectra that will satisfy these criteria. Spectrum I missiles include a 1,800 kg automobile, a $125 \mathrm{~kg}$ 8-inch armor-piercing artillery shell, and a 1-inch solid steel sphere. The impact speed required is 35 percent of the maximum horizontal wind speed of the design basis tornado. The first two missiles are to impact at normal incidence, the last to impinge upon barrier openings in the most damaging directions. Spectrum II missiles may be used as an alternative to Spectrum I missiles. Spectrum II missiles and associated horizontal speed are shown in Table 10-9.

Vertical velocities of 70 percent of the postulated horizontal velocities are used in both spectra except for the small missile in Spectrum I or missile $\mathrm{C}$ in Spectrum II. These missiles should have the same velocity in all directions. Missiles A, B, C, and E are to be considered at all elevations and missiles $\mathrm{D}$ and $\mathrm{F}$ at elevations up to 30 feet above all grade levels within 0.5 mile of the facility structures. 
Table 10-9. Spectrum II Missiles

\begin{tabular}{|l|c|c|c|}
\hline \multicolumn{1}{|c|}{ Missile } & $\begin{array}{c}\text { Mass } \\
(\mathbf{k g})\end{array}$ & $\begin{array}{c}\text { Dimensions } \\
(\mathbf{m})\end{array}$ & $\begin{array}{c}\text { Velocity } \\
(\mathbf{m} / \mathbf{s e c})^{\star}\end{array}$ \\
\hline A. Wood Plank & 52 & $0.092 \times 0.289 \times 3.66$ & 58 \\
\hline B. 6-inch Sch 40 pipe & 130 & $0.168 \mathrm{D} \times 4.58$ & 10 \\
\hline C. 1-inch Steel Rod & 4 & $0.0254 \mathrm{D} \times 0.915$ & 8 \\
\hline D. Utility Pole & 510 & $0.343 \mathrm{D} \times 10.68$ & 26 \\
\hline E. 12-inch Sch 40 pipe & 340 & $0.32 \mathrm{D} \times 4.58$ & 7 \\
\hline F. Automobile & 1,810 & $5 \times 2 \times 1.3$ & 41 \\
\hline
\end{tabular}

Source: NRC (1987).

NUREG-0800 (NRC 1987).

${ }^{*}$ Associated with Region III, Regulatory Guide 1.76.

Note: $\mathrm{kg}=$ kilogram; $\mathrm{m}=$ meter $; \mathrm{m} / \mathrm{sec}=$ meters per second.

\subsubsection{Wind and Tornado Protection Requirements}

The typical method showing compliance with the protection of SSCs important to radiological safety and waste isolation that have to withstand the effects of extreme winds and tornadoes is provided in NUREG-0800 (NRC 1987, Sections 3.5.2) and Regulatory Guide 1.117, Tornado Design Classification. SSCs to be protected from externally generated missiles include all SSCs that have been provided to ensure radiological safety and waste isolation. Based on their relation to safety, SSCs are identified as requiring protection from externally generated missiles if a missile could prevent the intended safety function or if, as a result of a missile impact on a SSC non-ITS, its failure could degrade the intended safety function of an SSC ITS.

The primary repository surface facilities to be considered for protection should include any facility structure that contains radioactive material. The SSCs ITS within identified affected structures must be protected against extreme winds, tornadic winds, and tornado or straight-wind generated missiles because of the potential to cause a radiological release. It is necessary to demonstrate that failure of any SSC will not affect the capability of any other SSC to perform its required safety function(s).

\subsection{LIGHTNING AND EXTREME WEATHER}

Lightning and extreme weather are natural phenomena that will be assumed to occur at least yearly. Lightning is a large-scale high-tension natural electric discharge in the atmosphere. When lightning strikes a building, a transporter, or an electrical component, the consequences may be a localized temperature increase, an LOSP, or a short circuit. In addition, a lightning strike may initiate a fire.

Lightning and/or extreme weather are, at a minimum, to be analyzed as potential initiators for a LOSP event and an internal fire. Analysis of lightning- and extreme weather-initiated event sequences is expected to demonstrate that there are no credible release scenarios that result from a lightning strike. 


\subsection{FIRES}

The PSA will evaluate the potential effects of fires on radiological safety of workers and the public. Section 10.5.1 addresses fires that could occur internally in the MGR surface and subsurface operations areas. Section 10.5.2 addresses wildfires that could occur outside of the MGR operations area.

\subsubsection{Fires in MGR Operations Areas}

A fire initiated in a MGR building, in the subsurface, or on-board a transporter vehicle may have the potential to initiate an event sequence that could lead to exposure to, or release of, radioactivity to workers or the public. In 10 CFR Part 63, such occurrences are treated like any other event sequence and subject to the same dose limits per 10 CFR 63.111 and event sequence categories per 10 CFR 63.2. Therefore, much of the methodology described in Section 7 for event sequence analysis and quantification, Section 8 for consequence analyses, and Section 9 on uncertainty, may be applied to fires analysis, if required. However, through qualitative and quantitative screening analyses that are part of the approach, there may not be a need for detailed analyses of the initiation and propagation of internal fires for the PSA.

Overall, the Fire Protection Program and its associated Fire Hazards Analysis will ensure that any fire is a low probability occurrence for the MGR operations areas. Design and operational bases will minimize the likelihood of fires in areas or equipment that handle or store radioactive material. Nevertheless, in support of the risk-informed performance-based approach of 10 CFR Part 63, the PSA will evaluate the credibility, frequency, and potential radiological consequences of fire-initiated event sequences.

Techniques for quantitative fire initiation and propagation analyses have been developed as part of the methods for PRA, provided in the NRC PRA Procedures Guide, A Guide to the Performance of Probabilistic Risk Assessments for Nuclear Power Plants (NRC 1983, Section 11). Although the NRC PRA methods are directed toward reactor safety (e.g., core damage sequences), the overall framework may be adapted to the PSA for the MGR.

Recently, the NRC has sponsored a systematic review, NUREG/CR-6738, of the approaches and assumptions of fire-PRAs against experiences reported for fire incidents at NPPs in the United States and other countries (NRC 2001). The NRC review provides insights on those portions of prior fire-PRA methods that are deemed adequate or conservative versus those aspects that are not, given the evaluation of actual fire incidents at nuclear power stations in the United States and other countries. According to this study, there will be advances in the modeling techniques to overcome some of the current limitations. Should the need arise for a detailed fire-PRA approach for the PSA, the advanced methodology will be obtained and applied as appropriate. However, for the present, the methods described in the NRC PRA Procedures Guide are considered to be sufficient to orient the PSA fires analyst and to integrate the analysis with the Fires Protection Program under development by design engineering.

Further, the methods outlined in this section may be applied, in large measure, to analyses of internal flooding. 


\subsubsection{Overview of Approach}

The fires-PRA approach, based on the approach described in the PRA Procedures Guide (NRC 1983) has four steps:

Step 1. Fire-hazards identification and location screening analysis

Step 2. Quantitative Screening and Propagation analysis

Step 3. Systems analysis

Step 4. Consequence analysis (frequency and dose).

These four steps restate the overall PSA steps described in Section4, although there are some fire-specific situations described in the following paragraphs.

Fire Hazards Identification and Location Screening Analysis-The fire-hazards screening analysis (FHSA) uses as inputs: (1) the results of the facilities Fire Hazard/Fire Protection Analysis performed by personnel from the design organization, and (2) the results of the internal events hazards analysis. The principle task of the FHSA is to apply a qualitative evaluation to identify any locations in the MGR operations areas where SSCs are vulnerable to a fire and where fire-initiated or influenced event sequences are potentially risk-significant, or to screen out locations that are not potentially risk-significant. Section 10.5.1.2 provides more guidance on FHSA part of the fires-PRA.

Quantitative Screening and Propagation Analysis-The quantitative screening and propagation analysis is applied to locations not screened out by the qualitative approach. Initially, this analysis attempts to screen out event sequences based on the initiating event frequency or, if necessary, to screen out event sequences based on the frequency of a sequence of events. Section 10.5.1.3 provides more guidance on the quantitative screening and propagation analysis part of the fires-PRA.

Systems Analysis-The systems analysis task, if necessary, will require more detailed event-tree, fault-tree, and human-reliability analyses, using methods described in Section 7, augmented with physical analysis of fire-propagation. Prior safety analyses of MGR designs have not developed this amount of detail, so there are no precedent examples. It is unlikely that such detailed analyses will be required, so this revision of the PSA guide does not address these details. If required in the future, fire analyses may proceed by adapting appropriate techniques presented in the NRC PRA Procedures Guide or from more recent fires-PRA studies.

Consequence Analysis (frequency and dose)-The frequency analysis follows the processes used for other event sequences. The fire initiating frequency is quantified using a suitable fires database and conditional probabilities for detection and suppression and dependencies between fire-induced failures of SSCs or fire-enhanced human failure event probabilities. While the fire database used for screening may suffice to support this analysis, a detailed systems and frequency analysis may require a more refined fires database and treatment of uncertainty. Since it is unlikely that such detailed analyses will be required for MGR operations, Revision 1 of the PSA guide does not address these details. Dose analyses, if required, are performed as described in Section 8. Where ppropriate, release characteristics in fire sequences may have to be increased relative to non-fire event sequences. 


\subsubsection{Fire Hazards Identification and Location Screening}

Inputs to the FHSA to perform a qualitative evaluation consist of: (1) the results of the facilities Fire Hazard/Fire Protection Analysis performed by personnel from the design organization, and (2) the results of the internal events hazards analysis.

Fire locations are considered to be coincident with the fire zones defined in the Fire Hazards/Fire Protection Analysis performed by design personnel. Fire zones consist of one or more compartments that are separated from other fire zones by rated fire barriers. The spread of fire between compartments is unlikely, notwithstanding the historical spread of fire through the sealed cable penetrations at the Browns Ferry reactor plant. Lessons learned from that fire have been applied in the fire-protection design and operations of nuclear facilities.

The Internal Events Hazards Analysis (see Section 6.2) provides an initial evaluation of sites and/or SSCs within the MGR operations areas that are potentially vulnerable to fire-initiated radiological hazards. By correlating the potential fire-vulnerable sites or SSCs to the fire zones, the Internal Events Hazards Analysis provides initial guidance for the PSA fires identification and screening analysis.

The following approach that will be used to identify potentially vulnerable SSCs at the MGR is an adaptation of Method 2, Section 11.3.3.1, of the PRA Procedures Guide (NRC 1983). The approach applies two questions from the risk triad used in Method 2. The third question of "How likely is it?" will be applied in separate quantitative screening and event sequence frequency analysis.

What Can Happen?-To answer the first question in the risk triad of "What can happen as a result of a fire in a given fire zone?" SSCs and their functions are listed for each fire zone. For this portion of the evaluation, SSCs in each fire zone are assumed to fail as a result of a fire in that zone. The loss of function of each SSC is then evaluated with respect to radiological safety as either:

1. A cause of an initiating event due to a direct flame, heat, thermal radiation, or smoke effects on SSCs or waste forms located in the in that fire zone, such as:

a. The fire causes a crane or handling device to drop a waste form, which may be refined to include only potential drops beyond the design basis drop height of the waste form.

b. The fire heats up a waste form to cause an overpressure breach of the waste form confinement barrier (e.g., cladding of a fuel assembly, waste package).

c. The fire results in combustion of vulnerable waste forms (e.g., zircalloy cladding, combustion of HEPA filters containing entrapped radionuclides). 
2. A cause of an initiating event in a different fire zone due to a flame, heat, thermal radiation, or smoke effects on power cables, motor control centers, or instrumentation and control systems located in the fire zone, such as:

a. The fire causes a control system malfunction that leads to a crane or handling device to drop a waste form, which may be refined to include only potential drops beyond the design basis drop height of the waste form.

b. The fire causes a loss of power to a system ITS (e.g., the HVAC/HEPA system).

c. The fire causes a short circuit in a control or power circuit that causes a spurious unsafe operation or cessation of a safety function.

3. A fire in an adjacent fire zone could burn through and cause effects listed in items 1 or 2. Generally, the fire barriers that define the fire zones prevent this item as being a credible contributor.

4. The effects of the actuation of the fire suppression system as a source of damage that may initiate or propagate an undesirable event sequence. In particular, a water-based suppression system may cause failures of control or power systems or direct damage to equipment (e.g., motors of handling or HVAC equipment). This loss of function also requires the performance of a limited flooding analysis.

What are the Consequences?-The second question in the risk triad of "What are the consequences?" is addressed qualitatively with consideration of the credible fire loadings, geometries, and credible fire-related failure mechanisms of the affected SSCs. If the fire loadings are deemed too small to support a fire of sufficient intensity and duration to affect a given SSC, then the initiating event and associated consequences are screened out. This is repeated for potentially vulnerable SSCs and waste forms potentially affected by a fire in each fire zone. If no fire-induced initiating events are deemed possible or credible due a fire in a given fire zone, then that fire zone is screened out from further consideration in the PSA.

\subsubsection{Quantitative Screening and Propagation Analysis}

The quantitative screening and propagation analysis is applied to locations that survive the location screening. Initially, this analysis attempts to screen out event sequences based on detailed qualitative considerations before reporting to quantitative screening. The qualitative or quantitative screening is applied first to the initiating event and then, if necessary, to a sequence of events. A fires initiation database appropriate to the MGR operations and fire zones must be applied. An example of such a database, for reactor PRAs, is presented in Tables 11-4 and -5 of the NRC PRA Procedures Guide (NRC 1983). Typical median values of probability of a fire per room-year are:

1. Control room: $3 \times 10^{-3}$ per room-year

2. Cable-spreading room: $6 \times 10^{-3}$ per room-year

3. Diesel generator room: $2 \times 10^{-3}$ per room-year. 
As note in NUREG/CR-6738 (NRC 2001), more extensive and recent fires databases have been compiled by the NRC, EPRI, and Sandia National Laboratories.

Based on the typical values for fire per room-year, presented in the previous paragraphs, fire initiation sequences start with frequencies in the Category 2 range. Hence, compliance with dose limits of 10 CFR Part 63 must address public dose only. Therefore, if a postulated fire in a given fire zone can be demonstrated, through qualitative arguments, to not result in a public dose of 5 rems or more, then the fire-protection provisions in that fire zone can be screened out from further consideration as SSCs ITS in the PSA. Qualitative arguments must include consideration of potential concurrent effects on radiological sequences involving SSCs that are not in the same fire zone. Otherwise, more extensive analyses may be required, as described in the following paragraphs.

Event sequence diagrams and event trees, including fire propagation/suppression tress may be used to screen out low frequency event sequences based on the likelihood of the initiating fire and the conditional probabilities of propagating events (or qualitatively with reasoned arguments). A goal of this exercise is to demonstrate that, for each location that survives the qualitative screening in Step 1 (see Section 10.5.1.1), the frequency of the fire initiator and probability of propagation to an SSC ITS can be screened out as a Beyond Category 2 event sequence. This analysis will consider the actions of fire detection and suppression systems as well as the likelihood of an initiating fire.

The event sequence diagram approach described in Section 10.1 (e.g., Figure 10-3) provides a high-level depiction of how a fire in a given fire zone may propagate to cause a radiological release by: (1) causing a drop of waste form, (2) causing a loss of confinement, and/or (3) causing a loss of HEPA filtration.

A fire event tree, illustrated in Figure 10-11, provides a structure for evaluating the likelihood of occurrence of the event sequences defined in the ESD. The waste form in the example event tree is a suspended spent fuel assembly. It is assumed that any drop will result in contamination. For example, if a spent fuel assembly is dropped, then radioactivity will be released from the surface crud and from the interior of the fuel rods if the spent fuel assembly cladding breaches on impact with the floor. The ESD illustrates that a single fire might be able to initiate a drop and cause either a loss of confinement and/or a loss of particulate filtration. The fire event tree depicts these alternative evolutions by the branching under the respective event headings.

The fire event tree illustrated in Figure 10-11, is comprised of upper and lower parts that have similar structures; however, each part represents the main branching according to whether the initiated fire is detected. In Figure 10-11, it is assumed that the fire event tree addresses only automatic fire detection and automatic actuation of the fire suppression system. A more detailed fire can be constructed to include backup manual detection or delayed detection, and backup manual or delayed fire suppression.

The source term column in Figure 10-11 illustrates hypothetical sources of released radioactivity at the site boundary due to the dropped spent fuel assembly. The term C/SC refers to release of crud and surface contamination, and SNF refers to the release from the interior of SNF rods. The source term also characterizes the effect of the sequence end-state with respect to mitigation of 
the release to the environment. Mitigated releases are confined by the structure and filtered though the HVAC, while unmitigated releases are released unfiltered, either because of a failure of the filter system or because a failure of the confinement structure permits the release effluent to bypass the filter.

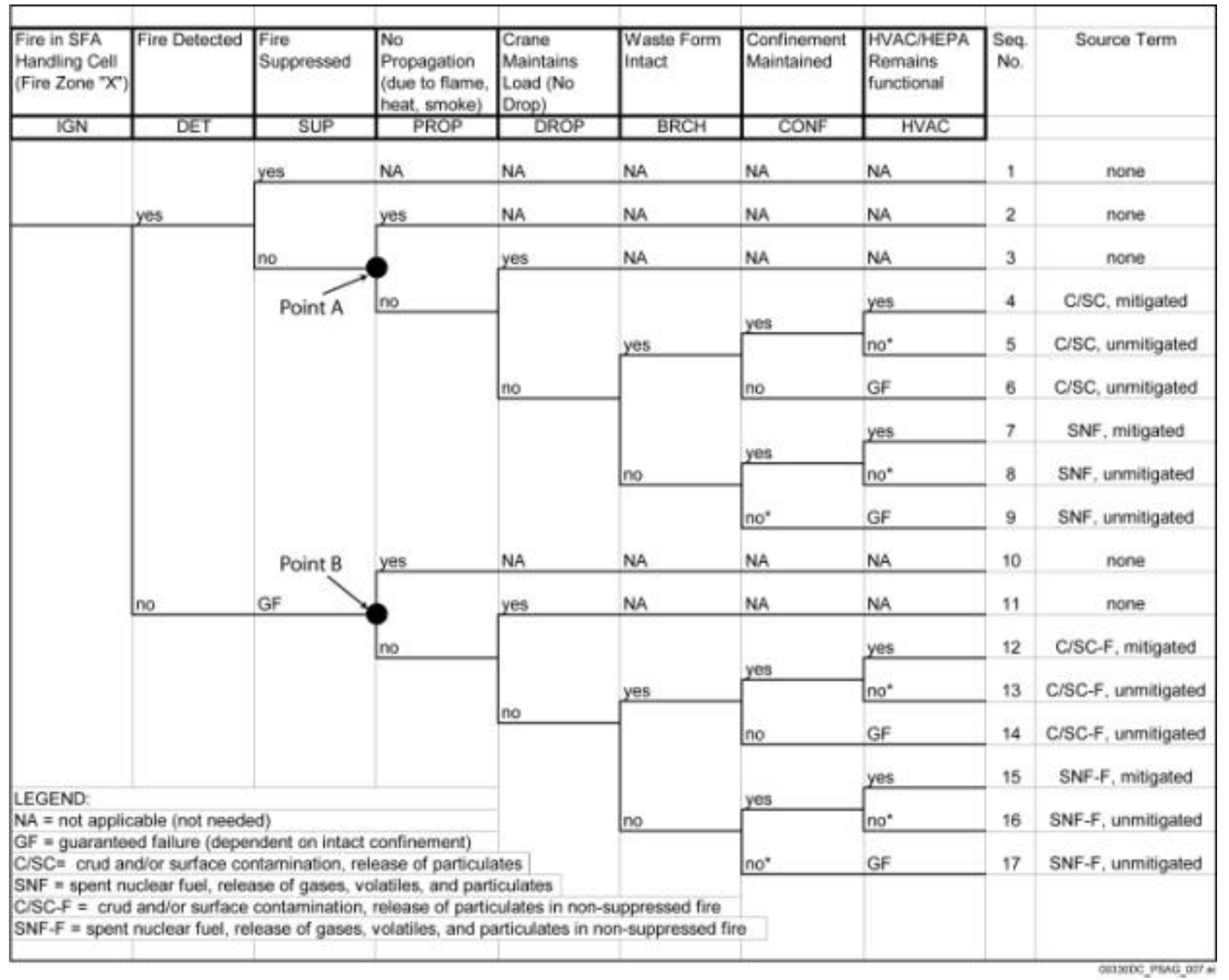

Figure 10-11. Example of Fire Event Tree for Drop of Spent Fuel Assembly

As previously noted, a typical frequency of occurrence of fire initiation in representative locations in an NPP is on the order of $2 \times 10^{-3}$ to $6 \times 10^{-3}$ per room-year. It appears that even if fire-initiation frequencies for the fire zones of the MGR were shown to be a factor of 100 less, then the incidence of fire cannot be screened out on initiating event frequency alone.

Automatic fire detection and suppression systems are typically very reliable. For example, assuming an initiation frequency of $6 \times 10^{-3}$ per room-year, a failure probability of automatic detection of 0.001, and guaranteed failure (GF) of the suppression system exists, given that the failure of automatic detection occurs (a probability of 1.0), then the frequency of a nonsuppressed fire becomes about $6 \times 10^{-6}$ per year. This is labeled "Point B" in Figure 10-11. 
Similarly, if the detection occurs, but the probability of failure to suppress is 0.001 given that automatic detection is available, then again the frequency of a non-suppressed fire becomes $6 \times 10^{-6}$ per year. This is labeled "Point A" in Figure 10-11.

Neither of the sequences up to Point A or Point B are below the cutoff frequency for Category 2 event sequences, so the fire could not be screened out for this example location.

If the probability of detection also includes a secondary or late detection (e.g., visual observation either direct or video) with a probability of failure of say 0.1 and the failure of suppression can be reduced by taking credit for manual intervention (e.g., fire brigade), then the frequencies of both non-suppressed fire scenarios (Point A or Point B) can be reduced to $6 \times 10^{-7}$ and may be screened out without addressing other event headings shown in the fire ET (Figure 10-11).

If either (or both) sequences to Point A or Point B cannot be screened out, then the probability of the event labeled PROP in Figure 10-11 must be quantified by either inspection (using reasoned arguments for spatial factors, heat flux, etc.), or by employing a physical fire propagation model. It is assumed, for Revision 1 of this guide, that such quantification will not be necessary for the MGR PSA. Therefore, this approach is not developed further. Should the need arise during the PSA fires analysis, the most recent and appropriate fire-PRA methodology will be applied. NUREG/CR-6738, for example, has provided insights on prior fire-PRA methods that are deemed adequate or conservative, given the evaluation of actual fire incidents at NPPs in the United States and other countries.

\subsubsection{Wildland Fires}

The objective of this section is to outline an approach for analysis of an externat initiated fire and related hazards identification for repository facilities sufficient to minimize the potential for:

1. Damage from a wildland fire or related event

2. An externally initiated fire that causes an unacceptable onsite or offsite release of hazardous or radiological material that will threaten the health and safety of employees, the public, or the environment

3. Critical process controls and safety class systems being damaged as a result of an externally initiated fire and related events.

The MGR External Events Hazards Analysis (CRWMS M\&O 2000a) has previously identified wildland fire as a potential hazard to the repository. An analysis of the wildland fire hazard should consider the potential event sequences that could result in fire or fire-related damage to the repository facilities. The area surrounding the repository site is mostly barren with no trees and small low-growing vegetation. The Standard for the Protection of Life and Property from Wildfire, NFPA 299 (NFPA 1997), should be used as guidance for site protection from wildfire. This standard presents minimum planning criteria for the protection of life and property from wildfire. The practices of having defensible spaces around buildings NFPA 299 (NFPA 1997) and using noncombustible building materials reduce the probability of damage from wildfire. 
The section of the PSA that provides the analysis of fires should provide a comprehensive list of wildland fire hazards such that mitigation and response plans can adequately address the hazard, including adequate water supplies, reliable means of taking water to the fire, access route for emergency response vehicles, and personnel trained in wildland fire-fighting.

The hazards from a wildland fire can be reduced by the use of a fire protection program and design requirements for facilities that are designed and constructed to meet the applicable building code and National Fire Protection Association codes and standards, or exceeding them when necessary to meet safety objectives. The fire hazards analyses for the repository facilities will consider the hazards of wildland fires. The conclusions of the fire hazards analyses will be integrated into design basis and beyond design basis accident conditions.

\subsection{OTHER EXTERNAL EVENTS}

\subsubsection{Loss-of-Offsite Power}

The likelihood of LOSP should be estimated for the Yucca Mountain site based on historical information for the region.

LOSP events at the MGR may be likely to occur one or more times during preclosure operations due to random failures on the power supply system (grid). Therefore, LOSP will be a credible Category 1 initiating event. The strategy for this event is to prevent credible release scenarios by design. MGR SSCs ITS may be designed to fail safe during a LOSP event. Cranes that are ITS may also be designed in accordance with NUREG-0554 (NRC 1979) to preclude loss of safety function folloiwng a LOSP.

Emergency backup power sources and redundant offsite power lines/sources may be used to ensure a continuous power supply to SSCs ITS, where necessary, to ensure compliance with 10 CFR Part 63. The MGR design may also include special features (e.g, external lightning rods to protect against a lightning-initiated LOSP event).

Event trees (Section 7.1) and fault trees (Section 7.2) should be developed using the frequency of LOSP to perform the analysis. Event sequences determined from evaluation of the trees can be used to identify possible credible event sequences that result in offsite releases. Furthermore, seismic events may be a cause of LOSP. Seismic imitated event sequences are analyzed methods described in Section 10.1.

\subsubsection{Aircraft Hazard Analysis}

\subsubsection{Purpose}

This guide recommends methods to determine aircraft hazard potential and the extent of any protection required for SSCs ITS. Aircraft crashes were determined to be potentially applicable to the repository at Yucca Mountain in the MGR External Hazards Analysis (CRWMS M\&O 2000a). This determination was conservatively based on limited knowledge of the flight data in the area of concern and the crash data on aircraft of the type flying near the MGR. 
An aircraft frequency analysis will meet the requirements of NUREG-0800, Standard Review Plan for the Review of Safety Analysis Reports for Nuclear Power Plants (NRC 1987). The aircraft frequency analysis will establish the frequency of aircraft crashes into radioactive material control facilities at the repository.

\subsubsection{Scope}

The recommended approach to be used in performing aircraft crash analysis for the repository surface facilities is presented herein. The NRC requires a determination of the probability of an aircraft crash and a consequence analysis if the probability exceeds allowable dose limits. Meeting this requirement could involve up to three phases:

1. Development of a vicinity map

2. Crash frequency analyses

3. A consequence analysis, if necessary.

An aircraft hazard analysis for the PSA will focus on the approach to be used for the first two phases. Example calculations are described to illustrate how these methods can be applied. All information used in these examples is subject to change.

\subsubsection{Overview of Approach}

Nuclear waste repository licensing requirements are defined in 10 CFR Part 63, wherein events with probabilities greater than one in 10,000 (based on an expected surface facility lifetime of 100 years) are considered credible event sequences. This probability limit equates to an event sequence frequency of $1.0 \times 10^{-6}$ per year for a 100 -year preclosure period, which is used to determine if an aircraft crash event is credible. If so, the consequences of the event must be evaluated. If the event is not credible and the NRC accepts this conclusion, no further analysis is required.

The Nellis Air Force Base is located near Las Vegas. The repository site is located in the southwestern section of the Nevada Test Site (NTS). The Nevada Test and Training Range includes the Nellis Air Force Range and surrounding military operations areas. The Nevada Test and Training Range surrounds the NTS on the east, north, and west sides. As such, it must be shown that aircraft flying from the base to the range and other aircraft related activities in the range and other surrounding areas would not result in a safety issue that cannot be prevented or mitigated. In addition, civilian air traffic to and from the Las Vegas McCarran International Airport and other smaller airports must be considered.

The airspace in southern Nevada includes military operations areas, restricted areas, and general aviation areas. The responsibility for managing the airspace within these areas is delegated to the U.S. Air Force, DOE, and the Federal Aviation Administration, as appropriate. Air traffic outside of restricted areas is routed on commercial airways and military training routes. Air traffic within restricted areas does not follow specific flight corridors; instead, mission-specific routes are flown resulting in a random distribution of aircraft within these areas. The Air Force has agreements with DOE for use of the NTS airspace for ingress and egress of the Nevada Test and Training Range. 
Military air traffic is mainly composed of fighter and attack aircraft such as F-15s, F-16s, and A-10s. During large training exercises, other types of aircraft including bombers, tankers, helicopters, and other U.S. and non-U.S. fighter aircraft are added to the air traffic. Military aircraft fly in normal cruise mode during ingress and egress of the test and training ranges.

The typical military training missions within the military operations areas and restricted areas include basic flight maneuvers, air combat maneuvers, day/night weapons delivery, and large multi-aircraft exercises. Several types of ordnance are carried on these aircraft. Military training routes are used for low-altitude and navigational training.

\subsubsection{Details of Approach}

NUREG-0800 (NRC 1987) includes three acceptance criteria. Meeting all three criteria would eliminate the need for crash frequency analyses. Because of the extensive military traffic in the vicinity of the repository, each of the three criteria may not be met and frequency analysis is performed as part of phase 2. Various analytical models used to determine the crash frequencies of different aircraft-related activities involve a determination of effective target areas, crash rates, number of flights, flight corridor widths, and potential crash areas.

Because use of the NUREG-0800 (NRC 1987) airway model may be too conservative for application to a repository at Yucca Mountain, alternative models were developed in the preliminary aircraft crash frequency analysis (BSC 2003a). A review of existing models is provided in the following sections.

\section{Use of NUREG-0800}

The analytical model in NUREG-0800 (NRC 1987, Section 3.5.1.6.III.2) is best suited for calculating crash frequency of aircraft that fly well-defined routes (e.g., Federal Aviation Administration commercial airways and jet routes). This NUREG addresses aircraft hazards to NPPs; however, this same methodology can be applied to other nuclear facilities. The NUREG includes proximity criteria, which, if met, would dismiss the event by inspection. If the proximity criteria are not met, then a detailed review of the aircraft hazards must be performed.

The NUREG defines a process to be used by the NRC staff in reviewing the license applicant's assessment of aircraft hazards. This process includes models for determining the probability of an aircraft crash at the repository site from airways, airports, and designated airspace. The total aircraft hazard probability at the repository equals the sum of the individual probabilities obtained from these models. An example aircraft crash hazard defined in the MGR External Events Hazards Analysis (CRWMS M\&O 2000a) involves military aircraft flying through the R4808N restricted airspace (DMA 1995) over the NTS, which includes the site of the repository surface facilities. These aircraft are at high altitudes in an enroute/inflight phase while inside the R4808N airspace. Although they are not flying in standard Federal Aviation Administration airways, they fly within specifically defined areas. The model provided in NUREG-0800 (NRC 1987) for airways can be used to approximate the crash frequency and determine if the event is credible. 


\section{Device Assembly Facility Model}

Kimura et al. (2002) performed a crash hit frequency analysis as part of a safety analysis for the Device Assembly Facility, a DOE facility located on the NTS. A model was developed in that analysis to address U.S. Air Force overflights of the DOE R4808N restricted area. In this model, the aircraft crash frequency equals the product of the number of aircraft (which overfly a particular area), the probability that the aircraft crashes in that particular area, and the probability that the aircraft hits a facility in this particular area.

\section{NUREG Airport Model}

NUREG-0800 (NRC 1987) provides a model for determining the crash frequency associated with aircraft takeoff and landings from civilian and military airports. However, the NRC has determined that the crash frequency is negligible beyond 10 miles from the end of a runway (NRC 2000b). There are no airports or airstrips within 10 miles of the repository surface facilities site. If this situation were to change, an analysis using the NUREG-0800 Airport Model would be performed.

\section{Designated Airspace Model}

A variation of a model developed by Kimura et al. (2002) was developed by the Private Fuel Storage (PFS) Limited Liability Company for their aircraft crash analysis of a nuclear fuel storage facility in Utah. The analysis model by Kimura et al. is termed the PFS model and the nuclear fuel storage facility used in the model is located near a U.S. Air Force test and training range (Private Fuel Storage 2000). The crash impact hazard for each altitude band for each range sector is shown in Private Fuel Storage (2000).

The PFS model develops an annual crash rate per square mile and multiplies it to the site specific cutout area. The cutout area is bounded by the edge of a specific range and an arc, centered on the nuclear facility, with a radius equal to the maximum distance wherein loss of pilot control is possible. The model developed for the MGR in the preliminary aircraft frequency analysis (BSC 2003a) is similar to the PFS model, except that it does not credit pilot crash avoidance as used in the PFS model.

\subsubsection{Regulatory Requirements}

NUREG-0800 (NRC 1987) defines the requirements for reviewing the adequacy of a license applicant's aircraft hazard evaluation. Additionally, nuclear waste repository licensing requirements are defined in 10 CFR Part 63 wherein events with probabilities greater than 1 in 10,000 (based on an expected surface facility lifetime of 100 years) are considered credible events. This probability limit equates to an event frequency of $1.0 \times 10^{-6}$ per year, which is used to determine if an aircraft crash event is credible and, if so, the consequences of the event must be evaluated. If the event is deemed to be not credible and the NRC accepts this conclusion, then no further analysis is required.

The results of the repository aircraft crash frequency analysis will be compared with an evaluation criterion that determines if a crash hit event is credible. A crash hit event is defined as an aircraft impacting a repository surface radiological control facility that has sufficient 
radionuclide inventory to exceed 10 CFR Part 63 dose limits. The event is not credible and needs no further analysis if it meets the following criterion:

The Crash Hit Frequency of an aircraft into a radiological control facility from aircraft shall be less than $1 \times 10^{-6}$ per year.

\section{Example of Application of NUREG-0800 Proximity Criteria}

NUREG-0800 (NRC 1987, Section 3.5.1.6.II) defines proximity criteria that applies to the various types of aircraft flying in the regional airspace surrounding the repository surface facilities. According to the NUREG, the probability is considered below the threshold for further evaluation if the distances from the plant (repository surface facilities) meet all of the following proximity criteria (NUREG requirements):

1. The plant-to-airport distance, $\mathrm{D}$, is between 5 and 10 statute miles, and the projected annual number of operations is less than $500 \mathrm{D}^{2}$ or the plant-to-airport distance $\mathrm{D}$ is greater than 10 statute miles, and the projected annual number of operations is less than $1,000 \mathrm{D}^{2}$.

2. The plant is at least 5 statute miles from the edge of military training routes, including low-level training routes, except for those associated with a usage greater than 1,000 flights per year, or where activities (such as practice bombing) may create an unusual stress situation.

3. The plant is at least 2 statute miles beyond the nearest edge of a federal airway, holding pattern, or approach pattern.

\section{Defining the Vicinity for Crash Frequency Analysis}

A preliminary crash frequency analysis that was completed in late 1998 focused on military aircraft traversing the NTS en-route from the Nellis Air Force Base to the Nevada Test and Training Range. After review of this analysis by the NRC, it was agreed that extended evaluations over a wider area were needed to determine if other aircraft-related activities could impact the frequency of a crash into repository surface facilities. Military operations areas are located on the east and north sides of the Nellis Air Force Range.

The area extending south below Las Vegas, Nevada, north to Tonopah, Nevada, and east beyond Highway 93 and west to Death Valley, California, should define the vicinity for detailed frequency analysis.

The approach to be used to establish this vicinity involves screening of non-credible events using both qualitative and quantitative methods. Identification of Aircraft Hazards (BSC 2002) describes the various areas and airfields within the area, the aircraft flying in those areas, and the activities being performed by these aircraft. This includes describing military test and training missions conducted in each sub-range and military operations area within the Nevada Test and Training Range and determining the distances from these areas to the repository surface facilities site. The description includes relevant characteristics of each aircraft and ordnance carried by 
these aircraft. For an example of an aircraft analysis that was performed for the Yucca Mountain site see Frequency Analysis of Aircraft Hazards for License Application (BSC 2003a).

\subsubsection{Military and Industrial Hazards}

\subsubsection{Scope}

Example impacts due to nearby installations and operations were evaluated in the Preliminary MGR Hazards Analysis (CRWMS M\&O 1996) and then in Industrial/Military Activity-Initiated Accident Screening Analysis (BSC 2002d). This determination was conservatively based on limited knowledge of the potential ongoing activities being conducted on or off the NTS. The methodology described herein for performing industrial/military activity-initiated accident screening anlaysis is intended to meet the requirements of the Standard Review Plan (NRC 1987) in establishing whether this external event can be: (1) screened from further consideration or (2) must be included as an initiator in the development of event sequences for the repository.

\subsubsection{Methodology}

The approach recommended is defined in NUREG-0800 (NRC 1987). NUREG-0800 (NRC 1987, Sections 2.2.1 and 2.2.2) address identification of potential hazards in the vicinity of a nuclear facility. The methodology involves identifying facilities within specified criteria, describing these facilities, describing the nature and extent of activities conducted, and providing statistical data about hazardous materials used at these facilities. The criteria in NUREG-0800 (NRC 1987, Section 3.1) include:

Identified facilities and activities within 8 kilometers (5 miles) of the plant should be reviewed. Facilities and activities at greater distances should be considered if they otherwise have the potential for affecting plant features that are ITS.

Any facilities that meet the stated criteria have to be evaluated in accordance with the following sections of NUREG-0800, as appropriate:

- $\quad$ Section 2.2.3, Evaluation of Potential Accidents

- $\quad$ Section 3.5.1.5, Site Proximity Missiles (Except Aircraft)

- $\quad$ Section 3.5.1.6, Aircraft Hazards.

Hazards from an aircraft crash are covered in Section 10.6.2 while hazards from objects/ordnance falling from aircraft are covered in this section.

Initiating events may be screened from further consideration if they have: (1) a frequency that is less than $1.0 \times 10^{-6}$ per year (i.e., are beyond Category 2 event sequence frequencies) or (2) no impact on the repository due to the combination of the event magnitude (e.g., minimal overpressure and temperature) and distance from the repository. Types of events that are screened include explosions, fires, chemical releases, and objects or ordnance falling from aircraft.

Specific evaluations of the overpressure from an explosion and the frequency of a radiological release from the WHB due to dropped objects or ordnance are performed to: demonstrate that 
events can be screened from further event sequence consideration based on their inability to cause a radiological release or based on their low frequency of occurrence.

\subsubsection{Application of NUREG-0800 Proximity Criteria}

NUREG-0800 (NRC 1987, Section 2.2.1.III.1) specifies that all identified facilities and activities within 8 kilometers ( 5 miles) of the plant shall be reviewed. When applying this criterion, surface and subsurface facilities should be considered. DTN: MO9907YMP97128.001 shows the relationship of the surface facilities and the current extent of the subsurface facility with a 5-mile perimeter drawn around the both the surface and subsurface areas.

\subsubsection{Application of NUREG-0800 Plant-Affecting Criteria}

NUREG-0800 (NRC 1987, Section 2.2.1.III.1) specifies that facilities and activities at distances greater than 5 miles should be considered if they otherwise have the potential for affecting plant ITS features. The area surrounding the 5-mile perimeter includes the balance of the land withdrawal area, the balance of the NTS, Air Force land, and U.S. Bureau of Land Management land. The land withdrawal area extends another 2 miles to the west and 8 miles to the south. The NTS extends over 30 miles to the north and over 20 miles to the east of the land withdrawal area. The Air Force land is part of the Nellie Air Force Range which extends over 50 miles to the north of the withdrawal area. Bureau of Land Management land extends beyond the withdrawal area to the west and south and includes U.S. Highway 95 providing the major route between Las Vegas and Reno, Nevada. The potential for transportation accidents and Air Force dropped objects affecting the ITS features should be covered.

Descriptions to be included in this study are the NTS facilitates/activities and their potential to impact the repository; facilities/activities on Bureau of Land Management land, and facilities/activities on the Nellis Air Force Range.

\subsubsection{Parametric Evaluation of Potential Explosions}

Some of the NTS and Nellis Air Force Range facilities handle high-explosive materials; in addition, events such as transportation and industrial accidents may result in explosions. The overpressure generated by an explosion (i.e., detonation) is a function of the amount of explosive material involved and the distance between the site of the explosion and the repository.

A methodology is given in Regulatory Guide 1.91, Evaluations of Explosions Postulated to Occur on Transportation Routes Near Nuclear Power Plants, for evaluating the safe distance from a postulated explosion.

For example, a value for the mass of explosive can be calculated by setting the safe radius equal to the 5-mile (26,400 ft) criterion (NRC 1987, Section 3.1) and using the methodology in Regulatory Guide 1.91. The value can then be compared with any of the explosive inventories currently associated with NTS facilities and any transportation or industrial explosive sources. Data from the Lake Denmark Explosion that occurred at the Picatinny Arsenal in 1926 (Kinney and Graham 1985, p. 13) should also be reviewed for determination of a safe distance from a large-scale explosion. 


\subsubsection{Objects Dropped from Aircraft}

Objects inadvertently dropped from aircraft can be screened from further event sequence consideration by demonstrating that the frequency of a release of radiological material is less than $1.0 \times 10^{-6}$ per year. An event tree (see Section 7.1) can be used to evaluate the frequency of a dropped object causing a radiological release. Some events to consider in the construction of the event tree and sample numbers are as follows:

Frequency of Ordnance Drop (per sortie)-Dropped objects are defined in SAIC (1991, p. 2-48) (e.g., screws, bolts, coverplates). The frequency at which objects are dropped from military aircraft is given as 1.5 drops per 1,000 sorties (SAIC 1991, p. 2-48).

Number of Sorties that Overfly the NTS-The number of sorties that overfly the NTS is 18,910 per year. This is the 95 percent confidence value as calculated in MGR Aircraft Crash Frequency Analysis (CRWMS M\&O 1999a, p. V-2).

Fraction of Sorties that Fly in the Vicinity of the WHB-It is estimated that no more than 2 percent $\left(2.0 \times 10^{-2}\right)$ of the total sorties that overfly the NTS fly within a 6-mile by 6-mile box centered on the WHB.

Probability of an Object being Dropped in the Vicinity of the WHB-If it is assumed that drop frequency is uniform with respect to the flight path of an aircraft, then the conditional probability that a dropped object falls while an aircraft is within the 6-mile by 6-mile box is the ratio of the flight path length within the box to the total flight path length.

Probability of an Object Dropped in the Vicinity of the WHB Striking the WHB-The conditional probability of an object dropped within the 6-mile by 6-mile box centered on the WHB actually striking the building is equal to the ratio of the WHB footprint $\left(0.01 \mathrm{mi}^{2}\right)$ to the footprint of the 6-mile by 6 -mile box:

$$
(e)=\frac{0.01 \mathrm{mi}^{2}}{(6 \text { miles }) \times(6 \text { miles })}=2.78 \times 10^{-4}
$$

Probability of an Object that Hits WHB Striking Nuclear Material-To cause a radiological release, a dropped object that hits the WHB must strike nuclear material; the conditional probability is equal to the ratio the available strike area of nuclear material to the area of the WHB footprint.

A calculation that can be reviewed for examples of the treatment of objects dropped from aircraft is Industrial/Military Activity-Initiated Accident Screening Analysis (BSC 2003b).

\subsubsection{Ordnance Dropped from Aircraft}

Ordnance inadvertently dropped from aircraft can be screened from further event sequence consideration by demonstrating that the frequency of a release of radiological material is less than $1.0 \times 10^{-6}$ per year. An event tree (see Section 7.1) can be used to evaluate the frequency of dropped ordnance causing a radiological release. A calculation that can be reviewed for 
examples of the treatment of ordnance dropped from aircraft is Industrial/Military ActivityInitiated Accident Screening Analysis (BSC 2003b). Some events to consider in the construction of the event tree and example numbers are listed below:

Frequency of Ordnance Drop (per sortie)-The frequency at which armaments are dropped from military aircraft is given as $0.005\left(5.0 \times 10^{-3}\right)$ drops per 1,000 sorties (SAIC 1991, p. 2-48).

Number of Sorties that Overfly the NTS-The number of sorties that overfly the NTS is 18,910 per year. This is the 95 percent confidence value as calculated in CRWMS M\&O (1999a, p. V-2).

Fraction of Sorties that Fly in the Vicinity of the WHB-It is estimated that no more than 2 percent $\left(2.0 \times 10^{-2}\right)$ of the total sorties that overfly the NTS fly within a 6-mile by 6-mile box centered on the WHB.

Probability of Ordnance being Dropped in the Vicinity of the WHB-For dropped ordnance to affect the WHB, and potentially cause a release of nuclear material, it must fall off of the aircraft as its flight path passes near the WHB. If it is assumed that drop frequency is uniform with respect to the flight path of an aircraft, then: the conditional probability that dropped ordnance falls while an aircraft is within the 6-mile by 6-mile box is the ratio of the flight path length within the box to the total flight path length.

Fraction of Sorties that Fly in the Vicinity of the WHB with Live Ordnance-Only 10 percent $\left(1.0 \times 10^{-1}\right)$ of the sorties flown in the vicinity of the WHB carry live ordnance. Based on "Nellis Airspace and Crash Data for Yucca Mountain Hazard Analysis" (Tullman 1997), most aircraft flying through the western NTS near the repository are armed with simulated ordnance.

Fraction of Sorties that Fly in the Vicinity of the WHB with armed ordnance that could be dropped-Restrictions imposed by the Air Force on NTS overflights forbid overflight of the NTS with armed live ordnance unless the ordnance is carried internally and the bomb bay doors are confirmed closed (i.e., in a configuration where a drop cannot occur) (Irving 1997). Based on these restrictions and engineering judgement, the conditional probability of an inadvertent drop of armed live ordnance is $0.01\left(1.0 \times 10^{-2}\right)$.

Fraction of Dropped Live Ordnance that Explodes Upon Impact-It is conservatively assumed that any ordnance that is live (i.e., not simulated) and armed will explode upon impact.

Probability that Dropped Ordnance Affects the WHB-The conditional probability of dropped ordnance affecting nuclear material inside the WHB is dependent upon: whether the ordnance explodes on impact, the probability of which depends on whether the ordnance is live (as opposed to simulated), and whether the ordnance, if live, is armed.

\subsubsection{Transportation}

The following general discussion is provided as an example to be considered for assessing transportation hazards: 
U.S. Highway 95 and roads on the NTS are used to haul large quantities of explosives, munitions, propellants, hazardous materials, and radioactive materials. At its closest point, U.S. Highway 95 is approximately 13 miles from the repository surface facilities (DMA 1995).

Most transportation of hazardous materials on the NTS occurs on roads located at least 15 miles from the repository surface facilities (DMA 1995). The Lathrop Wells Road, which traverses the southeastern area of the repository withdrawal area, is used to support testing in the Xand Y tunnels. Assuming that materials are transported onto the NTS via the Lathrop Wells Road for this testing, the transport vehicles will be approximately 10 miles from the repository surface facilities (DMA 1995).

There are no transportation railroad lines within 20 miles of the repository surface facilities (DMA 1995).

These transportation routes are expected to be sufficiently distant from the repository to preclude adverse effects of transportation accidents resulting from explosions. Specific evaluations of the overpressure from an explosion on a nearby transportation route are to be performed to demonstrate that these events can be screened from further event sequence consideration. These distances are also sufficiently distant from the repository to preclude adverse effects of fires associated with transportation accidents. In the case of toxic releases, the NRC regulatory position for evaluating the habitability of a NPP control room can be found in Regulatory Guide 1.78 .

\subsubsection{Evaluation of Application of NUREG-0800, Plant-Affecting Criteria, to Independent Spent Fuel Storage Installations and Nuclear Power Plants}

Safety analysis reports (specifically Chapter 2.2, Nearby Industrial, Transportation, and Military Facilities) of other NRC-licensed facilities should be reviewed to identify any cases where detailed analyses were performed to assess facilities outside the NUREG-0800 (NRC 1987) 5-mile evaluation limit. Some examples to consider include:

- Idaho National Engineering and Environmental Laboratory TMI-2 Independent Spent Fuel Storage Installation (INEL 1996)

- $\quad$ Rancho Seco Independent Spent Fuel Storage Installation (Shelter 1993).

\subsubsection{Consequence Analysis}

Perform the following activities for each applicable credible event sequence on an individual basis or in combination with other events in an event sequence:

1. A frequency analysis that demonstrates the event sequence is not credible.

2. A safety system analysis that demonstrates a radiological release does not occur as a result of the event sequence.

3. A consequence analysis that demonstrates that the radiological consequences of the event sequence are within regulatory requirements or a consequence analysis that 
identifies required preventative or mitigative SSCs that ensure that the radiological consequences are within regulatory requirements.

For each credible event sequence identified, dose assessments will be performed to show compliance to requirements as applicable.

The frequency analysis of an event sequence determines if the event is credible. If not credible, no quantitative dose limits are promulgated by 10 CFR Part 63, no further analysis is required, and there is no impact to other repository design or licensing organizations. If the event sequence is determined to be credible, then it is categorized based on the 10 CFR Part 63 definition and a consequence analysis is performed to determine if the dose limits associated with the applicable event category can be met.

\subsection{REFERENCES}

\subsubsection{Documents Cited}

BSC (Bechtel SAIC Company) 2002. Identification of Aircraft Hazards. TDR-WHS-RL-000001 REV 00. Las Vegas, Nevada: Bechtel SAIC Company. ACC: MOL.20020716.0626.

BSC (Bechtel SAIC Company) 2003a. Frequency Analysis of Aircraft Hazards for License Application. CAL-WHS-RL-000001 REV 00B. Las Vegas, Nevada: Bechtel SAIC Company. ACC: DOC.20030618.0024.

BSC (Bechtel SAIC Company) 2003b. Industrial/Military Activity-Initiated Accident Screening Analysis. ANL-WHS-SE-000004 REV 01. Las Vegas, Nevada: Bechtel SAIC Company. ACC: DOC.20030416.0004.

CRWMS M\&O 1996. Preliminary MGDS Hazards Analysis. B00000000-01717-0200-00130 REV 00. Las Vegas, Nevada: CRWMS M\&O. ACC: MOL.19961230.0011.

CRWMS M\&O 1997. Engineering Design Climatology and Regional Meteorological Conditions Report. B00000000-01717-5707-00066 REV 00. Las Vegas, Nevada: CRWMS M\&O. ACC: MOL.19980304.0028.

CRWMS M\&O 1999a. MGR Aircraft Crash Frequency Analysis. ANL-WHS-SE-000001 REV 00. Las Vegas, Nevada: CRWMS M\&O. ACC: MOL.19981221.0203.

CRWMS M\&O 2000a. MGR External Events Hazards Analysis. ANL-MGR-SE-000004 REV 00. Las Vegas, Nevada: CRWMS M\&O. ACC: MOL.20000310.0069.

CRWMS M\&O 2000b. Monitored Geologic Repository Internal Hazards Analysis. ANL-MGR-SE-000003 REV 00. Las Vegas, Nevada: CRWMS M\&O. ACC: MOL.20000310.0070.

DMA (Defense Mapping Agency) 1995. Nellis AFB Range Chart. St. Louis, Missouri: Defense Mapping Agency. TIC: 243134. 
INEL (Idaho National Engineering Laboratory) 1996. Safety Analysis Report for the INEL TMI-2 Independent Spent Fuel Storage Installation, Revision 0. Docket 72-20. Idaho Falls, Idaho: U.S. Department of Energy, Idaho Operations Office. TIC: 233637.

Irving, D.E. 1997. "R-4808N Airspace Scheduling." Memorandum from D.E. Irving (USAF) to Distribution List, August 8, 1977, with attachment. ACC: MOL.19990301.0229.

Kimura, C.Y.; Sanzo, D.L.; and Sharirli, M. 1998. Crash Hit Frequency Analysis of Aircraft Overflights of the Nevada Test Site (NTS) and the Device Assembly Facility (DAF).

UCRL-ID-131259. Livermore, California: Lawrence Livermore National Laboratory. ACC: MOL.20010724.0327.

Kinney, G.F. and Graham, K.J. 1985. Explosive Shocks in Air. 2nd Edition. New York, New York: Springer-Verlag. TIC: 242469.

NRC (U.S. Nuclear Regulatory Commission) 1979. Single-Failure-Proof Cranes for Nuclear Power Plants. NUREG-0554. Washington, D.C.: U.S. Nuclear Regulatory Commission. TIC: 232978.

NRC 1983. PRA Procedures Guide, A Guide to the Performance of Probabilistic Risk Assessments for Nuclear Power Plants. NUREG/CR-2300. Two volumes. Washington, D.C.: U.S. Nuclear Regulatory Commission. TIC: 205084.

NRC 1986. Recommendations to the Nuclear Regulatory Commission on Trial Guidelines for Seismic Margins Reviews of Nuclear Power Plants. NUREG/CR-4482. Livermore, California: Lawrence Livermore National Laboratories. On Order.

NRC 1987. Standard Review Plan for the Review of Safety Analysis Reports for Nuclear Power Plants. NUREG-0800. LWR Edition. Washington, D.C.: U.S. Nuclear Regulatory

Commission. TIC: 203894.

NRC 1990. Seismic Margins Review of Plant Hatch Unit 1: Systems Analysis.

NUREG/CR-5632. Livermore, California: Lawrence Livermore National Laboratories. On Order.

NRC 1997. Standard Review Plan for Dry Cask Storage Systems. NUREG-1536. Washington, D.C.: U.S. Nuclear Regulatory Commission. ACC: MOL.20010724.0307.

NRC 2000a. Standard Review Plan for Spent Fuel Dry Storage Facilities. NUREG-1567. Washington, D.C.: U.S. Nuclear Regulatory Commission. TIC: 247929.

NRC 2000b. Safety Evaluation Report Concerning the Private Fuel Storage Facility, Docket No. 72-22. Washington, D.C.: U.S. Nuclear Regulatory Commission. TIC: 249827.

NRC 2001 or Sandia 2001. Risk Methods Insights Gained from Fire Incidents. U.S. Washington, D.C.: Nuclear Regulatory Commission. TIC: xxxxxx 
NRC 2003. Yucca Mountain Review Plan, Final Report. NUREG-1804, Rev. 2. Washington, D.C.: U.S. Nuclear Regulatory Commission, Office of Nuclear Material Safety and Safeguards. TIC: $\underline{254568}$.

Ramsdell, J.V. and Andrews, G.L. 1986. Tornado Climatology of the Contiguous United States. NUREG/CR-4461. Washington, D.C.: U.S. Nuclear Regulatory Commission. ACC: MOL.20010727.0159.

SAIC (Science Application International Corporation) 1991. Special Nevada Report, September 23, 1991. Las Vegas, Nevada: Science Application International Corporation.

ACC: NNA.19920131.0361.

Smith, C.L.; Wood, S.T.; Kvarfordt, K.L.; McCabe, P.H.; Fowler, R.D.; Hoffman, C.L.; Russell, K.D.; and Lois, E. 2000. Testing, Verifying, and Validating SAPHIRE Versions 6.0 and 7.0. NUREG/CR-6688. Washington, D.C.: U.S. Nuclear Regulatory Commission. TIC: 249459.

Tullman, E.J. 1997. "Nellis Airspace and Crash Data for Yucca Mountain Hazard Analysis." Letter from E.J. Tullman (USAF/DOE Liaison Office) to W.E. Barnes (DOE/YMSCO), June 5, 1997, with enclosure. ACC: MOL.19970806.0389.

YMP (Yucca Mountain Site Characterization Project) 1995. Seismic Design Methodology for a Geologic Repository at Yucca Mountain. Topical Report YMP/TR-003-NP. Las Vegas, Nevada: Yucca Mountain Site Characterization Office. ACC: MOL.19960404.0325.

YMP (Yucca Mountain Site Characterization Project) 1997. Preclosure Seismic Design Methodology for a Geologic Repository at Yucca Mountain. Topical Report YMP/TR-003-NP, Rev 02. Las Vegas, Nevada: Yucca Mountain Site Characterization Office.

ACC: MOL.19971009.0412.

\subsubsection{Codes, Standards, Regulations, and Procedures}

10 CFR 20. Energy: Standards for Protection Against Radiation. Readily available.

10 CFR 50. Energy: Domestic Licensing of Production and Utilization Facilities. Readily available.

10 CFR 60. Energy: Disposal of High-Level Radioactive Wastes in Geologic Repositories. Readily available.

10 CFR 63. Energy: Disposal of High-Level Radioactive Wastes in a Proposed Geologic Repository at Yucca Mountain. Readily available.

10 CFR 100. Energy: Reactor Site Criteria. Readily available.

ANSI/ANS-2.3-1983. Standard for Estimating Tornado and Extreme Wind Characteristics at Nuclear Power Sites. La Grange Park, Illinois: American Nuclear Society. TIC: 6420. 
ANSI/ANS-2.8-1992. American National Standard for Determining Design Basis Flooding at Power Reactor Sites. La Grange Park, Illinois: American Nuclear Society. TIC: 236034.

ASCE 7-98. 2000. Minimum Design Loads for Buildings and Other Structures. Revision of ANSI/ASCE 7-95. Reston, Virginia: American Society of Civil Engineers. TIC: 247427.

NFPA (National Fire Protection Association) 299. 1997. Standard for the Protection of Life and Property from Wildfire. 1997 Edition. Quincy, Massachusetts: National Fire Protection Association. On Order

Regulatory Guide 1.102, Rev. 1. 1976. Flood Protection for Nuclear Power Plants. Washington, D.C.: U.S. Nuclear Regulatory Commission. Readily available.

Regulatory Guide 1.117, Rev. 1. 1978. Tornado Design Classification. Washington, D.C.: U.S. Nuclear Regulatory Commission. Readily available.

Regulatory Guide 1.165. 1997. Identification and Characterization of Seismic Sources and Determination of Safe Shutdown Earthquake Ground Motion. Washington, D.C.: U.S. Nuclear Regulatory Commission. Readily available.

Regulatory Guide 1.29, Rev. 3. 1978. Seismic Design Classification. Washington, D.C.: U.S. Nuclear Regulatory Commission. Readily available.

Regulatory Guide 1.59, Rev. 2. 1977. Design Basis Floods for Nuclear Power Plants. Washington, D.C.: U.S. Nuclear Regulatory Commission. Readily available.

Regulatory Guide 1.76, Rev. 0. 1974. Design Basis Tornado for Nuclear Power Plants. Washington, D.C.: U.S. Atomic Energy Commission. TIC: 2717.

Regulatory Guide 1.78. 1974. Assumptions for Evaluating the Habitability of a Nuclear Power Plant Control Room During a Postulated Hazardous Chemical Release. Washington, D.C.: U.S. Atomic Energy Commission. ACC: NNA.19891109.0074.

Regulatory Guide 1.91, Rev. 1. 1978. Evaluations of Explosions Postulated to Occur on Transportation Routes Near Nuclear Power Plants. Washington, D.C.: U.S. Nuclear Regulatory Commission. Readily available.

\subsubsection{Source Data}

MO9907YMP97128.001. Land Use and Ownership within a 25-Mile Radius of Yucca Mountain. Submittal date: 07/07/1999. 


\section{INTENTIONALLY LEFT BLANK}




\section{CRITICALITY}

\subsection{INTRODUCTION}

The safety strategy described in Section 3 outlines the basic design philosophy for the MGR to achieve a level of safety that complies with the requirements of 10 CFR Part 63. As part of preclosure safety analysis to support the license application submittal, a preclosure criticality analysis is performed to evaluate criticality hazards and to ensure that adequate criticality prevention and controls are present during surface and subsurface spent nuclear fuel (SNF) handling and high-level radioactive waste operations at the repository.

The criticality safety analysis applies systems analysis methods described in Section 6 and Section 7 as well as neutronic calculations described in this section. The hazards analyses identify potential failures of SSCs that are designed to prevent or control the occurrence of a criticality. Criticality hazards are hazards associated with handling fissionable materials contained in SNF or other waste forms. The event sequence frequency analysis provides the means to evaluate the likelihood and to demonstrate that such occurrences are not credible (i.e., have a frequency less than $1 \times 10^{-6}$ per year). The neutronics analyses provide (1) design bases to prevent or control criticality, and (2) verification that sub-criticality is maintained during the occurrence of Category 1 or Category 2 event sequences.

This section describes the design approach for criticality prevention and the application of hazards and event sequence analyses. The Preclosure Criticality Analysis Process Report (BSC 2003) describes the process for performing criticality safety and design analyses for the waste handeling and process facilities.

\subsection{REGULATORY REQUIREMENTS}

Regulatory requirements relating to criticality safety are described in 10 CFR 63.112(e)(6), which requires the preclosure safety analysis to include means to prevent and control criticality. The regulatory requirements applicable to operations involving SNF assemblies or canisters in transportation casks are derived from 10 CFR Part 71, which will not be addressed in Section 11. It is assumed that the transportation casks have been designed in accordance with applicable Certificates of Compliance and have met the criticality safety requirements in 10 CFR Part 71. As described in the Preclosure Criticality Analysis Process Report (BSC 2003), there are numerous regulatory guides, standard review plans, and industrial codes and standards that will be applied in the design for prevention.

\subsection{REPOSITORY PRECLOSURE CRITICALITY SAFETY STRATEGY}

The fundamental approach to preclosure criticality safety is to prevent any credible criticality event for normal operations and Category 1 or Category 2 event sequences. The strategy to prevent criticality is to rely, where practicable, on moderator exclusion and equipment design that uses passive-engineered controls (e.g., geometry control, fixed neutron absorbers) rather than on administrative controls. Where passive engineering controls alone are not practical or sufficient, administrative controls on fissionable material mass or other reliable and verifiable reactivity control methods, such as minimum burnup requirements on commercial SNF, will be established. 
The criticality safety strategy and analyses will be applied respectively to non-waste package (or out-of-waste package) event sequences and waste-package (or in-waste-package) event sequences. Strategies for in-waste package criticality safety are described in Preclosure Criticality Analysis Process Report (BSC 2003).

The repository preclosure criticality safety strategy also relies on a defense-in-depth approach. The defense-in-depth approach involves taking advantage of the natural site and engineering design features. These features are expected to reduce the probability of a preclosure criticality event to below the regulatory thresholds established in 10 CFR Part 63. The natural site and engineering design features accounted for in the preclosure criticality safety strategy will be identified and credited in the criticality analysis.

\subsection{CRITICALITY ANALYSIS PROCESS}

Criticality is attained when the effective neutron multiplication factor, $k_{\text {eff }}$, of a system of fissionable material in a given geometry becomes equal to or greater than unity. Conversely, subcriticality is defined by a $\mathrm{k}_{\text {eff }}$ less than unity. When designing a system (e.g., a waste package) to be subcritical, it must be demonstrated that the calculated $\mathrm{k}_{\mathrm{eff}}$ conservatively represents the true neutron multiplication of the system. This is accomplished by choosing a value below unity where nuclear criticality is assumed to occur. This value is known as the upper subcritical limit.

The criticality analysis has three parts: (1) identify potential criticality event sequences and evaluate their frequency, Step 1 through Step 6, (2) ensure that subcrticality is maintained for credible event sequences, including redesign as necessary, Step 7 through 9, and (3) in the event that criticality is credible, ensure that doses meet the performance limits of 10 CFR 63.111. The criticality analysis process consists of the following steps:

Step 1. Examine the results from the hazard analyses (see Section 6.2).

Step 2. Identify the SSCs and processes associated with criticality hazards.

Step 3. Identify the types of waste forms that could achieve criticality.

Step 4. Develop a criticality event tree using guidance from Section 7.1.

Step 5. Quantify the criticality event tree using guidance from Section 7, including fault tree analysis, human reliability analysis, common-cause failure analysis.

Step 6. If an event sequence frequency is less than $1.0 \times 10^{-6}$ per year, the event sequence is screened from additional analysis per the requirements of 10 CFR Part 63.

Step 7. If an event sequence frequency is equal to, or greater than, $1.0 \times 10^{-6}$ per year, perform criticality analysis to determine $\mathrm{k}_{\mathrm{eff}}$, where $\mathrm{k}_{\mathrm{eff}}$ is the effective neutron multiplication factor.

Step 8. If the calculated $\mathrm{k}_{\text {eff }}$ is less than the upper subcritical limit, the event sequence has no potential for criticality and additional analysis is not required. 
Step 9. If the calculated $\mathrm{k}_{\mathrm{eff}}$ is equal to, or greater than, the upper subcritical limit, initiate an appropriate redesign of the SSCs and process, make the appropriate modifications to the criticality event tree, and then repeat steps 5 through 9 until the calculated $k_{e f f}$ is below the upper subcritical limit.

Step 10. If practical modifications to the SSCs and processes have been evaluated, the event sequence frequency still exceeds $1.0 \times 10^{-6}$ per year, and the calculated $\mathrm{k}_{\mathrm{eff}}$ still equals or exceeds the upper subcritical limit, a consequence analysis of the event sequence will be performed to calculate the doses to members of the public and workers. The calculated doses will be compared with the regulatory dose limits (Table 8-1). It will be shown that the calculated doses are below the regulatory dose limits.

In steps 8,9 , and 10 , the upper subcritical limit is defined as:

Upper Subcritical Limit $=1$ - bias - bias uncertainty - administrative margin

The upper subcritical limit should not be confused with the critical limit that is defined as one minus the bias and the bias uncertainty. The bias is determined by comparison of criticality calculation results using a code such as MCNP-A General Monte Carlo N-Particle Transport Code (Briesmeister 1997) to critical benchmarks. The administrative margin is an additional arbitrary margin applied to ensure subcriticality.

The process for evaluating potential criticality events associated with the handling of waste forms containing fissionable materials is shown in Figure 11-1.

\subsubsection{Identify the Systems, Structures, Components, and Processes Associated with Criticality Hazards}

The results of external and internal event hazard analyses will be reviewed to identify the SSCs and processes associated with the generic criticality hazards. Criticality event trees, described in Section 11.4.3, will help to define event sequences associated with external and internal initiating events that may result in criticality.

As noted, prevention of criticality is the design strategy. Therefore, the criticality hazards and event sequence analyses will consider how functional failures of SSCs and/or human failure events associated with operating the SSCs could lead to occurrence of criticality. The analyses will be part of the comprehensive PSA and will address in-waste-package and out-of waste-package criticality scenarios associated with each operation that handles or stores waste forms. 


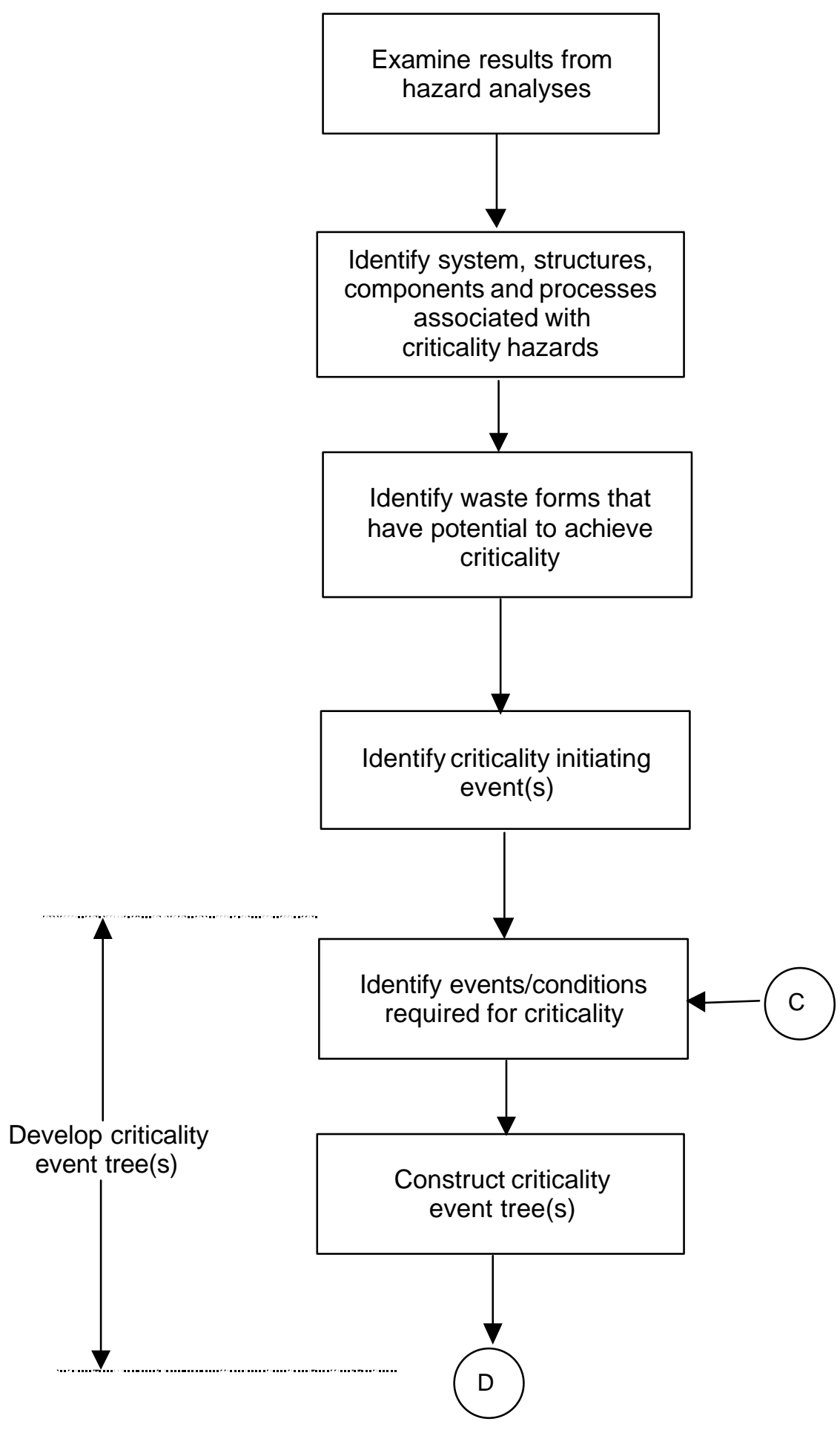

Figure 11-1. Criticality Analysis Flow Chart 


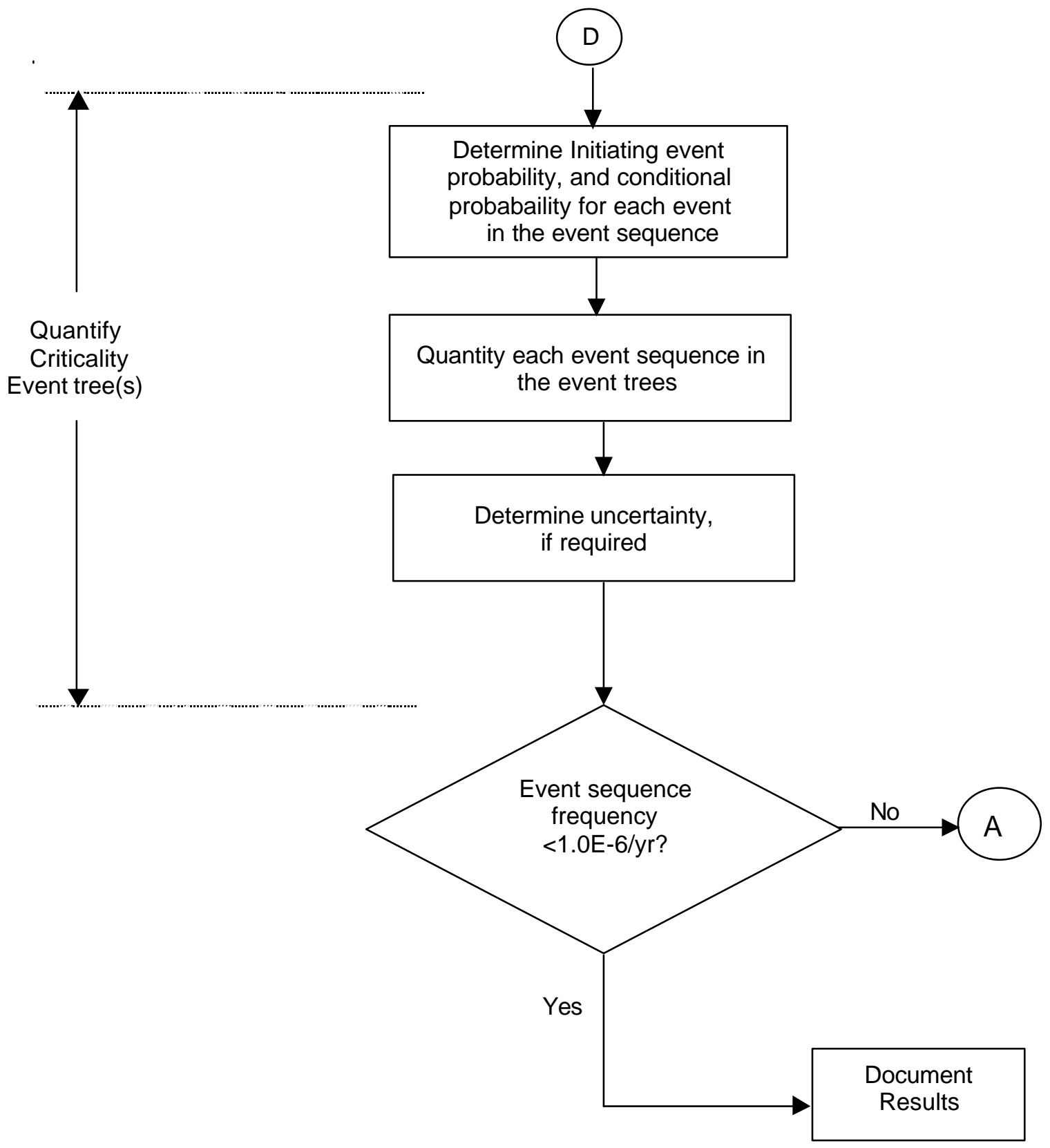

Figure 11-1. Criticality Analysis Flow Chart (Continued) 


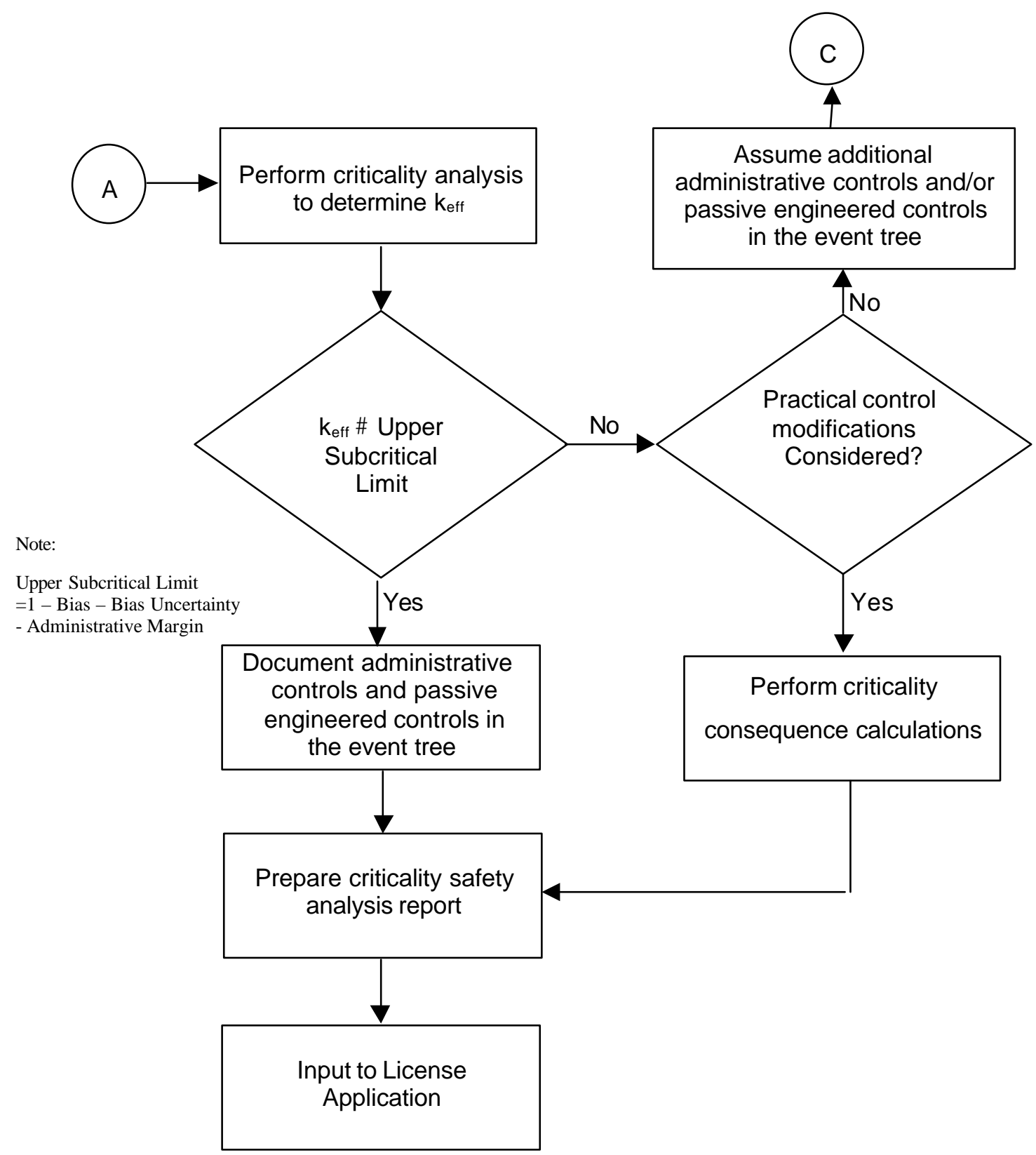

Figure 11-1. Criticality Analysis Flow Chart (Continued) 
As an example, the following repository functional areas and processes would be considered for criticality analysis:

- Waste receipt and carrier/cask transport

- Carrier preparation area

- $\quad$ Transfer cell (including any waste form staging areas)

- Waste package (WP) handling

- Waste package remediation

- Waste package transporter load area

- $\quad$ Surface storage or aging facility

- $\quad$ Subsurface transport, emplacement, and monitoring.

\subsubsection{Identify Those Waste Forms That Have the Potential to Achieve Criticality}

Key factors in determining the potential for waste form criticality are the configuration and the quantity and type of fissionable material it contains. Only a fraction of the waste forms in the currently-identified inventory to be received at the repository have the potential to achieve criticality. These waste forms have medium or high reactivity with the characteristics of a high initial enrichment or low burnup. Examples include some commercial PWR and BWR fuels and canisters with DOE SNFs (e.g., Fast Flux Test Facility, Enrico Fermi, Training Research Isotope General Atomic, Shippingport PWR and Light Water Breeder Reactor, Ft. St. Vrain and $\mathrm{N}$-Reactor SNF). Other waste forms such as high-level radioactive waste glass, contain insufficient fissionable material and, therefore, have no potential for criticality. The fraction of each of these waste forms in annual throughput should be determined and included in the calculation of the criticality event sequence frequency.

\subsubsection{Develop Criticality Event Trees}

Three potential preclosure criticality events were identified in Preclosure Design Basis Events Related to Waste Packages (CRWMS M\&O 2000, p. 60). The events identified in this analysis are:

1. Alteration of geometry events

2. Introduction of neutron moderator or reflector events

3. Waste form misload events.

These potential events are discussed in the following sections. 


\subsubsection{Event Trees for Altera tion Geometry Events}

Initiating events resulting in the drop, tipover and slapdown, or collision of the waste forms or waste form containers could occur during various repository processes. Further, external events (e.g., earthquakes, flooding, fires) may result in conditions that could support criticality. For an event sequence to have the potential for causing a criticality in a waste-form container or a waste form handling area, a number of events and conditions must occur. The events and conditions that must occur include the following:

1. The waste form container (transportation cask, canister, or waste package) must be breached (or not sealed prior to the initiating event).

2. The geometric spacing or configuration of the waste form and the neutron absorber materials of the waste form, waste form container, or waste form handling area must be disrupted or changed. The configuration of a waste form may change after a drop or tip-over/slap-down (e.g., fuel scrap could fall out of a scrap basket in a multicanister overpack (MCO) after a drop and slap-down).

3. A significant source of neutron moderator or reflector material must be present at the location where the initiating event occurs. In addition, the neutron moderator and reflector material must be able to remain in close proximity to the waste form.

4. The waste form must have the potential to achieve criticality.

\subsubsection{Event Trees for Introduction of Neutron Moderator and Reflector Material Events}

Initiating events resulting in the introduction of large quantities of a neutron moderator or reflector material (e.g., hydrogenous materials such as water) could occur in the repository surface facility. The current surface facility design philosophy is to preclude any water or moderator source in the waste form and WP handling areas. However, the potential for flooding events, such as a pipe break or an inadvertent actuation of the fire suppression system, will be assessed. The conditional probability of internal flooding could be determined using the fault tree methodology described in Section 7.3.

\subsubsection{Event Trees for Misload Events}

The methods described in Section 7.1 will be applied to develop event trees for potential criticality event sequences. The headings of the criticality event trees will be tailored, as appropriate, to include initiating events and event headings that stem from physical failures of SSCs due to internal or external events and human failure events.

Methods for loading waste forms into a WP have been developed such that subcriticality is ensured during the preclosure period. This method may be referred to as the Criticality Loading Curve Evaluation. This evaluation established a simple criterion, in terms of the available waste form information, to determine if a waste form can be loaded into a given WP. The available waste form information used in the determination for commercial SNF consists of four components: bundle identification number, initial enrichment, assembly average discharge 
exposure, and decay time. With this information, a curve is developed for each commercial SNF (PWR, BWR, and mixed oxide) that represents the required minimum-average assembly burnup as a function of the initialaverage assembly enrichment allowable for loading into a particular type of WP. For assemblies that fall below this curve, additional means of reactivity control are utilized. Such reactivity control increases the margin to criticality, either by addition of disposable control rods within the assembly or loading of these assemblies into an alternate WP, which is smaller and possesses a higher negative reactivity component inherent in its design. Adhering to this process ensures that a subcritical configuration exists. However, human failure events during loading of the waste form into a WP could potentially lead to a criticality event.

Initiating events resulting in the waste form misload of a waste package or waste form storage area could occur. During the loading of waste forms into a WP, selection and conceptual human failure events could occur resulting in an assembly misload event. A selection error simply represents an unintentional selection of the wrong item while trying to select the correct one. The conceptual human failure event represents intentionally selecting the wrong item based on the erroneous belief that it is the correct item, e.g., because of some error-forcing context (see Section 7.3).

The following paragraphs provide a brief list of examples of the types of potential human failure events that could result in a waste form misload.

Based on the characterization of the waste form removed from transportation casks, the operator decides what type of WP it is to be loaded into. Deciding on an inappropriate WP type or selecting a wrong WP type is a human failure event.

Some fuel assemblies will require the insertion of a neutron absorber rod assembly for permanent disposal. It is expected that these fuel assemblies will be shipped with a neutron absorber rod assembly already in place. For those assemblies that require the insertion of a neutron absorber rod assembly, but are not shipped with one in place, the following two scenarios are possible: the operator fails to identify the assembly as requiring the insertion of the neutron absorber assembly, or having identified the assembly as requiring the insertion of the neutron absorber assembly, the operator fails to insert it.

An additional scenario is possible for those fuel assemblies that will require the insertion of a neutron absorber rod assembly for permanent disposal. It is expected that these fuel assemblies will be shipped with an inadequate neutron absorber rod assembly. The operator could fail to recognize that the assembly has an inadequate neutron absorber assembly and, therefore, fail to replace it with an acceptable assembly.

The selection of the waste form to be placed in the WP is another opportunity for human failure event. The operator could select an incorrect waste form, or after selecting the correct waste form for the WP, make a manipulation error with the crane and transfer the wrong one. Only the misload of medium or high reactivity waste forms into a WP would have the potential for criticality. 
After placing the waste forms into the WP, the operator performs a physical verification to ensure that correct waste forms were loaded. Failure to detect a misloaded SNF assembly in the WP during the physical verification process is another possible human failure event.

The calculated average assembly burnup could be different from the actual average assembly burnup because of calculation errors, incorrect data in the assembly records, use of the wrong assembly records, and other causes. Thus, it could be specified that fuel assemblies that do not meet the criticality loading curve evaluation be placed in a waste package and then loaded correctly.

Human failure probability can be reduced through the use of an independent checker during the physical verification task. Additionally, passive engineering controls have been utilized in the design of the WP internals such that some waste form types will not fit into a WP for which it was not intended. The methods for analysis of human failure events are discussed in Section 7.3.

\subsubsection{Quantify the Criticality Event Trees}

The event sequence frequency analysis will be performed using the methods in Section 7. Quantification of the initiating event frequency, probabilities of branches, and the event sequence frequency should be performed in accordance with Section 7.1.4.

\subsubsection{Perform Criticality Analysis to Determine $k_{\text {eff }}$}

The criticality analysis methods for criticality analysis for the repository are detailed for the preclosure period in the Preclosure Criticality Analysis Process Report (BSC 2003). This report provides the design requirements; applicable regulations, codes, and standards; summary descriptions of the types of computational tools to be used; and the types of analyses to be performed.

Criticality analyses will be performed when an event sequence frequency is determined to equal or exceed $1.0 \times 10^{-6}$ per year. These criticality analyses will be performed to determine the sequence configuration $\mathrm{k}_{\text {eff }}$ using criticality analysis tools such as the MCNP code (Briesmeister 1997). MCNP is a general-purpose Monte Carlo N-Particle code that can be used for neutron transport, and has the capability of calculating $\mathrm{k}_{\mathrm{eff}}$ for generalized systems containing fissionable material. MCNP uses the isotopic compositions of the materials, a detailed representation of the geometry, and a set of nuclear information libraries to calculate $\mathrm{k}_{\mathrm{eff}}$ for the system. The nuclear information libraries used by MCNP are comprised of continuous-energy cross sections of materials. A full set of these material cross sections has been evaluated and is provided through the MCNP code package.

If the calculated $\mathrm{k}_{\mathrm{eff}}$ is below the upper subcritical limit, the system is considered to be subcritical and the event sequence is screened out.

\subsubsection{Perform Criticality Consequence Analyses}

If the criticality event sequence evaluation results in a frequency equal to or exceeding the regulatory threshold of $1.0 \times 10^{-6}$ per year, then it is necessary to determine the consequences of the criticality event. The doses to members of the public and workers will be calculated using 
the methods presented in Section 8. The calculated doses will be compared with the regulatory dose limits. It will be shown that the calculated doses are below the regulatory dose limits.

\subsubsection{Document the Results}

A criticality safety analysis will be prepared to document the results of the criticality analysis. The documentation of the results of the criticality event tree evaluations should include the frequency of each event sequence identified. If administrative controls and natural site and engineered design features are relied on to reduce the criticality event sequence frequency to below the regulatory threshold of $1.0 \times 10^{-6}$ per year, these controls and features should be documented through the SSCs system description documents.

\subsection{REFERENCES}

\subsubsection{Documents Cited}

Briesmeister, J.F., ed. 1997. MCNP-A General Monte Carlo N-Particle Transport Code. LA-12625-M, Version 4B. Los Alamos, New Mexico: Los Alamos National Laboratory. ACC: MOL.19980624.0328.

BSC (Bechtel SAIC Company) 2001. Preliminary Preclosure Safety Assessment for Monitored Geologic Repository Site Recommendation. TDR-MGR-SE-000009 REV 00 ICN 03.

Las Vegas, Nevada: Bechtel SAIC Company. ACC: MOL.20010705.0172.

BSC (Bechtel SAIC Company) 2003. Preclosure Criticality Analysis Process Peport. TDREBS-NU-000004 REV 01. Las Vegas, Nevada: Bechtel SAIC Company.

CRWMS M\&O 2000. Preclosure Design Basis Events Related to Waste Packages. ANL-MGR-MD-000012 REV 00. Las Vegas, Nevada: CRWMS M\&O.

ACC: MOL.20000725.0015.

\subsubsection{Codes, Standards, Regulations, and Procedures}

10 CFR 63. Disposal of High- Level Radioactive Wastes in a Geologic Repository at Yucca Mountain, Nevada. Readily available.

10 CFR 71. Energy: Packaging and Transportation of Radioactive Material. Readily available. 


\section{INTENTIONALLY LEFT BLANK}




\section{SAFETY SIGNIFICANT CLASSIFICATION OF SSCs ITS}

\subsection{INTRODUCTION}

The safety category (SC) classification of SSCs identified as ITS are an integral part of the design process and of the PSA. SC classification of SSCs ITS for preclosure supports the LA for the MGR. SSCs determined to be important to waste isolation during postclosure are identified in the Total System Performance Assessment (see Section 12.3). This section includes:

- Information on the evolution of SC clas sifications and associated criteria

- An overview of the risk-informed classification process for SSCs ITS as required by 10 CFR 63.112(e)

- $\quad$ Discussion on the application of the risk-informed performance-based screening criteria through functional failure analysis as explained in Section 12.3.

ITS, with reference to SSCs, means those engineered features of the GROA whose function is (10 CFR 63.2):

- To provide reasonable assurance that high-level waste can be received, handled, packaged, stored, emplaced, and retrieved without exceeding the requirements of $\S 63.111(\mathrm{~b})(1)$ for Category 1 event sequences

or

- $\quad$ To prevent or mitigate Category 2 event sequences that could result in radiological exposures exceeding the values specified at $\$ 63.111(\mathrm{~b})(2)$ to any individual located on or beyond any point on the boundary of the site.

SSCs are screened and assigned SC classifications based on risk-informed performance-based criteria per 10 CFR 63.112(e) before application of quality assurance (QA) program criteria per 10 CFR 63.142. QA criteria are applied to provide adequate assurance that SSCs will satisfactorily perform assigned safety functions. SC classifications are assigned to SSCs that represent the relative importance of SSCs to the health and safety of the public or to the radiological safety of workers. In part, 10 CFR Part 63 states the following for a high-level radioactive waste (HLW) repository:

DOE is required by $63.21(\mathrm{c})(20)$ to include in its safety analysis report a description of the quality assurance program to be applied to all structures, systems, and components important to safety, to design and characterization of the barriers important to waste isolation, and to related activities (63.142(a)).

The QA program must control activities affecting the quality of the identified structures, systems, and components, to an extent consistent with their importance to safety $(63.142(\mathrm{c})(1))$. 
The phrase "to an extent consistent with their importance to safety" recognizes that a QA program could impose graded QA requirements commensurate with the relative importance to radiological safety of an SSC (structure, system, or component).

Regulatory Guide 1.176 provides guidance for nuclear power plants (NPPs) to apply risk-informed decision making to graded QA program controls. Although risk measures (e.g., core-damage frequency) for NPPs are not relevant to an HLW repository, the principles of Regulatory Guide 1.176 provide general guidance and potential areas for implementing graded QA program controls, should the DOE pursue a graded QA approach for the MGR. Thus far, the DOE has decided against a graded QA approach, choosing instead the full application of 10 CFR 63.142 criteria.

The U.S. Nuclear Regulatory Commission (NRC) established a risk-informed framework for defining a multiple-category SC classification process for SSCs that sets the stage for implementation of graded QA program controls. In NUREG-0800, Section 19.0, the NRC states the following in regards to the use of a probabilistic risk assessment (PRA) for risk-informed decision making (NRC 1987):

...the decision making process will use the results of the risk analysis in a manner that complements traditional engineering approaches, supports the defense-in-depth philosophy, and preserves safety margins. Thus, risk analysis will inform, but it will not determine regulatory decisions.

SSCs ITS for the MGR are classified using a PSA that employs elements of PRA supplemented by applicable regulatory and industry precedents. SSCs ITS that are subject to the QA requirements of $10 \mathrm{CFR} 63.142$ are classified as SC; SSCs that are not subject to the QA requirements of 10 CFR 63.142 are classified as Non-SC.

\subsection{SUMMARY OF THE PSA PROCESS}

Recognizing that 10 CFR Part 63 is a risk-informed performance-based rule, the Yucca Mountain Project has adopted a risk-informed performance-based approach for the PSA. Figure 12-1 illustrates the overall process for developing a PSA and for defining the event sequences for an HLW repository. While parts of the safety strategy for an HLW repository is based on deterministic principles and industry and regulatory precedents, much of the safety evaluation of preclosure operations applies techniques used in a PRA. An overview of the PSA process is provided in Section 4; details are provided in Sections 7 through 11.

The PSA is an iterative process that evolves as the repository design develops, as site characteristics are more fully defined, and as operational features are identified. While the evolution progresses, consistent with the current state of repository development, potential internal and external hazards are identified, event sequences are developed, frequency assessments are performed, event sequences are categorized, and potential resultant consequences are evaluated. Additional information regarding these steps is shown in Table 12-1.

If the consequences of an event sequence do not meet regulatory requirements, then preventative or mitigative design features and administrative controls are implemented until the event 
sequence risk is reduced to meet performance objectives. Sensitivity and uncertainty analyses are performed, as required, to demonstrate that categorization of event sequences and potential consequences meet preclosure performance objectives. SSCs ITS are identified through the use of sensitivity and uncertainty analyses and the use of the SC classification process. The identification of SSCs ITS is documented in classification analyses (a.k.a. functional failure analyses, see Section 12.3) and is subject to independent checking and interdisciplinary review.

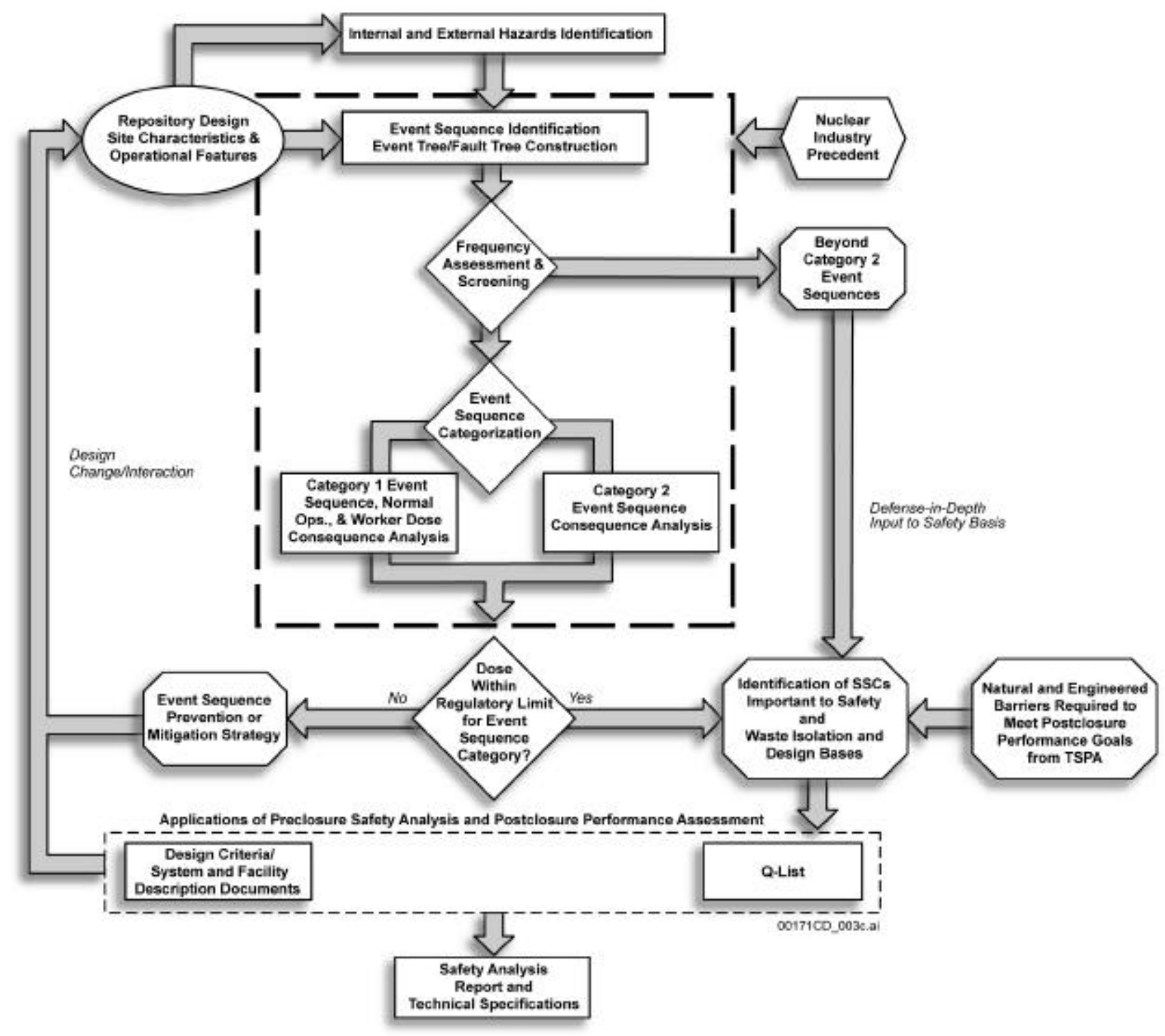

Figure 12-1. Preclosure Safety Analysis 
Table 12-1. Development of a Preclosure Safety Analysis

\begin{tabular}{|c|c|}
\hline $\begin{array}{l}\text { Internal and External } \\
\text { Hazards Identification }\end{array}$ & $\begin{array}{l}\text { Hazards analysis is a systematic identification and evaluation of naturally occurring and } \\
\text { human-induced hazards. To ensure completeness, the analysis begins with checklists } \\
\text { of generic categories of hazards that have been developed for safety and risk analyses } \\
\text { of NPPs, spent fuel storage facilities, fuel cycle facilities, and spent fuel transportation. } \\
\text { The generic hazards are screened to determine which hazards, either internal or } \\
\text { external to the repository facilities, are applicable. The purpose of the hazards analysis } \\
\text { is to identify energy-source categories that can potentially interact with a waste form } \\
\text { (e.g., collision or crushing, chemical contamination or flooding, explosion or implosion, } \\
\text { fire, radiation, thermal, natural phenomena, and potential criticality). Initially, qualitative } \\
\text { evaluations are applied to screen out inapplicable or hazards that are not credible*. } \\
\text { Potentially credible** external hazards that are not eliminated in the initial qualitative } \\
\text { screening are subjected to quantitative analyses to screen them out, if possible. } \\
\text { Otherwise, they are incorporated into the design bases to prevent initiation of a } \\
\text { radiological release that would exceed preclosure performance objectives } \\
\text { (e.g., earthquakes, winds, tornadoes, and loss of offsite power). Potentially credible } \\
\text { internal hazards that are not eliminated in the qualitative screening are evaluated } \\
\text { further in accident sequence analyses. }\end{array}$ \\
\hline $\begin{array}{l}\text { Event Sequence } \\
\text { Identification }\end{array}$ & $\begin{array}{l}\text { Potential accident scenarios (or event sequences) may be displayed in the form of } \\
\text { event trees that include an initiating event (from an identified hazard) and one or more } \\
\text { enabling events that must occur to result in a release of radioactivity, a criticality, or an } \\
\text { abnormal exposure of a worker. The event tree format provides a framework for } \\
\text { estimating the event sequence frequency by displaying the frequency of the initiating } \\
\text { event and the conditional probabilities of contributing (enabling) events. Where } \\
\text { necessary and appropriate, fault-tree analysis is used to estimate the frequency of an } \\
\text { initiating event or probability of an enabling event. Potential criticality event sequences } \\
\text { are subjected to specialized analyses to demonstrate that sufficient design and } \\
\text { operational controls will be in place to ensure that the frequency of an accidental } \\
\text { criticality will be below } 1 \times 10^{-6} \text { events per year (for a } 100 \text {-year preclosure period). }\end{array}$ \\
\hline $\begin{array}{l}\text { Frequency } \\
\text { Assessment } \\
\text { Screening and Event } \\
\text { Sequence } \\
\text { Categorization }\end{array}$ & $\begin{array}{l}\text { The frequency (or events per year) is estimated for each event sequence. The } \\
\text { frequencies of initiating events for internal hazards are estimated from the annual } \\
\text { frequency of each operation multiplied by the conditional probability of the initiating } \\
\text { event per operation. For example, the frequency of a potential canister drop is } \\
\text { estimated by the product of the frequency of canister lifts (i.e., the number per year) } \\
\text { and the conditional probability of dropping the canister per lift. Uncertainties in data } \\
\text { and models will be addressed in the frequency assessment. } \\
\text { This analysis results in a categorization of each event sequence according to its mean } \\
\text { frequency as either Category } 1 \text {, Category } 2 \text {, or Beyond Category } 2 \text {. This frequency } \\
\text { categorization is important because it establishes which portion of the preclosure } \\
\text { performance objectives of } 10 \text { CFR } 63.111 \text { must be met for each sequence. Note that } \\
\text { the frequency categorization is based on the mean frequency of an entire sequence of } \\
\text { events and not just the frequency of the initiating event. }\end{array}$ \\
\hline $\begin{array}{l}\text { Consequence } \\
\text { Analysis }\end{array}$ & $\begin{array}{l}\text { In this portion of the PSA the potential mean consequences are calculated for Category } \\
1 \text { and Category } 2 \text { event sequences and compared against the regulatory limits of } \\
10 \text { CFR } 63.111 \text {. For Category } 1 \text { event sequences, consequences are evaluated from } \\
\text { relevant pathways as potential contributors to chronic exposures and are aggregated. } \\
\text { The aggregate total is then added to the dose for normal operations. For Category } 2 \\
\text { event sequences, consequences are evaluated for relevant pathways for each } \\
\text { sequence as an acute exposure. Uncertainties will be addressed in the consequence } \\
\text { analyses. }\end{array}$ \\
\hline
\end{tabular}

* Not credible (derived from 10 CFR Part 63) is defined such that the event sequence has less than a one in 10,000 chance of occurring before permanent closure (10 CFR 63.2).

${ }^{*}$ Credible (also derived from 10 CFR Part 63) is defined such that the event sequence has at least one chance in 10,000 of occurring before permanent closure. 
The PSA demonstrates with reasonable assurance that HLW can be received, handled, packaged, stored, emplaced, and retrieved without exceeding regulatory performance objectives. The results of the PSA are included in the License Application. The PSA considers the means for providing radiation protection to workers, for detection and suppression of fires, for control of radioactive wastes and effluents, and for implementation of criticality safety principles. PSA results demonstrate the ability of SSCs ITS to perform their intended safety functions based on reliability requirements. SSCs ITS are documented in the Q-List (YMP 2001).

\subsection{BASIS OF THE RISK-INFORMED SC CLASSIFICATION PROCESS}

The QA requirements imposed on safety-related SSCs in commercial NPPs per 10 CFR Part 50, Appendix B, include: complex systems relied upon to ensure the integrity of the reactor coolant pressure boundary, to ensure the capability to shut down the reactor, and to prevent or mitigate the consequences of accidents having significant radiological consequences. However, regulation of NPPs has transitioned from the traditional, deterministic basis to a risk-informed basis.

NUREG-0800 (NRC 1987, Section 19.0), and Regulatory Guides 1.174 and 1.176, establish the bases for graded QA requirements for NPPs and through PRAs both safety-related and non-safety-related SSCs are classified into four risk-informed categories that provide the bases for QA grading at NPPs. This graded approach for identifying risk significance provides general guidance for applying risk-informed SC classification to an HLW repository. However, the approach is not directly applicable since, compared to an NPP, an HLW repository is a lowenergy nonvolatile-hazard facility. Further, 10 CFR Part 63 does not define a "risk measure" that is analogous to the "core damage frequency" for "large early release frequency" used in reactor risk informed regulations.

SSC ITS features at an HLW repository are basically passive with a limited need for automatic safety response to events. There are no expected short-term operator actions required for meeting preclosure performance objectives and no major risk-significant events for receipt, handling, packaging, storage, emplacement, or retrieval have been identified in site recommendation safety assessments (BSC 2001). Therefore, while NUREG-0800 (NRC 1987) and Regulatory Guides 1.174 and 1.176 do not directly apply to the MGR, they do provide conceptual guidance to establish a risk-informed SC classification process.

Consistent with NUREG-0800 (NRC 1987), different levels of risk significance were developed for the MGR, similar to risk-informed safety significance levels for an NPP, using the bases for event sequence frequency and consequence performance objectives established by 10 CFR Part 63. SSCs ITS will be classified as SC as will SSCs that are important to waste isolation. SSCs ITS for the MGR are credited in the PSA with performing a prevention or mitigative function to ensure that radiation exposures meet the performance requirements of 10 CFR 63.111(b).

SSCs important to waste isolation for the MGR are credited with performing a prevention or mitigative function to ensure that radiation exposures meet the performance requirements of 10 CFR 63.113(c) in the Total System Performance Assessment. These SSCs are not considered for risk significance or subsequent QA grading, and are classified as SC. 
The performance objectives of 10 CFR 63.111(b)(1) and (2) can be interpreted from a public risk perspective as: to define acceptable and unacceptable risk regions in terms of event sequence frequency (Category 1 or Category 2), and to define offsite dose consequences (performance objectives for the Category 1 and Category 2 event sequences). While the absolute risk associated with the performance objectives is small, relative risk regions were established to identify the relative safety significance of an SSC, which are summarized in Table 12-2.

Note that the event sequence frequencies in Table 12-2 are derived from the definitions of Category 1 and Category 2 event sequences in 10 CFR Part 63 based on a 100-year preclosure period. The use of a 100-year preclosure period results in a frequency of $1 \times 10^{-2}$ events per year for event sequences that have at least one chance of occurrence during the life of the facility. The 100-year preclosure period also results in a frequency of $1 \times 10^{-6}$ events per year for event sequences that have one chance in 10,000 of occurrence during the life of the facility. The consequence value of $15 \mathrm{mrem}$ is derived from $10 \mathrm{CFR} 63.204$ and 5 mrem from 10 CFR 63.111(b)(2).

Table 12-2. Relative Risk Significance Regions

\begin{tabular}{|c|c|c|c|}
\hline \multirow[t]{2}{*}{$\begin{array}{l}\text { Event Sequence } \\
\text { Frequency }\end{array}$} & \multicolumn{3}{|c|}{$\begin{array}{l}\text { Consequences } \\
\text { (Dose - TEDE) }\end{array}$} \\
\hline & $\mathrm{d}<15$ mrem & $\mathrm{d} \geq 15$ mrem & $\mathrm{d} \geq 5 \mathrm{rem}$ \\
\hline $\begin{array}{c}\geq 10^{-2} \text { per year } \\
(\text { Category } 1)\end{array}$ & $\begin{array}{c}\text { Low } \\
\text { (Classified as Non-SC) }\end{array}$ & $\begin{array}{c}\text { Medium } \\
\text { (Classified as SC) }\end{array}$ & NA \\
\hline $\begin{array}{c}\geq 10^{-6} \text { per year } \\
\text { (Category } 2)\end{array}$ & NA & $\mathrm{NA}$ & $\begin{array}{c}\text { High } \\
\text { (Classified as SC) }\end{array}$ \\
\hline
\end{tabular}

$\mathrm{d}=$ dose, TEDE $=$ total effective dose equivalent.

An event sequence complies with the performance objectives when the event sequence frequency and consequences are within the boundaries of the acceptable risk region. Any event sequence with a frequency-consequence ordered-pair that is outside of these regions is an unacceptable risk.

Figure 12-2 displays the acceptable risk regions based on 10 CFR Part 63 preclosure performance objectives for public (offsite) exposure. The acceptable risk region for Category 2 event sequences is derived from the definitions of Category 1 and Category 2 event sequences and the Category 2 preclosure performance objectives in 10 CFR 63.2. The acceptable risk region for Category 2 event sequeces is the rectangular region shown in Figure 12-2 between the frequencies of $1 \times 10^{-2}$ events per year and $1 \times 10^{-6}$ events per year bounded by the vertical consequence line at 5 rem.

Category 1 event sequences are defined in 10 CFR 63.2 as:

Those event sequences that are expected to occur one or more times before permanent closure of the geologic repository area...

Category 2 event sequences are defined in 10 CFR 63.2 as: 
Other event sequences that have at least one chance in 10,000 of occurring before permanent closure...

Assuming a preclosure operating period of 100 years, the sequence frequency separating Category 1 and Category 2 event sequences becomes 1 per 100 years, or a frequency of occurrence greater than or equal to $1 \times 10^{-2}$ events per year:

- The frequency above which event sequences are defined as Category 2 is 1 in 10,000 per 100 years, or $1 \times 10^{-6}$ events per year. Event sequences with frequencies greater than or equal to $1 \times 10^{-6}$ events per year, but less than $1 \times 10^{-2}$ events per year, are defined as Category 2 event sequences.

- Event sequences at or above a frequency of $1 \times 10^{-2}$ events per year are Category 1 event sequences.

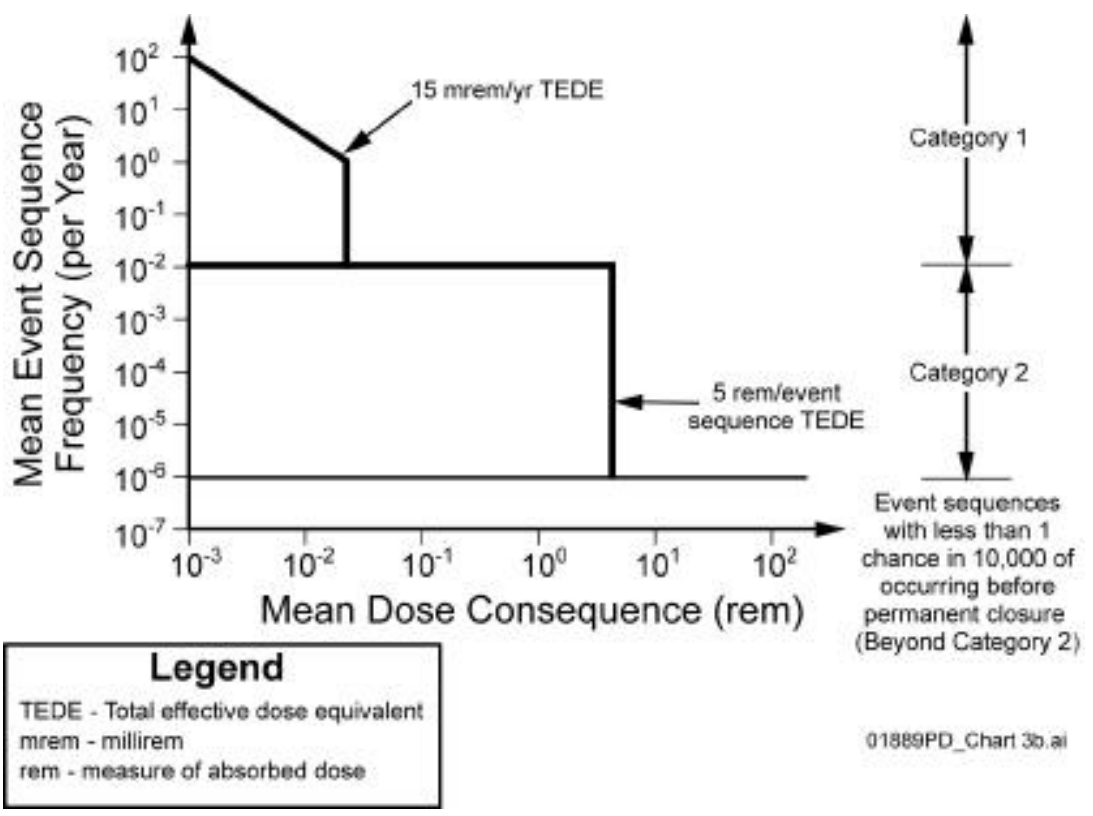

Figure 12-2. Relative Risk Significance Regions

The Category 2 performance objective of 5 rem per event sequence, as stated in 10 CFR 63.111, is represented in Figure 12-2 as a vertical line at 5 rem ending at frequencies of $1 \times 10^{-2}$ and $1 \times 10^{-6}$ events per year. The acceptable risk region Category 1 event sequences is the trapezoidal area above the frequency of $1 \times 10^{-2}$. The slanted side represents an isorisk line meeting the annual performance objective of 15 mrem per year from 10 CFR 63.111(a)(1) and the description of the numerical guide given in 10 CFR 63.111(b)(1). The truncation of the isorisk line with a vertical line at a dose of 15 mrem reflects an interpretation of the Category 1 performance objective that no single event sequence shall exceed $15 \mathrm{mrem}$ in any year. 
In addition, Category 1 event sequences must be compliant with worker dose limits specified per 10 CFR 63.111(a).

Figure 12-3 illustrates the classification of SSCs and engineered and natural barriers SC classification is consistent with the risk significance of an SSC, as shown in Table 12-3. Any SSC that is credited with ensuring that the frequency, and/or consequence, of an event sequence are compliant with 10 CFR Part 63 (see acceptable risk regions shown in Figure 12-2) is termed important to safety and is classified as SC.
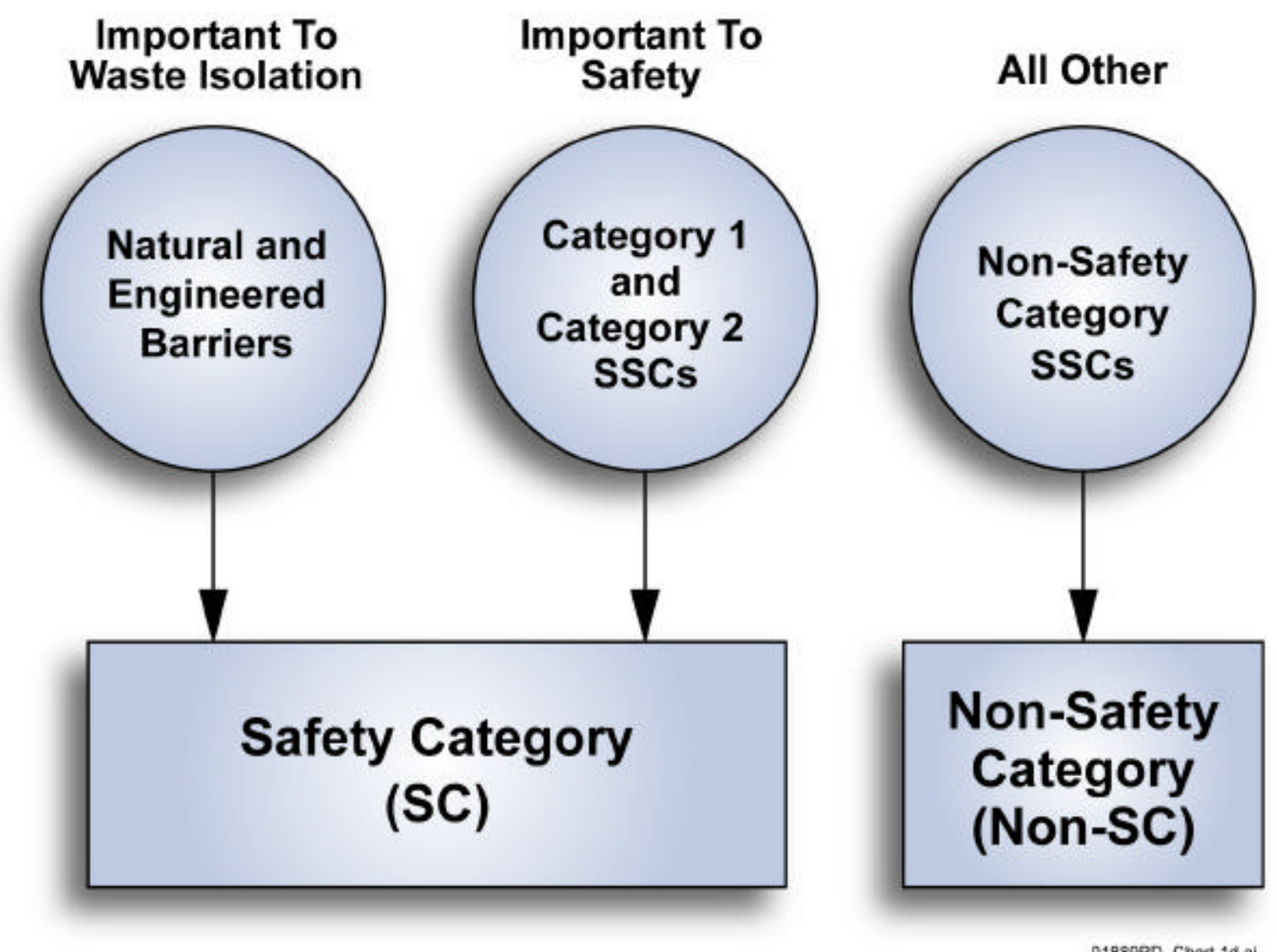

01889PD_Chart 1d.ai

Figure 12-3. SC Classification of SSCs 
Table 12-3. Classifications Based on Risk Significance

\begin{tabular}{|c|c|c|}
\hline \multirow{2}{*}{ Event Sequence Frequency } & \multicolumn{2}{|c|}{$\begin{array}{c}\text { Risk Significance } \\
\text { (Dose - TEDE) }\end{array}$} \\
\cline { 2 - 3 }$\geq 10^{-2}$ per year \\
$($ Category 1) & $\mathbf{d} \geq \mathbf{1 5} \mathbf{~ m r e m}$ & $\mathbf{d} \geq \mathbf{5}$ rem \\
\hline $\begin{array}{c}\geq 10^{-6} \text { per year } \\
\text { (Category 2) }\end{array}$ & SC & N/A \\
\hline
\end{tabular}

$\mathrm{d}=$ dose, TEDE $=$ total effective dose equivalent

where

SC - Classification associated with high relative risk significance; requires full application of 10 CFR 63.142 QA criteria.

Non-SC - Classification associated with little or no relative risk significance; application of 10 CFR 63.142 criteria is not required.

\subsection{THE SC CLASSIFICATION PROCESS}

The SC classification process is illustrated in Figure 12-4, which presents a more detailed view of the compliance evaluation shown in Figure 12-1. Similar to the PSA, SC classification is an iterative process based on, and consistent with, the level of development of the repository design, which provides inputs to the SC classification of SSCs.

The classification decision criteria can be answered only with the support of PSA elements: hazards analyses for external and internal events; event sequence analyses; radiological consequence analyses; or discipline-specific analyses such as criticality analyses. Functional failure analyses are used to identify the significance of SSCs in event sequences. The resultant SSC ITS classifications are presented in the Q-List (YMP 2001), which is updated using the process depicted in Figure 12-4.

\subsection{FUNCTIONAL FAILURE ANALYS IS IN RISK INFORMED SC CLASSIFICATION}

The functional failure analysis portion of the SC classification process is applied to individual SSCs in sequential order. The process is different for Category 1 and Category 2 event sequences due to the differences in the regulatory performance objectives.

The steps in the SC classification process for Category 1 event sequences involve evaluating both the consequences of normal operations and Category 1 event sequences, which are then summed to estimate an annual dose. The dose summation provides aggregated consequences before permanent closure to show compliance with the performance objectives stated in 10 CFR 63.111(b)(1). 


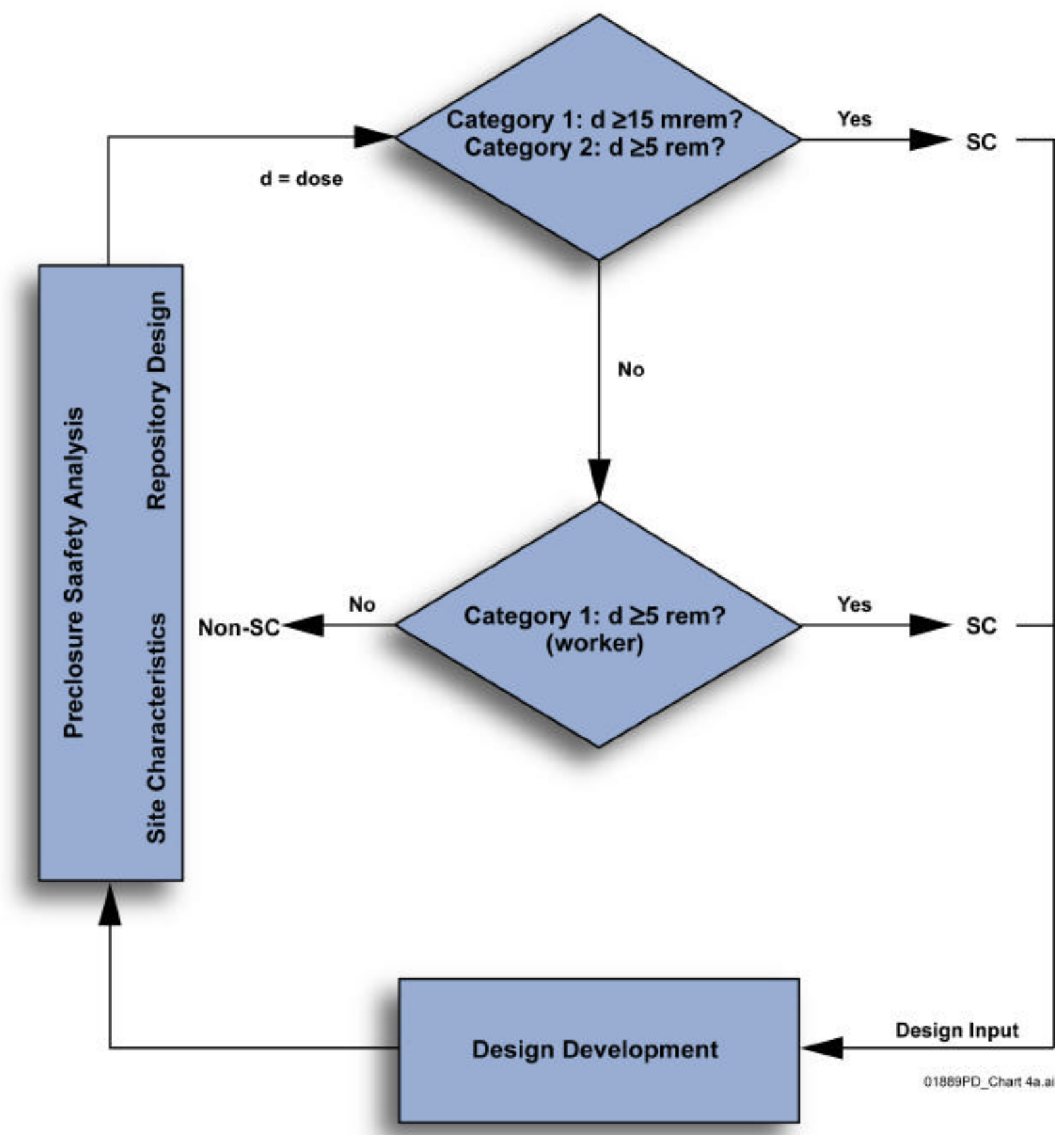

Figure 12-4. SC Classification Process

Category 2 event sequences are assessed on an individual basis; the process for Category 2 has fewer steps than for Category 1 event sequences. 


\subsection{RISK-INFORMED SC CLASSIFICATION OF SSCS ASSOCIATED WITH CATEGORY 1 EVENT SEQUENCES}

Category 1 event sequences are demonstrated to comply with performance objectives before application of the SC classification process (see Section 12.3). Demonstrating compliance for normal surface and subsurface operational doses and offsite radiological releases from Category 1 event sequences are summed in annualized dose estimates. These contributions to the annualized dose estimates are a part of the aggregation of exposures required by 10 CFR Part 63.

Compliance with Category 1 annual performance objectives is performed as follows:

1. Demonstrate that the radiation exposure and the radiation levels in both restricted and unrestricted areas and releases of radioactive materials to unrestricted areas for each Category 1 event sequence meet the annual performance objectives in 10 CFR 63.111(a).

2. Demonstrate that the aggregate radiation exposures and the aggregate radiation levels in both restricted and unrestricted areas, and the aggregate releases of radioactive materials to unrestricted areas from normal operations in addition to the Category 1 event sequences meet the annual performance objectives in 10 CFR 63.111(a).

3. Demonstrate that the radiation exposure and the radiation levels in both restricted and unrestricted areas, and releases of radioactive material to unrestricted areas resulting from combinations of two or more Category 1 event sequences that could occur in a single year with a mean frequency greater than or equal to a frequency of $1 \times 10^{-2}$ events per year, meet the annual performance objectives in 10 CFR 63.111(a).

\subsubsection{Compliance Demonstration for Normal Operation Releases and Category 1 Event Sequences}

Annual offsite dose is calculated to demonstrate compliance of Category 1 event sequences and normal operating releases from the surface and subsurface facilities, as follows:

$$
\mathrm{D}_{\text {Cat } 1}=\mathrm{D}_{\text {norm }}+\Sigma \mathrm{F}_{i} \mathrm{D}_{i}
$$

where

$$
\begin{array}{ll}
\mathrm{D}_{\text {Cat1 }}= & \begin{array}{l}
\text { total annual offsite doses from Category } 1 \text { event sequences and normal } \\
\text { operations (mrem per year) }
\end{array} \\
\mathrm{D}_{\text {norm }}= & \begin{array}{l}
\text { the expected annual offsite dose from surface and subsurface normal } \\
\text { releases (mrem per year) }
\end{array} \\
\mathrm{F}_{i} & =\quad \text { frequency for event sequence } i \text { (per year) } \\
\mathrm{D}_{i} & =\text { offsite dose for } i^{\text {th }} \text { Category } 1 \text { event sequences (mrem) }
\end{array}
$$


$\Sigma \mathrm{F}_{i} \mathrm{D}_{i}=$ sum of the frequency-weighted offsite doses for the Category 1 event sequences in any given year, summed over sequences $i=1$ to $\mathrm{n}$, where $\mathrm{n}$ is the number of Category 1 event sequences (mrem per year).

Compliance is demonstrated by meeting performance objectives in 10 CFR 63.111(a) (e.g., when $\mathrm{D}_{\text {Cat1 }}$ is demonstrated to be less than 15 mrem per year TEDE). Further, compliance is assessed for each individual Category 1 event sequence to ensure that no single event sequence exceeds performance objectives, as follows:

$$
\mathrm{D}_{i}<15 \text { mrem }
$$

where

$\mathrm{D}_{i}=$ offsite TEDE dose for individual Category 1 event sequence $i$ (mrem).

Compliance is further demonstrated by estimating and evaluating total offsite doses of combinations of two or more Category 1 event sequences, selected from the $Q$ List (YMP 2001), that can occur with an estimated mean frequency of $1 \times 10^{-2}$ events per year or greater, as follows:

$$
\mathrm{D}_{\text {Comb }}=\Sigma \mathrm{D}_{i}
$$

where

$$
\begin{aligned}
& \mathrm{D}_{\text {Comb }}=\quad \begin{array}{l}
\text { total offsite dose for credible combinations of individual Category } 1 \text { event } \\
\text { sequences (mrem) }
\end{array} \\
& \mathrm{D}_{i}=\begin{array}{l}
\text { offsite dose for the } i^{\text {th }} \text { Category } 1 \text { event sequence considered in the } \\
\text { combination (mrem). }
\end{array}
\end{aligned}
$$

Offsite doses for each event sequence in a combination are evaluated, summed, and compared to performance objectives. Compliance is demonstrated when the dose from the combination of two or more Category 1 event sequences that could credibly occur is shown to be less than 15 mrem per year TEDE.

\subsubsection{Process for Risk-Informed SC Classification of SSCs in Category 1 Event Sequences}

Category 1 event sequences may require iterations of a functional failure analysis for a particular SSC to determine its SC classification. The first analysis is applied to SSCs that are involved in individual Category 1 event sequences. The second analysis is applied to those same SSCs that may also appear in credible combinations of Category 1 event sequences.

For the classification analysis of each SSC, the offsite doses that result after the assumed functional failure of the SSC are evaluated in the following manner: 


$$
\mathrm{D}_{\mathrm{ce}}=\left[\mathrm{D}_{\text {norm }}+\Sigma \mathrm{F}_{i} \mathrm{D}_{i}\right]+\mathrm{D}_{e} *
$$

where

$\mathrm{D}_{\text {norm }}$ and $\Sigma \mathrm{F}_{i} \mathrm{D}_{i}$ are defined previously

$\mathrm{D}_{\mathrm{ce}}=$ offsite classification event dose with the assumed functional failure of the SSC (i.e., the SSC is hypothetically removed from the sequence being evaluated) (mrem per year)

$\mathrm{D}_{\mathrm{e}} \quad=$ dose from an event sequence that includes the SSC being classified; however, the mitigation function of the SSC is assumed to have failed (the sequence is assumed to occur no more than once per year) (mrem per year).

NOTE: The Category 1 event sequences are assumed to have an estimated mean frequency of less than once per year. However, for the purpose of SC classification, these event sequences are assumed to have occurred every year and are not annualized.

The steps for performing the SC classification evaluation of SSCs in Category 1 event sequences are summarized in Table 12-4.

Table 12-4. Steps for Performing an SC Classification Analysis of SSCs Associated with Category 1

1. Calculate $D_{\text {norm }}$, the annual offsite dose from surface and subsurface normal operations.

2. Calculate $\mathrm{D}_{i}$, the offsite dose from a Category 1 event sequence $i$.

3. Calculate $\Sigma \mathrm{F}_{\mathrm{i}} \mathrm{D}_{\mathrm{i}}$, the frequency-weighted offsite dose sum of the Category 1 event sequences [i.e., $i=1$ to $\mathrm{n}$ sequences].

4. Identify event sequences that include the SSC being classified and its associated offsite dose $D_{e}$ (after the SSC is assumed removed).

5. Perform an SSC functional failure analysis for each event sequence that includes the SSC being classified using classification event dose $\mathrm{D}_{c e}$ where

$$
\mathrm{D}_{c e}=\left[\mathrm{D}_{\text {norm }}+\Sigma \mathrm{F}_{i} \mathrm{D}_{i}\right]+\mathrm{D}_{e} \text {. }
$$

6. Perform an SSC functional failure analysis for each Category 1 combination of event sequences that includes the SSC being classified (the $D_{e}$ from each event sequence is included).

7. Classify SSCs based on highest classification level identified and based on the functional failure analysis from each Category 1 event sequence or Category 1 combination that includes the SSC being evaluated. If applicable, each SSC is also evaluated for classification according to Category 2 event sequences and consideration of event sequences with annual frequencies less than $1 \times 10^{-6}$ events per year.

The final SSC classification is the highest classification level resulting from applying the SC classification objectives from Category 1, Category 2, and event sequences that are beyond the Category 2 event sequence frequency. 
The offsite classification event dose $\left(D_{\mathrm{ce}}\right)$ represents the potential dose for Category 1 event sequences if the SSC under study was assumed to fail when called upon to mitigate consequences. The increase in dose resulting from the removal of the SSC is $\mathrm{D}_{e}$. The $\mathrm{D}_{\mathrm{e}}$ is added to aggregate offsite doses of $\mathrm{D}_{\text {norm }}+\Sigma \mathrm{F}_{i} \mathrm{D}_{i}$. This approach provides a risk-informed basis for classifying each SSC. If $D_{e}$ is less than 15 mrem per year TEDE, the SSC ITS is classified as Non-SC. If $\mathrm{D}_{\mathrm{ce}}$ exceeds or equals 15 mrem per year TEDE, the SSC ITS is classified as SC.

If the same SSC is part of a credible combination of two or more Category 1 event sequences, at a mean frequency of $1 \times 10^{-2}$ events per year or greater, then consideration is given to the unavailability of each SSC with a mitigation function in the combination. The annual offsite dose resulting from the combination of credible Category 1 event sequences after the assumed functional failure of an SSC determines its SC classification. For example, if $\mathrm{D}_{\text {Comb }}$ is less than 15 mrem per year TEDE, then the SSC ITS is classified as Non-SC; if DComb exceeds or equals 15 mrem per year TEDE, then the SSC ITS is classified as SC.

SC is the classification for each SSC credited for maintaining Category 2 event sequences less than $5 \mathrm{rem}$.

\subsection{RISK INFORMED SC CLASSIFICATION OF SSCS ASSOCIATED WITH CATEGORY 2 EVENT SEQUENCES}

Category 2 event sequences are first shown to meet preclosure performance objectives stated in 10 CFR Part 63 through compliance analyses that demonstrate an offsite dose less than 5 rem TEDE (10 CFR 63.111(b)(2)) (see Section 12.3). Subsequently, classification analyses reassess the dose after performing an SSC functional failure whereby if the dose is equal to or exceeds 5 rem then the SSC ITS is classified as SC. Otherwise, the SSC is classified as Non-SC and is not subject to the QA program requirements of 10 CFR Part 63.

As an example, consider an event sequence with a mean frequency of $5 \times 10^{-5}$ events per year and an offsite dose of $5 \times 10^{-3}$ rem TEDE. This event sequence complies with the performance objectives based on the performance of one or more SSCs ITS. The consequences are then re-estimated after the assumed removal of an SSC ITS considered in the original event sequence evaluation. As a result, the consequence is determined to be 6 rem TEDE (a value used for illustration only) after the assumed functional failure of the same SSC ITS. This dose of 6 rem exceeds the 10 CFR 63.111(b)(2) performance objective of 5 rem TEDE. Consequently, the resulting event sequence has a mean frequency of $5 \times 10^{-5}$ events per year and dose of 6 rem TEDE. This example demonstrates that the SSC under consideration is ITS and that without the performance of its safety function the event sequence results in exceeding the performance objectives of 10 CFR 63.111(b)(2); therefore, the SSC ITS is classified as SC.

In addition, appropriate functional failure analyses are performed if the same SSC ITS appears in more than one event sequence, regardless of whether it is in the risk region of Category 1 or Category 2. The functional failure analyses are completed for each affected event sequence and the highest SC classification resulting from these analyses is assigned to the SSC ITS. 


\subsection{REFERENCES}

\subsubsection{Documents Cited}

BSC (Bechtel SAIC Company) 2001. Preliminary Preclosure Safety Assessment for Monitored Geologic Repository Site Recommendation. TDR-MGR-SE-000009 REV 00 ICN 03.

Las Vegas, Nevada: Bechtel SAIC Company. ACC: MOL.20010705.0172.

NRC (U.S. Nuclear Regulatory Commission) 1987. Standard Review Plan for the Review of Safety Analysis Reports for Nuclear Power Plants. NUREG-0800. LWR Edition.

Washington, D.C.: U.S. Nuclear Regulatory Commission. TIC: 203894.

YMP (Yucca Mountain Site Characterization Project) 2001. Q-List. YMP/90-55Q, Rev. 7. Las Vegas, Nevada: Yucca Mountain Site Characterization Office.

ACC: MOL.20010409.0366.

\subsubsection{Codes, Standards, Regulations, and Procedures}

10 CFR 63. Energy: Disposal of High-Level Radioactive Wastes in a Geologic Repository at Yucca Mountain, Nevada. Readily available.

Regulatory Guide 1.174, Rev. 01 Draft. 2001. An Approach for Using Probabilistic Risk Assessment in Risk-Informed Decisions on Plant-Specific Changes to the Licensing Basis. Washington, D.C.: U.S. Nuclear Regulatory Commission. Readily available.

Regulatory Guide 1.176. 1998. An Approach for Plant-Specific, Risk-Informed Decisionmaking: Graded Quality Assurance. Washington, D.C.: U.S. Nuclear Regulatory Commission. Readily available. 


\section{INTENTIONALLY LEFT BLANK}




\section{SELECTION OF 10 CFR 63.2 DESIGN BASES FOR STRUCTURES, SYSTEMS, AND COMPONENTS IMPORTANT TO SAFETY}

\subsection{INTRODUCTION}

This section describes the development of the design bases for SSCs important to preclosure safety including background information from 10 CFR Part 63, followed by a general discussion of the methodology for developing the design bases for SSCs.

\subsection{BACKGROUND INFORMATION}

SSCs ITS will have design bases established as defined in 10 CFR 63.2:

Design bases means that information that identifies the specific functions to be performed by a structure, system, or component of a facility and the specific values or ranges of values chosen for controlling parameters as reference bounds for design. These values may be constraints derived from generally accepted "state-of-the-art" practices for achieving functional goals or requirements derived from analysis (based on calculation or experiments) of the effects of a postulated event under which a structure, system, or component must meet its functional goals. The values for controlling parameters for external events include:

1. Estimates of severe natural events to be used for deriving design bases that will be based on consideration of historical data on the associated parameters, physical data, or analysis of upper limits of the physical processes involved; and

2. Estimates of severe external human-induced events to be used for deriving design bases that will be based on analysis of human activity in the region taking into account the site characteristics and the risks associated with the event.

When describing the content of application, 10 CFR 63.21 states that the safety analysis must include, among other items:

3. (ii) The design criteria used and their relationship to the preclosure and postclosure performance objectives specified at \$63.111(b), §63.113(b) and $\S 63.113(\mathrm{c})$; and (iii) The design bases and their relation to the design criteria.

Design basis requirements are developed from the geologic repository Category 1 and Category 2 event sequences that are identified through a PSA (as discussed in Section 4 and Section 7.6 of this guide). Category 1 and Category 2 event sequences are evaluated against their respective dose performance objectives. SSC safety functions are identified from these event sequences.

SSCs involved in the event sequences that are required to prevent or mitigate an offsite dose from exceeding the 10 CFR Part 63 preclosure performance objectives are classified as ITS (see 
Section 12). A design basis is developed for each of these SSCs. The design basis describes the SSC safety function. Design criteria are established for each safety function. Design criteria are bounding values for controlling specific values or ranges of values chosen for controlling parameters as reference bounds for the design. Per 10 CFR 63.112(f), the relationship of each SSC design criteria to the design bases must be tied directly to the preclosure performance objectives specified in 10 CFR 63.111(b).

A distinction is made between the repository design bases (in toto) and the subset termed "10 CFR 63.2 design bases" for SSCs ITS. All SSCs that comprise the repository design will have design bases. However, only SSCs that are ITS will have design bases developed per 10 CFR 63.2. These 10 CFR 63.2 design bases are a subset of the licensing bases and are required pursuant to $10 \mathrm{CFR} 63.112$ to be included the safety analysis report (SAR). The SAR will set forth a safety assessment of the 10 CFR 63.2 repository design bases. Both 10 CFR 63.2 design bases and supporting design information are subjected to design control and other quality assurance criteria of 10 CFR 63.142. The 10 CFR 63.2 design bases and supporting information contained in the SAR are controlled in accordance with 10 CFR 63.44.

Figure 13-1 illustrates the relationship of 10 CFR 63.2 design bases to the repository design bases and the SAR.

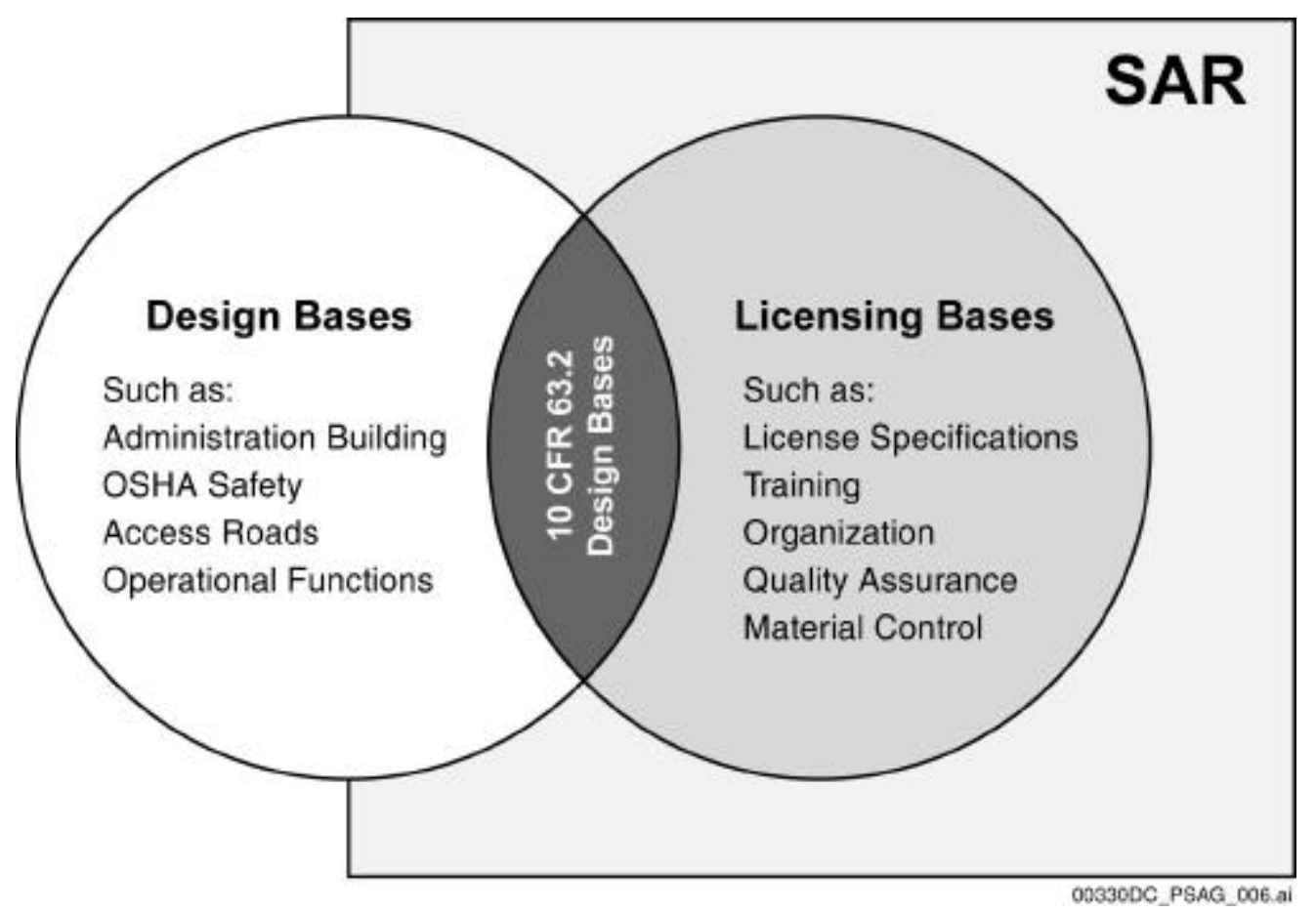

Figure 13-1. Relationship of Repository Design Bases to 10 CFR 63.2 Design Bases and the Safety Analysis Report (SAR)

The white circle represents the set design bases for all SSCs comprising the repository facility. The light gray circle represents the complete set licensing bases presented in the SAR. The dark 
gray oval depicts those SSCs that are ITS and have 10 CFR 63.2 design bases (the intersection of the set of design bases and the set of licensing basis).

The assessment of the SSCs ITS should consist of sufficient detail to provide enough information for the NRC to make an independent determination that there is reasonable assurance that safe operation will be achieved. Underlying 10 CFR 63.2 design bases is supporting design documentation that includes design inputs, design analyses, and design outputs. Supporting design information may be contained in the SAR or other documents; some of which are docketed and some of which are retained by the licensee.

\subsection{METHOD FOR DEVELOPING 10 CFR 63.2 DESIGN BASES}

The basic steps in developing the 10 CFR 63.2 design bases are illustrated in Figure 13-2 and are summarized as follows:

Step 1. Identify, through a PSA, the Category 1 and Category 2 event sequences that are derived from internal, external, and manmade hazards (see Sections 6, 7, 10, and 11).

The list of Category 1 and Catergory 2 event sequences form a part of the repository licensing bases and will appear in the SAR. Each Category 1 or Category 2 event sequence contains SSCs modeled within the PSA to assess the likelihood and consequences of an event sequence.

This list of SSCs may change as the design matures. Changes in the list will result in a reassessment of the affected SSCs and the associated design bases and design criteria. Design iterations, design improvements, or design modifications can lead to changes in the list throughout the licensing process and beyond.

Step 2. Identify and list those SSCs that are ITS based on the Category 1 and Catetgory 2 event sequences (see Section 12).

Every SSC on the SSC ITS list will require the establishment of 10 CFR 63.2 design bases and design criteria.

Step 3. Select an SSC ITS from the SSC ITS list and identify the Category 1 and Category 2 event sequences that contain the SSC ITS.

Category 1 and Category 2 event sequence compliance with 10 CFR Part 63 performance requirements are significantly different. Category 1 compliance assessments are based on annual performance requirements that require an aggregation of releases to unrestricted areas, as described in Section 8. Category 2 event sequence compliance assessment is on a per event basis. No aggregations of release are to be done for Category 2 event sequences. Because of these compliance differences, it is easier to start with developing the design bases and design criteria for SSCs ITS involved in Category 2 event sequences.

Step 4. Identify the design criteria by safety function from the selected Category 2 event sequences for the selected SSC ITS. 
Beginning with an SSC ITS identified from Category 2 event sequences, establish the design criteria and safety functions or design bases. Document the relationship between design criteria and design bases and the performance objectives that are met by the SSC in the event sequence under study. Maintain this relationship within a database or some other organizational tool that is searchable by SSC ITS.

In some cases, the PSA includes an evaluation of the consequences of selected sequences that are below the Category 2 frequency threshold using the best estimate conditions to provide confidence in the repository preclosure design. The purpose of this evaluation is to ensure that such an event sequence with unacceptable consequences is not arbitrarily excluded, based on probability. Any features added to mitigate the consequences of such events would not be considered ITS. Such analysis will not be part of the safety case, but the analysis has the potential of providing additional confidence in the repository performance.

Step 5. Select the Category 2 bounding design criteria per 10 CFR 63.2 for each safety function identified for the selected SSC ITS.

Step 6. Repeat Step 3 through Step 5 until all of the SSCs ITS have design bases developed per 10 CFR 63.2 for Category 2 event sequences.

Step 7. Select an SSC ITS for meeting Category 1 performance criteria.

Step 8. Examine the Category 1 event sequences containing this SSC ITS and develop design bases per 10 CFR 63.2 and design criteria.

Step 9. Select the bounding design bases per 10 CFR 63.2 and design criteria for this SSC ITS that will meet the performance objectives of 10 CFR 63.111.

Step 10. After the bounding Category 1 design bases are established for an SSC ITS, per 10 CFR 63.2, review the established Category 2 design bases per 10 CFR 63.2 and optimize the Category 1 and Category 2 design bases to meet the most limiting performance objectives from 10 CFR 63.111.

Step 11. Repeat Step 7 through Step 10 until SSCs ITS in Category 1 event sequences have established design bases per 10 CFR 63.2.

Step 12. Review the total set of bounding design criteria for each SSC ITS for completeness and consistency. 


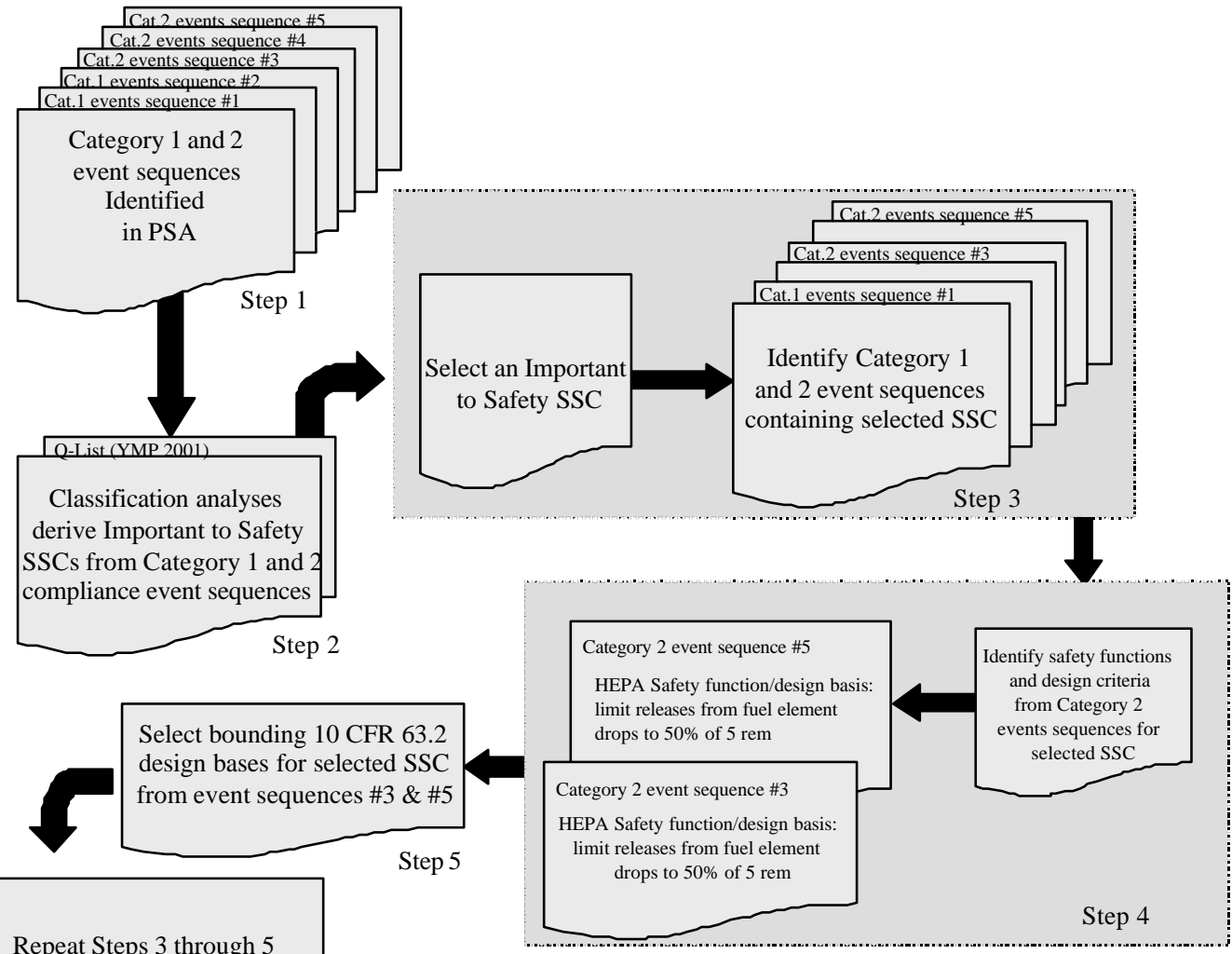

for all SSC Important to Safety

for Category 2 event sequences

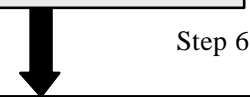

Based on Steps 1 through 3:

select an SSC that is Important to Safety for meeting Category 1 performance objectives

Step 7

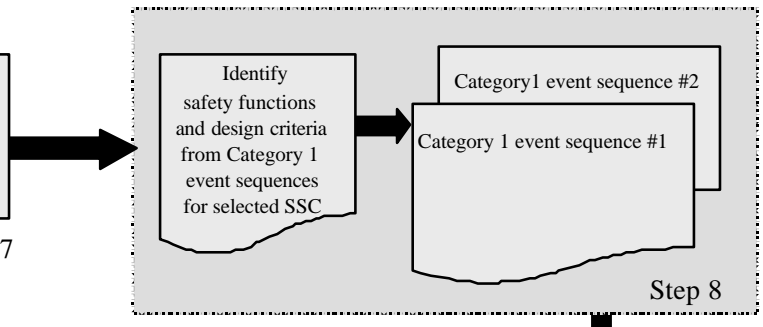

Repeat Steps 7 through 10 until all the Category 1 Important to Safety SSCs have design bases established

Select the Category 1 and 2 10 CFR 63.2 design bases such that the most limiting performance objectives of 10 CFR 63.111 are met for each SSC
Select bounding 10 CFR 63.2 design bases for selected SSC from event sequences \#1 \& \#2

Review the final set of bounding 10 CFR 63.2 design

bases for each Important to Safety SSC for completeness and consistency

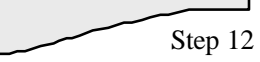

Figure 13-2. Basic Steps in Developing 10 CFR 63.2 Design Bases 


\subsection{REFERENCES}

\subsubsection{Documents Cited}

YMP (Yucca Mountain Site Characterization Project) 2001. Q-List. YMP/90-55Q, Rev. 7. Las Vegas, Nevada: Yucca Mountain Site Characterization Office. ACC: MOL.20010409.0366.

\subsubsection{Codes, Standards, Regulations, and Procedures}

10 CFR 63. 2002. Energy: Disposal of High-Level Radioactive Wastes in a Proposed Geologic

Repository at Yucca Mountain, Nevada. Readily available. 


\section{DOCUMENTATION AND PREPARATION OF LICENSE APPLICATION}

\subsection{PRECLOSURE SAFETY ANALYSIS DOCUMENTATION}

This section presents a discussion on the various documents that are required to provide the input for the PSA (Figure 4-4 illustrates the information flow of the PSA).

\subsubsection{Internal and External Hazards Analyses}

The internal and external hazards analyses provide documentation of the potential hazards that may be present at the repository. These analyses should be consistent with the 10 CFR 63.2 repository design bases. The process used to identify hazards is described in Section 6.

The internal hazards analysis describes the potential hazards that are related to the design and operation of the repository during the preclosure period, including potential chemical and criticality hazards. The external hazards analysis describes the spectrum of potential external events and natural phenomena. The credible hazards (i.e., initiating events) during the preclosure period will be based on historical data or NRC regulatory guidance.

\subsubsection{Categorization of Event Frequencies}

Using the results of the internal and external hazards analyses, potential event sequences will be categorized as Category 1, Category 2, or beyond Category 2 (BC2) event sequences by analysis. The analyses will be continually updated as design develops to ensure that the categorization, design, and hazards identification are consistent with the LA design. The evaluation of potential hazards will be captured in analyses and calculations, such as:

Aircraft Hazards Assessment-The credibility of aircraft hazards within the selected vicinity of the general repository operations area will be analyzed using current flight information. The appropriateness of flight information for the repository operating period is evaluated and future efforts to support aircraft hazards categorization, if required, are identified. Section 10.6.2 describes the approach and methodology used to perform an aircraft hazards assessment.

Wind and Tornado Analysis-The design basis tornado and wind loadings will be identified in accordance with nuclear and regulatory guidance. The tornado missile spectra for the Project will be developed and the features and controls that are required to ensure that design bases for tornadoes and winds will not result in a radiological release that exceeds regulatory requirements will be identified. Section 10.6.3 describes the approach and methodology used to perform a wind and tornado analysis.

Industrial and Military Hazards Assessment-The potential industrial and military hazards for potential consideration in the repository design consistent with nuclear industry precedents will be identified and evaluated. Any features or controls required to screen or mitigate industrial and military hazards will be identified. Section 10.3 describes the approach and methodology used to peform an industrial and military hazards assessment.

Rainstorm and Flooding Analysis-The rainstorm and flooding criteria is determined in accordance with accepted nuclear precedents. Any features or controls required to ensure that a 
rainstorm or flooding event does not result in a radiological release will be identified. Section 10.2 describes the approach and methodology for performing a rainstorm and flooding analysis.

Seismic Analysis-The appropriate SSC seismic design bases will be identified consistent with regulatory requirements, preclosure seismic design strategy, and associated seismic topical reports for the repository. Preclosure seismic event sequence analyses will be presented to demonstrate compliance with 10 CFR Part 63. Section 10.1 describes the approach and methodology for performing the seismic analysis.

Fire Sequence Analysis-Using the results of the facility fire hazards analyses, credible fires will be evaluated as initiating events for the potential to result in a radiological release. Potential fire scenarios should include surface, subsurface, and external fires (e.g., range fires, lightning-initiated fires). Any features or controls that ensure that fires do not result in a radiological release that exceeds regulatory requirements will be identified. Section 10.4 describes the approach and methodology for performing the fire sequence analysis.

Loss of Power Evaluation-Loss of power as an initiating event will be evaluated. It should be demonstrated that loss of power does not result in a radiological release that exceeds regulatory requirements. Any features or controls that are required to ensure loss of power does not result in releases that exceed regulatory requirements will be identified. Section 10.6.1 describes the approach and methodology for performing the loss of power evaluation.

Fault Tree Analysis-The reliability of handling systems for use in event trees that include handling branches will be determined. To support event sequence frequency analyses, as necessary, fault tree anlaysis will be used to quantify the reliability and availability of waste handling equipment, transport vehicles, HVAC, etc. Section 7.2 describes the approach and methodology for performing a fault tree analysis.

Component Failure and Reliability Analysis Database-Industry failure rate information to support the development of event trees will be collected and analyzed. Justification for appropriateness of failure rates for use at the Project will be included. An uncertainty analysis of the failure rates that is appropriate to support categorization of event sequences will be included. Section 7.5 describes the approach and methodology for performing a component failure and reliability analysis.

\subsubsection{Consequence Analysis}

Potential consequences from Category 1 and 2 event sequences will be evaluated to demonstrate any radiological releases meet regulatory requirements. Consequence analyses will be available to support the classification of SSCs ITS. Mean consequences, including the associated uncertainty distribution, will be calculated using a computer code or other methods. Any features and controls that are required to limit radiological consequences to within regulatory limits will be identified. The potential radiological consequences of the selected beyond Category 2 (BC2) event sequences will be determined. BC2 event sequences will be selected for evaluation to gain risk insights into the design and support identification of defense in depth features. Atmospheric dispersion factors based on site meteorological data will be developed 
Dispersion factor calculation will be used to support calculations of mean and upper bound consequences from event sequences. Section 8 describes the approach and methodology for performing a consequence analysis.

\subsubsection{Preclosure Safety Analysis}

The PSA will be consistent with 10 CFR Part 63 requirements, the Yucca Mountain Review Plan (when issued by the NRC), and other NRC guidance and interactions. The PSA will demonstrate compliance with PSA regulatory requirements; summarize hazards analyses, event categorization, consequence analyses, worker dose, ALARA (i.e., as low as is reasonably achievable), radiation protection program, preclosure criticality, and classification processes and results.

Preclosure Safety Analysis Guide-The PSA guide will present the project approach to developing a PSA. The guide will identify PSA project interfaces and responsibilities. It will describe processes for performing hazards analyses and for developing event trees, fault trees, and event scenarios. Guidance on performing uncertainty analyses, Category 1 and 2 consequence analysis approaches, and developing classification analyses will be included. Also, discussions on the integration of PSA work performed in other project areas should be included (e.g., design requirements and criticality). Examples of products to be used in preparation of the PSA include:

- Internal hazards analysis

- $\quad$ External hazards analysis

- $\quad$ Aircraft hazards analysis

- Wind, tornado, and tornado missile analysis

- Industrial and military hazards analysis

- $\quad$ Rainstorm and flooding analysis

- $\quad$ Seismic analysis

- $\quad$ Fire sequence analysis

- $\quad$ Loss of power analysis

- $\quad$ Failure rate and reliability data analysis

- Categorization of event sequences analysis

- $\quad$ Consequence analysis

- BC2 evaluation plan 
- $\quad$ Atmospheric dispersion factors calculation

- $\quad$ 10 CFR 63.2 design bases report

- $\quad$ Classification analysis updates (consistent with design needs) and Q-List (YMP 2001) updates.

These products will support the final major PSA input into the LA design.

\subsubsection{Identify SSCs ITS and Important to Waste Isoloation}

10 CFR 63.2 design bases, classification analyses, and Q-List (YMP 2001) will be maintained consistent with the latest regulatory requirements, the Yucca Mountain Review Plan (NRC 2003), safety analyses, and design concepts. SSCs will be identified and maintained for the Q-List (YMP 2001) and the selection and implementation of quality assurance requirements of 10 CFR 63.142. 10 CFR 63.2 design bases report and Q-List (YMP 2001) will be maintained by integrating with the design organizations and updating the products, as appropriate, to ensure consistency between the products and the design. Section 12 describes the approach and methodolgy for performing SSC classification.

\subsection{PRECLOSURE SAFETY ANALYSIS AND LICENSE APPLICATION SUBMITTAL}

The license application submittal will be prepared in accordance with The Management Plan for Development of the Yucca Mountain License Application (Lugo 2003). SA analysts should become familiar with the overall purpose and content of the plan and, in particular Section 4, LA Development, which provides guidance on the preparation of LA chapters (Lugo 2003).

\subsection{REFERENCES}

\subsubsection{Documents Cited}

Leigh, C.D.; Thompson, B.M.; Campbell, J.E.; Longsine, D.E.; Kennedy, R.A.; and Napier, B.A. 1993. User's Guide for GENII-S: A Code for Statistical and Deterministic Simulations of Radiation Doses to Humans from Radionuclides in the Environment. SAND91-0561.

Albuquerque, New Mexico: Sandia National Laboratories. ACC: MOL.20010721.0031.

Lugo, C.L. 2003. Management Plan for Development of the Yucca Mountain License Application. PLN-MGR-RL-000001 REV 00 ICN 01. Las Vegas, Nevada: Bechtel SAIC Company. ACC: DOC.20030505.0004.

NRC (U.S. Nuclear Regulatory Commission) 1987. Standard Review Plan for the Review of Safety Analysis Reports for Nuclear Power Plants. NUREG-0800. LWR Edition.

Washington, D.C.: U.S. Nuclear Regulatory Commission. TIC: 203894.

YMP (Yucca Mountain Site Characterization Project) 2001. Q-List. YMP/90-55Q, Rev. 7. Las Vegas, Nevada: Yucca Mountain Site Characterization Office.

ACC: MOL.20010409.0366. 


\subsubsection{Codes, Standards, Regulations, and Procedures}

10 CFR 63. 2002. Energy: Disposal of High-Level Radioactive Wastes in a Proposed Geologic Repository at Yucca Mountain, Nevada.

Regulatory Guide 1.76, Rev. 0. 1974. Design Basis Tornado for Nuclear Power Plants. Washington, D.C.: U.S. Atomic Energy Commission. TIC: 2717. 


\section{INTENTIONALLY LEFT BLANK}




\section{GLOSSARY}




\section{INTENTIONALLY LEFT BLANK}




\section{GLOSSARY}

\begin{tabular}{|c|c|c|}
\hline Term & Definition & Reference \\
\hline Acceptance Lim it & $\begin{array}{l}\text { A value that accounts for uncertainty about the conditions to which } \\
\text { structures, systems, and components will be subjected and } \\
\text { accounts for variability in the properties of component materials. } \\
\text { This value provides a margin for unacceptable conditions. Whether } \\
\text { the value is a maximum or a minimum depends on the type of } \\
\text { variable being discussed. }\end{array}$ & \\
\hline Analysis & $\begin{array}{l}\text { A documented study, mathematical process, or evaluation defining, } \\
\text { investigating, validating, solving, or reviewing: an engineering } \\
\text { problem using formula or computer code for the resulting } \\
\text { engineering parameters; the development of design inputs; } \\
\text { translation of design input into design output; or performance of } \\
\text { engineered structures, systems, and components. }\end{array}$ & AP-3.12 Q \\
\hline Assumption & $\begin{array}{l}\text { A statement or proposition that is taken to be true or representative } \\
\text { in the absence of direct confirming data or evidence. }\end{array}$ & AP-SIII.9Q \\
\hline Breach & $\begin{array}{l}\text { An opening in a transportation cask, spent nuclear fuel canister, } \\
\text { waste package, waste package, or drip shield caused by corrosion } \\
\text { or mechanical stress. }\end{array}$ & \\
\hline Calculation & $\begin{array}{l}\text { A documented study, mathematical process, or evaluation defining, } \\
\text { investigating, validating, solving, or reviewing: an engineering } \\
\text { problem using formula or computer code for the resulting } \\
\text { engineering parameters; the development of design inputs; } \\
\text { translation of design input into design output; or performance of } \\
\text { engineered structures, systems, and components. }\end{array}$ & AP-3.12Q \\
\hline Calculated Value & $\begin{array}{l}\text { Values used as input assumptions for safety analyses or } \\
\text { evaluations, or which result from the performance of a safety } \\
\text { analysis or evaluation, and which the U.S. Nuclear Regulatory } \\
\text { Commission has accepted during its review of a license application. }\end{array}$ & \\
\hline Certification & $\begin{array}{l}\text { The act of determining, verifying, and attesting in writing to the } \\
\text { achievement or compliance with specified requirements. }\end{array}$ & DOE 2000 \\
\hline $\begin{array}{l}\text { Codes and } \\
\text { Standards }\end{array}$ & $\begin{array}{l}\text { Applicable industry codes and standards are those codes and } \\
\text { standards applicable to the design of the structures, systems, and } \\
\text { components }\end{array}$ & \\
\hline Computation & $\begin{array}{l}\text { A mathematical process of solving a problem by formula or } \\
\text { computer code for the resulting engineering or scientific } \\
\text { parameters. See the definition of Calculation. }\end{array}$ & \\
\hline Confinement & To keep within limits; restrict. & \\
\hline $\begin{array}{l}\text { Committed Effective } \\
\text { Dose Equivalent }\end{array}$ & $\begin{array}{l}\text { The sum of products of the weighting factors applicable to each of } \\
\text { the body organs or tissues that are irradiated and the committed } \\
\text { dose equivalent to those organs or tissues. The committed dose } \\
\text { equivalent means the dose equivalent to organs or tissues of } \\
\text { reference that will be received from an intake of radioactive material } \\
\text { by an individual during the } 50 \text {-year period following the intake. }\end{array}$ & 10 CFR Part 20 \\
\hline Conventional Quality & $\begin{array}{l}\text { Conventional quality items are not subject to the requirements of } \\
\text { the Quality Assurance Requirements Description (DOE 2000). } \\
\text { Program management controls are applied commensurate with } \\
\text { regulatory requirements, industry standards, local codes, and good } \\
\text { engineering practices. }\end{array}$ & \\
\hline
\end{tabular}




\begin{tabular}{|c|c|c|}
\hline Term & Definition & Reference \\
\hline Conservative & $\begin{array}{l}\text { In developing and applying mathematical models of physical } \\
\text { systems, choices can be made regarding assumptions, } \\
\text { approximations, data values, and data distributions. If these } \\
\text { choices are made so that the resulting models and the estimates } \\
\text { produced by them tend to make the estimated performance of a } \\
\text { safety system worse than might actually be expected, the choices } \\
\text { made are considered conservative or pessimistic. If the } \\
\text { development and application of the model are such that the } \\
\text { estimated performance tends to be better than might actually be } \\
\text { expected the choices made are considered optimistic. }\end{array}$ & $\begin{array}{l}\text { Eisenberg et al. } \\
1999\end{array}$ \\
\hline Consequence & Result or effect. & \\
\hline Containment & The confinement of radioactive waste within a designated boundary. & 10 CFR 63.2 \\
\hline Credible Event & $\begin{array}{l}\text { An event or event sequence having a probability of occurrence of at } \\
\text { least } 1 \text { in 10,000 prior to the final closure of the repository. }\end{array}$ & \\
\hline Criticality & $\begin{array}{l}\text { The condition in which nuclear fuel sustains a chain reaction. It } \\
\text { occurs when the effective neutron multiplication factor (the number } \\
\text { of fissions in one generation divided by the number of fissions in the } \\
\text { preceding generation) of a system equals one. }\end{array}$ & \\
\hline Data & $\begin{array}{l}\text { As it pertains to Supplement III, information developed as a result of } \\
\text { scientific investigation activities associated with site characterization } \\
\text { of the Yucca Mountain repository or the results of reducing, } \\
\text { manipulating, or interpreting data after its field or laboratory } \\
\text { acquisition to prepare it for use in analyses, models, or calculations } \\
\text { used in performance assessment, integrated safety analyses, the } \\
\text { design process, performance confirmation, or other similar work } \\
\text { using data as an input. }\end{array}$ & $\begin{array}{l}\text { Document Action } \\
\text { Request D813 to the } \\
\text { Quality Assurance } \\
\text { Requirements and } \\
\text { Description } \\
\text { document (DOE } \\
\text { 2000) }\end{array}$ \\
\hline \multirow[t]{2}{*}{ Defense-In-Depth } & $\begin{array}{l}\text { (1) A design strategy based on a system of multiple, independent, } \\
\text { and redundant barriers, designed to ensure that failure in any } \\
\text { one barrier does not result in failure of the entire system. } \\
\text { (2) A term used to describe a system of multiple barriers that } \\
\text { mitigate uncertainties in conditions, processes, and events. }\end{array}$ & DOE 2001 \\
\hline & $\begin{array}{l}\text { An element of the U.S. Nuclear Regulatory Commission safety } \\
\text { philosophy that employs successive compensatory measures to } \\
\text { prevent accidents or mitigate damage if a malfunction, accident, or } \\
\text { naturally caused event occurs at a nuclear facility. The defense-in- } \\
\text { depth philosophy ensures that safety will not be wholly dependent } \\
\text { on any single element of the design, construction, maintenance, or } \\
\text { operation of a nuclear facility. The net effect of incorporating } \\
\text { defense-in-depth into design, construction, maintenance, and } \\
\text { operation is that the facility or system in question tends to be more } \\
\text { tolerant of failures and external challenges. }\end{array}$ & NRC 1998 \\
\hline Design Agency & $\begin{array}{l}\text { The design agency is the organization that performs design } \\
\text { activities particularly those associated with design analysis and } \\
\text { calculations. The design agency performs design activities at the } \\
\text { direction of and under the responsibility of the design authority. }\end{array}$ & \\
\hline Design Authority & $\begin{array}{l}\text { The design authority is the organization responsible for establishing } \\
\text { the design requirements and ensuring that design output } \\
\text { documents accurately reflect the design requirements. The design } \\
\text { authority is responsible for the design control and ultimate technical } \\
\text { adequacy of the design processes. }\end{array}$ & \\
\hline
\end{tabular}




\begin{tabular}{|c|c|c|}
\hline Term & Definition & Reference \\
\hline Design Bases & $\begin{array}{l}\text { Design bases are statements that refer to design requirements for } \\
\text { structures, systems, and components and identify why the } \\
\text { requirement exists, why it is specified in a particular manner, and } \\
\text { why a specified value is used. The design bases provide } \\
\text { information that identifies the specific functions performed by the } \\
\text { structures, systems, and components of a facility and the specified } \\
\text { range of values chosen for controlling the parameters that are the } \\
\text { referenced boundaries for the design of the structures, systems, } \\
\text { and components. }\end{array}$ & \\
\hline $\begin{array}{l}10 \text { CFR } 63.2 \text { Design } \\
\text { Bases }\end{array}$ & $\begin{array}{l}\text { That information that identifies the specific functions to be } \\
\text { performed by a structure, system, or component of a facility and the } \\
\text { specific values or ranges of values chosen for controlling } \\
\text { parameters as reference bounds for design. These values may be } \\
\text { constraints derived from generally accepted state-of-the-art } \\
\text { practices for achieving functional goals or requirements derived } \\
\text { from analysis (based on calculation or experiments) of the effects of } \\
\text { a postulated event under which a SSC must meet its functional } \\
\text { goals. The values for controlling parameters for external events } \\
\text { include: } \\
\text { (1) Estimates of severe natural events to be used for deriving } \\
\text { design bases that will be based on consideration of historical } \\
\text { data on the associated parameters, physical data, or analysis } \\
\text { of upper limits of the physical processes involved } \\
\text { (2) Estimates of severe external human-induced events, to be } \\
\text { used for deriving design bases that will be based on analysis of } \\
\text { human activity in the region, taking into account the site } \\
\text { characteristics and the risks associated with the event. }\end{array}$ & 10 CFR 63.2 \\
\hline Design Criteria & $\begin{array}{l}\text { Design criteria consist of the standards, codes, laws, regulations, } \\
\text { general discipline design criteria, event sequences, and hazards } \\
\text { that shall be used as a basis for acceptance of design for } \\
\text { structures, systems, and components to satisfy requirements. }\end{array}$ & 10 CFR 63.112(f) \\
\hline Design Input & $\begin{array}{l}\text { Design inputs shall be defined as the design requirements, } \\
\text { supporting design bases, applied design criteria, and any other } \\
\text { design parameters, conditions, boundaries, limits, or values used to } \\
\text { develop and complete design configuration(s) and design output } \\
\text { documents. }\end{array}$ & $\begin{array}{l}\text { DOE 2000, ASME } \\
\text { NOG-1-1995 }\end{array}$ \\
\hline Design Output & $\begin{array}{l}\text { Design outputs shall be defined as the drawings, specifications, and } \\
\text { other design documents prepared to present the design } \\
\text { configuration(s) of structures, systems and components that satisfy } \\
\text { design inputs. }\end{array}$ & $\begin{array}{l}\text { DOE 2000, ASME } \\
\text { NOG-1-1995 }\end{array}$ \\
\hline Design Requirement & $\begin{array}{l}\text { Detail design requirements are engineering technical requirements } \\
\text { (determined by design processes) that define, for example, the } \\
\text { functions, capabilities, capacities, physical size, configurations, } \\
\text { dimensions, performance parameters, limits, and setpoints, that are } \\
\text { developed and specified by the design authority for structures, } \\
\text { systems, and components to satisfy the mission design input } \\
\text { requirements. The detail design requirements are the result (often } \\
\text { iterative) of design processes. } \\
\text { (Example: Lateral load resisting systems elements for surface } \\
\text { structure will be designed to withstand } 100 \text { mph wind loads.) }\end{array}$ & \\
\hline
\end{tabular}




\begin{tabular}{|c|c|c|}
\hline Term & Definition & Reference \\
\hline Design Verification & $\begin{array}{l}\text { Documented, traceable measures (e.g., design review, alternate } \\
\text { calculation, and qualification testing) applied to a design package or } \\
\text { technical output by qualified individuals or groups other than those } \\
\text { who performed the original design work. These measures verify the } \\
\text { technical validity, adequacy, and completeness of a design package } \\
\text { or technical output in context with the total design, natural or } \\
\text { engineered barrier system, or integrated technical work. }\end{array}$ & AP-3.20Q \\
\hline \multirow[t]{2}{*}{ Disposal } & $\begin{array}{l}\text { The emplacement of radioactive waste in a geologic repository with } \\
\text { the intent of leaving it there permanently. }\end{array}$ & 10 CFR 63.2 \\
\hline & $\begin{array}{l}\text { The emplacement of radioactive material into the Yucca Mountain } \\
\text { disposal system with the intent of isolating it for as long as } \\
\text { reasonably possible and with no intent of recovering the material. } \\
\text { Disposal of radioactive material in the Yucca Mountain disposal } \\
\text { system begins when the ramps and other opening into the Yucca } \\
\text { Mountain repository are sealed. }\end{array}$ & 10 CFR 63.302 \\
\hline $\begin{array}{l}\text { Documentary } \\
\text { Material }\end{array}$ & $\begin{array}{l}\text { (1) Any information that a party, potential party, or interested } \\
\text { governmental participant intends to use or to cite in support of } \\
\text { their position in the proceeding for a license to receive and } \\
\text { possess high-level radioactive waste at a GROA pursuant to } \\
10 \text { CFR Part } 60 \text { or } 10 \text { CFR Part } 63 \text {. } \\
\text { (2) Any information that is known to, in the possession of, or } \\
\text { developed by the party that is relevant to, but does not support, } \\
\text { that information or that party's position. } \\
\text { (3) Reports and studies, prepared by or on behalf of the potential } \\
\text { party, interested governm ental participant, or party, including } \\
\text { related circulated drafts, relevant to the license application and } \\
\text { the issues set forth in Regulatory Guide 3.69, Topical } \\
\text { Guidelines, regardless of whether they will be relied upon or } \\
\text { cited by a party. The scope of documentary material will be } \\
\text { guided by the topical guidelines in the applicable U.S. Nuclear } \\
\text { Regulatory Commission regulatory guides. }\end{array}$ & 10 CFR 2.1001 \\
\hline $\begin{array}{l}\text { Electrical One-Line } \\
\text { Diagrams }\end{array}$ & $\begin{array}{l}\text { Electrical One Line Diagrams are diagrams of single lines showing } \\
\text { the electrical power sources, distribution busses, major loads, and } \\
\text { associated circuit breakers. Electrical one-line diagrams may be } \\
\text { generated based on the general system description and the design } \\
\text { information required to perform the safety analyses, such that no } \\
\text { additional supporting information will be required. }\end{array}$ & \\
\hline Evaluation & $\begin{array}{l}\text { (1) To examine and judge carefully. } \\
\text { (2) To form an opinion about. } \\
\text { (3) To determine the significance, worth, or condition, usually by } \\
\text { careful appraisal and study. }\end{array}$ & \\
\hline Event Sequence & $\begin{array}{l}\text { A series of actions or occurrences within the natural and engineered } \\
\text { components of a GROA that could potentially lead to radiation } \\
\text { exposure. An event sequence includes one or more initiating } \\
\text { events and associated combinations of repository system } \\
\text { component failures, including those produced by the action or } \\
\text { inaction of operating personnel. Those event sequences that are } \\
\text { expected to occur one or more times before permanent closure of } \\
\text { repository are referred to as Category } 1 \text { event sequences. Event } \\
\text { sequences that have at least one chance in } 10,000 \text { of occurring } \\
\text { before permanent closure are referred to as Category } 2 \text { event } \\
\text { sequences. }\end{array}$ & 10 CFR 63.2 \\
\hline
\end{tabular}




\begin{tabular}{|c|c|c|}
\hline Term & Definition & Reference \\
\hline $\begin{array}{l}\text { General } \\
\text { Arrangement } \\
\text { Drawings }\end{array}$ & $\begin{array}{l}\text { General arrangement drawings provide an overall view of a } \\
\text { structure, component, or area showing the arrangement of major } \\
\text { structural features and major equipment. Only overall dimensions } \\
\text { are included. General arrangement drawings may be generated } \\
\text { based on the general system description and the design information } \\
\text { required to perform the safety analyses such that no additional } \\
\text { supporting information will be required. }\end{array}$ & \\
\hline $\begin{array}{l}\text { General System } \\
\text { Description }\end{array}$ & $\begin{array}{l}\text { A general system description provides a summary of the system } \\
\text { functions, operations, the system design, concept of operations, } \\
\text { and a description of system interfaces, such as in Section } 1 \text { of the } \\
\text { System Description Documents. This description should include a } \\
\text { discussion on any special construction or fabrication techniques, } \\
\text { unique testing programs or special design and analysis procedures } \\
\text { used for the structures, systems, and components, as applicable. }\end{array}$ & \\
\hline GROA & $\begin{array}{l}\text { A high-level radioactive waste facility that is part of a geologic } \\
\text { repository, including surface and subsurface areas, where waste } \\
\text { handling activities are conducted. }\end{array}$ & 10 CFR 63.2 \\
\hline Handling Diagrams & $\begin{array}{l}\text { Handling diagrams depict major handling paths and sequence of } \\
\text { operations at a summary level (e.g., fuel movement in the Waste } \\
\text { Handling Building). Handling diagrams may be generated based on } \\
\text { the general system description and the design information required } \\
\text { to perform the safety analyses, such that no additional supporting } \\
\text { information will be required. }\end{array}$ & \\
\hline Important to Safety & $\begin{array}{l}\text { With reference to structures, systems, and components, engineered } \\
\text { features of the GROA, that: } \\
\text { (1) Provide reasonable assurance that high-level radioactive waste } \\
\text { can be received, handled, packaged, stored, emplaced, and } \\
\text { retrieved without exceeding the requirements of } \\
10 \text { CFR } 63.111 \text { (b)(1) for Category } 1 \text { event sequences } \\
\text { (2) Prevent or mitigate Category } 2 \text { event sequences that could } \\
\text { result in doses exceeding the values specified } \\
10 \text { CFR } 63.111(b)(2) \text { to any individual located on or beyond } \\
\text { any point on the boundary of the site. }\end{array}$ & 10 CFR 63.2 \\
\hline $\begin{array}{l}\text { Important to Waste } \\
\text { Isolation }\end{array}$ & $\begin{array}{l}\text { With reference to design of the engineered barrier system and } \\
\text { characterization of natural barriers, those engineered and natural } \\
\text { barriers whose function is to provide a reasonable expectation that } \\
\text { high-level waste can be disposed of without exceeding the } \\
\text { requirements of } 10 \text { CFR } 63.113 \text { (b) and (c) (10 CFR 63.2). }\end{array}$ & 10 CFR 63.2 \\
\hline Initiating Event & A natural or human induced event that causes an event sequence. & 10 CFR 63.2 \\
\hline Licensing Basis & $\begin{array}{l}\text { The currently effective requirements imposed on the facility } \\
\text { including the requirements at the time the initial license was applied } \\
\text { for and granted, together with requirements subsequently imposed. } \\
\text { The licensing bases are contained in U.S. Nuclear Regulatory } \\
\text { Commission regulations, orders, license conditions, exemptions, } \\
\text { and licensee commitments contained in the safety analysis report } \\
\text { and other docketed licensee correspondence. }\end{array}$ & \\
\hline Margin & $\begin{array}{l}\text { Margin is the difference between the calculated event sequence } \\
\text { dose and the prescribed regulatory compliance limit, which provides } \\
\text { confidence that the repository design features can adequately } \\
\text { protect public health and safety and the environment from any } \\
\text { uncontrolled radiological event. }\end{array}$ & \\
\hline
\end{tabular}




\begin{tabular}{|c|c|c|}
\hline Term & Definition & Reference \\
\hline \multirow[t]{2}{*}{ Model } & $\begin{array}{l}\text { A representation of a system, process, or phenomenon, along with } \\
\text { any hypotheses required to describe the process or system or to } \\
\text { explain the phenomenon, often mathematically. }\end{array}$ & DOE 2000 \\
\hline & $\begin{array}{l}\text { Model development typically progresses from conceptual to } \\
\text { mathematical models. Mathematical model development typically } \\
\text { progresses from process, to abstraction, and to system models. }\end{array}$ & AP-SIII.10Q \\
\hline Negligible & $\begin{array}{l}\text { So small, unimportant, or of so little consequence as to warrant little } \\
\text { or no attention. }\end{array}$ & \\
\hline Non-Safety Category & $\begin{array}{l}\text { SSCs not credited for compliance to the performance objectives in } \\
10 \text { CFR } 63.111 \text { and natural/engineered barriers that are not } \\
\text { important to meeting the performance objectives in } 10 \text { CFR } 63.113 \text {. }\end{array}$ & \\
\hline $\begin{array}{l}\text { Piping and } \\
\text { Instrumentation } \\
\text { Diagrams (Process } \\
\text { and Instrumentation } \\
\text { Diagrams) }\end{array}$ & $\begin{array}{l}\text { Piping and instrumentation diagrams are diagrams showing only } \\
\text { major flow paths, equipment, and instrumentation (e.g., pumps, } \\
\text { tanks, ion exchangers, major valves, and instrumentation used for } \\
\text { operation). Interfaces with other systems and seismic and quality } \\
\text { interfaces shall be included on the piping and instrumentation } \\
\text { diagrams. These piping and instrumentation diagrams may be } \\
\text { generated based on the general system description and the design } \\
\text { information required to perform the safety analyses, such that no } \\
\text { additional supporting information will be required. }\end{array}$ & \\
\hline Permanent Closure & $\begin{array}{l}\text { The final backfilling of the underground facility, if appropriate, and } \\
\text { the sealing of shafts, ramps, and boreholes. }\end{array}$ & 10 CFR 63.2 \\
\hline Postclosure & $\begin{array}{l}\text { Refers to the period of time after permanent closure of the } \\
\text { repository system. }\end{array}$ & \\
\hline Preclosure & $\begin{array}{l}\text { Refers to the period of time before and during permanent closure of } \\
\text { the repository system. }\end{array}$ & \\
\hline $\begin{array}{l}\text { Preclosure Safety } \\
\text { Analysis }\end{array}$ & $\begin{array}{l}\text { A systematic examination of the site; the design; and the potential } \\
\text { hazards, initiating events, and event sequences; and their } \\
\text { consequences (e.g., radiological exposures to workers and the } \\
\text { public). The analysis identifies SSCs ITS. }\end{array}$ & 10 CFR 63.2 \\
\hline $\begin{array}{l}\text { Qualification } \\
\text { (Personnel) }\end{array}$ & $\begin{array}{l}\text { The capabilities gained through education, training, or experience } \\
\text { that qualify an individual to perform a required function. }\end{array}$ & DOE 2000 \\
\hline $\begin{array}{l}\text { Reasonable } \\
\text { Assurance }\end{array}$ & $\begin{array}{l}\text { The test of compliance with the standards and criteria. This } \\
\text { concept recognizes that absolute assurance of compliance is } \\
\text { neither possible nor required. }\end{array}$ & $\begin{array}{l}\text { Eisenberg et al. } \\
1999\end{array}$ \\
\hline $\begin{array}{l}\text { Regulatory } \\
\text { Commitment }\end{array}$ & $\begin{array}{l}\text { An explicit statement made to ensure compliance, agreed to or } \\
\text { volunteered by the U.S. Department of Energy, to take a specific } \\
\text { action. Regulatory commitments are made in written } \\
\text { correspondence with the U.S. Nuclear Regulatory Commission or } \\
\text { the U.S. Environmental Protection Agency. }\end{array}$ & $\begin{array}{l}\text { AP-REG-005, } \\
\text { Sections } 3.1 \text { and } \\
3.10\end{array}$ \\
\hline Regulatory Limit & $\begin{array}{l}\text { Limit specified by U.S. Nuclear Regulatory Commission regulations } \\
\text { or other regulatory requirements document (e.g., Standard Review } \\
\text { Plan, regulatory guides, and NUREGs). Whether the value is a } \\
\text { maximum or a minimum depends on the type of variable being } \\
\text { discussed. }\end{array}$ & \\
\hline Regulatory Margin & $\begin{array}{l}\text { Regulatory margin is the difference between the event sequence } \\
\text { dose and the prescribed regulatory compliance limit. }\end{array}$ & \\
\hline Retrieval & $\begin{array}{l}\text { The act of permanently removing radioactive waste from the } \\
\text { underground location at which the waste had been previously } \\
\text { emplaced for disposal. }\end{array}$ & 10 CFR 63.2 \\
\hline
\end{tabular}




\begin{tabular}{|c|c|c|}
\hline Term & Definition & Reference \\
\hline Risk & $\begin{array}{l}\text { (1) The probability that an undesirable event will occur, multiplied } \\
\text { by the consequences of the undesirable event. } \\
\text { (2) Expected (mean) value of the consequences of an undesirable } \\
\text { process or event. }\end{array}$ & DOE 2001 \\
\hline Risk Informed & $\begin{array}{l}\text { An approach to regulatory decision-making whereby risk insights } \\
\text { are considered together with other factors to establish requirements } \\
\text { that better focus licensee and regulatory attention on design and } \\
\text { operation issues commensurate with their importance to public } \\
\text { health and safety. }\end{array}$ & NRC 1998 \\
\hline Risk Insights & The results and findings that come from risk assessments. & NRC 1998 \\
\hline Safety Case & $\begin{array}{l}\text { The logic, analyses, and calculations that show that the repository } \\
\text { system would meet performance objectives. }\end{array}$ & CRWMS M\&O 2001 \\
\hline Safety Category & $\begin{array}{l}\text { The assigned designation of whether an SSC or natural/engineered } \\
\text { barrier requires quality assurance program control activities. }\end{array}$ & \\
\hline Significant & $\begin{array}{l}\text { More than a minimal increase in the consequences of an accident } \\
\text { (e.g., the margin to the regulatory limit is eroded by more than ten } \\
\text { percent). }\end{array}$ & NEI 2000 \\
\hline $\begin{array}{l}\text { Technical } \\
\text { Information }\end{array}$ & $\begin{array}{l}\text { Information available from drawings, specifications, calculations, } \\
\text { analyses, reactor operational records, fabrication records, } \\
\text { construction records, other design basis documents, regulatory or } \\
\text { program requirements documents, or consensus codes and } \\
\text { standards that describe physical, performance, operational, or } \\
\text { nuclear characteristics or requirements. }\end{array}$ & $\begin{array}{l}\text { Document Action } \\
\text { Request D813 to the } \\
\text { Quality Assurance } \\
\text { Requirements and } \\
\text { Description } \\
\text { document (DOE } \\
\text { 2000) } \\
\end{array}$ \\
\hline $\begin{array}{l}\text { Total Effective Dose } \\
\text { Equivalent }\end{array}$ & $\begin{array}{l}\text { For purposes of assessing doses to workers, the sum of the deep- } \\
\text { dose equivalent (for external exposures) and the committed } \\
\text { effective dose equivalent (for internal exposures). For purposes of } \\
\text { assessing doses to members of the public (including the reasonably } \\
\text { maximally exposed individual), total effective dose equivalent } \\
\text { means the sum of the effective dose equivalent (for external } \\
\text { exposures) and the committed effective dose equivalent (for internal } \\
\text { exposures). }\end{array}$ & 10 CFR 63.2 \\
\hline Traceability & $\begin{array}{l}\text { The ability to trace the history, application, or location of an item, } \\
\text { data, or sample using recorded documentation. } \\
\text { Traceability exists when there is an unbroken chain linking the } \\
\text { result of an assessment (e.g., final dose calculation) with models, } \\
\text { assumptions, expert opinions, and data used in the formulation of } \\
\text { the result. }\end{array}$ & DOE 2000 \\
\hline Transparent & $\begin{array}{l}\text { A document (e.g., a calculation, analysis, or model) is transparent if } \\
\text { it is sufficiently detailed as to purpose, method, assumptions, inputs, } \\
\text { conclusions, references, and units such that a person technically } \\
\text { qualified in the subject can understand the document and ensure its } \\
\text { adequacy without recourse to the originator. }\end{array}$ & $\begin{array}{l}\text { DOE 2000, } \\
\text { Section 3.2.2 }\end{array}$ \\
\hline Uncertainty & $\begin{array}{l}\text { The interval above and below the measurement, parameter, or } \\
\text { result that contains the true value at a given confidence level. }\end{array}$ & AP-SIII.9Q \\
\hline
\end{tabular}




\begin{tabular}{|c|c|c|}
\hline Term & Definition & Reference \\
\hline & $\begin{array}{l}\text { There are two types of uncertainty: } \\
\text { 1) Stochastic (or aleatory) uncertainty is caused by the random } \\
\text { variability in a process or phenomenon } \\
\text { 2) State-of-knowledge (or epistemic) uncertainty results from a } \\
\text { lack of complete information about physical phenomena. } \\
\text { State-of-knowledge uncertainty is further divided into: } \\
\text { i) Parameter uncertainty, which results from imperfect knowledge } \\
\text { about the inputs to analytical models } \\
\text { ii) Model uncertainty, which is caused by imperfect models of } \\
\text { physical systems, resulting from simplifying assumptions or an } \\
\text { incomplete identification of the system modeled } \\
\text { iii) Completeness uncertainty, which refers to the uncertainty as to } \\
\text { whether the important physical phenomena, relationships } \\
\text { (coupling), and events have been considered. }\end{array}$ & $\begin{array}{l}\text { Eisenberg et al. } \\
1999\end{array}$ \\
\hline Unrestricted Area & Areas where access is neither limited nor controlled by the licensee. & 10 CFR 63.2 \\
\hline \multirow[t]{2}{*}{ Validation } & $\begin{array}{l}\text { A process used to establish confidence that a conceptual model (as } \\
\text { represented in a mathematical model, software, or analysis) } \\
\text { adequately represents the phenomenon, process, or system in } \\
\text { question. }\end{array}$ & DOE 2000 \\
\hline & $\begin{array}{l}\text { A process carried out by comparison of model predictions with field } \\
\text { observations and experimental measurements. A model is } \\
\text { considered validated when sufficient testing has been performed to } \\
\text { ensure an acceptable level of predictive accuracy over the range of } \\
\text { conditions over which the model may be applied. }\end{array}$ & $\begin{array}{l}\text { Eisenberg et al. } \\
1999\end{array}$ \\
\hline \multirow[t]{2}{*}{ Verification } & $\begin{array}{l}\text { The act of reviewing, inspecting, testing, checking, auditing, or } \\
\text { otherwise determining and documenting whether items, processes, } \\
\text { services, or documents conform to specified requirements. }\end{array}$ & DOE 2000 \\
\hline & $\begin{array}{l}\text { A process of assuring that the implementation of a mathematical } \\
\text { model (in the form of a computer code) is free of coding errors, and } \\
\text { that the numerical schemes used are with in the bounds of required } \\
\text { accuracy. The process consists of following established Quality } \\
\text { Assurance procedures during the development of the code, } \\
\text { comparison of the code with analytic solutions, and comparison with } \\
\text { results from other codes. }\end{array}$ & $\begin{array}{l}\text { Eisenberg et al. } \\
1999\end{array}$ \\
\hline Waste Form & $\begin{array}{l}\text { The radioactive waste materials and any encapsulating or } \\
\text { stabilizing matrix. }\end{array}$ & 10 CFR 63.2 \\
\hline
\end{tabular}

\section{GLOSSARY REFERENCES}

\section{GLOSSARY DOCUMENTS CITED}

ASME (American Society of Mechanical Engineers) NOG-1-1995. Rules for Construction of Overhead and Gantry Cranes (Top Running Bridge, Multiple Girder). New York, New York: American Society of Mechanical Engineers. TIC: 238309.

CRWMS M\&O 2001. Repository Safety Strategy: Plan to Prepare the Safety Case to Support Yucca Mountain Site Recommendation and Licensing Considerations. TDR-WIS-RL-000001 
REV 04 ICN 01. Two volumes. Las Vegas, Nevada: CRWMS M\&O.

ACC: MOL.20010329.0825.

DOE (U.S. Department of Energy) 2000. Quality Assurance Requirements and Description. DOE/RW-0333P, Rev. 10. Washington, D.C.: U.S. Department of Energy, Office of Civilian Radioactive Waste Management. ACC: MOL.20000427.0422.

DOE 2001. Yucca Mountain Science and Engineering Report. DOE/RW-0539. Washington, D.C.: U.S. Department of Energy, Office of Civilian Radioactive Waste Management. ACC: MOL.20010524.0272.

Eisenberg, N.A.; Lee, M.P.; Federline, M.V.; Wingefors, S.; Andersson, J.; Norrby, S.; Sagar, B.; and Wittmeyer, G.W. 1999. Regulatory Perspectives on Model Validation in High-Level Radioactive Waste Management Programs: A Joint NRC/SKI White Paper. NUREG-1636.

Washington, D.C.: U.S. Nuclear Regulatory Commission. TIC: 246310.

NEI (Nuclear Energy Institute) 2000. Guidelines for 10 CFR 50.59 Implementation. NEI 96-07, Rev. 1. Final Pre-publication Draft. Washington, D.C.: Nuclear Energy Institute.

TIC: 249183.

NRC 1998. "White Paper on Risk-Informed and Performance-Based Regulation.”

Correspondence from L.J. Callan (NRC) to the Commissioners, June 22, 1998, with attachment. SECY-98-144. Washington, D.C.: U.S. Nuclear Regulatory Commission. Accessed August 24, 1998. TIC: 240107. http://www.nrc.gov/NRC/COMMISSION/SECYS/1998144scy.html.

\section{GLOSSARY CODES, STANDARDS, REGULATIONS, AND PROCEDURES}

10 CFR 2. 1998. Energy: Rules of Practice for Domestic Licensing Proceedings and Issuance of Orders. Readily available.

10 CFR 20. Energy: Standards for Protection Against Radiation. Readily available

10 CFR 63. 2002. Ene rgy: Disposal of High-Level Radioactive Wastes in a Proposed Geologic Repository at Yucca Mountain, Nevada. Readily available.

AP-3.12Q, Rev. 1. Design Calculations and Analyses. Washington, D.C.: U.S. Department of Energy, Office of Civilian Radioactive Waste Management. ACC: MOL.20020102.0198.

AP-3.20Q, Rev. 0, ICN 1. Technical/Design Verification. Washington, D.C.: U.S. Department of Energy, Office of Civilian Radioactive Waste Management. ACC: MOL.20010403.0149.

AP-REG-005, Rev. 0, ICN 0. Managing External Recommendations and Commitments. Washington, D.C.: U.S. Department of Energy, Office of Civilian Radioactive Waste Management. ACC: MOL.20010514.0165.

AP-SIII.9Q, Rev. 0, ICN 0. Scientific Analyses. Washington, D.C.: U.S. Department of Energy, Office of Civilian Radioactive Waste Management. ACC: MOL.20020102.0199. 
AP-SIII.10Q, Rev. 0, ICN 0. Models. Washington, D.C.: U.S. Department of Energy, Office of Civilian Radioactive Waste Management. ACC: MOL.20020102.0197 
ERRATA SHEET

\begin{tabular}{|c|c|c|c|}
\hline Page & Line & From & Read \\
\hline $1-3$ & 7 & occuring & occurring \\
\hline $2-3$ & 16 & probablistic & probabilistic \\
\hline $2-3$ & 26 & techncial & technical \\
\hline $2-4$ & 29 & reveiwed & reviewed \\
\hline 4-14 & 40 & availablity & availability \\
\hline $5-1$ & 3 & suppoting & supporting \\
\hline $5-2$ & 5 & geoglogy & geology \\
\hline $5-2$ & 16 & crieteria & criteria \\
\hline $7-11$ & 22 & Russel & Russell \\
\hline $7-31$ & 10 & arithmatic & arithmetic \\
\hline $7-72$ & Figure 7-17 & Precedural & Procedural \\
\hline $7-73$ & 16 & probibility & probability \\
\hline $7-103$ & 11 & needesd & needed \\
\hline 7-105 & 21 & Unannuciated & Unannunciated \\
\hline $7-105$ & 23 & unanunciated & unannunciated \\
\hline $7-106$ & 5 & Annuciated & Annunciated \\
\hline $8-15$ & 11 & demonistrate complience & demonstrate compliance \\
\hline $8-23$ & 27 & complience & compliance \\
\hline $9-8$ & 16 & transfomed & transformed \\
\hline $10-1$ & 4 & respository & repository \\
\hline $10-26$ & 22 & secismic & seismic \\
\hline $10-31$ & 29 & probibility & probability \\
\hline $10-32$ & 7 & HCFLP & HCLPF \\
\hline $10-32$ & 32 & probibility & probability \\
\hline $10-56$ & 20 & folloiwng a & following an \\
\hline $10-61$ & 10 & anlaysis & analysis \\
\hline $11-1$ & 21 & handeling & handling \\
\hline $11-2$ & 20 & subcrticality & subcriticality \\
\hline $11-11$ & 18 & Peport & Report \\
\hline $12-6$ & 24 & sequeces & sequences \\
\hline $12-7$ & 17 & region Category 1 & region for Category 1 \\
\hline $13-3$ & 14 & Catergory 2 & Category 2 \\
\hline $13-3$ & 22 & Catetgory 2 & Category 2 \\
\hline 14-1 & 35 & peform & perform \\
\hline $14-2$ & 22 & anlaysis & analysis \\
\hline $14-4$ & 6 & Isoloation & Isolation \\
\hline $14-4$ & 14 & methodolgy & methodology \\
\hline
\end{tabular}

